Hans-Georg Napp

Kommunale

Finanzautonomie und

ihre Bedeutung für

eine effiziente lokale

Finanzwirtschaft 


\section{Kommunale Finanzautonomie und ihre Bedeutung für eine effiziente lokale Finanzwirtschaft}

Obwohl die Notwendigkeit einer Reform des Gemeindefinanzsystems weitgehend anerkannt wird, tut sich die Politik mit konkreten Reformmaßnahmen schwer. Mit der vorliegenden Arbeit soll daher der Versuch unternommen werden, die Diskussion um die Gemeindefinanzen und ihre Reform einer systematischen Analyse zu unterziehen und konkreten Lösungen näher zu bringen. Dabei resultieren zwei Schwerpunkte: Der eine, kommunale Finanzautonomie, ist im wesentlichen politisch orientiert; der andere, Effizienz, ist eine im ökonomischen Sinne theoretisch ausgerichtete Sichtweise. Beide Aspekte werden miteinander verknüpft und aufeinander bezogen. Wichtig für das Gesamtverständnis ist dabei, daß kommunale Finanzautonomie Bedeutung für die Effizienz lokaler Finanzwirtschaften hat und nicht umgekehrt. Aufbauend auf der Feststellung, daß vorgefundene kommunale Finanzsysteme keine zufriedenstellende Autonomie garantieren, wird das gesamte System im Sinne einer umfassenden Erneuerung zur Diskussion gestellt. Es werden systematische Komponenten für ein äquivalenzorientiertes Gemeindesteuersystem entworfen, wobei auch die bestehenden Elemente kommunaler Finanzwirtschaften einbezogen werden.

Hans-Georg Napp wurde 1958 in Gerblingerode geboren. Von 1975 bis 1981 war er als Verwaltungsangestellter bei der Stadt Duderstadt beschäftigt. Anschließend Studium der Volkswirtschaftslehre an der Universität-Gesamthochschule Paderborn; 1986 Diplom-Volkswirt. Von 1986 bis 1991 wissenschaftlicher Angestellter am Fachbereich Wirtschaftswissenschaften (Lehrstuhl Finanzwissenschaft) der Universität-Gesamthochschule Paderborn; 1991 bis 1993 Referent im Bundesministerium der Finanzen; seit Februar 1993 Referent im Bereich Kommunalgeschäft der Landesbank Hessen-Thüringen. Darüber hinaus nebenberufliche Tätigkeiten als Lehrbeauftragter für die Fachhochschulen für öffentliche Verwaltung Nordrhein-Westfalen und Brandenburg sowie die Fernuniversität Hagen. 
Kommunale Finanzautonomie und ihre Bedeutung für eine effiziente lokale Finanzwirtschaft 


\section{FINANZWISSENSCHAFTLICHE SCHRIFTEN}

Herausgegeben von den Professoren

Albers, Krause-Junk, Littmann, Oberhauser, Pohmer, Schmidt

Band 63

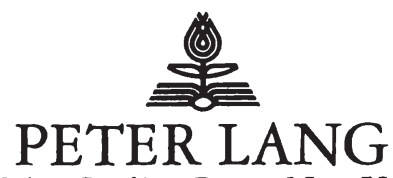

Frankfurt am Main - Berlin - Bern · New York · Paris - Wien 


\section{Hans-Georg Napp}

\section{Kommunale Finanzautonomie und ihre Bedeutung für eine effiziente lokale Finanzwirtschaft}

2., unveränderte Auflage

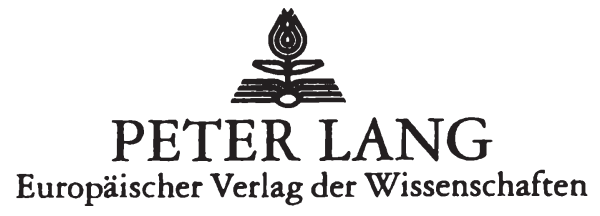


Die Deutsche Bibliothek - CIP-Einheitsaufnahme

Napp, Hans-Georg:

Kommunale Finanzautonomie und ihre Bedeutung für eine effiziente lokale Finanzwirtschaft / Hans-Georg Napp. -

2., unveränd. Aufl. - Frankfurt am Main ; Berlin ; Bern ; New York ; Paris ; Wien : Lang, 1994

(Finanzwissenschaftliche Schriften ; Bd. 63)

Zugl.: Paderborn, Univ., Diss., 1993

ISBN 3-631-46799-0

NE: GT

Open Access: The online version of this publication is published on www.peterlang.com and www.econstor.eu under the international Creative Commons License CC-BY 4.0. Learn more on how you can use and share this work: http://creativecommons.org/ licenses/by/4.0.

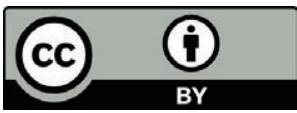

This book is available Open Access thanks to the kind support of ZBW - Leibniz-Informationszentrum Wirtschaft.

\author{
D 466 \\ ISSN 0170-8252 \\ ISBN 3-631-46799-0 \\ ISBN 978-3-631-75263-0 (eBook) \\ (C) Peter Lang GmbH \\ Europäischer Verlag der Wissenschaften \\ Frankfurt am Main 1994 \\ 2., unveränderte Auflage 1994 \\ Alle Rechte vorbehalten.
}

Das Werk einschließlich aller seiner Teile ist urheberrechtlich geschützt. Jede Verwertung außerhalb der engen Grenzen des Urheberrechtsgesetzes ist ohne Zustimmung des Verlages unzulässig und strafbar. Das gilt insbesondere für

Vervielfältigungen, Übersetzungen, Mikroverfilmungen und die Einspeicherung und Verarbeitung in elektronischen Systemen.

Printed in Germany 123467 
"Nicht die Größe der Aufgabe entscheidet, sondern das 'Wie', mit dem wir die kleinste zu lösen versuchen."

Theodor Fontane 
Hans-Georg Napp - 978-3-631-75263-0

Downloaded from PubFactory at 01/11/2019 06:33:05AM

via free access 


\section{Vorwort}

Die vorliegende Arbeit, die im Juni 1993 vom Fachbereich Wirtschaftswissenschaften der Universität-Gesamthochschule Paderborn als Dissertation angenommen wurde, wäre ohne das Dazutun einer Vielzahl von Personen und Institutionen nicht in dieser Form entstanden.

Meine Tätigkeit als wissenschaftlicher Angestellter am finanzwissenschaftlichen Lehrstuhl des Fachbereichs Wirtschaftswissenschaften in Paderborn und das gemeinsam mit der Bergischen Universität Wuppertal durchgeführte Forschungsprojekt "Fiskalföderalismus im Europäischen Binnenmarkt", das von der Volkswagen-Stiftung gefördert wurde, lenkten mein Interesse auf diese Thematik. Die Diskussionen mit meinen Kolleginnen und Kollegen in Paderborn und Wuppertal sowie später während meiner Beschäftigung im Bundesministerium der Finanzen haben den Inhalt dieser Arbeit nicht unwesentlich beeinflußt.

Mein besonderer Dank gebührt meinem akademischen Lehrer Prof. Dr. Bernd Rahmann für wertvolle Anregungen, fruchtbare Diskussionen sowie vielfältige Unterstützung. Eine große Hilfe für mich waren auch die Hinweise und inhaltlichen Gespräche mit Prof. Dr. Otto Roloff. Ihm gilt ebenfalls mein Dank.

Ich bedanke mich darüber hinaus bei alle jenen, die zur Entstehung und Fertigstellung dieser Arbeit beigetragen haben. Gern würde ich alle namentlich aufführen, doch dies würde trotz aller Sorgfalt möglicherweise nicht vollständig und umfassend gelingen. Gleichwohl möchte ich einige besonders hervorheben. Jörg Ihlau, Markus Kelle und Stefan Pelgrim haben sich viel Zeit genommen, ausgewählte Problembereiche dieser Arbeit mit mir zu erörtern. Für diesen freundschaftlichen Dienst danke ich ihnen ebenso wie Monika Hentschel, Gabriele Müller, Christiane Rennert und Ulrike Teutrine, die während meiner Tätigkeit am Lehrstuhl (aber auch später) umfangreiche organisatorische und praktisch-institutionelle Unterstützung geleistet haben.

Die Landesbank Hessen-Thüringen hat sich bereit erklärt, eine Sonderauflage dieses Buches erstellen zu lassen, die im Rahmen der Betreuung des Geschäftsfeldes "Kommunale Kunden" interessierten Personen und Institutionen zur Verfügung gestellt 
werden soll. Über diese Auszeichnung habe ich mich sehr gefreut, nicht zuletzt deshalb, weil damit meine theoretischen Überlegungen auch einem weiten Kreis von kompetenten und erfahrenen Praktikern vorgestellt werden.

Bonn, im September 1993

Hans-Georg Napp 


\section{Inhaltsverzeichnis}

Inhaltsverzeichnis

Verzeichnis der Tabellen und Schaubilder

1.

Einleitung

1.1

Wirtschaftstheoretische Problemstellung

Foderalismustheoretische Vorbemerkungen

2.

4. Vorbemerkungen 
5.

5.1

5.1 .1

5.1 .2

5.2

5.3

5.4

5.4 .1

5.4 .2

5.4 .3

6.

6.1

6.1.2

6.1.3

6.1 .4

6.1 .5

6.1.5.1

6.1.5.2

6.1.5.3

6.1.5.4

6.1.5.5

6.2

6.3

6.3.1

6.3.2

6.3.2.1

6.3.2.2

7.

Bereitstellung und Finanzierung lokaler öffentlicher Güter - Eine modelltheoretische Analyse der Bedingungen einer effizienten Ressourcenallokation

Allokationseffizienz und der lokale Sektor

Bedingungen einer effizienten Ressourcenallokation $\quad 84$

Optimale Gemeindegroße und effiziente Allokation $\quad 92$

Die Effizienzeigenschaften eines Gleichgewichts 95

Die Effizienzbedingungen für die lokale Entscheidungsebene - Eine Fallunterscheidung

99

Realităt und Modellwelt 104

Exkurs: Kommunale Unternehmensbesteuerung 105

Überblick der theoretischen Behandlung kommunaler Finanzsysteme 107

Ökonomische Problembereiche und organisatorisch-institutionelle Aspekte einer finanziell autonomen gemeindlichen Ebene

Răumliche externe Effekte

Das Konzept der externen Effekte und seine Ausweitung auf zwischenstaatliche Beziehungen

Begriff und Wesen răumlicher extemer Effekte $\quad 114$

$\begin{array}{ll}\text { Ursachen răumlicher externer Effekte } & 116\end{array}$

Răumliche Externalităten und gesamtwirtschaftliche Allokation 118

Konzepte zur Internalisierung răumlicher externer Effekte 122

Die Gebühr: Ein einfaches Mittel gegen überregionale "Trittbrettfahrer"? 123

Freiwillige Verhandlungen der Kommunen untereinander $\quad 124$

Vertikale Transfers $\quad 127$

Zentralisierung und/oder horizontaler Verbund 132

Würdigung der Internalisierungskonzepte 133

Skalenertrăge in der Produktion offentlicher Güter 134

Administrative Aspekte der Dezentralisierung 136

Die Existenz von Organisationskosten sowie Aufwendungen für eine Beteiligung am politischen Entscheidungsprozeß 136

Eine administrative Rechtfertigung der lokalen Ebene $\quad 137$

Dekonzentration als alternative Organisationsform 137

$\begin{array}{ll}\text { Dekonzentration versus Dezentralisierung } & 141\end{array}$

Fiskalische Äquivalenz und ihre Bedeutung bei der lokalen öffentlichen Leistungsbereitstellung und ihrer Finanzierung

Formen fiskalischer Äquivalenz und ihre Reichweite $\quad 145$

Das Äquivalenzprinzip - Beschreibung und Grundlagen 147

Das "Teiläquivalenzkonzept" 150

Das Äquivalenzprinzip und der Grundsatz des Interessenausgleichs 152

Möglichkeiten und Grenzen des Äquivalenzprinzips bzw. des Grundsatzes des Interessenausgleichs bei der Auswahl kommunaler Finanzierungsinstrumente

Kriterien zur Kostenverteilung des lokalen offentlichen Leistungsangebots und zur Etablierung kommunaler Finanzierungskomponenten 
8. Gebühren und Beitrăge als kommunale Finanzierungsinstrumente

8.1 Geschichtlicher Ursprung, Begriff und Abgrenzung $\quad 164$

$\begin{array}{lll}\text { 8.2 Beurteilung unter Effizienzgesichtspunkten } & 169\end{array}$

8.3 Gebühren und Beitrăge als Komponenten kommunaler Finanzierungssysteme 172

8.3.1 Der kommunale Gestaltungsspielraum bei ihrer Erhebung 174

8.3.2 Ökonomische Rechtfertigung einer Ausschöpfung der Finanzierungspoten-
tiale im Gebühren- und Beitragsbereich

9. Gemeindesteuern: Beschreibung, Beurteilung und Verwendbarkeit

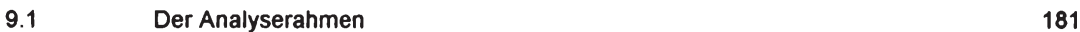

$\begin{array}{llr}9.1 .1 & \text { Beschreibung der Vorgehensweise } & 181\end{array}$

9.1.2 Allgemeine Effizienzaspekte 182

9.1.3 Besondere Bewertungskriterien für kommunale Steuern $\quad 184$

$\begin{array}{llr}\text { 9.1.3.1 Lokale Kriterien allokativer Natur } & 184\end{array}$

\begin{tabular}{lr} 
9.1.3.2 & Lokale Kriterien stabilitătspolitischer Natur \\
\hline 9
\end{tabular}

$\begin{array}{llr}9.2 & \text { Einwohnerbezogene Steuerformen } & 191\end{array}$

9.2.1 Verknüpfte kommunale Einkommensteuer $r 191$

$\begin{array}{llr}9.2 .2 & \text { Eigenstăndige lokale Einkommensteuer } & 193\end{array}$

9.2.3 Einwohner- bzw. Bürgersteuer 196

9.2.3.1 Das Konzept der Kopfsteuer als Basis einer kommunalen Einwohnersteuer 197

9.2.3.1.1 Allokationswirkungen einer nationalen Kopfsteuer 197

9.2.3.1.2 Allokationswirkungen einer "lokalen Kopfsteuer" 198

$\begin{array}{llr}\text { 9.2.3.2 } & \text { Einwohnersteuer und Distribution } & 202\end{array}$

9.2.3.3 Die Eignung der Einwohnersteuer als Gemeindesteuer 203

$9.3 \quad$ Produktionsbezogene Steuerformen 206

9.3.1 Der Analyserahmen: Ein neoklassisches Investitionsmodell 207

$\begin{array}{llr}\text { 9.3.2 Die Gewerbesteuer } & 211\end{array}$

$\begin{array}{lll}\text { 9.3.2.1 Skizzierung der Gewerbesteuer } & 211\end{array}$

9.3.2.2 Allokative Wirkungen der Gewerbesteuer $\quad 212$

$\begin{array}{llr}\text { 9.3.2.3 Die Eignung der Gewerbesteuer als Gemeindesteuer } & 217\end{array}$

$\begin{array}{llr}\text { 9.3.3 Die Wertschöpfungsteuer } & 219\end{array}$

$\begin{array}{lll}\text { 9.3.3.1 Skizzierung der Wertschøpfungsteuer } & 220\end{array}$

$\begin{array}{lll}\text { 9.3.3.2 Allokative Wirkungen der Wertschöpfungsteuer } & 222\end{array}$

9.3.3.3 Die Eignung der Wertschopfungsteuer als Gemeindesteuer $\quad 224$

$\begin{array}{lll}\text { 9.3.4 Die Cash-flow-Steuer } & 230\end{array}$

9.3.4.1 Skizzierung der Grundzüge der Cash-flow-Besteuerung 231

9.3.4.2 Allokative Wirkungen der Cash-flow-Steuer 2233

9.3.4.3 Die Eignung der Cash-flow-Steuer als Gemeindesteuer $\quad 235$

$\begin{array}{lll}\text { 9.3.5 Die Umsatzsteuerbeteiligung der Gemeinden } & 238\end{array}$

$\begin{array}{lll}\text { 9.3.5.1 Die Grundkonzeption } & 238\end{array}$

9.3.5.2 Allokative Wirkungen der Umsatzsteuer(-beteiligung) 239

9.3.5.3 Die Umsatzsteuerbeteiligung als Finanzierungskomponente des kommunalen Steuersystems

9.3.5.3.2 Die Beurteilung alternativer Verteilungsschlüssel 242

9.3.6 Der Vorschlag einer Umsatzsteuerbeteiligung mit modifiziertem Hebesatzrecht

\begin{tabular}{llr} 
9.3.6.1 Skizzierung des Vorschlags & 244 \\
\hline & Allokative Beurteilung & 245
\end{tabular} 
9.3.6.3 Die Eignung des Vorschlags hinsichtlich der Einordnung in ein Gemeindesteuersystem

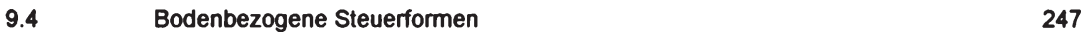

9.4.1 "Traditionelle" Grundsteuer 247

$\begin{array}{lll}\text { 9.4.1.1 Skizzierung } & 247\end{array}$

9.4.1.2 Bewertung 248

9.4.2 Ein alternativer Ansatz: Die (ăquivalenzorientierte) "Grundsteuer neuer Art" 250

$9.5 \quad$ "Exportbezogene" Steuerformen 254

9.5.1 Wirkungsweise einer kommunalen Einzelhandelsumsatzsteuer 254

9.5.2 Allokative und raumwirtschaftliche Wirkungen einer kommunalen Einzelhandelsumsatzsteuer 256

9.5.3 Die Eignung der kommunalen Einzelhandelsumsatzsteuer als Gemeindesteuer 262

10. Finanzzuweisungen als Einnahmekategorie der Kommunen 267

$10.1 \quad$ Okonomische Begründungen 267

$10.2 \quad$ Arten und Zielsetzungen 268

10.2.1 Zuweisungsarten 268

$\begin{array}{lll}\text { 10.2.2 Zielsetzungen } & 270\end{array}$

10.2.2.1 Finanzzuweisungen als Instrument zur Internalisierung răumlicher externer 270

10.2.2.2 Finanzzuweisungen zur Sicherung eines bestimmten Versorgungsniveaus sowie zur Gewăhrleistung von Mindeststandards $\quad 271$

$\begin{array}{lll}\text { 10.2.2.3 Fiskalische Ungleichgewichte } & 274\end{array}$

10.2.2.3.1 Vertikale fiskalische Ungleichgewichte 274

10.2.2.3.2 Horizontale fiskalische Ungleichgewichte 275

$\begin{array}{lll}10.3 & \text { Wirkungsweise } & 278\end{array}$

10.3.1 Zuweisungen mit allokativer Zielsetzung 278

10.3.1.1 Modelliahmen 278

$\begin{array}{ll}\text { 10.3.1.2 Wirkungsanalyse } & 279\end{array}$

10.3.1.2.1 "Klassische" Ansătze $\quad 279$

$\begin{array}{lll}\text { 10.3.1.2.2 Bürokratiemodelle } & 288\end{array}$

10.3.2 Zuweisungen mit "distributiver" Zielsetzung - "Equalization grants" und lokale 294

$10.4 \quad$ Gesamtbeurteilung 298

11. Grundstrukturen eines kommunalen Finanzsystems 301

Die Vorteilhaftigkeit kommunaler Finanzautonomie - Zusammenfassung we-
sentlicher Ergebnisse

11.2 Grundstruktur eines kommunalen Finanzsystems 305

11.2.1 Ausschopfung der Gebührenpotentiale 307

11.2.2 Erhebung aquivalenzorientierter Steuern 308

11.2.2.1 Von der einzelsteuerlichen Beurteilung zur Konstruktion eines Steuersystems $\quad 308$

11.2.2.2 Zur Notwendigkeit eines mehrgliedrigen gemeindlichen Steuersystems $\quad 309$

11.2.2.3 Teilkomponenten eines aquivalenzorientierten Gemeindesteuersystems 311

11.2.2.3.1 Einwohnerbezogene Komponente 312

$\begin{array}{lll}\text { 11.2.2.3.2 } & \text { Produktionsbezogene Komponente } & 315\end{array}$

11.2.2.3.3 Bodenbezogene Komponente 316 
11.2.2.3.4 "Exportbezogene" Komponente

11.2.3 Ergănzende Gewăhrung von Finanzzuweisungen

11.3

Zusammenfassende Darstellung der Saulen eines kommunalen Finanzsystems

12. Zur Frage der politischen Durchsetzbarkeit und Realisierbarkeit neugestalteter kommunaler Finanzierungssysteme

$12.1 \quad$ Das Gemeindefinanzsystem der Bundesrepublik Deutschland 323

12.1.1 Die verfassungsrechtliche Stellung der Gemeinden 323

12.1.2 Die gegenwärtige Finanzsituation der Gemeinden 327

12.1.2.1 Die Finanzsituation der Gemeinden im alten Bundesgebiet 327

12.1.2.2 Die Finanzsituation der Gemeinden in den neuen Lăndern 329

12.2 Die einzelnen Elemente des bundesdeutschen Gemeindefinanzsystems 330

12.2.1 Gemeindesteuem 330

$\begin{array}{llr}\text { 12.2.1.1 Die Realsteuem } & 331\end{array}$

$\begin{array}{lll}\text { 12.2.1.1.1 Gewerbesteuem } & 333\end{array}$

$\begin{array}{llr}\text { 12.2.1.1.2 Grundsteuem } & 335\end{array}$

12.2.1.2 Der Gemeindeanteil an der Einkommensteuer 336

12.2.1.3 Örtliche Verbrauch- und Aufwandsteuern $\quad 337$

$\begin{array}{lll}12.2 .2 & \text { Zuweisungen } & 338\end{array}$

$\begin{array}{ll}\text { 12.2.2.1 Der kommunale Finanzausgleich } & 339\end{array}$

$\begin{array}{llr}\text { 12.2.2.2 Interkommunale Transfers } & 340\end{array}$

$\begin{array}{llr}\text { 12.2.3 Gebühren und Beitrăge } & 340\end{array}$

12.2.4 Weitere Einnahmen $\quad 342$

$\begin{array}{ll}\text { 12.2.5 Kommunale Verschuldung } & 342\end{array}$

12.3 Zur Notwendigkeit einer Gemeindefinanzreform in der Bundesrepublik $\begin{array}{ll}\text { Deutschland } & 344\end{array}$

$\begin{array}{llr}\text { 12.3.1 } & 344 \\ 12.3 .2 & 344\end{array}$

$\begin{array}{ll}\text { 12.3.2 Lósungswege } & 350\end{array}$

$\begin{array}{lll}\text { 12.3.2.1 Vorbemerkungen } & 350\end{array}$

12.3.2.2 Grundstrukturen eines reformierten kommunalen Finanzsystems 351

12.3.2.2.1 Produktionsbezogene Komponente $\quad 352$

12.3.2.2.2 Einwohnerbezogene Komponente $\quad 355$

$\begin{array}{llr}\text { 12.3.2.2.3 Bodenbezogene Komponente } & 358\end{array}$

12.3.2.2.4 "Exportbezogene" Komponente $\quad 359$

12.3.2.3 Mogliche Ergănzungsteuern eines effizienz-orientierten kommunalen Steuersystems

12.3.2.3.1 Weitere aktuelle Vorschlăge 360

$\begin{array}{lll}\text { 12.3.2.3.2 } & \text { Beurteilung dieser Vorschläge } & 361\end{array}$

12.3.2.3.2.1 Kommunale Mineralolsteuer(-beteiligung) und deren Eignung als Komponente eines Gemeindesteuersystems

12.3.2.3.2.2 Kommunale Kraftfahrzeugsteuer und deren Eignung als Komponente eines Gemeindesteuersystems

12.3.2.4 Abschließende Bewertung des vorgestellten Gesamtkonzepts 368

$12.4 \quad$ Ergănzende politisch-institutionelle Aspekte 368

12.5 Beurteilung der aktuellen finanz- und steuerpolitischen Lage aus kommunaler Sicht 
13. AbschlieBende Bemerkungen 


\section{Verzeichnis der Tabellen und Schaubilder ${ }^{\mathrm{a})}$}

Tabelle 2.1

Tabelle 8.1

Tabelle 9.1

Tabelle 10.1

Tabelle 11.1

Tabelle 11.2

Tabelle 12.1

Tabelle 12.2

Tabelle 12.3

Tabelle 12.4

Tabelle 12.5

Tabelle 12.6

Tabelle 12.7

Tabelle 12.8

Schaubild 12.1

Schaubild 12.2

Schaubild 12.3
Allokationsverfahren für offentliche Güter

Abgrenzung von Benutzungsgebühren und Beitrăgen

167

Zusammenstellung der Zahlungsströme

208

Zuweisungsarten

270

Rangfolge der Finanzquellen der kommunalen Ebene gemaß des jeweiligen Grades fiskalischer Autonomie

Struktur eines kommunalen Finanzsystems

Die Steuereinnahmen des Bundes, der Lănder und der Gemeinden

Ausgaben, Einnahmen und Finanzierungssalden der Gemeinden (GV) in den alten Lăndern

Struktur der kommunalen Einnahmen (Kommunen West)

Kommunale Einnahmen in den neuen Lăndern

Struktur und Zusammensetzung der gemeindlichen Steuereinnahmen

Struktur der staatlichen Zuweisungen

Einnahmen der Gemeinden aus Gebühren und Beiträgen

Kommunale Verschuldung

a) Bei der Kennzeichnung der Tabellen und Schaubilder gibt die erste Zahl das entsprechende Kapitel an, in dem diese zu finden sind; die zweite Zahl spiegelt die laufende Numerierung der Tabellen bzw. Schaubilder im Kapitel wider. 
Hans-Georg Napp - 978-3-631-75263-0

Downloaded from PubFactory at 01/11/2019 06:33:05AM

via free access 
"The federal system was created with the intention of combining the different advantages which result from the magnitude and the littleness of nations"

Alexis de Tocqueville

\section{Einleitung}

Obwohl die Notwendigkeit einer Reform des Gemeindefinanzsystems weitestgehend anerkannt wird, tut sich die Politik mit konkreten Reformmaßnahmen schwer. Einerseits scheiterten viele in der jüngeren Vergangenheit unterbreitete Reformvorschläge am Widerstand der potentiellen "Verlierer", andererseits führten die meisten der aus steuerpolitischen Gründen vorgenommenen Eingriffe in die Gewerbesteuer zur fortgesetzten Aushöhlung der kommunalen Finanzautonomie. Geradezu zwangsläufig präsentiert sich die Reform des kommunalen Finanzsystems daher als ein Dauerthema, das auch gegenwärtig wieder im Brennpunkt des Interesses steht (vgl. etwa Wissenschaftlicher Beirat, 1982; Leibfritz, 1984; Karrenberg, 1986; Gewerkschaft Öfentliche Dienste, Transport und Verkehr, 1987; Kommission zur Verbesserung der steuerlichen Bedingungen für Investitionen und Arbeitsplätze, 1991, 221ff; Karrenberg/Münstermann, 1992, 117; Schäfer, 1992b).

Im Rahmen der Diskussionen sind zwei Argumentationsebenen vorzufinden, die sich hinsichtlich der unterschiedlichen Reichweite der vorgeschlagenen Reformen voneinander abgrenzen lassen. Auf der einen Seite gibt es Forderungen nach einer umfassenden Emeuerung des Gemeindefinanzsystems mit seinen Teilkomponenten Gebühren und Beiträge, Gemeindesteuern sowie Zuweisungen (Finanzausgleich). Auf der anderen Seite - und dies gilt für die Mehrzahl der Beiträge - konzentriert sich die Reformdiskussion auf eine Modifizierung des kommunalen Steuersystems und hier insbesondere auf die Gewerbesteuer, d.h. deren Ersatz, Abschaffung oder Revitalisierung.

Innerhalb der umfangreichen Reformdiskussionen fällt jedoch auf, daß die Vorschläge (gleich welcher Ausrichtung) oft sehr vordergründige (interessenbezogene) Rechtfertigungen erfahren. Diese Tatsache ist wohl mit dafür verantwortlich, daß es trotz mannigfaltiger Erörterungen in Wissenschaft und Politik bis auf die Gemeindefinanzreform des Jahres 1969 (BGBl. I, S. 1587) nur sehr wenige echte Reformschritte mit entsprechenden Auswirkungen auf die Gemeindefinanzen gegeben hat. Gleichwohl wurden die Gemeindefinanzen im Rahmen von Steuerrechtsänderungen und anderen bundesgesetzlichen Regelungen häufig berührt (vgl. Napp, 1993, 2ff); am häufigsten waren dabei Änderungen der Gewerbesteuer. Dazu kann festgehalten werden, daß bei 
den angesprochenen steuerpolitischen Eingriffen des Bundesgesetzgebers die kommunale Ebene zwar zumeist einen vollen Ausgleich für die mit den Steuerrechtsänderungen verbundenen Einnahmenausfälle erhalten hat, gerade aber die Eingriffe in die Gewerbesteuer den eigentlichen Charakter dieser Abgabe als Objektsteuer und damit die autonome Ausgestaltung durch die Gemeinden sehr eingeschränkt haben.

Das bestehende Gemeindefinanzsystem ist durch eine zunehmende und nicht bedarfsgerechte Streuung der Gewerbesteuereinnahmen gekennzeichnet, die trotz des teilweise stark nivellierenden kommunalen Finanzausgleichs zu erheblichen Finanzkraftunterschieden geführt hat. Neben die Stadt-Land-Disparitäten ist ein ausgeprägtes SüdNord-Gefälle und eine Abkoppelung altindustrieller Problemkommunen getreten (vgl. Junkemheinrich, 1991, 37ff). Des weiteren ist ein Umverteilungsprozeß des Gemeindeanteils an der Einkommensteuer zu Lasten der Kernstädte sowie der Regionen mit einer ungünstigen Wirtschaftsstruktur beobachtbar (vgl. Held/Hötker/Junkernheinrich, 1992, 89). Gerade in den Regionen, die von Strukturkrisen betroffen sind (beispielsweise das Ruhrgebiet, das Saarland oder die Werftenregionen), kumulieren beide Prozesse. Die Abwanderung von jungen, einkommensstarken Bevölkerungsgruppen ins Umland entzieht den Kernstädten Einkommensteueranteile, während gleichzeitig die Zahl einkommensschwacher Einwohner, die im wesentlichen von Transfereinkommen leben, ansteigt.

Trotz dieses Handlungsbedarfs befindet sich die Reform des Gemeindesteuersystems politisch in einer Sackgasse. Obwohl - wie eingangs bereits beschrieben - die Notwendigkeit einer Reform allseits anerkannt wird, unterliegt das politisch-administrative System seit geraumer Zeit einer "Selbstblockade". Auf der einen Seite stehen die Kommunen mit unterschiedlichen Verteilungsinteressen von Städten und Gemeinden (also etwa von altindustriellen Problemkommunen, modernen Ballungszentren, verdichteten Umlandgemeinden oder ländlich strukturierten Gemeinden); auf der anderen Seite stehen die Steuerzahler (Einkommensteuerzahler und insbesondere die örtliche Wirtschaft) mit ebenfalls unterschiedlichen Interessen. Das Durchsetzungspotential der Politik scheint angesichts dieses komplexen Interessengefüges und des praktisch vollständigen Verzichts auf einen konzeptionellen Reformvorschlag durch die Bundesregierung begrenzt zu sein.

Dieser empirische Befund ist Motivation und Ausgangspunkt für eine systematische Betrachtung von Anforderungen an ein kommunales Finanz(Steuer-)system. Diese Analyse soll unter Effizienzgesichtspunkten durchgeführt werden. Es ist folglich Ziel und Anliegen dieser Arbeit, die Effizienzaspekte kommunaler Autonomie und deren Bedeutung für die Ausgestaltung eigenständiger Finanzierungssysteme offenzulegen. Die dabei gewonnenen Ergebnisse sollen schließlich helfen, dem konstatierten Hand- 
lungsbedarf gerecht zu werden und aus theoretischer Sicht die Grundstrukturen eines Gemeindefinanzsystems zu entwerfen, das die wesentlichen Zielvorstellungen erfüllt und möglicherweise infolge dieser Vorzüge auch politische Durchsetzungschancen beinhaltet.

\subsection{Wirtschaftstheoretische Problemstellung}

Die Bedeutung staatlich angebotener Güter und Dienstleistungen und damit ihr Anteil am Sozialprodukt ist heutzutage fast fünfmal so hoch wie in den Zeiten, als der "Zehnt" die entscheidende Finanzierungsquelle des Staates war (vgl. Schultz, 1986). Diese Entwicklung stellt Wissenschaft und Praxis vor die Aufgabe, Antworten darauf zu geben, wie auch in der Staatswirtschaft knappe Ressourcen effizienter eingesetzt werden können und wie Nutzen und Lasten der öffentlichen Leistungen "gerecht" zu verteilen sind. Dabei geht es nicht um die populärwissenschaftliche Diskussion des "richtigen" Niveaus öffentlicher Ausgaben (also um die Höhe des Staatsanteils an sich), sondern vielmehr um eine "entsprechende" Struktur des öffentlichen Leistungsangebots und dessen möglichst effiziente Bereitstellung. Die Suche nach entsprechenden Lösungen ist trotz des "free rider"-Problems und der fehlenden Präferenzoffenbarung eine Aufgabe, der zumindest partiell Erfolge beschieden sein könnten.

Aus der obigen Aufgabenstellung resultierte zunächst die wohlfahrtsökonomische Suche nach dem "optimalen" Budget als einem der zentralen Anliegen der Finanzwissenschaft (vgl. Mackscheidt, 1973) und später der Versuch der Steuertheorie, eine (die) unter ökonomischen Effizienzkriterien (pareto-)optimale Ausgestaltung einzelner Steuern bzw. des Steuersystems aufzuzeigen ("optimal taxation"). ${ }^{1}$

Nach herrschender Auffassung stehen öffentliche Güter infolge ihrer spezifischen Merkmale prinzipiell allen Staatsbürgern in gleichem Ausmaß zur Verfügung (vgl. Musgrave, 1959). Aufgrund des Fehlens bzw. der Nichtidentifizierbarkeit individueller Präferenzen für öffentliche Güter übernimmt in der Regel die normative Budgetregel von der Gleichheit der Grenznutzen die Funktion der Aufteilung der Mittel auf die einzelnen Aufgabenbereiche, d.h. die Effizienz der Mittelverwendung wird durch Opportunitätskosten gesteuert. Es fehlt aber auch bei dieser Vorgehensweise an einer Norm zur Bestimmung der eigentlichen Budgethöhe. Zur Lösung dieses Problems sind eine Reihe von Ansätzen entstanden, die auf eine Bestimmung des bestmöglichen Umfangs

\footnotetext{
${ }^{1}$ Der Beginn der "optimal taxation"-Debatte kann im angelsăchsischen Sprachraum in den Arbeiten von Mirrlees (1971) sowie Diamond/Mirrlees (1971) gesehen werden. An diese Ansätze schloß sich rasch eine rege Diskussion an, die vor allem mit Namen wie Atkinson, Boadway, Fair, Sandmo und Stiglitz verbunden ist. Einen aktuellen Überblick der steuertheoretischen und -politischen Ansätze liefert Kay (1990).
} 
der öffentlichen Ausgaben (die "optimale" Budgethöhe) abzielen. Unter dem Einfluß der Grenznutzenlehre ${ }^{2}$ hat die Finanzwissenschaft lange Zeit angenommen, man könne die vom Staat bereitzustellenden Leistungen (Umfang und Art betreffend) inhaltlich festlegen. Die Ergebnisse waren und sind jedoch für praktische Lösungen nahezu ungeeignet, da sie die politischen Entscheidung kaum erleichtern, wenn sie auch formal höchst ansprechend gefaßt sein mögen.

Die Ansätze im Bereich der "optimal taxation", die von einer gegebenen Ausgabenhöhe ausgehen, haben die Zielsetzung, die zur Finanzierung des jeweiligen staatlichen Leistungsangebots notwendigen Deckungsmittel möglichst effizient zu beschaffen. Dabei sind folgende Wesensmerkmale vorzufinden:

- Entwicklung von Lösungen (zur Erreichung einer "optimalen Lastverteilung" der Finanzierungsbeiträge des einzelnen zum öffentlichen Leistungsangebot) in ökonomischen Modellen, denen die Hypothesen des neoklassischen Grundmodells zugrunde liegen.

- Ableitung einer optimalen Ausgestaltung (Struktur) des Steuersystems als Ganzes oder einzelner Steuern unter ökonomischen Effizienzkriterien (Pareto-Optimalität).

- Beschränkung des Lösungsraumes auf "second best"-Lösungen, da erstbeste Ergebnisse sich lediglich bei unter Verteilungsgesichtspunkten nicht akzeptablen Pauschsteuern einstellen würden. Diese Beschränkung deutet an, daß die Allokationseffizienz nicht das alleinige Kriterium für die Wahl der Steuerform sein kann. Daher lassen sich innerhalb der "optimal taxation" solche Analysen unterscheiden, die allein auf das Allokationsziel gerichtet sind, und solche, die darüber hinaus auch der Verteilungszielsetzung Beachtung schenken (unter Verwendung sozialer Wohlfahrtsfunktionen). Beiden Zielsetzungen im Rahmen der "Theorie der optimalen Besteuerung" liegt dabei jedoch die ausschließliche Betrachtung der Finanzierungsseite bei vorgefundenem (unterstellten) Ausgabenniveau zugrunde; angestrebt wird die allokationsneutrale Finanzierung eines gegebenen (öffentlichen) Gütervolumens (vgl. auch Dick/Tiepelmann, 1988).

Beiden bedeutsamen Schwerpunkten finanzwissenschaftlicher Forschung sind somit einige Defizite anzulasten. Die Festlegung eines "optimalen Budgets" zielt zu sehr auf Ergebnisse kollektiver Entscheidungen ab, beschäftigt sich also zu wenig mit den

2 Die wohl erste grenznutzen-theoretische Regel für den offentlichen Haushalt lieferte Schăffle $(1880,16)$ mit seinem "Prinzip der verhältnismäßigen Deckung sowohl der staatlichen als der nicht-staatlichen Bedarfe". Konkrete Verfahrensanweisungen erarbeitete spăter Sax (1887, 297ff); weitere wesentliche Erklärungsversuche für die optimale Ausgabenhöhe sowie entsprechende Diskussionsbeiträge findet man bei Lindahl (1919), Bowen (1948), Samuelson (1954; 1958; 1969), Downs (1960), Colm (1965), Hedtkamp (1967), Pahlke (1967) sowie Musgrave (1970). 
eigentlichen Verfahren ${ }^{3}$ selbst. Die "optimal taxation" konzentriert sich bei gegebenem Budgetvolumen im wesentlichen auf die Einnahmenseite und ihre effiziente Ausgestaltung. Unter Berücksichtigung dieser Kritikpunkte (die jeweils andere Budgetseite wird ausgeklammert) hat zunehmend auch die Beschäftigung der Finanzwissenschaft mit der Frage, wie man eine möglichst große "Übereinstimmung" über die Versorgung mit gemeinschaftlich nutzbaren Gütern (einschließlich ihrer Finanzierung) erreichen kann (so Mackscheidt, 1973, 3), Bedeutung erlangt. In diesem Zusammenhang spielt die "Präferenzerkundung" für öffentliche Güter eine wichtige Rolle.

Je stärker jedoch die Suche nach einem "Konsens" bezüglich der Bereitstellung öffentlicher Leistungen in den Mittelpunkt des Interesses rückt, desto offenkundiger wird, $\mathrm{da} ß$ die Vorstellung, beim Staat handele es sich um einen "monolithischen Block" (Kirsch, 1977, 9), zu grob und damit für Erkenntnisgewinne wenig hilfreich ist. Vielmehr gilt es, die Möglichkeit einer föderalen Ausgestaltung eines Staatswesens in die finanztheoretische Analyse aufzunehmen.

Dies wird um so wichtiger, wenn man bedenkt, daß sich nicht nur der Staatsanteil, sondern auch die Struktur der öffentlichen Ausgaben gewandelt hat (vgl. dazu Timm, 1961, 201ff; Albers, 1964, 835ff; Hansmeyer, 1967, 197ff sowie Recktenwald, 1977a, 715ff). Dominierten einst die rein hoheitlichen Tätigkeiten des Zentralstaates, so stehen heute im wesentlichen Versorgungsleistungen im Vordergrund, die regional (und auch personell) oft höchst ungleich verteilt sind.

Diese Entwicklung wirft die Frage auf, wie die räumliche Gliederung der Staatswirtschaft selbst die Effizienz staatlicher Aktivitäten beeinflußt. Der Föderalismus wird somit zum Erkenntnisgegenstand der ökonomischen Wissenschaft. Im Unterschied zu verfassungsrechtlichen (also juristischen) oder politischen Erklärungsansätzen (vgl. Stern/Burmeister, 1975; Stern, 1977, 297ff; Hill, 1987, 18ff), die sich in erster Linie mit der "Machtverteilung" zwischen der zentralen und der regionalen/lokalen Ebene befassen, analysiert die Ökonomie die Aufgaben- bzw. Ausgabenverteilung und/oder die Finanzierungskompetenzen zwischen den einzelnen gebietskörperschaftlichen Ebenen (vgl. dazu die Bemerkungen in Abschnitt 1.2).

\footnotetext{
${ }^{3}$ Gemeint sind mit diesen Verfahren nicht nur die kollektiven Entscheidungsprozesse und ihre Ergebnisse im Sinne der "Public Choice"-Ansătze (Mueller, 1979), sondern darüber hinaus insbesondere die wohlfahrtsökonomische Betrachtung bestimmter Allokationsverfahren (Hurwicz, 1960; 1972; 1973) für öffentliche Güter und die Bedeutung dieser Allokationsverfahren für die Versorgung einer Volkswirtschaft mit entsprechenden Leistungen (vgl. Blümel, 1987). Einen Überblick über diesen Forschungsgegenstand geben Conn (1978) sowie Pethig (1979, 137ff; 1985).
} 
Diese Vorgehensweise soll auch in dieser Arbeit im Mittelpunkt stehen, wobei das Schwergewicht der Ausführungen gemäß der Themenstellung im Bereich der Kommunen bzw. der lokalen Ebene und ihrer ökonomischen Bedeutung liegt. Dabei sollen Effizienzaspekte (Wohlfahrtsgesichtspunkte) der lokalen Bereitstellung öffentlicher Leistungen sowie ihrer Finanzierung analysiert werden. Letztlich sollen, sofern möglich, Rahmenbedingungen für eine effiziente Ausgestaltung kommunaler Finanzierungssysteme aufgezeigt werden, die via "Verknüpfung" des lokalen öffentlichen Leistungsangebots und seiner Finanzierung gemäß des "Prinzips der fiskalischen Äquivalenz" für entsprechende Ergebnisse sorgen.

\subsection{Föderalismustheoretische Vorbemerkungen}

In Anlehnung an die Funktionen des öffentlichen Sektors (vgl. Musgrave, 1959, 5), nämlich den effizienten Einsatz der Ressourcen zu sichern (Allokationsfunktion), eine bestimmte Einkommensverteilung zu gewährleisten (Distributionsfunktion) und ein hohes Beschäftigungsniveau bei vertretbarer Preisstabilität in einer Volkswirtschaft zu bewahren (Stabilisierungsfunktion), wurde im Rahmen der Föderalismusdiskussion die Aufgabenverteilung innerhalb eines Staatsgebildes und damit die Struktur des möglichen Aufbaus untersucht. Oates (1972) kam zu dem Ergebnis, daß sowohl die Lösung des Distributions- als auch des Stabilisierungsproblems in einem durch weitgehende Dezentralisierung des öffentlichen Sektors gekennzeichneten System nur bedingt erreicht werden kann. Er konstatiert, daß der Gemeindehaushalt zur Verwirklichung personeller Verteilungsziele generell kaum geeignet ist, weil erhebliche lokale Unterschiede der Steuer- und Transfersätze zu unerwünschten Wanderungsbewegungen (vgl. auch Tiebout, 1956) Anlaß geben könnten. Vollbeschäftigung, Preisniveaustabilität oder gar außenwirtschaftliches Gleichgewicht können aufgrund der erheblichen Restriktionen, denen Kommunen und Regionen bei der Steuerung des aggregierten Niveaus ökonomischer Aktivitäten innerhalb ihres Hoheitsgebiets unterliegen, ebenfalls wirkungsvoller über die zentralen Budgets beeinflußt werden. Aus diesem Grund ist eine Wahrnehmung dieser Aktivitäten (öffentliche Leistungserstellung mit nationaler Reichweite) durch die Zentralinstanz anzustreben (vgl. Oates, 1972, 4ff).

Auf der anderen Seite sprechen im Bereich der Allokationsfunktion ${ }^{4}$ des Staates wichtige Gründe für eine dezentrale Verteilung der Aufgabenkompetenz und damit für

\footnotetext{
${ }^{4}$ Aktivităten der sogenannten Allokationsabteilung haben das Ziel, die optimale Allokation der Ressourcen zu ermoglichen bzw. zu sichern. Diese Zielsetzung verlangt, daß zum einen mit den vorhandenen Produktionsfaktoren ein Maximum an Gütern und Leistungen hergestellt wird und zum anderen die Produktion an die Präferenzen der Wirtschaftssubjekte weitestgehend angepaßt wird. Vgl. hierzu Musgrave $(1959,6 \mathrm{ff})$ sowie Peffekoven $(1988,611)$.
} 
einen hohen Autonomiegrad der Kommunen. So ist eines der Hauptargumente für die Forderungen nach Dezentralisierung auf dem Gebiet der öffentlichen Finanzwirtschaft die grundlegende Unfähigkeit zentraler Entscheidungsträger, auf die regional unter Umständen erheblich variierenden Präferenzen der Staatsbürger bei ihrer jeweiligen Leistungsbereitstellung Rücksicht zu nehmen.

Werden alle öffentlichen Güter von der Zentralregierung bereitgestellt, so ergäbe sich in allen Kommunen ein gleiches Angebotsniveau. Doch gerade diese einheitlichen Konsumniveaus können sich als nicht effizient herausstellen, weil unterschiedliche Präferenzen der Einwohner unberücksichtigt blieben. Hätte jede Kommune Entscheidungsbefugnis in bezug auf das Angebot des betreffenden öffentlichen Gutes, würde sich die ökonomische Effizienz aufgrund der größeren Sensitivität für Präferenzen der Mitglieder einer Kommune erhöhen. Je kleiner eine Gebietskörperschaft ist, um so wahrscheinlicher ist es, daß ein einzelnes Individuum Einfluß nehmen und damit seine Präferenzen zur Geltung bringen wird. Auch auf der untersten Ebene wird es zwar Minderheiten geben, die sich den Wünschen der Mehrheit unterordnen müssen (was ökonomisch gesehen Wohlfahrtsverluste bedeutet), aber die Zahl der Wirtschaftssubjekte, deren Präferenzen als Minderheit übergangen werden, ist üblicherweise geringer als bei zentralisiertem Leistungsangebot. Ein dezentralisiertes Regierungssystem verspricht daher eine höhere ökonomische Effizienz, weil die Struktur des öffentlichen Angebots den differierenden Ansprüchen der Nachfrager gerechter wird. ${ }^{5}$

Die Möglichkeit einer Wohlfahrtssteigerung durch Dezentralisierung wird ferner durch das Phänomen der "consumer mobility" (Tiebout, 1956, 416ff) verbessert. In einem dezentralisierten öffentlichen Gemeinwesen führt die Vielzahl lokaler Entscheidungskollektive zu einem differenzierten Leistungsangebot, das den Bürgern der einzelnen Kollektive die Möglichkeit eröffnet, durch "Abstimmung mit den Füßen" jene Kommune zu wählen, deren Angebotsniveau ihren Präferenzen am ehesten entspricht. ${ }^{6}$ Dieser Mechanismus bewirkt, daß die Ressourcen effizienter eingesetzt werden.

Des weiteren führt Dezentralisierung zu vermehrtem Experimentieren und Innovieren bei der Erstellung öffentlicher Leistungen. Dieser aus einer großen "Produzentenzahl"

\footnotetext{
5 Die entsprechenden Ausführungen gelten jedoch nur unter der Prămisse, daß die Prăferenzen in kleineren Kollektiven homogener sind als in größeren. Dies muß nicht unbedingt der Fall sein. Des weiteren ist vorstellbar, daß übergeordnete (größere) Gebietskörperschaften differenziertere Leistungen anbieten und daher Minderheitenprăferenzen berücksichtigen können.

6 Voraussetzung für ein solchen Verhalten der Wirtschaftssubjekte ist ihre hinreichende Mobilităt. In diesem Zusammenhang sind die Wanderungskosten der einzelnen Bürger zu beachten, die den zusătzliche Nutzen aus dem alternativen Angebot offentlicher Leistungen kompensieren oder gar überkompensieren können. Schließlich sind über die Herstellung der "fiskalischen Äquivalenz" auch die in den einzelnen Regionen zu zahlenden Steuern zu berücksichtigen. Vgl. zur Problematik u.a. Buchanan/Goetz (1972, 37ff).
} 
resultierende Konkurrenzdruck erzwingt tendenziell die Anwendung der effizientesten Produktionstechnik. Auch unter diesem Aspekt könnte man von einem dezentralisierten Staatsgebilde mehr ökonomische Effizienz erwarten. ${ }^{7}$

Bisher wurde bei der Begründung dezentraler öffentlicher Leistungserstellung in erster Linie die Ausgabenseite und damit das Angebot an sich betrachtet. In Zusammenhang mit der angestrebten Thematik ist insbesondere Oates' Argumentation in bezug auf die Finanzierung der öffentlichen Güter durch Steuern von entscheidender Bedeutung. Für den Staatsbürger sollen die Steuern den Charakter von Preisen bzw. Kosten der öffentlichen Leistungen, die ihm angeboten werden, erhalten (vgl. auch Buchanan, 1967, 88). Das Individuum soll durch den Zusammenhang zwischen Kosten und Nutzen in Verbindung mit lokalen Wahlentscheidungen angeregt werden, seine Präferenzen für öffentliche Güter - zumindest ansatzweise - offenzulegen und so zu einer verbesserten Allokation der Ressourcen beitragen (vgl. Oates, 1972, 127).

Es bleibt somit zunächst festzuhalten, daß ein dezentralisierter öffentlicher Sektor folgende ökonomisch erwünschte Kennzeichen aufweist. Erstens stellt er eine Möglichkeit dar, die Konsumniveaus öffentlicher Güter an den Präferenzen von Subgruppen der Gesellschaft auszurichten. ${ }^{8}$ Zweitens kann Dezentralisierung die Effizienz bei der Produktion und Bereitstellung öffentlicher Güter erhöhen, indem Innovationen gefördert und Kommunen über den Konkurrenzdruck zum effizientesten Produktionsverfahren veranlaßt werden. Drittens kann der mit einem dezentralisierten System verbundene institutionelle Rahmen die öffentliche Entscheidungsfindung dahingehend verbessern, daß eine engere Beziehung zwischen öffentlichen Leistungen und deren (Bereitstellungs-)Kosten hergestellt wird (vgl. Oates, 1972, 11ff).

\footnotetext{
${ }^{7}$ Die entsprechenden Ausfuihrungen lassen erkennen, daß Oates im Rahmen seines Ansatzes eine gewisse Marktmodell-Analogie bei der Analyse des Foderalismusproblems unterstellt (vgl. Marcus, 1986, 23).

${ }^{8}$ Das gilt jedoch nur, soweit die offentlichen Leistungen tatsăchlich ausgerichtet auf die individuellen Prăferenzen angeboten werden sollen. Es kann allerdings auch das Ziel des Staates sein, aus gesamtwirtschaftichen Überlegungen beim Angebot von offentlichen Leistungen gegen die Präferenzen der Bürger einer Region zu verstoßen (Fall der "social wants"; Musgrave, 1959, 9ff). Eine solche Situation beschreibt Frey (1977, 35) anhand eines treffenden Beispiels. Eine vergleichbare Argumentation ergibt sich, wenn in einem foderativen Staat (wie etwa der Bundesrepublik Deutschland) eine "Einheitlichkeit der Lebensverhăltnisse" [Art. 72 Abs. 2 GG in Verbindung mit Art. 105 Abs. 2 GG, Art. 9la Abs. 1 Nr. 2 GG (Gemeinschaftsaufgabe "Verbesserung der regionalen Wirtschaftsstruktur"), Art. 104a Abs. 4 GG (Sonderkompetenz des Bundes für Zuweisungen an Lảnder und Gemeinden) sowie Art. 107 Abs. 2 GG] angestrebt wird. Diese "garantierte Mindestversorgung" mit bestimmten offentlichen Leistungen - sie werden für so verdienstvoll erklärt ("meritorisiert"), daß ein Verstoß gegen die Präferenzen der Bürger einzelner Regionen in Kauf genommen wird kann ein zentrales Leistungsangebot rechtfertigen.
} 


\subsection{Gegenstand und Aufbau der Arbeit}

Innerhalb der Finanzwissenschaft hat es - wie die vorstehenden Ausführungen des Abschnitts 1.2 zeigen - in der jüngeren Vergangenheit eine Anzahl theoretischer Erklärungsansätze gegeben, in deren Mittelpunkt die Suche nach den Bedingungen für einen "optimalen Finanzföderalismus" stand. ${ }^{9}$ Die meisten Analysen haben ihr Schwergewicht dabei entweder auf der Seite der Nachfrage oder auf der des Angebots staatlicher Leistungen bzw. beschäftigen sich nur mit den öffentlichen Aufgaben oder ausschließlich mit der Finanzierung.

Diese zweifache Trennung ${ }^{10}$ zusammenhängender Aspekte schränkt die Aussagefähigkeit der gewonnenen Ergebnisse ein und liefert somit Ansatzpunkte für eine neue Aufgabenstellung, nämlich Nutzer, Zahler, Anbieter und Entscheidende bei der Bereitstellung von öffentlichen Leistungen in einem interdependenten Sinne zu betrachten. Es soll also im weiteren Verlauf versucht werden, die bisher kurz vorgestellten Ansätze sinnvoll zusammenzufügen, um eine umfassende Beurteilung der Effizienzaspekte lokaler Leistungserstellung und ihrer Finanzierung zu ermöglichen.

Ausgangspunkt des beabsichtigten Vorhabens ist die Tatsache, daß es infolge von Marktversagen Güter und Leistungen gibt, die durch den Staat bereitgestellt werden müssen. Bekanntermaßen sind bei Vorliegen von Nichtrivalität im Konsum und der fehlenden Ausschlußmöglichkeit für solche Güter und Leistungen keine positiven Marktpreise determinierbar, so daß für die angesprochenen Bereiche kein privates Angebot erfolgt. Diese "public goods" unterscheiden sich aber bezüglich ihres Wirkungskreises." Sie reichen von einem ganz globalen nationalen Gut wie der äußeren Sicherheit oder gar einem internationalen Niveau (Beispiel Zollunion) bis hin zum Fall der Straßenbeleuchtung oder anderen kommunalen Leistungen. Zunächst sollen folglich in

\footnotetext{
${ }^{9}$ Einen resümierenden Überblick bieten Scott (1964), Musgrave (1969b) sowie Bulutoglu (1976). Grundlegende Modelle entwickelten - neben dem bereits angesprochenen Ansatz von Oates (1972), dessen "Fiscal Federalism" mittlerweile ein Standardwerk der modernen Foderalismusliteratur darstellt - Tiebout (1956) und Breton (1965).

${ }^{10}$ Eine Ausnahme bildet vor allem Oates (1972), der durch die Forderung nach einer "fiscal equivalence" die entscheidende Bedeutung der Finanzierungsseite in Zusammenhang mit einer okonomischen Begründung dezentraler Leistungserstellung im offentlichen Sektor hervorhob und berücksichtigte. Im deutschsprachigen Raum sind die Arbeiten von Liedtke (1972) sowie Wust (1981) zu nennen, die besonderen Wert auf die Integration von Ausgabeentscheidung und Finanzierungsform innerhalb der Diskussion foderalismustheoretischer Modelle und ihrer Implikationen legen.

$11 \mathrm{Vgl}$. in diesem Zusammenhang mögliche Klassifizierungsversuche offentlicher Leistungen, die im Rahmen der Foderalismusdiskussion in großer Zahl vorliegen. Als Beispiele seien Breton (1965), Williams (1966); Pauly (1970a) sowie Frey (1977) genannt.
} 
Kapitel 2 die Existenz und die Besonderheiten lokaler öffentlicher Güter aufgezeigt werden. ${ }^{12}$

Aus den Ansätzen der "Ökonomischen Theorie des Föderalismus" (s. Abschnitt 1.2) ist bekannt, daß (im Rahmen der Allokationsfunktion des Staates) die Bereitstellung von Gütern und Leistungen - also das Angebot einer differenzierten Palette öffentlicher Güter - in einem dezentralisierten Staatswesen Effizienzvorteile bietet. Eines der Hauptargumente für die Dezentralisierung des Staatswesens wird in der Unfähigkeit der zentralen Entscheidungsinstanz gesehen, auf die lokal/regional unter Umständen stark variierenden Präferenzen der Staatsbürger in bezug auf die öffentlichen Leistungen Rücksicht nehmen zu können. Dezentrale Entscheidungskollektive, insbesondere die lokalen Gebietskörperschaften, verfügen über eine größere Sensitivität. Sie sind damit in der Lage, ihre Leistungsbereitstellung stärker an den Präferenzen der Mitglieder zu orientieren und damit präferenznähere Entscheidungen zu treffen.

Es stellt sich jedoch die Frage, wie diese unterstellte größere Präferenznähe und die höhere Sensitivität lokaler öffentlicher Leistungsbereitstellung für die Allokationsentscheidung selbst (nämlich die Ressourcenverwendung im lokalen öffentlichen Sektor und das daraus resultierende Angebot) nutzbar gemacht werden kann. Das Augenmerk muß sich daher auf eine Betrachtung und Bewertung sogenannter Allokationsverfahren $^{13}$ für öffentliche Güter und ihre Besonderheiten richten. Allokationsverfahren zur Bereitstellung öffentlicher Güter umfassen den unregulierten Markt, sogenannte marktnahe Verfahren (so die vorgestellte "Club-Lösung" in Kapitel 3) sowie politische Versorgungskonzepte. Bei den letztgenannten spielen insbesondere politische Abstimmungen und ihre Bedeutung für die Allokationsentscheidungen öffentlicher Leistungen eine bedeutende Rolle. Daher wird in Kapitel 4 diesem Aspekt auch für die lokalen öffentlichen Güter und ihre Bereitstellung entsprechende Beachtung geschenkt.

Bekanntlich können die "staatlichen" Allokationsverfahren zur wahren Präferenzenthüllung für öffentliche Güter und Leistungen wenig beitragen. Unzulänglichkeiten bei der beabsichtigten Präferenzenthüllung durch politische Abstimmungen bzw. den Wahlmechanismus selbst liefern meist unbefriedigende Lösungen. Es verbleibt jedoch

\footnotetext{
12 In diesem Zusammenhang wird oft argumentiert, daß der Staat so aufgeteilt sein müßte, daß eine Übereinstimmung zwischen Kosten und Nutzern bei offentlichen Gütern erreicht würde. Aber aufgrund der unterschiedlichen Reichweite der jeweiligen offentlichen Leistungen wăre bei einer ausschließlichen Orientierung an diesem Grundsatz ein Staatsgebilde mit unendlich vielen Ebenen das Ergebnis. Es stellt sich also das Problem, wie beispielsweise bei einem dreistufigen Staatsaufbau die unterschiedlichen Wirkungskreise der angebotenen offentlichen Leistungen sinnvollerweise erfaßt werden, so daß möglichst geringe spillover-Effekte die Folge sind.
}

13 Vgl. dazu den Überblicksartikel von Blümel/Pethig/von den Hagen (1986). 
gerade auf der kommunalen Ebene eine weitere Möglichkeit, um einer "Präferenzerkundung" für lokale öffentliche Leistungen näherzukommen. Hierbei handelt es sich um einen Mechanismus, der ausschließlich dezentralen staatlichen Entscheidungsträgern zur Verfügung steht - nämlich die Tatsache der Mobilität der Bevölkerung oder anders ausgedrückt die Möglichkeit der "Abstimmung mit den Füßen" (vgl. Tiebout, 1956). Wenn Individuen lokal/regional mobil sind, erscheint es unter bestimmten Rahmenbedingungen durchaus möglich, daß ein Individuum sich hinsichtlich seiner Wohnsitzwahl für die Gemeinde entscheidet, in der aus dem Blickwinkel des "Konsumenten" das kommunale Leistungsangebot mit seinen eigenen Präferenzen weitgehend übereinstimmt.

Dieser Entscheidungsprozeß führt dann dazu, daß die "Enthüllung" der individuellen Präferenzen für lokale öffentliche Güter durch die "Allokation" der Individuen auf die lokalen Gebietskörperschaften erreicht werden könnte. Dieses Verfahren soll im Rahmen einer entsprechenden Modellstruktur in Kapitel 5 vorgestellt und auf seine Effizienzeigenschaften hin getestet werden. Darüber hinaus wird der Versuch unternommen, auf der Basis dieses Modells eine effiziente Finanzierung des lokalen öffentlichen Leistungsangebots zu begründen, um der gestellten Aufgabenstellung - nämlich der Verknüpfung des kommunalen Leistungsangebots mit seiner Finanzierung und der damit realisierbaren "fiskalischen Äquivalenz" - näher zu kommen. ${ }^{14}$

Im Verlauf der theoretischen Modellanalyse können aber aufgrund der (notwendigen) stringenten Modellannahmen eine Reihe ökonomisch bedeutsamer Faktoren nicht berücksichtigt werden. Diesen Faktoren - wie die Existenz von Kosten- und/oder Nutzenexternalitäten zwischen den einzelnen Gebietskörperschaften einer Ebene, das Auftreten von "economies of scale" bei der Produktion und Bereitstellung bestimmter lokaler öffentlicher Leistungen oder auch das Vorhandensein von Informations-, Transaktions- und Kontrollkosten der administrativen Gliederung des Staatsapparates muß in bezug auf die Untersuchung der Effizienzaspekte kommunaler Autonomie ebenfalls Bedeutung beigemessen werden. Dies soll im sechsten Kapitel geschehen, in dem die ökonomischen Problembereiche und organisatorisch-institutionellen Aspekte eines dezentral organisierten Gemeinwesens in die Untersuchung einfließen und die auf den ersten Blick "verlockenden" Ergebnisse der Modellanalyse in bezug auf die "Präferenzerkundung" für lokale öffentliche Leistungen mit daraus folgenden Implikationen für deren Bereitstellung und Finanzierung relativiert werden.

\footnotetext{
${ }^{14}$ Für die Analyse der Rahmenbedingungen einer effizienten Ressourcenallokation für den kommunalen Bereich tauchen athnliche Probleme auf wie bei der generellen Behandlung des offentlichen Sektors. So beeinflussen kommunale offentliche Ausgaben die Wohlfahrt vieler Individuen, lokale Steuern verzerren die Allokation der Ressourcen und verăndern Gleichgewichtspreise. Die bekannten Probleme bei der Suche nach einem effizienten Niveau offentlicher Ausgaben und ihrer Finanzierung treten zutage.
} 
Ist also der Nutzen (via individueller Präferenzoffenbarung), den die "Konsumenten" aus öffentlichen Leistungen ziehen, den über die Bereitstellung Entscheidenden nicht in dem Maße bekannt, wie dies im Verlaufe der theoretischen Analyse (über die unterstellte uneingeschränkte Mobilität der Haushalte und die damit verbundenen Ergebnisse) möglich erschien, bleibt die Art und Weise der Kollektivgüterfinanzierung weiterhin ein Problem.

Gleichwohl kann im Sinne eines Zwischenfazits die Möglichkeit einer Nutzbarmachung des Prinzips der "fiskalischen Äquivalenz" auf der lokalen Ebene festgehalten werden. Dies impliziert, daß derjenige, der Nutznießer öffentlicher Leistungen ist, auch dafür anfallende Kosten über entsprechende Finanzierungsbeiträge abdecken sollte. Die Frage ist jedoch, wie läßt sich fiskalische Äquivalenz jeweils realisieren. Gibt es nur die strenge (individuelle) Auslegung oder sind auch andere - weniger strenge - Ausprägungen dieses Prinzips denkbar. Diesem Problem soll im siebten Kapitel nachgegangen werden.

Wenn das Äquivalenzprinzip dann in seinen unterschiedlichen Ausprägungen zur Anwendung gelangt, ist es letztlich das Ziel der kommunalen Abgabenerhebung in Form von Entgelten (Gebühren oder Beiträgen) bzw. Steuern die Nutznießer bzw. die Nutznießergruppen des kommunalen Leistungsangebots zu belasten. Ein an diesen Zielsetzungen orientiertes Gemeindefinanzsystem umfaßt daher Gebühren und Beiträge (Kapitel 8), ein auf mehreren Pfeilern basierendes Gemeindesteuersystem (Kapitel 9) sowie ergänzend die Gewährung von Finanzzuweisungen (Kapitel 10), die vor allem bei der Realisierung eines externen Interessenausgleichs (sprich der Internalisierung räumlicher spillovers) Anwendung finden (sollten). In den Kapiteln 8 bis 10 werden daher im Sinne einer partial-analytischen Betrachtung geeignete Elemente für das abschließend zu formulierende kommunale Finanzierungssystem herausgegriffen und analysiert. Es stehen dabei vor allem Effizienzaspekte und mit der (lokalen) Wahrnehmung der Allokationsaufgabe zusammenhängende gemeindespezifische Anforderungen im Mittelpunkt der Betrachtungen. Es soll nämlich überprüft werden, ob eine "lastorientierte" Verteilung der Finanzierungserfordernisse die Allokationsentscheide in der Volkswirtschaft weniger stark verzerrt, weil entsprechende Unterschiede in der Abgabenbelastung letztlich nur die differierenden lokalen öffentlichen Leistungsangebote in den Gemeinwesen abbilden.

Die Analyse der kommunalen Finanzautonomie und ihrer Bedeutung für eine effizientere Wahrnehmung lokaler finanzwirtschaftlicher Aufgaben soll schließlich konstitutive Elemente erkennen lassen, die durch ihre Berücksichtigung bei der Ausgestaltung kommunaler Finanzierungssysteme ein "raumordnungspolitisch wirksames Signal" (Littmann, 1968, 28) für mehr Wirtschaftlichkeit darstellen. Daher soll im Kapitel 11 
ein unter Effizienzgesichtspunkten "optimales" kommunales Finanzsystem (durch die Zusammenfügung der bis dahin abgeleiteten Grundstrukturen kommunaler Finanzierungssysteme zu einer geschlossenen Konzeption) dargestellt werden. Dieses kann dann als Richtschnur und Orientierungsmaßstab für die Ausgestaltung kommunaler Finanz- und Steuersysteme dienen und macht die ökonomische Bedeutung kommunaler (Finanz-)Autonomie erkennbar.

Es dürfte den Leser einer theoretischen Arbeit kaum zufriedenstellen, wenn er nicht auch etwas darüber erfährt, wie sich der Autor die Übertragung seiner Überlegungen auf real existierende Systeme (und damit verbundene Reformdiskussionen) vorstellt. Daher ist das letzte Kapitel der Praktikabilität und der politischen Relevanz der gewonnenen Ergebnisse gewidmet. Dabei tritt auch noch einmal der real-politische Hintergrund der Thematik zutage, der durch die Verwirklichung des europäischen Binnenmarktes und die deutsche Einheit determiniert wird. Der europäische Binnenmarkt mit der weitgehenden Aufhebung nationaler Grenzen verändert die vorgefundenen Strukturen bzw. schafft durch die neue europäische Zentralebene gebietskörperschaftliche Strukturierung auch dort, wo vorher nationaler Zentralismus herrschte. Das wirft die Frage auf, ob lokale Finanzwirtschaften an Bedeutung verlieren, weil das $\mathrm{Ma} B$ an Zentralismus in Europa zugenommen hat, oder ob sie an Bedeutung gewinnen, weil nunmehr der Schutz nationaler Grenzen entfallen ist und eine verschärfte Standortkonkurrenz nicht nur zwischen Nationen sondern auch (und vielleicht vor allem) zwischen dezentralen Regionen entsteht. Ist letzteres der Fall, wird es um so bedeutender sein, die dezentrale (lokale) Ebene in ihrer Autonomie zu stärken, um ihr bessere Chancen für effizientes Wirtschaften einzuräumen. Darüber hinaus hat die Vereinigung Deutschlands insbesondere für die Kommunen der neuen Bundesländer Probleme geschaffen, denn die Systemtransformation erfordert dort Kosten, die in den alten Bundesländern so nicht auftreten. Diese Ausgangslage verschlechtert natürlich auch im europäischen Wettbewerb der dezentralen Regionen die ökonomischen Möglichkeiten der ostdeutschen Städte und Gemeinden.

Die aktuelle (bundesdeutsche) Diskussion um eine Reform des Gemeindefinanz- bzw. Gemeindesteuersystems wird im Kapitel 12 also aufgegriffen und mit den unter Effizienzgesichtspunkten formulierten "idealen" Strukturen kommunaler Finanzsysteme konfrontiert. Gleichzeitig soll der Frage nachgegangen werden, warum sich die Politik - und hier vor allem der (Bundes-)Gesetzgeber - so passiv verhält, wenn es gilt, umfassende Reformen der Gemeindefinanzen anzugehen. Aber auch auf der Seite der Städte und Gemeinden selbst sind Berührungsängste beobachtbar, wenn über ein stark an Autonomiegesichtspunkten ausgerichtetes Einnahmensystem diskutiert wird. Viele Kämmerer bevorzugen (scheinbar immer noch) den Alimentationscharakter des gegenwärtigen Systems mit einem Schwergewicht auf Zuweisungsströmen und anderen 
von der Gemeinde nicht selbst beeinflußbaren Einnahmen. Mögliche Ursachen dafür sollen - mit einem Seitenblick auf politische, institutionelle und juristische Erklärungsansätze - abschließend verdeutlicht werden. 
"Ich halte dafür, daß das einzige Ziel der Wissenschaft darin besteht, die Mühseligkeit der menschlichen Existenz zu erleichtern. Wenn Wissenschaftler ... sich damit begnügen, Wissen um des Wissens willen anzuhdufen, kann die Wissenschaft zum Krüppel gemacht werden ... Ihr mögt mit der Zeit alles entdecken, was es zu entdecken gibt, und euer Fortschritt wird doch nur ein Fortschreiten von der Menschheit weg sein."

(Galilei zu seinem Schüler)

\section{Effizienz, Marktversagen und öffentliche Güter}

\subsection{Das Grundproblem}

Bei der Lösung des Allokationsproblems im Sinne des methodologischen Individualismus ist in einer Volkswirtschaft die Kenntnis der unverzerrten individuellen Präferenzen Voraussetzung für eine effiziente Verwendung der Ressourcen. Für den privaten Sektor weist die ökonomische Theorie nach, daß bei Zugrundelegung wesentlicher Annahmen diese Präferenzen durch den Preis (bzw. die Bereitschaft einen bestimmten Preis zu entrichten) offenbart werden. Man spricht daher in diesem Zusammenhang auch von der Präferenzaufdeckungsfunktion des Preissystems. Da es dem Prinzip nach keinen Kontrahierungszwang gibt, wird gefolgert, daß der aus dem Konsum eines Gutes gezogene Nutzen mindestens seinem Preis entspricht.

Diese Bemühungen, einen Nachweis zu führen, daß das "Theorem der unsichtbaren Hand" Gültigkeit besitzt und somit vollkommene Konkurrenz unter bestimmten Bedingungen zur optimalen Allokation der Ressourcen führt (vgl. etwa Arrow/Debreu, 1954 bzw. Debreu, 1959), stoßen an Grenzen, wenn der Marktmechanismus nicht mehr ohne weiteres optimale Ergebnisse gewährleisten kann. Probleme treten auf, wenn der Markt nicht selbst in der Lage ist, Nutzen und Kosten exakt zu koordinieren bzw. zuzurechnen (Vorliegen von Externalitäten), auf bestimmten Märkten Monopolsituationen beobachtbar bzw. wohlfahrtsökonomisch erwünscht sind (Auftreten von "economies of scale") sowie aus privater Bereitstellung bestimmter Güter und Leistungen ein sub-optimales Niveau resultiert (Vorhandensein von Kollektivgütern). Es existieren also folglich Allokationsaufgaben, die infolge Marktversagens anderweitig gelöst werden müssen. ${ }^{15}$

15 Die allgemeinen theoretischen Grundlagen für solche "Marktergănzungen" bzw. "Marktinterventionen" wurden in der Finanzwissenschaft sowie der modernen Wohlfahrtsökonomie erarbeitet. Letztere will vor allem eine Entscheidungshilfe für die Marktkorrektur als Teilbereich der staatlichen Wirtschaftspolitik geben. 
Es ist hinlänglich bekannt, daß die Bereitstellung sogenannter öffentlicher Güter ${ }^{16}$ erhebliche Probleme bereitet. Weil diese Güter nicht individuell zurechenbar sind - ihr Nutzen also nicht aufgeteilt werden kann und ihr Konsum nicht rivalisiert -, erhält ein Individuum Anreize, eine niedrigere als seine wahre Wertschätzung bekanntzugeben, sofern die von ihm geäußerte Zahlungsbereitschaft positiv mit der für die Bereitstellung des Gutes später zu entrichtenden Summe verbunden wird.

Der Einzelne kann zum einen davon ausgehen, daß sein Finanzierungsbeitrag im Vergleich zu den Gesamtkosten ohnehin verschwindend klein ist, und zum anderen wird er aufgrund der Vermutung, daß die weiteren Individuen eine hinreichend hohe positive Zahlungsbereitschaft äußern, versuchen, in den Genuß des Gutes zu gelangen, ohne selbst zur Finanzierung beizutragen. Verhalten sich jedoch alle als "free rider", kommt es bestenfalls zu einer sub-optimalen Bereitstellung des öffentlichen Gutes; das betreffende Gut wird folglich marktlich nicht angeboten.

Nach dem bisherigen Verständnis ist die gemeinsame Konsumierbarkeit ("joint consumability") ${ }^{17}$ die konstitutive Eigenschaft öffentlicher Güter. Darüber hinaus weisen öffentliche Güter weitere Eigenschaften - wie fehlende Ausschließbarkeit ("non-excludability") oder Übernutzbarkeit ("crowding" oder "congestion") - auf. Diesen Merkmalen wird jedoch lediglich akzessorischer Charakter in dem Sinne zugewiesen, daß sie öffentliche Güter kategorisieren (vgl. Blümel/Pethig/von den Hagen, 1986, 241ff). Für einen Effizienzvergleich bezüglich der Versorgung der in einem Staat lebenden Individuen mit öffentlichen Leistungen durch unterschiedliche Ebenen ist aber die Kategorie der "Ausschließbarkeit" von besonderem Interesse. Dies wird im Verlauf dieser Arbeit (vgl. bereits Abschnitt 2.3) noch mehrfach deutlich werden.

\subsection{Effizienz und öffentliche Güter}

Wie bereits angedeutet, soll bei der Abgrenzung des Terminus "öffentliches Gut" die Eigenschaft der gemeinsamen Konsumierbarkeit vorrangige Bedeutung erhalten. In Zusammenhang mit der Existenz solcher Güter klingt eine gewisse Aufforderung zum staatlichen Handeln an, so daß der Begriff an sich schon eine komplementäre Beziehung zum staatlichen Sektor nahelegt. Da im weiterem Verlauf jedoch mögliche Allo-

\footnotetext{
${ }^{16}$ Neben dem Begriff "öffentliches Gut" taucht häufig auch die Bezeichnung "Kollektivgut" auf. Beide Begriffe werden im Schriftum meist synonym verwendet. Manche Autoren sprechen auch von "social goods" (vgl. etwa Musgrave/Musgrave, 1984, 51ff).

${ }^{17}$ Die Eigenschaft der "joint consumability" wird in der Literatur auch unter Begriffen wie "jointness" oder "joint supply" (Head, 1974), "indivisibility" (Buchanan, 1968) oder "non rivalness" (Musgrave, 1959) diskutiert.
} 
kationsverfahren, durch die öffentliche Güter bereitgestellt werden (im Vordergrund steht dabei die Frage der zentralen versus dezentralen staatlichen Bereitstellung), miteinander verglichen werden, ist die zwangsläufige Komplementarität von Staat und öffentlichen Gütern eine die Betrachtungsmöglichkeiten einengende Sichtweise. ${ }^{18}$ Daher soll nochmals betont werden, daß sich der Begriff "öffentlich" ausschließlich auf die Eigenschaft der gemeinsamen Konsumierbarkeit betroffener Güter und Leistungen bezieht - also auf die Kriterien, die ein öffentliches Gut auszeichnen - und nicht eine Vorentscheidung für das auszuwählende Allokationsverfahren darstellt. ${ }^{19}$

Um unterschiedliche Allokationsverfahren (vgl. Abschnitt 2.5) beurteilen zu können, werden Kriterien benötigt, die über die "Güte" der festgelegten Ressourcenverwendung Auskunft geben. In der neoklassischen Wirtschaftstheorie wird als Leistungsmaßstab allokativer Ergebnisse üblicherweise das Kriterium der Pareto-Effizienz herangezogen. ${ }^{20}$ Es handelt sich beim Pareto-Kriterium um das wohl am wenigsten umstrittene Wohlfahrtskriterium (vgl. Sohmen, 1976, 36ff). Für den weiteren Gang dieser Untersuchung ist es daher nützlich, zunächst die Bedingungen für eine pareto-effiziente Allokation öffentlicher Güter ganz generell herzuleiten. ${ }^{21}$

Dies soll im Rahmen einer einfachen Modellökonomie demonstriert werden, in der $\mathrm{N}$ Individuen (mit $\mathrm{i}=1, \ldots, \mathrm{N}$ ) leben. Jede Person verfügt über einen Ressourcenbestand $\mathrm{r}$ eines privaten Gutes (Numéraire-Gut), der entweder für Konsumzwecke oder die Pro-

18 Diese Klarstellung ist von Bedeutung, weil im Zusammenhang mit der Diskussion um die Bereitstellung lokaler offentlicher Güter mit der "Clublösung" ein marktnahes Allokationsverfahren Relevanz besitzt. Vgl. dazu Buchanan (1965a) sowie Olson (1985).

19 Randall (1983, 131ff) schlägt in diesem Zusammenhang vor, auf den Terminus "offentlich" ganz zu verzichten und statt dessen den institutionell neutralen Begriff der "gemeinsamen Konsumierbarkeit" zu verwenden. Weil sich der Begriff "offentliches Gut" in der Literatur jedoch weitgehend durchgesetzt hat, soll im weiteren Verlauf an dieser Bezeichnung festgehalten werden.

${ }^{20}$ Ein optimaler Zustand, der nach dem Ökonomen Vilfredo Pareto (1927) benannt wird, liegt vor, wenn die Preise aller einzelnen Güter und Dienstleistungen gleichzeitig sowohl die relative Wertschătzung durch die Konsumenten als auch die Grenzkosten der Produzenten widerspiegeln (vgl. Giersch, 1961, 106ff). Es ist dann nicht möglich, durch Tausch von Gütern und Dienstleistungen oder/und Verănderungen im Produktionssektor (Reallokation) auch nur ein Wirtschaftssubjekt besser zu stellen, ohne gleichzeitig ein anderes hinsichtlich seiner wirtschaftlichen Lage zu verschlechtern.

21 Die Überlegungen Paretos abstrahieren von der Existenz offentlicher Güter. Er kennt diese Güter - mit denen sich die Bedürfnisse mehrerer Personen gleichzeitig befriedigen lassen - noch nicht. Erst Samuelson (1954; 1955) vereinte die Existenz offentlicher Güter und das Pareto-Kriterium, indem er Bedingungen für die optimale (also pareto-effiziente) Allokation bei Existenz offentlicher Güter formulierte. 
duktion des öffentlichen Gutes Verwendung finden kann und dessen Wertschätzung durch die folgende quasi-lineare Nutzenfunktion ${ }^{22}$ charakterisiert wird.

$$
u^{i}=U^{i}\left(r_{x}^{i}, z\right)=r_{x}^{i}+v^{i}(z)
$$

Dabei stellt $r_{x}^{i}$ den Nutzen aus dem Konsum des privaten Gutes $\mathrm{r}^{\mathrm{i}}$ dar. Aufgrund der Vereinfachung durch die Zugrundelegung einer quasi linearen Nutzenfunktion ist die maximale Zahlungsbereitschaft einer Person i für das öffentliche Gut $z^{i=z}$ (Nicht-Rivalitäts-Eigenschaft) genau vi(z). Die Zahlungsbereitschaft für das öffentliche Gut ist also unabhängig vom Konsum des privaten Gutes. Es liegen damit für öffentliche Güter keine Einkommenseffekte vor. Es gilt $d v / d z>0$ und $d^{2} v / d z^{2}<0$. Weiterhin wird eine lineare Produktionstechnologie

$$
r_{z}=p_{z} z
$$

unterstellt, wobei $r_{z}$ der zur Produktion des öffentlichen Gutes erforderliche Ressourcenaufwand und $\mathrm{p}_{z}$ ein konstanter Input-Output-Koeffizient ist. Zusammen mit der Ressourcenbeschränkung

$$
\sum_{i} r^{i} \geq r_{z}+\sum_{i} r_{x}^{i}
$$

impliziert die Technologie (2.2) eine konvexe Transformationsmenge. Zur Bestimmung der pareto-effizienten Menge des öffentlichen Gutes wird die Lagrange-Funktion gebildet:

$$
L=\sum_{i} h^{i}\left[r_{x}^{i}+v^{i}(z)\right]+l\left(\sum_{i} r^{i}-p_{z} z-\sum_{i} r_{x}^{i}\right)
$$

wobei $h^{i}>0$ eine beliebige Konstante und $1>0$ ein Lagrange-Multiplikator ist. Aus der Differenzierung der Lagrange-Funktion folgt als Bedingung für die optimale Allokation

$$
\sum_{i} r_{z}^{i}\left(z^{*}\right)=p_{z}
$$

${ }^{22}$ Quasi-lineare Nutzenfunktionen (d.h. linear im privaten Gut) sind dann keine ernsthafte Einschränkung, wenn die Einkommenselastizităt der Nachfrage nach dem offentlichen Gut relativ klein oder wenn gemessen am gesamten Konsum der Nutzen aus dem öffentlichen Gut relativ gering ist. 
Die Allokation eines öffentlichen Gutes ist also pareto-effizient, wenn die Summe der marginalen Zahlungsbereitschaften aller Individuen den Grenzkosten der Produktion entspricht. Die Gleichung (2.5) ist als sogenannte Summenbedingung von Samuelson $(1955,354)$ bekannt. Diese Bedingung verlangt, daß die Summe der Grenzraten der Substitution im Konsum des öffentlichen und des privaten (Numéraire-)Gutes der Grenzrate der Transformation entspricht.

Die Effizienzkriterien des Samuelson-Modells bleiben jedoch als Nachweis einer pareto-optimalen Allokation in einer Ökonomie mit öffentlichen Gütern unbefriedigend, wenn das Problem der Präferenzoffenbarung öffentlicher Güter nicht weiter verfolgt wird. Für das öffentliche Gut funktioniert bekanntermaßen der Koordinationsmechanismus Markt und damit die Präferenzaufdeckungsfunktion des Preises nicht. Deshalb muß die Analyse weiter ausgedehnt werden auf die Theorie der Wahlsysteme. Um zu einer operationalen Budgetbetrachtung zu gelangen, ist ein Wahlsystem (oder ein alternativer Mechanismus) ${ }^{23}$ so auszugestalten, daß eine effiziente Präferenzenthüllung möglich wird und darauf aufbauend ein Steuer- und Ausgabensystem konzipiert werden kann, das einer Preisbildungsregel unter den Samuelson'schen Effizienzbedingungen möglichst nahe kommt.

Die vorstehenden Bemerkungen verdeutlichen, daß Effizienz im öffentlichen Sektor nicht die Verwirklichung des erwerbswirtschaftlichen Prinzips durch das Streben nach wirtschaftlichen (d.h. möglichst eng an den Präferenzen der Staatsbürger orientiertes und mit den in Anspruch genommenen Ressourcen gewichtetes) Angebot einer im übrigen politisch bestimmten Leistung bedeutet. Die Irrelevanz des Gewinnstrebens hat zur Folge, daß staatlichen Entscheidungsträgern die Entscheidungsparameter der privaten Unternehmung nicht in der dort gebräuchlichen Vielfalt zur Verfügung stehen. Diese Tatsache und die Feststellung, daß die öffentliche Leistungsbereitstellung häufig ist es sogar eine Leistungspflicht ${ }^{24}$ - in der Regel über die privatwirtschaftliche Leistungsabsicht hinausgeht, ändern jedoch nichts daran, daß in beiden Sektoren die Effizienzbedingungen die gleichen sind, sofern man die moderne Auffassung als gültig

\footnotetext{
${ }^{23}$ Beispielsweise die Wanderungsanalyse von Tiebout (1956), der ein Modell mit mobiler Bevölkerung und damit interkommunalen Wanderungen konstruiert hat und nachzuweisen versuchte, daß im Ergebnis unter bestimmten Annahmen eine Prăferenzoffenbarung für lokale offentliche Güter möglich ist. Im Ergebnis könnte dieses Verfahren eine Möglichkeit darstellen, eine Allokation der Ressourcen zu realisieren, die bei Existenz bestimmter offentlicher Güter (nämlich derjenigen mit begrenzter Nutzenreichweite) Effizienzkriterien genügt.

${ }^{24}$ Wahrend der private Unternehmer eine bestimmte Leistung an einem bestimmten Ort nur dann anbietet, wenn er einen Gewinn erwartet, obliegt der offentlichen Hand bei bestimmten infrastrukturellen Grundleistungen (Bahn, Post, Energieversorgung, Volksschule, Krankenhaus) eine zwar nur politisch begründbare aber dennoch allgemein anerkannte - Leistungspflicht.
} 
akzeptiert, daß der Staatswirtschaft wie der privaten Ökonomie die Aufgabe zukommt, knappe Ressourcen in einer Volkswirtschaft wirtschaftlich einzusetzen.

\subsection{Lokale öffentliche Güter}

Nach der einführenden und daher global gehaltenen Betrachtung öffentlicher Güter und ihrer prinzipiellen Bedeutung für eine effiziente Ressourcenallokation in einer Volkswirtschaft soll nunmehr die Kategorie öffentlicher Leistungen abgegrenzt werden, die für den Gang der vorliegenden Untersuchung von besonderem Interesse ist. Die Fragen, die an dieser Stelle aufgeworfen werden müssen, sind die nach der Existenz und (falls diese erste Frage bejaht werden kann) die nach den Merkmalen der sogenannten lokalen öffentlichen Güter. Folglich kann infolge des Auftretens der besonderen Charakteristika des örtlichen Leistungsangebots eine spezielle Analyse dieser Güter unter ökonomischen und föderativen Gesichtspunkten gerechtfertigt werden.

\subsubsection{Kriterien und Unterscheidungsmerkmale}

Bei einer Abgrenzung lokaler öffentlicher Leistungen wird zumeist auf pragmatisch orientierte bzw. institutionell begründete Aufgabenzuordnungen zurückgegriffen (vgl. Frey, 1977; Seiler, 1988). Als lokale Aufgaben eignen sich demnach öffentliche Leistungen, die gekennzeichnet sind durch

- lokal begrenzte Nutzenreichweite, d.h. es liegen keine oder nur geringe "spillover"Effekte vor,

- die Möglichkeit einer kostengünstigen Produktion oder zumindest Bereitstellung ("contracting out") in kleineren Einheiten,

- eine relativ homogene Präferenzstruktur innerhalb einer Gemeinde,

- keine gravierenden Koordinationsprobleme mit anderen Gebietskörperschaften,

- die Gewährleistung eines Minderheitenschutzes und

- die Realisierung bzw. Nichtverletzung von Mindestversorgungsniveaus im Sinne der Gleichartigkeit der Lebensverhältnisse. ${ }^{25}$

${ }^{25}$ Eine enge Auslegung dieser Kriterien würde bei einer Betrachtung der kommunalen Aufgaben zu einer erheblichen Reduktion potentieller Aufgabenfelder führen. Die formale Abgrenzung soll zunächst einmal einen Rahmen für die weitere Diskussion abstecken. Eine Verletzung des einen oder anderen Kriteriums muß unter Effizienzgesichtspunkten noch nicht zwangsläufig zu einer Verlagerung der Aktivităt auf eine höhere gebietskörperschaftliche Ebene führen. Insbesondere die Forderung nach Kongruenz der Nutzenreichweite (als wesentlichem Kriterium in bezug auf die Abgrenzung lokaler öffentlicher Güter) und der Gebietsgrenze, d.h. eine Vermeidung von Nutzen- und Kosten-spillovers, erscheint vor dem Hintergrund tat- 
Kristallisationspunkt in diesem Zusammenhang ist die begrenzte Nutzenreichweite der betreffenden öffentlichen Leistungen. In Anlehnung an die beschriebenen Charakteristika öffentlicher Güter soll daher die Bedeutung dieses Merkmals theoretisch fundiert und der Gang der Argumentation nachgezeichnet werden.

Wie weiter oben aufgezeigt (vgl. Abschnitt 2.1), bedient sich die auf Samuelson (1954) zurückgehende Klassifizierung von Gütern in private und öffentliche der Kriterien der "Ausschließbarkeit" und der "Rivalität des Konsums". Man spricht demnach von einem öffentlichen Gut im engeren Sinne (Kollektivgut), wenn es bei einer gegebenen Menge dieses Gutes nicht möglich ist, einzelne Individuen vom Konsum auszuschlieBen, und bei steigender Zahl von Konsumenten die individuelle Bedürfnisbefriedigung irgend eines Individuums nicht beeinträchtigt wird.

Das Rivalitätskriterium spiegelt die in der angelsächsischen Literatur auch mit "crowding" oder "congestion" bezeichneten Phänomene wider. In Abgrenzung zum Ausschlußprinzip - das als "technologische" Eigenschaft eines Gutes unabhängig von der Anzahl der Konsumenten, deren Präferenzstruktur und der Produktionstechnologie einer Ökonomie beschrieben werden kann - resultieren die als crowding bezeichneten Effekte entweder in Verbindung mit der Präferenzstruktur (crowding im Konsumbereich) oder in Verbindung mit der Produktionstechnologie (crowding im Produktionsbereich).

Lokale öffentliche Güter lassen sich als öffentliche Güter definieren, für die eine Ausschlußtechnologie existiert. Ob von der Ausschlußtechnologie Gebrauch gemacht wird, also verschiedene Kommunen unterschiedliche lokale öffentliche Güterbündel anbieten, hängt von den auftretenden crowding-Effekten ab. Ein crowding-Effekt im Produktionsbereich liegt vor, wenn der Output des lokalen öffentlichen Gutes von der Zahl der Konsumenten abhängig ist. Er kann durch folgendes Beispiel verdeutlicht werden. Das betrachtete öffentliche Gut sei ein Park, der von allen Einwohnern einer Gemeinde besucht werden kann. Sei der Output die Anzahl der Blumenbeete in diesem Park (welche durch den Input [Anzahl der eingesetzten Gärtner] produziert werden), n die Besucherzahl und muß außerdem je nach Besucherzahl eine bestimmte Anzahl an Gärtnern dazu abgestellt werden, aufzupassen, daß niemand der Besucher die Blumenbeete zerstört, tritt mit steigender Besucherzahl die Situation ein, daß immer mehr Gärtner als Aufpasser eingesetzt werden und damit immer weniger Blumenbeete "produziert" werden können. Der beschriebene crowding-Effekt im Produktionsbereich 
kann daher auch als "Kosten des nicht angewandten Ausschlusses" interpretiert werden.

Ähnlich wie im Produktionsbereich kann im Falle lokaler öffentlicher Güter ein derartiger Einfluß der Gemeindegröße im Konsumbereich à priori nicht ausgeschlossen werden. Dabei kann jedoch - im Gegensatz zum crowding des Produktionsbereiches bei einer Formulierung der Präferenzen des Konsumenten i durch folgende Nutzenfunktion

$$
u^{i}\left(x^{i}, z^{i}, n\right) \quad m i t u_{x}^{i}, u_{z}^{i}>0 ; \quad u_{n}^{i}<0
$$

der Einfluß der Bevölkerungsentwicklung (Gemeindegröße) auf den Nuztenindex des Konsumenten i nicht eindeutig der Existenz des lokalen öffentlichen Gutes (Gut z) zugeschrieben werden. Ein anderes Beispiel für einen crowding-Effekt im Konsumbereich liefert Buchanan (1965a, 8). Er betrachtet die Bildung eines Schwimmclubs, wobei der crowding-Effekt des Konsumbereichs darin besteht, daß die individuelle Bedürfnisbefriedigung bei steigender Zahl der Benutzer ab einer bestimmten Größe sinkt.

\subsubsection{Lokale öffentliche Güter und das Problem der "optimalen Kollektivgröße"}

Unter Beachtung der crowding-Effekte ergibt sich daher die Entscheidung über eine effiziente Anwendung der Ausschlußtechnologie (also die Bestimmung der optimalen Gemeindegröße) als Lösung eines Optimierungsproblems. Bei diesem Optimierungsproblem werden die "Kosten des nicht angewandten Ausschlusses" in Form des beschriebenen crowding den "Kosten des Ausschlusses" gegenübergestellt.

Im folgenden wird anhand eines einfachen 3-Güter-Modells das Problem der optimalen Gemeindegröße beschrieben. In einer Ökonomie gibt es zwei private Güter (A und B) und ein lokales öffentliches Gut z. Gut B ist ein Produktionsfaktor ${ }^{26}$ und stiftet beim Einsatz in Konsumprozessen keinerlei Nutzen. Durch Einsatz des Gutes B wird das Gut A produziert, das entweder direkt als Konsumgut $x$ nutzbar oder als einziger Pro-

${ }^{26}$ Der im nachfolgenden Modell benutzte exogene Produktionsfaktor B kann auch endogenisiert werden (wenn wir ihn als Faktor Arbeit charakterisieren) und folglich als Funktion der Bevölkerung abgebildet werden. Somit ergåbe sich für die Produktionsfunktion $A=f(B)$ [Gleichung (2.6)] nunmehr $A=f] g(n)]$; wobei $g(n)=$ B. Im Ergebnis käme es nunmehr zu gegenläufigen Wirkungen bezüglich der Einwohnerzahl und der optimalen Gemeindegrőße. Die optimale Gemeindegröße wăre folglich dann erreicht, wenn die Produktivităt des letzten Einwohners (als Produktionsfaktor Arbeit) gleich dem sogenannten crowding-Effekt ist ("marginal congestion costs"). 
duktionsfaktor y zur Herstellung des Gutes z dient. Die beschriebene Technologie der Ökonomie kann beschrieben werden durch:

$$
A=f(B) \quad \text { mit } d A / d B>0 ; d^{2} A / d^{2}<0
$$

$$
z=g(y, n)
$$

$$
\begin{aligned}
& \text { mit } \frac{\partial z}{\partial y}>0 ; \quad \frac{\partial^{2} z}{\partial y^{2}}<0 \\
& \text { und } \frac{\partial z}{\partial n}<0
\end{aligned}
$$

Über das Produktionsverfahren $\mathrm{f}$ kann mit einer bestimmten Inputmenge $\mathrm{B}$ eine bestimmte Menge A produziert werden, analog bei konstanter Zahl der Konsumenten $\mathbf{n}$ mit einer Menge y eine jeweilige Outputmenge z. Die Abhängigkeit des Outputs des Gutes z von der Zahl der Konsumenten n wird als "crowding" im Produktionsbereich bezeichnet. Dieser crowding-Effekt läßt sich wie folgt interpretieren: Der Inputkombination $\left(y_{0}, n_{o}\right)$ sei der Output $z_{o}$ zugeordnet. Um bei der Konsumentenzahl $n_{1}>n_{o}$ die Menge $z_{o}$ zu produzieren, ist der Faktoreinsatz $y_{1}>y_{0}$ erforderlich. Dieser crowdingEffekt kann daher auch als die "Kosten des nicht angewandten Ausschlusses" interpretiert werden.

In den vorstehenden Ausführungen wurde ein speziell mit der Existenz lokaler öffentlicher Güter zusammenhängendes Problem bereits ansatzweise erkennbar. Es handelt sich hierbei um die Diskussion der optimalen Gemeindegröße. Die Effizienz eines dezentralen staatlichen Allokationsverfahrens (wie etwa des "voting by feet"-Mechanismus) ist davon abhängig, inwieweit sich ein derartiger Mechanismus zur Lösung dieses Problems eignet. Untersucht werden daher im weiteren Verlauf Eigenschaften (speziell die Optimalität möglicher Konzepte zur Realisierung des dezentralen Allokationsmechanismus) auch unter dem Blickwinkel der optimalen Gemeindegröße und der Abgrenzbarkeit dieser selbst. Daneben wird der Frage nachgegangen, ob durch Konsumentenmobilität ein "marktmäßiges Äquivalent" für eine Ökonomie mit lokalen öffentlichen Gütern konstruierbar ist.

Zunächst kann also festgehalten werden, daß lokale öffentliche Güter dadurch charakterisiert sind, daß für diese Güter eine Ausschlußtechnologie existiert ${ }^{27}$, weil sie nur eine begrenzte Nutzenreichweite besitzen. Die vorstehende Argumentation kann auch

\footnotetext{
${ }^{27}$ Einen formalen Nachweis liefern Dudenhöffer/Gebauer (1982, 98ff). In diesem Zusammenhang ist auch der Überblicksartikel von Blümel/Pethig/von den Hagen (1986) zu nennen.
} 
auf Bezirke, Regionen und Länder übertragen werden, so daß es öffentliche Güter auf unterschiedlichen Niveaus, d.h. mit unterschiedlich großen Wirkungskreisen/-graden (vgl. Oates, 1977c, 20ff) gibt. ${ }^{28}$

\subsubsection{Problembereiche der Allokation lokaler öffentlicher Güter}

Innerhalb der Diskussion der unterschiedlichen Wirkungskreise öffentlicher Leistungen wird oft argumentiert, daß idealtypisch gesehen ein Staatsgebilde so strukturiert sein müßte, daß eine Übereinstimmung zwischen Kosten- und Nutzerkreisen ("fiscal equivalence") bei öffentlichen Gütern erreicht wird (vgl. Olson, 1977, 71). In diesem Zusammenhang sind zwei Problembereiche zu nennen:

- Wenn man davon ausgeht, daß es viele öffentliche Güter mit unterschiedlich weiten Wirkungskreisen gibt, und konstatiert, daß die Etablierung der gleichen Anzahl von Ebenen in einem Staat nicht möglich bzw. sinnvoll ist, stellt sich die Frage, wie dann eine Entscheidung bezüglich der Wahrnehmung der einzelnen Allokationsaufgabe auf eine einzurichtende lokale Ebene ausfällt.

- Auf der lokalen Ebene besteht die Möglichkeit für die Individuen, von einer Kommune zur anderen zu wandern. Diese Mobilität gilt es zu hinterfragen und zu analysieren und ihre Auswirkungen auf eine effiziente Ressourcenallokation bei unterstellten divergierenden Präferenzen zu untersuchen.

Bei der Beschäftigung mit Fragestellungen hinsichtlich einer effizienten Ressourcenallokation und ihrer Bedeutung für den kommunalen Bereich tauchen also die gleichen Probleme auf wie bei der Behandlung des öffentlichen Sektors im allgemeinen. Kommunale öffentliche Ausgaben beeinflussen die Wohlfahrt vieler Individuen und lokale Zwangsabgaben verändern die marktlichen Gleichgewichtspreise. Lokale öffentliche Leistungserstellung und deren Finanzierung beeinflußt demnach (natürlich) die Allokation der Ressourcen. Die bekannten Probleme, nämlich die Suche eines effizienten Niveaus öffentlicher Ausgaben, die Frage der Steuerinzidenz und die Analyse der Wohlfahrtsverluste durch Besteuerung, treten folglich auch hier zutage.

28 Offentliche Leistungserstellung reicht folglich von einem globalen nationalen Gut wie der außeren Sicherheit oder gar einem internationalen Niveau (Beispiel Zollunion) bis hin zum Feuerschutz, kulturellen, sportlichen und sozialen Einrichtungen (wie Jugendmusikschulen, Sportplătzen, Bădern, Altenheime, Volkshochschulen), Einrichtungen des Gesundheitswesens, Erschließungsstraßen, Parkplătzen, Straßenreinigung oder -beleuchtung, Versorgungs- sowie Entsorgungseinrichtungen, innerortliche Verkehrsbetriebe, Schlachthöfe, Friedhöfe und in zunehmendem Maße neben dem traditionellen Wohnungswesen die Stadt- bzw. Dorferneuerung als möglichen Beispielen für kommunale Leistungen. 
2.4 Allokationsverfahren öffentlicher Güter und die Einordnung der lokalen öffentlichen Leistungen

Die wirtschaftstheoretische Literatur (vgl. beispielsweise Bator, 1958; Alchian/Demsetz, 1972; Donges, 1985; Watrin, 1986) schlägt eine Reihe von Schritten zur Lösung der Probleme aus der Existenz öffentlicher Güter vor. Es gibt grob klassifiziert zunächst drei Wege, mit Marktversagen und den daraus resultierenden Implikationen umzugehen. Der Staat kann zunächst versuchen, den Markt funktionsfähiger zu gestalten, d.h. die Rahmenbedingungen neu zu setzen bzw. zu modifizieren. Er kann weiterhin versuchen, den Markt durch staatliche Aktivitäten zu ersetzen (Intervention), oder er beläßt die Fehlallokation, die Resultat des existierenden Marktversagens ist, weil der staatliche Eingriff höhere Kosten als Nutzen und damit ein unter Effizienzgesichtspunkten nicht erwünschtes Resultat mit sich bringt. Die drei Alternativen können als marktnahe Lösung, als Staatslösung und als Marktlösung benannt werden.

Allokationsverfahren zur Bereitstellung öffentlicher Güter umfassen mithin den unregulierten Markt, marktnahe Verfahren und politische Versorgungskonzepte. Da diese Allokationsverfahren recht unterschiedlich gestaltet sein können, ist eine genaue Typisierung bedeutsam. Üblich ist dabei die Gegenüberstellung der relevanten Allokationsbereiche "Markt" und "Staat" (Polarisierung); dieses Vorgehen ist jedoch idealtypisch und in der Realität nicht aufrechtzuerhalten, da in einem marktwirtschaftlich orientierten Wirtschaftssystem die Institutionen Markt und Staat notwendigerweise interdependent sind.

Empirisch gesehen gibt es zahlreiche Mischformen von Bereitstellungsverfahren mit unterschiedlicher Staats- bzw. Marktnähe. Häufig wird neben den Sektoren Staat und Markt noch ein dritter Sektor unterschieden, der die privaten Organisationen ohne Erwerbscharakter umfaßt (vgl. Weisbrod, 1977 sowie Badelt, 1980). Die vielfältigen Organisationsformen in diesem Sektor gehen von kirchlichen und karitativen Initiativen über Selbsthilfegruppen und Bürgerinitiativen bis hin zu "alternativen" Arbeits- und Lebensformen. Ein Beispiel für eine sogenannte "Koordinierung der Selbstorganisation" liefert Sugden (1984).

Unter dem Gesichtspunkt einer weitestgehenden Vereinfachung (Darstellung der wesentlichen Elemente von Allokationsverfahren) soll dennoch mit einer polarisierenden Überzeichnung begonnen werden, wobei in dem vorliegenden Zusammenhang letztlich speziell die Allokationsverfahren behandelt werden sollen, innerhalb derer Güter bereitgestellt werden, die sich durch eine gemeinsame Konsumierbarkeit für einen in der Regel geographisch bestimmten Personenkreis auszeichnen. Es handelt sich hierbei um 
die Spalten 2 und 3 der Tabelle 2.1, die den Fall der Clubgüter und der lokalen öffentlichen Güter umfassen.

Tabelle 2.1: Allokationsverfahren für öffentliche Güter

\begin{tabular}{|c|c|c|c|c|}
\hline & \multicolumn{4}{|c|}{ Güterart } \\
\hline & $\begin{array}{l}\text { "marktfáhiges" } \\
\text { offentliches Gut }\end{array}$ & Club-Gut & $\begin{array}{c}\text { lokales } \\
\text { offentliches Gut }\end{array}$ & $\begin{array}{c}\text { Kollektivgut } \\
\text { (offentliches Gut i.e.S.) }\end{array}$ \\
\hline $\begin{array}{l}\text { Mitteilung der } \\
\text { Angebots- bzw. } \\
\text { Nachfragewünsche }\end{array}$ & \multicolumn{2}{|c|}{ preisgesteuert } & \multicolumn{2}{|c|}{ preis- und/oder mengengesteuert } \\
\hline $\begin{array}{l}\text { Bestimmung des } \\
\text { Versorgungs- } \\
\text { niveaus }\end{array}$ & \multicolumn{2}{|c|}{ marktliche Entscheidungsfindung } & \multicolumn{2}{|c|}{ politische Entscheidungsfindung } \\
\hline Bereitstellung & \multicolumn{2}{|c|}{ privat- bzw. marktwirtschaftlich } & \multicolumn{2}{|c|}{ politisch bzw. staatlich } \\
\hline Produktion & \multicolumn{2}{|c|}{ privat } & \multicolumn{2}{|c|}{ privat bzw. staatlich } \\
\hline $\begin{array}{l}\text { Staatliche } \\
\text { Regulierung }\end{array}$ & \multicolumn{2}{|c|}{ marktspezifisch } & \multicolumn{2}{|c|}{ staatlich oder bürokratisch } \\
\hline Verfuigungsrechte & \multicolumn{2}{|c|}{ kollektiv } & \multicolumn{2}{|c|}{ politisch und/oder kollektiv } \\
\hline $\begin{array}{l}\text { Ausschluß- } \\
\text { möglichkeit }\end{array}$ & $\begin{array}{c}\text { "Preis- } \\
\text { Ausschluß" }\end{array}$ & \multicolumn{2}{|c|}{$\begin{array}{c}\text { Nicht-Preis-Ausschluß (begrenzte } \\
\text { Nutzenreichweite) }\end{array}$} & ökonomisch | \\
\hline
\end{tabular}

In Tabelle 2.1 ist eine Palette von Allokationsverfahren für öffentliche Güter zusammengefaßt. ${ }^{29}$ Bei den marktmäßigen Allokationsverfahren werden die Angebots- und Nachfragewünsche durch preisgesteuerte Marktprozesse offenbart. Die Konsumenten reagieren - wie bei privaten Gütern - bei gegebenem Einkommen und vorgegebenen Marktpreisen durch Wahl eines optimalen Konsumplans. Analog erstellen die Unternehmen ihren Produktionsplan. Politische Allokationsverfahren können preis- und/oder mengengesteuert sein. Im Falle der Mengensteuerung wird beispielsweise von der Regierung eine bestimmte Allokation mit dem öffentlichen Gut vorgegeben. Idealtypisch gesehen (ein voll funktionsfähiges Wahlverfahren vorausgesetzt) teilen die Individuen unter Zugrundelegung ihres gegebenen Einkommens dann etwa durch eine Abstimmung mit, wieviel Steuern sie bereit wären, für die öffentliche Leistung zu entrichten.

In bezug auf die Produktion der öffentlichen Güter besteht bekanntermaßen die Möglichkeit, daß die staatliche Instanz diese bei einem privaten Anbieter erwirbt (man spricht in diesem Fall von staatlicher Bereitstellung bei privatwirtschaftlicher Produktion) oder die Herstellung des Gutes selbst übernimmt (Bürokratie, staatliches Unternehmen), was als staatliche Produktion bezeichnet werden soll.

${ }^{29}$ Es ist ohne weiteres möglich und bei bestimmten Fragestellungen auch nützlich, Allokationsverfahren für öffentliche Güter noch tiefer zu strukturieren. Für die hier beabsichtigten Zielsetzungen reicht die vorgenommene Klassifikation m.E. aus. Umfassendere Unterscheidungen liefert Blümel (1987, 27). 
In der Regel sind politische Arrangements im Gegensatz zu marktgesteuerten Verfahren entscheidungszentralisiert. Daneben lassen sich für Allokationsverfahren aber auch noch andere Klassifikationskriterien finden. Beispielsweise unterscheiden sich marktmäßige und politische Allokationsverfahren für öffentliche Güter noch nach der Struktur der Verfügungsrechte und dem Ausmaß der staatlichen Regulierung. Verfügungsrechte und Regeln legen den rechtlichen Rahmen für individuelles Verhalten fest. Ferner sind unterschiedliche Allokationsverfahren nach den akzessorischen Eigenschaften öffentlicher Güter einteilbar.

Da im Zusammenhang mit der Abgrenzung lokaler öffentlicher Güter insbesondere die Ausschlußproblematik eine Rolle spielt, soll auf diesen Problemkreis (d.h. den möglichen Konsumentenausschluß im räumlichen Kontext) näher eingegangen werden. Wenn in einem Verfahren Konsumentenausschluß praktiziert wird, spricht man von einem exklusiven Koordinierungsverfahren; andernfalls heißt das Verfahren nicht exklusiv. Bezüglich der unterschiedlichen Ausschlußmöglichkeiten lassen sich öffentliche Güter schließlich folgendermaßen klassifizieren: Von einem sogenannten marktfähigen öffentlichen Gut wird gesprochen, wenn über einen "Preis-Ausschluß" bei gemeinsamer Konsumierbarkeit die Nutzung für weitere potentielle "Konsumenten" an die Zahlung einer Gebühr oder eines Entgeltes gebunden ist. Die Spalten 2 und 3 umfassen die Allokationsverfahren, in denen Clubgüter bzw. lokale öffentliche Güter bereitgestellt werden. Bei diesen Gütern ist - wie weiter oben bereits ausgeführt - die gemeinsame Konsumierbarkeit auf einen in der Regel geographisch bestimmten Personenkreis eingegrenzt. Der Ausschluß erfolgt anhand bestimmter Eigenschaften, wie der regionalen Zuordnung, Mitgliedschaft oder auch demographischer Merkmale (beispielsweise altersspezifische Güter wie Kindergärten, Schulen oder Altersheime). Die damit zusammenhängenden Allokationsprobleme sollen im Verlaufe einer Betrachtung der Theorie der Clubgüter sowie der Theorie der lokalen öffentlichen Güter analysiert und für den weiteren Gang der Untersuchung aufbereitet werden.

Der Vollständigkeit halber sei noch erwähnt, daß die Spalten 4 und 5 sogenannte "reine" öffentliche Güter (Kollektivgüter) umfassen, die durch beide Eigenschaften (NichtRivalität, Nicht-Ausschluß) gekennzeichnet sind. Im Fall des Nicht-Ausschlusses aus ökonomischen Gesichtspunkten ist eine Durchsetzung von Eigentumsrechten unter Kostenerwägungen nicht sinnvoll, im Fall der technischen Begründung des Nicht-Ausschlusses ist diese generell nicht möglich. 
Hans-Georg Napp - 978-3-631-75263-0

Downloaded from PubFactory at 01/11/2019 06:33:05AM

via free access 


\section{Marktnahe Allokation lokaler öffentlicher Güter: Die Clublösung}

\subsection{Möglichkeiten und Voraussetzungen}

Eine marktnahe Lösung für die Bereitstellung öffentlicher Güter (ob lokal, regional oder national) zielt auf die Eigenschaft des Nichtausschlusses und deren Überwindung ab. Das Nichtausschlußprinzip resultiert aus der fehlenden technischen Durchsetzbarkeit von Eigentumsrechten bei öffentlichen Gütern. Eigentumsrechte stellen jedoch eine wesentliche Voraussetzung für marktliche Lösungen dar.

In diesem Zusammenhang wird in der ökonomischen Literatur (vgl. Buchanan, 1965a sowie Olson, 1985) vorgeschlagen, daß einige öffentliche Leistungen unter bestimmten Voraussetzungen privat bereitgestellt werden könnten, wenn sich ein sogenannter "Club" bildet. ${ }^{30}$ Besonders geeignet sind solche Clublösungen bei Existenz "kleiner Gruppen" (Olson, 1985, 21ff), die folgende Eigenschaften aufweisen:

- niedrige Mitgliederzahl

- geringe Organisationskosten

- homogene Präferenzstruktur

Im Kontext dieser Arbeit ist die Diskussion dieser Eigenschaften kleiner Gruppen von Interesse, da sie in bezug auf die Bereitstellung lokaler öffentlicher Leistungen besondere Relevanz besitzen. So zeichnet sich die lokale Ebene dadurch aus, daß sie im Vergleich zu übergeordneten Ebenen relativ niedrige Mitgliederzahlen aufweist. Kommunen sind zwar bezüglich ihrer tatsächlichen Größenordnung (Städte bzw. Gemeinden) sehr ungleich, aber dennoch als kleinste organisatorische Einheit innerhalb des föderativen Staatsaufbaus am ehesten mit der Olson'schen Situation vergleichbar. Daher stellt - nicht nur aufgrund dieses Aspekts - die marktnahe Lösung durch Bildung einer Organisation (Club) eine mögliche Alternative zur öffentlichen Bereitstellung entsprechender Leistungen dar. Zudem erlaubt die größere Präferenznähe auf der lokale Ebene (wie im Fall der kleinen Gruppe) die Ausnutzung geringerer Organisationsbzw. Informationsbeschaffungskosten.

Darüber hinaus ist auf lokalem Niveau in der Regel eine homogene Präferenzstruktur beobachtbar, wie beispielsweise Pennock (1959) durch eine entsprechende Untersuchung nachzuweisen versuchte. Er kommt bezüglich einer Beurteilung des föderativen Staatsaufbaus und damit im Zusammenhang mit der staatlich-dezentralen Bereitstel-

\footnotetext{
${ }^{30}$ Einen leicht zugänglichen Einstieg in die "Theorie der Clubs" liefern Sandler/Tschirhart (1980); eine eher theoretische Behandlung dieser Thematik führen Pauly (1970b) sowie Cornes/Sandler (1986) durch.
} 
lung öffentlicher Leistungen zu dem Schluß, daß "... the federal system does minimize the number of voters whose will, as expressed by the ballot, is frustrated" (Pennock, 1959, 157). Damit stellt dezentrale öffentliche Leistungserstellung und die damit verbundene politische Abstimmung einen gewissen Minderheitenschutz dar und macht erkennbar, daß innerhalb der lokalen Ebene eine homogenere Präferenzstruktur zum Ausdruck kommt als auf nationalem oder gar internationalem Niveau. Bei der später zu betrachtenden "Wanderungsanalyse" wird noch deutlicher, warum es beinahe geradezu zwangsläufig zu einer homogeneren lokalen Präferenzstruktur kommt (vgl. dazu Abschnitt 4.4).

Die Gruppengröße spielt also bei marktnahen Allokationsverfahren eine wichtige Rolle. Schwierigkeiten treten immer dann auf, wenn eine Beziehung zwischen der Gruppengröße und dem Verhalten des Einzelnen - was im Kontext dieser Arbeit von besonderer Relevanz ist - analysiert werden soll. Diese Probleme resultieren teilweise daraus, daß jedes Individuum in einer Gruppe verschieden großen Wert auf das öffentliche Gut legen kann. Daneben steht jede Gruppe (Club), die eine öffentliche Leistung wünscht, einer anderen Kostensituation gegenüber.

In allen Fällen werden jedoch Anlauf- oder Fixkosten in einem beträchtlichen Umfang auftreten. Dies hängt mit der Etablierung einer formellen Organisation zusammen, die - wie weiter oben bereits beschrieben - in Zusammenhang mit der gewünschten Zielsetzung zunächst notwendig ist und dazu führt, daß die erste erlangte Einheit eines öffentlichen Gutes relativ teuer sein wird. Selbst wenn keine Organisation oder Koordination erforderlich ist, sorgen mangelnde Teilbarkeit und andere spezifische Merkmale der kollektiven Leistungen dafür, daß die erste Einheit unverhältnismäßig teuer sein wird.

\subsection{Funktionsweise und Merkmale}

Das folgende Beispiel soll die Möglichkeiten und Grenzen einer Clublösung in $\mathrm{Zu}$ sammenhang mit lokalen öffentlichen Gütern und ihrer Bereitstellung aufzeigen. Angenommen ein lokaler Raum (beispielsweise die Einwohner eines Stadtteils, eines Straßenviertels oder einer kleinen Gemeinde) möchte zur Aufrechterhaltung der inneren Sicherheit (Schutz vor Diebstahl und Einbruch) eine entsprechende Einrichtung schaffen. Die zu produzierende - oder exakter ausgedrückt bereitzustellende - Leistung weist einige typische Charakteristika eines lokalen öffentlichen Gutes auf. D.h. eine zu schaffende Sicherheitseinrichtung (private Wach- und Schließgesellschaft) produziert Leistungen, die durch lokalen Nichtausschluß der Nutzen dieser Einrichtungen sowie Nichtrivalität im Konsum gekennzeichnet sind. 
Die betroffenen Einwohner könnten sich nunmehr freiwillig zu einer Gemeinschaft zusammenschließen, deren Ziel die Finanzierung dieser Sicherheitseinrichtung darstellt. Bei näherer Betrachtung wird durch die Gründung eines solchen Clubs letztlich versucht, die angesprochene lokale öffentliche Leistung (marktlich) bereitzustellen und deren Finanzierung durch Umlage der gesamten Kosten (fixe und variable Kosten) auf die Mitglieder sicherzustellen. Alle Einwohner, die den Schutz der Sicherheitseinrichtung wünschen, sind potentielle Mitglieder des Clubs. Dabei müßte als Anreiz für einen Beitritt sichergestellt werden, daß den nicht der Gemeinschaft angehörenden Individuen "ein Teil"31 der Dienstleistung verweigert wird, weil sie sich nicht an der Finanzierung der Leistungen beteiligen. Das auf diese Weise erstellte Produkt wird somit zu einem teilweise den Ausschluß realisierenden Clubgut. Es kann somit möglicherweise durch den privaten Sektor - also ein marktliches Allokationsverfahren (vgl. Schaubild 2.1) - bereitgestellt werden.

\subsection{Bewertung}

Das Marktversagen - in der Existenz der beiden Kriterien der Nichtrivalität und des Nichtausschlusses begründet - ist aber keinesfalls vollständig eliminiert worden, weil das resultierende Konsumniveau einer Clublösung in der Regel im Sinne der Allokationseffizienz nicht optimal ist. ${ }^{32}$ Dies liegt darin begründet, daß beim Konsum des vorliegenden lokalen öffentlichen Gutes die Grenzkosten eines zusätzlichen Konsumenten gleich Null sind. Es stellt sich kein optimales Konsumniveau ein, weil potentielle zusätzliche Nutzer (trotz Grenzkosten von Null) aufgrund eines zu übernehmenden Anteils an den Fixkosten der Bereitstellung nach wie vor Anreize besitzen, ihre wahre Präferenz nicht bekanntzugeben und sich damit nicht an der Finanzierung des Gutes zu beteiligen. Das Ausmaß der "Unterkomsumtion" hängt damit eindeutig vom Erfolg des Ausschlusses der Nichtmitglieder ab. Es gilt also sicherzustellen, daß Nut-

31 Gesamt gesehen weist die bereitzustellende Leistung die Merkmale eines offentlichen Gutes auf. Partiell sind aber durchaus Möglichkeiten gegeben, Teile der Leistung zu verweigern, wenn kein Beitritt und damit keine Finanzierungsbeteiligung erfolgt. Beispielhaft kann in diesem Zusammenhang angefuihrt werden, daß in der beschriebenen Situation bei Beobachtung eines Einbruchs in das Haus eines Nichtmitglieds kein Einschreiten durch die Wach- und Schließgesellschaft erfolgt.

32 Nur in der - zugegebenermaßen aber relativ unrealistischen - Situation, daß eine offentliche Leistung zu Kosten bereitgestellt werden kann, welche gemessen an ihrem Nutzen so gering sind, daß irgendein Individuum der Gruppe noch gewinnen würde, wenn es das Gut allein bereitstellte, wird sich ein effizientes Konsumniveau einstellen. Der Gesamtgewinn wăre dann im Verhăltnis zu den Gesamtkosten so groß, daß der Vorteil für jeden einzelnen die Gesamtkosten überstiege (vgl. Olson, 1985, 21). Dieser Tatbestand wird häufig auch in Zusammenhang mit der privaten Organisierbarkeit der Bereitstellung bestimmter offentlicher Leistungen als notwendige Eigenschaft erwăhnt. Neben der Notwendigkeit des Vorliegens einer kleiner Gruppe und geringer Organisations- bzw. Koordinationskosten nimmt also bei sehr unterschiedlichen Bedürfnisintensitäten der Mitglieder die Wahrscheinlichkeit der Realisierung eines marktnahen Allokationsverfahrens zu (vgl. etwa Kirsch, 1974, 30). 
zen aus der Bereitstellung eines solchen Gutes Nichtmitgliedern in möglichst geringer Form zugute kommen.

Die erforderlichen Voraussetzungen für die optimale Versorgung mit einem lokalen öffentlichen Gut durch selbstgeleitetes Handeln der Gruppenmitglieder lassen sich zusammenfassend folgendermaßen formulieren: Die Grenzkosten zusätzlicher Einheiten des Kollektivgutes müssen in derselben Weise aufgeteilt werden wie die zusätzlichen Nutzen. Nur wenn das geschieht, wird jedes Mitglied feststellen, daß seine eigenen Grenzkosten und -nutzen gerade dann gleich sind, wenn die Summe der Grenzkosten gleich den aggregierten Grenznutzen ist. Falls die Grenzkosten auf irgendeine andere Weise in Form der Mitgliedsbeiträge aufgeteilt werden, wird das Kollektivgut in suboptimaler Menge bereitgestellt. Selbst in kleinen Gruppen wird das öffentliche Gut dann nicht in der optimalen Menge bereitgestellt. Die Mitglieder einer Gruppe werden folglich nicht das Niveau des betreffenden Gutes realisieren können, das tatsächlich ihren gemeinsamen Interessen (also ihren Präferenzen) entspricht. Nur durch gewisse institutionelle Vorkehrungen können den einzelnen Mitgliedern Anreize geboten werden, die eine Bereitstellung und damit natürlich auch Finanzierung der öffentlichen Leistung ermöglichen würde, die vom Standpunkt der Gruppe als ganzes unter Wohlfahrtsgesichtspunkten optimal wäre.

Diese Tendenz zur Sub-Optimalität folgt aus der Tatsache, daß ein öffentliches Gut definitionsgemäß Eigenschaften aufweist, die eine Verhinderung des Konsums von Nichtmitgliedern nicht möglich machen. Da einem einzelnen Mitglied also nur ein Teil des Nutzens einer Ausgabe (die es vornimmt, um ein solches öffentliches Gut zu erlangen) zugute kommt, wird es den Kauf des Gutes "unterbrechen", bevor die optimale Menge für die Gruppe erreicht worden ist. Überdies werden die Mengen des Gutes, die ein Gruppenmitglied kostenlos von anderen Mitgliedern erhält, den Anreiz, sich mehr von diesem Gut auf eigene Kosten zu beschaffen, weiter vermindern. Dies bedeutet, daß mit steigender Gruppengröße die Möglichkeit der Bereitstellung der optimalen Menge eines öffentliches Gutes weiter reduziert wird.

Das unzureichende und nicht zufriedenstellende Ergebnis einer marktlichen Lösung (freiwilliger privatwirtschaftlicher Art) durch Bildung von Organisationen erklärt selbst aber noch nicht, warum sich aus der staatlichen Bereitstellung durch dezentrale Entscheidungseinheiten eine wohlfahrtstheoretisch bessere Lösung ergibt; d.h. eine Bereitstellung des Kollektivgutes in einem sub-optimalen Niveau verhindert wird. Um dafür eine Begründung bzw. Rechtfertigung zu liefern, gilt es, die Notwendigkeit einer staatlichen Korrektur des zugrunde liegenden Marktversagens herzuleiten. Zwei Problemkomplexe, die sich bei Clublösungen einstellen würden, sind in dieser Hinsicht zu nennen. 
In Zusammenhang mit der Bereitstellung räumlich begrenzter öffentlicher Leistungen besteht die Möglichkeit, daß sich solche Leistungen überlappen (räumliche externe Effekte). Die Planung und Kontrolle des Verkehrswesens, das Angebot größerer Erholungsanlagen oder Freizeiteinrichtungen (Parks o.ä.) bietet Nutzungsmöglichkeiten auch über die "Clubgrenzen" hinaus. In Verbindung mit den für diese Leistungen vorliegenden Eigenschaften der Nichtrivalität im Konsum sowie der Nicht-Ausschließbarkeit potentieller Nutzer ${ }^{33}$, kommt es zur Bildung sogenannter "Super-Clubs" (Helm/ Smith, 1987, 4). Diese unter ökonomischen Gesichtspunkten erfolgende Verschmelzung einzelner Clubs zu größeren Organisationen ist neben der umfassenden Beteiligung potentieller Nutzer an der Finanzierung der entsprechenden Leistung (nutzenseitige Rechtfertigung) notwendig, weil bei der Produktion der beschriebenen Güter in der Regel "economies of scale" auftreten, die auch von der Kostenseite her eine Vergrößerung rechtfertigen. Ziel ist die Realisierung einer Mitgliederzahl, die ein Angebot der betreffenden Leistung zu den geringst möglichen Durchschnittskosten erlaubt (vgl. Buchanan, 1968, 6ff). Die beschriebenen großen Organisationen haben nun ihrerseits einige Charakteristika mit lokalen öffentlichen Einrichtungen gemeinsam, wie sich bei der Betrachtung lokaler staatlicher Entscheidungseinheiten unter organisatorischen Gesichtspunkten im weiteren Verlauf der Arbeit noch zeigen wird (vgl. Abschnitt 6.3).

Der zweite wesentliche Problembereich bezüglich der Bereitstellung lokaler öffentlicher Güter durch Clubs tritt im Zusammenhang mit der für die Struktur und das Ausmaß der Leistungen erforderlichen Informationsbeschaffung zutage. Das Problem bei einer privatwirtschaftlich organisierten Lösung ist die Kenntnis der Präferenzstruktur der Mitglieder und ihre Umsetzung in ein bestimmtes Güter- bzw. Dienstleistungsangebot.

Zwei Wege sind bezüglich der Lösung dieser Problematik denkbar, nämlich die Beschaffung der notwendigen Informationen über die Präferenzstruktur der Mitglieder mittels der individuellen Nachfrage und einer selbstgeleiteten Organisation von Gruppeninteressen zum einen (marktnahe Club-Lösung) oder durch Wahlen (also politische Abstimmungsprozesse) zum anderen. Versagt aufgrund des nicht zu sanktionierenden "free rider"-Verhaltens der Nutzer ("potentielle" Gruppenmitglieder) die erstgenannte Option, verbleibt nur die politische Abstimmung und damit ein nicht-marktliches Allokationsverfahren.

\footnotetext{
33 Es gibt zwar - wie bei der Abgrenzung lokaler öffentlicher Güter hergeleitet - für diese Leistungen eine bestimmte Ausschlußtechnologie, nămlich einen begrenzten răumlichen Wirkungskreis. Gleichwohl ist diese Grenze aber nicht exakt bestimmbar, so daß̧ răumliche "spillovers" (Cornes/Sandler, 1986) möglich, ja im Prinzip sogar die Regel sind.
} 
Hans-Georg Napp - 978-3-631-75263-0

Downloaded from PubFactory at 01/11/2019 06:33:05AM

via free access 
"Die meisten Leute meinen, ein Staat, der die Menschen glücklich machen könne, müsse groß sein. Aber selbst wenn sie recht haben sollten, wissen sie doch nicht, was eigentlich 'groß' und 'klein' bei Staaten bedeuten soll. ... Auch fur die Große von Staaten gibt es eine Grenze, so wie fur jedes andere Ding, fur Pflanzen, Tiere und fur Handwerkszeuge. Denn diese Dinge verlieren ihre natürliche Wirksamkeit, wenn sie zu groß oder zu klein sind."

Aristoteles (322 v. Chr.)

\section{Staatliche Allokationsverfahren}

\subsection{Charakteristika der lokalen Bereitstellung öffentlicher Leistungen}

Die Alternative zu einer marktlichen Lösung (wie sie am Beispiel der Clublösung beschrieben wurde) ist die staatliche Interventionslösung. Da eine marktliche Bereitstellung von Parks, Sportanlagen oder Sicherheitseinrichtungen wegen fehlender "incentives" nicht in effizienter Weise möglich ist, wird in der Regel der Staat allokative Aufgaben übernehmen müssen. Aufgrund der nicht vorhandenen Zahlungsbereitschaft der privaten Haushalte für diese Güter wird der Staat folglich diese Leistungen anbieten und finanzieren, da ihm mit der Besteuerung Zwangsabgaben zur Durchsetzung seiner fiskalischen Erfordernisse zur Verfügung stehen. Die Nachfrage nach den angesprochenen Leistungen versucht der Staat wegen des existierenden free-rider-Problems über den politischen Entscheidungsprozeß zu ergründen. Die staatliche Allokationslösung tritt also an die Stelle der marktlichen und die Besteuerung als Finanzierung an die Stelle der Zahlung eines Marktpreises.

Zunächst tauchen für den kommunalen Bereich die gleichen Allokationsprobleme auf, wie wir sie generell aus der Diskussion um Marktversagen und dessen Konsequenzen kennen. So weisen auch die meisten lokalen öffentlichen Güter Eigenschaften auf, die aus auftretenden Externalitäten, nicht formulierbaren bzw. durchsetzbaren Eigentumsrechten oder bestehenden Monopolsituationen resultieren. Des weiteren hat sich gezeigt, daß private Allokationsverfahren - wie die Bildung von Clubs - nicht dazu führen können, daß die Beiträge des einzelnen in einer direkten Beziehung zu seinem Konsum stehen. Folge dieser Ineffizienzen ist eine Unterkomsumption der betreffenden Leistungen. Aber auch bei einer Verlagerung der Bereitstellung lokaler öffentlicher Leistungen auf staatliche Instanzen bleibt die Frage bestehen, in welchem Umfang das jeweilige Gut angeboten werden muß.

Um diese Frage - die Suche des optimalen Bereitstellungsniveaus öffentlicher Güter auf der kommunalen Ebene - zu beantworten, soll zunächst auf Samuelson (1954) als Ausgangspunkt zurückgegriffen werden. Dieser hat nachgewiesen, daß bei der Bereit- 
stellung öffentlicher Güter ein Optimum realisiert sei, wenn die Summe der individuellen Grenzraten der Substitution beim Konsum identisch ist mit der Grenzrate der technischen Substitution bei der Produktion, also der Grenzrate der Transformation. Der Staat sieht sich jedoch dem Problem gegenüber, die individuellen Grenzraten der Substitution der Individuen erfragen zu müssen. Das zentrale Problem ist also die Offenbarung der Präferenzen für öffentliche Güter.

Alle Verfahren der Nachfrageoffenbarung in Form der dazu erforderlichen Mechanismen bei einer staatlichen Bereitstellung öffentlicher Güter sehen sich auch mit dem free-rider-Problem konfrontiert, denn jedes Individuum besitzt bekanntermaßen Anreize, seine wahren Präferenzen nicht zu enthüllen. In Anlehnung an diese Situation sind in der ökonomischen Theorie ${ }^{34}$ eine Reihe von Ansätzen formuliert worden, die das beschriebene Problem einer Lösung zuführen sollen. Im Ergebnis soll (trotz der existierenden Komplexität politischer Entscheidungssituationen) eine Rangordnung möglicher Alternativen gewonnen werden, die letztlich nichts anderes als eine "Soziale Wohlfahrtsfunktion"35 abbildet. Diese Ermittlungen sozialer Wohlfahrtsfunktionen sind als "Theorie der Präferenzaggregation" und als "Public Choice" Teilbereiche der ökonomischen Theorie der Politik und stellen sich die Frage, wie gesellschaftliche Entscheidungen zustande kommen. Ziel ist dabei die Aggregation individueller Präferenzen, die bestimmten Bedingungen genügen soll.

In der ökonomischen Literatur sind in diesem Zusammenhang eine Reihe von Methoden vorgeschlagen worden, die eine Lösung dieser Problematik anstreben. In erster Linie sind unterschiedliche Wahlverfahren und ihre Eignung zur Präferenzoffenbarung analysiert worden. Im Kontext dieser Arbeit interessieren insbesondere politische Abstimmungen (als "public choice without mobility" bezeichnet) sowie die Möglichkeit der Abstimmung mit den Füßen, auch als "public choice through mobility" zu benennen (vgl. Wildasin, 1977, 326ff). Letzterer kann gerade auf der lokalen Ebene eine entscheidende Bedeutung beigemessen werden.

\footnotetext{
34 In diesem Zusammenhang ist vor allem die okonomische Theorie der Politik zu nennen, die vor allem mit Namen wie Arrow (1963), Buchanan/Tullock (1971), Downs (1968), Hirschman (1974), Mueller (1979), Niskanen (1971), Tullock (1965) sowie Williamson (1975) verbunden ist. Die okonomische Theorie der Politik wendet die Denkweise und das Instrumentarium der modernen Wirtschaftswissenschaften auf politische Prozesse an. Ihr liegt das ökonomische Verhaltensmodell zugrunde, demzufolge Individuen systematisch auf Anreize reagieren und diejenigen Alternativen wăhlen, die ihnen den größten Nettonutzen einbringen. Die okonomische Theorie der Politik wird zuweilen auch "Neue Politische Ökonomie" genannt; im anglo-amerikanischen Sprachraum hat sich die Bezeichnung "Public Choice" durchgesetzt.
}

35 Finanzpolitisch autonome Gemeinden maximieren also diese "eigene" gemeindespezifische Wohlfahrtsfunktion, die es zunächst zu ermitteln gilt. Es könnte etwa die Wohlfahrtsfunktion des Durchschnittsbürgers bzw. des Medianwählers (vgl. 4.3.2) oder - in reprăsentativen Gemeindeverfassungen - jene Nutzeneinschătzung sein, die der Gemeinderat als repräsentativ ansieht (vgl. 4.3.3). Dazu liefert Seiler (1988, 509f) einen entsprechenden Ansatz. 
Im Rahmen dieser theoretischen Ansätze hat sich sehr bald gezeigt, daß eine widerspruchsfreie Aggregation im allgemeinen nicht möglich ist und daß auch bei der am häufigsten verwendeten Mehrheitsregel paradoxe Ergebnisse auftreten können, wie Arrow's (1963, 46ff) Unmöglichkeitstheorem offenbart. Die Konstruktion einer solchen sozialen Wohlfahrtsfunktion stößt also schon theoretisch sehr bald an scheinbar unüberwindliche Schranken; gleichwohl stellt sich trotz dieser grundsätzlichen Schwierigkeiten in jeder Demokratie die Frage, wie die Präferenzen der Individuen erfaßt werden können.

Daher soll in den folgenden Abschnitten ein kurzer Überblick der speziell für den lokalen Bereich geeigneten Wahlmechanismen bzw. theoretischen Erklärungen zur Lösung des Problems der Präferenzenthüllung für lokale öffentliche Güter gegeben werden.

4.2 Die Übertragung der individuellen Wahlhandlungs- oder Nutzentheorie auf den öffentlichen Bereich - Das "community preference"-Modell

Der einfachste Weg der Bestimmung des Niveaus der lokalen öffentlichen Ausgaben basiert auf der Hypothese, daß eine örtliche Gemeinschaft wie ein einzelner privater nutzenmaximierender Haushalt (oder zumindest eine Gruppe identischer Haushalte, d.h. Haushalte mit homogener Präferenzstruktur) ${ }^{36}$ betrachtet werden kann (vgl. Wilda$\sin , 1986,37 \mathrm{ff}$ ). In der ökonomischen Literatur finden sich eine Reihe von Ansätzen, die diesen Zugang gewählt haben, um ausgehend von einem solchen Modellrahmen Grundlagen für die weitergehende theoretische und empirische Arbeit $\mathrm{zu}$ formulieren (vgl. dazu Gramlich, 1968; Henderson, 1979; Scott, 1952 sowie Wilde, 1968).

Im Rahmen der angesprochenen Vorgehensweise wird unterstellt, daß eine örtliche Gemeinschaft ähnlich handelt wie ein einzelnes Individuum. D.h. bei gegebenem Einkommen I ("aggregate community income") entscheidet die Gemeinschaft über die Verwendung zwischen zwei möglichen Alternativen, nämlich der Konsumtion des privaten Gutes $x$ oder der Konsumtion des lokalen öffentlichen Gutes z. Das Entscheidungsproblem der Gemeinde stellt sich somit als Maximierung einer Nutzenfunktion $\mathrm{U}(\mathbf{x}, \mathbf{z})$ unter Beachtung der Budgetrestriktion ${ }^{37} \mathbf{x}+\mathrm{z}=\mathrm{I}$ dar, die determiniert ist durch

\footnotetext{
36 Diese Annahme finden wir in ähnlicher Form in der Tiebout'schen Wanderungsanalyse (vgl. Abschnitt 4.4) wieder. Bei Tiebout stellt sich diese homogene lokale Prafferenzstruktur aber erst nach erfolgter Allokationsentscheidung anhand des "voting by feet"-Mechanismus ein.

${ }^{37}$ Der Einfachheit halber wird für die beiden betrachteten Güterarten pro konsumierter Einheit jeweils ein konstanter Preis von $\mathrm{p}_{\mathrm{x}}=1$ und $\mathrm{p}_{\mathrm{z}}=1$ angenommen, so daß sich daraus die formulierte Budgetbeschrănkung ergibt.
} 
das gesamte Einkommen der Haushalte der Gemeinde, welches für Konsumzwecke in Form des privaten und/oder lokalen öffentlichen Gutes zur Verfügung steht.

An die Formulierung einer solchen Ausgangssituation schließt sich sofort die Frage an, warum das zugrundeliegende Entscheidungsproblem zur Bestimmung der effizienten Höhe des lokalen öffentlichen Güterangebots in einer sich an die Nutzenmaximierung der privaten Haushalte anlehnenden Form geschehen kann. Oder anders ausgedrückt, was legitimiert die Verwendung einer solchen Annahme, d.h. welche Präferenzen - bei bekanntlich nicht möglicher kardinaler Nutzenmessung und damit Aggregation individueller Nutzen - werden bei Verwendung von $U(x, z)$ durch diese Nutzenfunktion repräsentiert. Unterschiedliche Interpretationen sind denkbar.

Zunächst könnte man vermuten, daß alle Individuen einer Gemeinde identische Präferenzen aufweisen. Es wird also eine homogene Präferenzstruktur auf der lokalen Ebene unterstellt. ${ }^{38}$ Unter diesen Rahmenbedingungen ist die verwendete Nutzenfunktion die Abbildung der Präferenzstruktur irgendeines der in der Gemeinde wohnenden Individuen, die schließlich alle diese identische Präferenzstruktur aufweisen.

Es wird bereits erkennbar, daß die verwendete Annahme identischer Präferenzen äußerst restriktiv ist. Doch wenngleich es zugegebenermaßen eher unrealistisch ist, von solchen identischen Präferenzstrukturen auf lokalem Niveau auszugehen, bietet die Annahme einer homogenen Präferenzstruktur durchaus einige Möglichkeiten für die theoretische Auseinandersetzung. So können die Ergebnisse solcher auf homogenen Präferenzstrukturen aufbauender Analysen Bezugspunkte für weitergehende Untersuchungen liefern. ${ }^{39}$

Eine weitere Möglichkeit wäre, daß die Nutzenfunktion U(x,z) die Präferenzstruktur eines sogenannten "city-managers" (Wildasin, 1986, 38) repräsentiert.40 Dieser city-

\footnotetext{
${ }^{38}$ Es gibt eine Reihe empirischer Arbeiten, die den Versuch unternehmen, sich mit dieser Problematik zu beschăftigen (vgl. etwa Pennock, 1959). Fazit all dieser Ansătze ist im wesentlichen, daß auf der lokalen Ebene zwar durchaus homogenere Prăferenzstrukturen vorzufinden sind als auf zentralstaatlichem Niveau, gleichwohl aber durchaus noch Abweichungen denkbar sind. $\mathrm{Zu}$ tatsăchlich identischer Prafferenzstruktur im kommunalen Raum kommt es vielmehr nur dann, wenn man gemå der Tiebout'schen Wanderungsanalyse an die unbegrenzten Mőglichkeiten răumlicher Mobilităt glaubt und dabei die Existenz von Informations-, Transaktions- und Mobilitătskosten vernachlăssigt. (vgl. auch Abschnitt 4.4 sowie Tiebout, 1956)
}

39 Gramlich (1977) liefert eine guten Überblick solcher Arbeiten. Daneben sind vor allem zu nennen: Bishop (1964), Bowman (1974), Craig/Inman (1982), Davis/Haines (1966), Feldstein (1975) und Sacks/Harris (1964).

40 Dieser "city-manager" kann in einer repräsentativen Demokratie auch allgemeiner als das politisch verantwortliche Entscheidungsgremium (Gemeinderat) angesehen werden, das als potentieller "Anbieter" der lokalen öffentlichen Leistungen dies gemäß "seiner" Prăferenz vornimmt (vgl. etwa Romer/Rosenthal, 1979a). 
manager kontrolliert die politischen Entscheidungen in einer Kommune. Bei näherer Betrachtung der lokalen Ebene wird aber sehr bald offensichtlich, daß gerade die Kommunen durch einen dezentralisierten politischen Entscheidungsprozeß gekennzeichnet sind (Präferenznähe, Merklichkeit, Betroffenheit). Damit wird eine Kontrolle in Form eines solchen city-managers sehr schwierig und daher dürfte diese Rechtfertigung für die genannte Vorgehensweise wenig sinnvoll erscheinen.

Unter realistischeren Gesichtspunkten reicht also die Unterstellung einer homogenen Präferenzstruktur auf der kommunalen Ebene nicht aus. "Clearly, however, its theoretical and empirical limitations [des "community preference"-Modells] invite consideration of alternative models which give more explicit attention to the mechanism of collective choice at local level." (Wildasin, 1986, 40)

\subsection{Politische Abstimmungen - "Public Choice without Mobility"}

Ein bedeutsamer Weg zur Lösung des fundamentalen Problems - der Präferenzoffenbarung für öffentliche Leistungen - sind für die lokalen genau wie für die zentralstaatlichen Entscheidungsträger politische Abstimmungen. Durch Wahlentscheidungen soll versucht werden, unterschiedliche Präferenzen zu erkennen, und über eine bestimmte Entscheidungsregel letztlich ermöglicht werden, brauchbare Ergebnisse bei der Bestimmung des Niveaus staatlich bereitzustellender Güter und Dienste zu erzielen.

Zur Illustration der Entscheidungssituation sollen die unterschiedlichen Präferenzen ${ }^{41}$ dreier Individuen in bezug auf die Bereitstellung eines bestimmten lokalen öffentlichen Gutes als Pseudo-Nachfragekurven in einem Preis-Mengen-Diagramm verwendet werden. Die Individuen A, B und C erzielen aus dem Konsum des betreffenden Gutes unterschiedliche Grenznutzen. ${ }^{42}$ Dieser Grenznutzen spiegelt sich in der Bereitschaft der

Durch Wahlen wird dann diese Praferenz immer wieder zur Abstimmung gestellt. Vgl. hierzu auch Abschnitt 4.3.3.

41 An dieser Stelle soll nochmals darauf hingewiesen werden, daß die "wahren" Präferenzen für offentliche Güter wegen der existierenden free-rider-Problematik dem staatlichen "Anbieter" so nicht bekannt sind. Deshalb ist eine Verwendung individueller Präferenzen bei der Bestimmung des staatlichen Angebots nur über Mechanismen möglich, die dieses Problem überwinden helfen; also zum Beispiel politische Abstimmungen ("voting").

42 Es ist aber auch denkbar, daß bei gleicher Nutzeneinschätzung der Individuen der Grund für die unterschiedlichen "Pseudo-Nachfragen" unterschiedliche Einkommen (I) der Individuen sind. Wenn nämlich lokale offentliche Leistungen normale Güter sind, erhöht sich bekanntlich die Nachfrage mit steigendem Einkommen. Für das gewăhlte Beispiel hieße das: $\mathrm{I}_{\mathrm{A}}<\mathrm{I}_{\mathrm{B}}<\mathrm{I}_{\mathrm{C}}$. 
Individuen, einen bestimmten "Preis" 43 zu entrichten, wider. Der Preis für jedes Individuum ist sein Anteil am gesamten Steueraufkommen $(h=\overline{O H} / 3)$.

Abbildung 4.1: Die "Nachfrage" nach einem lokalen öffentlichen Gut

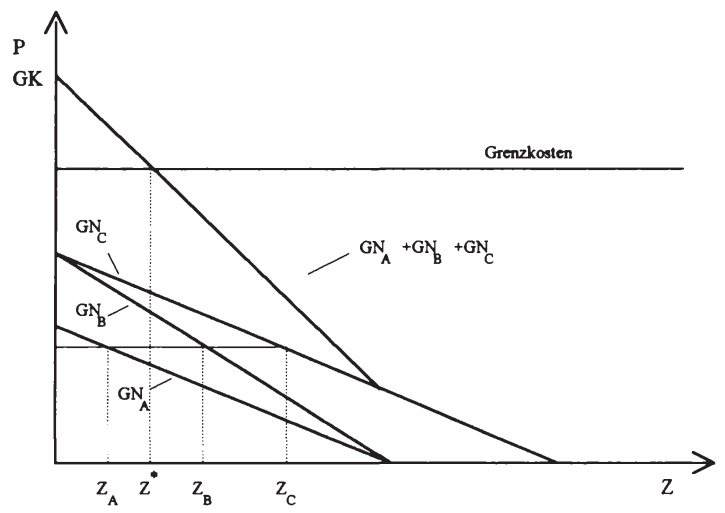

Aufgrund der Summenregel (vgl. Samuelson, 1955) ergibt sich die Gesamtnachfrage der öffentlichen Leistung aus der Addition der Preisbeiträge der einzelnen Individuen $\left(\mathrm{GN}_{\mathrm{A}}+\mathrm{GN}_{\mathrm{B}}+\mathrm{GN}_{\mathrm{C}}\right)$. Unter Effizienzgesichtspunkten würde eine marktliche Lösung bei $z^{*}$ resultieren. Doch infolge der bekannten Eigenschaften öffentlicher Güter ist dieses Ergebnis unrealistisch. Zu suchen ist ein Mechanismus, der bei der Präferenzoffenbarung hilft und somit für die staatliche Ebene die Bestimmung der Höhe des öffentlichen Leistungsangebots ermöglicht. Dieser Mechanismus könnte eine Wahlentscheidung sein. Der Anbieter der öffentlichen Leistung entschließt sich, den Steueranteil jedes einzelnen Individuums in Höhe von einem Drittel der jeweiligen Grenzkosten festzulegen. Da diese konstant sind, ist auch der "Preis" $h$ unabhängig von der angebotenen Menge konstant. Daraus resultieren Nachfragewünsche bezüglich der öffentlichen Leistung in Höhe von $\mathrm{z}_{\mathrm{A}}$ für das erste Individuum, $\mathrm{z}_{\mathrm{B}}$ für das zweite Individuum und $\mathrm{z}_{\mathrm{C}}$ für das dritte Individuum (dabei ist $\mathrm{z}_{\mathrm{A}}<\mathrm{z}^{*} ; \mathrm{z}_{\mathrm{B}}, \mathrm{z}_{\mathrm{C}}>\mathrm{z}^{*}$ ). Das Problem für den Anbieter der betreffenden Leistung ist nun, in welcher Höhe diese angeboten werden soll. Wegen der Eigenschaft der gemeinsamen Konsumierbarkeit wird schließlich nur ein bestimmtes Niveau der öffentlichen Leistung angeboten, das durch politische Abstimmungen zu finden ist und letztlich einen Kompromiß darstellt.

\footnotetext{
43 Individuen "kaufen" öffentliche Leistungen durch Zahlung von Steuern oder Gebühren. Auf diese Weise bestimmt die Steuerstruktur den Preis für jedes Individuum. Der Einfachheit halber wird hier eine Steuerstruktur unterstellt, die nicht mit der Höhe der Ausgaben für die Erstellung der öffentlichen Leistung variiert. Es ändern sich also lediglich die Steuersătze, wenn die staatliche Ebene mehr oder weniger Einnahmen benötigt, die Zusammensetzung und damit der Anteil jeder Steuerquelle bleibt jedoch identisch. 


\subsubsection{Die Mehrheitswahl}

Eine mögliche politische Abstimmungsmethode ist die sogenannte Mehrheitswahl; d.h. bei Entscheidungen zwischen unterschiedlichen Alternativen gewinnt dabei diejenige, die eine bestimmte Anzahl von Stimmen auf sich vereinigt (einfache Mehrheit, absolute Mehrheit oder andere qualifizierte Mehrheiten sind denkbar).

In der vorstehend aufgezeigten Entscheidungssituation führt eine Abstimmung mit einfacher Mehrheit (bei unterstellter transitiver Präferenzordnung) zu folgendem Ergebnis: Das Ausgabenniveau $\mathrm{z}_{\mathrm{B}}$ ist der "Gewinner" bei einer Mehrheitswahlentscheidung (vgl. Abbildung 4.1). Warum ist das so? Schon dieses einfache Beispiel demonstriert einen wichtigen Tatbestand, der bei der Bewertung des Mehrheitsverfahrens häufig mißverstanden wird. Das Ausgabenniveau $z_{B}$ wird zwar nicht von der Mehrheit der Wähler präferiert (ebenso wie $z_{A}$ bzw. $z_{C}$ ), wird aber letztlich doch als Endergebnis resultieren, weil es die einzige Alternative darstellt, die die Unterstützung der "Mehrheit" erfährt. Ein höheres oder auch ein niedrigeres Ausgabevolumen kann jeweils von zwei der beteiligten Individuen (also mit Mehrheit) verhindert werden. ${ }^{44}$ Die Individuen A und $\mathrm{C}$ sind also gezwungen einen Kompromiß mit $\mathrm{B}$ einzugehen, der letztlich das "gewählte" Ausgabevolumen $\mathrm{z}_{\mathrm{B}}$ darstellt. Folglich hat sich auch nur Individuum B mit seiner Präferenz durchgesetzt und ist "zufrieden" mit dem Ergebnis. ${ }^{45}$

Das Problem von Mehrheitswahlen ist jedoch die in der Regel nicht vorhandene Transitivität der gewonnenen Ergebnisse. ${ }^{46}$ Immer dann, wenn intransitive Ergebnisse vorliegen, ergibt sich kein eindeutiges Ergebnis und somit wird sich auch nicht (wie im vorstehenden Beispiel) die Präferenz des Medianwählers durchsetzen. Die Problematik soll am nachfolgenden Beispiel kurz illustriert werden.

Die Präferenzen der drei betrachteten Individuen A, B und C bezüglich der bereitzustellenden Menge einer öffentlichen Leistung lauten wie folgt (wobei $z_{1}<z_{2}<z_{3}$ ):

\footnotetext{
44 Ein hoheres Ausgabenniveau (wie es C präferieren würde) wird von Individuum A und B abgelehnt; ein niedrigeres Ausgabevolumen (wie es A präferieren würde) wird von B und C abgelehnt. Beide Varianten sind also nicht durchsetzbar.

45 Dieses Resultat wird im năchsten Abschnitt als sogenannte "Medianwăhler-Lösung" nochmals aufgegriffen und einer detaillierteren Behandlung unterzogen.

46 Schon Borda (1781) und Condorcet (1785) haben sich mit dem sogenannten Aggregationsproblem (der Gewinnung einer gesellschaftlichen Wohlfahtsfunktion aus individuellen Präferenzen) befaßt. Die moderne Forschung geht auf Arrow $(1963,46 \mathrm{ff})$ zurück. Er untersuchte die Möglichkeit, eine gesellschaftliche Wohlfahrtsfunktion unter Erfüllung bestimmter normativer Kriterien (vgl. auch Frey, 1988b, 494f) abzuleiten. Dieses Werk hat die nachfolgende Forschung maßgeblich beeinflußt ("Arrows Unmoglichkeitstheorem").

Hans-Georg Napp - 978-3-631-75263-0 
Individuen

A

B

C

$\begin{array}{lll}\mathrm{z}_{1} & \mathrm{z}_{2} & \mathrm{z}_{3} \\ \mathrm{z}_{2} & \mathrm{z}_{3} & \mathrm{z}_{1} \\ \mathrm{z}_{3} & \mathrm{z}_{1} & \mathrm{z}_{2}\end{array}$

Bekanntermaßen ist das Ergebnis einer Mehrheitswahl bei einer solchen Konstellation der Präferenzen nicht transitiv, denn je nach Vorgehensweise gewinnt bei paarweiser Abstimmung eine andere Alternative und resultiert damit ein anderes Bereitstellungsniveau. Dieses Ergebnis wird hervorgerufen durch die nicht transitive Präferenzordnung des Individuums C. Dieser Wähler präferiert das höchste Bereitstellungsniveau, die geringste Menge des betroffenen öffentlichen Gutes bedeutet für ihn die zweite Wahl, aber eine dazwischen liegende Größenordnung der Leistung schätzt er am geringsten ein. Er ist sozusagen bei einem "moderaten" Bereitstellungsniveau am unzufriedensten. "Of course, individuals still might have extremist positions regarding statelocal finance issues - for instance, favoring a high level of education spending so that the public schools provide academic and extracurricular services to all students or, in the alternative, having all education done privately." (Fisher, 1987, 52)

Darüber hinaus bleibt festzuhalten, daß viele - wenn nicht die meisten - Wahlentscheidungen unter Inkaufnahme einer Reihe von Einflüssen und Problemen (wie Stimmentausch, strategischem Verhalten, Einfluß von Lobbyisten) zustandekommen. Das Fehlen praktikabler Wahlmechanismen, die bei der Lösung des Problems der Präferenzoffenbarung für die staatliche Bereitstellung bestimmter Leistungen helfen könnten, führt zu der Schlußfolgerung, daß trotz der Möglichkeit, daß Wahlverfahren infolge der Eigenschaften öffentlicher Güter als "Marktersatz" durchaus Informationsund Koordinationsaufgaben wahrzunehmen imstande sind, es in der Regel unvermeidbar ist, daß sich aufgrund der aufgezeigten Mängel eine Lösung in bezug auf die Bereitstellung lokaler öffentlicher Güter vom "Idealzustand" (der effizienten Allokation dieser Leistungen) entfernt. Dabei ist jedoch anzumerken, daß die bisher diskutierten Unzulänglichkeiten bei der Präferenzenthüllung bzw. dem Wahlmechanismus an sich typisch für demokratische Entscheidungsprozesse sind und nicht spezifisch für die lokalen Entscheidungsprozesse (vgl. Bernholz 1972; 1975).

\subsubsection{Das Medianwählermodell}

Einer der populärsten theoretischen Ansätze für die Bestimmung des Niveaus (lokaler) öffentlicher Aufgaben ist das Medianwählermodell. Es geht zurück auf die grundle- 
genden Arbeiten von Bowen (1943) und Black (1958). ${ }^{47}$ An dieser Stelle soll nur ein kurzer Überblick der wesentlichen Grundzüge des Medianwähleransatzes gegeben und insbesondere die Bedeutung dieses Modells für die beabsichtigte Zielsetzung - die Bestimmung eines effizienten Niveaus kommunaler Ausgaben - analysiert werden.

Wird bei einem politischen Abstimmungsprozeß nach der Regel der einfachen Mehrheit entschieden, sind die Präferenzen des Medianwählers von ausschlaggebender Bedeutung. Bei einer direkten Abstimmung über die zur Auswahl stehenden Alternativen setzt sich diejenige durch, für die sich der Medianwähler ausspricht. Allerdings wird ein solches "majority voting equilibrium" (Wildasin, 1986, 40) nur dann erreicht, wenn die Alternativen auf einer Dimension angeordnet werden können und die Präferenzordnungen eingipfelig sind (vgl. Black, 1958). ${ }^{48}$

Das Medianwählermodell kann somit zur Erklärung der "Nachfrage" nach öffentlich bereitgestellten Gütern und Leistungen und damit für die Bestimmung des Angebots herangezogen werden. Dabei wird bei Anwendung dieses Ansatzes zur Analyse staatlicher bzw. lokaler politischer Entscheidungsprozesse davon ausgegangen, daß die betreffende Abstimmung durch direkte Wahl der Steuerzahler zwischen mehreren Alternativen durchgeführt wird. Für die empirische Untersuchung werden dabei multiple Regressionen verwendet; als unabhängige Variable dienen der "Steuerpreis" und das Einkommen des Medianwählers. ${ }^{49}$ (vgl. auch Frey, 1988a, 660)

Dabei gilt das Medianwählermodell nur unter restriktiven Bedingungen. Insbesondere müssen die zur Entscheidung anstehenden Alternativen beliebig veränderbar sein; daneben wird die Stimmenbeteiligung als konstant angesehen (vgl. Fisher, 1987, 53ff). Außerdem weist das Ergebnis (die Präferenz des Medianwählers "gewinnt" unter bestimmten Voraussetzungen bei politischen Mehrheitsentscheidungen) einige Merkmale auf, die Anlaß zu einer kritischen Auseinandersetzung geben.

\footnotetext{
${ }^{47}$ Umfangreiche Arbeiten bezüglich der Konsequenzen für die okonomische Theorie der Politik im besonderen sowie die Wohlfahrtsökonomie im allgemeinen schlossen sich an die grundlegende Behandlung des Medianwăhler-Modells an. Beispielhaft werden hier genannt: Arrow (1963), Downs (1968) sowie Sen (1970). Die wesentlichen Charakteristika des Modells werden aufgegriffen und weiterentwickelt bei Boadway/Wildasin (1984), Feldman (1980), Mueller (1979) sowie Musgrave/Musgrave (1984).
}

48 Slutsky (1977) analysiert mehrdimensionale Entscheidungssituationen und formuliert Bedingungen, die bei der Realisierung einer gleichgewichtigen Lösung erfüllt sein müssen.

49 Das Medianwăhlermodell wurde am hăufigsten mit Hilfe von Querschnittsdaten auf der lokalen Ebene für die USA und die Schweiz empirisch getestet (vgl. Bergstrom/Goodman, 1973 sowie Pommerehne, 1978). Die wirtschaftichen Variablen haben in der Regel einen statistisch signifikanten Einfluß: Eine Erhöhung des "Steuerpreises" (d.h. eine Kostensteigerung für die Individuen) vermindert und eine Einkommenserhöhung steigert die Nachfrage und damit das Angebot der offentlichen Leistung. 
Als erstes Merkmal ist die dem Wahlergebnis anhaftende Unzufriedenheit der Steuerzahler mit dem jeweiligen Resultat zu nennen. "In fact, it is possible that only one voter, the median voter, will be perfectly satisfied with the outcome of a majority vote. This characteristic is inherent in the model because the reason for voting in the first place is to choose among different desired outcomes with the resulting compromise requiring some dissatisfaction." (Fisher, 1987, 55)

Ein zweiter bedeutsamer Kritikpunkt am Medianwählermodell ist die Tatsache, daß die resultierende Entscheidung (also die Wahl der Alternative des Medianwählers) keine ökonomisch effiziente Entscheidung darstellt. Eine wirklich effiziente Allokationsentscheidung würde sich nur zufällig ergeben, in der Regel stellt sie sich jedoch nicht ein. ${ }^{50}$ Dies soll am gewählten Eingangsbeispiel (vgl. Abbildung 4.1) verdeutlicht werden. Es ist leicht nachzuvollziehen, daß im angesprochenen Beispiel das Ergebnis einer einfachen Mehrheitswahl (die Präferenz des Medianwählers) nicht identisch mit der effizienten Lösung $z^{*}$ ist. Wie schon in Abschnitt 2.2 ausgeführt, gilt für die effiziente Allokation öffentlicher Güter, daß die Summe der Grenznutzen der Individuen der Höhe der Grenzkosten bei der Produktion entsprechen muß. Das Ergebnis des Medianwähleransatzes (erzielt durch eine Mehrheitswahl) muß aber lediglich der Bedingung genügen, daß die Grenznutzen jedes einzelnen Individuums seinem Steueranteil (Anteil an den Grenzkosten) entsprechen. Wahlentscheidungen können also Ergebnisse liefern, die mit einem größeren öffentlichen Güterangebot als dem effizienten Niveau verbunden sind (vgl. dazu auch das Ergebnis in der Abbildung 4.2). Es ist aber genauso gut möglich, daß das Wahlergebnis ein Bereitstellungsniveau unterhalb des effizienten ergibt. Das jeweilige Ergebnis hängt vom Zusammenhang von Steuerpreis und Grenznutzen sowie der Preiselastizität der Nachfrage ab. Offensichtlich wird aber, daß Wahlentscheidungen nur zufällig zur effizienten Lösung führen. ${ }^{51}$

Zusammenfassend bleibt festzuhalten, daß die aus Wahlentscheidungen resultierenden Ergebnisse (in der Regel die Medianwähleralternative) nicht die gleichen sind wie ökonomisch effiziente Resultate bei Marktallokation. Gleichwohl bleibt aufgrund der Eigenschaften öffentlicher Güter das Problem bestehen, daß die Marktkräfte nicht nutzbar sind und somit existierende Mechanismen der Präferenzoffenbarung weiterentwickelt oder neue gefunden werden müssen. Eine Möglichkeit wäre die Verän-

\footnotetext{
50 Ausnahme ist die Wicksell'sche (1896) Einstimmigkeitsregel (vgl. dazu auch Frey, 1988b, 497f).

51 Fisher $(1987,56 \mathrm{f})$ bringt dazu ein Beispiel: "Suppose that in a community of three voters one prefers school spending of \$ 1000 per student, another \$ 1500 , and the third \$ 5000. If tax shares are the same for all three, these amounts reflect only the relative benefits perceived by the three. The median is obviously $\$ 1500$ per student. The choice of the efficient amount, however, recognizes that the third voter has a substantially higher marginal benefit than do the others at every amount, which causes the efficient amount to exceed the median. Majority voting does not take account of strength or magnitude of preference."
} 
derung der Steuerstruktur in der Form, daß über eine Art "Nutzensteuer" ein Zusammenhang zwischen individuellem Grenznutzen und Steuerpreis hergestellt wird, der Anreize für die Wahlentscheidung des Individuums liefert und somit bezüglich der gewünschten Höhe der öffentlichen Leistung effiziente Ergebnisse garantieren könnte. Diese "first best solution" ist aber bekanntermaßen nicht möglich, denn die generelle Herstellung eines solchen Zusammenhanges stößt infolge der Besonderheiten öffentlicher Leistungen an unüberwindliche Grenzen.

Ein anderer Weg steht gerade auf der lokalen Ebene zur Verfügung, nämlich die Nutzung der räumlichen Mobilität der Einwohner und damit die Möglichkeit, durch $\mathrm{Ab}$ wanderung ("exit") der "dissatisfied voters" aus einer Gemeinde in eine andere und Zuwanderung von Individuen mit ähnlichen Nachfragewünschen wie die des jeweiligen Medianwählers letztlich homogene Präferenzstrukturen zu erreichen. In diesem Fall werden die divergierenden Nachfragestrukturen bezüglich der öffentlichen Leistung beseitigt, das Ausmaß der nicht realisierten Präferenzen reduziert bzw. im Idealfall eliminiert und damit Wohlfahrtsverluste beseitigt. Diese Möglichkeit wird im Abschnitt 4.4 ausführlich diskutiert.

\subsubsection{Wähler versus Bürokraten}

Obgleich Mehrheitswahlen die gebräuchlichste Form politischer Abstimmungen sind und das Medianwählermodell unter gewissen relevanzbesitzenden Annahmen operiert, gibt es daneben noch eine Reihe weiterer Ansätze im Rahmen der "Ökonomischen Theorie der Politik", die vor allem eine stärkere Berücksichtigung der institutionellen Strukturen fordern. Dabei spielt die Einbeziehung des Eigeninteresses öffentlicher Institutionen bzw. der sie tragenden Personen bei der Festlegung des Angebots öffentlicher Güter und Leistungen eine besondere Rolle. Dieses Selbstinteresse der Bürokraten fand speziell bei Niskanen (1971) Eingang in die Ansätze der "Public Choice".52

Im Gegensatz zu den üblichen Public-Choice-Ansätzen geht es bei den sogenannten "Monopolmodellen"s3 im Rahmen der theoretischen Betrachtung der Wahlverfahren um den Einfluß der Bürokratie auf den politischen Entscheidungsprozeß. Die generelle These dabei lautet: Bürokraten besitzen infolge ihrer Erfahrung und Information eine gewisse Monopolstellung im politischen Entscheidungsprozeß und sind somit in der

\footnotetext{
52 Einen umfassenden Überblick der "Bürokratietheorie" bietet Acheson (1988).

53 In Abgrenzung dazu sehen Romer/Rosenthal (1979a, 563) das Medianwăhlermodell als einen Ansatz, der "... is 'competitive' in spirit, for it assumes that any government that spends far from the median will soon be driven from office by an opposition that proposes an expenditure 'closer' to the median".
} 
Lage, ihre eigenen Präferenzen durchzusetzen und die Wähler bei ihrer Entscheidung zu beeinflussen (vgl. Wintrobe, 1988, 16ff). Dabei werden Bürokraten zunächst versuchen, ihr jeweiliges Ausgabevolumen und damit ihre fiskalische Bedeutung zu maximieren und in diesem Zusammenhang letztlich das Ziel verfolgen, im Amt zu bleiben (vgl. Breton/Wintrobe, 1975; 1982; Downs, 1967 sowie Tullock, 1965).

Romer und Rosenthal (1979a) haben dieses Problem weiter verdichtet und folgende Annahmen formuliert: ${ }^{4}$

- Bürokraten verfolgen zwei Ziele, nämlich zum einen die Maximierung ihres fiskalischen Gewichts und zum anderen streben sie danach, im Amt zu verbleiben. ${ }^{5 s}$

- Bürokraten kennen die Präferenzen der Einwohner ihrer Gemeinde.

- Die Ausgaben für öffentliche Leistungen werden mit einer Mehrheitswahlentscheidung durch die Einwohner bestimmt. Die Bürokratie schlägt dabei eine Reihe von unterschiedlichen Alternativen vor, die dann zur Abstimmung gelangen. "Voters have only a choice between some institutionally defined reversion expenditure and the proposal offered by the bureau or proposal setter." (Romer/Rosenthal, 1979a, 564)

- Falls sich im Rahmen der Mehrheitswahl keine der von seiten der Bürokraten vorgeschlagene Option durchsetzt, erreichen die öffentlichen Ausgaben ein sogenanntes "reversion"-Niveau." If the bureaucrats' proposal is rejected, then the budget is set at an alternative level, called the reversion level, which is determined according to some procedural rule. For example, the level of expenditure could be set equal to zero, or equal to the previous year's budget, or the previous year's budget plus a given percentage increase ..." (Wildasin, 1986, 55f)

Die Merkmale dieses Modells lassen sich an einem Beispiel verdeutlichen. Betrachtet man eine lokale öffentliche Leistung z, die den Einwohnern einer Gemeinde bereitgestellt wird und deren "Konsum" mit der Zahlung eines bestimmten "Steuerpreises" für das jeweilige Individuum verbunden ist (dieser Preisbetrag kann für alle Individuen identisch sein), ergibt sich folgende Situation. Falls das sogenannte "reversion level" von $\mathrm{z}$ identisch ist mit der Präferenz des Medianwählers $\left(\mathrm{z}_{\mathrm{M}}\right)$, gilt also $\mathrm{z}_{\mathrm{R}}=\mathrm{z}_{\mathrm{M}}$, wird als

\footnotetext{
${ }^{54}$ Sie analysieren mit diesem Modell die Einflüsse der Bürokratie auf die Wahlentscheidungen auf kommunaler Ebene und damit die Auswirkungen dieser Aktivităten auf das lokale offentliche Leistungsangebot. Vgl. dazu auch Fisher $(1987,58)$.

55 Epple/Zelenitz (1981a; 1981b) entwerfen ein Modell für den lokalen Bereich, wobei die kommunale Bürokratie eher versucht, maximale Einnahmemöglichkeiten anzustreben. Vielleicht ist gerade ein solches Verhalten "optimal" zu nennen, denn schließlich gewährt ein Einnahmenüberschuß bzw. ein größerer Handlungsspielraum auf der Einnahmeseite die Umsetzung weiterer Eigeninteressen der Bürokraten. Ähnlich argumentiert auch Inman (1982).
} 
Wahlergebnis auch bei Bürokratieeinfluß $\mathrm{z}_{\mathrm{M}}$ resultieren. Die Bürokratie ist nicht in der Lage, ein höheres Leistungsangebot und damit ein größeres Ausgabevolumen von $z$ durchzusetzen, da ein solcher Vorschlag nicht die Zustimmung der Mehrheit erlangt.

Wenn $z_{R}>z_{M}$ wird das Wahlergebnis $z_{R}$ lauten, da die lokalen Bürokraten mindestens ein Ausgabeniveau von $z_{R}$ anbieten und daher eine Mehrheit der Wähler diesen Vorschlag unterstützt, um ein noch höheres Ausgabevolumen zu verhindern. Letztlich - der interessanteste Fall - kann $z_{R}<z_{M}$ sein, was dazu führt, daß sich ein Ausgabeniveau oberhalb von $z_{M}$ einstellt. Je geringer das Bereitstellungsniveau $z_{R}$ ist, um so weiter oberhalb von $z_{M}$ kann das sich möglicherweise erreichbare Ergebnis $z_{B}$ liegen. Dieser letzte Fall soll in Abbildung 4.2 illustriert werden.

Abbildung 4.2: Nutzenfunktionen und das Bürokratie - Public Choice - Modell

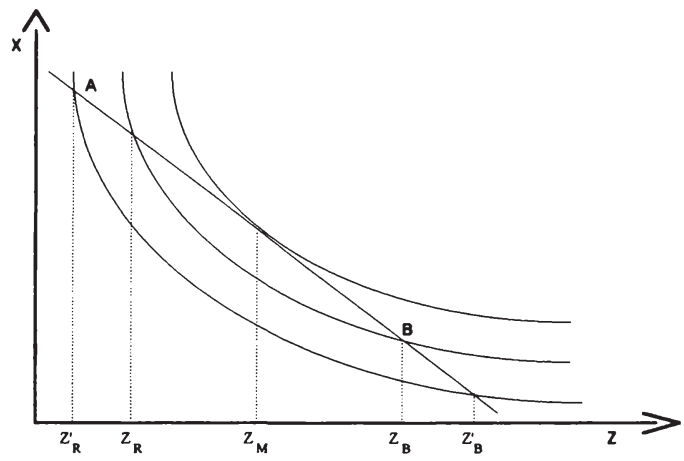

Wenn eine Präferenzordnung des Haushalts bezüglich des privaten Gutes $\mathbf{x}$ und des lokalen öffentlichen Gutes $\mathrm{z}$ als Indifferenzkurvensystem abgebildet wird, ergibt sich unter Nutzenerwägungen folgende Entscheidungsstituation. Der Konsum der beiden Güter $\mathbf{x}$ und $\mathbf{z}$ des Individuums $\mathrm{i}$ ist bestimmt durch die Preise ${ }^{56}$ der beiden Güter und das Einkommen des Haushalts. Wenn das Individuum (Wähler) frei und unabhängig in seiner Entscheidung wäre (ohne den Bürokratieeinfluß), würde sich bei einer Mehrheitswahl bezüglich der Bereitstellung des lokalen öffentlichen Gutes das Bereitstellungsniveau $\mathrm{z}_{\mathrm{M}}$ ergeben. Nun ist aber der Wähler bei seiner Wahlentscheidung bekanntermaßen nicht frei von Einflüssen und sieht sich - wie weiter oben beschrieben - den Vorgaben der Bürokratie (diese schlägt eine Reihe von unterschiedlichen Alternativen

\footnotetext{
56 Für das lokale offentliche Gut wird ein sogenannter "Steuerpreis" unterstellt. Dieser Preis kann für jedes Individuum konstant sein (also etwa ein bestimmter Prozentsatz der Gesamtkosten der Bereitstellung) oder auch der "Steuerpreis" des Medianwăhlers sein. Vgl. dazu Romer/Rosenthal (1979a, 566).
} 
vor, die dann zur Abstimmung gelangen) und damit der Einengung seiner Wahlmöglichkeiten ausgesetzt. Folglich ist der Wähler nicht frei in der Wahl eines bestimmten Bereitstellungsniveaus des lokalen öffentlichen Gutes $z$, sondern kann sich nur zwischen einem von der Bürokratie vorgeschlagenen Level $z_{B}$ und dem "reversion level" $\mathrm{z}_{R}$ entscheiden. Die Wahlentscheidung des einzelnen Individuums ist also eine "all-ornon choice" (Romer/Rosenthal, 1979a, 567) zwischen den beiden Alternativen $z_{B}$ und $z_{R}$. Diese Annahme bedeutet für das Wählerverhalten, daß diese natürlich auch jetzt das Angebotsniveau (Bereitstellungsniveau) von $\mathrm{z}$ wählen, das ihnen einen höheren Nutzen ermöglicht. Nun ist der Wähler zwischen $z_{B}$ und $z_{R}$ indifferent, doch wenn die Bürokraten $z_{\tilde{B}}$ anbieten, "... the voter will choose the level of spending that yields the higher utility" (Romer/Rosenthal, 1979a, 567), d.h. dieses Bereitstellungsniveau $z_{\hat{B}}$, denn $U\left(z_{\bar{B}}, \bar{x}\right)>U\left(z_{B}, \bar{x}\right)$. Wenn das sogenannte "reversion level" ("Widerstandslevel") $z_{R}$ ist, wird das Individuum jede Bereitstellungsmenge, die zwischen $z_{M}$ und $z_{B}$ liegt, akzeptieren, weil damit ein höherer Nutzen einhergeht. Es ist somit möglich, daß infolge der spezifischen Vorgaben der Bürokratie eine Angebotsmenge oberhalb von $z_{M}$ (also etwa $z_{\dot{B}}$ ) die "Zustimmung" der Mehrheit findet.

Wenn es darüber hinaus der Bürokratie gelingt, das "reversion level" von $z_{R}$ auf $z_{R}{ }^{\prime} z u$ senken, dann akzeptiert bei gleichbleibender Präferenzstruktur die Mehrheit ein höheres Bereitstellungsniveau. Das maximale Bereitstellungsniveau von $\mathrm{z}$ - das von seiten der Bürokratie durchgesetzt werden kann, weil es die Zustimmung der Mehrheit bekommt - steigt also mit sinkendem "reversion level" (vgl. Romer/Rosenthal, 1979a, 565ff). "This is an intuitive result: voters might accept a very high level of public services if the alternative is, say, to do without them altogehter." (Wildasin, 1986, 57)

Ein wesentliches Charakteristikum des vorstehenden Ansatzes, nämlich die Existenz eines gewissen "reversion amount" bei der Bereitstellung öffentlicher Güter, ist zugleich auch eine zur Kritik auffordernde Besonderheit. Obwohl sicherlich die Rolle der Bürokraten innerhalb der ökonomischen Theorie der Politik nicht vernachlässigt werden sollte, Romer und Rosenthal (1979b) ihr vorgestelltes einfaches Modell weiter verfeinert haben und eine Reihe empirischer Tests die Relevanz des Romer-RosenthalModells nachweisen konnten ${ }^{57}$, bleibt die Festlegung bzw. Bestimmung des "reversion level" eine Schwäche des Ansatzes. Über Höhe und Ausmaß dieses Level läßt sich durchaus kritisch reflektieren. Darüber hinaus läßt eine Fehlinterpretation des "reversion amount" auch andere als bisher betrachtete Ergebnisse zu. ${ }^{58}$ Daher kann mit

57 Vgl. bezüglich weiterführender Diskussionen sowie der empirischen Evidenz beispielsweise Ott (1980), Courant/Gramlich/Rubinfeld (1979), Bush/Denzau (1977) sowie Gramlich/Rubinfeld (1982).

58 Eine umfangreicheren Auseinandersetzung mit diesem Merkmal findet man bei Fisher $(1987,59 f)$. 
Fisher $(1987,60)$ abschließend festgestellt werden: "Proponents of monopoly fiscalchoice models must identify the institutional factors in each case where the model is to be used, which allow officials to continually not satisfy the voters' desires."

4.4 Mobilität und die Bestimmung öffentlicher Ausgaben: Das Tiebout-Modell

\subsubsection{Vorbemerkungen}

Es hat sich bisher gezeigt, daß keines der Verfahren zur Präferenzenthüllung für öffentliche Güter und Leistungen eine zufriedenstellende oder gar optimale Basis für die Bereitstellung lokaler öffentlicher Güter liefert. Sub-optimale Allokationsergebnisse können also durch eine marktnahe Bereitstellung der Güter mit beschränkter Nutzenreichweite (Bildung von Organisationen und Clubs) oder durch staatliche Bereitstellung und Bestimmung des Niveaus der öffentlichen Leistungen im Wege der politischen Abstimmung nicht ausgeschlossen werden. Obwohl beide Verfahren in der Lage sind, für den lokalen Entscheidungsprozeß einige notwendige Informationen zu liefern, ist es unvermeidbar, daß Unzulänglichkeiten bei der Präferenzenthüllung bzw. dem Wahlmechanismus selbst eine unbefriedigende Lösung liefern. Die angesprochenen Probleme sind jedoch keineswegs spezifisch für die lokale Ebene im besonderen sondern typisch für demokratische Entscheidungsfindungsprozesse im allgemeinen.

Es verbleibt jedoch eine dritte Möglichkeit, um dem Problem der Ermittlung individueller Präferenzen für öffentliche Güter näherzukommen. Hierbei handelt es sich um einen Mechanismus, der ausschließlich dezentralen staatlichen Entscheidungsträgern zur Verfügung steht - nämlich die Tatsache der Mobilität der Bevölkerung oder anders ausgedrückt die Möglichkeit der "Abstimmung mit den Füßen" (Tiebout, 1956). Auf diese Weise ("public choice through mobility") sind Individuen idealtypisch gesehen in der Lage, sich die Kommune auszuwählen, deren angebotenes öffentliches Leistungsbündel den eigenen Wünschen weitestgehend entspricht. Tiebout's Argumentation kann dabei als direkte Antwort auf die Schlußfolgerungen Samuelson's (1954; 1955) verstanden werden, daß die Präferenzen für öffentliche Güter ausschließlich durch politische Abstimmungen festgestellt werden können. ${ }^{59}$

\footnotetext{
59 In einer Antwort auf den Tiebout-Ansatz argumentiert Samuelson $(1958,337)$, daß "... people might not migrate to areas offering more tempting packages, first because they would rather improve their own communities than abdicate from them, and secondly because people often like heterogenity even though it involves conflict. Formally, these points can be seen as restraints on mobility that reduce the effectiveness of the Tiebout process." Diese Problembereiche werden bei der Bewertung des Tiebout-Modells wieder aufgegriffen.
} 
In seinem Ursprungsartikel schlug Tiebout vor, daß an Stelle der Wahlverfahren die Bürger innerhalb eines begrenzten Gebietes (beispielsweise einer Gemeinde) zur Preisgabe ihrer Präferenzen veranlaßt werden könnten, indem man sich die Mobilität der Bevölkerung und damit interkommunale Wanderungsbewegungen zunutze macht. Tiebout's Analyse steht also den "Public Choice"-Ansätzen gegenüber, in deren Kontext interkommunale Wanderungen keine Berücksichtigung finden, sondern die Präferenzenthüllung über politische Abstimmungen erfolgen muß. "In Tiebout's view, differences in public-good demand may also be resolved by moving or, more correctly, by grouping together consumers with the same demand. Consumers, then, may influence fiscal choices either by participating in the local political process (what political scientists call 'voice') or by 'voting with one's feet' (exit)." (Fisher, 1987, 66)

Wenn Individuen mobil sind (d.h. die Möglichkeit der Wohnsitzverlagerung besitzen), erscheint es möglich, daß ein Individuum sich die Gemeinde auswählt, in der aus dem Blickwinkel des "Konsumenten" (bei sonst gleichen Rahmenbedingungen) das kommunale Leistungsangebot mit seinen eigenen Präferenzen möglichst weitgehend übereinstimmt. Dies bedeutet, daß ein Individuum eine Reihe von alternativen Kombinationen eines öffentlichen Güterangebots prüft und auf der Basis dieser Optionen seinen Wohnort auswählt. ${ }^{60}$ Dieser Auswahlprozeß führt dann dazu, daß die Enthüllung der individuellen Präferenzen für lokale öffentliche Güter durch die "Allokation" der Individuen auf die lokalen Gebietskörperschaften erreicht wird. Es ist natürlich auch möglich, durch Einflußnahme auf den kommunalen Entscheidungsfindungsprozeß das Angebot in der "eigenen" Kommune den entsprechenden Wünschen anzupassen, um damit eine Wohnortverlagerung an den präferierten Standort zu vermeiden. Wahlverfahren verlieren also nicht völlig ihre "präferenzenthüllende" Bedeutung, sondern werden immer dann Relevanz erlangen, wenn Mobilitätskosten vorhanden sind und das Individuum daher Wohnsitzverlagerungen nicht problem- bzw. kostenlos realisieren kann.

Obwohl Tiebout's Ansatz einen klassischen Beitrag auf dem Gebiet der ökonomischen Theorie des Föderalismus darstellt und - zumindest in seinen Kernaussagen - allgemein bekannt sein dürfte, erscheint es im Hinblick auf die Bedeutung der interkommunalen Wanderungen für den weiteren Gang dieser Untersuchung sinnvoll und notwendig, die wesentlichen Grundzüge noch einmal vorzustellen.

\footnotetext{
${ }^{60}$ Wenn also beispielsweise die öffentlichen Bibliotheken in Gemeinde A höher eingeschătzt werden als die Büchereien in Gemeinde B, entscheiden sich eifrige Bibliotheksbenutzer bei der Wahl ihres Wohnortes für Gemeinde A, wenn die Präferenz für die Bibliotheksbenutzung alle anderen Präferenzen bezüglich lokaler öffentlicher Leistungen dominiert.
} 


\subsubsection{Grundlagen und explizite Modellannahmen}

Der Tiebout-Beitrag gilt als die klassische Grundlage der Wanderungsanalyse im Rahmen der Theorie lokaler Ausgaben (vgl. Miller/Tabb, 1973, 161; Pestieau, 1977, $184 ; 1983,11 \mathrm{ff}$ ). Er gehört trotz seines Alters auch noch in der aktuellen Literatur (vgl. etwa Wust, 1981, 17ff oder Meisterling, 1986, 14ff) zu den meistbeachteten Aufsätzen der ökonomischen Theorie des Föderalismus und findet in bezug auf den Erklärungswert und als partielles ordnungspolitisches Vorbild grundsätzliche Anerkennung. ${ }^{61}$

Ausgangspunkt des Tiebout'schen Ansatzes sind die Werke von Musgrave (1955) und Samuelson $(1954 ; 1955)$ und deren Erkenntnis, daß keine marktmäßige Lösung zur Bestimmung des Umfanges staatlicher Ausgaben für öffentliche Güter existiert. Das Nichtvorhandensein einer solchen "market type solution" (Tiebout, 1956, 416) für den Bereich der Versorgung mit öffentlichen Leistungen ist für Tiebout ein Indiz dafür, daß die Allokation einer beträchtlichen Anzahl von Gütern in sub-optimaler Weise erfolgt. Dabei ist der von Tiebout verwendete Optimalitätsbegriff aber nicht ohne weiteres mit einer modelltheoretisch ermittelten Pareto-Optimalität gleichzusetzen, sondern wie der gesamte Beitrag eher "realitätsbezogen". 62

Tiebout erkennt die Unvollkommenheiten des Marktes für private Güter ebenso wie die Unvollkommenheiten seines "Marktes für öffentliche Güter". Er versucht daher lediglich aufzuzeigen, daß sich die zu vergleichenden Märkte sowohl in ihren Vorzügen als auch in ihren Unvollkommenheiten ähneln und daher durch einen konkurrenzwirtschaftlich konzipierten Föderalismus vergleichbare "optimale" Ergebnisse zu erwarten sind wie auf einem konkurrenzwirtschaftlich organisierten Markt für private Güter. Dabei geht Tiebout davon aus, daß Marktergebnisse trotz existierender Unvollkommenheiten auf beiden "Märkten" Resultate liefern, die allen anderen vorzuziehen sind. "While the solution may not be perfect because of institutional regidities, this does not invalidate its importance. The solution, like a general equilibrium solution for

\footnotetext{
61 "Es scheint aber klar zu sein, daß die Möglichkeit der 'Abstimmung durch Wanderung' ('voting with the feet') die Individuen im Rahmen räumlich konkurrierender lokaler Regierungen in einem foderativen System zu Ergebnissen führt, die der Art nach näherungsweise mit denen effizient ablaufender, wettbewerblicher Mărkte verglichen werden können." (Buchanan, 1977, 55) "Sicher kann der Tiebout'schen These nicht abgesprochen werden, daß sie einen wichtigen Teil der Wirklichkeit durchaus richtig sieht: Wanderungen von einem Kollektiv zum anderen können den intrakollektiven Konflikt entschärfen und der Übereinstimmung von Zielvorstellungen und Gütererstellung dienlich sein." (Kirsch, 1980, 176)

62 Diese Ausrichtung läßt sich auch daran erkennen, daß Tiebout abschließend bemerkt: "Those who are tempted to compare this model with the competitive private model may be disappointed. Those who compare the reality described by this model with the reality of the competitive model - given the degree of monopoly, friction, and so forth - may find that local government represents a sector where the allocation of public goods (as a reflection of the preferences of the population) need not take a back seat to the private sector." (Tiebout, 1956, 424)
} 
a private spatial economy, is the best that can be obtained given preferences and resource endowments." (Tiebout, 1956, 424) Diese erreichbare "front-seat-Optimalität" erkennt Tiebout allerdings nicht für den gesamten Bereich öffentlicher Güter an, sondern lediglich für die Leistungen, für die sich die von ihm intendierte marktmäßige Lösung realisieren läßt - also die lokalen öffentlichen Güter.

In Abweichung zu den von ihm zitierten Ansätzen von Musgrave und Samuelson versucht Tiebout zu demonstrieren, daß für einen Teilbereich des öffentlichen Güterangebots eine Reduktion des Umfanges der "sub-optimalen" Allokation durch eine marktmäßige Lösung möglich ist. Durch eine dezentrale Bereitstellung dieses Teils der öffentlichen Leistungen werden die individuell unterschiedlichen Bürgerpräferenzen letztlich besser reflektiert als durch ein von der Zentralregierung bereitgestelltes öffentliches Angebot. (vgl. Tiebout, 1956, 416)

Eine präzise Definition lokaler öffentlicher Güter, wie sie weiter oben versucht worden ist, erhält der Betrachter Tiebout'scher Vorstellungen jedoch nicht. Tiebout betont zwar mit Hilfe empirischer Nachweise die quantitative Bedeutung real existierender lokaler Ausgaben für öffentliche Güter (vgl. Tiebout, 1956, 418) bzw. fordert in Zusammenhang mit der modellmäßigen Betrachtung, daß lokale öffentliche Güter keine positiven oder negativen externen Effekte über die Gemeindegrenzen hinaus aufweisen sollen (vgl. Tiebout, 1956, 419); einer qualitativen Überprüfung würde diese Vorgehensweise aber kaum standhalten. In Anbetracht seiner auch politisch-praktischen Orientierung wird man Tiebout also vermutlich eher gerecht, wenn man ihm eine pragmatische Definition lokaler öffentlicher Güter unterstellt. Lokale öffentliche Güter sind demnach für ihn jene Güter, die dezentral bereitgestellt werden. Dezentral werden nur solche Güter bereitgestellt, die keine "zentralen" Wirkungen aufweisen. Eine Aufgabe wäre dann keine lokale (kommunale) mehr, wenn eine Kommune sie gleichzeitig für mehrere Kommunen erledigen würde (vgl. Hansmeyer, 1966).

Wichtig für das Tiebout-Konzept sind die weiter oben als crowding oder congestion beschriebenen Eigenschaften lokaler öffentlicher Güter dennoch. Auf der lokalen Ebene ist die Bereitstellung dieser öffentlichen Leistungen hinsichtlich der Eigenschaft der Nicht-Rivalität anders zu beurteilen als gesamtstaatlich. Die Größe einer Gemeinde (also deren Einwohnerzahl) bzw. die Suche nach der optimalen Gemeindegröße spielt in diesem Kontext eine entscheidende Rolle.

Die Hauptaufgabe zur Realisierung einer effizienten Allokation sieht Tiebout darin, die Präferenzen der Bürger korrekt zu ermitteln. Diese Präferenzen sind zur Bestimmung des öffentlichen Angebots so zu berücksichtigen, wie es auf dem Markt für private Güter geschehen würde, und die Bürger sind adäquat - "ability to pay principle" 
(Tiebout, 1956, 417) - zu besteuem. In der Tiebout-Perspektive besteht das Problem bei der Lösung dieser Aufgabe hauptsächlich darin, daß der rationale Bürger (Konsument) seine Präferenzen für lokale öffentliche Güter in der Hoffnung untertreiben wird, aufgrund des Nicht-Ausschlusses die entsprechenden Steuern bei verbleibender Konsummöglichkeit zu vermeiden. (Tiebout, 1956, 417)

Um seine "marktmäßige" Lösung für die beschriebene Aufgabenstellung zu demonstrieren, bedient sich Tiebout zunächst einer Basis-Modellversion. Diese besteht im wesentlichen aus folgenden sieben Grundannahmen (vgl. auch Meisterling, 1986, 19):

(1) Konsumenten (Wähler) haben vollständige Informationen über die unterschiedlichen kommunalen öffentlichen Angebote und die dafür zu entrichtenden Finanzierungsbeiträge.

(2) Konsumenten (Wähler) sind vollkommen mobil und wählen jeweils diejenige Kommune als Wohnort, deren öffentliches Angebot und seine Finanzierung ihren Präferenzen am besten entspricht.

(3) Es gibt eine große Anzahl von Kommunen, zwischen denen der einzelne Bürger bei seiner Wohnortentscheidung wählen kann.

(4) Es gibt keine externen Effekte öffentlicher Güterbereitstellung zwischen den verschiedenen Gemeinden (keine räumlichen "spillovers").

(5) Es gibt keine Restriktionen durch abweichende Beschäftigungsmöglichkeiten. Wanderungskosten werden also vernachlässigt und somit quasi kostenlose Mobilität unterstellt.

(6) Für jede lokale öffentliche Leistung existiert eine (in Einwohnerzahlen gemessene) optimale Gemeindegröße, bei der die jeweilige Leistung zu den geringsten Durchschnittskosten bereitgestellt werden kann. ${ }^{63}$

(7) Kommunen, die diese optimale Einwohnerzahl nicht erreicht haben, versuchen entweder (bei zu geringer Bevölkerung) zusätzliche Bürger zu attrahieren oder versuchen (bei Überschreiten der optimalen Einwohnerzahl) das Gegenteil. ${ }^{64}$

63 Die Kosten (K) sind eine Funktion der Menge des lokalen offentlichen Gutes z, also $K=f(z)$; die Durchschnittskostenfunktion hat einen u-formigen Verlauf.

64 Wie dieser Anpassungsmechanismus funktionieren soll, wird von Tiebout nur beispielhaft und nicht ganz schlüssig beschrieben. Für den Fall, daß eine Kommune ihre optimale Großße noch nicht erreicht hat, nennt er kommunale Industrieansiedlungsbemühungen (Verbesserung der sogenannten "harten" Standortfaktoren (vgl. Napp, 1990, 22ff)) als eine Möglichkeit, um die Einwohnerzahl der Gemeinde zu erhöhen. Die Empfehlung zielt offenbar stärker auf die praktische Anwendung des Tiebout-Konzepts, denn ansonsten stünde sie im Widerspruch zur Annahme (5) seines Basismodells. Für den Fall, daß eine Gemeinde ihre optimale Einwohnerzahl überschritten hat und demgemåß versuchen müßte, diese zu reduzieren, schreibt Tiebout skeptisch: "No alderman in his right political mind would ever admit that the city is too big" (Tiebout, 1956, 420). Andererseits deutet er aber an, daß "Nevertheless, economic forces are at work to push people out of it. 


\subsubsection{Funktionsweise des Modells}

In der räumlichen Mobilität des Konsumenten (Wählers) kommunaler öffentlicher Leistungen erkennt Tiebout den wesentlichen Unterschied im Verhältnis der Bürger zum Staat. Während die Anpassung des öffentlichen Angebots und dessen Finanzierung an die unterschiedlichen Präferenzen für die staatlichen Instanzen im allgemeinen eine problematische Aufgabe (auch bei Nutzung von politischen Abstimmungsprozessen) bleibt, kann diese Anpassung im lokalen Bereich aufgrund einer Vielzahl verschiedener öffentlicher Angebote und der räumlichen Mobilität der Bürger quasi automatisch erfolgen. Die ansonsten mit der Präferenzermittlung verbundenen Probleme bei Existenz öffentlicher Güter werden also durch diesen Mechanismus weitestgehend vermieden.

Bei Kenntnis der unterschiedlichen Angebote lokaler öffentlicher Leistungen wandern die Bürger einfach in die Kommune, deren Finanzierungs-Leistungs-Angebot ihren Präferenzen am ehesten entspricht, und offenbaren damit gleichzeitig ihre Präferenzen für bestimmte öffentliche Güter sowie ihre Bereitschaft, sich dafür an der Finanzierung eines solchen Gutes zu beteiligen. (vgl. Tiebout, 1956, 418)

Dieser Prozeß gestaltet sich um so erfolgversprechender, je größer die Anzahl der Kommunen und je größer die Vielfalt ihrer Leistungsangebote ist. ${ }^{65}$ Die interkommunale Wanderung an sich ersetzt dabei "... the usual market test of willingness to buy a good and reveals the consumer-voter's demand for public goods" (Tiebout, 1956, 420).

Die Bürger bekunden ihre Präferenzen also nicht losgelöst von jeglichen Preisvorstellungen (Finanzierungsbeiträgen) und haben somit kaum Anreize, ihre Wünsche bezüglich des öffentlichen Leistungsangebotes zu verschweigen und sich als "free-rider" zu verhalten. Mit jeder Entscheidung für ein bestimmtes öffentliches Angebot ist gleichzeitig die Verpflichtung zur anteiligen Kostenübernahme verbunden.

Die "Nachfrage" nach einem lokalen öffentlichen Gut kommt (wie in Abbildung 4.3 verdeutlicht) folgendermaßen zum Ausdruck. Jedes Individuum - das sich für die betreffende Gemeinde als Wohnort entscheidet - hat die gleiche Präferenz und fragt damit die jeweilige öffentliche Leistung (z) gemäß seinem erzielbaren Grenznutzen nach. Der Grenznutzen für ein Individuum ist in Abbildung 4.3 dargestellt durch die Nach-

Every resident who moves to the suburbs to find better schools, more parks, and so forth, is reacting, in part, against the pattern the city has to offer." (Tiebout, 1956, 420)

65 "The greater number of communities and the greater the variance among them, the closer the consumer will come to fully realizing his preference position." (Tiebout, 1956, 418) 
fragekurve $\mathrm{GN}_{\mathrm{i}}$. Die Summe aller Grenznutzen ist folglich identisch mit der Addition der individuellen (identischen) Nachfragekurven, so daß sich $\mathrm{GN}_{\text {ges }}=\mathrm{GN}_{\mathrm{i}} \cdot \mathrm{N}$ ergibt.

Abbildung 4.3: Die Bereitstellung eines lokalen öffentlichen Gutes in einer "TieboutGemeinde"

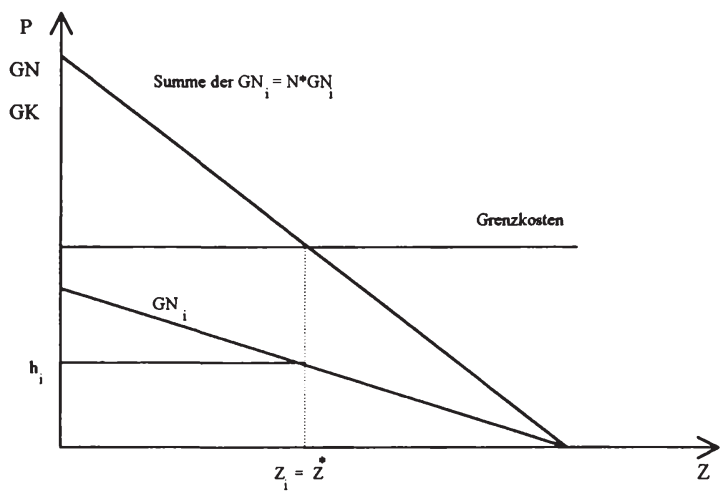

Wenn alle Konsumenten (Wähler) einen gleichen Finanzierungsbeitrag $\left(\mathrm{FB}_{\mathrm{i}}\right)$ leisten (also einen bestimmten Teil der Kosten tragen), dann wird das lokale öffentliche Gut in der Größenordnung $z_{i}=z^{*}$ bereitgestellt. Aufgrund der Nicht-Rivalität im Konsum steht die angebotene öffentliche Leistung für alle Individuen in gleichem Maße zur Verfügung. Wenn nun die Grenznutzen jedes einzelnen Konsumenten seinem Finanzierungsbeitrag (Anteil an den Grenzkosten) entsprechen (beides ergibt sich aus $1 / \mathrm{N}$, wenn $\mathrm{N}$ die Anzahl der Konsumenten ist), wird folglich die öffentliche Leistung in einem effizienten Ausmaß bereitgestellt. Die Tiebout-Lösung bringt also für jede Gemeinde ein Ergebnis, das man als "benefit tax equilibrium" (Fisher, 1987, 68) bezeichnen kann.

Sowohl im Hinblick auf sein Modell als auch explizit mit Blick auf die Realität sieht Tiebout auf der Angebotsseite eine Tendenz dafür, daß die "Kräfte des Marktes" die lokalen Anbieter zur Minimierung der Produktionskosten zwingen (vgl. Tiebout, 1956, 422). ${ }^{66}$ Für die Nachfrager formuliert er in Anlehnung an Samuelson $(1954,388) \mathrm{zu}-$ versichtlich: "... each individual, in seeking as a competitive buyer to get to the highest

\footnotetext{
66 Denn selbst bei "optimaler Besteuerung" spielt die Art der Verausgabung der Mittel eine Rolle, denn das Angebot an Infrastruktur kann infolge divergierender lokaler Produktivitäten bei gleichem Ausgabenbetrag variieren. In einer solchen Situation besteht für die lokalen Anbieter der Anreiz, seine Produktivităt zu erhöhen und damit für eine Minimierung der Produktionskosten zu sorgen, um "konkurrenzfähig" zu sein.
} 
level of indifference subject to given prices and tax, would be led as if by an Invisible Hand to the grand solution of social maximum position" (Tiebout, 1956, 422).

\subsubsection{Bewertung des Ansatzes}

Tiebout erkennt selbstverständlich die Restriktionen seines auf bestimmten Annahmen basierenden Modells und will seinen Ansatz daher auch "nur" als eine Verdeutlichung der Bedingungen verstanden wissen, unter denen die Versorgung der Bürger mit lokalen öffentlichen Leistungen die gleichen allokativ-optimalen Ergebnisse liefert wie ein funktionierender Markt für private Güter (vgl. Tiebout, 1956, 421). Realistischerweise sind natürlich Unvollkommenheiten zu erwarten, die die optimale Allokation beeinträchtigen. Tiebout vergleicht jedoch zum einen diese Probleme mit ähnlichen Unvollkommenheiten der Märkte für private Güter, die dann auch dort die Allokation beeinträchtigen würden, und zum anderen nimmt er an, daß man die angestrebten Zielsetzungen "nur geringfügig verfehlen würde" (vgl. Tiebout, 1956, 422).

Doch auch bei Zugrundelegung der weiter oben genannten Annahmen handelt es sich beim vorliegenden Modell nur um eine approximative Realisation der idealen Marktlösung. Schwierigkeiten in bezug auf die Erreichung einer optimalen Nutzenposition sind durch die Nichtberücksichtigung möglicher Wanderungskosten zu erwarten, denn Tiebout selbst führt in seinem Beitrag keine explizite Analyse von Wanderungskosten durch. In bezug auf die Untersuchungen Koopmans (1954) räumt er aber ein, "... that in a space economy with transport cost there is no general equilibrium solution as set by market forces" (Tiebout, 1956, 422). Die Berücksichtigung möglicher Wanderungskosten beeinträchtigt die Exaktheit der Ermittlung der Nachfrage der Bürger nach lokalen öffentlichen Leistungen und damit auch die "Korrektheit" des öffentlichen Leistungsangebots. Die Bürger müssen mögliche Verbesserungen ihrer Nutzenposition gegen die damit verbundenen Wanderungskosten abwägen. Wenn Wanderungskosten den Wert der möglichen Verbesserungen kompensieren, sind Abweichungen der lokalen Preis-Leistungs-Kombinationen von den günstigsten Lösungen der Bürger möglich. In der Existenz von Mobilitätsbarrieren in Form von Wanderungskosten erkennt Tiebout speziell die Schwierigkeit, daß Kostenänderungen bei einzelnen lokalen öffentlichen Angeboten nicht zu einer Einschränkung der angebotenen Menge in dem Maße führen würden, wie es geschähe, wenn es keine Wanderungskosten gäbe. ${ }^{67}$

Ein weiterer Einwand hinsichtlich der Zugrundelegung kostenloser Mobilität hängt mit den sogenannten "Ballungskosten" (Wust, 1981, 178) vieler öffentlicher Leistungen 
zusammen. Wenn sich Nutzer gegenseitig beim Konsum "behindern", die optimale Gemeindegröße also bereits überschritten ist und somit Rivalitätsaspekte durch Überschreiten der Kapazitätsgrenze sichtbar werden, muß ungehinderte Mobilität nicht automatisch zu allokativer Effizienz führen. Ein potentieller "Einwanderer" wird (schließt man altruistisches Verhalten aus) nur den eigenen Nutzen kalkulieren, den er durch seine Wanderung zu erlangen hofft, nicht aber die Kosten und Nutzen, die sein Verhalten ortsansässigen Bürgern beschert (vgl. Forte, 1977; Buchanan/Goetz, 1972 sowie Vardy, 1973, 82ff).

Im engen Modellrahmen (vgl. Annahme (5)) werden bei Tiebout interkommunale externe Effekte ausgeklammert. Diese unter den Effizienzgesichtspunkten seines Ansatzes notwendige Einschränkung ist immer wieder Kristallisationspunkt kritischer Auseinandersetzungen (vgl. etwa Fisher, 1987, 69ff). So konstatiert Tiebout selbst (1956, 423): "There are obvious external economies and diseconomies between communities." Die Anerkennung der Existenz räumlicher externer Effekte liefert zwar im Rahmen der Tiebout-Welt immer noch eine Lösung, die für die jeweilige Kommune ein effizientes Versorgungsniveau bedeutet, aber gesamtgesellschaftlich eben keine wohlfahrtsoptimale Situation erlaubt. In bezug auf das mögliche Auftreten solcher räumlicher "spillovers" und der damit verbundenen Probleme beschränkt sich Tiebout auf den relativ allgemeinen Hinweis: "In cases in which the external economies and diseconomies are of sufficient importance, some form of integration may be indicated" (Tiebout, 1956, 423). ${ }^{68}$

Im Rahmen der Diskussion hinsichtlich der Rolle räumlicher externer Effekte werden eine Reihe von Lösungsmöglichkeiten diskutiert, die die Sub-Optimalität bei Auftreten dieser Nutzen-spillovers beseitigen bzw. zumindest einschränken sollen. Einen ersten Weg stellt die Vergrößerung des Gemeindegebiets und damit die Realisierung einer höheren Bevölkerung dar, durch die die räumlichen externen Effekte quasi internalisiert werden. "If all those who benefit or pay for a public service are members of the same government, then there is no externality." (Fisher, 1987, 70) Eine Verlagerung der Bereitstellung öffentlicher Leistungen (die diese Nutzen-spillovers mit sich bringen) auf die nächsthöhere gebietskörperschaftliche Ebene verfolgt dabei die gleiche Zielsetzung. ${ }^{69}$

\footnotetext{
${ }^{68}$ Die "lokale" Ebene wăchst folglich zur Region, denn man kann sagen, daß im Falle răumlicher Externalităten "some form of integration" den Übergang der lokalen Ebene zur Region bedeutet.

69 Sind aber Gemeinden letztlich so groß, daß keine răumlichen externen Effekte mehr auftreten, bzw. werden alle mit Nutzen-spillovers verbundenen offentlichen Leistungen auf eine höhere gebietskörperschaftliche Ebene verlagert, kann sich im Ergebnis die Möglichkeit von Wanderungen und damit eine Entscheidung über das Bereitstellungsniveau bestimmter offentlicher Leistungen nicht mehr entfalten. Ein trade-off zwi- 
Eine zweite Möglichkeit, in Zusammenhang mit der Existenz räumlicher externer Effekte bei dezentraler öffentlicher Leistungsbereitstellung effiziente Lösungen zu garantieren, sind die sogenannten "intergovernmental grants". Diese Zuweisungen können im Sinne einer interkommunalen Verrechnung als Ausgleich für die Nutzen-spillovers eingesetzt werden. Deren Ziel ist letztlich, eine gesamtgesellschaftlich optimale Nutzenposition zu realisieren, ohne die Vorteile der dezentralen Bereitstellung öffentlicher Leistungen zu schmälern und die kommunale Autonomie zu beseitigen. ${ }^{70}$

Tiebout erkennt weiterhin, daß der Markt für lokale öffentliche Güter nicht durch vollkommene Transparenz und damit vollkommene Information der Konsumenten (Wähler) gekennzeichnet ist. Diese Einschränkungen reduzieren die Aussagekraft der gewonnenen Ergebnisse. Daher stellt sich furr den Betrachter in praktischer Hinsicht die Frage, mit welcher Intensität die Bürger unter diesen Rahmenbedingungen auf divergierende kommunale Preis-Leistungs-Kombinationen reagieren. Tiebout verweist in diesem Zusammenhang auf die wenigen (zu seiner Zeit) existierenden Untersuchungen, welche "... seem to indicate a surprising awareness of differing revenue and expenditure patterns" (Tiebout, 1956, 423).

Als Zwischenergebnis läßt sich zunächst festhalten, daß sich Konsumenten (Wähler) bei Existenz von Wanderungs- und Informationskosten aufgrund relativ geringer Unterschiede des lokalen öffentlichen Leistungsangebots noch nicht für die Option "exit" entscheiden, sondern über Wahlentscheidungen ("voice") versuchen, das kommunale Leistungsangebot vor Ort zu beeinflussen. Erst wenn die Nutzen einer interkommunalen Wanderung größer als die Informations- und Wanderungskosten sind, wird eine Wohnsitzverlagerung angestrebt. Der Tiebout-Mechanismus führt realistischerweise nicht (wie in Abbildung 4.3 demonstriert) zu völlig gleicher Nachfrage der ortsansässigen Bevölkerung nach lokalen öffentlichen Gütern, sondern wird im Ergebnis "nur" ähnliche Nachfragewünsche der Gemeindeeinwohner bringen (schwach homogene Präferenzstrukturen). Mobilitäts- und Wanderungskosten als Unvollkommenheiten des Wanderungsmechanismus im Tiebout'schen Sinne führen zwar zu Effizienzeinbußen, sie können aber immerhin noch durch Nutzung der Mobilität beim Versuch einer Präferenzoffenbarung bessere Resultate liefern, als politische Abstimmungen allein.

schen weitgehender Internalisierung răumlicher externer Effekte und den Vorteilen dezentraler Bereitstellung des offentlichen Leistungsangebots wird offenkundig.

70 "Föderative Systeme erreichen jedoch im allgemeinen nur mit Hilfe von Finanzzuweisungen eine optimale Allokation der Ressourcen. ... Falls sich aus der Natur der nicht-privaten Güter (gemeint sind hier die lokalen offentlichen Güter; Anm. des Verf.) Spillovers ergeben, werden gebundene staatliche Zuweisungen eine pareto-optimale Allokation der Ressourcen bewirken, selbst wenn Nutzenbesteuerung vorliegt." (Breton, $1977,89)$ 
Bei abschließender Beurteilung des Tiebout-Konzepts ist festzuhalten, daß dieser Ansatz auf der Einsicht basiert, daß ein System dezentraler Bereitstellung bestimmter öffentlicher Leistungen - zumindest partiell - Eigenschaften besitzt, die in ihren Wesenszügen denen eines konkurrenzwirtschaftlich organisierten Marktes für private Güter ähneln. Die Aufdeckung solcher marktähnlicher Beziehungen findet daher auch nicht nur als Bestandteil der methodischen Vorgehensweise in der Tiebout-Konzeption, sondern auch in der ökonomischen Theorie des Föderalismus breite Anwendung und Anerkennung. ${ }^{71}$ So schreibt beispielsweise Neumann"2: "Die Entwicklung der Theorie knüpft dabei an einen recht alten Denkansatz an, in dem das gesamte gesellschaftliche Leben als ein Geflecht von Marktbeziehungen interpretiert wird" (Neumann, 1971, 494).

Mit dem erfolgreichen Versuch, in einem System des partiell dezentralen Angebots öffentlicher Leistungen ein Geflecht von Marktbeziehungen zu erkennen, die denen konkurrenzwirtschaftlich organisierter Märkte für private Güter ähneln, werden nicht nur die ökonomischen Charakteristika der zugrunde liegenden Fragestellung dokumentiert. Darüber hinaus werden für den Ökonomen auch die Voraussetzungen geschaffen, die zu leistende Analyse mit dem ihm vertrauten "Handwerkszeug" anzugehen. In diesem Zusammenhang bemerkt Oates: "I want to explore at a relatively general level what the basic principles of economics have to say about the organization and functioning of public sector in a federal system" (Oates, 1977b, 3f).

Mit dem Aufzeigen marktanaloger Beziehungen im Rahmen der dezentralen Bereitstellung öffentlicher Leistungen ist gleichzeitig eine Richtung vorgezeichnet, die der Ökonom einschlagen kann, um Lösungen des Problems einer unter Wohlfahrtsgesichtspunkten optimalen Bereitstellung lokaler öffentlicher Güter zu suchen. Dies gilt insbesondere dann, wenn man als Betrachter der zugrunde liegenden Situation mit Tiebout der Überzeugung ist, daß auch bei Abweichungen von den Bedingungen seiner Modellwelt der vollkommenen Konkurrenz die marktmäßige Koordination von Angebot und Nachfrage (dort wo sie sich installieren läßt) zu allokativ besseren Ergebnissen führt als andere Allokationsverfahren.

So kommt Tiebout letztlich auch zu der Überzeugung, daß seine marktmäßige Lösung zur Versorgung mit lokalen öffentlichen Leistungen auch in der politischen Praxis an-

\footnotetext{
71 Als wesentliche Beiträge sind Buchanan/Goetz (1972), Oates (1972), Pestieau (1977), McGuire (1974), Berglas/Pines (1981) und Berglas (1984) zu nennen.

72 Neumann $(1971,493 \mathrm{ff})$ untersucht selbst u.a. die Wettbewerbsmechanismen durch Parteienkonkurrenz im foderativen System, die ihrerseits auf der Angebotsseite zu einer allokativen Verbesserung der offentlichen Leistungsversorgung führen können.
} 
deren - von ihm nicht näher beschriebenen - zentralstaatlich-planerischen Lösungen vorzuziehen ist. Er hat seinen Ansatz auch bewußt mit Anspruch auf praktische Gestaltungsempfehlungen verfaßt. Dies wird in dem Abschnitt über die politischen Implikationen (vgl. Tiebout, 1956, 423f) deutlich, denn er erkennt grundsätzlich an, daß "... policies that promot residential mobility and increase the knowledge of the consumervoter will improve the allocation of government expenditures in the same sense that mobility among jobs and knowledge relevant to the location of industry and labor improve the allocation of private resources" (Tiebout, 1956, 423).

Im Ergebnis dient der Tiebout-Ansatz nicht nur der Formulierung eines abstrakten Modells des perfekten Marktes für lokale öffentliche Güter (als Äquivalent zum vollkommenen Markt für private Güter), sondern betrachtet föderalistische Wettbewerbsmechanismen durchaus als ein praktisch geeignetes Instrument zur Verbesserung der lokalen öffentlichen Versorgung der Bevölkerung. Die "marktgemäße" Versorgung mit öffentlichen Gütern führt nicht zu perfekten - aber dem Markt für private Güter offenbar vergleichbaren - Ergebnissen, die in der Tiebout'schen Sichtweise allokativ besser sind als zentralstaatlich-planerische Versorgungslösungen.

Der Tiebout-Lösung kann also trotz Existenz positiver Wanderungs- und Informationskosten sowie einer Einbeziehung räumlicher externer Effekte nach wie vor Bedeutung beigemessen werden. Das heißt zwar nicht, daß man sich an einem perfekten "Tiebout-Gleichgewicht" zu orientieren hat, sondern vielmehr die Möglichkeit interkommunaler Wanderungen im Sinne der Präferenzoffenbarung für lokale öffentliche Güter akzeptiert. Sind die Anreize für einen Wohnortwechsel aufgrund eines präferierten öffentlichen Leistungsangebots so groß, daß unter Zugrundelegung möglicher Transaktionskosten immer noch ein Nettonutzen für das Individuum verbleibt, ist räumliche Mobilität mit ihren Wirkungen ein "einmaliges" Hilfsmittel für den lokalen Bereich, um eine effizientere Leistungsbereitstellung zu ermöglichen. "The Tiebout process serves to reduce the variance in desired government service within communities. If the differences are not eliminated, voting is required and can be used to find a compromise position within those remaining differences of opinion." (Fisher, 1987, 80)

Die vorgestellten Verfahren zur Präferenzoffenbarung für lokale öffentliche Güter konkurrieren also keineswegs miteinander, sondern befinden sich eher in einer Art komplementärer Beziehung. Diese soll abschließend aufgezeigt und daher das Augenmerk noch einmal auf die Bedeutung politischer Abstimmungen, jetzt aber in Zusammenhang mit der Wanderungsanalyse, geworfen werden. 


\subsection{5 "Polit-ökonomische Wanderung" und "Politische Teilhabe"}

Ein Blick auf die Realität zeigt, daß sich Bürger bei der Wahl ihres Wohnortes nicht nur an dem lokalen öffentlichen Leistungsangebot orientieren ${ }^{73}$, sondern daneben auch privaten, gesellschaftlichen und beruflichen Faktoren ${ }^{74}$ Bedeutung beigemessen werden muß. ${ }^{75}$ Natürlich ist zu bedenken, daß die lokale Infrastruktur ${ }^{76}$ ein wichtiger Faktor ist, der andere Mobilitäts- und Verweilursachen mitbestimmt (vgl. etwa Schönbäck, 1975; 1976); in dem Maße aber, wie die nicht-fiskalischen Lebensbedingungen die Suche nach dem "richtigen" Wohnsitz beeinflussen, steigen die Kosten der polit-ökonomischen Wanderung. Der Beitrag des "Wanderungswettbewerbs" zur pareto-optimalen Allokation der Ressourcen muß deshalb (wie weiter oben bereits angedeutet) zwar relativiert ${ }^{77}$, darf aber keineswegs vernachlässigt werden. So ist der Argumentation Neumanns $(1971,94)$ entgegenzuhalten, daß der "Wanderungswettbewerb" keineswegs nur eine ergänzende Rolle zur politischen Wahl einnimmt, sondern durchaus ein Mehr an ökonomischer Effizienz liefern kann (vgl. auch Epple/Zelenitz, 1981a).

Gleichwohl soll nicht vernachlässigt werden, daß die Aktionsparameter polit-ökonomische Wanderung (exit) und politische Teilhabe (voice) interdependent sind. Der Konsument lokaler öffentlicher Güter wird also überprüfen, inwieweit sein zukünftig zu erwartender Nutzen abhängt:

- vom Ausmaß, in dem es ihm möglich ist, auf die kollektiven Entscheidungen Einfluß zu gewinnen und

- von der Wahrscheinlichkeit, mit der von ihm nicht gewünschte Entscheidungen von anderen getroffen und gegen ihn durchgesetzt werden können.

73 Wust $(1981,179)$ spricht in diesem Zusammenhang von "politischer Wanderung". M.E. ist die Bezeichnung "polit-هkonomische Wanderung" wegen der starken wirtschaftlichen Ausrichtung der Entscheidungssituation die exaktere Bezeichnung dieses "Tiebout-Prozesses".

74 Vor allem Forte $(1977,91)$ beschätigt sich mit der Tatsache, daß der Mensch nicht nur Konsument privater und offentlicher Güter, sondern gleichzeitig auch "Produktionsfaktor" ist.

75 Empirische Untersuchungen bezüglich des Mobilitatsverhaltens der privaten Haushalte liefern Hadermann/Kăppli/Koller, 1975; Gatzweiler, 1975 sowie Röder, 1974.

${ }^{76}$ So ist etwa das Angebot an ortlicher Infrastruktur ein wichtiger Standortfaktor für die Ansiedlung von privaten Unternehmen, die ihrerseits für die privaten Haushalte wieder Arbeitsplätze bereitstellen und somit berufliche Aspekte der Wohnsitzwahl beeinflussen. Theoretische und empirische Überlegungen zur Ansiedlungsproblematik von Unternehmen liefert Due (1961, 163ff); den Zusammenhang zwischen dem TieboutModell und der Kapitalmobilităt erörtert Schönbăck $(1976,88 f)$.

${ }^{77} \mathrm{Zu}$ dieser Auffassung gelangen auch Oates (1969, 957ff), Aronson/Schwartz (1973, 137ff) und Miller/Tabb (1973, 161ff). 
Mit einer Interdependenzkosten-Analyse (vgl. Kirsch, 1978, 14ff) läßt sich dieses Problem verdeutlichen. Bei seinem Mobilitätsentscheid wird der Bürger Größe und Zusammensetzung der ihm zur Wohnsitzauswahl stehenden Kommunen miteinander vergleichen. Er handelt rational, wenn er diejenige Gemeinde auswählt, in der bei gegebener Entscheidungsregel seine Interdependenzkosten am niedrigsten sind.

Die Kosten der Teilnahme am kollektiven Entscheid lassen sich in zwei (analytisch trennbare) Kategorien zerlegen, die mit der in der Gemeinde vorzufindenden Entscheidungsregel funktional verknüpft sind. Die "decision-making costs" (D) (Buchanan/ Tullock, 1971, 68f) sind jener Aufwand, den jedes einzelne Individuum aufbringen muß, um andere Gemeindebürger zu einer Stimmabgabe in seinem Sinn zu veranlassen (also der "Preis" dafür, die eigenen Vorstellungen in den Kollektiventscheid einzubringen). Diese Konsensfindungskosten steigen mit zunehmender Zahl der erforderlichen Ja-Stimmen progressiv an.

Die sogenannten "expected external costs" (E) (Buchanan/Tullock, 1971, 63ff) treffen ein Individuum, wenn andere Gemeindebürger ihre Vorstellungen in die Kollektiventscheidung einbringen und gegen ihn durchsetzen können. Sie fallen mit zunehmender Zahl der Ja-Voten, da mit wachsender Zustimmung die Gefahr der Bürger sinkt, Entscheidungsfolgen ausgesetzt zu sein, die selbst nicht gewünscht sind. Addiert man beide Kostenarten vertikal auf, erhält man die Interdependenzkosten-Kurve (I) mit einem u-förmigen Verlauf (vgl. Buchanan/Tullock, 1971). ${ }^{78}$

In Abbildung 4.4 wird dieser Entscheidungsprozeß verdeutlicht. Hat ein Individuum zwischen der Gemeinde $\mathrm{A}$ und der Gemeinde B bezüglich eines möglichen Wohnsitzes zu entscheiden, wägt es die Interdependenzkosten der einzelnen Wohnorte gegeneinander ab. Im Kalkül des Individuums i wird in der Gemeinde B ein Angebot an lokalen öffentlichen Leistungen verfügbar sein, das seinen Präferenzen näher kommt als jenes in der Gemeinde A. In diesem Beispiel wird diese Bevorzugung des Wohnortes B unabhängig von der in den beiden Gemeinden praktizierten Entscheidungsregel sein. Denn $I_{B}^{i}$ ist für alle Entscheidungsverfahren (von der Diktatur bis zur Einstimmigkeit) kleiner als $I_{A}^{i}$. Läge eine der beiden Kurven bei irgend einer Stimmenzahl höher als die andere, würde erst eine Gegenüberstellung der Entscheidungsregeln in den beiden Kommunen eine endgültige Wahl zulassen.

$78 \mathrm{Vgl}$. dazu auch Kirsch/Theiler (1976, 37ff). 
Abbildung 4.4: Interdependenzkosten und Wohnsitzentscheidung

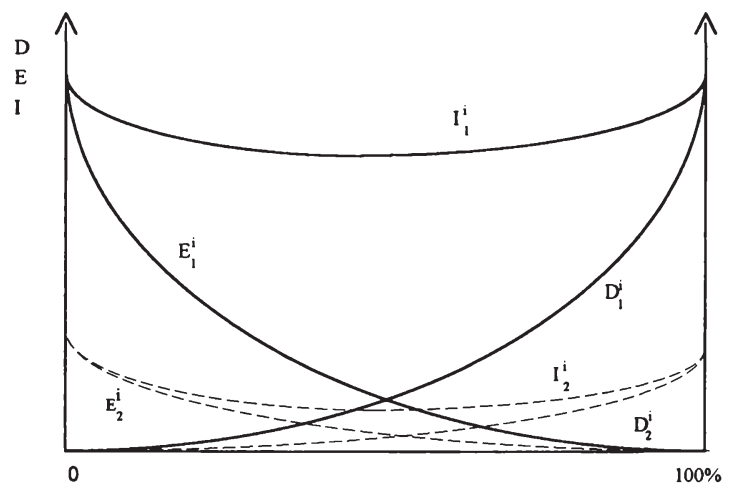

Allerdings bedeutet diese Entscheidung noch nicht zwangsläufig, daß für das betrachtete Individuum i eine "Wanderung" nach Gemeinde B günstiger als der Verbleib in der ursprünglichen Gemeinde $A$ ist. Der Nettovorteil nach Berücksichtigung der Wanderungs-, der Informations- und der Interdependenzkosten kann erst endgültig Aufschluß darüber geben, ob das seinen Präferenzen eher entsprechende Angebot der Gemeinde $\mathrm{B}$ eine "Wanderung" rechtfertigt.

Festzuhalten bleibt, daß die Kurven der Konsensfindungs- sowie der externen Kosten in ihrem Verlauf abhängig von der Größe und Zusammensetzung des Kollektivs sind. Dabei ist davon auszugehen, daß

- mit steigender Größe und steigender Heterogenität Niveau und Krümmung der Interdependenzkosten-Kurve steigen, denn die Entsprechung von individuellen Präferenzen und Kollektiventscheidungen wird loser;

- mit steigender Mitgliederzahl und gleichem Homogenitätsgrad der Zusammensetzung die Interdependenzkosten-Kurve sich nach oben verschiebt, ohne ihren Krümmungsgrad zu verändern;

- bei gleicher Mitgliederzahl und heterogener werdender Zusammensetzung die Kurve der Interdependenzkosten höher und gekrümmter verläuft.

Unter dem Aspekt der Beherrschbarkeit der Kollektive durch ihre Mitglieder erscheint es also wünschenswert, kleine und homogene Kollektive zu haben. In ihnen ist die Entsprechung von Kollektiventscheidungen und individuellen Mitgliederpräferenzen am engsten. "Hier wird eines der wichtigsten Argumente der Apologeten des föderalistischen Staatsaufbaus in seiner ganzen Tragweite verständlich: Die Einrichtung einer 
Vielzahl und Vielfalt von Kollektiven soll die Voraussetzungen dafür schaffen, daß die Kollektivguterstellung in kleinen und homogenen Kollektiven erfolgt, also der Abstand zwischen individuellen Mitgliederpräferenzen und Kollektiventscheidungen gering ist" (Kirsch, 1978, 15).79

Mit der Betrachtung der Interdependenzkosten-Analyse sollte die Vielschichtigkeit kommunaler Wanderungsprozesse und ihrer Rechtfertigungen begründet und der $\mathrm{Zu}$ sammenhang zwischen "exit" und "voice" zur Präferenzoffenbarung im öffentlichen Sektor veranschaulicht werden.

Es kann zunächst resümierend festgestellt werden, daß Teilbereiche eines Gemeinwesens - also die Länder bzw. die Gemeinden - in ihrer Zusammensetzung homogener (wenn auch nicht völlig homogen im Tiebout-Sinne) sind als das Gemeinwesen als ganzes, so daß die Entscheidungsfindung über einen bestimmten Gegenstand in den einzelnen Kommunen wesentlich weniger konfliktträchtig ist, als eine für alle (Kommunen) verbindliche Entscheidung auf zentraler Ebene.

Für den einzelnen Bürger heißt das: Mit steigender Heterogenität des für seine Bedürfnisbefriedigung zuständigen Kollektivs, d.h. mit steigender Zentralisierung, wachsen für ihn die Schwierigkeiten, seine eigenen Vorstellungen mit Erfolg in den im Ergebnis auch für ihn verbindlichen Kollektiventscheid einzubringen. Außerdem resultieren aus den Abweichungen des Leistungsangebots auf der Grundlage der gesellschaftlichen Entscheidungen Wohlfahrtsverluste, die um so größer ausfallen, je heterogener die Einzelinteressen der beteiligten Wirtschaftssubjekte sind.

Am Schluß dieses Kapitels steht eine kurze Bewertung der Mechanismen zur Präferenzoffenbarung für lokale öffentliche Güter. Welche Rolle spielen also politische Abstimmungen und Migration in der Realität? Kaum jemand wird behaupten, daß ein perfektes Tiebout-Gleichgewicht (mit identischer Präferenzstruktur innerhalb einer Kommune) erreichbar ist, denn positive Informations- und Wanderungskosten, die zwangsläufig Mobilitätshemmnisse darstellen, verhindern dies. Und selbst bei einer Berücksichtigung und Verarbeitung der Informations- und Wanderungskosten verbleibt das Problem räumlicher externer Effekte, welches dafür verantwortlich zeichnet, daß bei deren Vorliegen keine effiziente Allokation der Ressourcen realisiert werden kann.

\footnotetext{
${ }^{79}$ Pennock (1959) bemüht in diesem Zusammenhang Argumente, die den Überlegungen von Buchanan/Tullock (1971) nicht unähnlich sind. Buchanan/Tullock sprechen beispielsweise von wahrscheinlichen externen Kosten oder von Konsensfindungskosten, Pennock von "frustration" oder "harmony". 
Trotz dieser Einschränkungen verbleiben einige wichtige Ergebnisse des Tiebout-Ansatzes. Die Berücksichtigung der Transaktionskosten reduziert zwar die Reichweite der Migration als Mittel bzw. Instrumentarium zur Präferenzoffenbarung, trotzdem resultiert aus "polit-ökonomisch" motivierten Wanderungen eine homogenere Präferenzstruktur auf der lokalen Ebene und vermeidet somit die größten Divergenzen im gewünschten Angebot öffentlicher Leistungen. "The Tiebout process serves to reduce but not eliminate the variance in desired government service within communities, thus the inherent dissatisfaction with the voted outcome" (Fisher, 1987, 79). Somit ist das wohl bedeutendste "Vermächtnis" des Tiebout-Ansatzes die Betonung der Wohlfahrtsgewinne eines dezentralisierten öffentlichen Sektors. 
Hans-Georg Napp - 978-3-631-75263-0

Downloaded from PubFactory at 01/11/2019 06:33:05AM

via free access 
Just as the consumer may be visualized as walking to a private market place to buy his goods, ... we place him in the position of walking to a community where the prices (taxes) of community services are set. Both trips take the consumer to the market. There is no way in which the consumer can avoid revealing his preferences in a spatial economy."

Charles M. Tiebout $(1956,422)$

\section{Bereitstellung und Finanzierung lokaler öffentlicher Güter - Eine modelltheore- tische Analyse der Bedingungen einer effizienten Ressourcenallokation}

Folgt man der Erkenntnis der vorausgegangenen Kapitel, daß ein dezentralisiertes öffentliches Gemeinwesen Effizienzgewinne mit sich bringt, gilt es nunmehr, die Bedingungen zu formulieren, unter denen diese Effizienzgewinne maximal sind und damit eine effiziente Ressourcenallokation versprechen. Dieses Vorhaben soll in einem modelltheoretischen Ansatz angegangen werden. Die dabei zugrunde liegende Vorgehensweise verknüpft die Bereitstellung und die Finanzierung lokaler öffentlicher Güter miteinander und kann auf diese Weise für die effiziente Ausgestaltung kommunaler Finanzierungssysteme Orientierungspunkte liefern.

\subsection{Allokationseffizienz und der lokale Sektor}

Im Rahmen der in Kapitel 2.2 erfolgten Herleitung von Bedingungen für eine effiziente Ressourcenallokation bei Existenz öffentlicher Güter (Kollektivgüter) lag das Schwergewicht auf der generellen Behandlung des öffentlichen Sektors und seines Leistungsangebots. Nach der Differenzierung öffentlicher Güter und Leistungen, der Betrachtung der Möglichkeiten und Grenzen staatlicher Allokationsverfahren für das lokale öffentliche Leistungsangebot sowie ihrer Bedeutung bei der Enthüllung der Präferenzen für lokale öffentliche Güter soll nunmehr im Grunde genommen der Samuelson'sche Ansatz erweitert werden. Daher sollen in diesem Kapitel zunächst die Bedingungen für eine effiziente Ressourcenallokation bei Vorhandensein lokaler öffentlicher Güter formuliert werden.

Das dafür benutzte Modell baut auf Ansätzen von Buchanan/Wagner (1970), Buchanan/Goetz (1972), Flatters/Henderson/Mieszkowski (1974) sowie Wildasin (1980) auf. Dabei ist es jedoch allgemeiner gehalten als die meisten dieser Ansätze (vgl. auch Wildasin, 1986). Die formale Darstellung erlaubt einen Einblick in die Problematik, die aus der Existenz lokaler öffentlicher Güter resultiert, und liefert so Interpretationshil- 
fen für Ansätze, die in Zusammenhang mit Effizienzüberlegungen für den kommunalen Bereich entstanden sind.

\subsubsection{Bedingungen einer effizienten Ressourcenallokation}

Ausgangspunkt des Modells ist die Annahme, daß der lokale Sektor aus mindestens zwei Kommunen (denkbar sind aber auch größere Räume wie Regionen oder Bezirke) besteht $(M \geq 2)$. Jede dieser Kommunen i stellt ein öffentliches Gut $z_{i}$ bereit, das den Einwohnern dieser Kommune Nutzen stiftet, aber eben nicht den Einwohnern anderer Kommunen. Diese Annahme bedeutet, daß keine räumlichen Nutzen-spillovers existieren ("nonspillover assumption"). Ferner wird unterstellt, daß es $N \geq 1$ Typen von Individuen gibt, wobei alle Mitglieder des gleichen Typs $\mathrm{k}$ identische Präferenzen haben. Dabei ist $n_{i}^{k}$ die Anzahl der Individuen des Typs k, die in der Gemeinde i wohnen. Die Kosten der Herstellung des öffentlichen Gutes $z_{i}$ sind für die Bevölkerung $n_{i}=\left(n_{i}^{1}, \ldots, n_{i}^{N}\right)$ gegeben durch die Kostenfunktion $C_{i}=C_{i}\left(n_{i}, z_{i}\right)$; wobei die Kosten als Opportunitätskosten in Mengeneinheiten des privaten "Numéraire"-Gutes ausgedrückt werden.

Um mögliche Komplikationen oder Ungenauigkeiten zu vermeiden, muß eine weitergehende Erklärung der Kosten des lokalen öffentlichen Gutes vorgenommen werden. Dabei gilt es zu unterscheiden, welche Gruppe der Bevölkerung von den angebotenen öffentlichen Gütern und Leistungen profitiert. Am Beispiel des Gutes "Bildung" soll dies verdeutlicht werden. Die Grenzkosten der Erstellung dieser Leistung - dargestellt durch die partielle Ableitung $\partial C_{i} / \partial_{i}$ - repräsentieren notwendigerweise die benötigten Ressourcen für die Bereitstellung einer weiteren Ausbringungseinheit der öffentlichen Leistung. Die Kosten der Bereitstellung eines bestimmten durchschnittlichen Bildungsniveaus hängen aber auch von der Anzahl der Einwohner einer Gemeinde ab, dargestellt als Grenzkosten durch die partielle Ableitung $c_{i k}=\not C_{i} / \partial_{i}^{k}$. Dabei sind die Grenzkosten in Abhängigkeit von der Zahl der Nutzer im Grunde genommen die Aufwendungen der bereitstellenden Körperschaft, die infolge des "Hinzukommens" einer weiteren Person (Einwohner) als potentiellem Nutzer entstehen. ${ }^{80}$ Im Falle der lokalen öffentlichen Güter repräsentieren die Grenzkosten $c_{i k}$ die "impurity", "rivalness" oder "congestibility" lokaler öffentlicher Güter (vgl. Musgrave, 1969a; Hamilton, 1983), die infolge der begrenzten Nutzenreichweite dieser Leistungen und der damit zusammenhängenden Kapazitätseffekte auftreten. Die Grenzkosten in Abhängigkeit von der Be-

\footnotetext{
$\mathbf{8 0}$ Bei reinen öffentlichen Gütern sind die Grenzkosten aufgrund der entsprechenden Charakteristika gleich
} Null. Vgl. dazu Samuelson $(1954 ; 1955 ; 1969)$. 
völkerungsgröße sind demnach zurückzuführen auf die sogenannten "Grenzüberfüllungskosten" oder die "marginal cost with respect to population" (Wildasin, 1986, 6).

Noch einmal zur Abgrenzung: Im Falle der "reinen" öffentlichen Güter hängt der Konsum eines Individuums in keiner Weise vom Konsum anderer Individuen ab (Nicht-Rivalität im Konsum). Die Leistungen sind also gemeinsam konsumierbar. In einem solchen Fall wäre $c_{i k}=0$ für alle k. Für die meisten lokalen öffentlichen Güter ergibt sich aber der angesprochene Zusammenhang zwischen Bevölkerungsgröße und Outputniveau der lokalen öffentlichen Leistung. "Congestion" bzw. "Überfüllung" - also Kapazitätseffekte - sind auf lokalem Niveau häufig die Regel. ${ }^{81}$

Im folgenden soll davon ausgegangen werden, daß sich die Kosten proportional zur Bevölkerungsgröße verhalten, also

$$
\mathrm{C}_{\mathrm{i}}\left(\mathrm{n}_{\mathrm{i}}, \mathrm{z}_{\mathrm{i}}\right)=\left(\sum_{k} n_{i}^{k}\right) c_{i}\left(z_{i}\right) .82
$$

Differenziertere Ergebnisse wären mit Kostenfunktionen vom Typ $C_{i}^{k}\left(n_{i}^{k} ; z_{i}^{k}\right)$ möglich. Im Gegensatz zu Kostenfunktionen, bei denen die Kosten nur von der Gesamtbevölkerung als ganzes

$$
\left(\sum_{k} n_{i}^{k}\right)
$$

abhängen (s. oben), erlaubt dieser erweiterte Typ eine Spezifizierung unterschiedlicher Haushaltsgruppen $\mathbf{k}$ und damit die Analyse verschiedenartiger "congestion"-Effekte, die sich aus der Betrachtung einzelner Bevölkerungsgruppen (beispielsweise Rentnerhaushalte, junge Familien, Singles usw.) ergeben.

Jede Kommune $i$ verfügt über einen exogen vorgegebenen fixen Ressourcenbestand $T_{i}$ (den Faktor Boden), der völlig homogen aber räumlich immobil ist. Dieser Ressourcenbestand kann alternativ als direktes Konsumgut von den Haushalten $\left(n_{i} t_{i}\right)$ genutzt werden (der Boden wird als Wohngrundstück oder für andere private Konsumaktivitäten verwendet), wobei dann $t_{i}^{k}$ der Teil des fixen Ressourcenbestandes ist, der von einem Haushalt des Typs $\mathbf{k}$ in der Kommune $\mathrm{i}$ genutzt wird.

\footnotetext{
81 Empirische Arbeiten von Bergstrom/Goodman (1973) und vielen anderen (vgl. dazu eine detaillierte Literaturliste bei Hirsch (1970) bestătigen diese Hypothese und damit die bedeutende Rolle von "crowding" und "congestion" auf kommunalem Niveau (vgl. auch Abschnitt 2.3).

82 Dieser spezielle Fall spielt in der wirtschaftstheoretischen Literatur bei Fragen der Produktions-, Kostenund Angebotsplanung of eine bedeutende Rolle. Es ist die Annahme konstanter Skalenerträge (vgl. etwa Varian, 1985, 30).
} 
Der Faktor Boden kann ebenso als Input im Produktionsprozeß zusammen mit dem Produktionsfaktor Arbeit für die Erstellung des privaten Gutes $\mathbf{x}_{\mathrm{i}}$ eingesetzt werden. Für diese private Produktion bietet jeder Haushalt eine Einheit Arbeit an; unterschiedliche Haushaltstypen $\mathrm{k}$ bieten unterschiedliche Typen von Arbeit an. Wenn $t_{i}^{p} \operatorname{der}$ Teil der fixen Ressorcenbestände $\mathrm{T}_{\mathrm{i}}$ ist, der in der örtlichen privaten Produktion genutzt wird, können wir eine linear-homogene Produktionsfunktion $F_{i}\left(n_{i} ; t_{i}^{p}\right)$ mit den Produktionsfaktoren Arbeit und Boden unterstellen (s. Gleichung (5.1)).

Der feste Ressourcenbestand $T_{i}$ in der Kommune kann schließlich auch als alleiniger Input $^{83}$ in landwirtschaftlichen Produktionsprozessen Verwendung finden. Diese landwirtschaftlichen Produktionsprozesse erbringen einen bestimmten Output $\phi_{i}\left(t_{i}^{L}\right)$ an Agrarerzeugnissen, die dann ihrerseits $\left(\right.$ als $\left.n_{i} q_{i}\right)$ neben dem eigentlichen privaten Gut $x_{i}$ und einem Teil des fixen Ressourcenbestandes $\left(n_{i} t_{i}\right)$ für Konsumzwecke der Haushalte zur Verfügung stehen (vgl. dazu die anschließend vorgestellten Gleichungen (5.1), (5.2) und (5.3)).

Gemäß der oben geschilderten Ausgangsbedingungen läßt sich nunmehr das Gesamtmodell formulieren. Gleichung (5.1) stellt die Gleichgewichtsbedingung für den "Markt" des privaten Gutes $\left(\mathbf{x}_{\mathbf{i}}\right)$ dar. Die private Produktion

$$
\sum_{i} F_{i}\left(n_{i}, t_{i}^{p}\right)
$$

(also folglich das "Marktangebot") findet Verwendung (folglich die "Nachfrageseite") für Konsumzwecke der privaten Haushalte

$$
\left(\sum_{i} n_{i} x_{i}\right)
$$

oder Produktionszwecke für das lokale öffentliche Gut

$$
\left(\sum_{i} C_{i}\left(n_{i}, z_{i}\right)\right) .
$$

Der letztgenannte Term stellt - im Sinne von Opportunitätskosten (ausgedrückt in Mengeneinheiten des privaten "Numéraire"-Gutes $\mathbf{x}_{\mathbf{i}}$ ) - die "Produktionskosten" des lokalen öffentlichen Gutes für das betrachtete Kollektiv dar.

\footnotetext{
${ }^{83}$ Es wird im Rahmen des vorgestellten Modells unterstellt, daß (aus Vereinfachungsgründen) für die Produktion des landwirtschaftlichen Outputs lediglich der Produktionsfaktor Boden notwendig sei. Diese vereinfachende Annahme erleichtert die Analyse, da sie keinerlei Substitutionseffekte des Faktoreinsatzes der Arbeit zwischen den einzelnen Sektoren berücksichtigen muß, zumal auch die Produktionskosten des lokalen offentlichen Gutes als Opportunitätskosten ausgedrückt in Einheiten des privaten Numéraire-Gutes veranschlagt werden
} 


$$
\sum_{i} F_{i}\left(n_{i}, t_{i}^{p}\right)=\sum_{i} n_{i} x_{i}+\sum_{i} C_{i}\left(n_{i}, z_{i}\right) \quad\{\mu\}^{84}
$$

Gleichung (5.2) stellt die Gleichgewichtsbedingung für den "Markt" des landwirtschaftlichen Outputs (Agrarprodukt) dar. Für die landwirtschaftliche Produktion und deren Output ("Angebotsseite") ergibt sich im Rahmen der Verwendung für den Konsum der privaten Haushalte ("Nachfrageseite") folglich:

$$
\sum_{i} \phi\left(t_{i}^{L}\right)=\sum_{i} n_{i} q_{i}
$$

wobei $n_{i} q_{i}$ die Verwendung des landwirtschaftlichen Outputs durch die Haushalte einer Gemeinde für Konsumzwecke darstellt.

Für den Ressourcenbestand $T_{i}$ existieren folgende mögliche Verwendungen (vgl. auch die vorstehenden Ausführungen):

$$
T_{i}=n_{i} t_{i}+t_{i}^{p}+t_{i}^{L}
$$

Ist der Ressourcenbestand exogen vorgegeben, ergibt sich die Verwendung als Input in landwirtschaftlichen Produktionsprozessen zwangsläufig als Restgröße ${ }^{85}$; ist dieser Faktor endogen, kann $t_{i}^{L}$ zusätzlich als Instrumentvariable im Planungsproblem berücksichtigt werden, so daß sich $t_{i}^{L}=T_{i}-n_{i} t_{i}-t_{i}^{p}$ ergibt.

Gleichung (5.4) zeigt an, daß alle Haushalte in einer der betrachteten Gemeinden $i$ ihren Wohnsitz haben.

$$
N^{k}=\sum_{i} n_{i}^{k}
$$

Die Präferenzen der Haushalte sind repräsentiert durch eine Nutzenfunktion vom Typ $U_{i}^{k}\left(x_{i}^{k}, t_{i}^{k}, q_{i}^{k}, n_{i}, z_{i}\right)$, wobei $x_{i}^{k}$ und $q_{i}^{k}$ die Kosumniveaus des privaten "Numéraire"Gutes sowie des landwirtschaftlichen Outputs durch einen Haushalt vom Typ k in der

\footnotetext{
84 Hinter jeder Gleichung (Nebenbedingung) ist in geschweiften Klammern der für das spătere Maximierungsproblem notwendige Lagrange-Multiplikator aufgefuhrt.

85 Wenn $t_{i}^{L}$ exogen vorgegeben ist, kann $t_{i}^{L}=\bar{t}_{i}^{L}$ gesetzt werden und schließlich $t_{i}^{L}$ aus dem Kreis der Instrumentvariablen ausgeschlossen werden. Der Leser kann leicht überprüfen, daß das Ergebnis davon unberührt bleibt.
} 
Kommune $i$ sind. Wenn man die Bevölkerungsgröße $n_{i}$ als Komponente in der Nutzenfunktion betrachtet, erlaubt diese Vorgehensweise neben der Berücksichtigung des "crowding" im Produktionsbereich (wie weiter oben beschrieben) eine Berücksichtigung des "crowding"-Phänomens im Konsumbereich (vgl. auch Abschnitt 2.3).

Bedingung (5.5) bestimmt den Nutzen der Haushalte vom Typ $k>1$ als Konstante im Rahmen des Planungsproblems. ${ }^{86}$

$$
U_{i}^{k}\left(x_{i}^{k}, t_{i}^{k}, q_{i}^{k}, n_{i}, z_{i}\right)=\bar{U}^{k} \quad\left\{\lambda_{i}^{k} ; k>1\right\}
$$

Gleichung (5.6) stellt fest, daß der Nutzen eines Haushaltstyps 1 in allen Gemeinden identisch sein muß. Diese Bedingung ist für die Herleitung eines Pareto-Optimums (also einer effizienten Allokation) notwendig, da ansonsten durch Migration für den Haushalt Anreize bestehen, seine Nutzensituation zu verbessern.

$$
U_{i}^{1}\left(x_{i}^{1}, t_{i}^{1}, q_{i}^{1}, n_{i}, z_{i}\right)=U_{1}^{1}\left(x_{1}^{1}, t_{1}^{1}, q_{1}^{1}, n_{1}, z_{1}\right) \quad\left\{\lambda_{i}^{1} ; i>1\right\}
$$

Beide Gleichungen - (5.5) und (5.6) - reflektieren die Annahme kostenloser Mobilität der Haushalte im Sinne Tiebouts, so daß also zwischen den Gemeinden im Optimum keine Nutzendifferentiale existieren dürfen. Folglich muß infolge der Nichtexistenz von Nutzendifferentialen bei kostenloser Mobilität gemäß Gleichung (5.6) der erzielbare Nutzen des betrachteten Haushaltstyps $k=1$ in jeder Gemeinde identisch sein.

Das Planungsproblem kann nun modelltheoretisch formuliert werden. Ziel des Modellansatzes ist die Realisierung einer pareto-optimalen Allokation der Ressourcen (hier: Einwohner bzw. Haushalte und damit des Produktionsfaktors Arbeit) durch Variation der Parameter $x_{i}, t_{i}, q_{i}, n_{i}, t_{i}^{p}$ und (im Falle eines endogenen urbanen Ressourcenbestandes) $t_{i}^{L}$. "The problem is to allocate goods and workers between the ... regions in a $\mathrm{Pa}$ reto-optimal fashion - so that there exist no reallocations which permit someone to be made better off without making someone else worse off" (Flatters/Henderson/Mieszkowski, 1974, 102).

Das Planungsproblem in der vorliegenden Situation ist also die Nutzenmaximierung des $\mathbf{k}=1$ Haushaltstyps in der Gemeinde 1; Zielfunktion ist damit die Nutzenfunktion

\footnotetext{
${ }^{86}$ Diese Festlegung ist analog zum Vorgehen von Samuelson (1954, 387ff; 1955, 350ff) für die "reinen" offentlichen Güter zu sehen (Resttransformationskurve). Für die Nutzenmaximierung des k=1 Haushaltstyps werden die Nutzenniveaus der Haushalte vom Typ $\mathrm{k}>1$ festgelegt und konstant gehalten, um schließlich dieses Planungsproblem zu lösen (Nutzenmaximienung des $k=1$ Haushaltstyps) und die Bedingung für eine effiziente Allokation zu formulieren
} 
$U_{1}^{1}=U_{1}^{1}\left(x_{1}^{1}, t_{1}^{1}, q_{1}^{1}, n_{1}, z_{1}\right)$, die es unter den in (5.1) bis (5.6) genannten Nebenbedingungen zu maximieren gilt. Eine pareto-effiziente Allokation der Ressourcen kann folglich als Lösung eines solchen Planungsproblems beschrieben werden (vgl. für den sogenannten "zwei-Regionen-Fall" Flatters/Henderson/Mieszkowski, 1974, 102ff).

Die Lagrangefunktion lautet:

$$
\begin{aligned}
L= & U_{1}^{1}\left(x_{1}^{1}, t_{1}^{1}, q_{1}^{1}, n_{1}, z_{1}\right) \\
& +\mu\left[\sum_{i} F_{i}\left(n_{i}, t_{i}^{p}\right)-\sum_{i} n_{i} x_{i}-\sum_{i} C_{i}\left(n_{i}, z_{i}\right)\right] \\
& +\eta\left[\sum_{i} \phi\left(t_{i}^{L}\right)-\sum_{i} n_{i} q_{i}\right] \\
& +\xi_{i}\left[T_{i}-n_{i} t_{i}-t_{i}^{p}-t_{i}^{L}\right] \\
& +\rho^{k}\left[N^{k}-\sum_{i} n_{i}^{k}\right] \\
& +\lambda_{i}^{k}\left[U_{i}^{k}\left(x_{i}^{k}, t_{i}^{k}, q_{i}^{k}, n_{i}, z_{i}\right)-\bar{U}^{k}\right] \\
& +\lambda_{i}^{1}\left[U_{i}^{1}\left(x_{i}^{1}, t_{i}^{1}, q_{i}^{1}, n_{i}, z_{i}\right)-U_{1}^{1}\left(x_{1}^{1}, t_{1}^{1}, q_{1}^{1}, n_{1}, z_{1}\right)\right]
\end{aligned}
$$

Aus diesem Maximierungsproblem ergeben sich durch partielles Differenzieren hinsichtlich der einzelnen Instrumentvariablen folgende Bedingungen erster Ordnung:

$$
\frac{\partial L}{\partial x_{i}^{k}}=\bar{\lambda}_{i}^{k} u_{i 1}^{k}-\mu n_{i}^{k} \stackrel{!}{=} 0 \quad \text { für alle } i, k
$$

$$
\frac{\partial}{\partial q_{i}^{k}}=\bar{\lambda}_{i}^{k} u_{i 3}^{k}-m_{i}^{k}=0 \quad \text { fir alle } i, k
$$

$$
\frac{\partial L}{\partial t_{i}^{k}}=\bar{\lambda}_{i}^{k} u_{i 2}^{k}-\xi_{i} n_{i}^{k}=0 \quad \text { für alle } i, k
$$

$$
\begin{array}{r}
\frac{\partial}{\partial n_{i}^{k}}=\sum_{k^{\prime}} \bar{\lambda}_{i}^{k^{\prime}} u_{i 4 k}^{k^{\prime}}+\mu\left(F_{i k}-x_{i}^{k}-c_{i k}\right)-v q_{i}^{k}-\xi_{i} t_{i}^{k}-\rho^{k}=0 \\
\text { fuir alle } i, k
\end{array}
$$




$$
\frac{\partial}{\partial_{i}^{p}}=\mu F_{i t}-\xi_{i}=0 \quad \text { für alle } i, k
$$

$$
\frac{\partial L}{\partial_{i}^{L}}=v \phi_{i t}-\xi_{i}=0 \quad \text { für alle } i, k
$$

wobei:

$$
\bar{\lambda}_{1}^{1}=\left(1-\sum_{i>1} \lambda_{i}^{1}\right) \quad \text { und } \quad \bar{\lambda}_{i}^{k}=\lambda_{i}^{k}
$$

$F_{i k}$ ist das Grenzprodukt der Arbeit, die von einem Haushalt des Typs $\mathbf{k}$ in der Gemeinde i angeboten wird. Außerdem sind $\mu, v, \xi_{i}, \rho^{k}$ die bekannten Lagrangemultiplikatoren; $u_{i 1}^{k}, u_{i 2}^{k}$ und $u_{i 3}^{k} \quad$ sind der Reihe nach die Grenznutzen

- aus der Konsumtion einer weiteren Einheit des privaten Gutes $\left(x_{i}^{k}\right)$ gemäß der ersten Nebenbedingung (Verwendungsgleichung für die private Produktion),

- aus der Verwendung des landwirtschaftlichen Outputs $\left(q_{i}^{k}\right)$ gemäß der zweiten Nebenbedingung (Verwendungsgleichung für die landwirtschaftliche Produktion)

- sowie aus der Verwendung des Ressourcenbestandes, der als direktes Konsumgut genutzt wird $\left(t_{i}^{k}\right)$ gemäß der dritten Nebenbedingung (Verwendungsmöglichkeiten des Faktors Boden).

$u_{i 4 k}^{k^{\prime}}$ drückt gemäß der vierten Nebenbedingung die Abhängigkeit des Nutzens eines Konsumenten beim Konsum des lokalen öffentlichen Gutes von der gleichzeitigen Konsumtion anderer potentieller Nutzer (also die "crowding-Effekte" bzw. Grenzüberfüllungskosten) aus. $\mathrm{F}_{\mathrm{it}}$ und $\phi_{i t}$ sind die Grenzprodukte des fixen urbanen Ressourcenbestandes beim Einsatz in der Produktion des privaten "Numéraire"- sowie des landwirtschaftlichen Gutes (Outputs).

Zur näheren Interpretation dieser Bedingungen werden jeweils die Quotienten zweier Gleichungen betrachtet. Es gilt für:
(a) $\frac{(5.2)}{(5.1)} \quad \frac{v}{\mu}=\frac{u_{i 2}^{k}}{u_{i 1}^{k}}$

d.h. das Grenznutzenverhältnis der Konsumtion einer weiteren Einheit des landwirtschaftlichen Outputs $\left(u_{i 2}^{k}\right)$ und der Konsumtion einer weiteren Einheit des privaten Gutes $\left(u_{i 1}^{k}\right)$ stellt folglich den Schattenpreis des landwirtschaftlichen Outputs in Einheiten des privaten "Numéraire"-Gutes dar. 
(b) $\frac{(5.3)}{(5.1)} \quad \frac{\xi_{i}}{\mu}=\frac{u_{i 3}^{k}}{u_{i 1}^{k}}=F_{i t}=\frac{v \phi_{i t}}{\mu}$

(weil gemäß Gleichung (5.12) $\frac{\xi_{i}}{\mu}=F_{i t}$ und gemäß Gleichung (5.13) $\xi_{i}=v \phi_{i t}$ )

d.h. das Grenznutzenverhältnis der Konsumtion einer weiteren Einheit des fixen Ressourcenbestandes $\left(u_{i 3}^{k}\right)$ und der Konsumtion einer weiteren Einheit des privaten Gutes $\left(u_{i i}^{k}\right)$ stellt folglich den Schattenpreise der konsumtiven Verwendung des fixen Ressourcenbestandes in Einheiten des privaten "Numéraire"-Gutes dar.

Die entscheidende Bedingung ist Gleichung (5.11), die die Rahmenbedingungen einer optimalen Verhaltensweise der Haushalte beschreibt. Unter Zugrundelegung von Gleichung (5.8) kann $\bar{\lambda}_{i}^{k^{\prime}}$ in (5.11) durch $\mu m_{i k} / u_{i 1}^{k}$ ersetzt werden und wenn darüber hinaus das Grenznutzenverhältnis $u_{i 4 k}^{k^{\prime}} / u_{i 1}^{k^{\prime}}$ als $M C C_{i k}^{k^{\prime}}$ bezeichnet wird ${ }^{87}$, ergibt sich:

$$
F_{i k}-\left(x_{i}^{k}+\frac{v}{\mu} q_{i}^{k}+\frac{\xi_{i}}{\mu} t_{i}^{k}\right)-\left(c_{i k}+\sum_{k^{\prime}} n_{i}^{k^{\prime}} M C C_{i k}^{k^{\prime}}\right)=\frac{\rho^{k}}{\mu} \quad \text { für alle } i, k
$$

Dabei ist $F_{\mathrm{ik}}$ der ertragbringende Produktionsbeitrag (Grenzprodukt der Arbeit) eines Haushalts vom Typ k, wenn er sich in der Gemeinde i niederläßt. Der erste Klammerausdruck stellt den Wert des privaten Gutes beim Konsum durch einen solchen Haushalt dar. Der zweite Klammerausdruck gibt die sogenannten "Überfüllungskosten" an, die als "congestion" im Produktionsbereich

$$
\sum_{k^{\prime}} n_{i}^{k^{\prime}} M C C_{i k}^{k^{\prime}}
$$

aus der öffentlichen Leistung und deren Bereitstellung selbst bzw. als "congestion" im Konsumbereich $\mathrm{c}_{\mathrm{ik}}$ in Verbindung mit zusätzlichen Einwohnern anfallen. Somit drückt Gleichung (5.14) die gesellschaftlichen Grenznutzen abzüglich der gesellschaftlichen Grenzkosten aus. Der sich ergebende Nettogrenznutzen, der sich durch die Wohnortentscheidung eines Haushalts vom Typ $\mathrm{k}$ für die Gemeinde i einstellt, ist folglich $\rho^{k} / \mu$.

${ }_{87} M C C_{i k}^{k^{\prime}}$ sind die sogenannten "marginal congestion costs", die einem Haushaltstyp k' durch einen Haushaltstyp $k$ auferlegt werden (Grenzüberfüllungskosten und damit "Kosten des nicht angewandten Ausschlusses"). Diese können alternativ auch interpretiert werden als die Zahlungsbereitschaft eines Haushalts vom k'-Typ, die Anzahl der Haushalte des k-Typs zu reduzieren ("Kosten des angewandten Ausschlusses"). 
Er ist im Ergebnis infolge der Mobilitätsannahmen zwischen allen Gemeinden identisch, da keine Nutzendifferentiale existieren dürfen.

Auf den ersten Blick mag es überraschen, daß der Nutzen des Haushalts aus dem Konsum des lokalen öffentlichen Gutes $\left(z_{i}\right)$ nicht explizit in der Gleichung (5.14) auftaucht. Dieser Nutzen ist jedoch implizit vorhanden, weil der Konsum des privaten "Numéraire"-Gutes $x_{i}^{k}$ zusammen mit dem lokalen öffentlichen Gut und den sogenannten "consumer congestion costs" das gleiche Nutzenniveau für den k-ten Typ eines Haushalts in allen Gemeinden hervorbringt (vgl. dazu die Restriktionen (5.5) und (5.6)). Dabei gilt: Je höher der Nutzen und damit die Präferenz für das lokale öffentliche Gut, desto weniger Bedeutung erlangt das private Konsumgut und desto weniger "kostspielig" ist somit $x_{i}^{k}$ in Gleichung (5.14) bei der Realisierung eines bestimmten vorgegebenen Nutzenniveaus und desto größer ist folglich der Nettonutzen, welcher auf der linken Seite der Gleichung (5.14) resultiert.

\subsubsection{Optimale Gemeindegröße und effiziente Allokation}

Dieses Ergebnis ist graphisch illustrierbar, wenn man lediglich den Konsum des privaten "Numéraire"-Gutes $x_{i}^{k}$ und den eines lokalen öffentlichen Gutes $z_{i}$ betrachtet. In diesem speziellen Fall sind die Optimalitätsbedingungen leicht anhand einer einfachen konvexen Nutzenfunktion $u_{i}=u_{i}\left(x_{i}^{k}, z_{i}\right)$ zu interpretieren. Abbildung 5.1 veranschaulicht diesen Zusammenhang und zeigt, daß im Vergleich zur Gemeinde 1 ein identischer Nutzen bei einem höheren Niveau der lokalen öffentlichen Leistungen in Gemeinde 2 nur bei gleichzeitig geringer Konsumtionsmenge des privaten Gutes $x_{i}^{k}$ realisierbar ist. Haushalte des Typs $\mathbf{k}$, die in der Gemeinde 1 oder der Gemeinde 2 ihren Wohnsitz haben, erreichen somit bei unterschiedlicher Ausstattung mit dem lokalen öffentlichen Gut $z_{i}$ aufgrund der Anpassung über die Konsummenge des privaten "Numéraire"-Gutes das gleiche Nutzenniveau $\bar{u}^{k}$. Ein höheres Angebotsniveau des öffentlichen Gutes in Gemeinde 2 ist folglich mit einem niedrigeren Bereitstellungs- und damit Konsumtionsniveau des privaten Gutes verbunden. Dies ist u.a. auch zurückzuführen auf die gewählte Betrachtungsweise, da die Kosten der Produktion des lokalen öffentlichen Gutes $\mathrm{C}_{\mathrm{i}}\left(\mathrm{n}_{\mathrm{i}}, \mathrm{z}_{\mathrm{i}}\right)$ im Sinne von Opportunitätskosten in Einheiten des privaten "Numéraire"-Gutes ausgedrückt worden sind (vgl. Wildasin, 1986, 10).

In Anlehnung an Buchanan/Wagner (1970, 143ff) sollen die Bedingungen für eine pareto-effiziente Allokation der Ressourcen in einer Ökonomie mit lokalen öffentlichen Gütern noch einmal graphisch veranschaulicht werden. Betrachtet wird diese Situation unter der Annahme, daß nur Haushalte des Typs $k$ existieren $(k=1)$ und es zwei Ge- 
meinden gibt; also $M=2$. Den Haushalten stehen zwei Güter für Konsumzwecke zur Verfügung, die unter Nutzung des Produktionsfaktors Arbeit erstellt werden. Der fixe Ressourcenbestand und seine unterschiedliche Verwendung (siehe 5.1.1) wird in dieser knappen graphischen Darstellung aus Praktikabilitätsgründen ebenso vernachlässigt wie die landwirtschaftliche Produktion und der Konsum des entsprechenden Outputs.

Abbildung 5.1: Nutzenniveau eines Haushaltstyps $\mathrm{k}$ in den Gemeinden 1 bzw. 2

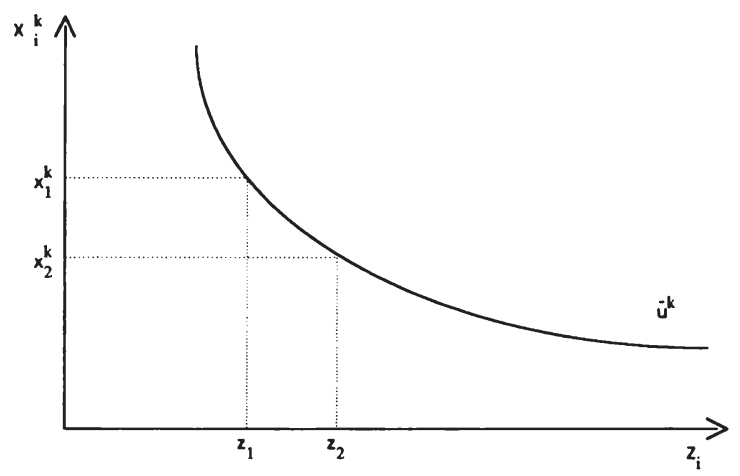

Die Gerade $\mathrm{MPP}_{\mathrm{i}}$ ("marginal product of population") in Abbildung 5.2 repräsentiert das Grenzprodukt des Arbeitsangebots als eine Funktion der Bevölkerung in Gemeinde i. ${ }^{88}$ Wenn beide betrachtete Güter privat sind (also kein öffentliches Gut und kein "congestion"-Effekt existiert), folgt aus der notwendigen Realisierung des gleichen Nutzenniveaus für die Konsummengen des privaten Gutes $x_{1}^{1}=x_{2}^{1}$ und die Optimalitätsbedingung (Gleichung (5.14)) reduziert sich unter Zugrundelegung der Annahmen für den "Buchanan-Wagner-Fall" auf

$$
M P P_{i}-x_{i}=\frac{\rho^{k}}{\mu} ;
$$

d.h. der erreichbare Nutzenzuwachs $\rho^{k} / \mu$ durch einen "einwandernden" Haushalt in den Gemeinden 1 und 2 muß im Gleichgewicht identisch sein. Solange diese Bedingung nicht erfüllt ist bestehen für die Haushalte Migrationsanreize, denn sie können möglicherweise durch Wohnsitzverlagerung eine Verbesserung ihrer Nutzenposition realisieren.

88 Dieses "marginal product of population" ist letztlich nichts anderes als der im vorstehenden Modell (s. auch Gleichung (5.14)) verwendete Ausdruck $F_{i k}$, nămlich das Grenzprodukt der Arbeit. Da aus Veranschaulichungsgründen jetzt nur noch ein Haushaltstyp $k=1$ betrachtet wird, ergibt sich demnach $F_{i}=M_{P P}$. 
Mit rein privaten Gütern wird eine effiziente Ressourcenallokation (hier des mobilen Faktors Arbeit und damit der Bevölkerung) folglich durch Outputmaximierung und damit verbundene höchstmögliche Bedürfnisbefriedigung erreicht. Das Optimum ergibt sich bei $n_{1}^{1}=\bar{n}_{1}^{1}$; hier gilt:

$$
M P P_{1}=M P P_{2}
$$

Abbildung 5.2: Optimale Allokation (der Einwohner) im 2-Kommunen-Fall

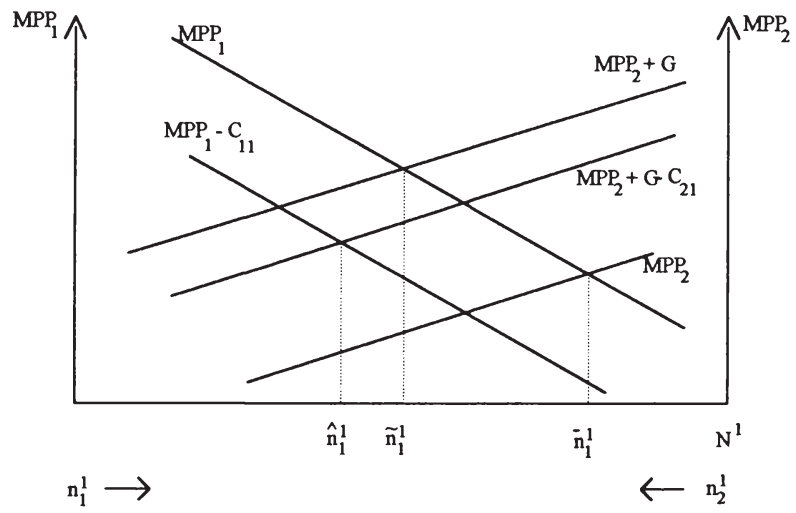

Mit einem "uncongestible local public good" (also öffentlicher Leistungserstellung ohne Überfüllungsphänomen und den damit einhergehenden Kapazitätseffekten) und einem privaten Gut ergibt sich aus Gleichung (5.16)

$$
M P P_{1}=M P P_{2}+x_{1}^{1}-x_{2}^{1}
$$

denn gemäß Abbildung 5.1 können wir die Nutzendifferenz des öffentlichen Gutes, die den Einwohnern in Gemeinde 2 zufält, als $G=x_{1}^{1}-x_{2}^{1}$ definieren. Ein Optimum tritt dann bei $n_{1}^{1}=\tilde{n}_{1}^{1}$ auf, wo der Nettonutzen $\rho^{k} / \mu$ aus privatem und öffentlichem Gut eines "einwandernden" Haushalts in jeder Gemeinde gleich ist.

Abschließend wird der Fall untersucht, in dem das lokale öffentliche Gut mit "congestion"-Effekten ausgestattet ist. Gleichung (5.17) muß so verändert werden, daß der Nettonutzen eines zusätzlichen Einwohners in jeder Gemeinde um $c_{i 1}$ (nämlich den 
"congestion effect") nach unten angepaßt werden muß.8 In Abbildung 5.2 liegt das Optimum nun bei $\hat{n}_{1}^{1}$.

\subsection{Die Effizienzeigenschaften eines Gleichgewichts}

Nach der Herleitung und Charakterisierung der Bedingungen einer effizienten Ressourcenallokation bei Existenz lokaler öffentlicher Güter sollen nunmehr die Effizienzeigenschaften eines möglichen Gleichgewichts betrachtet werden. Wir unterstellen Wettbewerbsbedingungen in der gesamten Volkswirtschaft und eine uneingeschränkte Mobilität der Haushalte. Das private Gut wird nach wie vor als "NuméraireGut" betrachtet. $w_{i}^{k}$ drückt die Entlohnung für die Arbeitskraft des Haushaltstyps $\mathrm{k}$ in der Gemeinde i aus, für die gesamten Lohnzahlungen in Gemeinde i ergibt sich demnach

$$
w_{i}=\sum_{k} w_{i}^{k} .
$$

Weiterhin ist $\mathbf{r}_{\mathrm{j}}$ der Preis (Pacht, Mietzins) für die Nutzung des fixen Ressourcenbestandes $T_{i}$ und $p$ der Preis des landwirtschaftlichen Outputs $\phi\left(t_{i}^{L}\right)$. Der Einfachheit halber wird ferner unterstellt, daß die Verwendungsmöglichkeiten des fixen Ressourcenbestandes $T_{i}$ in jeder Gemeinde völlig frei sind, so daß dieser entweder als direktes Konsumgut $\left(\mathrm{n}_{\mathrm{i}} \mathrm{t}_{\mathrm{i}}\right)$, als Input im Produktionsprozeß für das private "Numéraire-Gut" $\left(t_{i}^{p}\right)$ oder als alleiniger Input in landwirtschaftlichen Produktionsprozessen $\left(t_{i}^{L}\right)$ genutzt werden kann. Diese Annahme erlaubt die Verwendung eines gleichen Bruttopreises (Pachtzinses) für den Faktor Boden in den unterschiedlichen Verwendungen. ${ }^{90}$

Die Grundstückspachten fallen wie die landwirtschaftlichen Profite auch den Haushalten in Abhängigkeit ihres Ressourcenbesitzes sowie der Eigentumsanteile an den landwirtschaftlichen Produktionsstätten zu. Aus Vereinfachungsgründen wird in diesem Zusammenhang unterstellt, daß diese Bodenerträge sowie die landwirtschaftlichen Profite für Haushalte des gleichen Typs $k$ identisch sind.

Die Gemeinden finanzieren ihre Ausgaben durch Kopfsteuern, Lohnsteuern, Grundsteuern sowie Gewinnsteuern auf die landwirtschaftlichen Profite. Alle Steuern fallen

89 Vgl. dazu nochmals die allgemein gehaltene Optimalitătsbedingung (5.14).

90 Die Analyse kann ohne Verănderungen auch dann durchgeführt werden, wenn die freie Wahlmöglichkeit zwischen den alternativen Nutzungsmoglichkeiten des fixen Ressourcenbestandes eingeschrănkt ist (vgl. dazu Wildasin, 1986, 12). 
am Ort ihrer Entstehung an ("source-based taxes") ${ }^{91}$, d.h. die Steuern auf Grund und Boden bzw. die landwirtschaftlichen Profite werden in der Gemeinde erhoben, in der sich der Besitz befindet bzw. die Gewinne entstehen und eben nicht in der Gemeinde, in der die Eigentümer ihren Wohnsitz haben.

Somit ist $t_{i}^{k}$ der Anteil am fixen Ressourcenbestand (Grund und Boden) der Haushalte vom Typ $\mathbf{k}$ in Gemeinde $\mathrm{i}$; für den gesamten Bodenbestand der Haushalte vom Typ $\mathbf{k}$ gilt dann

$$
t^{k}=\sum_{i} t_{i}^{k}
$$

$\sigma_{i}^{k}$ ist der Gewinnanteil der Haushalte vom Typ $\mathrm{k}$ aus landwirtschaftlicher Produktion in Gemeinde $i^{92}$, auch hier gilt

$$
\sigma^{k}=\sum_{i} \sigma_{i}^{k}
$$

$\tau_{\text {in }}^{k}$ ist die Kopfsteuer der Haushalte des Typs $\mathrm{k}$ in Gemeinde $\mathrm{i}$ und somit ist

$$
\tau_{i n}=\sum_{k} \tau_{i n}^{k}
$$

das gesamte Aufkommen einer Kopfsteuer in der entsprechenden Gemeinde. $\tau_{i w}$ ist der Lohnsteuersatz in Gemeinde i, $\tau_{i r}$ die Steuer auf den Faktor Boden (Grundsteuer) und $\tau_{i L}$ die Gewinnsteuer für die landwirtschaftliche Produktion.

$$
\begin{array}{ll}
\sum_{k} N^{k} t_{i}^{k}=T_{i} & \text { für alle } \mathrm{i} \\
\sum_{k} N^{k} \sigma_{i}^{k}=\sigma_{i} & \text { für alle } \mathrm{i}
\end{array}
$$

(5.18) und (5.19) geben an, daß alle Bodenbestände (Grundstücke) in einer Kommune i sich in Besitz der privaten Haushalte befinden und daß die einzelnen Gewinnanteile aus der landwirtschaftlichen Produktion zusammen gefaßt dem Gesamtprofit entsprechen müssen (volle Ausschüttung).

\footnotetext{
91 Im Gegensatz dazu sind sogenannte "residence-based taxes" zu nennen, die dort anfallen, wo der Besitzer der Produktionsmittel oder der Gewinnempfänger seinen Wohnsitz hat.

92 Der Gesamtgewinn aus landwirtschaftlicher Produktion ergibt sich aus $p \phi_{i}\left(t_{i}^{L}\right)-r_{i} t_{i}{ }^{2}$; also Ertrag minus Kosten des landwirtschaftlichen Sektors.
} 
In der Folge können nun die Budgetbeschränkungen, die für eine gleichgewichtige Situation notwendig sind, für die einzelnen Haushalte und Gemeinden spezifiziert werden. Für einen Haushalt vom Typ $\mathrm{k}$ in der Gemeinde i ergibt sich folglich:

$$
\begin{aligned}
x_{i}^{k}+r_{i} t_{i}^{k}+p q_{i}^{k} & =\left(1-\tau_{i w}\right) w_{i}^{k}-\tau_{i n}^{k}+\left(r_{i}-\tau_{i r}\right) t_{i}^{k}+\sum_{j}\left(1-\tau_{j L}\right) \sigma_{j}^{k}\left[p \phi_{j}\left(t_{j}^{L}\right)-r_{j} t_{j}^{L}\right] \\
& =\left(1-\tau_{i w}\right) w_{i}^{k}-\tau_{i n}^{k}+I^{k}
\end{aligned}
$$

Dabei ist $p \phi_{j}\left(t_{j}^{L}\right)-r_{j} t_{j}^{L}$ der Gewinn aus landwirtschaftlicher Produktion in Gemeinde $\mathrm{j}$ und $I^{k}$ ist das Nettoeinkommen eine Haushalts vom Typ $k$, das unabhängig von seiner Wohnortwahl ist. Wenn $v_{i}^{k}$ das Nutzenmaximum des Haushalts aus $u_{i}^{k}\left(x_{i}^{k}, t_{i}^{k}, q_{i}^{k}, n_{i}, z_{i}\right)$ unter Berücksichtigung der Budgetbeschränkung (5.20) beschreibt, ergibt sich für das Budgetgleichgewicht der Gemeinde i folgende Beziehung:

$$
c_{i}\left(z_{i}, n_{i}\right)=\tau_{i w} w_{i} n_{i}+\tau_{i n} n_{i}+\tau_{i r} T_{i}+\tau_{i L}\left[p \phi\left(t_{i}^{L}\right)-r_{i} t_{i}^{L}\right]
$$

Für ein Gleichgewicht muß diese Bedingung (5.21) erfüllt sein; die örtlichen Entscheidungsträger müssen also die vorliegende Budgetbeschränkung bei der Bereitstellung des lokalen öffentlichen Gutes beachten. Für eine Gleichgewichtssituation muß ferner auf den Märkten, welche in den Gleichungen (5.1), (5.2) und (5.3) beschrieben sind, Angebot und Nachfrage (Produktion und Verwendung) identisch sein. Die Haushalte treffen ihre Wohnsitzentscheidung unter Nutzengesichtspunkten, so daß gilt:

$$
v_{i}^{k}=\tilde{v}^{k} \quad \text { fir alle } i, k
$$

Dabei ist $\tilde{v}^{k}$ das gleichgewichtige Nutzenniveau der Haushalte vom Typ k. Alle Haushalte haben gemäß Gleichung (5.4) in einer der Gemeinden einen Wohnsitz. Die Unternehmen, die das private "Numéraire-Gut" herstellen, erzielen bei dessen Produktion und Bereitstellung infolge der Wettbewerbssituation und der daraus resultierenden Faktorentlohnung gemäß dem Wertgrenzprodukt keine Gewinne.

Im folgenden sollen nunmehr die Effizienzeigenschaften eines möglichen Gleichgewichts untersucht werden. Dazu gilt es zu prüfen, ob die notwendigen Bedingungen einer effizienten Allokation (die Gleichungen (5.8) bis (5.13)) eingehalten werden.

Es ist offensichtlich, daß nutzen- bzw. gewinnmaximierendes Verhalten impliziert, daß im Gleichgewicht: 


$$
\frac{u_{i 2}^{k}}{u_{i 1}^{k}}=F_{i t}=p \phi_{i t} \quad \text { für alle } i, k
$$

also das Grenznutzenverhältnis zwischen landwirtschaftlichem Output und privatem "Numéraire"-Gut dem Wertgrenzprodukt des fixen urbanen Ressourcenbestandes beim Einsatz in der Produktion des privaten "Numéraire"-Gutes $\left(\mathrm{F}_{\mathrm{it}}\right)$ sowie der Erstellung des landwirtschaftlichen Outputs $\left(p \phi_{i t}\right)$ entsprechen muß. Bei Grenzproduktivitätsentlohnung entspricht das Wertgrenzprodukt der Faktorentlohnung (also $F_{i t}=p \phi_{i t}=r_{i}$ ).

$$
\frac{u_{i 3}^{k}}{u_{i 1}^{k}}=p \quad \text { für alle } i, k
$$

d.h. das Grenznutzenverhältnis zwischen der konsumtiven Verwendung des fixen urbanen Ressourcenbestandes und des privaten "Numéraire"-Gut entspricht dem Preis des landwirtschaftlichen Outputs. Es sei noch einmal in Erinnerung gerufen, daß der landwirtschaftliche Output annahmegemäß ausschließlich durch den Einsatz des fixen urbanen Ressourcenbestandes (also Grund und Boden) als Produktionsfaktor erstellt wird, so daß der Preis des landwirtschaftlichen Outputs gleich dem "Schattenpreis" des fixen Ressourcenbestandes in Einheiten des privaten "Numéraire"-Gutes ist (vgl. auch die Interpretation der innerhalb des Lagrange-Verfahrens ermittelten Ergebnisse in den Gleichungen (5.8) bis (5. 13)). Bei der Produktion des landwirtschaftlichen Outputs sind also ebenso wie bei der Produktion des privaten Gutes infolge der Wettbewerbssituation und der daraus resultierenden Faktorentlohnung gemäß des Wertgrenzprodukt keine Gewinne erzielbar.

Die Bedingungen (5.23) und (5.24) sind zur Ermittlung der nutzenmaximalen Position eines Haushalts unter den zugrundeliegenden Modellbedingungen in den Gleichungen (5.7) bis (5.14) bereits verwendet worden. Sie beschreiben über das entsprechende Nutzenmaximum des Haushalts (vgl. Gleichung (5.14)) damit auch die effiziente Nutzung des fixen urbanen Ressourcenbestandes sowie des landwirtschaftlichen Outputs in Produktion und Konsumtion.

In Anlehnung an die Budgetbeschränkung für einen privaten Haushalt gemäß Gleichung (5.20) kann - wenn sich die Budgetbeschränkung folgendermaßen darstellt:

$$
x_{i}^{k}+r_{i} t_{i}^{k}+p q_{i}^{k}=\left(1-\tau_{i w}\right) w_{i}^{k}-\tau_{i n}^{k}+I^{k}
$$


d.h. der Haushalt verwendet sein nach der Besteuerung durch Lohn-(Einkommen-) bzw. Kopfsteuern verbleibendes Nettoeinkommen (I $\left.{ }^{k}\right)$ für den Konsum des privaten "Numéraire"-Gutes, des urbanen fixen Ressourcenbestandes sowie des landwirtschaftlichen Outputs - nach Umformung dieser Budgetrestriktion aus der Gleichung (5.20) und Multiplikation beider Seiten mit (-1) folgende Gleichung ermittelt werden:

$$
w_{i}^{k}-\left(x_{i}^{k}+r_{i} t_{i}^{k}+p q_{i}^{k}\right)=\tau_{i w} w_{i}^{k}+\tau_{i n}^{k}-I^{k}
$$

Daraus folgt, daß die Effizienzbedingung gemäß Gleichung (5.14) nur erfüllt ist, wenn gleichzeitig

$$
\tau_{i w} w_{i}^{k}+\tau_{i n}^{k}-\left(c_{i k}+\sum_{k^{\prime}} n_{i}^{k^{\prime}} M C C_{i k}^{k^{\prime}}\right)=\tau_{j w} w_{j}^{k}+\tau_{j n}^{k}-\left(c_{j k}+\sum_{k^{\prime}} n_{j}^{k^{\prime}} M C C_{j k}^{k^{\prime}}\right)
$$

für zwei Gemeinden $\mathrm{i}$ und $\mathrm{j}$ und für jeden Haushalt vom Typ $\mathrm{k}$ gilt. Diese Gleichung (5.26) besagt, daß die Summe aus Lohn-(Einkommen-) und Kopfsteuern sowie den "Überfüllungskosten" (congestion-Effekte im Produktions- und Konsumbereich) für einen Haushaltstyp $k$ in den einzelnen Gemeinden (hier $i$ und $j$ ) identisch sein muß. Wir benutzen nun diese Gleichung (5.26), um unterschiedliche Rahmenbedingungen und damit einhergehende Finanzierungsalternativen zu analysieren. Dieses soll anhand einer Fallunterscheidung geschehen.

5.3 Die Effizienzbedingungen für die lokale Entscheidungsebene - Eine Fallunterscheidung ${ }^{93}$

Fall 1:

$$
\tau_{i L}=\tau_{i r}=0 ; \quad c_{i k}=M C C_{i k}^{k^{\prime}}=0 \quad \text { für alle } i, k, k^{\prime}
$$

In dieser Situation gibt es keine Überfüllungsphänomene $\left(c_{i k}=M C C_{i k}^{k^{\prime}}=0\right)$ und die lokale Besteuerung erfolgt in Form von Lohn- bzw. Einkommensteuern und/oder Kopfsteuern (lump-sum taxes). Damit gilt für die Gleichung (5.26):

$$
\tau_{i w} w_{i}^{k}+\tau_{i n}^{k}=\tau_{j w} w_{j n}^{k}+\tau_{j n}^{k}
$$

Die Gleichung (5.27) verdeutlicht, daß die Steuerbelastung aus Einkommen-(Lohn-) und/oder Kopfsteuern für einen Haushalt des Typs $k$ in allen Gemeinden identisch sein

${ }^{93} \mathrm{Vgl}$. in diesem Zusammenhang eine ausführlich Diskussion denkbarer Fălle bei Wildasin (1986, 14ff). 
muß, um den Effizienzbedingungen zu genügen. Abweichende Steuerbelastungen führen folglich wegen der entsprechenden Migrationsanzreize zu ineffizienten Allokationsentscheidungen.

Die vorstehenden Argumente verdeutlichen bereits, daß eine "lokale Kopfsteuer"94 eben keine neutrale Steuer darstellen kann. Dieses Ergebnis steht im Gegensatz zur nationalen Kopfsteuer, die die Entscheidungsstrukturen nicht verzerrt, damit keine Substitutionseffekte auslöst und folglich keine Migrationsanreize produziert. Die Ursache für die Nicht-Neutralität einer lokalen Kopfsteuer beruht auf der Tatsache, daß diese "Kopfsteuer" (wegen ihres Charakters einer Einwohnersteuer) durch Wanderungsbewegungen entweder gänzlich vermieden oder zumindest teilweise substituiert (also in ihrer Belastungswirkung eingeschränkt) werden kann. Dieses Charakteristikum und damit der Unterschied zwischen staatlichen und lokalen Kopfsteuern wird in der ökonomischen Literatur häufig übersehen (vgl. etwa Oates, 1972 oder Bewley, 1981). Daher wird im weiteren Verlauf der Arbeit auf diesen Aspekt nochmals zurückzukommen sein (vgl. Kapitel 9).

\section{Fall 2:}

$$
\tau_{i w}=\tau_{i n}^{k}=0 ; \quad c_{i k}=M C C_{i k}^{k^{\prime}}=0 \quad \text { für alle } i, k, k^{\prime}
$$

In diesem Fall basiert die kommunale Besteuerung entweder ausschließlich auf einer Boden- bzw. Grundsteuer $\left(\tau_{i r}\right)$ oder einer Besteuerung des landwirtschaftlichen Ertrags $\left(\tau_{i L}\right)$, die infolge der Annahme, daß der Produktionsfaktor Boden alleiniger Inputfaktor in landwirtschaftlichen Produktionsprozessen ist, auch als Bodenertragsteuer bezeichnet werden kann. Diese Steuerformen genügen der notwendigen (Effizienz-)Bedingung gemäß Gleichung (5.26). Das bedeutet, daß bei einem reinen öffentlichen Gut und der Nichtexistenz entsprechender "Überfüllungsphänomene" beim Konsum dieses Gutes ein effizientes Ergebnis vorliegt.

Die Begründung für dieses Optimum bei lokalen Boden- bzw. Bodenertragsteuern ist leicht illustrierbar. Im Gleichgewicht würde die Wohnsitznahme eines Haushalts in einer Gemeinde (also dessen Zuzug) keinerlei zusätzliche Wohlfahrtsgewinne auslösen, der Outputwert des lokalen öffentlichen Gutes - ausgedrückt in Einheiten des privaten Gutes - wäre unverändert zwischen den einzelnen Gemeinden. Es gibt also folglich keinerlei fiskalische Externalitäten durch Migration, denn die Steuerlast des einzelnen Haushalts ist unabhängig von seiner Wohnsitzwahl. Letztlich hängt es nicht da-

\footnotetext{
94 Weil eine gemeindliche Kopfsteuer eine lokal differenzierte Abgabe darstellt, handelt es sich nicht mehr um eine Kopfsteuer ("lump-sum tax") im eigentlichen Sinne, denn durch interlokale Wanderung ist eine räumliche Substitution möglich. In Anlehnung an die Kopfsteueridee vorgeschlagene lokale Abgabeformen werden daher treffender auch als Einwohner- bzw. Bürgersteuern bezeichnet. 
von ab, ob der Haushalt in der entsprechenden Gemeinde lebt, in der er für ein dort liegendes Grundstück Steuern zahlt. Es entsprechen sich also aufgrund einer unter diesen Besteuerungsformen erfolgenden Wohnsitzwahl der Haushalte privater und sozialer (gesellschaftlicher) Nettonutzen, da die Entscheidungsstrukturen anderer Haushalte bezüglich der Konsummöglichkeiten des lokalen öffentlichen Güterangebotes nicht beeinflußt werden.

Fall 3:

$$
\tau_{i w}=\tau_{i n}^{k}=0 ; \quad c_{i k} \neq 0 \quad \text { und /oder } \quad M C C_{i k}^{k^{\prime}} \neq 0
$$

Wie im Fall 2 erfolgt die lokale Besteuerung mittels einer Boden- bzw. Bodenertragsteuer. Im Unterschied zum vorstehenden Sachverhalt wird nunmehr aber von der Existenz von "congestion"-Effekten (also Überfüllungsphänomenen) ausgegangen. Gleichung (5.26) und damit die Effizienzbedingung ist nur dann erfüllt, wenn die congestion-Effekte im Optimum zufällig identisch sind. Auch wenn dies ein durchaus mögliches Resultat darstellt (es kann in Modellen mit perfekten symmetrischen Strukturen bezüglich der charakteristischen Merkmale der Kommunen auftreten), kann in der Regel wohl davon ausgegangen werden, daß es unter diesen Rahmenbedingungen zu Ineffizienzen kommt.

Die Gründe für diese Ineffizienzen sind darin zu sehen, daß Migration externe Kosten durch den Zuzug in eine Gemeinde verursacht, nämlich durch die Reduzierung öffentlicher Leistungen (über die Einschränkung der Konsummöglichkeiten der ortsansässigen Einwohner) und daraus folgend (um das Versorgungsziel zu garantieren) die Notwendigkeit der Ausdehnung öffentlicher Ausgaben, damit das öffentliche Leistungsangebot (pro Kopf) annähernd konstant gehalten werden kann. Mit einer zugrundeliegenden festen Steuerstruktur (bestehend aus Boden- und Bodenertragsteuern) werden diese Effekte aber nicht in die Entscheidungskalküle bei der Migration von Haushalten einbezogen (internalisiert), weil wie weiter oben bereits betont, Wohnsitzwahl und Steuerpflicht nicht zwangsläufig miteinander verzahnt sein müssen. ${ }^{95}$ Folglich resultieren aufgrund dieser Externalitäten Ineffizienzen.

Grund- und Bodenertragsteuern sind also bei auftretenden congestion-Effekten in Produktion und Konsum des lokalen öffentlichen Leistungsangebots kein geeignetes kommunales Steuerinstrumentarium, um eine effiziente lokale Aufgabenerfüllung zu realisieren.

\footnotetext{
95 Es ist also denkbar, daß ein Haushalt in die Gemeinde B zieht (als Bewohner einer Mietwohnung), aber weiterhin als Grundstücksbesitzer in der Gemeinde A aufgrund seines dort vorhandenen Grundstücks für dessen Wert bzw. dessen Ertrăge steuerpflichtig bleibt.
} 
Fall 4:

$$
\tau_{i L}=\tau_{i r}=0 ; \quad c_{i k}+M C C_{i k}^{k^{\prime}} \neq 0
$$

Wie im Fall 1 werden zur Finanzierung der lokalen Ausgaben Kopf- und/oder Einkommen- bzw. Lohnsteuern benutzt. Jetzt wird darüber hinaus aber angenommen (wie im Fall 3), daß congestion-Effekte auftreten. Im allgemeinen existiert dann keine Kombination aus Kopf- und/oder Einkommensteuer, die eine gleichzeitige Erfüllung der beiden Gleichgewichts- bzw. Effizienzbedingungen (5.21) und (5.26) erlaubt.

Doch betrachten wir trotz dieser desillusionierenden Feststellung einmal den folgenden Fall. Angenommen lokale öffentliche Güter werden mit konstanten Skalenerträgen produziert, so daß

$$
c_{i k}=c_{i}\left(z_{i}\right)=\frac{c_{i}}{\sum_{k} n_{i}^{k}}
$$

und keine crowding Effekte im Konsumbereich $\left(M C C_{i k}^{k^{\prime}}=0\right)$ existieren. Unter diesen Voraussetzungen erfüllt eine allgemeine Kopfsteuer die Effizienzbedingungen (5.21) und (5.26), wenn $\tau_{i n}=c_{i}\left(z_{i}\right)=c_{i k}$ gilt und folglich ist die sich einstellende Lösung effizient. Verallgemeinert ausgedrückt heißt das: Effiziente Ergebnisse werden erreicht, wenn $c_{i}$ (lokal) linear homogen in $n_{i}$ ist und die jeweilige Kopfsteuer der Haushaltstypen $\mathbf{k}$ sich unterscheidet gemäß $\tau_{i n}^{k}=c_{i k}$.

Eine allgemeine Einkommensbesteuerung (Lohnsteuer) liefert identische Ergebnisse, wenn alle Haushalte gleiche Löhne beziehen. Mit unterschiedlichen Löhnen und identischen congestion-Effekten führt eine Lohnsteuer aber nicht zu effizienten Lösungen. Diese wären - wenn sie einträten - rein zufällig.

Obwohl Kopf- und Einkommensteuern als äquivalente Instrumente in einfachen Modellstrukturen benutzt werden, liefern lokale Kopfsteuern in der Regel - obwohl auch sie bekanntermaßen keine neutralen Steuern darstellen (denn eine interlokal unterschiedliche Ausgestaltung "produziert" Migrationsanreize") - im allgemeinen effizientere Ergebnisse.

Fall 5: $\quad \tau_{i n}^{k}=c_{i k}+\sum_{k^{\prime}} M C C_{i k}^{k^{\prime}} ; \quad \tau_{i w}=0$

Neben der Entsprechung von lokaler Kopfsteuer und congestion-Effekten wird angenommen, daß $\tau_{i r}$ und $\tau_{i L}$ jeweils so variiert werden können, daß sie Gleichung (5.21) bei einer gegebenen Kopfsteuer $\left(\tau_{\text {in }}\right.$ ) erfüllen, also ein Budgetgleichgewicht realisieren. 
Diese Situation beschreibt folglich den Fall, in dem die Kopfsteuer für den einzelnen Haushalt so festgesetzt wird, daß sie den durch ihn ausgelösten congestion-Effekt exakt abdeckt (perfekte Internalisierungsabgabe im Sinne der sogenannten Pigou-Lösung bei Vorliegen externer Effekte). Daneben gibt es eine Grund- oder Bodenertragsteuer, deren Aufkommen als Residualeinnahme zum jeweiligen Ausgleich des lokalen Budgets benutzt werden kann. Dieser Fall 5 generalisiert Fall 2 und zeigt - vgl. Gleichung (5.26) -, daß unter der Annahme, daß Kopfsteuern zur Internalisierung von congestion-Effekten variiert werden können, effiziente Lösungen denkbar sind. Die Kopfsteuer wird dabei je nach Haushaltstypus $\mathbf{k}$ variieren, wenn die jeweiligen congestion-Effekte je nach Haushaltstyp in unterschiedlicher Größenordnung auftreten. ${ }^{96}$

Fall 6:

$$
\tau_{i n}=0 \neq \tau_{i w} ; \quad c_{i k}+\sum_{k^{\prime}} M C C_{i k}^{k^{\prime}} \geq 0
$$

Aus Gleichung (5.26) und den vorstehenden Bemerkungen wurde deutlich, daß eine allgemeine Lohn- und Einkommensteuer - gekoppelt mit Bodenwert- bzw. Bodenertragsteuern - nicht zur effizienten Ressourcenallokation auf lokalem Level führt.

Nur wenn $\tau_{i w} w_{i}^{k}$ (also die Einkommensteuerschuld eines Haushaltstyps $\mathbf{k}$ in Gemeinde i) zufällig den "Grenzüberfüllungskosten" (congestion-Effekt) entspricht, werden effiziente Allokationsentscheide getroffen. Dies ist offensichtlich nur dann der Fall, wenn die Einkommensteuersätze variiert werden können und sich somit an den Überfüllungsphänomenen orientieren, die durch Zuwanderung ausgelöst werden. ${ }^{97}$

\subsection{Bewertung der Ergebnisse}

Aus der vorstehenden Analyse unterschiedlicher Rahmenbedingungen wurde erkennbar, daß eine effiziente Ressourcenallokation auf lokalem Niveau durch die uneingeschränkte Möglichkeit interkommunaler Wanderungen erreicht werden kann, aber

\footnotetext{
96 Als (Teil-)Lösung im beschriebenen Sinne kommen Gebühren und Beitrăge (sofern eine individuelle Zurechnung möglich bzw. unter technischen und Kostengesichtspunkten vertretbar erscheint) in Frage. Individuell bemeBbare Leistungsentgelte (Gebühren und Beitrăge) sind, da streng ăquivalenzbezogen, nahezu ideale Nutzensteuern ("perfect benefit based taxes"). Durch Leistungsentgelte kann Überfüllung (congestion) vermieden werden; und auch spillovers (vgl. Kapitel 6) können, soweit die Kosten (Grenzkosten) gedeckt sind, internalisiert werden. Daher sollten - gerade auf der lokalen Ebene (in Kapitel 8 werden Begründungen dafür geliefert) - unter Effizienzgesichtspunkten vorhandene Gebührenpotentiale ausgeschöpft und damit die Bereitstellung lokaler offentlicher Leistungen stärker an den Wünschen und Präferenzen der Gemeindeeinwohner ausgerichtet werden.
}

97 "Note that in the special case where $\mathrm{N}=1$, it is always possible to find an efficient wage income tax. This is likewise true if wage income tax rates could be varied across households according to the congestion that they generate." (Wildasin, 1986, 17) 
nicht zwangsläufig auch erreicht werden muß. Problematisch ist in diesem Zusammenhang vor allem die Erreichbarkeit einer Steuerstruktur, die Allokationseffizienz und damit eine optimale Ressourcenverwendung garantiert. Nichtsdestotrotz sind die präsentierten Ergebnisse durchaus hilfreich, etwas über lokale Steuern (Abgaben) und ihre Implikationen auszusagen. So schließt sich das vorstehende Modell an die Argumentationsreihen in Zusammenhang mit der Begründung einer dezentralen öffentlichen Aufgabenerfüllung und ihrer Finanzierung an und macht ebenfalls deutlich, daß Dezentralisierung mit einer höheren Wirtschaftlichkeit verbunden ist.

Gleichwohl kann aber nicht abschließend fixiert werden, wie ein "effizientes kommunales Steuersystem" in seiner Grundzusammensetzung aussehen sollte. Ein solches System hängt vielmehr von den unterschiedlichen Rahmenbedingungen ab und scheitert, wie gesehen, schon theoretisch an den Charakteristika des öffentlichen Leistungsangebots. Damit ist es nicht ausreichend, wenn aus der theoretischen Modellwelt Implikationen auf die realen Situationen der kommunalen Finanzierungssysteme übertragen oder im Sinne normativer Aussagen Grundzüge und Grundstrukturen eines kommunalen Steuersystems abgeleitet werden. Die empirische Relevanz des vorstehenden Modells ist für politisch-pragmatische Handlungsempfehlungen zu gering und muß um Praktikatiblitätskriterien erweitert werden. Dies wird daher in den folgenden Kapiteln geschehen.

\subsubsection{Realität und Modellwelt}

Ein Blick auf die realen Gegebenheiten zeigt, daß im internationalen Vergleich die Vermögensteuer in verschiedenartigen Formen auf der kommunalen Ebene die dominierende Zwangsabgabe darstellt. Häufig ist diese Steuer gleichbedeutend mit einer Besteuerung des räumlich fixen urbanen Ressourcenbestandes, nämlich des Produktionsfaktors Boden bzw. der Grundstücke und Gebäude. Diese Art der Besteuerung des Grundvermögens mittels der Grundsteuer und der eigentlichen Vermögensteuer sind die häufigsten kommunalen Abgabeformen. Dabei ist ihr Gewicht im internationalen Vergleich aber durchaus unterschiedlich. ${ }^{98}$

\footnotetext{
98 Kommunale Vermögensteuer gibt es vor allem in den USA und Kanada; jedoch mit Schwergewicht auf dem Grundbesitz. In Europa (s. auch mit Einschrănkungen in der Bundesrepublik Deutschland) sind vor allem kommunale Grundsteuern weit verbreitet und (wie beispielsweise in Irland) einzige und bedeutendste Finanzierungsquelle der Kommunen. In Deutschland ging die Bedeutung der Grundsteuer seit Ende des neunzehnten Jahrhunderts trendmäßig zurück; sie erbringt heute nur noch rund zehn Prozent des gemeindlichen Steueraufkommens.
} 
Aus der vorstehenden Analyse konnten einige Begründungen für die Bevorzugung und Vorteilhaftigkeit dieser Steuerformen auf der lokalen Ebene abgeleitet werden. Grundstücke und Gebäude als Vermögensteile sind räumlich nicht mobil und infolgedessen durch ökonomische Besonderheiten gekennzeichnet. Diese Besonderheiten schlagen sich in einem relativ unelastischen Angebots- und Nachfrageverhalten der Haushalte nieder, das dazu führt, daß eine solche Steuer (je unelastischer die Marktstrukturen sind) ähnliche Wirkungen wie eine allgemeine Kopfsteuer (lump-sum tax) mit sich bringt. Damit könnte die Besteuerung starr angebotener, immobiler Produktionsfaktoren (wie die Grundsteuer im Sinne einer reinen Bodensteuer) ein ideales Einzelinstrument zur Verwirklichung von Steuersouveränität und Effizienz auf lokalem Niveau sein. Die Bodensteuer (Grundsteuer) verzernt selbst bei unabgestimmter Steuersatzwahl die Allokation mobiler Produktionsfaktoren (Arbeit und Kapital) nicht und läßt daher auch die Wohnsitzwahl der privaten Haushalte bzw. die Standortwahl von Unternehmen unbeeinflußt.

Realistisch gesehen wird die Vermögens(Boden-)besteuerung die ihr zugedachte Rolle aber nur bedingt wahrnehmen können. Insbesondere natürlich auch dann, wenn die Nachfrage nach Gebäuden und Grundstïcken nicht unelastisch und das Angebot variabel ist, wird die Grund- bzw. Vermögensbesteuerung dann eher strukturverzerrend wirken und ist somit bezüglich ihrer Einflüsse anders einzuschätzen, als die idealisierten Steuerformen, die innerhalb des vorstehenden Modells im Mittelpunkt der Diskussion standen. Die Bestimmung des Nettoeffektes der Vermögen- und Grundsteuern bei den ökonomischen Entscheidungen der Haushalte (aber natürlich auch der bisher vernachlässigten Unternehmen) ${ }^{99}$ auf lokalem Niveau stellt somit eine bedeutende - aber auch nach wie vor offene - Frage dar.

\subsubsection{Exkurs: Kommunale Unternehmensbesteuerung}

Richter (1992) hat versucht, die Tiebout-Hypothese für den eingeschränkten Bereich der Unternehmensbesteuerung nachzuweisen. Er leitet für diesen Bereich ein "Steuersystem" her, das die Eigenschaften eines effizienz-theoretisch "guten" Systems kommunaler Unternehmensbesteuerung besitzt; also die Erwartung rechtfertigt, daß die effiziente Allokation der als Produktionsfaktoren dienenden lokalen öffentlichen Güter (Vorleistungscharakter) "... ohne zentralstaatlichen Eingriff und ohne Harmonisierung der Steuersätze, allein durch dezentrale Entscheidungen von Unternehmen und Kom-

\footnotetext{
99 Die Übertragung der Tiebout-Hypothese auf die Ableitung kommunaler Unternehmensteuern hat Richter (1992) vorgenommen. Im Abschnitt 5.4 .2 soll in einem kurzen Exkurs dieser Ansatz skizziert und bewertet werden.
} 
munen, gelingt" (Richter, 1992, 569). Er wählt diesen Ansatz, so seine Argumentation, weil Wanderungsbewegungen generell zu undifferenziert seien, um eine effizienzsichernde Bewertung der dem Konsum dienenden lokalen öffentlichen Leistungen zu erlauben. Vor diesem Hintergrund beschränkt sich Richter daher auf die Sphäre der Produktion und das Ziel der Realisierung produktionseffizienter Allokationen in einer räumlich strukturierten Welt. ${ }^{100}$

Ein solches Resultat bedarf selbstverständlich (ebenfalls) der Relativierung, um überzogenen Erwartungen entgegenzuwirken. Wie auch in der vorstehenden formalen Analyse erkennbar, ermangelt die originäre Tiebout-Hypothese einer überzeugenden modelltheoretischen Fundierung und kann daher nur eingeschränkt als Leitbild der Wirtschaftspolitik dienen. Richter $(1992,569)$ stellt demgegenüber jedoch fest, daß sich die originäre Tiebout-Hypothese nicht auf die Unternehmensbesteuerung, sondern die Allokation der dem Konsum dienenden lokalen öffentlichen Güter bezieht. Die Literatur - so Richter $(1992,569)$ weiter - hat gezeigt, "... daß Tiebouts Vision im allgemeinen zu optimistisch ist. Einerseits ist bei realistischer Modellierung davon auszugehen, daß die Entscheidungen von Kommunen und Haushalten 'fiskalische Externalitäten' hervorrufen, die bei unabgestimmtem Verhalten in Effizienzverlusten resultieren." ${ }^{101}$ Vor diesem Hintergrund konzentriert sich Richter also auf die Sphäre der Produktion. Die vorgenommene Analyse ist partialanalytisch in dem Sinne, daß von einer Separabilität der Entscheidungen ausgegangen wird, die die Ressourcenverwendung im Konsum einerseits und in der Produktion andererseits betreffen. Die Problematik einer solchen Annahme ist darin zu sehen, daß sich kommunale Leistungen nicht ohne weiteres eindeutig als konsumtiv oder produktiv klassifizieren lassen. Daneben sind eine Reihe weiterer modellspezifischer Vereinfachungen vorgenommen worden. So wird etwa eine Abhängigkeit der Bereitstellungskosten von der Zahl der das lokale öffentliche Gut nutzenden Wirtschaftseinheiten (deswegen) vernachlässigt, "... weil die Literatur das eigentliche Problem in der Allokation reiner öffentlicher Güter sieht" (Richter, 1992, 570). Auch von anderen agglomerationscharakteristischen Begleiterscheinungen wird abgesehen, insbesondere von spillover-Effekten. Sobald diese aber Bedeutung erlangen, gilt das weiter oben bereits gesagte, nämlich das ein auf solchen vereinfachenden Modellannahmen basierendes Gemeindesteuersystem seinen Anspruch verfehlt und nur zusätzliche steuerliche Instrumente im Pigou'schen Sinne Abhilfe schaffen können.

100 Unberücksichtigt bleiben konjunktur- und wachstumspolitische Gesichtspunkte genauso wie andere kommunalspezifische Zielsetzungen, die in diesem Kontext zur Güte eines kommunalen Steuersystems beitragen (können).

101 Vgl. etwa Buchanan und Goetz (1972), Starrett (1980), Boadway (1982) und Wildasin (1989). 


\subsection{3 Überblick der theoretischen Behandlung kommunaler Finanzsysteme}

Die vorstehende theoretische Analyse kann zwar - die geschilderten Einwände belegen dies - das Ausmaß lokaler Effizienz aktueller kommunaler Finanzierungssysteme nicht exakt aufzeigen bzw. gar quantifizieren; dennoch liefert sie entscheidende Hilfen bei der Untersuchung der Problembereiche des behandelten Themenkomplexes. So kann sie verdeutlichen, daß die teilweise sehr unterschiedlichen Resultate wissenschaftlicher Forschungen in diesem Bereich keineswegs überraschen, sondern Ausdruck der unterschiedlichen Herangehensweise sowie entsprechender Modellannahmen sind. Dies soll abschließend exemplarisch auch ein kurzer Literaturüberblick dokumentieren.

Zunächst ist aus der vorstehenden Analyse festzuhalten, daß räumlich immobile und damit fixe Vermögenswerte (Grundstücke und Gebäude) eine entscheidende Rolle bei der Realisierung einer "locational efficiency" (Wildasin, 1986, 20) spielen (können). ${ }^{102}$ In Anlehnung an diese Beurteilung untersuchen beispielsweise Negishi (1972) und später darauf aufbauend Wildasin (1977) eine Modellwelt mit einem reinen öffentlichen Gut; also einer Leistung die durch Nicht-Rivalität und Nicht-Ausschluß gekennzeichnet ist und die keinerlei Kapazitätseffekte infolge begrenzter Nutzenreichweite aufweist. Obgleich sich beide Autoren mit der generellen sowie globalen Möglichkeit einer effizienten Ressourcenallokation befassen, ist diese in bezug auf die gewählte Problemstellung insbesondere dann erreichbar, wenn auf lokaler Ebene eine Grundsteuer als wesentliche Finanzierungsquelle genutzt wird (vgl. dazu in Abschnitt 5.3 den Fall 2). In einer im Vergleich zu den Ansätzen von Negishi bzw. Wildasin analogen Vorgehensweise kommt Rufolo (1979) infolge der Berücksichtigung des Überfüllungsphänomens ("congestion effects") für das lokale öffentliche Leistungsangebot zu dem Ergebnis, daß eine effiziente Lösung eine Besteuerung des Grund und Bodens sowie sogenannte "congestion fees"103 (die für eine Internalisierung der Überfüllungseffekte sorgen) voraussetzt (vgl. in Abschnitt 5.3 den Fall 5).

$\mathrm{Zu}$ ähnlichen Ergebnissen gelangt auch Hochman (1981), der die Nutzung von Grundsteuern zur Finanzierung aller lokalen öffentlichen Ausgaben vorschlägt. Einzige Ausnahme stellen notwendige Versuche einer Internalisierung der Überfüllungseffekte durch Einnahmen aus einer Kopfsteuer dar, die aber einzig und allein diese Zielset-

102 "Das ideale Einzelinstrument zur Verwirklichung von Steuersouveränităt und Effizienz ist die Besteuerung starr angebotener, immobiler Produktionsfaktoren, wofür die Grundsteuer im Sinne einer reinen Bodensteuer stehen mag. Die Bodensteuer verzernt selbst bei unabgestimmter Steuersatzwahl weder die Standortwahl von Unternehmen noch die Allokation mobiler Produktionsfaktoren. Die Ursache liegt darin, daß sie im Ideal allein zu Lasten der Bodenrente geht." (Richter, 1991, 3)

103 Diese "congestion fees" können mit den sogenannten Leistungsentgelten (also individuellen Gebühren und Beiträgen) verglichen werden, sofern diese im idealtypischen Sinne "perfect benefit based taxes" sind. 
zung besitzen (sollten). Eine solche Kopfsteuer im Hochman'schen Sinne ist im Prinzip analog zum vorgeschlagenen "congestion fee" bei Rufolo zu sehen. Diese Argumentation entspricht daher im wesentlichen auch den Rahmenbedingungen der angesprochenen Fälle 2 und 5 im Abschnitt 5.3. Im Gegensatz zu den etwas einfacher gehaltenen Modellen von Negishi und Wildasin berücksichtigt Hochman darüber hinaus bereits die denkbare Existenz einer nicht einheitlichen Grundrentenstruktur innerhalb einer Kommune. So konstatiert er, daß zwischen Grundstückspreisen und damit auch Grundstückserträgen im Zentrum und denen am Stadtrand oder im Umland durchaus beachtliche Unterschiede zu beobachten sind. Diese und damit einhergende Transportbzw. Mobilitätskosten zwischen Wohnung und Arbeitsstätte beeinflussen mögliche Modellergebnisse und folglich auch die angestrebte Neutralität einer Grundsteuer. Diese Erweiterungen der einfachen Grundmodelle nehmen u.a. auch Helpman/Pines/Borukhov (1976) sowie Hochman (1982a; 1982b) vor.

Es überrascht aufgrund der bisherigen Ausfuihrungen sicherlich nicht, daß Analysen, die eine Grundsteuer als mögliche Besteuerungsform ausschließen, andere Ergebnisse als die bisher vorgestellten Untersuchungen liefern. Dies bedeutet in der Regel, daß ohne eine Besteuerung des räumlich immobilen Ressourcenbestandes (Faktor Boden) eine effiziente Allokation innerhalb einer föderalen Struktur nicht den Regelfall darstellt. Vielmehr - so stellen vor allem Buchanan/Wagner (1970), Buchanan/Goetz (1972) und Flatters/Henderson/Mieszkowski (1974) fest - ist ein effizientes Ergebnis dann eher zufallig. Die vorgenannten Autoren richten ihre Aufmerksamkeit in Zusammenhang mit der vorgestellten Fallunterscheidung in Abschnitt 5.3 vor allem auf die Fälle 1, 4 und 6. Die aus den entsprechenden Analysen gewonnenen Schlußfolgerungen sind aber keineswegs zwangsläufig, weil auch diese Modelle einen räumlich festen Ressorcenbestand (Grundstücke und Gebäude) keineswegs ausschließen. Insbesondere für den Fall, daß eine entsprechende Steuerstruktur mit einer geeigneten Kombination aus Kopf- und Grundsteuer auf lokaler Ebene unterstellt wird, kann sich durchaus ein effizientes Ergebnis einstellen.

McGuire (1974), Wheaton (1975), Berglas (1976) oder auch Bewley (1981) knüpfen hingegen bei ihren Analysen nicht am räumlich immobilen Faktor an. Sie schlagen vielmehr Finanzierungsalternativen auf der lokalen Ebene vor, die im wesentlichen auf einer Kopfsteuer - die gleiche Steuerbelastung und damit Kostenanteile an den Bereitstellungskosten des lokalen öffentlichen Leistungsangebots pro Individuum garantiert basieren. McGuire's Analyse unterstellt bei der Produktion und Bereitstellung des lokalen öffentlichen Gutes konstante Skalenerträge, so daß bei der gewählten Finanzierungsform "Kopfsteuer" logischerweise effiziente Ergebnisse resultieren. Auch Bewley unterstellt konstante Skalenerträge, untersucht aber die gesamte Ressourcenallokation einer Volkswirtschaft (einschließlich lokaler öffentlicher Ausgaben) und untermauert 
auf der Basis konstanter Skalenerträge die gewonnenen Ergebnisse. Daneben weist aber Bewley auch daraufhin, daß mit reinen lokalen öffentlichen Gütern ein effizientes Gleichgewicht nicht möglich ist. Diese unterschiedlichen Ergebnisse werden bei einem Blick auf die Fälle 1 und 4 im Abschnitt 5.3 nachvollziehbar und können so einer eigenen Bewertung unterzogen werden.

Um Mißverständnissen vorzubeugen, sei noch einmal betont, daß die Existenz eines räumlich immobilen Ressourcenbestandes und seiner Besteuerung nicht sicherstellt, daß sich "locational efficiency" quasi automatisch ergibt. So untersucht Bucovetsky (1981) beispielsweise eine Volkswirtschaft, in der lokale öffentliche Güter mit konstanten Skalenerträgen produziert und durch eine Grundsteuer finanziert werden. Wie aus der Diskussion des Falles 3 in Abschnitt 5.3 bekannt ist, wird sich unter diesen Rahmenbedingungen kein effizientes Gleichgewicht einstellen. Statt dessen muß - so Bucovetsky - als Finanzierungsalternative eine Kopfsteuer gewählt werden, um zu einer effizienten Lösung zu gelangen (vgl. Fall 4).

Dieser kurze Überblick kann natürlich keine erschöpfende Darstellung aller Arbeiten sein, in denen "locational efficiency" eine Behandlung erfährt. ${ }^{104}$ Gleichwohl erlaubt er aber einen weiteren Einblick in die Möglichkeiten und Problembereiche kommunaler öffentlicher Leistungserstellung und deren Finanzierung. In Anlehnung an den vorgestellten Modellrahmen lassen sich abschließend folgende Resultate festhalten. Eine effiziente Ressourcenallokation auf lokalem Niveau ist generell erreichbar, wenn die lokalen Entscheidungsträger über ein geeignetes ("bewegliches") steuerliches Instrumentarium verfügen; also lokale Finanzautonomie besitzen. Das kann uneingeschränkte Steuerhoheit bedeuten, aber auch Hebesatzrechte oder Beeinflussungen der Bemessungsgrundlagen entsprechender Steuern beinhalten. Trotz dieser Möglichkeit (in einem föderal strukturierten Staatsgebilde mit entsprechenden Autonomiegraden) ist es nicht möglich, die konkrete Ausgestaltung eines effizienten lokalen Steuersystems zu charakterisieren, also ein sogenanntes "optimales lokales Steuersystem" abzuleiten. So kann in bestimmten Situationen die Besteuerung des Grund und Bodens angebracht d.h. unter Effizienzgesichtspunkten notwendig - sein, bei anders gearteten Rahmenbedingungen wiederum können Einkommen- bzw. Kopfsteuern effizient erscheinen oder es kann schließlich eine Kombination unterschiedlicher Steuerarten effiziente Ergebnisse erbringen. Es hängt von den jeweiligen Rahmenbedingungen ab, wie ein kommunales Steuersystem unter Effizienzgesichtspunkten ausgestaltet sein sollte. Damit

104 Ausgeklammert sind u.a. auch die Studien, in deren Mittelpunkt Finanzierungsströme zwischen den gebietskorperschaftlichen Ebenen stehen. So können beispielsweise durch Zuweisungen (Boadway/Wildasin, 1984, 518ff) fiskalisch induzierte interlokale Wanderungsursachen kompensiert und damit Fehlallokationen verhindert werden. Diesem Problemkomplex wird spăter noch einmal Beachtung beigemessen werden müssen (vgl. Kapitel 10). 
ist ohne genaue Kenntnis dieses jeweiligen Umfeldes eine Effizienzbewertung real existierender kommunaler Steuersysteme unmöglich.

Schließlich führt die Verwendung unterschiedlicher Annahmen über den Umfang bzw. das Ausmaß der Finanzierung und der Kapazitätseffekte lokaler öffentlicher Leistungen zu abweichenden Schlußfolgerungen über die Möglichkeiten und Grenzen bei Erreichung einer optimalen Ressourcenallokation in föderalen Systemen. Auch hier läßt sich im Widerstreit der Ansätze kein eindeutiges Ergebnis formulieren, da die empirische Relevanz der einzelnen Ansätze von der praktischen Eignung der verwendeten Annahmen abhängt (vgl. auch Wildasin, 1986, 20f).

Fazit bleibt letztlich, daß eine formal-theoretische Analyse - die sich mit dem Problem der "locational efficiency" aus gesamtwirtschaftlicher Perspektive beschäftigt ${ }^{105}$ - zwar nachweisen kann, daß in einem föderal ausgestalteten Staatswesen eine effiziente Ressourcenallokation unter bestimmten Bedingungen resultiert, sich aber nicht zwangsläufig und eindeutig (bei einer bestimmten Ausgestaltung des Finanzierungssystems) auch einstellt. Daher müssen, um zu weiteren Erkenntnissen zu gelangen, zum einen die bisher zugrunde gelegten Annahmen - insbesondere die kostenfreie Mobilität der Haushalte und die Nichtexistenz von räumlichen spillovers - überprüft und letztlich ein pragmatischerer Ansatz gewählt werden, um die gewonnenen Ergebnisse für eine sinnvolle Ausgestaltung des lokalen Finanzierungssystems benutzen und die theoretischen Überlegungen als Orientierungsbasis verwenden zu können.

Zum anderen ist bisher lediglich die Bedeutung lokaler öffentlicher Leistungen und ihre Nutzung durch private Haushalte untersucht worden. ${ }^{106}$ Unternehmen, ebenfalls

105 Diese Vorgehensweise ist nicht die einzig mögliche. Zwar sind Effizienzanalysen letztlich darauf ausgerichtet, die pareto-optimale Ressourcenallokation in einer Volkswirtschaft zu ermitteln bzw. die Bedingungen dieser Situation zu beschreiben, doch man kann in Zusammenhang mit der lokalen Ebene auch danach fragen, ob und auf welche Weise die maximale Wohlfahrt der Bevolkerung in einer Gemeinde isoliert erreichbar ist. Diese Fragestellung spielt vor allem bei der Entwicklung von Verhaltensmodellen bei der Bestimmung lokaler politischer Entscheidungen eine Rolle. Die entsprechende Diskussion ist in bezug auf die Formulierung entsprechender Effizienzbedingungen als "Henry George Theorem" (George, 1955) bekannt geworden und hat bei Flatters/Henderson/Mieszkowski (1974), Stiglitz (1977; 1983a; 1983b), Arnott (1979a; 1979b), Arnott/Stiglitz (1979), Atkinson/Stiglitz (1980, Kap. 17), Berglas (1982) sowie Schweizer (1983) umfassende Behandlung erfahren. Wildasin (1986, 22ff) liefert eine formale Aufbereitung der Diskussion. Dieser Ansatz soll an dieser Stelle jedoch nicht weiter verfolgt werden, da im Rahmen der Studie die gesamtwirtschaftliche Perspektive des Föderalismus und seiner praktischen Ausgestaltung im Vordergrund steht.

106 Mit der Ausnahme des Exkurses in Abschnitt 5.4.2, der aber in Analogie zum bisherigen Vorgehen ebenfalls nur eine Gruppe (hier die Unternehmen) als Besteuerungsbasis kommunaler Finanzierungssysteme benutzt hat. Gerade aber die "Mehrdimensionalităt" der kommunalen Leistungsangebote und ihre unterschiedlichen Nutzungsintensităten sind es aber, die Beachtung erfahren müssen. Denn keine Einzelsteuer, aber auch nicht ein alleiniger Anknüpfungspunkt für kommunale Abgaben, wird den verschiedenen Zielsetzungen einer effizienz-orientierten lokalen Leistungsbereitstellung und deren Finanzierung gerecht. 
Nutznießer des lokalen öffentlichen Leistungsangebots, blieben im Rahmen der bisherigen Betrachtungen ebenso unberücksichtigt wie andere noch $\mathrm{zu}$ identifizierende "Nutzergruppen" (vgl. Kapitel 7). Das Äquivalenzprinzip bliebe also insofern außer acht, da (Teil-)Nutzergruppen des kommunalen Leistungsangebot bei der Finanzierung desselben ausgeklammert würden. Dies ist unter Effizienzgesichtspunkten genauso problematisch wie unter Verteilungsgesichtspunkten, denn beispielsweise bliebe Produzentenrente ungeschmälert (abgesehen von der indirekten Einflußnahme über Bodenwert- bzw. Bodenertragsteuern), während die privaten Haushalte je nach Steuerform allein zur Finanzierung des lokalen Leistungsangebots beitragen.

Diese Aspekte machen mehr als deutlich, daß keine Einzelsteuer auf der kommunalen Ebene über eine genügende Flexibilität verfügt, um den verschiedenen Zielsetzungen kommunaler Besteuerung umfassend zu entsprechen. Nur ein differenziertes - aus mehreren Steuerarten bestehendes - System kann das Gewünschte leisten. Darüber hinaus werden auch kommunale Leistungsentgelte in Form von Gebühren und Beiträgen zur Finanzierung des lokalen öffentlichen Leistungsangebots eine Rolle spielen (dies wurde schon mehrfach betont); aber auch Zuweisungen übergeordneter Ebenen dürften unter Effizienzgesichtspunkten nicht völlig überflüssig sein, zumal wenn man von der Existenz räumlicher spillover-Effekte und der Notwendigkeit ihrer Internalisierung ausgeht. 
Hans-Georg Napp - 978-3-631-75263-0

Downloaded from PubFactory at 01/11/2019 06:33:05AM

via free access 


\section{6. Ökonomische Problembereiche und organisatorisch-institutionelle Aspekte einer finanziell autonomen gemeindlichen Ebene}

In den vorstehenden Kapiteln wurden die Vorteile eines dezentralen öffentlichen Gemeinwesens in bezug auf die Möglichkeiten einer Präferenzerkundung (von Präferenzoffenbarung zu sprechen, wäre wohl etwas gewagt) für lokale öffentliche Güter verdeutlicht. Autonome gebietskörperschaftliche Ebenen erlaubten - so argumentiert beispielsweise Tiebout (1956) - eine effizientere Befriedigung unterschiedlicher Bedürfnisse der Konsumenten nach öffentlichen Leistungen. Dabei kommt speziell den lokalen bzw. regionalen Räumen ein Schwergewicht im Rahmen der Allokation öffentlicher Leistungen zu, denn auf dieser Ebene funktioniert der "voting by feet"-Mechanismus am effektivsten und ermöglicht - so die modelltheoretische Grundhypothese - für einen Teilbereich des öffentlichen Leistungsangebots (nämlich die lokalen Güter und Dienste) den wahren Präferenzen der Bürger näher zu kommen. Es wurde daher aufbauend auf dem Allokationsmechanismus "Migration" der Versuch unternommen, Modellstrukturen zu entwickeln, die die Funktionsweise der "public choice trough mobility" aufzeigen sollten.

Doch so faszinierend sich diese Modellstruktur auch darstellt, für die Entwicklung bzw. Ableitung eines auch unter politisch-pragmatischen Gesichtspunkten brauchbaren "effizienzfördernden" Gemeindefinanzsystems müssen auch bisher unberücksichtigt gebliebene Faktoren Eingang in die Untersuchung finden. So kann es zwischen den einzelnen Gebietskörperschaften einer Ebene Kosten- und/oder Nutzenexternalitäten geben (räumliche "spillovers"), die Produktion bestimmter öffentlicher Leistungen kann mit "economies of scale" verbunden sein oder die administrative Gliederung des Staatsapparates selbst verursacht bestimmte Informations- und Kontrollkosten, die ihrerseits wieder entsprechende Allokationsentscheide und ihre Ergebnisse tangieren.

\subsection{Räumliche externe Effekte}

6.1.1 Das Konzept der externen Effekte und seine Ausweitung auf zwischenstaatliche Beziehungen

Einer der wichtigsten Gründe dafür, daß der Markt allein und damit das Preissystem nicht ausreicht, um eine optimale Allokation der Ressourcen zu sichern, liegt bekanntlich in der Interdependenz von Produktions- und Nutzenfunktionen einzelner Unternehmen und Individuen sowie in der Unmöglichkeit, die Auswirkungen dieser Interdependenzen in die individuellen Wirtschaftlichkeitsrechnungen einzubeziehen. Wo aber 
der Preis seine Aufgaben - für Erträge eine Zahlung und für Kosten eine Kompensation zu erzwingen - nicht erfüllen kann, gibt der Markt dem Individuum keine Informationen und folglich keine Anreize, die Auswirkungen der eigenen Tätigkeit auf das "Wohlergehen" anderer in seinen Entscheidungen zu berücksichtigen. Bleiben aber Nutzen- und Kostenströme unbewertet, sind die Marginalbedingungen für ein Wohlfahrtsoptimum verletzt. Keine "Unsichtbare Hand" führt dann vom dezentralen Maximierungskalkül zu einem optimalen harmonischen Ganzen. ${ }^{107}$ Das durch unbewertete Interdependenzen verursachte Auseinanderfallen von einzel- und gesamtwirtschaftlichen Kosten und Erträgen trägt vielfältige Namen: volkswirtschaftliche Kosten und Gewinne, soziale Kosten, externe Effekte, unkompensierte Effekte, Externalitäten, Kopplungswirkungen, Interdependenzeffekte, "neighbourhood effects" und "spillovers" sind davon die gängigsten (vgl. Pawlowsky, 1972, 3 sowie Sälter, 1989, 3). In der Folge soll von "externen Effekten" und in derem speziellen räumlichen Sinn von "spillovers" die Rede sein.

\subsubsection{Begriff und Wesen räumlicher externer Effekte}

Die Bürger verschiedener Gemeinwesen beeinflussen sich vielfach gegenseitig durch Konsum und Produktion öffentlicher wie privater Güter. Ihre Produktions- und Nutzenfunktionen sind also interdependent. ${ }^{108}$ Diese Verflechtungen gehen häufig nicht in die individuellen oder kollektiven Allokationsentscheide ein und führen so zu einer Verletzung der Marginalbedingungen für ein Wohlfahrtsoptimum, weil Nutzen- bzw. Kostenströme unberücksichtigt bleiben. Wie in der Wirtschaftstheorie generell externe Kosten und externe Erträge unterschieden werden, unterscheidet man auch im räumlichen Sinn Kosten- und Ertrags-spillovers (auch Nutzen-spillovers). ${ }^{109}$

Um das Wesen dieser räumlichen Externalitäten erfassen zu können, geht man in der Regel davon aus, daß jedes Kollektiv (Gebietskörperschaft) als einheitlicher Entschei-

107 Stellvertretend für eine Vielzahl entsprechender Beitrăge seien genannt: Pigou (1962), Samuelson (1954; 1955; 1958), Meade (1952), Scitovski (1954), Turvey (1963), Coase (1960), Buchanan/Stubblebine (1962) sowie zusammenfassend Krüger (1975) und Endres (1976). Eine kritische Würdigung der externen Effekte liefert Sälter (1989). Die Bedeutung der externen Effekte und ihre wissenschaftliche Behandlung hat dabei mit fortschreitender wirtschaftlicher Entwicklung zugenommen; von der Verunreinigung der Umwelt durch Industrie und Haushalte bis zur Nutzendiffusion von Ausbildung und Forschung lassen sich Beispiele dafür anführen.

108 Theoretische und empirische Arbeiten zeigen, daß räumliche externe Effekte - auch als "regionale Überlappungen" (Wust, 1981, 74) bezeichnet - durchaus bedeutend sind. Vgl. dazu beispielsweise McLure (1967; 1969), Hirsch (1964), Pauly (1970a), Jeanrenaud (1975) sowie Tetsch (1978).

109 Diese können wiederum - je nach Standort des Betrachters - nach "spillins" (beim Empfänger) und "spillouts" (beim Verursacher) unterschieden werden. Vgl. dazu Pawlowsky $(1972,21)$. 
dungsträger handelt, dessen Ziel es ist, einen möglichst hohen Nutzen aus dem Angebot an öffentlichen Gütern und Leistungen zu ziehen. Dabei wird aus Sicht der einzelnen nachgeordneten Körperschaft auf die Belange des Gesamtstaates keinerlei Rücksicht genommen. Dabei ist es gleichgültig, ob die Kategorien der individuellen Wahlhandlungs- oder Nutzentheorie verwendet werden, indem man die Gebietskörperschaft als "Quasi-Konsument" oder "Quasi-Produzent" betrachtet, oder aber auf gesellschaftliche Indifferenzkurven (Wohlfahrtsfunktionen) zurückgegriffen wird, wobei dann allerdings deren Schwächen in bezug auf Validität und Praktikabilität in Kauf zu nehmen sind (vgl. Breton, 1970; Oates, 1972, 105 sowie Pawlowsky, 1972, 21). Um grundlegende Wirkungen räumlicher externer Effekte zu erkennen, genügt diese vereinfachte Sicht (vgl. Wust, 1981, 73ff).

Abbildung 6.1: Bereitstellung lokaler öffentlicher Güter und räumliche spillovers

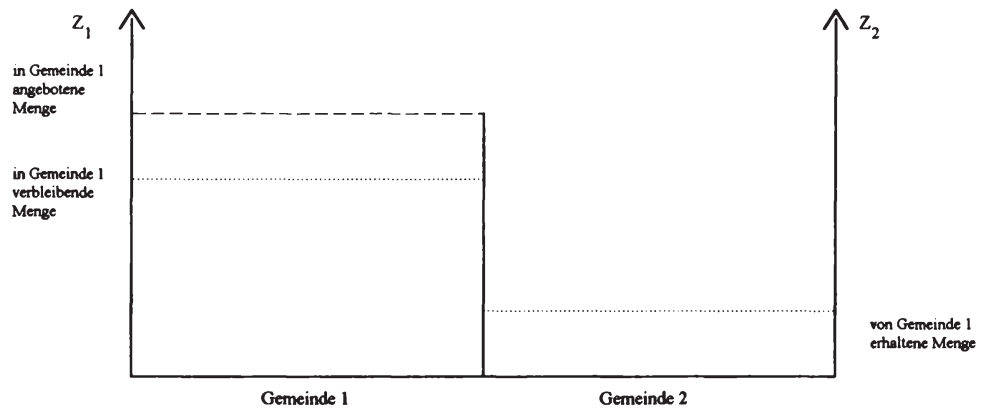

Verursacht die lokal autonome Bereitstellung einer öffentlichen Leistung externe Nutzeffekte für eine Nachbargemeinde, hängt deren Höhe natürlich von der produzierten Menge des betreffenden Gutes ab. Abbildung 6.1 zeigt zwei benachbarte Kommunen $G_{1}$ und $G_{2}$. Die Gemeinde $G_{1}$ gibt einen bestimmten Anteil des von ihr bereitgestellten lokalen öffentlichen Gutes als externen Nutzen an die zweite Gemeinde ab. Je nach dem interkollektiven Grad an Offentlichkeit des Gutes ${ }^{110}$ wird $G_{1}$ einen unterschiedlich hohen Anteil der von ihr bereitgestellten Leistung verlieren. Ist das Gut zwischen den beiden Gemeinden völlig privat (das ist der in der Abbildung 6.1 skizzierte Fall), verliert $G_{1}$ alle von ihr erzeugten "spillover-Einheiten" (vgl. Pauly, 1970a, 573f).

110 Eine gelungene Übersicht dazu liefert Pauly (1970a, 573ff). Er unterscheidet aus der Sicht des einzelnen Kollektivs vier Falle: - ein Gut ist vollig privat sowohl innerhalb als auch zwischen den Gliedstaaten; - ein Gut ist vollig offentlich in beiderlei Hinsicht (dies ist der Fall des "reinen" offentlichen Gutes, und zwar sowohl in intra- als auch interkollektiver Sicht); - ein Gut ist vollig offentlich innerhalb, aber völlig privat zwischen den Gliedstaaten; - ein Gut ist nicht völlig offentlich innerhalb, aber völlig privat zwischen den Gliedstaaten. 
Ist das betreffende Gut jedoch zwischen den beiden Gemeinwesen im Samuelson'schen Sinne $(1954 ; 1955)$ völlig öffentlicher Natur, bleibt eine Überlappung ohne nutzenmindernde Wirkung auf die "Bereitstellungsgemeinde" (gemeinsame Konsummöglichkeit durch $G_{1}$ und $G_{2}$, da der Konsum nicht rivalisiert). In Abbildung 6.1 wäre dann die in $G_{1}$ verbleibende Menge identisch mit dem dort angebotenem Niveau (vgl. Pauly, 1970a, 574ff).

Der Großteil der lokalen öffentlichen Leistungen steht indes selbst innerhalb der sie anbietenden Gemeinde nicht jedermann gleichermaßen und in gleichem Umfang und gleicher Qualität zur Verfügung. Die weiter oben bereits herausgearbeiteten Charakteristika lokaler öffentlicher Güter, die ihren Ursprung in der begrenzten Nutzenreichweite und den damit verbundenen Kapazitätseffekten in Form des "crowding" oder "congestion" haben, führen daher dazu, daß mit zunehmender Distanz zum Entstehungsort die externen Effekte einer Leistung immer geringer werden. Im Idealfall reichen sie bis zur Grenze der Erzeugergruppe, bleiben also intrakollektiv und werden damit nicht zu räumlichen Nutzen-spillovers (vgl. Wust, 1981, 77).

\subsubsection{Ursachen räumlicher externer Effekte}

Bei der Erstellung öffentlicher Leistungen entstehen durch den Einsatz von Ressourcen Kosten, die im Regelfall als "interne" Kosten die Bürger der Gebietskörperschaft belasten, welche die betreffende öffentliche Leistung anbietet. Entfallen nun jedoch auch auf Individuen außerhalb des angesprochenen Gemeinwesens Kostenanteile, zu deren Übernahme sich diese nicht freiwillig entschieden haben, wird von sogenannten räumlichen externen Kosten (spillovers) gesprochen. Hirsch/Marcus (1969) nennen zwei Gründe dafür, daß ein Teil der Kosten der öffentlichen Leistungserstellung einer Gebietskörperschaft andere Gemeinwesen belastet, zum einen eine "fiskalische Interdependenz" (vgl. auch Pawlowsky, 1972, 25), die durch die Steuererhebung und Ausgabentätigkeit einer übergeordneten Gebietskörperschaft entsteht, und zum anderen ökonomische Wechselwirkungen über den Markt, welche die Steuerlast über die Grenzen des Gemeinwesens hinausträgt. Eine solche räumliche Kostenüberwälzung kann sich auf das Einkommen und Vermögen (Besteuerung der Einkommensentstehung) oder auf den Konsum (Besteuerung der Einkommensverwendung) beziehen. ${ }^{111}$

Spillovers aufgrund fiskalischer Interdependenzen liegen dann vor, wenn eine übergeordnete Gebietskörperschaft beispielsweise eine Einkommensteuer oder eine Umsatz-

111 Methodologische Vorarbeiten für die Quantifizierung der Steuerbelastungen der einzelnen Gemeinwesen liefern Hirsch/Segelhorst/Marcus (1964). 
steuer in der untergeordneten Gebietskörperschaft $G_{1}$ erhebt, deren Erträge aber so verwendet, daß sie auch $G_{2}$ einen Nutzen stiften. $G_{1}$ erleidet bei diesem Vorgehen einen "Kosten-spillin"; $G_{2}$ einen "Kosten-spillout". Spillovers können sich auch infolge von Überwälzungen durch den Marktprozeß ergeben, wenn beispielsweise Gebietskörperschaft $G_{1}$ in ihrem Gebiet eine Umsatzsteuer auf die Waren der dort niedergelassenen Produzenten erhebt und diese Waren aufgrund des interregionalen Handels auch von Einwohnern aus $G_{2}$ konsumiert werden. Damit wird ein Teil der Abgabe dort getragen. Wie hoch dieser Anteil tatsächlich ist, hängt vom Grad des interregionalen Handels, der Beschaffenheit der Märkte und dem Warenkorb - den die Einwohner der Gebietskörperschaft $\mathrm{G}_{2}$ nachfragen - ab. Spillovers aufgrund ökonomischer Wechselwirkung können auch entstehen, wenn in $G_{2}$ angelegte Realwerte (wie etwa Grundstücke, Häuser u.a.) sich im Eigentum von Einwohnern aus $G_{1}$ befinden und in $G_{2}$ eine Besteuerung dieser Vermögenswerte erfolgt, deren Erträge zur Finanzierung des öffentlichen Leistungsangebots in diesem Gemeinwesen benutzt werden. Dadurch sinkt bei gleichbleibendem Leistungsangebot die Steuerlast der Bürger in $G_{2}$, weil Einwohner aus $G_{1}$ über spillovers einen Teil der Kosten mittragen (vgl. Pawlowsky, 1972, 27). Kosten-spillovers können natürlich in beide Richtungen wirken. Die relative Größe solcher spillover-Ströme ist folglich von der Vermögensverflechtung beider Gemeinwesen und ihrer "interregionalen Zahlungsbilanz" abhängig.

"Ertrags-spillovers" haben ähnliche Ursachen wie Kosten-spillovers. So können für die Erträge aus Infrastrukturinvestitionen (die einen Zuwachs des Realeinkommens einer Volkswirtschaft, sei es in der Form von zusätzlichen Ressourcen, sei es in einer direkt dem Individuum zukommenden Wohlstandsmehrung, bilden) auf verschiedenen Wegen die Grenzen von Gebietskörperschaften überschritten werden. Wie bei den Kosten sind es fiskalische Interdependenzen und ökonomische Wechselwirkungen, die dafür verantwortlich zeichnen. ${ }^{112}$ Eine weitere Ursache der Ertrags-spillovers ist die räumliche Mobilität der Individuen, entweder in Form interregionaler Wanderungen oder in Form kurzfristiger Pendlerbewegungen.

Einer der bedeutendsten Faktoren in diesem Zusammenhang ist die Mobilität von Personen über die Hoheitsgrenzen einzelner Gebietskörperschaften hinweg. Wechselwirkungen zwischen Gemeinwesen treten demzufolge auf, wenn beispielsweise Bürger aus der Gebietskörperschaft, die ihre Ausbildung finanziert hat, abwandern. Besondere Erträge, die über einen längeren Zeitraum infolge der Investitionen entstehen und selbst Investitionscharakter aufweisen (was typisch für das Bildungssystem ist), wer-

112 Eine ausführliche Darstellung möglicher Ertrags-spillovers und ihrer Ursachen liefert Pawlowsky (1972, 32f). An dieser Stelle soll daher der Hinweis auf die Argumentation in Zusammenhang mit den Kostenspillovers genügen, da für die Ertrags-spillovers analog vorgegangen werden kann. 
den durch Migration in andere Gebietskörperschaften getragen. Das "mitgenommene" Humankapital kommt somit dem neuen Niederlassungsgebiet zugute (vgl. auch Musgrave/Musgrave, 1984, 509). Dieser als "brain drain" bezeichnete Vorgang wurde recht früh erkannt und als negativ empfunden, so daß gerade am Beispiel des öffentlichen Bildungssystem theoretische Überlegungen über die optimale Versorgung mit diesem Gut angestellt worden sind (vgl. Hirsch/Segelhorst/Marcus, 1964; Weisbrod, 1964; 1965; Hirsch/Marcus, 1969).

Interregionale Überlappungen entstehen aber nicht nur dann, wenn Individuen ihren Wohnsitz in eine andere Gemeinde verlegen. So nehmen auch Pendler vom Wohnort zum Arbeitsplatz oder vom Wohnort zum Einkaufs- und Dienstleistungszentrum Infrastrukturleistungen in Anspruch, ohne dafür (direkt oder mittelbar) zu "zahlen". Das ist immer dann der Fall, wenn für einen Bürger Wohnsitz, Arbeitsplatz und Einkaufszentrum auf verschiedene Gemeinden verteilt sind, er aber nur an seinem Wohnsitz mit lokalen Abgaben belastet wird. Dabei wird durchaus kontrovers diskutiert, ob letztlich die Wohngemeinden oder die innerstädtischen Ballungsgebiete die Kosten dieser Entwicklung ("Balkanisierung") tragen, weil sich durchaus wechselseitige Nutzen- und Kostenströme ableiten lassen. ${ }^{113}$ Fundierte empirische Arbeiten stehen in diesem $\mathrm{Zu}$ sammenhang noch aus.

\subsubsection{Räumliche Externalitäten und gesamtwirtschaftliche Allokation}

Nach der Erörterung möglicher Ursachen für räumliche spillovers soll nunmehr das Augenmerk auf den Einfluß der Externalitäten auf die gesamtstaatliche Versorgung mit öffentlichen Gütern gerichtet werden. In der wirtschaftstheoretischen Literatur besteht dahingehend Einigkeit, daß spillovers zwischen Gemeinwesen infolge der Nichtberücksichtigung einzelner Nutzen- und/oder Kostenströme zu einer Abweichung vom gesellschaftlichen Optimum und damit der effizienten Ressourcenverwendung führen. Strittig ist aber die Frage, in welcher Richtung man sich vom Idealzustand entfernt, d.h. ob das öffentliche Leistungsangebot letztlich zu hoch oder zu niedrig ausfällt.

Ein Grund für diese unterschiedlichen Auffassungen ${ }^{114}$ liegt neben den divergierenden Annahmen hinsichtlich des Öffentlichkeitsgrades der Güter (vgl. Pauly, 1970a) vor allem in der Schwierigkeit, den gesellschaftlich optimalen Zustand zu definieren. Seine

\footnotetext{
113 Näheres dazu bei Rothenberg (1970), Pawlowsky (1972), Sheshinski (1973) sowie Fisch (1975).

114 Stellvertretend für alternative Sichtweisen sei die Kontroverse zwischen Williams (1966; 1967) und Brainard/Dolbear (1967) genannt.
} 
Kenntnis ist aber notwendig, da nur dann normative Aussagen (wie "zuwenig" oder "zuviel") möglich werden.

Die "Pionieransätze" im Rahmen der theoretischen Behandlung räumlicher spillovers gehen in ihrem Ursprung auf die Bildungsökonomik zurück. Diese Betrachtungen stellten erste Schritte dar, das Konzept der Externalitäten auch auf den zwischenstaatlichen Bereich zu übertragen und am Beispiel des Bildungssystems die durch Migration möglichen Nutzen- oder Ertrags-spillovers zu analysieren. Im Vordergrund standen und stehen dabei die Allokationswirkungen und der Versuch, eine Antwort auf die Frage zu geben, ob die Existenz räumlicher spillovers zu einem zu hohen oder einem zu niedrigen öffentlichen Leistungsangebot führt.

Weisbrod $(1964$; 1965) kommt zu dem Ergebnis, daß spillovers immer zu einem gesamtwirtschaftlich zu niedrigen Angebot führen (vgl. auch Break, 1967), da eine Gebietskörperschaft den durch ihre Produktion verursachten Nutzen für die anderen Regionen bei ihrer Produktionsentscheidung nicht berücksichtigt. Daraus folgert Weisbrod die eindeutige Tendenz zu einer Unterversorgung mit spillovers verursachenden Gütern und Leistungen. Diese Tendenz, so Williams (1966, 19ff), wird noch verstärkt, wenn die profitierenden Gebietskörperschaften (entgegen Weisbrods Annahme) die zu erwartenden spillins in ihre Produktionspläne einbeziehen.

In Anlehnung an Williams (1966, 19ff) soll folgende Situation betrachtet werden. Angenommen wird die Existenz zweier Güter, nämlich eines privaten Gutes und eines lokalen öffentlichen Gutes. Betrachtet werden zwei Gemeinden. Die Gemeinde I ist bei der Bereitstellung des lokalen öffentlichen Gutes auf ihre eigene Produktion und die Nutzung der vorhandenen Ressourcen angewiesen. Dabei ist die Verwendung von Ressourcen für die Produktion eines der beiden Güter immer mit Opportunitätskosten in Form des Verzichts dieser Ressourcen für die Produktion des anderen Gutes verbunden. Die Produktionsmöglichkeiten werden daher durch die Transformationskurve vorgegeben. Die Linie $\mathrm{AA}^{\prime}$ stellt diese eigenen Produktions-115 und daraus folgend Konsummöglichkeiten dar (die bei der eigenen Produktion entstehenden spillouts sind bereits abgezogen), die Kurven BB', CC', DD' und EE' geben die Konsummöglichkeiten an, sofern ein räumlicher externer Nutzen von der Gemeinde II erwartet wird. Ist die Gemeinde I also von einem solchen räumlichen externen Effekt betroffen (Ertragsspillin), verfügt sie infolgedessen beispielsweise in Höhe von $\mathrm{Q}_{a} \mathrm{C}_{\mathrm{a}}{ }^{\prime}$ über zusätzliche Einheiten des öffentlichen Gutes. Dadurch verschiebt sich die Kurve AA' parallel nach BB'. Diese zeigt nun die aktuellen Konsummöglichkeiten an, wobei unter Nutzenma-

115 Unterstellt wird eine konstante Grenzrate der Transformation, d.h. eine lineare Transformationskurve (Williams, 1966, 20). 
ximierungsgesichtspunkten der Punkt b gewählt wird. ${ }^{116}$ Es stehen jetzt $0 C_{b}^{A}$ Einheiten des öffentlichen Gutes für den Konsum zur Verfügung (bei $\mathrm{X}_{\mathrm{b}}$ Einheiten des privaten Gutes); davon wird aber nur $0 Q_{b}$ selbst produziert (gemäß der internen Transformationskurve AA'). Die Menge $Q_{b} C_{b}^{A}$ wird als direkter Ertrags- oder Nutzen-spillin empfangen; daneben gibt es noch einen indirekten Nutzen-spillin (eine Art "excess benefit") in Form der bedingt durch den Substitutionseffekt größeren Konsummenge $\left(\mathbf{x}_{\mathrm{b}}-\mathbf{x}_{\mathbf{a}}\right)$ des privaten Gutes. Wenn diese Überlegungen bezüglich unterschiedlicher Größenordnungen des räumlichen externen Effektes analog durchgeführt werden, erhält man schließlich einen sogenannten "Konsumreaktionspfad"117.

Abbildung 6.2: Produktions- und Konsummöglichkeiten bei Existenz räumlicher spillovers

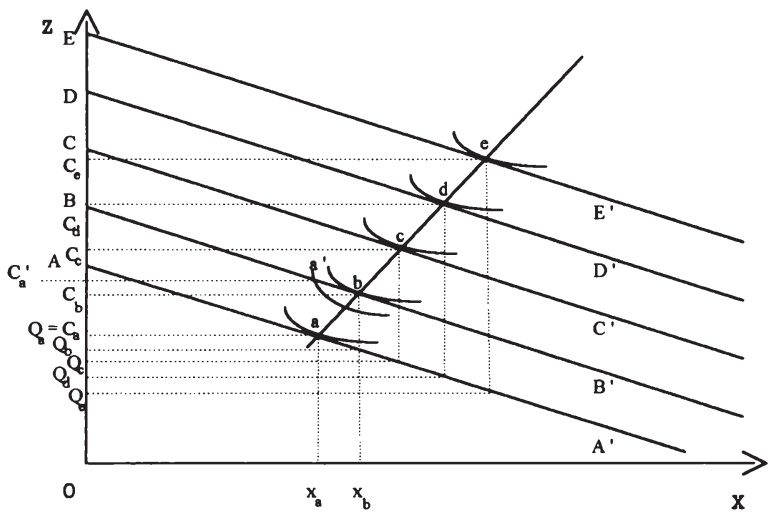

Interne Produktion $\left(\mathrm{Q}_{\mathrm{I}}\right)$ und eigener Konsum $\left(\mathrm{C}_{\mathrm{I}}\right)$ des lokalen öffentlichen Gutes hängen also von der Höhe des empfangenen externen Effekts - und damit von der Produktion in Gemeinde II $\left(\mathrm{Q}_{\mathrm{II}}\right)$ - ab (vgl. Wust, 1981, 87f). In Abbildung 6.3 wird dieser $\mathrm{Zu}$ sammenhang verdeutlicht: Wenn die Produktion in Gemeinde II zunimmt und damit der Bereitstellungsumfang der mit räumlichen externen Effekten verbundenen öffentli-

116 Unter Nutzenerwăgungen resultiert nicht der Punkt a', da dieser als Nichttangentiallösung mit einem niedrigeren Nutzenniveau für die Gemeinde I verbunden wăre. Im Punkt a' ist die Bedingung nicht erfüllt, daß die Grenzrate der Substitution im Konsum zwischen privatem und lokalem offentlichen Gut der Grenzrate der Transformation entspricht. Aufgrund dessen kommt es zu Anpassungsprozessen, d.h. infolge des erwarteten Ertrags-spillins produziert Gemeinde I weniger vom lokalen offentlichen Gut $\left(Q_{b}\right)$ und mehr vom privaten Gut $\left(\mathrm{X}_{\mathrm{b}}\right)$. Im Punkt $\mathrm{b}$ ist schließlich das Nutzenmaximum realisiert, dort entspricht die Grenzrate der Substitution der Grenzrate der Transformation.

${ }^{117}$ Dieser Konsumreaktionspfad ist der geometrische Ort aller Punkte, für die die Grenzrate der Substitution zwischen offentlichem und privatem Gut bei unterschiedlich großen "spillin-Effekten" jeweils gleich der als konstant unterstellten Grenzrate der Transformation ist (vgl. Williams, 1966, 21). 
chen Leistung, wird die eigene Produktion $\left(Q_{I}\right)$ immer weiter eingeschränkt, während gleichzeitig der interne Konsum $\left(\mathrm{C}_{\mathrm{l}}\right)$ der öffentlichen Leistung ansteigt (vgl. Williams, 1966, 21).

Abbildung 6.3: Reaktionskurven für Produktion und Konsum

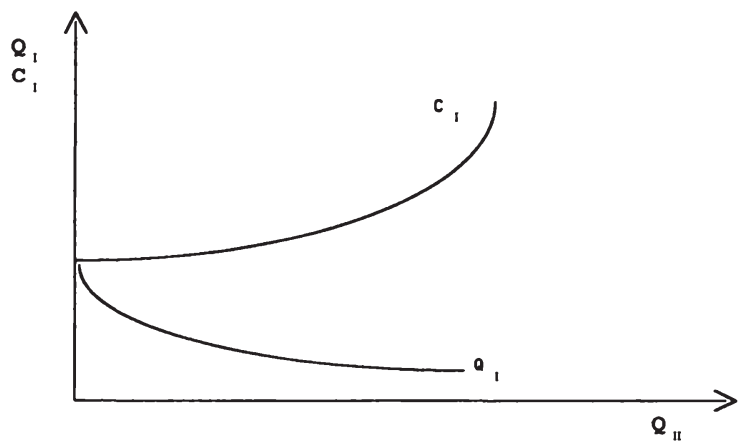

In der Regel ist zu erwarten, daß die Gemeinde II analog kalkuliert und auch diese mit erwarteten Ertrags-spillins einer öffentlichen Leistung rechnet. Infolgedessen kann man die vier Reaktionskurven (Konsumtions- und Produktionspfade) in einer Graphik (s. Abbildung 6.4) zusammenfügen. Über die zu erwartende Angebotshöhe des lokalen öffentlichen Gutes läßt sich folgendes festhalten: Im Punkt Q sind die Erwartungen beider Gemeinden über das Produktions- und damit Bereitstellungsniveau der jeweils anderen Kommune erfüllt. Gemeinde I produziert die Menge $0 Q_{I}^{*}$ und konsumiert $O C_{l}^{*}$, erhält also einen Ertrags-spillin in Höhe von $Q_{l}^{*} C_{I}^{*}$. Gemeinde II konsumiert $0 C_{I I}^{*}$ - wovon $Q_{I I}^{*} C_{I I}^{*}$ als externer Effekt aus dem Angebot von Gemeinde I stammt - und produziert selbst $0 Q_{I I}^{*}$ (vgl. Williams, 1966, 21f).

Werden diese Ergebnisse mit den Überlegungen von Weisbrod $(1964 ; 1965)$ verglichen, zeigt sich, daß die Unterversorgung im gerade skizzierten Fall größer ist; denn unter Weisbrods Annahmen würden die Gemeinden die Punkte $Q_{l}^{0}$ beziehungsweise $Q_{I I}^{0}$ realisieren (vgl. auch Ramser, 1968, 486).

Hinsichtlich der Allokationswirkungen bei Existenz räumlicher spillovers bleibt als Fazit festzuhalten, daß es zu Verzerrungen der Produktions- und Konsumentscheidungen und damit zu Wohlfahrtseinbußen kommt, da eine dezentrale Entscheidungsfindung zu einer Unterversorgung der Volkswirtschaft mit den entsprechenden öffentli- 
chen Leistungen führt. ${ }^{118}$ Eine wohlfahrtsmaximale Lösung ist also bei lokal unabhängiger Nutzenmaximierung zunächst nicht erreichbar. Nur eine Internalisierung der räumlichen Externalitäten kann dieses Problem lösen.

Abbildung 6.4: Wechselseitige räumliche spillovers, Reaktionskurven und die Allokationsentscheidung

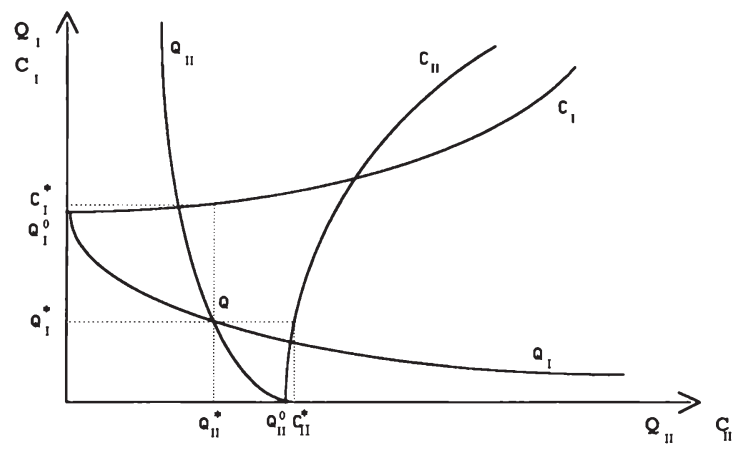

\subsubsection{Konzepte zur Internalisierung räumlicher externer Effekte}

Die Existenz von spillover-Effekten führt zu Wohlfahrtsverlusten - so das Fazit der vorstehenden Ausführungen. Ziel muß es im Sinne der Steigerung der Gesamtwohlfahrt demnach sein, diese Effekte in die Entscheidungen der selbständigen Gemeinwesen in einem föderalen Staatsaufbau einzubeziehen. Grundsätzlich sind in diesem Zu-

118 Williams $(1966,23)$ erklärt aber auch, wie es zu einer Überversorgung mit öffentlichen Leistungen kommen kann. Dazu definiert er ein "Optimum des status quo", in dem die beiden Gemeinwesen an den von ihnen produzierten spillovers Eigentumsrechte besitzen, und für deren Nutzung sie von den Empfängern eine Kompensation erhalten. Auf diesen speziellen Fall soll an dieser Stelle jedoch nicht weiter eingegangen werden (vgl. dazu Pawlowsky, 1972, 50ff). Daneben hat es eine Reihe von Versuchen gegeben, das Problem der Richtung der (aus der Existenz von răumlichen spillovers bedingten) Fehlallokation zu spezifizieren. In diesem Zusammenhang sind vor allem Buchanan/Kafoglis (1963), Oates (1972, 95 ff), Pauly (1970a) sowie Wust $(1981,90 \mathrm{ff})$ zu nennen. So hat Pauly $(1970 \mathrm{a}, 575)$ zur Beantwortung der Frage, ob bei autonomer lokaler Nutzenmaximierung zuviel oder zuwenig vom öffentlichen Gut bereitgestellt wird, einen entsprechenden Versuch unternommen, der zum Ergebnis führte, daß im vorgegebenen Modellrahmen externe Nutzen zu einer Unterversorgung mit dem offentlichen Gut führen (handelt es sich nicht um externe Nutzen, sondern um überwälzte Lasten - also Kosten-spillovers -, führen die gleichen Überlegungen selbstverständlich zu einer Überversorgung mit der öffentlichen Leistung). Dieses Ergebnis steht Resultaten gegenüber, die beispielsweise Buchanan/Kafoglis (1963) prăsentieren. Sie stellen fest, daß unter bestimmten Bedingungen bei autonomer Nutzenmaximierung zuviel vom öffentlichen Gut produziert werde. Diese gegensätzlichen Resultate beruhen nicht nur auf unterschiedlichen Annahmen, sondern sind erster Linie verursacht durch die unterschiedlichen Fähigkeiten der Gemeinden oder Regionen, externe Effekte zu erzeugen. Es muß eben keine einfache proportionale Beziehung zwischen produzierter und konsumierter Menge - wie vielfach vereinfachend angenommen - bestehen (vgl. auch Oates, 1972,96) 
sammenhang vier Wege gangbar, die sich jeweils nach dem Grad der Dezentralisation unterscheiden. ${ }^{119}$

Damit stellt sich auch bei der Beantwortung der Frage nach der Internalisierung räumlicher externer Effekte die Frage nach der praktischen Ausgestaltung eines föderativen Staatsaufbaus und damit der Rolle der kommunalen Autonomie und ihrer Effizienzwirkungen.

\subsubsection{Die Gebühr: Ein einfaches Mittel gegen überregionale "Trittbrettfahrer"?}

Die scheinbar einfachste und noch dazu sehr wirksame Alternative einer Internalisierung räumlicher externer Effekte liegt in der Entrichtung einer Gebühr. Dies bedeutet, daß ein Konsum externer Nutzen nur gegen die Zahlung einer solchen Gebühr möglich wäre. Während allgemeine Steuern nur die Bürger des Gemeinwesens, das die Leistung anbietet, belasten, hat das direkte Entgelt den Vorteil, jeden, der das Gut nutzt (unabhängig vom jeweiligen Ort, an dem er selbst steuerpflichtig ist), an der Finanzierung zu beteiligen.

Eine solche Vorgehensweise ist jedoch nur dann möglich, wenn es gelingt, einzelne vom Konsum lokaler öffentlicher Güter auszuschließen, sofern sie nicht bereit sind, den jeweiligen "Preis" zu entrichten. Münch (1976, 232ff) hat nachgewiesen, daß für viele lokale öffentliche Leistungen, die heute aus allgemeinen Steuermitteln finanziert werden, der Ausschluß vom Konsum unter vertretbaren Kosten durchsetzbar wäre. Weiterhin stellt er fest, daß diese angesprochenen Güter und Dienste sehr häufig gerade die Leistungen sind, die auf lokaler Ebene einen großen Teil der räumlichen spillovers verursachen. "Parasitäres Mitkonsumieren" erstreckt sich nämlich in der Regel auf Einrichtungen, die beispielsweise von einer großen Gemeinde kostenlos abgegeben und auch von den Bürgern der umliegenden Orte mitgenutzt werden.

Die infolge räumlicher Nutzen-spillovers vorhandene Trennung von Nutzern und Zahlem lokaler öffentlicher Leistungen verstärkt also negative Auswirkungen und Fehlallokationen. $\mathrm{Ob}$ es mit Hilfe der Entgeltfinanzierung letztlich gelingt, "Außennutzen" vollständig zu internalisieren, hängt freilich davon $a b$, in welcher Höhe die Gebühr die Kosten des Angebots decken kann. Doch selbst dann, wenn das direkte Entgelt in Form der Gebühr nur den Charakter eines Zuschusses besitzt, hilft es, die Probleme

\footnotetext{
119 Bei der sich anschließenden Behandlung der vier Mőglichkeiten einer Internalisierung rảumlicher Externalităten sind die möglichen Alternativen nach dem abnehmenden Grad kommunaler Eigenständigkeit geordnet.
} 
aus der räumlich abweichenden "Verteilung" von Nutzern und Zahlern zu entschärfen; also zumindest einen Teil der räumlichen externen Effekte zu internalisieren. Im Falle der Steuerfinanzierung werden aus der Sicht des einzelnen die externen Nutzen gleichsam zum "Nulltarif" angeboten, was ihren "verschwenderischen" Konsum geradezu provoziert. Erst wenn der Bürger für seine Inanspruchnahme öffentlicher Einrichtungen ersichtlich eine Gegenleistung zu entrichten hat, wird er sie nicht im Übermaß nutzen. Diese Tatsache wird um so bedeutender, je mehr lokale öffentliche Güter sich ihrer Kapazitätsgrenze (ihrem begrenzten räumlichen Wirkungskreis) nähern und je rascher folglich die gesellschaftlichen Kosten der Ballung zunehmen.

Die Finanzierung lokaler öffentlicher Leistungen mit Hilfe von Gebühren ist jedoch in der Regel nur begrenzt möglich (vgl. auch Kapitel 8). Die Gebührenlösung wird auch dann ungeeignet sein, wenn ein Gemeinwesen externe Lasten (Kosten) auf seine Nachbargemeinden abwälzt. Deren Internalisierung ist auf dezentralem Wege nur dann möglich, wenn die lokalen bzw. regionalen Gruppen miteinander verhandeln und sich auf kompensierende Zahlungen einigen. Diesem Aspekt wird im nächsten Abschnitt, der die Möglichkeiten und Grenzen horizontaler Absprachen aufzeigen soll, Beachtung geschenkt (vgl. Wust, 1981, 103ff).

\subsubsection{Freiwillige Verhandlungen der Kommunen untereinander}

Den analytischen Hintergrund für die sogenannte Verhandlungslösung zur Internalisierung externer Effekte liefert Coase (1960). ${ }^{120}$ Sein Ziel war es, einen Nachweis zu führen, daß freiwillige Absprachen "Tauschgewinne" (vgl. King, 1984, 126f) ermöglichen, sofern der ursprüngliche Zustand im paretianischen Sinne sub-optimal ist (vgl. dazu Coase, 1960, 1ff; aber auch Endres, 1976; Jaeger, 1975, Gifford/Stone, 1973 bzw. Aschinger, 1985).

Am Beispiel der externen Effekte in der privaten Produktion leitet Coase ab, daß dezentrale Verhandlungen zu einer optimalen Allokation der Ressourcen führen, wenn

${ }^{120}$ Dabei stellt er im Gegensatz zu den "herkömmlichen" Korrekturmöglichkeiten von Marktversagen (Steueroder Subventionslösungen) eine eher freiwillige Internalisierung über eine Ausweitung der Marktprozesse in den Vordergrund seiner Betrachtungen. Die zugrundeliegenden Arbeiten von Coase entstanden dabei in erster Linie auch aufgrund der Unzufriedenheit mit der Behandlung der externen Effekte in der Wohlfahrtsökonomie Pigou'scher Prägung. Coase hielt die in diesem Kontext resultierenden Lösung - Schadenshaftung des Verursachers, Besteuerung nach dem Verursacherprinzip, Verbot der Aktivităt des Verursachers - für nicht angemessen (vgl. Coase, 1960, lff). 
die Kosten der Verhandlungen vernachlässigt werden können sowie strategisches Verhalten der Beteiligten nicht vorkommt. ${ }^{121}$

Im Rahmen der von Coase vorgestellten Verhandlungslösung hängt das schließlich realisierte Allokationsergebnis nicht von der Form der Ausgestaltung der rechtlichen Grundordnung ab, der die Verhandlungspartner verpflichtet sind (vgl. etwa Demsetz, $1967,347 \mathrm{ff}$ ). Unter allokativen Gesichtspunkten ist es folglich gleichgültig, ob etwa im Falle externer Schäden der Geschädigte vom Schädiger ein Entgelt aufgrund eines rechtlich begründbaren Anspruchs auf Schadenersatz ${ }^{122}$ erhält, oder ob er eine Art Bestechungssumme (ähnlich einer "Schutzgebühr") bezahlt, damit der Schädiger seine schädigende Tätigkeit einstellt oder zumindest reduziert. Mit der unterschiedlichen Ausgestaltung der Rechtsordnung ändert sich zwar die Verteilungssituation, nicht aber die Pareto-Optimalität des Ergebnisses (vgl. Coase, 1960, 8). ${ }^{123}$

Abgesehen von der grundlegenden Frage, ob sich für die jeweiligen Verhandlungspartner überhaupt eine überlegene Strategie ableiten läßt ${ }^{124}$, interessiert im Kontext dieser Studie vor allem die Möglichkeit mittels zwischenstaatlicher Verhandlungen räumliche spillovers zu internalisieren. Die Frage lautet also, wie wahrscheinlich es ist, daß solche Verhandlungen zustande kommen. Jemand wird schließlich nur dann bereitwillig (also freiwillig) verhandeln, wenn der erwartete "Tauschgewinn" seine Kosten der Verhandlungsführung und Konsensfindung übersteigt. Ausschlaggebend für die Höhe der Verhandlungskosten ist zum einen der Grad, bis zu dem man externe Effekte messen kann, und zum anderen die Zahl der am Verhandlungsprozeß Beteiligten. Stehen sich beispielsweise recht viele Verhandlungspartner gegenüber, können die Kosten der Konsensfindung prohibitiv hoch sein. Private (freiwillige) Verhandlungen würden somit kaum zustandekommen. ${ }^{125}$ Je kleiner also die Anzahl der Teilnehmer, desto eher

121 Mumey $(1971,718 \mathrm{ff})$ analysiert eine Situation, in der die angedrohten von den tatsăchlichen Mengenentscheidungen abweichen, mit dem Ziel, eine günstigere Verhandlungsposition zu erreichen.

122 Dies ist die rechtliche Grundlage des "Verursacherprinzips". Für eine allgemeine Übersicht vgl. Bullinger/Rincke/Oberhauser/Schmidt (1974).

123 Eine Entscheidung, welche rechtliche Konstellation vorzuziehen ist, kann daher auch nur aufgrund von Distributionsaspekten - nicht aber aus dem Allokationsziel an sich - abgeleitet werden. Auch der Transaktionskostenansatz (vgl. etwa Calabresi, 1968, 67ff) liefert für die jeweilige Rechtsordnung nicht zwangslăufig operationale Entscheidungskriterien, da zumindest konzeptionell keine unterschiedlichen Informationsund Verhandlungskosten erklärbar sind.

${ }^{124}$ Den spieltheoretischen Hintergrund erörtert ausführlich Krüger (1975, 38ff).

125 Dabei ist es gleichgültig, ob die Zahl der Mitglieder auf der eigenen Seite zu hoch ist, um sich wirksam auf eine gemeinsame Vorgehensweise "einschworren" zu kőnnen (was realiter bedeutsam ist, um als Gruppe glaubhaft und überzeugend zu wirken), oder ob man sich als kleine Gruppe einer hohen Zahl von Verhandlungsgegnern gegenüber sieht, die Forderung also an viele adressieren muß (vgl. Wust, 1981, 108). 
dürften Absprachen über die Internalisierung zustandekommen (vgl. auch Oates, 1972, $68 \mathrm{ff})$.

Überträgt man die vorstehenden Gedanken auf Gruppen (Gemeinwesen), betrachtet man also das Kollektiv analog zum Individuum als nutzenmaximierende Einheit (vgl. auch Abschnitt 4.2), läßt sich auf den ersten Blick die Chance für interkollektive Verhandlungen als recht günstig ansetzen. Die Zahl der Verursacher ist in der Staatswirtschaft recht klein, da genau definierte Kollektive (Kommunen, Länder, Bund) für die Angebotsentscheidungen von öffentlichen Gütern verantwortlich zeichnen. Diese Tatsache ist vor allem für die juristische Zurechenbarkeit der Schadenersatzansprüche von entscheidendem Vorteil. Die Zahl der von den räumlichen spillovers Betroffenen kann indes stark schwanken, mithin auch groß sein, da in der Realität nicht Gruppen als solche, sondern meist einzelne Individuen von externen Effekten berührt werden. Handelt es sich beispielsweise um externe Nutzen beim Konsum, werden nur die betroffenen Bürger an Kompensationszahlungen interessiert sein, um den Verursacher der Außenwirkungen zu einem verstärkten Angebot des Kollektivgutes anzuhalten.

Hier setzt auch die Olson'sche Kritik (1977, 66ff) an der Verhandlungslösung an. Sind die "Interessenten" sehr zahlreich, so seien sie im Prinzip nicht zu einer Gruppe organisierbar. Der Zusammenschluß selbst hätte nämlich den Charakter eines öffentlichen Gutes. Er ließe sich nur dann realisieren, wenn man den einzelnen zwingen könnte, beizutreten, oder wenn man den Mitgliedern einen Anreiz geben könnte, die Organisation zu unterstützen.

Dem läßt sich entgegenhalten, daß mit steigendem Anteil der Betroffenen an der Gesamtzahl der Bevölkerung die Aussichten zunehmen, daß sich die Gemeindevertretung selbst für die Belange der Bürger einsetzt und mit dem Verursacher verhandelt. Fühlen sich andererseits nur wenige betroffen, so verliert der Einwand von Olson an Überzeugungskraft. Sie werden sich dann möglicherweise auch ohne Hilfe ihrer "Regierung" einigen können und dem Verhandlungspartner als eine Art Zweckverband (Bürgerinitiative) mit gemeinsamen Zielen gegenübertreten.

Trotz mancher Schwierigkeiten und Hindernisse erscheint die horizontale Zusammenarbeit aber als ein dem Äquivalenzgedanken adäquates und damit erstrebenswertes Mittel, um lokale bzw. regionale Außenwirkungen zu internalisieren. Da sie sich gut in den Rahmen der lokalen Eigenständigkeit einfügt und kommunale Autonomie nicht über Gebühr antastet, sollte man zuerst ihre Möglichkeiten nutzen, ehe der Ruf nach zentralen Lösungen erfolgt. 


\subsubsection{Vertikale Transfers}

Kommen die angesprochenen horizontalen Verhandlungen nicht zustande oder führen sie nicht zu befriedigenden Ergebnissen bieten Transfers bzw. Zuweisungen der höheren Ebene Möglichkeiten, regionale Verflechtungen mittels finanzieller Anreize oder Sanktionen vertikal zu koordinieren. In der wirtschaftstheoretischen Literatur zu den externen Effekten und zum Marktversagen wird "Pigou's Steuer-Subventions-Lösung"(vgl. Pigou, 1962, 224ff) - besonders im Umweltbereich - oft als "ultima ratio" vorgestellt. Im Kontext dieser Abhandlung interessiert das Pigou'sches Steuer-Subventions-Schema aber vor allem für seine Verwendbarkeit zur Internalisierung räumlicher spillovers im innerstaatlichen Bereich.

Wie weiter oben beschrieben (vgl. auch Samuelson, 1955, 354), wird das (lokale) öffentliche Leistungsangebot dann in einem optimalen Umfang angeboten und bereitgestellt, wenn bei Nichtexistenz externer Effekte die Grenzrate der Transformation $\left(\mathrm{GRT}_{x z}\right)$ zwischen dem lokalen öffentlichen Gut $\mathrm{z}$ und einem privaten Gut $\mathrm{x}$ gleich der Summe der Grenzraten der Substitution (GRS ${ }_{x z}$ ) der Gemeindeeinwohner (m) bezüglich der beiden Güter ist. Es gilt also folgende Optimalitätsbedingung:

$$
G R T_{x z}=\sum_{i=1}^{m} G R S_{x z}
$$

Ist also beispielsweise die Grenzrate der Transformation bei der Produktion der beiden Güter kleiner als die Summe der Grenzraten der Substitution, können Veränderungen in den Produktionsplänen (Mehrproduktion des lokalen öffentlichen Gutes, geringere Produktionsmenge des privaten Gutes) zu einer dann pareto-optimalen Allokation führen. Folglich wird jedes Gemeinwesen versuchen, ein optimales Bereitstellungsniveau des lokalen öffentlichen Gutes zu realisieren, um damit die Wohlfahrt seiner Einwohnerschaft zu maximieren.

Die zu betrachtende Situation zwischen zwei Kommunen sei nun die folgende. Jede Einheit des lokalen öffentlichen Gutes, die in der Kommune A (B) bereitgestellt wird, wirkt mit einem Anteilssatz $\beta(\alpha)$ erhöhend auf die (mögliche) Komsummenge der Einwohner in Gemeinde B (A). Es liegt also ein räumlicher externer Nutzen aus Sicht der Einwohner in B (A) vor. ${ }^{126}$ Demnach muß die Grenzrate der Transformation gleich sein der Summe der Grenzraten der Substitution der eigenen Einwohner, die ihr eige-

${ }^{126}$ Beispielsweise wird eine zusătzliche Bereitstellungseinheit des lokalen offentlichen Gutes "Straßenbeleuchtung" in A für einen Einwohner der Gemeinde A eine Ausdehnung der Konsummenge dieses Gutes um eine Einheit ausmachen, für einen Einwohner der Gemeinde B aber ebenfalls infolge des răumlichen externen Effekts (also des Nutzen-spillovers) eine Konsumausdehnung um einen Anteilssatz B bringen. 
nes Angebot des lokalen öffentlichen Gutes vollständig behalten ${ }^{127}$, plus der Summe der Grenzraten der Substitution der Konsumenten (Gemeindeeinwohner) aus der jeweils anderen Gemeinde, die den Anteil $\beta(\alpha)$ als spillover bekommen. ${ }^{128}$ Daraus folgen als Bedingungen für eine pareto-optimale Allokation:

$$
\begin{aligned}
G R T_{x z}=\sum_{i=1}^{m} G R S_{x(A)}+\beta \sum_{j=1}^{n} G R S_{x(B)} & \text { (für Gemeinde A) } \\
G R T_{x z}=\alpha \sum_{i=1}^{m} G R S_{x z(A)}+\sum_{j=1}^{n} G R S_{x(B)} & \text { (für Gemeinde B) }
\end{aligned}
$$

Dabei sind $\mathrm{m}$ und $\mathrm{n}$ die jeweiligen Einwohnerzahlen der beiden Gemeinden. Ohne räumliche Externalitäten (es würde also gelten: $\alpha=\beta=0$ ) reduziert sich die jeweilige Optimalitätsbedingung für die Gemeinden A und B wieder auf den Ausdruck in Gleichung (6.1).

Wegen der Existenz räumlicher externer Effekte bleibt es bei der verzerrten (sub-optimalen) Angebotsentscheidung bezüglich des lokalen öffentlichen Gutes innerhalb der jeweiligen Gemeinde. Das bedeutet, es wird zuviel vom privaten, aber zu wenig vom lokalen öffentlichen Gut bereitgestellt. Also jedes Gemeinwesen bietet nur die Menge an, bei der die interne Grenzrate der Substitution gleich ist dem Verhältnis der Grenzkosten von privatem und öffentlichem Gut.

$$
\begin{array}{ll}
G R T_{x z}=\sum_{i=1}^{m} G R S_{x z(A)} & \text { (für Gemeinde A) } \\
G R T_{x x}=\sum_{j=1}^{n} G R S_{x z(B)} & \text { (für Gemeinde B) }
\end{array}
$$

Eine Zuweisung (Subvention) je konsumierter Einheit des lokalen öffentlichen Gutes an die "Verursacher-Gruppe" mit dem Ziel der Internalisierung der externen Effekte verbilligt die Herstellung dieses Gutes, es resultieren also (wenn $g_{A}$ und $g_{B}$ die durch Subventionszahlung übernommenen relativen Kostenanteile sind) modifizierte Grenzraten der Transformation $\left(G R T_{x z}\left(1-g_{A}\right)\right.$ und $G R T_{x z}\left(1-g_{B}\right)$ ), so daß gilt (wobei $\mathrm{G}_{\mathrm{A}}$

\footnotetext{
${ }^{127}$ Wust $(1981,111 \mathrm{ff})$ betrachtet den Fall, in dem die einzelnen Gemeinwesen ihre als spillover abgegebene Angebotsmenge der offentlichen Leistung "verlieren". Hier soll jedoch in Analogie zu Oates (1972, 100f) der allgemeine Fall (vor allem auch wegen der besonderen Charakteristika des offentlichen Leistungsangebots) analysiert werden.
}

128 Analoge Ergebnisse findet man bei Pauly (1970a, 579) sowie Oates $(1972,97)$. 
bzw. $G_{B}$ die jeweiligen absoluten Kostenanteile und damit die Zuweisung (den Transfer) als solche(n) darstellen:

$$
G R T_{x z}-G_{A}=\sum_{i=1}^{m} G R S_{x(A)} \quad \text { (für Gemeinde A) }
$$

$$
G R T_{x}-G_{B}=\sum_{j=1}^{n} G R S_{x z(B)} \quad \text { (für Gemeinde B) }
$$

Die optimale Zuweisungshöhe für den zugrunde gelegten Fall reziproker Externalitäten - die notwendig ist zur Internalisierung der räumlichen spillovers - bestimmt sich dann wie folgt. Dazu werden die Gleichungen (6.2) und (6.3) sowie (6.6) und (6.7) benutzt. Ausgehend von den Gleichungen (6.2) und (6.3) folgt: 129

$$
\begin{aligned}
& G R T_{x z}(1-\beta)=\sum_{i=1}^{m} G R S_{x z(1)}(1-\alpha \beta) \\
& G R T_{x z}(1-\alpha)=\sum_{j=1}^{n} G R S_{x z(B)}(1-\alpha \beta)
\end{aligned}
$$

Durch Substitution in den Gleichungen (6.6) und (6.7) erhält man:

$$
\begin{gathered}
G_{A}=G R T_{x z} \frac{\beta(1-\alpha)}{(1-\alpha \beta)} \\
G_{B}=G R T_{x z} \frac{\alpha(1-\beta)}{(1-\alpha \beta)}
\end{gathered}
$$

Die Zuweisungshöhe hängt also von der Grenzrate der Transformation sowie von der Fähigkeit beider Gemeinden, externe Nutzen zu "produzieren" (ausgedrückt durch die Koeffizienten $\alpha$ und $\beta$ ), ab. Dabei gilt:

129 Gleichung (6.8) wird durch die Multiplikation von Gleichung (6.3) mit B und die Subtraktion dieses Ergebnisses von Gleichung (6.2) ermittelt; Gleichung (6.9) wird durch die Multiplikation von Gleichung (6.2) mit $\alpha$ und die Subtraktion dieses Ergebnisses von Gleichung (6.3) ermittelt. 


$$
\frac{\partial G_{A}}{\partial \beta}>0 \quad \text { sowie } \quad \frac{\partial G_{B}}{\partial \alpha}>0
$$

Folglich ist die erhaltene Zuweisung für eine Gemeinde um so größer, je größer ihre Fähigkeit ist, externe Nutzen zu erzeugen. ${ }^{130}$

Um die Wirkungsweise von Zuweisungen zur Internalisierung räumlicher externer Effekte deutlicher werden zu lassen, wird nunmehr von einem einseitigen räumlichen externen Effekt ausgegangen. Dieser soll ein externer Nutzen für die Gemeindeeinwohner in B sein, der ausgelöst wird durch die Produktion und Bereitstellung des lokalen öffentlichen Gutes $\mathrm{z}$ in A. In einem solchen Fall benötigt also Gemeinde B keinerlei Zuweisungen, da sie keine räumlichen spillovers (folglich ist $\alpha=0$ ) produziert (also verursacht). Gleichung (6.11) belegt dies. Hingegen benötigt Gemeinde A nach wie vor eine Zuweisung, damit der produzierte externe Effekt internalisiert werden kann und keine Fehlallokation erfolgt. Ausgehend von Gleichung (6.3) folgt bei analoger Vorgehensweise zur Ermittlung der Gleichung (6.10) für $\alpha=0$ :

$$
G_{A}=\beta \sum_{j=1}^{n} G R S_{x z(B)}
$$

Nunmehr ist die Zuweisung $G_{A}=g_{A} G R S_{x z}$, so daß der Kostenanteil der Gemeinde A, den sie mittels Zuweisung zur Internalisierung des externen Effekts für die Nachbargemeinde benötigt,

$g_{A}=\frac{G_{A}}{G R T_{x z}}$ ist. Daraus folgt dann $g_{A}=\frac{\beta \sum_{j=1}^{n} G R S_{x z(B)}}{G R T_{x z}}$ und unter Verwendung von

Gleichung (6.2) sowie der dortigen Definition der Grenzrate der Transformation beträgt dann die optimale Zuweisungshöhe

\footnotetext{
130 Entsprechend des Oates'schen Konzepts wurde bei der vorstehenden Analyse davon ausgegangen, daß die einzelnen Gliedstaaten ihre "spillovers" nicht verlieren; also selbst vollständige Konsummöglichkeiten haben. Dieser Fall dürfte infolge der charakterisierenden Besonderheiten öffentlicher Güter realistisch sein, jedoch ist gerade bei den lokalen öffentlichen Gütern mit begrenzter Nutzenreichweite auch an der Kapazitätsgrenze der Fall denkbar, daß die einzelnen Gemeinden ihre "spillovers" tatsăchlich verlieren. Eine solche Betrachtung nimmt Wust $(1981,111 \mathrm{ff})$ vor.
} 


$$
g_{A}=\frac{\beta \sum_{j=1}^{n} G R S_{x z(B)}}{\sum_{i=1}^{m} G R S_{x z(A)}+\beta \sum_{j=1}^{n} G R S_{x z(B)}} .
$$

Es bleibt abschließend festzustellen, daß es natürlich äußerst schwierig ist, die formalen Ergebnisse dieses Konzepts in praktische Politik umzusetzen. Sie sind rein analytischer Natur und beruhen auf äußerst einschränkenden Prämissen. So wurde im Rahmen der vorliegenden Modellbetrachtung von konstanten Skalenerträgen bei der Produktion der Güter $x$ und $z$ ausgegangen; d.h. die Grenzrate der Transformation ist konstant. Wenn aber zunehmende oder abnehmende Skalenerträge vorliegen, der Kostenanteil einer Produktionseinheit also mit der Ausbringungsmenge variiert, hängt auch das jeweilige Niveau der Grenzrate der Transformation vom Outputniveau von $\mathbf{x}$ und $\mathrm{z}$ ab. Damit wird die Bestimmung der optimalen Zuweisungshöhe zum Problem. Daneben wird unterstellt, daß $\alpha$ und $\beta$, also die spillover-Anteile, konstant seien. Schwanken diese Werte jedoch und sind sie noch dazu interdependent, wird die $\mathrm{Zu}$ weisungsbestimmung ebenfalls erschwert. Dritte kritische Annahme ist die Beschränkung des Modells auf zwei Gemeinwesen. Zwar kann das Modell auf mehr als zwei Kommunen ausgedehnt werden, doch der resultierende Ausdruck zur Bestimmung der optimalen Zuweisungshöhe wird wesentlich komplexer.

Allein die letzten zwei Problembereiche machen mehr als deutlich, daß Zuweisungen zur Internalisierung räumlicher spillovers "... could become a monstrously complicated problem although still conceptually soluble ..." (Oates, 1972, 102). Darüber hinaus ist festzuhalten, daß "... the problem needs solving for every subcentral service that generates externalities ..." (King, 1984, 126).

Die den Gemeinden übergeordneten Ebenen (also Bund und Länder) sollten daher nur dann mit Hilfe vertikaler Transfers in die örtliche Eigenständigkeit eingreifen, wenn dezentrale Absprachen zu keinem Ergebnis führen und die Unterversorgung im Falle lokaler Entscheidungen wirklich gravierend ist (vgl. Frey, 1977, 103). Will man bestimmte Leistungen in einer rentablen "Betriebsgröße" anbieten, so beschränken sich die Auswirkungen oft nicht nur auf die benachbarten Gemeinden, sondern streuen darüber hinaus regionen- oder gar landesweit. Hätten die Einwohner einer Gemeinde, die ein solches Gut anbietet, die Finanzierungslast allein zu tragen, wäre das resultierende Bereitstellungsniveau aus gesamtwirtschaftlicher Sicht sub-optimal. Es kann daher sinnvoll sein, daß sich die übergeordnete Ebene (deren Einwohner die Leistung potentiell nutzen) via konkurrierender Gesetzgebung an der Finanzierung einer solchen be- 
teiligt. Man sollte indes auch in diesem Fall versuchen, die tatsächlichen Konsumenten (mit Hilfe von Gebühren beispielsweise) zu belasten, um eine "ökonomische" Nutzung zu erzwingen.

\subsubsection{Zentralisierung und/oder horizontaler Verbund}

Die angesprochenen räumlichen externen Effekte werden im Regelfall gänzlich verhindert, wenn die betroffenen Gemeinwesen auf eigenständige Entscheidungen (folglich also auf ein autonomes lokales Angebot) verzichten und die Aufgabe der nächsthöheren gebietskörperschaftlichen Ebene überlassen (Zentralisierung) ${ }^{131}$ oder aber sich zu einem horizontalen Verbund zusammenschließen (Zweckverband, Gemeinschaftsaufgabe) ${ }^{132}$. Die von möglichen Außenwirkungen Betroffenen sind dann in den Kreis jener einbezogen, die über Angebot und Finanzierung öffentlicher Leistungen entscheiden.

Es mag analytisch durchaus möglich sein, Nutzer-, Zahler- und Entscheidergruppen deckungsgleich zu gestalten; bei der tatsächlichen Aufgabenzuweisung innerhalb eines föderativen Staatswesens ist dies aber im Regelfall kaum praktikabel, denn exakt aus diesen Ursachen heraus entstehen schließlich räumliche spillovers. Folglich garantiert ein Zusammenschluß von Gemeinwesen nicht zwangsläufig, daß sich Nutzer, Zahler und Entscheider räumlich völlig decken. Eine Verlagerung einer Aufgabe mit räumlichen spillovers (also etwa von der Gemeinde- auf die Länderebene) führt zwar dazu, $\mathrm{da}$ es nunmehr zwischen den Gemeinden keine Überlappungen mehr gibt, es kann aber keineswegs ausgeschlossen werden, daß diese Externalitäten nunmehr zwischen den Ländern auftreten (vgl. Biehl, 1979, 122).

Da heute die wirtschaftliche Verflechtung der Regionen und die Beweglichkeit der Bürger ausgeprägt ist, wirken letztlich fast alle öffentlichen Leistungen in irgendeiner Form nach außen. Die föderative Wahrnehmung der Aufgaben wäre stark reduziert, wollte man in jedem Falle interkollektive Effekte durch vertikale oder horizontale Konzentration abbauen.

Dabei ist die horizontale Variante aus der Sicht der kommunalen Autonomie günstiger zu beurteilen. Sie erlaubt den Kommunen immerhin, ihren Verbund selbst zu gestalten und örtliche Besonderheiten in die jeweilige Entscheidungsstruktur mit einzubeziehen.

131 Als Vergleichsmaßstab nennt Krüger $(1975,25 \mathrm{ff})$ die Fusionslösung in der privaten Produktion.

132 Einzelne Beispiele findet man bei Zohlnhöfer (1970, 681ff).

Hans-Georg Napp - 978-3-631-75263-0 
Wie Biehl (optimistisch) ausdrückt, zeige "... allein der Umstand, daß sich (verschiedene) Formen der freiwilligen Kooperation entwickelt haben, daß im dezentralen Bereich ausreichend starke Kräfte vorhanden sind, die effiziente Lösungen erarbeiten und realisieren können" (Biehl, 1979, 118).

Will man die Vorteile des föderalen Staatsaufbaus nicht aufgeben, kommt die Zentralisierung (bzw. vertikale Konzentration) nur dann in Betracht, wenn die anderen Instrumente untauglich erscheinen bzw. sich als solche erweisen. Aber auch für den Fall, daß bei der betroffenen öffentlichen Leistung alle Regionen diese gleichmäßig nutzen und/oder lokale bzw. regionale Überlappungen so gravierend sind, daß sie ein dezentrales Angebot verhindern oder stark verzerren, ist nutzen-kosten-analytisch zu prüfen, ob die gesellschaftlichen Lasten der Zentralisierung nicht höher sind als die Kosten, die entstehen, wenn man darauf verzichtet, die externen Effekte zu internalisieren.

\subsubsection{Würdigung der Internalisierungskonzepte}

Es ist durchaus einsichtig, daß einzelne Gemeinwesen nicht "hermetisch" voneinander getrennt sind und folglich aus vielerlei Gründen räumliche Überlappungen von Nutzen und Kosten zwischen Kommunen bzw. Regionen auftreten können. Unter Zugrundelegung der Annahme, daß jede Gebietskörperschaft bei ihren Angebotsentscheidungen nur die Nutzen- und Kostenströme erfaßt, die in ihren eigenen Grenzen anfallen, ist ersichtlich, daß die Marginalbedingungen für ein Wohlfahrtsoptimum bei Existenz räumlicher Externalitäten verletzt sind. Unter Wohlfahrtsgesichtspunkten ist es folglich notwendig, die auftretenden Externalitäten möglichst umfassend zu internalisieren.

Am einfachsten und unter Autonomiegesichtspunkten adäquat und legitim erscheint es, für die Inanspruchnahme der externen Vorteile ein direktes Entgelt zu zahlen. Diese Vorgehensweise entspräche dem Gedanken der fiskalischen Äquivalenz am ehesten. Die betroffenen Kollektive können sich aber auch durch freiwillige (dezentrale) Verhandlungen über einen finanziellen Ausgleich einigen. Kommen solche Absprachen nicht zustande, weil etwa die Kosten der Konsensfindung zu hoch sind, kann die nächst höhere Ebene als quasi "Schiedsrichter" oder Clearingstelle auftreten (ein Beispiel ist der Ausgleich zwischen Wohnsitz- und Arbeitsplatzgemeinde). Sind die räumlichen Außenwirkungen beträchtlich, so kann es sich lohnen, entweder auf ein eigenständiges Angebot entsprechender Leistungen zu verzichten und die Aufgabe einer übergeordneten Körperschaft zu übertragen, falls alle Regionen entsprechende Leistungen gleichmäßig nutzen (dies gilt besonders für typische zentralstaatliche Aufgaben wie Distribution und Stabilisierung), oder sie als Gemeinschaftsaufgabe im Wege der Kooperation anzubieten. Ein Lastenausgleich zwischen den Kollektiven muß 
dann dafür sorgen, daß die einzelnen Kommunen (Gemeinwesen) die gemeinsam angebotene Leistung entsprechend der Inanspruchnahme ihrer Bürger finanzieren.

\subsection{Skalenerträge in der Produktion öffentlicher Güter}

Im Verlaufe der bisherigen Ausführungen wurde weitestgehend davon abgesehen, die Kostenentwicklung bei der Bereitstellung und/oder der Produktion öffentlicher Güter zu analysieren. Dies entspricht der Annahme, daß die Grenz- und Durchschnittskosten für alle öffentlichen Leistungen konstant und unabhängig von der Ausbringungsmenge sind. Verlaufen die Grenz- und Durchschnittskosten im relevanten Bereich aber uförmig (s. auch Abschnitt 3.1), erhebt sich die Frage, wann und in welcher Form die an der Nachfrage ausgerichteten Bedingungen für ein effizientes Angebotsniveau zu modifizieren sind (vgl. Liedtke, 1972, 98). Der Grund für diese Überlegungen ist, daß das von einem Gemeinwesen bereitgestellte Leistungsniveau nicht gerade der Menge entsprechen muß, die zu minimalen Durchschnittskosten produziert bzw. angeboten werden kann. ${ }^{133}$ Die Stückkosten hängen in der Regel von der produzierten Menge und damit von der "Betriebsgröße" ab.

Beispiele für die Existenz von "economies of scale" im öffentlichen Bereich lassen sich durchaus in relevanter Größenordnung finden und auch empirische Arbeiten (vgl. Walters, 1963; Hirsch, 1964; 1970 sowie Blankart, 1979) haben deren Bedeutung nachgewiesen. Gleichwohl bleibt dieser Bereich nicht unumstritten, denn "...Most positive findings of scale economies are based on statistical results that show a negative relationship between population size and per capita expenditures. There are great statistical and theoretical problems with interpreting such results as showing scale economies, and about as many studies that find a negative relationship find a positive one." (Bahl/Vogt, 1975, 13f) So hat auch Blankart $(1979,15)$ auf eine "... relativ geringe Bedeutung eindeutig zunehmender Skalenerträge ..." hingewiesen.

Nicht überall dort, wo man Skalengewinne vermutet hat (vgl. Biehl, 1979, 117), sind die "Stückkosten" wirklich gesunken. ${ }^{134}$ Anhand der kommunalen Gebiets- und Funk-

133 Siehe auch Ostrom/Tiebout/Warren (1961), Warren (1964) und Heilbrun (1974). Zu spezifischen Ursachen von "economies of scale" im öffentlichen Sektor äußert sich Schönbäck (1976, 80ff).

134 Wie problematisch sich eine falsche Einschătzung der "optimalen Betriebsgrőß" auf die Kostenentwicklung auswirken kann, zeigt beispielsweise der Anstieg der Tagessätze im Krankenhausbereich. So hat man in den siebziger Jahren vergleichsweise viel in hochtechnisierte Krankenhäuser und Kliniken mit großer Kapazität investiert und darauf verzichtet, mit Hilfe kleinerer Einheiten auf die lokal bzw. regional abweichenden Bedürfnisse (differierende Anfälligkeiten für Krankheiten oder Pflegemöglichkeiten) einzugehen. Viele dieser "Bettenburgen" sind daher zu kapitalintensiv und führen dazu, daß auch einfache Leistungen Hans-Georg Napp - 978-3-631-75263-0 
tionalreformen kann man diese Problematik verdeutlichen. Kernstück der Reformen war der Versuch, "optimale" bzw. "Mindest-Einwohnerbereiche" zu schaffen, damit die Leistungskraft und Wirtschaftlichkeit der öffentlichen Verwaltung gestärkt wird (vgl. Wagener, 1974, 312f). In den zahlreichen Analysen, die sich mit den Ergebnisse der Gebietsreformen und damit verbundenen Kostenersparnispotentialen beschäftigt haben, werden vielfach kritische Bewertungen vorgenommen. Häufig sei diese Art der "Zentralisierung" mit dem Ziel der Ausschöpfung von Skalengewinnen eher erfolglos oder zumindest gemessen an den hochgesteckten Erwartungen nicht befriedigend gewesen. ${ }^{135}$

Gleichwohl sollen die Vorteile dieser Neugliederung nicht unerwähnt bleiben, denn eine bessere Planungsfähigkeit der Verwaltungen neugeordneter größerer Kommunen macht kommunale Vorhaben - wie beispielsweise den Ausbau von Wasserversorgung und Abwasserbeseitigung - schneller und effektiver durchführbar. ${ }^{136}$ Doch es kann zur Rechtfertigung einer stärkeren Zentralisierung nicht allein der Verweis auf die "economies of scale" genügen; vielmehr gilt es, diese Kostenvorteile zu belegen und nutzen-kosten-analytisch diese Skalengewinne möglichen Nachteilen aufgrund fehlender Präferenznähe und des Wegfalls dezentraler Allokationsvorteile gegenüberzustellen. Daher müssen die Auswirkungen steigender Skalenerträge in bezug auf eine effiziente Ressourcenallokation untersucht und deren Folgerungen für die Struktur eines Gemeinwesens nachgegangen werden.

Betrachtet man öffentliche Güter, deren Produktion und Bereitstellung nicht unmittelbar zusammenhängen müssen, läßt sich die Wirtschaftlichkeit der Produktion bei existierenden "economies of scale" erhöhen, wenn (ohne daß man auf die Vorteile dezentraler Bereitstellung bestimmter öffentlicher Leistungen verzichten muß) entweder verschiedene Gemeinden kooperieren - indem sie die gewünschten Mengen von einer gemeinsamen (staatlichen oder privaten) Unternehmung herstellen lassen - oder aber generell die Produktion an Dritte vergeben, um schließlich dann von dieser Einrichtung das Gut zu erwerben und selbst anzubieten (vgl. Oates, 1972, 45; Tullock, 1970, 65ff sowie Ostrom/Tiebout/Warren, 1961, 831ff). Ist das öffentliche Gut sogar nach den Spezialwünschen der einzelnen Gemeinden differenzierbar (vgl. Liedtke, 1972, 99),

zu überhöhten Preises abgegeben werden, weil Möglichkeiten der Leistungsdifferenzierung und damit auch zur flexiblen Preisgestaltung fehlen (vgl. Biehl, 1979, 117).

135 Diese Position vertritt Kappe (1978). Vgl. auch aus dem umfangreichen Schrifttum zur Gebiets- und Funktionalreform Wrage (1975), Thieme/Prillwitz (1981), Thiede (1981), Kulartz (1982) sowie Rosenfeld (1985).

${ }^{136}$ Bei einer differenzierteren Betrachtung zeigt sich, daß vor allem bei Aufgaben, "... die für viele Fälle in gleicher Weise und nach festen Verfahrensbestimmungen ausgeübt werden und sich daher für serielle Bearbeitung durch spezialisierte Sachbearbeiter oder Arbeitsgruppen eignen" (Kappe, 1978, 322), eine Konzentration in relevanten Bereichen zu Kosteneinsparungen führt. 
geht allein aus der Existenz der zunehmenden Skalenerträge und damit verbundenen Allokationswirkungen kein Zwang zum zentralen Angebot aus. "Brachliegende" Skalenerträge sind vielmehr durch interkommunale Zusammenarbeit (Gründung von Zweckverbänden, gemeinsamen Wirtschaftsbetrieben etc.) nutzbar und führen dann unter Effizienzgesichtspunkten zu annehmbaren Ergebnissen. Dabei wird die Notwendigkeit einer effizienten Ressourcenverwendung und damit einer Zusammenarbeit um so wichtiger, je stärker es gelingt, Bereitstellung, Finanzierung und Entscheidung des öffentlichen Leistungsangebots zu verknüpfen.

\subsection{Administrative Aspekte der Dezentralisierung}

6.3.1 Die Existenz von Organisationskosten sowie Aufwendungen für eine Beteiligung am politischen Entscheidungsprozeß

Im Rahmen der administrativen Rechtfertigung einer Zentralisierung staatlicher Aktivitäten werden häufig die Organisationskosten sowie die sogenannten "compliance costs" als Argumente genannt, die gegen eine starke Diversifizierung und damit eine umfangreiche kommunale Autonomie sprechen. Zum organisatorischen Aufwand gehören alle Ausgaben für Aufbau und Unterhalt von politischen und bürokratischen Entscheidungsbehörden. Dabei werden Kosten der Organisation, die innerhalb eines eigenständigen Gemeinwesens anfallen, in Anlehnung an Breton und Scott $(1978,8)$ als Verwaltungskosten bezeichnet; müssen mehrere Körperschaften zusammenarbeiten, um ihre räumlichen Beziehungen zu ordnen, entstehen sogenannte Koordinationskosten. ${ }^{137}$ In diesem Zusammenhang wird unterstellt, daß auch bezüglich der Wahrnehmung von Verwaltungsaufgaben im allgemeinen "economies of scale" 138 existieren und somit ein stark diversifizierter öffentlicher Sektor mit eigenständigen gebietskörperschaftlichen Ebenen höhere "administration costs" in Form von Verwaltungs- und Koordinationsaufwendungen mit sich bringt. ${ }^{139}$

137 Andere Gliederungen sind natürlich moglich. So unterscheidet Frey (1977, 38f) Planungs-, Einigungs- und Verwaltungskosten und Bulutoglu $(1976,6)$ Entscheidungs- und Verwaltungskosten.

138 Diese Meinung vertritt beispielsweise Wust $(1981,49)$. Er zeigt, daß bei einer differenzierten Betrachtung entscheidende Rationalisierungseffekte vor allem in der Hauptverwaltung, die sogenannten Facheinheiten (wie Bauaufsicht, Jugend- und Gesundheitswesen, Polizeiverwaltung u.a.) zentrale Dienste anbietet, zu erwarten sind. Weil dieses im wesentlichen Funktionen sind, "... die für viele Fălle in gleicher Weise nach festen Verfahrensbestimmungen ausgeübt werden und sich daher für serielle Bearbeitung durch spezialisierte Sachbearbeiter ... eignen" (Kappe, 1978, 322), führt ihre Konzentration zu Kosteneinsparungen.

139 Diese Argumentationsmuster waren - neben anderen - auch in Verbindung mit den Zielen der kommunalen Gebiets- und Funktionalreform wăhrend der siebziger Jahre in der Bundesrepublik Deutschland von entscheidender Bedeutung. Ein Versuch, die Gesamtheit moglicher Ziele der kommunalen Gebietsreform systematisch zu ordnen, stößt auf drei Bereiche, die als Oberziele definiert werden könnten. Es handelt sich 
In die gleiche Argumentationsrichtung zielt die Diskussion um die sogenannten "compliance costs". Diese entstehen in Form der Beteiligung der Bürger am politischen Entscheidungsprozeß, da sich die Wähler Informationen über Kandidaten, Programme und einzelne Maßnahmen beschaffen müssen und diese Aktivitäten mit zeitlichen oder aber auch finanziellen Aufwendungen verbunden sind (hierzu ausführlich Downs, 1968; Buchanan/Tullock, 1971; Kirsch/Theiler, 1976). ${ }^{140} \mathrm{Je}$ mehr staatliche Ebenen und Entscheidungsprozesse also existieren, desto größer sind diese Aufwendungen. Daraus wird dann gefolgert, "... if all city government functions are transferred to existing county governments and each county encompasses several cities, then each resident of the county will be a member of one rather than two local governments. This may reduce compliance costs because voters must participate in only one election and become informed about on set of candidates." (Fisher, 1987, 86f)

Organisationskosten sowie die Aufwendungen, die aus einer Beteiligung der Bürger am politischen Entscheidungsprozeß resultieren, scheinen also zunächst für eine Relativierung der Allokationsvorteile dezentralisierter Gemeinwesen zu sprechen. Daher ist die These, Zentralisierung führe zu größerer Wirtschaftlichkeit, häufig eine Begründung für normative Ansätze bezüglich der Anziehungskraft des "höheren" Etats. ${ }^{141}$

\subsubsection{Eine administrative Rechtfertigung der lokalen Ebene}

\subsubsection{Dekonzentration als alternative Organisationsform}

Die Existenz räumlicher spillovers, das Vorhandensein von "economies of scale" bzw. eventuell auftretende Organisationskosten sind in den vorhergehenden Abschnitten als Argumente für einen zentralisierten Staatsaufbau genannt worden. Eine einseitige und vordergründige Orientierung an diesen Aspekten würde zu einer dermaßen großen Ballung von Funktionen und Leistungen führen, daß die öffentliche Verwaltung (ähnlich wie große Unternehmungen) eine "Dekonzentration" bzw. eine "hierarchische

hierbei um die Verbesserung der Leistungsfahigkeit der Gemeinden, die Optimierung der politischen Form der Gemeinden sowie die Erfüllung überörtlicher Ziele (vgl. Wagener, 1974, 328ff). Innerhalb dieses Zielkatalogs findet man durchaus entsprechende Argumente wieder, deren Ursprung die administrative Rechtfertigung stărkerer Aufgabenbündelung im staatlichen Bereich darstellt. So sollte die "Verwaltungskraft der Gemeinde" gestărkt, "Planungsfáhigkeit und Planungseffektivităt" erhöht und die "Wirtschaftlichkeit und Leistungsfahigkeit des Verwaltungsapparates" gesichert werden (vgl. Thieme/Prillwitz, 1981, 45ff).

$140 \mathrm{Vgl}$. auch die Ausfuhrungen in Abschnitt 4.4.5.

141 Bei Autoren wie Popitz (1927), Albers (1962), Keller (1966) sowie ansatzweise Peacock/Wiseman (1967) kommen Thesen und Argumente zum Ausdruck, die unter Effizienzgesichtspunkten zentrale Kompetenzen befürworten und somit die Anziehungskraft des übergeordneten Haushalts als einen unvermeidbaren gesetzmaßigen Prozeß ansehen. 
Koordination" betreibt, um effektiver arbeiten zu können. D.h. einzelne Verwaltungsund Organisationsaufgaben werden auf bestimmte nachgeordnete Unternehmensteile verlagert. Solche Beispiele für Verlagerungen lassen sich im öffentlichen Bereich in großer Anzahl finden; man denke nur an die sogenannten "Auftragsangelegenheiten" der Kommunen, also Aufgaben, die diese in der Regel weisungsgebunden und/oder auf Rechnung der übergeordneten Gebietskörperschaft durchführen (vgl. Seiler, 1988, 511).

Der Frage einer möglichen Dekonzentration öffentlicher Aktivitäten soll in Analogie zur Diskussion der hierarchischen Koordination in Unternehmen nachgegangen werden. ${ }^{142}$ Den Ausführungen liegt ein Ansatz von Helm/Smith $(1987,9 f)$ zugrunde, der als Alternative zwischen den beiden Polen Zentralisierung und Dezentralisierung formuliert worden ist. Hintergrund dieses Ansatzes ist die Tatsache, daß Kommunen zwar ein vielfältiges Aufgabenspektrum erfüllen, in der Regel sind sie im Rahmen ihrer allokativen Funktion Anbieter lokaler öffentlicher Leistungen, doch neben diesen eigenverantwortlich wahrgenommenen (lokal begrenzten) Aufgaben eine Reihe von Aktivitäten ausführen (müssen), die gesamtgesellschaftlich von Bedeutung sind bzw. gesamtstaatliche Belange tangieren. Weil - so der Argumentationsgang (vgl. Helm/Smith, 1987, 10) - die Bedeutung beispielsweise verteilungspolitischer Belange im kommunalen (allokativen) Aufgabenspektrum durchaus beträchtlich ist, gilt es durch Regeln und Richtlinien sicherzustellen, daß lokale Einrichtungen die nationalen (Verteilungs-)Zielsetzungen nicht konterkarieren und nicht nur die eigenen Prioritäten bei der Durchführung der erforderlichen Maßnahmen zugrunde legen. ${ }^{143}$

Theoretisch sind zwei mögliche organisatorische Antworten auf dieses Phänomen denkbar. Entweder wird eine vertikale hierarchische Struktur eingerichtet (d.h. die nationale Regierung delegiert bestimmte Aufgaben an nachgeordnete Instanzen wie die Kommunen) oder eine horizontale und/oder vertikale Trennung der Wahrnehmung

142 Die Organisationstheorie bzw. "Theorie der Firma" ist aus der Unzufriedenheit mit den traditionellen neoklassischen Gewinnmaximierungsmodellen entstanden. Die grundlegenden Gedanken von Coase (1937) sind weiterentwickelt worden durch Cyert/March (1963), Alchian/Demsetz (1972), Arrow (1980), Williamson $(1975 ; 1990)$ sowie Radner (1985).

143 Resultat wäre ansonsten die von Oates (1977c, 17f) beschriebene Situation. "Dabei stellt sich in einem stark dezentralisierten Fiskalsystem ... das Problem, daß subsidiäre Einheiten, die unabhängig versuchen, unterschiedliche redistributive Ziele zu erreichen, mit großer Wahrscheinlichkeit in ernste Schwierigkeiten geraten. Betrachten wir z.B. eine Kommune, die über ein umfangreiches Programm negativer Einkommenssteuern eine Einkommensverteilung anzusteuern versucht, die relativ zur übrigen Nation merklich ausgeglichener ist. Solche Maßnahmen würden bei dem relativ hohen Grad individueller Mobilităt, der einen nationalen Wirtschaftsraum kennzeichnet, die Reichen veranlassen, in eine benachbarte Kommune abzuwandern und den Armen einen Anreiz zur Zuwanderung geben. Das Ergebnis wäre u.U. eine ausgeglichenere Einkommensverteilung, sie wäre aber auf die Abwanderung Reicher bzw. auf den Zuzug Armer zurückzuführen, was sich in einem sinkenden Pro-Kopf-Einkommen in der betreffenden Kommune äußern würde." 
bestimmter Funktionen etabliert. Letzteres ist mit der Übertragung bestimmter Funktionen an lokale oder regionale - möglicherweise auch gänzlich eigenständige - Einrichtungen (wie Parafisci) verbunden. In diesem Kontext ist als bekanntestes Beispiel die Sozialversicherung zu nennen. ${ }^{144}$

Der Vorteil der Dekonzentration öffentlicher Aufgabenerfüllung liegt in der Realisierung einer besseren Informationsbasis (so Helm/Smith, 1987, 9f). ${ }^{145}$ Der Verfolgung umfassender Informationserfordernisse und damit der Dekonzentration sind jedoch Grenzen gesetzt. Der Informationsgewinnungsprozeß wird eingeschränkt, weil mit zunehmender Dekonzentration ein steigender Verlust an Kontrollmöglichkeiten seitens der "Zentrale" verbunden ist. Informationsgewinnung durch Dekonzentration auf der einen und Kontrollmöglichkeiten durch Überschaubarkeit auf der anderen Seite sind also gegenläufige Entwicklungen. Die Aufgabe der Organisationen ist die Realisierung der im wesentlichen übergeordneten Ziele; folglich werden vor Ort "Agenten" benötigt, die eine Verfolgung der Ziele der Gesamtorganisation unterstützen und kontrollieren. In diesem Sinn ist also Dekonzentration bzw. hierarchische Koordination im staatlichen Bereich so zu verstehen, daß die Entscheidungsträger der Kommunen beispielsweise die Schule am Standort verwalten können, aber durch Kontrollmöglichkeiten davor zurückgehalten werden, entweder bestimmte Standards zu verletzen oder kostenaufblähende Maßnahmen durchzuführen (vgl. Helm/Smith, 1987, 9).

Diese Form einer Beziehung zwischen lokaler und zentraler Ebene ist also mit Blick auf die Verwaltungs- und Organisationsstruktur ein Beispiel für das sogenannte "principal agent problem" (Fama, 1980 sowie Rees, 1985a; 1985b). Die zentrale Frage in diesem Zusammenhang lautet: Wie können (notwendige) lokale Agenten mit der Aufgabe der Informationsbeschaffung (wegen der größeren lokalen Präferenznähe) dazu veranlaßt werden, letztlich die zentralstaatlichen Zielsetzungen des Prinzipals zu verfolgen? Das Problem wird verschärft durch konfligierende Zielsetzungen der loka-

144 Die Einrichtung eigenständiger Organisationen mit weitreichenden Autonomie- und Hoheitsrechten geht über die eigentliche Zielsetzung der Dekonzentration der offentlichen Verwaltung hinaus. Sie ist eher unter dem Stichwort der weitestgehenden Dezentralisierung und der damit verbundenen Autonomierechte einzuordnen und betrifft damit weniger innerorganisatorische Überlegungen, wie sie in diesem Abschnitt vorgenommen werden.

145 Die Dekonzentrationserfordernisse staatlicher Institutionen resultieren aus dem Tatbestand, daß mit der Grőße der Einrichtungen Informationsprobleme aufteten. Jede Organisation sieht sich Schwierigkeiten gegenüber, die darin bestehen, ihre Mitglieder über die eigenen und andere Aktivitäten zu informieren. Diese Situation führt in der Regel dazu, daß mit zunehmender Größe einer solchen Einrichtung die Anzahl der erforderlichen Informationswege und Koordinationserfordernisse überproportional zunimmt. Das ganze sei an einem einfachen Beispiel verdeutlicht. Beim Informationsaustausch zwischen zwei Individuen besteht eine (Informations-)Verbindung, bei drei Individuen sind es bereits drei Informationswege und bei vier Individuen erhöht sich die Zahl auf sechs (vgl. allgemein zur theoretischen Behandlung Hirshleifer, 1973; speziell im Hinblick auf das angesprochene Problem Bössmann, 1988, 184ff). 
len Agenten und durch die Informationsmängel der Zentralinstanz bezüglich der örtlichen Kostensituation und weiterer spezifischer Merkmale der Bevölkerung. Die Erlangung einer besseren Informationsbasis wird zudem erschwert, wenn unterschiedliche politische Zielsetzungen miteinander konkurrieren (vgl. Rees, 1984). ${ }^{146}$

Wenn also in Analogie zur Theorie der Firma die Beziehungen zwischen zentralen und lokalen staatlichen Instanzen betrachtet werden, wird offensichtlich, daß die Zentralinstanz die vorherrschende Situation (das Informationsmonopol des lokalen Agenten) durch die Suche nach Abhängigkeiten, Bewertungskriterien sowie ganz generell Informationen verbessern kann. Dabei spielen Bewertungskriterien der Leistungsfähigkeit (Verwaltungseffizienz) eine wichtige Rolle. So können Informationen über die Kostensituation in der Abfall- und Abwasserbeseitigung, der Energiebereitstellung oder anderer Leistungsangebote vor Ort Bewertungsmaßstäbe des örtlichen Prinzipals durch die Zentralinstanz sein. Solche Informationen (eine Art Rentabilitätskriterien) werden ihrerseits wieder zu Objekten des Wettbewerbs, durch die jede Kommune bei politischen Abstimmungen oder der Wohnsitzentscheidung des "Konsumenten" mit anderen vergleichbaren Kommunen konkurriert. Die Idee des "horizontalen Wettbewerbs" (Tiebout, 1956) zwischen den Kommunen kann also scheinbar auch in einem dekonzentrierten Staatsaufbau mit weitestgehender Entscheidungskompetenz der Zentrale und gewissen Durchführungs- und Verwaltungskompetenzen auf der lokalen Ebene realisiert werden (vgl. Helm/Smith, 1987, 10). Kommunen sind dann im wesentlichen ausführende Verwaltungsstellen der Zentrale und besitzen im Extremfall keinerlei Autonomie (weisungsgebundene Auftragsangelegenheiten und Pflichtaufgaben). Es ist aber auch denkbar, eine Ausgabenautonomie (eigenständige lokale Aufgabenerfüllung und Ausgabengestaltung) bei "fiskalischer Alimentierung von oben" zu rechtfertigen.

Dekonzentration (so resümierend Helm/Smith, 1987, 10f) erlaubt also die Ausnutzung der Allokationsvorteile eines dezentralen Gemeinwesens bei gleichzeitiger zentraler Finanzierung, denn "... they [die Betrachtungen] do not immediately explain the need for local revenue-raising powers" (Helm/Smith, 1987, 11). Dabei hängt die Funktionalität eines dekonzentrierten Verwaltungsaufbaus jedoch in starkem Maße von der Ausgestaltung der angesprochenen principal-agent-Beziehung ab.

146 Livesey (1987, 55ff) führt in diesem Zusammenhang aus, daß dieser Informationsfluß zwischen "Zentrale" und "lokaler Institution" als eine Art "... informational game between the two centres of authority" (Helm/Smith, 1987, 9) gesehen werden muß. 


\subsubsection{Dekonzentration versus Dezentralisierung}

Befürworter der Dekonzentrationslösung behaupten, daß zwar infolge der verbesserten Informationsbasis bei politischen Abstimmungen und der Möglichkeit der Nutzung des "voting by feet"-Mechanismus auf der kommunalen Ebene eine effektivere Outputbewertung erfolgen und damit größere Präferenznähe realisiert werde, aber daraus nicht zwangsläufig die Notwendigkeit einer dezentralen Finanzierung des lokalen öffentlichen Leistungsangebots mittels kommunaler Steuern abgeleitet werden könne. Der zentralstaatlichen Finanzierung - so der Argumentationsgang - komme nämlich eine Art "Sicherheitsventilfunktion" zu, mit der letztlich neben den weiter oben bereits angesprochenen Indikatoren die Beachtung nationaler Zielsetzungen kontrolliert werden soll (principal agent problem). Informations- und Kontrollkosten im Rahmen der administrativen Ausgestaltung des Staatsaufbaus sprechen also - wenn man dem dargestellten Argumentationsgang folgt - infolge der verwobenen Allokations- und Distributionsaspekte ${ }^{147}$ eher für Dekonzentration als für Dezentralisierung, also für im Normalfall ausgabenautonome, aber eben nicht einnahmenautonome Gemeinden bzw. Gemeindeverbände (vgl. Helm/Smith, 1987, 11).

Die vorstehenden Argumente sind sicherlich in bezug auf die Berücksichtigung der nicht immer einfachen Trennung von Allokations- und Distributionsaspekten durchaus nachvollziehbar. Die meisten der relevanten lokalen öffentlichen Leistungen besitzen allokative und distributive Elemente, wie es am Beispiel der Bildung aufgezeigt werden kann. Das Bildungsangebot ist sicherlich zunächst einmal unter rein allokativen Gesichtspunkten zu sehen, gleichwohl ist aber die Bereitstellung gewisser Mindeststandards (wie beispielsweise die Vermittlung von Grundfertigkeiten wie Lesen, Schreiben und Rechnen) auch von verteilungspolitischer Bedeutung. Diese Tatsache erklärt daher wohl ebenso die unterschiedlichen Zuständigkeiten der einzelnen gebietskörperschaftlichen Ebenen in Bildungsfragen.

Doch trotz dieser relevanten Einschränkungen einer rein allokationsorientierten Behandlung des Staatsaufbaus sprechen gewichtige Gründe für die Herstellung einer Äquivalenzbeziehung zwischen Zahler, Nutzer und Entscheider lokaler öffentlicher Leistungen. Jede Trennung dieses Zusammenhangs erschwert die Realisierung effizienter Ergebnisse und führt zu Wohlfahrtseinbußen. Nur die enge Verknüpfung der lokalen öffentlichen Leistungen mit ihrer Finanzierung erlaubt eine Annäherung an tatsächliche Präferenzen, die im Sinne der Realisierung effizienter Lösungen notwendig sind.

147 Die Betrachtung kann auf stabilitătspolitische Zielsetzungen ausgeweitet werden. Infolge des gegenwărtig geringeren Augenmerks wird auf eine explizite Behandlung der Stabilitätspolitik aber verzichtet. 
Eine föderale Ordnung soll schließlich helfen, eine effiziente Ressourcenverwendung in der Staatswirtschaft zu realisieren. Die Untersuchung der Ursachen und Auswirkungen von Wohlfahrtsverlusten und Verschwendung liefert dabei für die Beurteilung eine notwendige Grundlage. Eine der wohl schwerwiegendsten Probleme bei der Verwirklichung von mehr Effizienz in der Staatswirtschaft ist die Trennung von Nutzer, Zahler und Entscheider. Im Sinne der Dekonzentration bleibt diese Trennung im wesentlichen bestehen bzw. wird verfestigt. Nur eine optimale Informationsbasis auf seiten der Zentrale - also eine principal-agent-Beziehung mit funktionierenden Informations- und Kontrollströmen - würde ein ähnliches Ergebnis erbringen wie die Verknüpfung von Kosten und Nutzen. "Solange - so beim Tausch oder Kauf - am freien Markt Leistung und Gegenleistung und damit Nutzen und Kosten für die Betroffenen durch den Preis sichtbar miteinander verknüpft sind, steht die Wirtschaftlichkeit bei Tausenden täglicher spontaner Entscheidungen fest. Sobald aber der Nutznießer von öffentlichen Leistungen nicht unmittelbar und sichtbar zahlt, Nutzen und Kosten also getrennt werden, ja durchweg nicht einmal genauer bekannt sind, ist die Gefahr einer Vergeudung kostbarer Hilfsquellen groß." (Recktenwald, 1977b, 11)

Ein unverzichtbares Erfordernis für eine effiziente Verwendung der Ressourcen in einem Gemeinwesen ist daher eine Lasten-(Kosten-) und Nutzenverteilung, bei der Nutzer, Zahler und Entscheidende nicht getrennt werden. Auf diese Weise soll erreicht werden, daß die jeweils betroffenen Bürger, Politiker und Bürokraten in umfassender Kenntnis der finanziellen Belastungen über öffentliche Leistungen entscheiden. Diese Verknüpfung von Nutzen und Kosten zwingt den einzelnen dazu, öffentliche Güter "realistisch" zu bewerten, indem er den durch die Steuerzahlung entgangenen Nutzen (Opportunitätskosten) in sein Urteil bzw. seine Entscheidung einbezieht.

Resümierend kann bisher festgehalten werden, daß für eine Dezentralisierung der Entscheidungen über öffentliche Aktivitäten mit örtlich begrenztem Wirkungskreis (lokale öffentliche Güter) nachfolgende Gründe sprechen. ${ }^{148}$ Zunächst kann die untere Ebene effektiver als die Oberverbände entscheiden, im welchem Umfang solche Aktivitäten aufgenommen werden sollen. Die Suche nach dem "optimalen Budget" präsentiert sich also auf lokalem Niveau als ein weniger komplexes Problem als auf zentralstaatlicher Ebene. Die ökonomische Rechtfertigung der effizienteren Allokation und die daraus

148 Die "Philosophie der Größe" - wie sie auch für den privaten Sektor der Unternehmungen als Zentralthese lange Zeit propagiert wurde - hat sich aus heutiger Sicht als falsch erwiesen. Mammutprojekte haben sich häufig als teurer und weniger leistungsfahig erwiesen, als ihre Vergleichsobjekte. So gliedern auch Unternehmen zunehmend Funktionen aus und mindern ihre Produktionstiefe. Der Kauf ist hăufig günstiger als die Eigenproduktion. So dezentralisieren sich Großunternehmen im Innern und ersetzen hierarchische Koordination durch Dezentralisierung. Bei der Ankurbelung dieser Entwicklungen haben die Vertreter der institutionellen Ökonomie (so etwa Coase, 1937; Williamson, 1975; 1990 sowie Radner, 1985) eine entscheidende Rolle gespielt. 
abzuleitende Forderung nach kommunaler Selbstverwaltung oder "home rule" liegt zum einen in Informationsvorteilen der lokalen Ebene gegenüber vergleichsweise geringen zentralen Koordinations- und Kostenvorteilen, zum anderen in einer besseren Anpassung an lokale Präferenzen (größere Präferenznähe). Bei unterstellter weitreichender Homogenität der Präferenzen auf lokaler Ebene - erhöht noch durch interlokale Wanderungsbewegungen - ist es unter Allokationsgesichtspunkten geradezu erwünscht, nicht eine staatseinheitliche Lösung, sondern differenzierte lokale Lösungen anzustreben. Interlokale bzw. interregionale Unterschiede im gemeindlichen Leistungsangebot sind somit grundsätzlich positiv zu beurteilen.

Weil folglich sowohl die Struktur als auch der Umfang lokaler Aktivitäten von den Präferenzen der Betroffenen beeinflußt werden sollten, ist nicht nur eine lokale Ausgabenautonomie, sondern auch die Einnahmenautonomie Grundvoraussetzung für effiziente Lösungen. Da ein auf Zuschüssen und Zuweisungen basierendes Alimentationssystem einerseits diese autonome Einnahmengestaltung nicht ermöglicht, andererseits eine Beschränkung auf Gebühren und Beiträge ${ }^{149}$ und die daraus finanzierten öffentlichen Leistungen zu eng ist, sollte aus allokativen Erwägungen den Kommunen ein Einfluß auf die Höhe und die Struktur der eigenen Steuereinnahmen gewährt werden.

Daher wird trotz der Einschränkungen in Form von räumlichen Externalitäten, "economies of scale" und administrativen Problembereichen hinsichtlich der Bereitstellung lokaler öffentlicher Güter an der (effizienz-orientierten) dezentralen Lösung festgehalten. Das zu formulierende eigenständige kommunale Finanzierungssystem muß folglich versuchen, den genannten Problembereiche durch geeignete Finanzierungsinstrumente und eine entsprechende Ausgestaltung zu begegnen. Die vorstehend erörterten Aspekte sind damit letztlich zwar mit gewissen Einschränkungen eines an Effizienzzielsetzungen orientierten gemeindlichen Finanzsystems verbunden, führen aber nicht zwangsläufig - wie häufig vorschnell gefordert - zu ausschließlich zentralen Einnahmekompentenzen.

149 Gleichwohl sollten gerade auf lokaler bzw. regionaler Ebene die Möglichkeiten der Gebührenfinanzierung umfassend ausgeschöpft werden. Überall wo eine enge Beziehung zwischen Nutzen und Kosten individuelle Zurechnung erlaubt, sollten diese sogenannten gebührenfahigen Leistungen unter Effizienzgesichtspunkten gebührenfinanziert werden (vgl. Münch, 1976, 298ff). 
Hans-Georg Napp - 978-3-631-75263-0

Downloaded from PubFactory at 01/11/2019 06:33:05AM

via free access 
"Aber irgendwann wechselt die Farbe: die Bedeutung der unreflektiert verwerteten Gesichtspunkte wird unsicher, der Weg verliert sich in der Dammerung. Das Licht der großen Kulturprobleme ist weitergezogen. Dann rustet sich auch die Wissenschaft, ihren Standort und ihren Begriffsapparat zu wechseln und aus der Höhe des Gedankens auf den Strom des Geschehens zu blicken."

Max Weber (1922)

\section{Fiskalische Äquivalenz und ihre Bedeutung bei der lokalen öffentlichen Lei- stungsbereitstellung und ihrer Finanzierung}

\subsection{Formen fiskalischer Äquivalenz und ihre Reichweite}

Die normativ-utilitaristische Theorie der fiskalischen Dezentralisation geht von individuellen Nutzenfunktionen für private und öffentliche Güter aus und ermittelt die optimale Allokation der örtlichen (öffentlichen) Leistungen dort, wo ihre Grenznutzen gleich den Grenzkosten sind - und diese Grenzkosten gleich sind dem (entgangenen) Grenznutzen privater Güter. Die äquivalente Finanzierung der öffentlichen Leistungserstellung ist die Belastung der Einwohner (Nutzer) mit einem Steuerpreis ("tax price"), der dem als bekannt unterstellten Grenznutzen entspricht ("benefit taxation"). Diese marktähnliche Konstellation unterstellt in ihrer strengen Form individuell zurechenbare Leistungen und garantiert damit "fiskalische Äquivalenz".

Das Prinzip der fiskalischen Äquivalenz ("fiscal equivalence") $)^{150}$ geht populär umschrieben auf die Notwendigkeit zurück, daß bei staatlicher Leistungsbereitstellung für eine Realisierung effizienter Ergebnisse sichergestellt werden muß, daß jene, die aus öffentlichen Gütern Nutzen erhalten, auch die sind, die dafür "bezahlen". Wie weit die Übereinstimmung jedoch gehen muß, darüber gibt es durchaus unterschiedliche Sichtweisen.

Im Verlauf der bisherigen Analyse war dieser Grundsatz implizit bei der Realisierung optimaler Allokationsentscheidungen im Sinne von (individuellen) Nutzensteuern zur Finanzierung des jeweiligen Kollektivgüteranteils (gemäß der "geäußerten" Präferenzen) enthalten. Eine strenge Auslegung dieses Äquivalenzgedankens ("fiskalische Äquivalenz im engeren Sinne") impliziert also eine finanzielle Belastung exakt nach dem Nutzenanteil des jeweiligen Haushalts (vgl. auch Buchanan, 1950; Musgrave, 1961 sowie Oates, 1972; 1975; 1977a). Diese ist aber (praktisch) illusorisch, weil man

150 Vgl. dazu Olson $(1969,479 f)$, der diesen Begriff und seine Bedeutung für die offentliche Leistungsbereitstellung in einem foderativen Staatswesen begründet hat. 
bei entsprechender Auslegung des Nutzenprinzips in der Regel zu dem Ergebnis gelangt, daß jeder Konsument in Anlehnung an seine Nutzenbewertung eine individuelle (nutzenäquivalente) Gebühr entrichten müßte. Diese strenge Auslegung des Äquivalenzgedankens für die Gesamtheit des lokalen öffentlichen Leistungsangebots ist nicht nur unrealistisch, sondern - wie die vorhergehende Modellanalyse (s. Kapitel 5) aufgezeigt hat - auch nicht exakt genug, um darauf aufbauend allgemein gültige Rückschlüsse für die Ausgestaltung praktikabler und an Effizienzgesichtspunkten ausgerichteter Finanzierungssysteme für die kommunale Ebene zuzulassen. Die Gründe für diese ungenügende Eignung der Modellergebnisse liegen vor allem - wie bereits beschrieben - in den sehr stringenten Annahmen solcher Effizienzanalysen sowie der Vernachlässigung bedeutender real existierender Phänomene (vgl. deren Darstellung in Kapitel 6). Doch verzichtet man auf jede Form der Äquivalenzbesteuerung (oder die entsprechende Gebührenbemessung), fehlen jegliche "Steuerpreissignale". ${ }^{151}$

Daher wird im weiteren Verlauf eine "fiskalische Äquivalenz im weiteren Sinne" als Orientierungsmaßstab und Richtschnur für lokale Finanzierungsalternativen zugrunde gelegt. Der Basisgedanke bleibt dabei erhalten: Ziel ist die Belastung derjenigen Wirtschaftssubjekte mittels kommunaler Finanzierungsinstrumente, die als Nutznießer das lokale öffentliche Leistungsangebot in Anspruch nehmen. Von einer exakten individuellen Zurechnung im Sinne der fiskalischen Äquivalenz wird solange Gebrauch gemacht, wie dies möglich und sinnvoll erscheint (etwa im Bereich der Leistungsentgelte; also der Gebühren und Beiträge). ${ }^{152}$ Im Regelfall, d.h. infolge der besonderen Charakteristika des öffentlichen Leistungsangebots, ist jedoch diese strenge Zurechnung unbrauchbar. Daher müssen andere Verfahren Bedeutung erlangen, wie beispielsweise die sogenannte "Haller'sche gruppenbezogene kostenmäßige Äquivalenz"153 als Näherungslösung für das Allokationsproblem. Außerdem - das Ergebnis des Kapitels 5 zeigt dies - ist die angesprochene Aufgabenstellung (die Finanzierungs-

151 Bei gegebener Budgethöhe übernimmt dann die normative Budgetregel von der Gleichheit der Grenznutzen die Funktion der Aufteilung der Mittel auf die einzelnen Aufgabenbereiche, d.h. die Effizienz der Mittelverwendung wird durch Opportunitätskosten gesteuert. Es fehlt aber jetzt eine Norm zur Bestimmung der Budgethöhe. An dieser Stelle setzt eine andere (normative) Denkrichtung (vgl. dazu Popitz, 1932; Albers, 1962; Hansmeyer, 1966; Littmann, 1968; Bös, 1971) an, die vor dem Hintergrund einer gesamtstaatlichen Wohlfahrtsfunktion kommunale Bedarfe (auf der Ausgabenseite) und Finanzbedarfe gegenüberstellt und Anpassungsmechanismen über entsprechende Finanzausgleichssysteme konstruiert (vgl. Seiler, 1988, 513f).

$152 \mathrm{Vgl}$. dazu die entsprechenden Ausführungen in Kapitel 8.

153 Fiskalische Äquivalenz wird in diesem Kontext in einer schwächeren Form gefordert, denn jede Gruppe, die aus offentlichen Leistungen Nutzen zieht, soll sie auch bezahlen (vgl. Haller, 1971). Wie dann innerhalb dieser Gruppe die individuelle Lastverteilung auszusehen hat, ist im Einzelfall mit entsprechenden Indikatoren festzulegen. Oft wird hierbei vereinfachend von der Gleichheit der Grenznutzen ausgegangen, was demnach eine pro-Kopf-Aufteilung der Gesamtkosten der Gruppenleistung auf die einzelnen Gruppenmitglieder bedingt. Dieser Aspekt wird später (Kapitel 9) noch ausführliche Behandlung erfahren. 
frage lokaler öffentlicher Leistungen und damit die Ableitung effizienter Gemeindefinanzierungssysteme) nicht ganzheitlich und global zu erledigen. ${ }^{154}$ Dazu fehlt bekanntlich ein (auch nur nahezu uneingeschränkt wirksamer) Allokationsmechanismus zur Präferenzoffenbarung auf der lokalen Ebene, der auch durch die Mobilität des Faktors Arbeit (also der Bevölkerung) nur unzureichend gegeben ist.

Außerdem müssen die Mobilität des Faktors Kapital und seine Besonderheiten ebenso in eine Analyse integriert werden, wie Mobilitätshemmnisse, unvollständige Informationen sowie das Zusammenwirken der "Abstimmung mit den Füßen" und der politischen Wahlen. Gravierendstes Problem ist und bleibt jedoch die Isolierung von Wanderungsanreizen aufgrund des lokalen öffentlichen Leistungsangebots und seiner Finanzierung. Die ceteris paribus Annahme für die übrigen die Migration stimulierenden Faktoren ist sicherlich eine der am wenigsten zufriedenstellenden Modellannahmen des Tiebout-Ansatzes und seiner Weiterentwicklungen.

Doch trotz dieser Einschränkungen bleiben die Vorzüge der Mobilität auf der lokalen Ebene auch weiterhin ein wichtiger Aspekt, um die Besonderheiten der lokalen öffentlichen Leistungserstellung und ihre Effizienzaspekte zu verdeutlichen. Die Finanzierungsfrage für das Leistungsangebot stellt sich damit auf der kommunalen Ebene letztlich wesentlich anders dar als auf höheren gebietskörperschaftlichen Ebenen in einem föderativen Staatsaufbau. Doch beginnen wir die Betrachtung "fiskalischer Äquivalenz im weiteren Sinne" zunächst mit einem kurzen Blick auf das eigentliche Äquivalenzprinzip, seine Wurzeln und Grundlagen.

\subsection{Das Äquivalenzprinzip - Beschreibung und Grundlagen}

Das Äquivalenzprinzip führt heute als Norm für die Erhebung öffentlicher Abgaben neben dem Leistungsfähigkeitsprinzip in der Regel ein Schattendasein. ${ }^{155}$ Lediglich im Gemeindebereich - und in diesem Zusammenhang soll es auch in dieser Studie verwendet werden - besitzt es (noch) eine durchaus nicht zu vernachlässigende Bedeutung.

\footnotetext{
154 Musgrave (1961) geht sogar soweit, daß er jedes realisierte kommunale Finanzsystem als einen Kompromiß zwischen den auf individueller Freiheit und auf den nationalen Zielen gründenden Vorstellungen ansieht. Die richtige Wahl - so seine Argumentation - sei eher ein Stück Philosophie als ein ökonomisches Kalkül. Dies mag bei der praktischen Ausgestaltung kommunaler Finanzierungssysteme aufgrund politischer Machtkonstellationen sicherlich so sein, gleichwohl brächte aber ein ökonomisch abgeleitetes System möglicherweise die in Form der Abweichungen von einem solchen Referenzsystem eintretenden Wohlfahrtseinbußen zutage und kann somit als Richtschnur und Orientierungsbasis dienen.

155 Dessen unbeschadet hält Musgrave $(1956,184)$ das Äquivalenzprinzip für so bedeutsam, daß er fordert, ".. where direct sale of public services is possible, such should be the procedure".
} 
Haller (1961) ist dabei das Verdienst zuzuschreiben, mit seiner Arbeit über "Die Bedeutung des Äquivalenzprinzips für die öffentliche Finanzwirtschaft" eine umfassende und übersichtliche Darstellung dieser Thematik geliefert zu haben. Daher soll sich der weitere Verlauf der Argumentation zunächst an einem Tableau orientieren, welches Haller $(1971,14)$ in einer erweiterten Fassung der oben erwähnten Abhandlung vorgelegt hat. Haller benutzt seine Argumentation dabei nicht für eine spezielle Ebene, sondern behandelt den Sektor Staat im allgemeinen. Entsprechend der Aufgabenstellung sollen die folgenden Ausführungen jedoch im wesentlichen auf die lokale Ebene Bezug nehmen.

Haller unterscheidet eine "marktmäßige" ("marktwirtschaftliche") und eine "kostenmäßige" Äquivalenz. Beide Formen werden als "totale" und als "partielle" Äquivalenz aufgefaßt. Die marktmäßige Äquivalenz ist nur auf individueller Basis realisierbar; sie wird im angelsächsischen Sprachraum als "benefit principle" (vgl. etwa Buchanan/Flowers, 1975, 100ff) bezeichnet. Dieses "traditional principle of public finance" (Buchanan/Flowers, 1975, 94) soll Gleichheit zwischen den Vorteilen aus öffentlichen Leistungen (benefits) und den Nachteilen in Form von Beiträgen (contributions), die zur Finanzierung dieser Leistungen zu entrichten sind, beim einzelnen Individuum herstellen. ${ }^{156}$ Daher wird häufig auch vom "individualistischen" Äquivalenzprinzip gesprochen (vgl. etwa Elsner, 1979, 119). In diesem Sinne wird es auch von den Vertretern der sogenannten normativ-utilitaristischen Föderalismustheorie in der Regel benutzt. Sobald die Individuen "... die staatlichen Dienste mit dem Preis bezahlen würden, den sie ihnen wert sind, wobei sie nach dem 2. Gossenschen Gesetz ... entscheiden" (Haller, 1971, 13), liegt also marktmäßige Äquivalenz vor.

Von kostenmäßiger Äquivalenz wird demgegenüber gesprochen, wenn der einzelne Bürger "... soviel Kosten tragen (müßte; Anm. des Verf.), wie er verursacht hat, oder wie auf die von ihm beanspruchte Leistung anteilmäßig entfallen" (Münch, 1976, 120). Wird kostenmäßige Äquivalenz - die sowohl auf individueller wie auch auf gruppenbezogener Basis realisierbar ist - angestrebt, müssen die Kosten für einzelne oder alle Leistungen auf die Empfänger verteilt werden. Es stellt sich also zunächst die Frage, wer als Empfänger entsprechender Leistungen ermittelt werden kann. Daraufhin ist der Kostenanteil zu bestimmen, den jeder Empfänger tragen soll. Dabei bedient man sich in der Regel sogenannter Indikatoren, da eine direkte Ermittlung infolge der Besonderheiten des öffentlichen Leistungsangebots wohl nur in Ausnahmefallen sinnvoll und möglich sein wird (vgl. Münch, 1976). Über die Möglichkeiten einer Kostenverteilung 
nach dem Äquivalenzprinzip sind eine Vielzahl von Arbeiten entstanden, so daß an dieser Stelle diese generellen Ausführungen genügen sollen. ${ }^{157}$

Offensichtlich haben die bei den zuvor dargestellten Möglichkeiten äquivalenter Besteuerung erkannten Probleme dazu geführt, daß das Äquivalenzprinzip heute als Norm für die Erhebung öffentlicher Abgaben neben dem Leistungsfähigkeitsprinzip eher ein Schattendasein führt bzw. die Verfechter des Äquivalenzprinzips sich mit bescheideneren Fragestellungen im Rahmen ihrer Betrachtungen begnügen. Daher interessiert dann nicht mehr die Verteilung der (Gesamt-)Kosten auf die einzelnen Individuen, die einer solchen (Nutzer-)Gruppe angehören, sondern es wird lediglich gefragt, ob "... für bestimmte Gruppen das Anstreben einer kostenmäßigen Äquivalenz gerechtfertigt erscheint" (Haller, 1971, 38). Faßt man nun beispielsweise die Einwohner einer Gemeinde als Gruppe auf, so kann - im Haller'schen Sinne - die Verwirklichung der kostenmäßigen Äquivalenz auch dadurch angestrebt werden, daß von dieser Gruppe "zusätzliche Abgaben allgemeiner Art" (Haller, 1971, 40) gefordert werden, um das überdurchschnittliche kommunale Leistungsangebot zu finanzieren (vgl. Haller, 1971, 39ff). Wie die einzelnen Abgaben auf die einzelnen Mitglieder der Gruppe verteilt werden, wird oft falschlicherweise als davon unabhängiges Problem angesehen (vgl. etwa Wust, 1981). Warum das Problem der "internen" Finanzierungsanteile (also die Kostenbeteiligung des einzelnen Gruppenmitglieds an den gesamten der Gruppe aufzubürdenden Lasten) kein isoliertes und von der Auswahl geeigneter Finanzierungsinstrumente unabhängiges Problem darstellt, wird sich an späterer Stelle noch mehrfach zeigen.

Doch zunächst sollen die Vorstellungen Hallers unter Rückgriff auf weiter oben bereits angestellte Überlegungen noch einmal näher spezifiziert bzw. interpretiert werden. Im Rahmen der Diskussion spezifischer Forderungen an geeignete kommunale Steuern wurde darauf verwiesen, daß den Gemeinden infolge eigener politischer Entscheidung bezüglich ihres Leistungsangebots, das über einen als Versorgungsminimum aufgefaßten größenklassendurchschnittlichen Leistungsstandard hinausgeht, zusätzlicher Finanzbedarf erwächst. Das sogenannte Versorgungsminimum könnte man dabei als jenen Durchschnitt auffassen, an dem Haller die Leistungen der einzelnen Kommunen orientiert, um Gemeinden mit "überdurchschnittlich hohen" Leistungen herauszufinden. Wenn nun davon ausgegangen wird, daß der Nutzen der "überdurchschnittlichen" Versorgung ausschließlich den Mitgliedern der Gruppe zukommt, die sich für eine solche entschieden hat, und darüber hinaus angenommen wird, daß auch nur letztere die zusätzliche Leistung trägt, welche aus dieser Zusatzversorgung resultiert (beides auch Prämissen im Sinne des Haller-Ansatzes), so ist zur Deckung dieses aufgrund kommu- 
nalpolitischer Entscheidungen entstandenen zusätzlichen Finanzbedarfs eine stärkere Ausschöpfung der gemeindeeigenen Steuerkraft erforderlich. Auf diese Weise würden jene Einnahmen erzielt, die Haller aus "zusätzlichen Abgaben allgemeiner Art" erhalten möchte, um die in seinem Sinne "überdurchschnittlichen" Leistungen zu finanzieren (Haller, 1971, 40).

\subsection{Das "Teiläquivalenzkonzept"}

Ein leicht abgewandeltes Verfahren der gruppenäquivalenten Besteuerung ist von Kentmann (1978) vorgeschlagen worden. Es beschränkt sich nicht auf eine - wie auch immer interpretierte - "überdurchschnittliche" Versorgung. Statt dessen geht Kentmann davon aus, daß das Prinzip der gruppenbezogenen kostenmäßigen Äquivalenz auf die Gesamtversorgung von Gruppen mit diese Gruppe jeweils betreffenden Gütern und Leistungen ("Gruppengüter")158 anwendbar ist. Dabei kann es sich beispielsweise um räumlich (die Gemeinde), sachlich (Gesamtheit der Autofahrer in einer Gemeinde) oder zeitlich/altersspezifisch (Gesamtheit der älteren Gemeindebürger) abgegrenzte Gruppen handeln, also um die gesamte Gemeindebevölkerung oder Teile davon (vgl. Kentmann, 1978, 182f).

Diesem ersten Schritt der Nutzerbestimmung bei Gruppengütern in Form der Gruppenabgrenzung schließt sich die Bestimmung der Gruppenzugehörigkeit des Einzelnen an. Dies läßt sich beispielhaft wie folgt verdeutlichen. Für eine räumlich definierte Gruppe ergibt sich die Gruppenzugehörigkeit mit dem Wohnsitz am "Gruppenort" (beispielsweise in einer Kommune), für eine zeitlich definierte Gruppe etwa dadurch, daß der Betreffende einer bestimmten Altersgruppe angehör $t^{159}$, und für eine sachlich definierte Gruppe, indem das Vorhandensein des charakteristischen Gruppenmerkmals aufgezeigt wird.

Im nächsten Schritt erfolgt die Zurechnung des Gruppengutes auf die jeweiligen Gruppen. Da infolge der Charakteristika öffentlicher Güter diese Benutzerfestlegung nicht aus direkter individueller Artikulation (via Nachfrageäußerung unter Nennung eines bestimmten "Preises") erfolgen kann, gilt es die weiter oben vorgestellten Hilfsmittel im Rahmen der "Präferenzerkundung" für lokale öffentliche Leistungen sinnvoll zu

158 Vgl. auch die Behandlung dieser Gruppengüter im Rahmen der Ansätze der sogenannten "Theorie der Clubs" im Kapitel 3 dieser Arbeit.

159 Dieses Verfahren spielt zunehmend eine Rolle bei der Diskussion um sogenannte altersspezifische öffentliche Leistungen und deren Finanzierung bzw. der allgemeiner gehaltenen Fragestellung, ob es demographische Konsumquoten gibt. Vgl. dazu etwa Färber $(1988,66 \mathrm{ff})$ 
integrieren. Derartige Erkenntnisse können unter Verwendung weiterer Quellen (wie Befragungen, Zählungen o.ä.) Aufschluß darüber liefern, ob ein Gruppengut in vollem Umfang auf die beabsichtigte Nutzergruppe zugerechnet werden kann, oder ob auch andere Individuen begünstigt werden. Auf der Basis solcher Angaben ist es dann möglich abzuschätzen, für welchen Nutzungsanteil die Destinatare insgesamt als Vorteilsempfänger infrage kommen. Diese Aufteilung stellt dann die Grundlage für ein "Teiläquivalenzkonzept" (Kentmann, 1978, 184) dar, also für eine (Entgelt-)Finanzierung, bei der die fragliche Nutzergruppe nur für die Bestreitung eines Teils der gesamten Output-Kosten aufkommen muß. ${ }^{160} \mathrm{Da}$ bei den gruppenbezogenen öffentlichen Leistungen davon ausgegangen werden kann, da $\mathrm{B}$ sich die Summe der Vorteile (also alle öffentlichen Leistungen) in der Regel nicht auf die Destinatargruppe begrenzen läßt, wird auch in diesem Fall der partiellen Leistungszurechnung im Haller'schen Sinne (1971, 21ff) die größte Relevanz zugesprochen werden können (vgl. Kentmann, 1978, 184).

Das von Kentmann vorgeschlagene Verfahren der steuerlichen Lastverteilung ("Teiläquivalenzprinzip") läuft also darauf hinaus, daß eine jede Gruppe die Kosten für die Bereitstellung ihres/ihrer jeweiligen Gruppengutes/-güter aufzubringen hat. Um dieses leisten zu können, ist neben der beschriebenen Abgrenzung der Gruppen, der Bestimmung der Zugehörigkeit zu einer Gruppe und der Zurechnung des Gruppengutes auf die Gruppe vor allem die Berücksichtigung von "gruppenexternen Effekten" im Sinne von Nutzen-spillovers zu sichern. ${ }^{161}$ Trotz einer erfolgreichen Gruppenabgrenzung, der sinnvollen Bestimmung der Zugehörigkeit und der entsprechenden Zurechnung des Gruppengutes ist dieses Problem nicht vernachlässigbar, aber wohl doch zumindest reduzierbar. Räumliche spillovers im Sinne der Inanspruchnahme gruppenbezogener Gemeindeleistungen ihrerseits sind außerdem kein spezielles Problem der äquivalenzorientierten Finanzierung, sondern Charakteristikum der lokalen öffentlichen Leistungen und somit würde eine Lösung in diesem Rahmen die Teiläquivalenz überfordern. An anderer Stelle dieser Arbeit sind Möglichkeiten zur Internalisierung räumlicher externer Effekte bereits behandelt worden (vgl. die Ausführungen in Abschnitt 6.1.5). ${ }^{162}$

\footnotetext{
160 Vgl. zur Teilăquivalenz im Gruppenrahmen auch Dammroff $(1970,9)$.

161 Kentmann $(1978,184 \mathrm{ff})$ stellt ausführliche Überlegungen an, wie solche Effekte "internalisiert" werden könnten.

$162 \mathrm{Vgl}$. dazu aber auch die späteren Ausführungen in den Kapiteln 9 und 10 dieser Arbeit.
} 


\subsection{Das Äquivalenzprinzip und der Grundsatz des Interessenausgleichs}

Für eine allokationstheoretische Begründung und die Festsetzung der Gebühren und Beiträge (vgl. Kapitel 8) liefert das Äquivalenzprinzip - speziell hinsichtlich seiner strengen Auslegung - grundlegende Orientierungspunkte. Jedoch läßt sich dieses Prinzip (sein Schattendasein neben dem Leistungsfähigkeitsprinzip dokumentiert dies) nur eingeschränkt auf die generellen Probleme der Besteuerung übertragen, wenn es einen tatsächlichen Ausgleich der Vorteile, die der Einzelne aus bereitgestellten öffentlichen Leistungen zieht, oder der Kosten, die den Gebietskörperschaften durch Aktivitäten der Privaten entstehen, bewirken soll. Auch die Weiterentwicklung im Sinne von Kentmann (1978) und die Formulierung eines Teiläquivalenzkonzepts läßt diese Schwierigkeiten nicht vollends obsolet werden.

Gleichwohl findet das Äquivalenzprinzip bei der Diskussion um eine zweckmäßige Gestaltung kommunaler Finanzierungssysteme immer wieder (richtigerweise) entsprechende Beachtung. Schon bei der Rechtfertigung kommunaler Selbstverwaltung spielen - sehr allgemein gehaltene - Gedanken über die Äquivalenz eine Rolle. So wird im Rahmen föderalismustheoretischer Arbeiten zur Dezentralisierung des Staatshandelns gefordert, daß die Einwohnerschaft einer Gemeinde ihre Angelegenheiten selbst regeln soll, d.h. sie soll beispielsweise die Art und den Umfang der kommunalen Leistungen, welche ihr Nutzen stiften, ebenso eigenständig bestimmen (Ausgabenautonomie) wie die Finanzierung der lokalen Leistungen (Einnahmenautonomie), durch die die Betroffenen einen Nutzenentgang hinzunehmen haben.

Eine solche Äquivalenz kann für jeden einzelnen Bürger postuliert werden (individuelle Äquivalenz), sie kann aber auch auf Gruppen (wie beim Teiläquivalenzkonzept), im Extremfall auf die Gesamtheit aller Einwohner einer Gemeinde, bezogen werden (vgl. Kentmann, 1978, 184ff). Der Wissenschaftliche Beirat beim Bundesministerium der Finanzen (1982) geht noch einen Schritt weiter. Er bezieht bei der Gegenüberstellung der Leistung (lokales öffentliches Leistungsangebot) und der Gegenleistung (Finanzierung dieses Leistungspakets) politische Kompensationen mit ein und formuliert wegen der Unmöglichkeit, strenge Äquivalenzbeziehungen herzustellen, als "schwächere" Form das sogenannte "Prinzip des Interessenausgleichs" (Wissenschaftlicher Beirat, 1982, 32).

Der Ausgleich der Interessen ist vornehmlich ein Gebot, das die Verhältnisse innerhalb einer Gemeinde (beispielsweise das Verhältnis zwischen Wohnbevölkerung und produzierendem Gewerbe) betrifft. Der Wissenschaftliche Beirat $(1982,33)$ spricht daher in diesem Kontext von einem "internen Ausgleich". Ein Interessenausgleich kann aber auch gegenüber Bürgern anderer Gemeinden angestrebt werden. Dies geschieht sinn- 
vollerweise immer dann, wenn eine Kommune überörtliche Funktionen wahrnimmt. In einem solchen Fall ist daher von einem "externen Ausgleich" die Rede (vgl. Wissenschaftlicher Beirat, 1982, 33).

Der interne Interessenausgleich beruht auf der Vorstellung, daß spezifische Bedarfe einer sozialen Gruppe aus Abgaben finanziert werden sollen, die aus dieser Gruppe selbst - also von ihren Mitgliedern - aufgebracht werden. Ein Beispiel dafür wäre die Unterhaltung kommunaler Einrichtungen in einem Gewerbegebiet (lokale Infrastruktur), die im Interesse der örtlichen Wirtschaft (Unternehmen) geschaffen worden sind und demnach aus Steuern, welche diese Unternehmen aufbringen, finanziert werden sollen.

Dieses System des Interessenausgleichs hat primär die Aufgabe zu verhindern, daß politische Mehrheiten in die Lage versetzt werden, kommunale Leistungen zu veranlassen, die vornehmlich den Mitglieder ihrer Gruppe Vorteile verschaffen, aber zugleich eine Finanzierung zu beschließen, die vornehmlich andere Gruppen zu tragen hätten. Um derartigen Konstellationen - d.h. an Partikularinteressen ausgerichtetes Tätigwerden der Gemeinde - auf der Finanzierungsseite vorzubeugen, sollte ein kommunales Finanzsystem einschließlich des Gemeindesteuersystems so ausgestaltet sein, daß ein Interessenausgleich im vorgestellten Sinne möglichst wirkungsvoll erfolgt. Dies bedeutet hinsichtlich der Besteuerung beispielsweise, daß möglichst alle steuerfähigen Gemeindebürger wenigstens zu einer der von "ihrer" Kommune erhobenen Steuern herangezogen werden sollten. Außerdem müßten die einzelnen Finanzierungskomponenten aufeinander abgestimmt werden.

Das beschriebene Problem (Nichtvorhandensein fiskalischer Äquivalenz bzw. eines entsprechenden Interessenausgleichs) tritt auch im Rahmen der finanziellen Beziehungen zwischen den gebietskörperschaftlichen Ebenen zutage. Eine Kommune, die im wesentlichen von der übergeordneten Ebene alimentiert wird, verfährt bei der Festsetzung ihres Leistungsangebots ohne finanzielle Autonomie als "free rider". Sie kann kommunale Leistungen veranlassen, die vornehmlich den Mitgliedern "ihrer" Kommune Vorteile verschaffen, gleichzeitig aber hinsichtlich der Finanzierung auf "nationale" Steuertöpfe zurückgreifen und so dazu beitragen, daß "Nichtnutzer" in einem nicht unerheblichen Ausmaß an der Finanzienung dieser Leistungen beteiligt sind. Ein solches Trittbrettfahrerverhalten läßt sich prinzipiell (bei entsprechend ausgestaltetem Finanzierungssystem) bei allen Kommunen vermuten, so daß eine nicht-effiziente Mittelverwendung in erheblichem Ausmaß die Folge wäre. Die Bedeutung fiskalischer Äquivalenz bzw. des angesprochenen Interessenausgleichs für die Allokationsentscheidungen in einer Volkswirtschaft werden wiederum mehr als deutlich. Neben die interne und die externe Komponente des Interessenausgleichs auf der kommu- 
nalen Ebene tritt also auch ein "vertikaler Interessenausgleich" zwischen den gebietskörperschaftlichen Ebenen, der sich durch eigenständige lokale Finanzierungssysteme ebenfalls realisieren ließe.

Die bisher erörterten allgemeinen Gesichtspunkte sind nunmehr im Hinblick auf den Ausgleich spezifischer interner Interessen zu ergänzen. So können - müssen aber nicht - die Interessen der Wohnbevölkerung mit den Interessen der ortsansässigen Wirtschaft unverträglich sein. Im gleichen Sinne können Konflikte zwischen Interessen der gegenwärtigen und der potentiellen Grundeigentümer oder zwischen Grundeigentümern und anderen Gruppierungen bestehen. Derartige Gruppeninteressen schlagen sich teilweise in Bedarfsanforderungen gegenüber den kommunalen Entscheidungsträgern, teilweise in der Beanspruchung von Rechten gegenüber anderen öffentlichen Entscheidungsträgern oder gegenüber Privaten nieder. ${ }^{163}$ Obgleich nach allen Erfahrungen in solchen Fällen kaum individuelle Zurechnungen der Nutzen und der Kosten (Nachteile) möglich sind, läßt sich doch die Möglichkeit eines Interessenausgleichs vermuten. Diese wird um so wahrscheinlicher, wenn den lokalen Entscheidungsträgern Handlungsspielräume ${ }^{164}$ zugestanden werden, die es ihnen erlauben, zwischen den Interessen der örtlichen Wirtschaft und jenen der Wohnbevölkerung dadurch einen Ausgleich herzustellen, daß die Produktionsbetriebe die von ihnen verursachten Nachteile für die Wohnbevölkerung durch erhöhte Anteile an der Finanzierung der Kommunalausgaben oder durch eine Erhöhung der Kommunaleinnahmen, die zu zusätzlichen lokalen öffentlichen Leistungen führen, kompensieren.

Der Gedanke des Interessenausgleichs geht also über die ökonomisch bestimmten Äquivalenzvorstellungen hinaus. Es basiert zwar auf dem Ansatz der finanziellen Kompensation (fiskalische Äquivalenz), bezieht sich jedoch auf den politischen $\mathrm{Zu}$ sammenhang und regelt darüber hinaus nicht nur eindimensional die Beziehung "Bürger - Kommune" oder "Unternehmen - Kommune", sondern auch der betroffenen Nutzergruppen untereinander. Ein Interessenausgleich ist also qualitativ mehr als fiskalische Äquivalenz, wenn auch quantitativ etwa ungenauer und indirekter ("intangibles" werden einbezogen). Politisch-soziale Bestrebungen gegen den Ausweis neuer gewerblich zu nutzender Flächen oder gegen die Betriebserlaubnis für einen Gewerbebetrieb erhalten demnach erst dadurch ein politisches Gegengewicht, wenn die kom-

163 Beispielsweise können durch den Ausweis von Gewerbeflächen sowie durch Baugenehmigungen und Betriebserlaubnisse für eine Kommune gewisse Notwendigkeiten der Bereitstellung zusătzlicher lokaler Leistungen bewirkt und darüber hinaus mit der Inbetriebnahme des Gewerbes für die Wohnbevölkerung Lărmoder Geruchsbelästigungen verursacht werden (vgl. Wissenschaftlicher Beirat, 1982, 34).

164 Diese Handlungsspielräume finden dort ihre Grenzen, wo politische Mehrheiten einer Minderheit in ungebührlichem Ausmaß finanzielle Lasten aufbürden. 
munalen Entscheidungsträger der Bevölkerung unmittelbare Vorteile nachweisen können, die mit der Entscheidung verbunden sind.

7.5 Möglichkeiten und Grenzen des Äquivalenzprinzips bzw. des Grundsatzes des Interessenausgleichs bei der Auswahl kommunaler Finanzierungsinstrumente

Das zentrale Problem der kostenäquivalenten Finanzierung des örtlichen Leistungsangebots bzw. der Realisierung eines Interessenausgleichs besteht jedoch darin, geeignete Indikatoren zu finden, anhand derer die Verteilung der Kosten öffentlicher Leistungen auf die Nutzer bzw. Kostenverursacher erfolgen soll. Angenommen, man hätte dieses Problem für den Einzelfall einer Sonderleistung gelöst, so wären die erhaltenen Abgaben wohl eher der Sparte "Gebühren und Beiträge" als der Rubrik "Steuern" zuzuordnen. Wenn demnach individuelle Äquivalenz als Richtschnur zur Bestimmung und Lenkung kommunaler Aktivitäten dienen soll, muß für jede individuelle Inanspruchnahme gemeindlicher Leistungen eine Gebühr erhoben werden (vgl. dazu Kapitel 8). Bei den meisten kommunalen Leistungen, beispielsweise der Bereitstellung von Parks, Straßen usw. ist jedoch eine hinreichende individuelle Zurechnung der Vorteile nicht möglich; bzw. sie ist - wie u.a. bei bestimmten sozialen Diensten - nicht sachgerecht. Folglich versagt das individuelle Äquivalenzprinzip, d.h. Gebühren bewirken in diesen Bereichen der Kommunalpolitik nicht die erwünschten allokativen Ergebnisse.

Daher soll es im folgenden um die Frage der Verteilung der für die allgemeinen Leistungen anfallenden Kosten durch allgemeine Abgaben (sprich Steuern) gehen. Die zentrale Frage lautet also, ob sich gerade auch die gemeindliche Besteuerung am Grundsatz des Interessenausgleichs ausrichten sollte. Haller (1971, 39ff) möchte "seine" kostenmäßige Äquivalenz dann verwirklicht sehen, wenn es um die Finanzierung der in seinem Sinne "überdurchschnittlichen" Versorgung der Gemeindeeinwohner geht. Hinsichtlich der Forderung eines Interessenausgleichs müßte sich die gruppenäquivalente Besteuerung jedoch auf den Bereich der Gesamtversorgung, also sowohl auf die durchschnittliche (etwa "zentralnormierte", wie Marcus $(1986,127)$ es ausdrückt) als auch die gemeindlich bestimmte (überdurchschnittliche) Versorgung beziehen. ${ }^{165}$ Die Gemeinde als solche sollte also die Lasten ihres (öffentlichen) Leistungs-

165 In einer derart verstandenen gemeindlichen Besteuenungsvorschrift ist implizit die Forderung enthalten, daß es nicht zu Nutzentransfers aus der angegebenen Versorgung über die Gemeindegrenzen hinweg kommt. Dies wurde bereits mehrfach erwăhnt und hat keineswegs zur Folge, daß bei Existenz solcher răumlicher spillovers gruppenăquivalente Besteuerung völlig ungeeignet erscheint. Es ist vielmehr darüber hinaus sicherzustellen, daß diese răumlichen externen Effekte durch andere Verfahren internalisiert oder aber in die Ausgestaltung des kommunalen Steuersystems einbezogen werden, beispielsweise durch die Berücksichtigung einer sogenannten "externen Nutzergruppe", die die Inanspruchnahme lokaler offentlicher Güter und Leistungen durch "Nicht-Gemeindemitglieder" erfaßt und "verrechnet". 
angebots, das sie in der Regel selbst bestimmt bzw. zumindest mitbestimmen kann, weitestgehend tragen (vgl. Marcus, 1986, 128). ${ }^{166}$ Dies ist anders ausgedrückt nichts anderes als die Forderung nach kommunaler Autonomie sowohl auf der Ausgaben- als auch auf der Einnahmenseite. Mit dieser Forderung ist jedoch noch nichts darüber ausgesagt worden, welche Personen(-gruppen) aus der Gemeinde zur Zahlung herangezogen bzw. wie die Festlegung der individuellen Steuerpflicht sowie die interindividuelle Verteilung der Gesamtlast vollzogen werden sollte.

Zur Beantwortung dieser Fragen muß zunächst geklärt werden, welche Konsequenzen sich für die Ausgestaltung des Gemeindefinanzsystems ergäben, wenn der Grundsatz des Interessenausgleichs in Anlehnung an das "Teiläquivalenzprinzip" im Sinne Kentmann's $(1978,184)$ Verwendung fände. Zunächst müssen die potentiellen Steuer- bzw. Abgabenpflichtigen in den Gemeinden in (Nutzer-)Gruppen - hinsichtlich des lokalen öffentlichen Leistungsangebots - eingeteilt werden. Einteilungskriterium ist der kommunale Finanzierungsbedarf für das jeweilige Leistungspaket, das jeweils in einer bestimmten Beziehung zu den einzelnen Gruppen steht. Der notwendige Finanzbedarf kann zum einen aus der Versorgung irgendeiner Gruppe (beispielsweise der ortsansässigen Produzenten mit Infrastruktur) resultieren; dann wäre die Nutzungsmöglichkeit dieser Infrastruktur und der damit verbundene Nutzenzuwachs maßgeblich für die $\mathrm{Zu}$ ordnung zu dieser Gruppe. Der Finanzbedarf kann aber zum anderen auch dadurch entstehen, daß eine Gruppe durch ihre Aktivitäten kommunale Leistungen provoziert; hier würde die Zuordnung gemäß der Lastenverursachung erfolgen. Jede dieser Teilgruppen müßte nun für den ihr zurechenbaren Finanzbedarf aufkommen.

Wenn sich eine solche finanzbedarfsorientierte Verteilung der steuerlichen Lasten vollziehen ließe, würde ceteris paribus eine Umverteilung von Lasten auf einerseits Nichtnutznießer und andererseits Nicht-Lastverursacher (immer in bezug auf die einbezogenen "Teilgruppen-Leistungen" (Marcus, 1986, 128) vermieden werden. Diese Vorgehensweise würde zur Bevorzugung und Auswahl solcher kommunaler Abgaben führen, die eine engere Beziehung zwischen Nutzenempfang bzw. Lastverursachung und Finanzierungsbeitrag in Form der Kostenbeteiligung (Steuer) in einer Gemeinde herstellen gegenüber Abgaben, die lediglich am allgemeinen gruppenmäßigen Äquivalenzprinzip ausgerichtet sind. In Kommunen, in denen bestimmte Finanzierungstatbe-

166 Diese Grundmaxime erfahrt Einschränkungen, wenn entweder die zu niedrige finanzielle Grundausstattung (vor dem Hintergrund einer an der Einheitlichkeit der Lebensverhăltnisse vorgenommenen Orientierung) seitens der hőherrangigen Gebietskörperschaft kompensiert werden muß, oder allokative, distributive bzw. stabilitătsorientierte Notwendigkeiten eine Durchbrechung dieses Grundsatzes erfordern. Man denke beispielsweise an Finanzzuweisungen von Bund und Land zur Sicherung eines bestimmten Versorgungsniveaus oder zur Gewăhrleistung von Mindeststandards (vgl. Abschnitt 10.3.2). 
stände vorhanden sind, wären in der Regel auch die korrespondierenden Zensitengruppen anzutreffen.

Wenn nun gemäß der hier erörterten Variante einer "interessenausgleichsorientierten Kommunalbesteuerung" tatsächlich verfahren werden soll, sind folglich solche steuerlichen Tatbestände zu identifizieren, die zugleich auch Finanzbedarfstatbestände darstellen. Als drei grundlegende "lastverursachende Tatbestände" in den Kommunen kann man in Anlehnung an entsprechende Erfahrungswerte (vgl. etwa Marcus, 1986, 129 sowie 1987, 128) Grund und Boden, wirtschaftlich Tätige (Unternehmer) sowie Gemeindebürger identifizieren. Der erkennbare Zusammenhang zwischen den eigentlichen Produktionsfaktoren (Boden, Kapital, Arbeit) und dem örtlich angebotenen Güter- und Leistungspaket ist infolge des nachvollziehbaren "Vorleistungscharakters" vieler lokaler öffentlicher Leistungen nicht überraschend. Im Sinne einer effizienten Allokation der Ressourcen einer Volkswirtschaft funktioniert dieses Zusammenspiel also um so eher, je exakter diese interdependenten Nutzen- und Kostenbeziehungen Berücksichtigung finden.

Das kommunale Finanzierungssystem sollte also Steuertatbestände umfassen, die den angesprochenen drei Bedarfskategorien entsprechen. Innerhalb der einzelnen Bedarfskategorien könnten dann wiederum weitere Differenzierungen vorgenommen werden. Die einzelnen Gemeindesteuern sollten bezüglich ihres fiskalischen Gewichts (Anteil am gesamten Aufkommen innerhalb der Kommune) dem Umfang des mit ihnen korrespondierenden Finanzbedarfs (Anteil am Gesamtfinanzbedarf) entsprechen. ${ }^{167}$ Wenn sich diese Vorgehensweise verwirklichen läßt, ergeben sich daraus zwangsläufig gewünschte - weil durch die Verknüpfung von Kosten und Nutzen lokaler öffentlicher Leistungen realisierbare - Auswirkungen auf die Ziele gemeindliche Ausgabenpolitik. Diese Zielsetzungen können beispielhaft die Erhaltung bzw. Erweiterung der gewerblichen Aktivitäten, die Konstanz oder Ausweitung der Einwohnerzahl oder eine Erhöhung des Freizeitwertes sein. Die Mehrdimensionalität dieses Zielkataloges wie auch die Existenz mehrerer (unterschiedlicher) Teilgruppen verlangt in jedem Falle zur Umsetzung des Grundsatzes des Interessenausgleichs ein Gemeindesteuersystems, das sich aus mehreren Abgaben zusammensetzt (vgl. Marcus, 1986, 129), denn der interne Interessenausgleich setzt voraus, daß den Kommunen mehrere Steuerquellen zustehen, die ihrerseits den wichtigsten sozialen Gruppierungen zuzuordnen sind. Der Wissenschaftliche Beirat beim Bundesministerium der Finanzen $(1982,35 f)$ fordert mindestens zwei Steuerarten, "die sich an jenen Gruppierungen ausrichten, zwischen de-

167 Es wird ersichtlich, daß es nicht um eine feste "Verbundlosung" geht (wie sie etwa im Vorschlag des Frankfurter Institut für wirtschaftspolitische Forschung (1988) vorgesehen ist), sondern vielmehr je nach lokalen Gegebenheiten die eine oder andere Finanzierungskomponente je nach Finanzbedarf stärker oder weniger stark ausgeschöpft werden können muß. 
nen sich das stärkste Spannungsfeld erstreckt: der Wohnbevölkerung einerseits und der örtlichen Produktion andererseits". Er konstatiert aber auch, daß es darüber hinaus zweckmäßig sein könnte, "... einen dritten oder gar vierten Pfeiler in das kommunale Steuersystem einzuziehen, z.B. um die kommunalen Leistungen, die den Grundeigentümern zugute kommen, berücksichtigen zu können" (Wissenschaftlicher Beirat, 1982, 36).

Wenn das Äquivalenzprinzip in seiner speziellen Ausprägung als Teiläquivalenz im Sinne des Interessenausgleichs zur Anwendung gelangt, erscheinen Konflikte mit den zentralstaatlichen Lastverteilungsgrundsätzen - vorsichtig ausgedrückt - nicht ausgeschlossen zu sein. Wegen dieser möglichen Zielkonflikte - auf die später noch im konkreten Einzelfall zurückzukommen sein wird - ist das Äquivalenzprinzip und seine Umsetzung auf der lokalen Ebene keineswegs unumstritten. Dennoch hat sich über mehr als ein Jahrhundert hinweg die Meinung konserviert, daß dieses Prinzip eine spezifische Norm der gemeindlichen Besteuerung sei. ${ }^{168}$ Dabei darf allerdings nicht übersehen werden, daß im Zeitablauf die Interpretation des Äquivalenzprinzips durch seine Befüworter nicht gleich geblieben ist. Wurde es vormals in erster Linie als individualistisches Prinzip verstanden, so sind seine Anhänger in jüngerer Vergangenheit sowie in der Gegenwart in der Regel dazu übergegangen, es als gruppenspezifische Norm aufzufassen (vgl. Elsner, 1979, 117ff). Verfechter des Äquivalenzprinzips haben ihre Position u.a. mit der Feststellung verteidigt, daß der Charakter von Staat und Gemeinde unterschiedlich sei. So findet man bei Wagner $(1877,8)$ die kritische Auseinandersetzung mit einer solchen Feststellung ${ }^{169}$; gleichwohl bieten aber die im Verlauf dieser Studie herausgearbeiteten Besonderheiten der lokalen Ebene - wie beispielsweise die Möglichkeit einer "Abstimmung mit den Füßen", die größere Präferenznähe sowie die homogeneren Präferenzstrukturen - Rahmenbedingungen für den lokalen Anbieter, die sich von der zentralstaatlichen "anonymen" Leistungsbereitstellung nicht unerheblich unterscheiden. ${ }^{170}$

$168 \mathrm{Vgl}$. dazu Wagner $(1877,10)$ sowie Meier $(1877,84)$ als ältere und Steuerreformkommission $(1971,703)$, Wissenschafticher Beirat $(1982,32 \mathrm{ff})$ oder Marcus $(1986,122 \mathrm{ff})$ als neuere Quellen. So "... bejaht [die Steuerreformkommission] ... den Äquivalenzgedanken als Rechtfertigung und Maßstab für kommunale Steuern" (Steuerreformkommission, 1971, 703).

169 Diese Auffassung wurde seinerzeit nicht nur von Wagner heftig kritisiert. So verneint Meier $(1877,79)$ eine "Wesensverschiedenheit von Staat und Commune".

170 Daneben sollte auch die von Hansmeyer $(1980,709 \mathrm{ff})$ vorgetragene finanzpsychologische Erklärung zugunsten einer Realisierung ăquivalenter Besteuerung erwăhnt werden. Das Äquivalenzpostulat erleichtert in seinem Sinne eine Rechtfertigung beabsichtigter steuerpolitischer Maßnahmen. 
7.6 Kriterien zur Kostenverteilung des lokalen öffentlichen Leistungsangebots und zur Etablierung kommunaler Finanzierungskomponenten

Ziel der kommunalen Abgabenerhebung in Form von Entgelten (Gebühren oder Beiträge) bzw. Steuern ist also die Belastung der Nutznießer bzw. der Nutznießergruppen des Leistungsangebots und dadurch die Realisierung fiskalischer Äquivalenz bzw. eines Interessenausgleichs. Es geht also beim Aufbau und der Ausgestaltung eines an Effizienzgesichtspunkten orientierten kommunalen Finanzsystems zunächst einmal nicht um Probleme wie sie aus der steuertheoretischen Diskussion im Rahmen der "optimal taxation" bekannt sind - also die Begründung einer umfassenden Allokationsneutralität der Besteuerung - sondern um die Unterstützung bei der Realisierung einer effizienteren Allokation durch die entsprechende Verzahnung gruppenbezogener Kosten- und Nutzerkreise.

Bei der Verteilung des gruppenbezogenen Steueraufkommens auf die einzelnen Mitglieder der Gruppe muß eine Bemessungsgnundlage gefunden werden, die eine sinnvolle Beziehung zwischen der Nutzung des Einzelnen und seinem entsprechenden Kostenbeitrag ermöglicht. Bei der Frage der Steuerverteilung innerhalb der Gruppe ist man (wegen des Nichtvorhandenseins entsprechender individuell geäußerter Nutzeneinschätzungen) auf geeignete Hilfskriterien (Indikatoren) für eine Binnendifferenzierung angewiesen. Je leistungsfähiger solche Indikatoren sind, um so weniger notwendig wird die Inkaufnahme der verbleibenden (ernüchternden) Lösung, nämlich eine Kostenaufteilung nach dem Prinzip des "mangelnden Grundes" pro-Kopf (dieses Verfahren geht als normative Budgetregel vereinfachend von einer Gleichheit der Grenznutzen aus) vorzunehmen, zumal eine solche Vorgehensweise auch sozialpolitisch einige berechtigte Kritik ertragen müßte. Wichtig ist, dies sei abschließend betont, daß diese Verteilung der Finanzierungsanteile innerhalb der Gruppe sehr wohl ein Problem der Ausgestaltung entsprechende kommunaler Finanzierungssysteme ist und nicht ausgeklammert werden darf, wie es in entsprechenden Arbeiten häufig zu beobachten ist. ${ }^{171}$

Abschließend muß also ein an fiskalischer Äquivalenz bzw. einem Interessenausgleich orientiertes und diese Zielsetzungen unterstützendes Gemeindefinanzsystem folgenden Rahmenbedingungen genügen bzw. die entsprechenden Baustein umfassen:

171 So etwa auch der Wissenschaftliche Beirat $(1982,36)$, wenn er konstatiert, daß die "... Interessen innerhalb des Gewerbes einer Kommune ... jedoch ebenso beträchtlich divergieren wie die Interessen innerhalb der Wohnbevollkerung. Dieser Umstand ist nicht zu andern." 
- Intensiver Rückgriff auf das Instrumentarium der Gebühren und Beiträge, die unter allokativen Erwägungen gewünschte Ergebnisse erbringen.

- Ein auf mehreren Pfeilern basierendes Gemeindesteuersystem, mit dem ein Interessenausgleich zwischen den einzelnen Nutzergruppen innerhalb der Gemeinde angestrebt werden kann.

Dabei sind für den internen Interessenausgleich folgende Anknüpfungspunkte sinnvoll:

a) produktionsbezogene Abgaben

- Gewerbesteuer

- Wertschöpfungsteuer

- Cash-flow-Steuer

- Umsatzsteuerbeteiligung mit produktionsbezogenem Verteilungsschlüssel

b) wohnsitzbezogene Abgaben

- Gemeindeanteil an der Einkommensteuer

- lokale Einkommensteuer

- Einwohner- bzw. Bürgersteuer

- Miet- oder Wohnraumsteuer ${ }^{172}$

- Umsatzsteuerbeteiligung mit einwohnerbezogenem Verteilungsschlüssel

c) grundbesitzbezogene Abgaben

- Grund- bzw. Grundvermögenssteuer

- Für einen externen Interessenausgleich, der u.a. durch überörtlich wirksame Leistungen (räumliche spillovers) begründet werden kann, bieten die kommunalen Steuern nur hilfsweise Ansatzpunkte zu einer Lösung. Die geregelten überörtlichen Leistungen, die eine Kommune höherer Zentralörtlichkeit erbringt, sind zweckmäßigerweise im Rahmen von Zuweisungssystemen (also des Finanzausgleichs im eigentlichen Sinne) zu berücksichtigen. ${ }^{173}$ Daher schließt sich an die Betrachtung der Gebühren und Beiträge und der Gemeindesteuern auch eine unter Allokationsgesichtspunkten durchgeführte Behandlung der Finanzzuweisungen an (vgl. Kapitel 10).

172 In diesem Schema ergibt sich insofern eine Überschneidung, als beim Wohntatbestand Produktion und Konsum zusammenfallen und eine Besteuerung der Mieten daher auch in eine Wertschopfungsteuer oder eine allgemeine kommunale Verbrauchsteuer integriert werden kann (vgl. Strauß, 1984, 68).

173 Dies gilt insofern keine Finanzierung mittels Gebühren erfolgt, wie beispielsweise bei Aufenthalten in Krankenhăusern anderer Kommunen (vgl. Wissenschaftlicher Beirat, 1982, 36). 
Eine anders gelagerte Situation könnte sich allerdings ergeben, wenn eine Kommune der Ort zum Einkauf von Gütern und Leistungen der umliegenden Gemeinden ist. Solche privaten Aktivitäten des Handels dürften - mehr oder weniger stark den kommunalen Haushalt des Einkaufsortes berühren, denn für die Ortsfremden müssen beispielsweise Verkehrseinrichtungen erweitert bzw. insbesondere Parkplätze geschaffen werden. Ein externer Interessenausgleich wird dann in der Regel - wie gesagt - über Sonderansätze in den Schlüsselzuweisungen angestrebt werden. Dies erfordert aber praktikable und zuverlässige Schlüssel (Indikatoren), mit deren Qualität und Eignung auch der allokative Wert der entsprechenden Ergebnisse variiert. Als alternative Möglichkeit käme für diesen Ausgleich der Interessen möglicherweise dann auch das Instrumentarium der Kommunalbesteuerung in Frage, beispielsweise in Form einer Abgabe, die an den Umsatz des örtlichen Einzelhandels oder an den Endverbrauchsumsatz anknüpft.

- Abschließend können noch einige ergänzende Vorschläge bzw. überwiegend äquivalenztheoretisch bzw. von ihrem spezifischen Wirkungskreis her begründete $\mathrm{Ab}$ gaben das kommunale Finanzierungssystem abrunden. Dafür kämen in Betracht:

- kommunale Kraftfahrzeugsteuer

- gemeindliche Beteiligung an der Mineralölsteuer

- Stadtteiläquivalenzabgaben (Infrastrukturabgabe, Erschließungsteuer) ${ }^{174}$

- Agglomerationsteuer

- Bodenwertzuwachssteuer

- umweltpolitisch "motivierte" Abgaben ${ }^{175}$

Von diesen Anknüpfungspunkten ausgehend sollen in den folgenden drei Kapiteln geeignete Elemente für das unter Allokationsaspekten zu formulierende kommunale Finanzierungssystem herausgegriffen und analysiert werden.

\footnotetext{
$174 \mathrm{Zu}$ diesen Begriffen vgl. Kentmann (1978, 263ff).

175 Der Wissenschaftliche Beirat sieht in seinem Gutachten zum Gemeindesteuersystem vom 16. Mărz 1968 noch die Chance, durch solche Abgaben die finanzielle Situation vieler Gemeinden zu verbessern (vgl. Wissenschaftlicher Beirat, 1974, 429). Nach den ersten Erfahrungen mit der Abwasserabgabe dürfte dies jedoch inzwischen differenzierter gesehen werden (vgl. Strauß, 1984, 69).
} 
Hans-Georg Napp - 978-3-631-75263-0

Downloaded from PubFactory at 01/11/2019 06:33:05AM

via free access 
"Daher ist die freie und verantwortliche Gemeindeverwaltung unerlaßlich für die Entstehung eines demokratischen Ethos. Nur was im kleinsten Umfang in nachster Nahe jederzeit im Leben praktisch geübt wird, kann die Menschen reif machen zu dem, was sie in größeren und größten Raumen demokratisch verwirklichen sollen."

Karl Jaspers (1957)

\section{Gebühren und Beiträge als kommunale Finanzierungsinstrumente}

Auf keiner anderen gebietskörperschaftlichen Ebene gibt es so viele Leistungen, die mit Hilfe von Gebühren und Beiträgen einzeln oder pauschal verrechnet werden, wie bei den Städten und Gemeinden. In all jenen Fällen, in denen ohne unangemessenen Aufwand der individuelle Leistungsempfang ermittelt werden kann, können "Preise" je Leistungseinheit verlangt werden.

Diese Leistungsentgelte (Gebühren und Beiträge) ${ }^{176}$ sind im Idealfall streng äquivalenzbezogen und damit nahezu ideale "Nutzensteuern" ("perfect benefit based taxes"). Durch Leistungsentgelte kann Überfüllung (congestion) vermieden und spillovers können, soweit die Kosten (Grenzkosten) gedeckt sind, internalisiert werden. Leistungsentgelte können letztlich erhoben werden, wo das Ausschlußprinzip gilt und/oder Anschluß- und Benutzungszwang möglich ist.

Abweichungen von der dabei zugrundeliegenden "Preisbildungsregel" $\left(\mathrm{p}=\mathrm{K}^{\prime}\right)$ sind aus zwei Gründen möglich; dann handelt es sich aber keineswegs mehr um "perfect benefit based taxes". Zum einen können sogenannte "second best"-Preise gerechtfertigt werden, weil die Ausrichtung an den Vollkosten aus fiskalischen Gründen notwendig erscheint (die Gebührenhöhe liegt also über den Grenzkosten). Zum zweiten können die Gebühren aus meritorischen Gründen unter den Grenzkosten liegen. Beispiele hierfür sind die Entgeltfreiheit des Schulbesuchs, geringe Entgelte für die Überlassung von Sporteinrichtungen, ermäßigte Theatereintrittspreise für Schüler oder ermäßigte Fahrpreise für Senioren. Wie verteilungswirksam diese personellen Preisdifferenzierungen

176 Obgleich im deutschsprachigen Raum besonders ausgeprăgt, laß sich auch in anderen Lảndern eine Vielfalt der Begriffe nachweisen. So finden sich im englischen Sprachraum beispielsweise die Bezeichnungen "rate", "toll", "charge", "fee", "tax", "price" und "fare" sowie im französischen die Begriffe "rémunération", "taxe (administrative)", "timbre", "enregistrement", "péage", "contribution" und "prix public". Diese Begriffsvielfalt verdeutlicht, warum in der Frage der Abgrenzung - aber auch in der Argumentation zur Gebühren- und Beitragspolitik - trotz jahrzehntelanger Diskussion noch immer beachtliche Meinungsverschiedenheiten bestehen (vgl. auch Zeitel, 1988, 348). 
jedoch sind, hängt von der Inzidenz der zum Ausgleich benötigten Deckungsmittel oder der alternativen Gemeindeausgaben $a b .{ }^{177}$

$\mathrm{Zu}$ den Leistungsentgelten gehören die kraft Hoheitsrecht erhobenen Gebühren (wie Abwasser- oder Müllabfuhrgebühren), bei denen ein Abnahme- bzw. Anschlußzwang angeordnet wird und die Bemessung der individuellen Entgelte nur mit Hilfe bestimmter Indikatoren möglich ist (wie Anzahl der Wohnungen bzw. Zimmer in einem Gebäude, Anzahl der dort lebenden Personen usw.), die Beiträge (Erschließungs- oder Straßenanliegerbeiträge) sowie die durch Teilnahme am Marktgeschehen erzielten Erwerbseinkünfte (Mieten, Pachten, Erträge aus Versorgungs- und Verkehrsbetrieben). ${ }^{178}$

Soweit die Gemeinden ihre Leistungen aus der Erzielung von Erwerbseinnahmen, Gebühren und Beiträgen finanzieren können, wobei die Zurechnung der individuellen Finanzierungsbeiträge im Sinne des Äquivalenzprinzips ${ }^{179}$ erfolgt, tritt das eigentliche Problem der Suche geeigneter Gemeindesteuern noch gar nicht auf. Man kann daher in Anlehnung an Bohley $(1977,81 \mathrm{f})$ die Gebühren und Beiträge als Spezialfälle von Steuern bezeichnen.

\subsection{Geschichtlicher Ursprung, Begriff und Abgrenzung}

Kaum ein Begriff der Finanzwissenschaft spiegelt umstrittene dogmatische Standorte (vgl. auch Hansmeyer/Fürst, 1968, 9ff) so wider wie der Gebühren(Beitrags-)begriff. Trotz vieler Ansätze zur Definition der Gebühren (und Beiträge) konnte sich dennoch keine einheitliche Auffassung zum Gebührenbegriff durchsetzen (vgl. Wilke, 1973, 17). Wilke (1973, 19ff) sieht lediglich drei "Grundbestandteile" des Gebührenbegriffs, die sich als kleinster gemeinsamer Nenner aus den herkömmlichen Gebührendefinitionen herausschälen lassen. Demnach handelt es sich bei der Gebühr erstens um eine Leistung des einzelnen an den Staat, zweitens gewährt der Staat dem einzelnen seinerseits eine Leistung und drittens sind beide Leistungen miteinander verknüpft. Hansmeyer/Fürst $(1968,18 \mathrm{ff})$ unterscheiden im finanzwissenschaftlichen Schrifttum drei Interpretationen des Gebührenbegriffs. Einmal wird das klassische Konzept von Lei-

\footnotetext{
177 Der Anteil der Leistungsentgelte an den kommunalen Einnahmen ist in der Bundesrepublik Deutschland mit nahezu einem Viertel traditionsgemå relativ hoch (vgl. Karrenberg/Münstermann, 1992, 62). In internationalen Vergleich ist er vor allem in den USA noch höher, wo die Leistungsentgelte teilweise mehr als die Hälfte der eigenen Einnahmen der lokalen Ebene ausmachen.
}

$178 \mathrm{Zu}$ den Gebühren und Beitrăgen vgl. vor allem Zeitel (1988, 347ff); die Erwerbseinkünfte behandelt beispielsweise Kullmer (1988, 412ff).

179 Dabei handelt es sich im Haller'schen Sinne in der Regel um eine partielle individuelle kostenmaßßige Äquivalenz (Haller, 1971, 14). 
stung und Gegenleistung weiter ausgebaut; die Gebühr rückt damit in die Nähe des (Markt-)Preises. In der zweiten Gruppe werden mehr die kollektiven Bestandteile der Gebührenleistung in den Vordergrund gestellt; Anknüpfungspunkt der Gebühren ist aber immer noch eine individuell zurechenbare Leistung. Die dritte Gruppe lehnt eine Sonderbehandlung der Gebühren als "theoretisch sinnlos" (Hansmeyer/Fürst, 1968, 23) oder für die "Praxis unergiebig" (Hansmeyer/Fürst, 1968, 23) ab, denn die Gebühren werden den Steuern gleichgesetzt (vgl. etwa Kleinwächter, 1905, 433ff).

Historisch sind von den Gebühren "nahezu gefühlsmäßig" (Hansmeyer/Fürst, 1968, 26) die Beiträge als besondere Einnahmeart unterschieden worden (vgl. Rau, 1859, 105; von Stein, 1885; 1886); ihre Behandlung erfolgte jedoch im wesentlichen im Rahmen der Gebührentheorie. Neumann $(1874,46 \mathrm{ff})$ hatte dann in seinem Gutachten für den Verein für Socialpolitik erstmals ihre Sonderrolle herausgestellt und sie gegen die verwandte Einnahmeart der Gebühren abgegrenzt ${ }^{180}$, was jedoch in der Folgezeit kontroverse Ansichten über die Beiträge auslöste. ${ }^{181}$

Ein Blick auf die historische Entwicklung der wirtschaftlichen Funktionen der Gebühr und ihres Einflusses auf den wirtschaftlichen Ablauf, daß eine Behandlung erstmals durch die Kameralisten des späten 18. Jahrhunderts stattgefunden hat. Bis dahin wurden Gebühren allenfalls unter dem technischen Aspekt der Einnahmeerhebung gesehen. ${ }^{182}$ Eine Unterteilung nach Verwaltungs- und Benutzungsgebühren und nach Bei-

180 Neumann nennt diejenigen Abgaben Beitrăge, deren Verwendung einzelnen bestimmte Vorteile verschaff. "Und danach werden denn im Folgenden die der Pflicht ihre Ursprung verdanken, nach der Leistungskraft umzulegenden Abgaben ... einfach Beitrăge genannt werden (Neumann, 1874, 65). Von der Gebühr hebt er die Beitrăge wie folgt ab: "Denn auch die Gebühr bemißt sich nach den dem Einzelnen gewăhrten Vortheilen resp. dem Maaße seiner 'Kostenprovokation'. Von dem Beitrag unterscheidet sich die Gebühr durch ein specielleres, individuelleres Anpassen an die bezüglichen Verhalltnisse." (Neumann, 1874, 209). Neumann hat damit die Besonderheit der Beitrăge (speziell in Abgrenzung zu den Steuern), "Vorteile aus den Staatsanstalten" rechnerisch mit deren Kosten auszugleichen klar erkannt (vgl. Neumann, 1874, 54f). Das Bestreben Neumanns, die Beitrảge von den Steuern abzugrenzen wird verstăndlich, wenn man sich vor Augen führt, daß sich in jener Zeit das Leistungsfahigkeitsprinzip erst langsam durchzusetzen begann und bei den Steuern das Äquivalenzprinzip durchaus (noch) Bedeutung hatte. Dabei geht er soweit, die Beitrăge Preise zu nennen, freilich im weiten Sinne definiert als Entgelt für Gegenleistungen (vgl. Neumann, 1896, 259). Es mag daher verwundern, daß die Erörterung der Beitrăge gerade in einer Zeit beginnt, in der für die Besteuerung das Prinzip der Leistungsfähigkeit seinen Siegeszug antritt. Verstăndlich wird dies jedoch durch den Rahmen, innerhalb dessen die Beitrăge diskutiert wurden; es ging dabei um die Finanzreform der Gemeinden, denen ein finanzieller Sonderstatus offenbar nur über den Umweg des Äquivalenzprinzips eingerăumt werden konnte. Das Argument lautete: "Die Aufgaben der Gemeinden sind ortlich begrenzt und bieten nur lokale Vorteile" (Hansmeyer/Fürst, 1968, 27). Daher rankt sich die Rechtfertigung der Beitrăge folgerichtig um eine Rechtfertigung des Äquivalenzprinzips im kommunalen Finanzsystem.

181 Wagner $(1877,118)$ sah in ihnen noch eine Sonderform der Gebühr, widmete ihnen aber immerhin bereits vier Seiten $(1877,129 f f)$.

182 Der steigende Finanzbedarf veranlaßte die Staaten, diese Einnahmequelle immer mehr zu nutzen. Erst mit dem Vordringen des steuerlichen Deckungsverfahrens wurde der zeitweilige "Gebührenfiskalismus" (Zeitel, 1988,348 ) überwunden. 
trägen wird nicht vorgenommen. Beiträge werden - wenn sie überhaupt als besondere Einnahmegattung empfunden werden - den Gebühren zugerechnet.

Die Bedeutung des Gebührenbegriffs verändert sich mit der Einstellung der Finanzwissenschaft zum Verhältnis von Staatswirtschaft und Volkswirtschaft. Die Entwicklung vollzieht sich ausgehend vom kameralistischen Gedanken der fiskalischen Wirksamkeit gebührenpflichtiger Leistungen, dem ein bedeutender Teil der klassischen Gerechtigkeitsgedanken bereits innewohnt, über eine vorübergehende Gleichstellung von Gebühren und Verbrauchsteuern bis hin zu dem klassischen Gedanken der fiskalischen Äquivalenz von staatlich bereitgestellter Leistung und Gebührenentgelt (vgl. Hansmeyer/Fürst, 1968, 29f).

Die dreifache Wurzel der Gebühren und Beiträge - spezielles Finanzierungsmittel für einzelne Staatsinstitutionen, Leistungsentgelt für Amtspersonen und allgemeines Deckungsmittel im Haushalt (vgl. Zeitel, 1988, 347f) - hat sich in dem verwirrenden Sprachgebrauch und in der Argumentation zur Gebühren- und Beitragspolitik erhalten. So bezeichneten in der Vergangenheit Abgaben wie Maut, Brückenzoll, Registerabgabe, Hörergeld, Interessenzuschuß, Verbandslast, Hand- und Spanndienste Gebührenbzw. Beitragstatbestände.

Eine allgemeine Legaldefinition der Gebühren und Beiträge wie für die Steuern im $\S 3$ der Abgabenordnung gibt es nicht. Gesetzliche Bestimmungen finden sich in der Regel in den Gebühren- und Kommunalabgabengesetzen vieler Ländern. Gemeindeordnungen und Gemeindehaushaltsverordnungen liefern ergänzende Vorschriften. Darüber hinaus gibt es in vielen Einzelgesetzen Gebühren- und Beitragsregelungen, von denen die Verwaltungskostengesetze und das Bundesbaugesetz die wichtigsten sind.

Aus heutiger Sicht lassen sich Gebühren, Beiträge und öffentliche Erwerbseinkünfte daher wie folgt klassifizieren. Gebühren besitzen einen Doppelcharakter. In erster Linie sind sie "Entgelt". Sie werden als Gegenleistung für die Inanspruchnahme von besonderen Leistungen (Verwaltungsgebühren) oder für die Inanspruchnahme von öffentlichen Einrichtungen (Benutzungsgebühren) verstanden. Zur Erhebung von Gebühren soll es kommen:

- wenn öffentliche Leistungen veranlaßt werden (Veranlassungsprinzip);

- gleichgültig ob die korrespondierende Leistung eine Begünstigung darstellt oder nicht (Begünstigungsprinzip);

- wenn ein Interesse an einer Leistung vorliegt (Interessenprinzip);

- wenn eine Leistung (aktiv oder passiv) verschuldet wurde (Verschuldungsprinzip). 
Für die Gebührenbemessung gibt es grundsätzlich zwei Wege. Es kann nach dem nutzenmäßigen oder dem kostenmäßigen Äquivalenzprinzip verfahren werden. Im ersten Fall soll sich die Gebühr in ihrer Höhe nach dem individuell realisierten Nutzenzuwachs durch die Leistung bemessen; nach dem kostenmäßigen Äquivalenzprinzip müßte der Gebührenpflichtige die von ihm verursachten und auf ihn entfallenden Kosten für die Leistung über die Gebühr auferlegt erhalten.

Unter Beiträgen werden Abgaben verstanden, welche anläßlich öffentlicher (im öffentlichen Interesse liegender) Leistungen erhoben werden, wobei diese Leistungen einem Teilkollektiv oder einer Gruppe als speziellem Adressaten zugute kommen. Anders als bei den Gebühren wird also hier nicht auf die individuelle Identifikation abgestellt, sondern bei den Beiträgen wird die Gruppenbezogenheit hervorgehoben.

Tabelle 8.1: Abgrenzung von Benutzungsgebühren und Beiträgen

\begin{tabular}{|l|l|}
\hline Benutzungsgebühr & Beitrag \\
\hline $\begin{array}{l}\text { Gegenleistung für die konkrete Benutzung } \\
\text { einer öffentlichen Einrichtung oder Anlage }\end{array}$ & $\begin{array}{l}\text { Gegenleistung für wirtschaftliche Vorteile } \\
\text { durch die Möglichkeit der Inanspruchnahme } \\
\text { einer öffentlichen Einrichtung oder Anlage }\end{array}$ \\
\hline $\begin{array}{l}\text { Abdeckung sämtlicher betriebswirtschaftlicher } \\
\text { Kosten der öffentlichen Einrichtung oder An- } \\
\text { lage }\end{array}$ & $\begin{array}{l}\text { Abdeckung von Investitionsaufwendungen für } \\
\text { die öffentliche Einrichtung oder Anlage (Her- } \\
\text { stellung, Anschaffung, Erweiterung oder Ver- } \\
\text { besserung) }\end{array}$ \\
\hline $\begin{array}{l}\text { Vereinnahmung im Verwaltungshaushalt } \\
\text { öffentlichen Einrichtung oder Anlage }\end{array}$ & $\begin{array}{l}\text { Vereinnahmung im Vermögenshaushalt } \\
\text { Keiterung oder Verbesserung der öffentlichen } \\
\text { Einrichtung oder Anlage }\end{array}$ \\
\hline $\begin{array}{l}\text { Kostendeckende Kalkulation der Benut- } \\
\text { zungsgebühren als Regelfall }\end{array}$ & $\begin{array}{l}\text { In der Regel keine volle Abdeckung der In- } \\
\text { vestitionsaufwendungen durch Beitragsein- } \\
\text { nahmen (öffentliches Interesse an der Einrich- } \\
\text { tung oder Anlage ist durch einen gemeindlich } \\
\text { Anteil an den Aufwendungen auszuweisen) }\end{array}$ \\
\hline $\begin{array}{l}\text { Erhebung von sämtlichen Benutzern der öf- } \\
\text { fentlichen Einrichtung oder Anlage }\end{array}$ & $\begin{array}{l}\text { Erhebung nur von Grundstückseigentümern } \\
\text { oder Erbbauberechtigten }\end{array}$ \\
\hline
\end{tabular}

Die Beiträge müssen nicht die volle Finanzierung der Erstellung einer öffentlichen Einrichtung gewährleisten. Es kann auch auf die teilweise Deckung abgestellt werden. Dies gilt insbesondere dann, wenn die Erstellung mit Zuweisungen Dritter finanziert werden konnte. $\mathrm{Zu}$ den mittels Beiträgen finanzierten Maßnahmen zählt nicht nur die Erstellung neuer Einrichtungen, sondern auch die Erweiterung, Erneuerung, der Umbzw. Ausbau bestehender Einrichtungen. Öffentliche Einrichtungen, für die Beiträge 
erhoben werden, sind typischerweise Straßen, Plätze, Versorgungs- und Entsorgungsanlagen.

Für die Bemessung der individuellen Beitragsplicht muß auf Indikatoren zurückgegriffen werden, die in Zusammenhang mit dem individuellen Nutzenempfang, der aus der kommunalen Maßnahme gezogen werden kann, stehen (vgl. Lehmann, 1983). Als Indikatoren finden in der Praxis folgende Anwendung: Frontmeter, Grundstücksfläche, $\mathrm{Maß}$ der baulichen und sonstigen Nutzung, Baunutzungsfaktor nach zulässiger $\mathrm{Ge}-$ schoßzahl, Wohnungseinheit oder Kombinationen aus verschiedenen Faktoren. Der Grundstücksfläche kommt im Rahmen der Beitragsbemessung dabei besondere Bedeutung zu.

Von den später zu behandelnden Steuern unterscheiden sich Gebühren und Beiträge vor allem dadurch, daß sie nur bei Provokation einer besonderen Leistung bzw. Ordnungshandlung des Staates erhoben werden. Der Tatbestand, daß auf diese Weise Einnahmen erzielt werden, ist anders als bei den Steuern gegenüber dem spezifischen Ordnungswillen des Staates im betreffenden Tätigkeitsbereich nur sekundär bedeutsam (vgl. Zeitel, 1988, 349). Diese Grenzlinie wird freilich wiederum unscharf, wenn unter dem Begriff der Steuern auch Abgaben subsumiert werden, bei denen die Erzielung von Einnahmen Nebensache werden kann (Lenkungs- bzw. Ordnungssteuern).

Auch die äquivalenztheoretische Begründung von Steuern (speziell das Teiläquivalenzprinzip bzw. der Grundsatz des Interessenausgleichs) auf der kommunalen Ebene dies wird sich noch deutlich zeigen (vgl. Kapitel 9) - lehnt sich an das Konzept der Beitragserhebung, nämlich als Abgeltung der einer (Teil-)Gruppe Nutzen stiftenden öffentlichen Leistungen, an.

Im Rahmen der sogenannten Leistungsentgelte werden Gebühren und Beiträge von staatlichen Erwerbseinnahmen und sonstigen Kostenerstattungen abgegrenzt. Die Grenzlinie zwischen Gebühren und Beiträgen bzw. öffentlichen Erwerbseinkünften richtet sich nach der Eigenart der öffentlichen Leistung. Besondere Abgrenzungsschierigkeiten können sich bei den Einnahmen aus öffentlich-rechtlichen Anstalten ergeben. Für die Urteilsbildung, d.h. die Frage ob es sich um hoheitliche bzw. "marktfremde" Betätigungen der öffentlichen Hand und somit um Gebühren und Beiträge handelt oder nicht, ist in Grenzfällen bedeutsam, inwieweit solche Einrichtungen überwiegend aus wirtschaftlichen oder anderen (gesundheits-, sozial- und kulturpolitischen) Motiven unterhalten bzw. errichtet werden.

In der Praxis ist die Trennungslinie zwischen den verschiedenen öfentlichen Einnahmen nicht immer eindeutig. Dies ist insbesondere feststellbar, wenn Gebühren- und 
Beitragstatbestände dazu benutzt werden, daran Steuerpflichten zu knüpfen, oder Steuerpflichten aus steuerpsychologischen Gründen aufgeteilt werden. Zur Begriffsverwirrung trägt auch die Gepflogenheit bei, privatwirtschaftliche Entgeltzahlungen mit den Bezeichnungen "Gebühr" und "Beitrag" zu versehen (Gebühren bei freien Berufen, Vereinsbeiträge). Indessen dürften die vorgenannten Abgrenzungskriterien zumindest mehr Klarheit bei der Differenzierung gestatten und weniger dem Vorwurf ausgesetzt sein, die Begriffsbildung an sich diene schon dazu, Abgaben akzeptabler zu machen (oder auch zu diskreditieren).

\subsection{Beurteilung unter Effizienzgesichtspunkten}

Nachdem weiter oben das Argument der generellen Unteilbarkeit von kollektiven Gütern für die lokalen öffentlichen Leistungen bereits erhebliche Einschränkungen erfahren hat, soll im folgenden das Für und Wider eines entgeltlichen Angebots via Gebühren und Beiträgen untersucht werden. Bevor jedoch beurteilt werden kann, ob sich Gebühren und Beiträge als finanzwirtschaftliches Instrument eignen, um Staatsleistungen effizient(er) zu produzieren oder bereitzustellen, soll der Effizienzbegriff und seine Bedeutung im öffentlichen Sektor noch mal in Erinnerung gerufen werden.

Effizienz bedeutet im öffentlichen Sektor nicht die Verwirklichung des erwerbswirtschaftlichen Prinzips durch das Streben nach privatwirtschaftlicher Rentabilität, sondern wirtschaftliches (d.h. möglichst eng an den Präferenzen der Staatsbürger orientiertes und mit den in Anspruch genommenen Ressourcen gewichtetes) Angebot einer im übrigen politisch bestimmten Leistung. Die Irrelevanz des eigentlichen Gewinnstrebens hat zur Folge, daß den Entscheidungsträgern in den Gebührenhaushalten die Parameter der privaten Unternehmung (und das ist im wesentlichen der "Markt"-Preis mit seinen Funktionen) nicht in der dort gebräuchlichen Vielfalt zur Verfügung stehen. Beispielsweise ist die Nutzung einer Monopolstellung mit dem Zweck der Gewinnmaximierung im öffentlichen Sektor unzulässig ${ }^{183}$, obschon es akzeptiert werden kann, daß sich der staatliche Entscheidungsträger zum Erreichen eines anderen (politisch beispielsweise für richtig empfundenen) Zieles der vorhandenen Marktmacht bedient. So mag eine Selbstbeschränkung in der Vielfalt des Angebots, vergleichbar mit den betriebswirtschaftlichen Maßnahmen der Typenreduzierung und Sortimentsbeschränkung, mit Vorteilen für die Allgemeinheit verbunden sein und insofern ein teilweises Ignorieren der Bedürfnisse der Abnehmer rechtfertigen. Umgekehrt kann es auch Auf-

183 Was nicht bedeutet, daß damit die Wirtschaftlichkeit im Sinne einer allokativen Effizienz gesichert sei. Ganz im Gegenteil, das Fehlen von Konkurrenz wird (wie auch bei gemeinwirtschaftlichen Unternehmen ohne Wettbewerb) ganz von selbst dazu führen, daß der fehlende Druck auf die Kosten eine Preiserhöhung zur Folge hat. 
gabe der öffentlichen Hand sein, neue Bedürfnisse, beispielsweise kultureller Art, zu wecken oder den Bürgern bestimmte (meritorische) Leistungen, etwa im Dienste der Gesundheit, "aufzunötigen". Dies hat aber im Interesse der Allgemeinheit - wie sie auch immer definiert wird - zu geschehen und nicht etwa aufgrund von Rentabilitäts-, wohl aber von Wirtschaftlichkeitsüberlegungen.

Ein weiterer Unterschied zwischen öffentlicher Angebotspolitik und unternehmerischer Absatzstrategie ergibt sich aus struktur- und regionalpolitischer Sicht. Während der private Unternehmer eine bestimmte Leistung an einem bestimmten Ort nur dann anbietet, wenn er einen Gewinn erwartet, obliegt der öffentlichen Hand bei bestimmten infrastrukturellen Grundleistungen in wirtschaftlich schwächeren Regionen eine zwar nur politisch begründbare, aber dennoch allgemein anerkannte Leistungspflicht. Bekannte Beispiele sind Bahn, Post, Energieversorgung, Volksschule und Krankenhaus. Es wäre jedoch übereilt anzunehmen, eine solche Leistungspflicht zöge mit einem gewissen Automatismus für den gesamten Aufgabenbereich eine bestimmte Art der Finanzierung nach sich, wie man dies im Hinblick auf den überragenden Anteil der Steuerfinanzierung - in Verbindung mit der unentgeltlichen Bereitstellung eines Teils dieser und anderer Leistungen - vorschnell annehmen könnte.

Der Tatbestand, daß die öffentliche Leistungspflicht über die privatwirtschaftliche Leistungsabsicht hinausgeht, ändert nichts daran, daß in beiden Sektoren die Effizienzbedingungen die gleichen sind, sofern man die moderne Auffassung als richtig akzeptiert, daß der Staatswirtschaft wie der privaten Ökonomie die Aufgabe zukommt, knappe Ressourcen in einer Volkswirtschaft effizient einzusetzen, d.h. an den Präferenzen der Bürger auszurichten. Entsprechend dem ersten Gossenschen Gesetz gilt, daß man für die staatliche Leistung in der letzten bereitgestellten Einheit keinen höheren Wert an Ressourcen aufwenden darf, als sie damit Nutzen stiftet (vgl. Paulsen, 1965, 144).

Eine solche Übereinstimmung von relativer Wertschätzung der Nachfrager mit den Grenzkosten ist im Sinne eines Pareto-Optimums unabdingbare Voraussetzung für allokative Effizienz (vgl. Münch, 1976, 156); sie ist jedoch bei Steuerfinanzierung der öffentlichen Leistungen nicht von vornherein gewährleistet, da bei unentgeltlicher Inanspruchnahme der staatlichen Leistung und globaler Zwangsfinanzierung nicht sichergestellt werden kann, daß der einzelne zwischen dieser staatlichen und der von ihm nachgefragten privaten Leistung gemäß dem zweiten Gossenschen Gesetz (Ausgleich der Grenznutzen) entscheidet (vgl. Schneider, 1965, 168ff). Man muß daher, ehe aus der Sicht der allokativen Effizienz die steuerliche Finanzierung überprüft werden kann, jeden einzelnen Fall genau analysieren und mit der Alternative der Entgeltfinanzierung abwägen. 
Generell weist die Methode, Gebühren und Beiträge für hoheitliche Leistungen zu erheben, statt diese ohne ein direktes individuelles Entgelt zur Verfügung zu stellen (d.h. die benötigten Mittel mittels Steuern einzuziehen), vielerlei Vorzüge auf. Ganz allgemein macht sich die Gebührenpolitik die Vorzüge und Funktionen des Preismechanismus zunutze (vgl. Hansmeyer/Fürst, 1968, 65ff) und trägt dadurch wesentlich dazu bei, die Allokation der Ressourcen innerhalb des staatlichen Sektors und im Verhältnis zum (nicht-staatlichen) Privatsektor zu verbessern. Bemißt die öffentliche Hand die Gebühren nämlich an dem Wert der Ressourcen, die für die jeweilige staatliche Leistung erforderlich sind, so entspricht sie damit der paretianischen Optimierungsregel (vgl. Münch, 1976, 59ff) und trägt grundsätzlich dazu bei, die allgemeine Wohlfahrt zu heben. Denn der Nutzen, den die letzte Einheit dem einzelnen stiftet und der Wert, der für diese letzte Einheit eingesetzten Ressourcen, sind gleich groß.

Im Gegensatz dazu geben die "konventionellen" Praktiken ${ }^{184}$ (Allokationsverfahren) beim Konsum ("Verteilen") der meisten öffentlichen Leistungen den hoheitlichen Entscheidungsträgern keine oder höchst unzureichende Informationen an die Hand, mit denen sie erkennen könnten, ob ein bestimmtes Versorgungsniveau "seine Kosten wert ist" (vgl. Münch, 1976, 157), oder ob das Bereitstellungsniveau eingeschränkt oder ausgedehnt werden sollte. So darf es denn beispielsweise nicht die Aufgabe des Staates sein, jedes durch Interessenverbände, Bürgerinitiativen oder andere politische Mechanismen artikulierte Bedürfnis zu befriedigen. Dies gilt insbesondere dann, wenn es sich vorwiegend um individuelle oder spezifische Gruppeninteressen handelt oder die geforderten Leistungen über den - für das Zusammenleben in einem Staatswesen unbedingt erforderlichen - Grundbedarf hinaus gehen (vgl. Münch, 1976, 155).

Bei Anwendung des Gebührenprinzips könnten die Gewohnheiten und Reaktionen der Nachfrager unmittelbar reflektiert werden, das jeweilige Gemeinwesen kann sein Angebot einer erhöhten oder einer verminderten Nachfrage anpassen (vgl. Hansmeyer/

184 Durch den Wahlmechanismus (vgl. auch Kapitel 4) läßt sich das bei der kollektiven Bereitstellung von offentlichen Leistungen fehlende Plebiszit der Nachfrage nicht vollwertig ersetzen, denn der Bürger kann neben seinen "normalen" Beiträgen (Steuern) zu der Palette staatlicher Leistungen nur in größeren Zeitabständen im Wege der Wahl und hierbei auch nur höchst indirekt Einfluß nehmen (vgl. Haller, 1961, 253). Margolis $(1968,536)$ nennt einen weiteren wichtigen Grund für die unvermeidlichen Schwăchen und die subjektiven Züge des Wahlprozesses. Beim Anbieter steuerfinanzierter offentlicher Leistungen sind Konsumenten und "Kăufer" nicht identisch. Die "Käufer" sind eine Gruppe gewăhlter und administrativ bestimmter Entscheidungsträger, die mittels Steuern für die erforderlichen Einnahmen sorgen, ohne daß sie indes selbst unbedingt einen Nutzen von der staatlichen Einrichtung haben, noch die auferlegten Steuern mit aufbringen müssen. Ähnliches gilt für die Steuerzahler, denen unter Umständen die von der erhobenen Steuer finanzierte Einrichtung keinen Nutzen bringt bzw. denen ein eventueller Zusammenhang nicht ersichtlich ist. Selbst dann, wenn sich die Ausgaben der offentlichen Hand für eine bestimmte Einrichtung und die dafür zweckgebundenen Steuern insgesamt entsprechen, ist dies noch kein Indiz für den adäquaten Umfang des öffentlichen Leistungsangebots - denn was für die Gesamtheit im Durchschnitt gilt, muß nicht zwangsläufig auch für den einzelnen gelten. 
Fürst, 1968, 59ff). Während der einzelne die Möglichkeit hat, durch Nichtbeanspruchung oder stärkere Nutzung seine Präferenzen "kundzutun", kann der öffentliche Anbieter über die Gebührengestaltung lenkend eingreifen (vgl. Hansmeyer/Fürst, 1968, $105 f f$ sowie Seeger, 1969, 274f). Der Ausstoß an öffentlichen Leistungen läßt sich mit einer gewissen Automatik auf den Umfang bringen, den die Nachfrager zum gegebenen Preis wünschen. Der öffentliche Entscheidungsträger vermag weitgehend mittels Gebühren sicherstellen, daß keine Ressourcen für Bedürnisse vergeudet werden, deren Nutzwert hinter ihrem Ressourcenwert zurückbleibt (vgl. Buchanan, 1965b, 543f).

In der Realität kommt den Gebühren bislang - das gilt mit Einschränkungen auch für die kommunale Ebene - nur eine recht bescheidene Rolle zu. Für viele öffentliche Leistungen (gerade im kommunalen Bereich) gilt jedoch, daß sich bei Gebühren das Angebot an staatlichen Diensten weit eher in eine Richtung entwickeln kann, die den Wünschen der Bevölkerung entspricht (vgl. Haller, 1961, 254). Folglich wird eine Fehlallokation von Produktionsmitteln zur Erstellung des lokalen Leistungsangebots vermieden (vgl. Thiemeyer, 1964, 174); bei einem Angebot ohne direktes Entgelt (also beispielsweise Steuerfinanzierung) entfallt dagegen weitgehend das Plebiszit der Nachfrager. ${ }^{185}$

\subsection{Gebühren und Beiträge als Komponenten kommunaler Finanzierungssysteme}

Ein fiskalisch und finanzpolitisch nennenswertes Potential gemeindespezifischer Einnahmenpolitik im Sinne einer möglichst weitgehenden Entsprechung von kommunaler Belastung und eigenverantwortlich gestalteten gemeindlichen Aufgaben (und Ausgaben) kann also im Gebühren- und Beitragshaushalt der Städte und Gemeinden gesehen werden. ${ }^{186}$

Ohne in diesem Kontext die juristischen und finanzwirtschaftlichen Aspekte der Abgrenzung der Gebühren und Beiträge ${ }^{187}$ von den Steuern zu vertiefen, soll nochmals

185 Eine umfassende Betrachtung der Mőglichkeiten mit Gebühren und Beitrăgen eine effizientere Bereitstellung offentlicher Leistungen zu ermöglichen liefert auf der einen Seite Münch (1976) im Rahmen seines Versuchs, eine Gebührentheorie für Kollektivgüter zu entwickeln, auf der anderen Seite Bătz (1979) mit seiner "Administrativen Preispolitik offentlicher Unternehmen", wobei er die Gebühren und Tarife als Mittel zur Lenkung der Nachfrage nach offentlichen Leistungen untersucht. Hier findet sich in aller Ausführlichkeit eine theoretische und empirische Analyse der sogenannten Leistungsentgelte.

186 "There are two principal reasons urging wider use of public pricing and devices such as special benefit taxes. One is the rare possibility of increasing public revenue in an economically efficient way. The other really the other side of the same coin - is the improvement in the information available to guide the rational allocation of other public sector resources". (Bird, 1976, 35)

187 Vgl. dazu Oettle (1962), Zimmermann (1971), Bohley (1977) sowie Bohley (1980). 
verdeutlicht werden, daß die Gebühr also eine Abgabe für individuell zurechenbare öffentliche Leistungen, und zwar entweder als eine Gegenleistung für Amtshandlungen oder sonstige Tätigkeiten der öffentlichen Verwaltung (Verwaltungsgebühren), ist. Dabei ist die Entgelthöhe nach der Inanspruchnahme (also einem Wirklichkeitsmaßstab) oder - wenn dies besonders schwierig oder wirtschaftlich nicht vertretbar ist nach einem Wahrscheinlichkeitsmaßstab zu bemessen. Während die Gebühr das Entgelt für die tatsächliche Inanspruchnahme einer kommunalen Leistung darstellt und sich in ihrer Höhe prinzipiell auch an deren effektivem Vorteil orientiert, knüpft der Beitrag an dem Nutzen an, der dem Abgabenpflichtigen aus der Möglichkeit erwächst, eine kommunale Einrichtung oder Anlage in Anspruch nehmen zu können. Abgabenpflichtig sind bezüglich der Beiträge daher diejenigen, von denen ein besonderes Interesse an solchen lokalen öffentlichen Leistungen angenommen werden kann.

Motiv und Objekt für die Gebühren- und/oder Beitragserhebung, wenn auch nicht deren einzige Determinante - da sich die Höhe dieser Entgelte auch nach politischen Zielen unter Berücksichtigung der Nachfragestruktur richtet (vgl. Hansmeyer/Fürst, 1968, 34 sowie Bohley, 1980, 921) - ist also die Geldleistung als "Ersatz" für eine Gegenleistung in Form einer Amtshandlung oder sonstigen Tätigkeit der Verwaltung oder für die Inanspruchnahme öffentlicher Einrichtungen (Gebühr) bzw. der Ersatz des Aufwandes fuir die Herstellung, Anschaffung und Erweiterung von öffentlichen Einrichtungen (Beitrag). In diesem Zusammenhang stellt sich die Frage, ob die angenommene Äquivalenz im Einzelfall am Nutzen oder an den Kosten der öffentlichen Leistung zu bemessen ist (vgl. Elsner, 1979, 181). Der Nutzungsmaßstab, d.h. die Maxime der Entgeltbemessung nach dem individuellen Nutzen der öffentlichen Leistung, ist ein Verteilungsmaßstab. Das Kostenprinzip, d.h. die Entgeltbemessung nach den Kosten der öffentlichen Leistung ist dagegen ein Allokationsinstrument (vgl. Rehm, 1981, 212). Beide Ansätze sind nur in der Marginalbetrachtung, also in einem (theoretisch) optimalen fiskalischen System - infolge der Entsprechung von Grenzkosten und Grenznutzen - identisch (vgl. Bird, 1976, 35). Diese exakte Übereinstimmung wird zwar in der Realität kaum erreichbar sein, doch immerhin ist diese Identität bei den Gebühren und Beiträgen zumindest teilweise realisierbar, denn Entgeltfinanzierung wird im Bereich der sogenannten Mischgüter angewandt, also dort, wo das Vorhandensein von Privatkomponenten und die Möglichkeit der Identifizierung bzw. der Androhung des Ausschlusses eine Offenlegung der individuellen Präferenzen nicht nur erfordert, sondern auch am ehesten ermöglicht (vgl. Bohley, 1980, 933).

Der gemeindliche Gestaltungsspielraum bei den Gebühren und Beiträgen hängt also schließlich davon ab, 
- inwieweit kommunale Leistungen überhaupt der Entgeltpflicht unterworfen werden können;

- in welchem Umfang alle potentiell gebühren- bzw. beitragsfähigen kommunalen Leistungen tatsächlich der Entgeltpflicht unterworfen sind;

- inwieweit bei den gebühren- bzw. beitragsfähigen kommunalen Leistungen die Gemeinden über einen selbständig ausfüllbaren Gestaltungsrahmen verfügen;

- in welchen Maße innerhalb dieses Gestaltungsrahmens gegenwärtig tatsächlich der rechtlich vorgeschriebene Regelfall der Vollkostendeckung realisiert und insofern zumindest das durch eine Anpassung der Entgelte an steigende Kosten verfügbare Finanzierungspotential ausgenutzt wird.

\subsubsection{Der kommunale Gestaltungsspielraum bei ihrer Erhebung}

Gebühren und Beiträge sind im Grunde genommen "Kaufkraftübertragungen" (Rehm, 1981, 213), die bei der Gebühr seitens einzelner Wirtschaftssubjekte und beim Beitrag seitens einer Gruppe von Wirtschaftssubjekten bei Vorliegen einer an sie adressierten besonderen lokalen öffentlichen Leistung erfolgen. Diese öffentlichen Leistungen sind dabei in der Regel (wie bereits erwähnt) von einem Mischtypus, da sie durch das Vorliegen externer Effekte und durch die Anwendbarkeit des Ausschlußprinzips gekennzeichnet sind. Zwar besteht auch bei diesen Abgaben keine Zweckbindung in dem Sinn, daß die Entgelteinnahmen auf die Verwendung für bestimmte Ausgaben beschränkt sind; dennoch ist ihre Erhebung an die Bereitstellung bestimmter (im Grundsatz individuell zurechenbarer) Leistungen gebunden. Dies bedeutet insofern einen von dieser Seite her begrenzten einnahmepolitischen Handlungsspielraum.

Das Gebühren- und Beitragspotential wird aber weniger durch diese Feststellung als durch die grundsätzlichere, ordnungspolitische Überlegung bestimmt, daß die Entscheidung für die Abgeltung externer Effekte bei der Zurverfügungstellung öffentlicher Leistungen eine Gebühren- bzw. Beitragspflicht implizieren sollte. Denn die Existenz einer Kollektivgutkomponente öffentlicher Leistungen bedeutet nicht zwangsläufig eine Entscheidung für deren "Verstaatlichung". Es gibt eine verstaatliche Leistungserbringung mit marktwirtschaftlicher Preisgestaltung, wie es auch umgekehrt eine private Leistungserbringung mit "politisch gestalteten" Preisen, d.h. einer daran geknüpften Gebührenpflicht gibt (vgl. Bohley, 1977, 77). Das bedeutet, die Entscheidung darüber, welche Leistung gebühren- bzw. beitragsfähig und -pflichtig sein und welcher Kostendeckungsgrad für die einzelne Abgabe angestrebt werden soll, ist eine politische; d.h. sie beruht nicht auf einer gegebenen (gewissermaßen "überpolitischen") theoretischpositivistischen Abgrenzung, sondern auf einer normativen Wertung (vgl. Zeitel, 1988, 
349f). Je nach den Entscheidungskriterien für ein solches Urteil ergeben sich unterschiedliche Beitrags- und Gebührenpotentiale. ${ }^{188}$

Bei dieser Argumentation ist allerdings zu prüfen, inwieweit die Gemeinden dieses Einnahmepotential selbständig ausschöpfen können. So gibt es im Regelfall von Seiten der höherrangigen gebietskörperschaftlichen Ebenen (also beispielsweise der Länder) oft Eingriffe in die kommunale Gebührenhoheit, etwa im Bereich der Verwaltungsgebühren auf den Gebieten der Auftragsangelegenheiten und der weisungsgebundenen Pflichtaufgaben oder auch im Bereich der Benutzungsgebühren (vgl. Rehm, 1981, 214). 189

$\mathrm{Da} ß$ aber dennoch selbst innerhalb des gegenwärtig den Gemeinden zur eigenverantwortlichen Ausschöpfung verfügbaren Rahmens ein im Hinblick auf die Entgeltfinanzierung hinreichend großer einnahmepolitischer Spielraum gegebenen ist, wird deutlich, wenn man die tatsächlichen Gebührenhaushalte mit dem rechtlich vorgeschriebenen Regelfall der Vollkostendeckung ${ }^{190}$ vergleicht. Dabei ist zu diskutieren, welcher Kostendeckungsgrad bei den praktizierten Kalkulationsschemata in den einzelnen Leistungsbereichen zur Zeit tatsächlich erreicht ist bzw. welche Kostenarten in welcher Höhe in Ansatz gebracht werden sollten. So lassen sich bei gleichem Ressourcenbedarf für die Erstellung einer bestimmten öffentlichen Leistungseinheit in Abhängigkeit von den berücksichtigten Kostenarten und Bewertungsansätzen nicht unerheblich voneinander abweichende kostendeckende Gebührensätze ermitteln (vgl. Doose, 1981, $277 \mathrm{ff}$ ).

Im Hinblick auf das dem Äquivalenzprinzip entsprechende mengen- und wertmäßige "Kostengerüst" ist darauf zu verweisen, daß der Verwaltungskameralistik günstigstenfalls die pagatorischen Kosten als Teil der Gesamtkosten zu entnehmen sind. Von daher gilt bis heute auch als unumstritten, daß die Ermittlung der Selbstkosten öffentlicher Leistungsbereiche und damit die Kalkulation der Gebühren ein ergänzendes Rechnungssystem voraussetzt (vgl. Gornas, 1976, 140ff sowie Götz, 1978, 77ff). Allerdings kann auch die Anwendung betriebswirtschaftlicher Grundsätze für den öffent-

188 So kommt beispielsweise Münch $(1976,245)$ bei einer Gruppierung der kommunalen Aufgaben gemäß der Finanzstatistik in gebührenfahige Aufgabenbereiche - d.h. in jene Kategorien öffentlicher Aufgaben, bei denen die Adressaten der sogenannten "privaten Komponente" im technischen Sinn feststellbar bzw. ausschließbar sind und die Identifikation bzw. der Ausschluß mit wirtschaftlich vertretbarem Aufwand möglich ist - zu dem Ergebnis, daß das potentielle Gebührenaufkommen etwa doppelt so hoch wie das tatsăchliche ist.

189 Schließlich ist noch zu erwähnen, daß die Praxis der Verwaltungsgerichte offenbar immer dann eine gemeindeeigene Gebührenpolitik erschwert, wenn statt eines Wirklichkeitsmaßstabes ein leichter handhabbarer Wahrscheinlichkeitsmaßstab für die Gebührenbemessung gewăhlt wird (vgl. Fürst/Klein, 1972, $241 \mathrm{ff}$ ).

190 Vgl. dazu Ehle (1962, 45ff), Raecke (1971, 15ff), Clausen (1978) sowie Bătz (1979, $51 \mathrm{ff})$. 
lichen Bereich keineswegs eine vollständige Antwort auf die Frage geben, welche Kosten in welcher Höhe in die Gebühren eingehen sollen. Es stellt sich weiterhin die Frage, wie etwa die fixen Kosten in Abhängigkeit von der Zahl der simultanen Nachfrage (z.B. Besucherzahl pro Zeiteinheit in einem Schwimmbad) anfallen. Ist es dann etwa gerechtfertigt, (höhere) Gebührensätze in Abhängigkeit von der (steigenden) Besucherzahl zu erheben (vgl. auch Budäus, 1978, 365)? Ist bei den Abschreibungen vom Anschaffungs- oder vom Wiederbeschaffungswert auszugehen? Beide Methoden führen nämlich, da der Wiederbeschaffungswert in der Regel über dem Anschaffungswert liegt, zu unterschiedlichen Gebührensätzen. ${ }^{191}$

Weitere Problembereiche stellen die Fragen dar, ob kalkulatorische Zinsen auf das eingesetzte Kapital berechnet werden und (wenn ja) für welche Wertbasis sowie in welcher Höhe. ${ }^{192}$ Die Einbeziehung kalkulatorischer Zinsen läßt sich damit begründen, $\mathrm{daß}$ zugunsten der Benutzer der jeweiligen öffentlichen Leistung der Allgemeinheit ein bestimmter Nutzen in Höhe der Opportunitätskosten entzogen wird. Diesem Nutzenentgang kann bei Erreichen einer vorgegebenen Verschuldungsgrenze nur durch eine Verzinsung des Eigenkapitals mit einem Zinssatz Rechnung getragen werden, der mindestens dem Fremdkapitalzinssatz entspricht.

Unter Verweis auf die (verwaltungsrechtliche) Beschränkung des Ermessensspielraums bei der Festsetzung der Entgelthöhe durch das Kostenüberschreitungsverbot ${ }^{193}$ wird

191 Die Problematik der Kalkulationsgrundsătze soll am Beispiel kommunaler Regiebetriebe im Bereich der Abwasser-bzw. Abfallentsorgung verdeutlicht werden. "Nach allen Kommunalabgabengesetzen der Länder - so z.B. § 6 II KAG NW - sind bei der Entgeltkalkulation ... alle betriebswirtschaftlich ansatzfahigen Kosten zu berücksichtigen. Die dabei unterschiedlichen Vorschriften zum Ansatz kalkulatorischer Kosten auf der Basis von Anschaffungswerten oder Wiederbeschaffungszeitwerten spiegeln die unterschiedlichen betriebswirtschaftlichen Sichtweisen wider. Entsprechend der finanzwirtschaftlichen Refinanzierungsfunktion von kalkulatorischen Abschreibungen (als Gegenwert für die Wertminderung abnutzbarer Wirtschaftsgüter) für Erneuerungsinvestitionen ist mit Ausnahme von Bayern, Baden-Württemberg und Rheinland-Pfalz (keine Abschreibungen auf beitragsfinanzierte Vermögenswerte, da bei Emeuerungsinvestitionen wiederum Erneuerungsbeitrăge erhoben werden) hier von ungekürzten Vermögenswerten der Entsorgungsanlagen einschließlich zuschuß- und beitragsfinanzierter Teile auszugehen, um Emeuenungsinvestionen ohne erneute Beitrăge und staatliche Zuweisungen finanzieren zu können. Auf der Basis von Wiederbeschaffungszeitwerten, die in allen Kommunalabgabengesetzen mit Ausnahme der v.g. Bundesländer erlaubt sind, ist auch eine substantielle Kapitalerhaltung möglich, da alle leistungsbezogenen Kosten einschließlich der Preiseffekte erfaßt werden, um im Erneuerungsfall ausreichende Refinanzierungsmittel verfügbar $\mathrm{zu}$ haben." (Schweisfurth, 1991, 18)

192 Kalkulatorische Zinsen sind in allen Bundesländern auf gekürzte Vermögenswerte (d.h. ohne Abzugskapital) zu erheben, wobei auch hier in Nordrhein-Westfalen und Hessen die Zugrundelegung von Wiederbeschaffungszeitwerten erlaubt ist. Letzteres findet seine betriebswirtschaftiche Rechtfertigung darin, daß bei der kalkulatorischen Verzinsung für die Nutzung des im Anlagevermögens gebundenen Kapitals auf den jeweiligen Zeitwert des Anlagekapitals abzustellen ist (vgl. Schweisfurth, 1991, 19).

193 Nach den Kommunalabgabengesetzen der einzelnen Bundesländer bilden die Kosten der offentlichen Einrichtungen oder Anlagen die Obergrenze für die Bemessung der Gebühren. Überschüsse zur Finanzierung anderer Haushaltsausgaben dürfen nicht erzielt werden. Vgl. dazu Alvermann/Gebert $(1979,12 f)$. 
häufig die Auffassung vertreten, eine Intensivierung der Abgeltung öffentlicher Leistungen durch Gebühren und Beiträge über das gegenwärtige Maß hinaus sei nicht möglich (vgl. Weilepp, 1976, 579 sowie Institut "Finanzen und Steuern", 1978, 14f). Karrenberg/Münstermann (1992, 103ff) verdeutlichen jedoch, daß diese Auffassung so allgemein nicht zutrifft. Alle Analysen verdeutlichen zwar, daß die "klassischen" Gebührenhaushalte (wie Abwasserbeseitigung, Abfallbeseitigung, Straßenreinigung und Schlachthöfe) kostenrechnend geführt werden (aber selbst in diesen Bereichen eine Kostendeckung von $90 \%$ und darüber eher die Ausnahme darstellt). Die Intensität der betriebswirtschaftlichen Kostenermittlung nimmt hingegen schon beim Bestattungswesen und bei den Bädern ab; bei den kulturellen Einrichtungen (Volkshochschulen, Theatern, Museen) wird diese Methode bislang nur ausnahmsweise angewandt. ${ }^{194}$

8.3.2 Ökonomische Rechtfertigung einer Ausschöpfung der Finanzierungspotentiale im Gebühren- und Beitragsbereich

Abschließend soll nochmals thesenhaft verdeutlicht werden, warum eine stärkere Nutzung des Potentials der Gebühren- und Beitragserhebung für die Kommunen sinnvoll erscheint.

- Erstens würde die mit dem Äquivalenzprinzip (als der entscheidenden Gestaltungsmaxime der kommunalen Finanzwirtschaft) angestrebte Kongruenz des Nutzenund des Kostenkreises sowie des Kreises der Träger finanzpolitischer Entscheidungen erleichtert (vgl. etwa Kentmann, 1978, 65ff, aber auch die Bemerkungen in Kapitel 7 dieser Arbeit).

- Zweitens wären diese Leistungsentgelte unter äquivalenztheoretischen Gesichtspunkten ein geeignetes Instrumentarium der Kostenverteilung für zentralörtliche Einrichtungen (vgl. auch Abschnitt 6.1) bei jenen kommunalen Leistungen, bei de-

194 Die Einnahmen der Gemeinden aus Gebühren und Beitrăgen haben sich zwischen 1970 und 1990 in der Bundesrepublik Deutschland mehr als vervierfacht. Damit erhöhte sich im gleichen Zeitraum ihr Anteil an den kommunalen Einnahmen von etwa 16 auf über $20 \%$. Dieser Zuwachs geht nicht nur auf die Preisentwicklung zurück, sondern auch auf die Erhőhung der Kostendeckungsgrade, zumal die Lănder regelmåßig in ihren jährlichen Haushaltsführungserlassen für die Kommunen die Vergabe bestimmter Finanzzuweisungen davon abhängig machen, daß die betroffene Gemeinde ihre Gebühren und Beitrăge in zumutbarem $\mathrm{MaB}$ erhebt. Dennoch sind hohe Zuschußbedarfe (beispielsweise im Bildungs- oder Kulturbereich) ein deutliches Indiz für einen beachtlichen einnahmepolitischen Spielraum der Gemeinden bei der Erhebung der Leistungsentgelte (vgl. Wrobel/Münstermann/Zabel, 1976, 377ff). Dem wird hăufig entgegen gehalten, $\mathrm{da} B$ in diesen Bereichen aufgrund einer deutlich elastischeren Nachfrage und fehlender rechtlicher oder faktischer Zwănge zur Leistungsabnahme Gebührensteigerungen (infolge höherer Kostendeckungsgrade) zu Leerkapazităten und damit möglicherweise (noch) größeren Finanzierungsdefiziten führen (vgl. Karrenberg/Münstermann, 1981, 70). Die (wenigen) empirischen Untersuchungen zu diesem Komplex stützen jedoch diese Argumentation nicht; sie deuten vielmehr gerade bei diesen (lokalen) offentlichen Leistungen auf eine zumindest mittelfristig sehr geringe Nachfrageelastizităt hin (vgl. Hanusch, 1979, 184ff). 
ren Inanspruchnahme der Wohnort des Benutzers erfaßt wird (beispielsweise öffentliche Büchereien, Schulen etc.) und bei denen der mit wachsender Entfernung von den zentralörtlichen Einrichtungen abnehmende Nutzen in der Höhe dieser Entgelte Berücksichtigung finden könnte (vgl. Hansmeyer, 1979, 97f).

- Drittens würde die Struktur der kommunalen Leistungen besser auf die "Bedarfe" abgestimmt, da man davon ausgehen kann, daß das Entgeltprinzip die Gewohnheiten und Reaktionen der Nachfrager unmittelbar reflektiert (vgl. Hansmeyer/Fürst, 1968, 59ff), so daß die öffentliche Hand ihr Angebot im Einzelfall dem Niveau und der Struktur der "Nachfrage" anpassen kann (vgl. Mushkin/Bird, 1972, 23; Bird, 1976, 35 und 55; Wittmann, 1979, 287ff). Der Hinweis, die "Nachfrage" nach öffentlichen Leistungen sei allein deshalb nicht feststellbar, weil deren tatsächliche Inanspruchnahme wegen der fehlenden Kostenpreise überhöht sei (vgl. KrauseJunk, 1988, 349f), ist allenfalls als zutreffender Befund, nicht aber als normativer Einwand gegen die Möglichkeiten der Entgeltfinanzierung im Dienste der Allokationspolitik zu akzeptieren.

- Viertens würde ein stärkerer Rückgriff auf das Instrumentarium der Gebühren und Beiträge den Umfang und die Struktur kommunaler Leistungen auch insofern steuern, als so der zunehmenden "Sozialisierung" auch rein privater Güter entgegengewirkt werden könnte (vgl. Bonus, 1978, 49ff). ${ }^{195}$

- Fünftens ist das einnahmepolitische Potential der Gebühren und Beiträge durchaus auch wachstumsreagibel. Man denke nur an die mit der wirtschaftlichen Entwicklung zugenommene Differenzierung der Ansprüche an die öffentliche Leistungsdarbietung und die verbesserten technischen Möglichkeiten, das Ausschlußprinzip wirtschaftlich vertretbar umzusetzen (vgl. Münch, 1976, 232 sowie Ganter, 1980, 113).

Gegen eine Intensivierung der Abgeltung öffentlicher - insbesondere kommunaler Leistungen durch Gebühren und Beiträge werden oft distributive Gesichtspunkte vorgebracht. Es würden - so der Argumentationsgang - mit einer Gebühren- und Beitragserhebung insbesondere dann unerwünschte Verteilungseffekte verbunden sein, wenn vorher steuerfinanzierte Ausgaben über diese Instrumente finanziert würden. Den positiven Allokationsaspekten bei einer Anwendung des Äquivalenzprinzips stünden dann negative Distributionsaspekte gegenüber. Dieser mögliche Einwand verliert je-

195 Bonus (1978, 77f) weist darauf hin: "Der stăndig wachsende Staatsanteil ist nicht zuletzt unerwartete Nebenwirkung der Anwendung des Leistungsfahigkeitsprinzips anstelle des Äquivalenzprinzips bei der Staatsfinanzierung. Der fast durchgăngige Übergang zu diesem Prinzip erfolgte aus sozialen Gründen; er hat aber den Öffentlichkeitsgrad staatlicher Leistungen erhöht. Denn das Leistungsfăhigkeitsprinzip entkoppelt Leistungen und Gegenleistungen; dadurch versetzt es den Staatsbürger in ein Gefangenendilemma, sobald er die gesamtwirtschaftich gebotene Zurückhaltung bei der Inanspruchnahme staatlicher Leistungen üben wollte." 
doch an Bedeutung, wenn man bedenkt, daß die sogenannten "Sozialtarife" bzw. "Nulltarife" öffentlicher Leistungen gerade unter verteilungspolitischen Aspekten problematisch sein können, da sie bei Nichtdifferenzierung jedem (Be-)Nutzer zugute kommen, selbst wenn dieser aufgrund seiner Einkommens- und/oder Vermögensverhältnisse in der Lage wäre, ein kostendeckendes Entgelt zu entrichten (vgl. Buchanan, 1972, 1ff; Netzer, 1970, 188). Daher schließt dieses Argument (die negativen Verteilungswirkungen) die Anwendung des Äquivalenzprinzips über Gebühren- und Beitragshaushalte nicht aus. Vielmehr verdeutlicht diese Kritik die Notwendigkeit, auf dafür geeigneten Wegen für eine befriedigende Einkommensverteilung zu sorgen. ${ }^{196}$ Sofern Verteilungsaspekte beachtet werden müssen, ist es wirkungsvoller, kostendeckende Gebühren und Beiträge zu erheben und den Benutzern (soweit erforderlich), aus dem Sozialhaushalt entsprechend ihrer individuellen Einkommensverhältnisse Transfers zu zahlen. ${ }^{197}$

Andererseits können die Leistungsentgelte neben ihrer allokativen Funktion aber auch als verteilungspolitische Instrumente eingesetzt werden. Dabei ist vor allem an jene Fälle zu denken, in denen durch die Existenz öffentlicher Einrichtungen oder durch Amtshandlungen bei einzelnen oder bei Gruppen Einkommenszuwächse im Sinne von Differentialrenten entstehen (vgl. Bohley, 1980, 936ff). ${ }^{198}$

196 "The idea that everyone should be able to afford health service is more an argument for improved income distribution than for free services (Kafoglis, 1969, 171f). Bös demonstriert anhand von Modellen über das Wählerverhalten, daß bei gravierenden Abweichungen vom allokativen Optimum die Mehrheit der Wähler gegenüber weiteren allokativen Fehlentwicklungen sensibler ist als gegenüber einer weiteren Umverteilung (vgl. Bös, 1980, 76ff).

$197 \mathrm{Zu}$ Recht betont Bird $(1976,10)$ : "The traditional view that the presumably undesirable distributive effects of benefit taxes preclude them from playing a significant role in a modern public finance system simply misses the key point that the appropriate level and direction of redistributive transfers is, in principle, a quite separate question from that of financing public services and placing the allocatively correct price of resources used for public purposes."

198 Ein Beispiel dafür sind die durch staatliche (kommunale) Aktivität bewirkten Wertsteigerungen des privaten Grundbesitzes (vgl. Stemmler, 1973, 124ff sowie Engelken, 1974, 690). Allerdings würde die Verwendung dieser Entgelte zu distributiven Zwecken voraussetzen, daß das Prinzip der Kostendeckung im Sinne der Obergrenze der Entgeltbemessung aufgegeben wird. Stattdessen müßten sich diese am Umfang des Einkommens(Vermögens-)zuwachses orientieren dürfen. Daneben wirft die konkrete Abgrenzung der Bemessungsgrundlage die bekannten methodischen und administrativen Probleme auf, wie die Grenzziehung zwischen realisierten und nicht-realisierten Gewinnen, der zutreffenden Isolierung der speziell den staatlichen (kommunalen) Maßnahmen zurechenbaren Einkommenssteigerungen sowie der zeitlichen Abgrenzung der wertauslösenden Faktoren (vgl. Wissenschaftlicher Beirat beim Bundesministerium der Finanzen, 1988, 31ff; Leutner, 1977, 173ff sowie Andreae, 1980, 600ff). Diesen Schwierigkeiten könnte man möglicherweise damit begegnen, daß eine reine Infrastrukturabgabe oder ein sogenannter "aufgestockter" Erschießungsbeitrag erhoben wird (vgl. v. Einem, 1981, 252ff sowie Müller, 1981, 95), doch im Ergebnis würden dann die angestrebten allokativen und distributiven Zielsetzungen verfehlt (vgl. v. Nell-Breuning, 1977, 150ff und Bach, 1978, 89ff). 
Hans-Georg Napp - 978-3-631-75263-0

Downloaded from PubFactory at 01/11/2019 06:33:05AM

via free access 


\section{Gemeindesteuern: Beschreibung, Beurteilung und Verwendbarkeit}

\subsection{Der Analyserahmen}

\subsubsection{Beschreibung der Vorgehensweise}

In Anlehnung an die Grundgedanken zur gruppenbezogenen Äquivalenz und des Interessenausgleichs (vgl. Kapitel 7) und die entsprechende Identifikation von Nutzergruppen für kommunale Leistungen ergeben sich für die Gemeindebesteuerung vier Grundpfeiler. Ein an Effizienzgesichtspunkten ausgerichtetes Gemeindesteuersystem müßte demnach eine produktions-, eine einwohner- und eine grundbesitzbezogene Abgabe umfassen. Darüber hinaus sollte, da es nur im Idealfall möglich erscheint, den Nutzen aus den Leistungen einer Gemeinde völlig auf ihren Raum begrenzen zu können (Kongruenzprinzip), eine "exportbezogene" Abgabe diesem Tatbestand (nämlich dem Transfer kommunaler Leistungen über die Gemeindegrenzen hinweg) Rechnung tragen und daher Aufnahme in ein gemeindliches Steuersystem finden. Diese vier Grundpfeiler bilden das Gerüst dieses "Steuerkapitels", in dem versucht werden soll, für jede einzelne Säule eine geeignete Abgabeart - die den Anforderungen, die an eine Gemeindesteuer zu stellen sind, gerecht wird - zu finden.

Aus dem großen Bukett möglicher kommunaler Besteuerungsalternativen werden im weiteren Verlauf diejenigen herausgegriffen, die entweder schon als gemeindliche Abgaben Verwendung finden oder die sich im Rahmen der Diskussion um effiziente, ideale oder praktikable lokale Steuersysteme als denkbare Besteuerungsformen herauskristallisiert haben. In der Regel werden die diskutierten Abgaben zunächst unabhängig davon beurteilt, welche weiteren Steuern in das kommunale Finanzsystem einbezogen werden. ${ }^{199}$ Der Systemaspekt - d.h. die Zusammenstellung eines kommunalen Steuerbzw. Finanzierungssystem - soll dann abschließend in Kapitel 11 behandelt werden.

Infolge des allokativen Primats bei der Finanzierungsentscheidung auf der lokalen Ebene sollen im weiteren Verlauf geeignete Steuerarten vor allem unter Effizienzgesichtspunkten analysiert werden. Dabei wird bei der folgenden Betrachtung neben ge-

199 Doch auch wenn es gemäß der obigen Zielsetzung in erster Linie um das Auffinden geeigneter Kommunalabgaben geht, soll doch bereits im Rahmen einer Einordnung der jeweiligen Abgaben ins Gesamtsteuersystem eines offentlichen Gemeinwesens auf mögliche Probleme und Zielkonflikte mit der zentralstaatlichen Ebene und deren Aufgaben und Zielsetzungen hingewiesen werden. 
nerellen allokativen Zielsetzungen ${ }^{200}$ vor allem Wert auf die besonderen Steuerprinzipien im lokalen Kontext gelegt. Das bedeutet, daß sowohl eine Gesamtbeurteilung der einzelnen Steuern unter den üblichen Allokationsgesichtspunkten als auch eine Bewertung der einzelnen Abgabeformen speziell unter lokalen Aspekten (also ihrer Eignung als Gemeindesteuer) vorgenommen werden soll. Während hinsichtlich der generellen allokativen Wirkungen jeweils ein partial-analytischer Modellansatz Verwendung findet, werden Modifikationen bzw. Ergänzungen dieser allgemeinen Analysen vorgenommen, wenn die einzelne Steuer ihre spezifische Eignung für ein Gemeindesteuersystem beweisen muß.201

Daneben wird es notwendig sein, auch andere (wesentliche) allgemeine steuerpolitische Zielsetzungen bei ihrer Übertragung auf den kommunalen Bereich entweder abzuwandeln oder - wie bei der Frage nach der konjunkturpolitischen Einsetzbarkeit von Steuern - gegenteilig auszugestalten. Die spezifischen Anforderungen an kommunale Steuern bzw. ein kommunales Steuersystem sind dann letztlich entscheidend dafür, ob eine Steuer tatsächlich als Gemeindesteuer geeignet erscheint. Ein unter diesen ökonomischen Gesichtspunkten entwickeltes (Referenz-)System hebt sich vor allem von den häufig sehr unterschiedlich motivierten Ansätzen in der tagespolitischen Diskussion ab und erlaubt dadurch eine "objektivere" Beurteilung der Möglichkeiten und Grenzen kommunaler Besteuerung.

\subsubsection{Allgemeine Effizienzaspekte}

Die leistungshemmenden oder auch anreizschädigenden Wirkungen ("disincentives") der Besteuerung nehmen in der politischen und wissenschaftlichen Diskussion bekanntermaßen einen immer breiteren Raum ein (vgl. Wiegard, 1984, 15). "Beseitigung der negativen Anreizwirkungen", "Förderung der individuellen Leistungsbereitschaft", so oder ähnlich lauten entsprechende Forderungen, die an eine Reform des Steuersystems gestellt werden. Vorgeschlagen werden dazu eine Reihe steuerpolitischer Maßnahmen (wie eine Verringerung der Gesamtsteuerlasten, die Umstrukturierung des Steuersystems durch Verstärkung der indirekten bei gleichzeitiger Zurückdrängung der direkten Steuern oder eine Reduktion der Grenzsteuersätze), deren Zielsetzung vor allem die optimale Ausgestaltung (unter dem Gesichtspunkt der ökonomischen Effizienz) einzelner Steuern bzw. des Steuersystems ist. Die Zielsetzung der Ansätze im Rahmen

\footnotetext{
$200 \mathrm{Vgl}$. dazu die umfangreiche "Optimal-Taxation"-Literatur, für die hier nur exemplarisch die Ausgangsarbeiten von Mirrlees (1971) sowie Diamond/Mirrlees (1971) und der Überblicksartikel von Kay (1990) genannt werden sollen.
} 
der Theorie der optimalen Besteuerung (vgl. auch Tiepelmann/Dick, 1988, 416) ist deshalb die Reduktion bzw. Vermeidung steuerinduzierter Substitutionseffekte und damit die Gewährleistung bzw. Förderung einer effizienten (Faktor-)Allokation im privaten Sektor.

Um die optimale Allokation im privaten Sektor zu fördern, wird häufig auch für kommunale Steuern gefordert, daß sie die Faktorallokation in der Gemeinde nicht oder möglichst wenig beeinflussen sollten (vgl. etwa Milbradt, 1981, 523).202 Dabei wird generalisierend davon ausgegangen (vgl. Tiepelmann/Dick, 1988, 419), daß die Steuerung über den Markt prinzipiell ausreicht. Nur wenn diese nicht oder nicht zufriedenstellend funktioniert, könnte von der Neutralitätsforderung abgewichen werden. Dann werden beitrags- oder gebührenähnliche Belastungen für bestimmte öffentliche Leistungen, bei denen der einzelne entweder einen speziellen Nutzen hat oder der Gemeinschaft spezielle Kosten aufbürdet (Ziel der Internalisierung von externen Effekten), vorgeschlagen. Voraussetzung sei allerdings - so wird betont -, daß ein besonderer Konnex zwischen einzelnen Ausgaben und Abgaben eine solche Besteuerung rechtfertigt. Wenn und soweit eine "Besteuerung" nach dem Äquivalenzprinzip - nämlich eine Entsprechung von individuellem Nutzen (bzw. Kostenverursachung) und öffentlichen Ausgaben - nicht vorliegt, sollten zur Erfüllung der Neutralitätsforderung Steuern mit einer möglichst umfassenden Bemessungsgrundlage ("broad-based taxes")203 gewählt werden. Diese Steuern sollten dann aus Neutralitätsgründen mit proportionalen Sätzen ausgestattet sein. Dies sähe dann so aus, daß über die gruppenmäßige Äquivalenz die Nutzergruppe eines öffentlichen Leistungsangebots identifiziert würde, jedoch infolge der fehlenden Möglichkeit der individuellen Zurechnung ("Prinzip des mangelnden Grundes") die Steuerlast innerhalb der Gruppe möglichst neutral verteilt wird.

Diese Forderungen nach Neutralität auch der kommunalen Steuern und damit der Sicherstellung einer unverzerrten "privaten" Faktorallokation sind jedoch vordergründig und verallgemeinernd. Die herausgearbeiteten spezifischen Besonderheiten der kommunalen Ebene bieten im Vergleich zur allgemeinen Behandlung der Staatsausgaben und -einnahmen Möglichkeiten und Perspektiven für Effizienzsteigerungen, die sich im Grunde genommen nur für diese Ebene ergeben (vgl. Kapitel 2). Daher resultieren besondere Charakteristika, denen durch eine Formulierung besonderer (lokaler) Anforderungen an (Gemeinde-)Steuern Rechnung getragen werden soll und die die Wahrneh-

\footnotetext{
202 Richter $(1991,2)$ spricht in diesem Zusammenhang auch von "fiskalischer Wettbewerbsneutralităt".

${ }^{203}$ Der Grund liegt darin, daß zum einen bei gleichem Aufkommen der Steuersatz niedriger ist, je großßer die Bemessungsgrundlage gewăhlt ist, und zum anderen die Chance steigt, möglichst alle ökonomischen Aktivităten gleich zu behandeln (Neutralitătsforderung).
} 
mung der Allokationsaufgabe auf lokalem Level von der auf zentralstaatlichem Niveau unterscheiden. Kurz gesagt, die Steuern bekommen für die lokale Ebene im Hinblick auf eine möglichst effizienz-orientierte Bereitstellung öffentlicher Leistungen unter Allokationsgesichtspunkten eine aktive Rolle (zur Verknüpfung von Nutzer, Zahler und Entscheider) und sind nicht - wie im Regelfall für den Staat als ganzes unterstellt ausschließlich fiskalisch motivierte Zwangsabgaben, die infolge ihres fehlenden Bezugs zur eigentlichen (realen) Gegenleistung weitestgehend neutral und für die Faktorallokation im privaten Sektor unmerklich erhoben werden sollen.

\subsubsection{Besondere Bewertungskriterien für kommunale Steuern}

\subsubsection{Lokale Kriterien allokativer Natur}

Weil nicht nur die Struktur, sondern auch der Umfang lokaler Aktivitäten sich unter allokativen Erwägungen an den Präferenzen der Betroffenen orientieren sollte, ist neben einer kommunalen Ausgabenautonomie auch eine Einnahmenautonomie von Bedeutung. Da letztere im Grunde genommen bei der Gewährung von Zuweisungen der übergeordneten Gebietskörperschaften gänzlich ausscheidet bzw. eine Beschränkung der Finanzierungsmöglichkeiten auf Gebühren und Beiträge (Leistungsentgelte) zu eng ist, müssen aus Allokationserwägungen heraus den Gemeinden Steuereinnahmen zugewiesen und - dies ist von grundlegender Bedeutung - auch Einflußmöglichkeiten auf die Höhe der Steuereinnahmen gewährt werden.

Ein solcher Einfluß könnte zum einen darin bestehen, durch entsprechende Aktivitäten (etwa Wirtschaftsförderung) bei Steuern - die nach dem örtlichen Aufkommen verteilt werden - Steuerkraft zu attrahieren oder bei einer Aufteilung nach anderen Kriterien durch Einwirkungen auf die entsprechenden Schlüsselgrößen den Steueranteil einer Gemeinde zu beeinflussen. Die Möglichkeiten einer solchen indirekten Methode sind jedoch sehr beschränkt und allenfalls langfristig gegeben, so daß zur Realisierung von Einnahmenautonomie ein direkter Einfluß auf die Steuerhöhe über den Tarif und/oder die Bemessungsgrundlage notwendig erscheint. Dies muß jedoch nicht zwangsläufig so interpretiert werden, daß den Kommunen das Recht zur uneingeschränkten Tarifgestaltung oder gar ein Steuerfindungsrecht eingeräumt werden muß (vgl. etwa Mohl, 1992).

Wenn möglich sollte jedoch die kommunale Autonomie durch die laufende Steuerpolitik der Oberverbände möglichst wenig tangiert werden. Daher ist es sinnvoll, den Gemeinden Steuern zuzuweisen, bei denen die Chancen bzw. Notwendigkeiten späterer oberverbandlicher Eingriffe in die Bemessungsgrundlage und/oder die Tarifstruktur gering sind. Die Zubilligung eigener Variationen der Bemessungsgrundlage bzw. des 
Steuertarifs und die Gewährung eines eigenständigen kommunalen Hebesatz- oder $\mathrm{Zu}$ schlagsrechts bedeutet folglich eine "Aufteilung" des sich ergebenden kommunalen Steueraufkommens nach den örtlichen Bedürnissen und Rahmenbedingungen.

Wenn nun unter dem Leitbild einer möglichst an den Präferenzen der Bürger ausgerichteten kommunalen Aktivität die Gemeinden weitgehende oder eingeschränkte Autonomie bezüglich der Steuerfestsetzung besitzen, ergeben sich interlokal differierende Steuerbelastungen. Diese Unterschiede sollten für die jeweiligen Gemeindebürger fühlbar und transparent sein und möglichst viele - im Idealfall alle - Einwohner (Wirtschaftssubjekte) erfassen. Zur Realisierung dieser Fühlbarkeit, Spürbarkeit bzw. Merklichkeit sollten kommunale Steuern so ausgestaltet sein, daß die Wahrnehmung der jeweiligen Belastung durch die Steuerpflichtigen garantiert werden kann. Grundlegende Bedingung für die Eignung einer Abgabe als Gemeindesteuer ist also die Merklichkeit der spezifischen Steuerlast für die Gemeindeeinwohner ${ }^{204}$.

Die Träger steuerlicher Lasten müssen aber nicht nur "fühlen", daß sie steuerliche Aufwendungen tragen, sondern darüber hinaus auch noch feststellen können, daß sie diese für "ihre" jeweilige Gemeinde entrichten. Dazu ist es notwendig, mittels der Herstellung einer fiskalischen Äquivalenz ein "wirksames finanzielles Band" zwischen der Gemeinde und ihren Einwohnern zu knüpfen. Häufig wird in diesem Kontext die Meinung vertreten, "... daß sich nur sehr wenige Zensiten dafür interessieren, welcher Gebietskörperschaft die gezahlte Steuer zufließt" (Zwilling, 1971, 74). Gelingt es jedoch, den Trägern der gemeindlichen Steuern diese Lasten bewußt zu machen, und existiert die Möglichkeit, aufzuzeigen, daß die Gemeinde ihrerseits die individuelle Steuerlast je nach Bedarf (Ausgabennotwendigkeit) verändern kann, wird es den Zensiten nicht mehr gleichgültig sein, an welchen Gläubiger (also welche gebietskörperschaftliche Ebene im allgemeinen und welche Kommune im besonderen) ihre Abgaben fließen.

In diesem Zusammenhang wird in der Regel auch die sogenannte "örtliche Radizierbarkeit" erwähnt. Das Prinzip der örtlichen Radizierbarkeit ${ }^{205}$ von kommunalen Leistungen und ihrer Finanzierung ist in seiner Begründungslogik eingebettet in die unter Allokationsaspekten erhobene Forderung nach fiskalischer Äquivalenz bzw. einem In-

\footnotetext{
204 Neumark (1979, 29 und 42) bezeichnet das Merklichkeitspostulat daher auch als Forderung nach Transparenz des kommunalen Steuersystems.

205 Popitz $(1932,114)$ verwendete den Begriff der Radizierbarkeit das erste Mal und stellt in diesem Zusammenhang fest, daß sich die den Gemeinden überlassenen Steuern gemäß diesem Prinzip rechtlich und technisch auf die Einheit der Gemeinde abstellen lassen müssen. Als Gemeindesteuern sind demnach insbesondere Abgaben geeignet, "... bei denen eine starke örtliche Verknüpfung unmittelbar im steuerlichen Tatbestand selbst liegt" (Popitz, 1932, 114). Hansmeyer $(1966,171)$ fordert in diesem Kontext, daß Steuerobjekte und Bemessungsgrundlagen im Bereich einer Gemeinde "săuberlich getrennt" nachgewiesen werden müssen. Vgl. auch Zwilling (1971, 77).
} 
teressenausgleich. Demnach sollen die Nutzer kommunaler Leistungen auch für deren Finanzierung aufkommen. Darüber hinaus wird mit dieser Zielsetzung die Forderung verbunden, daß die zur Deckung von Gemeindeausgaben notwendigen Steuereinnahmen aus Steuerquellen geschöpft werden sollen, die auf die Gemeinde bezogen sind. Gemeindliche Steuern sollen also Objekte erfassen, die mit dem Gemeindegebiet räumlich verbunden sind (vgl. Popitz, 1932, 114). In jüngerer Zeit hat sich Neumark für radizierbare Kommunalsteuern ausgesprochen. Er stellt eine ähnliche Forderung wie Popitz auf und verlangt, daß Gemeindesteuern "... örtliche ... Tatbestände zum Gegenstand bzw. zur Bemessungsgrundlage haben" (Neumark, 1979, 30) sollen.

Wird dieser Forderung im Rahmen der konkreten Ausgestaltung eines Kommunalsteuersystems entsprochen, ist damit eine wesentliche Grundvoraussetzung geschaffen, auf der dann andere Besteuerungsgrundsätze aufbauen können und allokative (Effizienz-)Zielsetzungen erreichbar erscheinen. Die örtliche Radizierbarkeit besitzt besonders dann Relevanz, wenn es um die Verwirklichung einer (gruppen-)äquivalenten Besteuerung und die damit zusammenhängenden Forderungen nach Fühlbarkeit und Merklichkeit bzw. einer Korrespondenz zwischen Finanzbedarf und Steueraufkommen (vgl. Marcus, 1986, 140f) sowie die Realisierung eines entsprechenden internen Interessenausgleichs (vgl. Wissenschaftlicher Beirat, 1982, 32ff) zwischen Belasteten und Begünstigten geht.

Befürworter des Merklichkeitspostulates treten dafür ein, daß möglichst viele Gemeindeeinwohner an der Finanzierung gemeindlicher Lasten beteiligt werden sollen. Demnach bezieht sich die Wahrnehmung dann auch auf eine möglichst große Anzahl gemeindlicher Zensiten. Hinter diesem Grundsatz steht die Auffassung, daß bei Nichtvorhandensein eines Belastungsgefühls bezüglich der Nutzen aus steuerfinanzierten kommunalen Leistungen das Ziel, das Verantwortungsbewußtsein der Gemeindeeinwohner gegenüber der örtlichen politischen Entscheidungsfindung zu unterstützen, nicht erreicht werde. Hier wird deutlich, daß es nicht nur um das "Fühlen" von steuerlichen Lasten geht, sondern auch um die Merklichkeit der Nutzen aus den damit finanzierten kommunalen Leistungen. Das Interesse der verschiedenen Teilgruppen, das sich in ihren jeweiligen Leistungswünschen und in von ihren Aktivitäten verursachten kommunalen Ausgaben niederschlägt, kann im Rahmen der politischen Abstimmungsprozesse oder durch interkommunale Wanderungsbewegungen zum Ausgleich gebracht werden. Auf diese Weise dürfte eine einseitig orientierte Politik der Kommunen - also eine Verfolgung von und einseitige Ausrichtung an Partikularinteressen - die Ausnahme bleiben.

Folglich können Fehlallokationen infolge eines unreflektierten Anspruchsdenkens der Bevölkerung oder einer "Weihnachtsmannmentalität" vieler Politiker und Bürokraten 
reduziert werden. Diesem Aspekt sollte man einen hohen Stellenwert beimessen. Gerade auf der kommunalen Ebene besteht noch am ehesten die Chance, daß der einzelne die Zusammenhänge zwischen öffentlichen Ausgaben und der daraus resultierenden Steuerbelastung sieht und entsprechende Verhaltensanreize wirksam werden (vgl. dazu auch die Ausführungen in den Kapiteln 4 und 5). ${ }^{206}$

Kommunale Ausgaben- und Einnahmenautonomie kann also eine Verknüpfung von erhaltener öffentlicher Leistung und dafür notwendiger Gegenleistung für den privaten Sektor ermöglichen, denn dies ist auf lokalem Niveau wegen der größeren Präferenznähe eher möglich als auf zentralstaatlichem und läßt sich damit auch eher im Bewußtsein der Bürger verankern. Das einzelne Individuum kann somit die Auswahl eines bestimmten Leistungsangebots im Hinblick auf die "Kosten", die mit der Erstellung und Bereitstellung desselben verbunden und auch von ihm selbst zu tragen sind, bei insgesamt mehr Transparenz des Entscheidungsumfeldes vornehmen. Auch die Entscheidungsträger einer Gemeinde werden wegen der größeren "Bürgernähe" ihrer Entscheidungen stärker als die Entscheidungsträger der bürgerferneren (Zentral-)Staatsebene auf den Zusammenhang zwischen Leistungen und den mit ihrer Bereitstellung verbundenen Kosten achten.

Die Vorteilhaftigkeit dezentraler Leistungserstellung tritt also nur dann zutage, wenn die Gemeinden die Möglichkeit besitzen, ihr Leistungsangebot aufgrund autonomer Entscheidungen (notwendigerweise auch von der Finanzierungsseite) zu variieren. Diese Möglichkeit existiert nur dann in ausreichender Form, wenn die Gemeinden in der Lage sind, Einfluß auf die Höhe ihrer Einnahmen nehmen zu können, um diese an den aus ihren eigenverantwortlichen Entscheidungen resultierenden Finanzbedarf anpassen zu können. Falls diese Anpassung nicht vollzogen werden kann, sind die Möglichkeiten auf der Ausgabenseite entsprechend eingeschränkt; die kommunale Selbstverwaltung an sich also ebenfalls.

Damit kommunale Selbstverwaltung keine Leerformel bleibt und ihre Möglichkeiten in bezug auf die Erreichung ökonomischer Zielsetzungen ausgeschöpft werden können, benötigen die Gemeinden also eigenständige Entscheidungsbefugnisse sowohl auf der Ausgaben- als auch auf der Einnahmenseite ihres Budgets. Daraus resultieren - insbesondere durch die Berücksichtigung einer in einer einzelnen Gemeinde unter Umständen gewünschten besseren Ausstattung (höheres Versorgungsniveau) und damit verbundener höherer Belastungen durch Steuern oder zusätzliche Abgaben - interkommu-

206 Allerdings verliert dieses Argument mit steigender Gemeindegröße einen Teil seiner Überzeugungskraft und Faszination; man denke nur an Millionenstädte. Der dann als mögliche Lösung reizvoll erscheinende Gedanke einer Steucrautonomic von einzelnen Stadtbezirken in Millionenstädten soll jedoch nicht weiter verfolgt werden. 
nale Steuer(Aufkommens-)unterschiede, die aufgrund der gelieferten Begründungen jedoch durchaus positiv zu bewerten sind.

Folglich sind gleich große sowie gleichartige Gemeinden in der Lage, ein unterschiedliches Leistungspaket zu erstellen und anzubieten. Dies hat zur Folge, daß sich eine regionale Vielfalt der Lebensverhältnisse herbeiführen läßt, die in bezug auf die Autonomiezielsetzung der gemeindlichen Besteuerung durchaus erwünscht ist. ${ }^{207}$ Sobald sich also eine Gemeinde entscheidet, die erwähnte Mindestversorgung zu überschreiten, stellt sich für sie die Frage nach der Deckung des aus dieser Entscheidung resultierenden zusätzlichen finanziellen Bedarfs. Diesem Sachverhalt trägt die Forderung nach Beweglichkeit der Besteuerung Rechnung; also der Existenz steuerpolitischer Aktionsparameter im lokalen Bereich. Als Folge ist eine differierende Ausschöpfung von Steuerkraftpotentialen zu erwarten.

Neben den innergemeindlichen Allokationswirkungen (innerhalb des privaten Sektors oder zwischen privatem und öffentlichem Bereich) sind für die Beurteilung der Gemeindesteuern besonders die interlokalen Allokationseffekte von Bedeutung, d.h. die Wirkungen auf den Güteraustausch und die Faktorwanderungen. Solche Effekte werden bei finanzieller Autonomie in der Regel von unterschiedlichen Steuer(Hebe-)sätzen zwischen den einzelnen Kommunen ausgehen; sie können aber auch - bei gleicher Steueranspannung - in kommunalen Aktivitätsunterschieden begründet sein, die aufgrund von Differenzen der Steuerkraft pro Kopf, abweichender Inputpreise oder unterschiedlicher lokaler Präferenzen existieren. Eine weitere Erklärung für entsprechende Allokationseffekte können natürliche Standortvorteile sein, die dann zur Abschöpfung einer Art Standortrente infolge günstiger klimatischer, topographischer, verkehrstechnischer oder landschaftlicher Vorzüge führen können. Diese interlokalen Allokationseffekte (die in der Regel als Substitutionseffekte in vielfältiger Form - beispielsweise als Migrationsanreize - auftreten) sind immer dann nicht zu beanstanden, wenn sie Spiegelbild der lokalen Unterschiede der privaten und/oder kommunalen wirtschaftlichen Aktivitäten sind. Der herzustellende Interessenausgleich - soweit möglich - kann folglich unterschiedliche Steueranspannungen legitimieren, so daß auch Steuerkraftunterschiede pro Kopf zwischen den Gemeinden allokationspolitisch nicht zu kritisieren sind.

207 Dies steht in krassem Gegensatz zu Forderungen beispielsweise hinsichtlich einer sogenannten "bedarfsgerechten interkommunalen Steuerkraftverteilung" (vgl. Abschnitt 9.1.2), die wohl eher zu einer Angleichung des bei Normsteuersătzen erzielbaren Aufkommens tendieren. Die Diskussion um die Erfassung des dabei im Mittelpunkt stehenden "Finanzbedarfs" und seiner Bedeutung spielt vor allem bei der Beschăftigung mit dem institutionalisierten kommunalen Finanzausgleich eine entscheidende Rolle. Vgl. dazu Marcus (1986, 102 bzw. 1987, 120) sowie Peffekoven $(1988,631$ ). 
Die Orientierung an der privaten Wirtschaftsaktivität und die Beeinflussung dieser Handlungen durch die lokalen öffentlichen Leistungen ist folglich der entscheidende Ansatzpunkt effizienz-orientierter kommunaler Besteuerung. Der Begriff der privaten Wirtschaftsaktivität ist jedoch nicht exakt faßbar. Er beinhaltet Aspekte der Einkommensentstehung gleichermaßen wie Aspekte der Einkommensverwendung. Die Bemessungsgrundlagen von "broad-based taxes", nämlich Einkommen, Wertschöpfung, Konsum oder Faktorentlohnung, erfassen somit jeweils nur Teilbereiche dieser privaten Wirtschaftsaktivität. Zwar existiert zwischen allen eine Korrelation, so daß jeder der vier Indikatoren ein geeigneter Maßstab zur Messung der privaten Wirtschaftsaktivität und damit Anknüpfungspunkt einer kommunalen Besteuerung sein könnte, doch bestehen zwischen den einzelnen Alternativen auch nicht zu übersehende Differenzen bezüglich der resultierenden Steuerkraftverteilung. Solche Differenzen können durch die unterschiedliche Berücksichtigung der Pendlerströme, der Faktorwanderungen, der Bevölkerungszusammensetzung, des Industriebesatzes usw. entstehen. Daher stellt sich unter Allokationsgesichtspunkten letztlich die Frage, welche Bemessungsgrundlage für kommunale Steuern sinnvoll erscheint.

Aus den vorstehenden Ausführungen wurde deutlich, daß die kommunalen Aktivitäten nicht nur den in der jeweiligen Gemeinde ansässigen Haushalten zugute kommen, sondern ein nicht unbedeutender Teil in Form sogenannter räumlicher Externalitäten über die Gemeindegrenze hinaus Wirkungen aufweist. Damit partizipiert am kommunalen Leistungsangebot in der Regel auch die in der Gemeinde produzierende oder konsumierende Bevölkerung, die aber ihren Wohnsitz außerhalb des Gemeindegebietes hat. Um diesen unterschiedlichen Aspekten gerecht zu werden, dürfte ein aus mehreren "broad-based taxes" bestehendes Steuersystem geeigneter sein als eine kommunale Alleinsteuer. Dadurch werden auch extreme Steuerkraftschwankungen tendenziell abgebaut, so daß man auch Forderungen nach einer bedarfsgerechten interlokalen Steuerkraftverteilung entgegen käme und kein über Gebühr großer Finanzausgleichsbedarf resultieren würde.

Die Forderung nach einer Verstetigung der Entwicklung des gemeindlichen Steueraufkommens hat vordergründigen Charakter. Hinter ihr steckt die Absicht einer Verstetigung der Ausgabenaktivitäten der kommunalen Ebene. Eine solche anzustreben bedeutet, eine möglichst schwankungsfreie Realisierung des kommunalen Versorgungsziels zu erreichen; also die "Bedienung" der Gemeindeeinwohner und der Unternehmen vor Ort mit kommunalen Leistungen langfristig sicherzustellen. Das Verlangen nach verstetigten gemeindlichen Steuereinnahmen resultiert aus der Annahme, daß konjunkturbedingte Schwankungen des kommunalen Steueraufkommens zu Schwankungen des kommunalen Leistungsangebots führen können, die in bezug auf das erwähnte Versorgungsziel als problematisch angesehen werden (vgl. Marcus, 1986, 39). 


\subsubsection{Lokale Kriterien stabilitätspolitischer Natur}

Der Verstetigungsgrundsatz kann aber auch als eine Forderung aufgefaßt werden, die aus der Verfolgung des Stabilitätsziels abgeleitet wird. Durch eine Verstetigung der Entwicklung des kommunalen Steueraufkommens könne - so die Argumentation - dazu beigetragen werden, daß die gemeindliche Ausgabentätigkeit nicht an die mit den wirtschaftlichen Wechsellagen ansonsten stark schwankende Steueraufkommensentwicklung in einer Weise angepaßt wird, die man in der Literatur mit dem Schlagwort "Parallelpolitik der Gemeinden" zu kennzeichnen pflegt (vgl. Haller, 1967, 164ff; Timm, 1969, 441ff sowie Huppertz, 1977). Da das Stabilitätsziel nicht als eigenständige kommunalspezifische Besteuerungszielsetzung angesehen werden kann (vgl. etwa Oates, 1972, 4ff), wird auf diese Weise zumindest keine gegenläufige Entwicklung des kommunalen Finanzvolumens gefördert.

Für kommunale Steuern wird weiterhin gefordert, daß sie in ihrem Aufkommen mit dem allgemeinen Wirtschaftswachstum Schritt halten sollten. Bezogen auf die Gemeindeebene schlechthin läßt sich dieses Postulat damit begründen, daß die gemeindliche Aufgabenerfüllung und damit auch der Ausgabenbedarf entsprechend dem Wirtschaftswachstum zunimmt. In einem kommunalen Steuersystem, das quasi automatisch wachsende Einnahmen gewährleistet, wird eine finanzielle Absicherung dieser Notwendigkeiten gesehen. Da die Steuern bei finanziell autonomen Kommunen den bedeutendsten Teil der gesamten kommunalen Finanzmittel ausmachen, würde eine Stagnation ihres Aufkommens bedeuten, daß entweder andere Einnahmequellen stärker beansprucht werden müßten oder aber der Versorgungsaufgabe in nicht angemessenem Umfang nachgekommen werden kann.

Beide Postulate der steuerlichen Aufkommensentwicklung - Wachstumsreagibilität und Stetigkeit - sind also sichtbar miteinander verknüpft. Die Forderung nach mehr Stetigkeit bedeutet zugleich, geringeres Wachstum in Kauf zu nehmen. Wenn höhere Ansprüche an das Wachstum gestellt werden, so kann dies nur geschehen, wenn gleichzeitig Abstriche in bezug auf die Stetigkeit gemacht werden. Entscheidet man sich hingegen für minimale Schwankungen (optimale Erfüllung der Stetigkeitsforderung), so werden die Ansprüche an die Wachstumsreagibilität geringer anzusetzen sein. Hier wird also ein Zielkonflikt deutlich, der zu der Forderung geführt hat, daß die Bemessungsgrundlagen der Gemeindesteuern sich in ihrer Entwicklung in Richtung und (relativem) Ausmaß an der jährlichen Entwicklung des Sozialprodukts orientieren sollten und darüber hinaus kommunale Steuern zur Realisierung einer Wachstumsproportionalität nach Möglichkeit einen proportionalen Tarif erhalten müßten (vgl. Marcus, 1987, 119). 


\subsection{Einwohnerbezogene Steuerformen}

Die bedeutendste einwohnerbezogene Abgabeform (Personalsteuer) ist die Einkommensteuer. Bei einer Verwendung als gemeindliche Steuerquelle ist für die Einkommensteuer eine vielfältige Ausgestaltung möglich. Vereinfachend lassen sich diese unterschiedlichen Verwendungsmöglichkeiten in zwei grundlegende Varianten einteilen:

- die verknüpfte kommunale Einkommensteuer in Anlehnung an die staatliche Einkommensteuer (vgl. Abschnitt 9.2.1)

-ohne Hebesatzrecht

-mit Hebesatzrecht

- die eigenständige kommunale (Einkommen-)Steuer

-als gesondert konzipierte Einkommensteuer der Gemeinden (vgl. Abschnitt 9.2.2)

-als vereinfachte auf den Einwohner bezogene Steuer ${ }^{208}$ (vgl. Abschnitt 9.2.3)

\subsubsection{Verknüpfte kommunale Einkommensteuer}

Diese Form der lokalen Einkommensbesteuerung hat keinen eigenständigen Charakter. Eine verknüpfte bzw. gekoppelte Steuer ist dadurch gekennzeichnet, daß sie nicht durch ein eigenes Gesetz geregelt wird. Die staatlichen Vorschriften bezüglich Bemessungsgrundlage und/oder Steuertarif sind auch für die lokale Ebene bindend. Dabei sind zwei Varianten denkbar. Die Verknüpfung kann sich auf die Bemessungsgrundlage für die Staats- und die Gemeindesteuer beschränken, sie kann aber auch die Tarifgestaltung umfassen. Daneben ist dann - wie beispielsweise im Rahmen des bundesdeutschen Steuerverbundes - eine weitere Vorschrift notwendig, welche die Aufteilung des Aufkommens auf die Mitgliedskörperschaften der kommunalen Ebene zum Gegenstand hat (vgl. Gemeindefinanzreformgesetz 1969). ${ }^{209}$ Generell ist aber auch der Fall denkbar, daß es für eine nicht eigenständige Gemeindeeinkommensteuer ein besonderes Einkommensteuergesetz gibt, welches dann jedoch sehr eng mit dem staatlichen Einkommensteuerrecht verknüpft sein müßte. Dieses besondere kommunale Ein-

208 Dabei werden unter "eigenständigen kommunalen Einkommensteuern" in der Regel Abgaben verstanden, bei denen als gesetzliche Grundlage ein eigenständiges, nicht mit dem staatlichen Einkommensteuerrecht verknüpftes Steuergesetz vorhanden ist, durch das die kommunale Steuer eine von der staatlichen Steuer mehr oder weniger stark abweichende Ausgestaltung (vor allem auch hinsichtlich der Bemessungsgrundlage sowie des Steuertarifs), erfahren kann. Mit der staatlichen (Bundes- und/oder Landesabgabe) verknüpfte Steuern werden in der Regel in Form von Zuschlägen zur staatlichen Steuer erhoben. Das System der Vereinigten Staaten, gekennzeichnet durch ein "...vertical tax overlapping between federal, state and local government in the income tax field" (Head, 1983, 209), stellt eine Fundgrube unterschiedlicher Ausprăgungen der lokalen Einkommensbesteuerung dar (vgl. auch Marcus, 1986, 150f). Mögliche Varianten lokaler Besteuerung in den USA behandeln vor allem Maxwell/Aronson (1977), Fiedler (1981) oder Fisher (1987).

209 In diesem Zusammenhang auch Haller $(1987,9)$ und die dortigen Ausführungen zum Gemeindefinanzreformgesetz. 
kommensteuergesetz würde dann in der Regel eine Ergänzung (nicht aber einer Änderung) der staatlichen Vorschriften beinhalten.

Ein solches Modell einer kommunalen Einkommensteuer erfüllt eine Grundvoraussetzung kommunaler Steuern nur unzureichend, nämlich die Realisierung kommunaler Autonomie auf der Einnahmenseite. Im vorstehend erörterten Fall sind die Gemeinden aber lediglich am Gesamtaufkommen beteiligt. Ein weiterer bedeutender Kritikpunkt einer verknüpften kommunalen Einkommensteuer ist die nicht vorhandene Fühlbarkeit (Merklichkeit). Der Kreis der Steuerpflichtigen wird durch das staatliche Einkommensteuergesetz festgelegt und ist vermutlich kleiner (infolge distributionspolitischer Erfordernisse) als bei seiner Abgrenzung durch die kommunale Ebene. Man spricht in diesem Zusammenhang auch von einer fehlenden Breitenwirkung einer so ausgestalteten kommunalen Abgabe. In der Regel wird ein Großteil der staatlichen Einkommensteuer im Quellenabzugsverfahren eingeholt, was voraussichtlich dazu führt, daß der einzelne Steuerpflichtige die Rolle "seiner" Gemeinde als Steuergläubiger kaum noch wahrnimmt. Des weiteren anonymisiert das Verteilungsverfahren, wie oben angedeutet, die Beziehung zwischen dem Steuerpflichtigen und "seiner" Gemeinde.

Der Forderung nach Aufkommensvariation durch die jeweilige Gemeinde könnte jedoch auch bei der Anlehnung der gemeindlichen Einkommensbesteuerung an die staatliche Einkommensteuer nachgekommen werden. Wenn eine derart ausgestaltete Steuer eine Steuersatzvariation ermöglichen soll, so sind hierfür zwei Varianten denkbar. Ein Weg ist das "Huckepack-Verfahren" ("piggy-backing"), bei dem zur bestehenden staatlichen Steuer (möglicherweise mit kleineren Variationen der Bemessungsgrundlage) ein gemeindlicher Zuschlag erhoben wird. Diese Steuerform ist in den USA als Gemeinde- oder auch als Bundeslandsteuer üblich (vgl. Mennel, 1980, Länderteil USA, 53).

In der Bundesrepublik Deutschland ist die Ausgangssituation allerdings eine andere. Bund, Länder und Gemeinden partizipieren gemeinsam an der Einkommensteuer (als Gemeinschaftsteuer), die im wesentlichen nach dem örtlichen Aufkommen zugewiesen wird. Doch auch in dieser Konstellation - also bei einer Einkommensteuerbeteiligung könnte die Beweglichkeit der kommunalen Besteuerung durch Einräumung eines kommunalen Hebesatzrechts ${ }^{210}$ realisiert werden. Realistischerweise stößt aber ein solches Verfahren sehr schnell an Praktikabilitätsgrenzen. Im Ergebnis würde die lokale Ebene nämlich anhand einer Festlegung von Hebesätzen - selbst wenn diese innerhalb

210 Dieser Weg ist in der Bundesrepublik Deutschland durch Art. 106 Abs. 5 GG so weit geebnet, daß eine solche Regelung ohne Verfassungsänderung möglich wăre. Vgl. zur Einführung eines Hebesatzrechts beim gemeindlichen Einkommensteueranteil in der Bundesrepublik die Beitrăge von Hansmeyer/Zimmermann (1991;1992) sowie Böckels (1989). 
bestimmter Bandbreiten erfolgte - die Lastverteilung beeinflussen, die bei der Einkommensteuer den staatlichen Vorstellungen zufolge am Leistungsfähigkeitsprinzip bzw. entsprechenden distributionspolitischen Zielsetzungen orientiert sein sollte. Die letztliche Höhe der individuellen steuerlichen Belastung hinge folglich nicht nur von der Höhe der einkommensteuerpflichtigen Einkünfte ab, sondern auch vom jeweiligen Wohnsitz.

Die Einkommensteuer ist in modernen Volkswirtschaften neben der verteilungspolitischen Instrumentalisierung auch ein stabilitätspolitisches Hauptinstrument. Verknüpfte lokale Einkommensteuern würden daher dazu führen, daß auch der kommunale Teil in diesem Sinne instrumentellen Charakter erhält und in seiner Höhe ebenfalls von der stabilitätsorientierten Einflußnahme durch den Staat sowie der allgemeinen wirtschaftlichen Entwicklung abhängig wäre. Damit ist zum einen die Realisierung der Zielsetzungen hinsichtlich Stetigkeit und Wachstumsreagibilität problematisch, zum anderen kann die staatliche Ebene durch die wirtschaftspolitische Instrumentalisierung der Einkommensbesteuerung und durch Änderungen von Rechtsvorschriften (beispielsweise auch Steuerreformen) erheblichen Einfluß auf das gemeindliche Steueraufkommen nehmen. Dies widerspricht eindeutig dem Grundsatz, daß die Gemeindesteuern bezüglich der Aufkommensentwicklung in Abhängigkeit vom jeweiligen Finanzbedarf und unbeeinflußt vom Zentralstaat durch die jeweilige lokale Entscheidungsebene autonom bestimmt werden sollten. Darüber hinaus könnte das Hebesatzrecht in konjunkturpolitisch unerwünschtem Umfang ein prozyklisches Verhalten der Gemeinden fördern, beispielsweise wenn in Phasen der Rezession zum Zwecke der kommunalen Einnahmeerzielung die Hebesätze angehoben werden.

Im Hinblick auf die spezifischen kommunalen Besteuerungspostulate und die beabsichtigten Allokationswirkungen im kommunalen Bereich würde eine Bewertung einer nicht-eigenständigen Einkommensteuer damit eindeutig negativ ausfallen (vgl. auch Marcus, 1986, 158ff).

\subsubsection{Eigenständige lokale Einkommensteuer}

Unterstellt man, daß eine staatliche Einkommensteuer bereits existiert, bedeutet der Vorschlag einer eigenständigen - "beweglichen" (Hansmeyer/Zimmermann, 1991, 639ff) - lokalen Einkommensteuer, daß zusätzlich eine kommunale Abgabe auf die Einkommen der natürlichen Personen erhoben wird. Die Aufnahme einer derartigen Abgabe in das Gesamtsteuersystem eines öffentlichen Gemeinwesen bedeutet, daß sie der kommunalen Ebene zur alleinigen Ausschöpfung überlassen bleibt. Eine entsprechende Regelung ist in die jeweilige Finanzverfassung aufzunehmen. Dort könnte 
ebenfalls festgelegt werden, daß den Gemeinden das Recht eingeräumt wird, Aufkommensvariationen zur Deckung des spezifischen Finanzbedarfs vor Ort vorzunehmen. Im Sinne der gruppenbezogenen Äquivalenz dürften die Änderungen einer Einkommensteuer, die ausschließlich natürliche Personen betrifft, nur für die Haushalte jener Gemeinde gelten, welche durch ihre Rolle als Nutznießer bzw. Lastverursacher bestimmter öffentlicher Leistungen für den erhöhten Finanzbedarf "verantwortlich" zeichnen.

Falls man nicht zuläßt, daß die auf lokalen Entscheidungen beruhende Erhöhung der gemeindlichen durch einen gleich hohen Abzug von der staatlichen Einkommensteuerschuld wieder kompensiert wird ("tax credit"), werden entsprechende steuerpolitische Aktivitäten auch zu Belastungsänderungen führen. Diese stellen Veränderungen der mit der staatlichen Einkommensteuer angestrebten Belastungsstruktur dar und können im Widerspruch zu den Vorstellungen einer an der Leistungsfähigkeit orientierten Einkommensbesteuerung stehen (vgl. Marcus, 1986, 154).

Entscheidet sich die staatliche Ebene, eine Verrechnung der gemeindlichen mit der staatlichen Einkommensteuerschuld in Form eines sogenannten Steuerkredits zuzulassen, um damit kommunal bedingte Gesamtbelastungsänderungen zu verhindern, so bestimmt die staatliche Ebene zwar das gesamte Aufkommen der Einkommensbesteuerung aller Ebenen und damit die Belastungsstruktur; ihr eigenes Steueraufkommen ist jedoch variabel, da von den jeweiligen kommunalen Einkommensteueranteilen abhängig. Entscheidet sich die staatliche Ebene gegen die Möglichkeit der Einräumung eines "tax credit", befindet sie zwar allein und unabhängig über ihr Aufkommen aus der Einkommensbesteuerung; die Höhe des Gesamtaufkommens und die Belastungsstruktur sind aber nicht mehr nur von ihr beeinflußbar und damit infolge der unterschiedlichen lokalen Belastungsstrukturen variabel. Der Zentralstaat gerät hier offensichtlich in einen Interessenkonflikt.

Im Sinne der gruppenbezogenen Äquivalenz faßt eine kommunale Einkommensbesteuerung die Gemeindeeinwohner als lastverursachende Gruppe auf. ${ }^{211}$ Diese Einwohner - so die Begründung - sind es letztlich, zu deren Versorgung kommunale Aktivitä-

211 Einen anderen Ansatz in bezug auf die Verwendung der Einkommensteuer auf lokalem Niveau prăsentiert Haller $(1987,57 \mathrm{ff})$. Er betrachtet die Einkommensteuer bzw. eine Einkommensteuerbeteiligung der lokalen Ebene als "Leistungsfähigkeitssteuer" (Haller, 1987, 70), die für ihn als Hauptbestandteil eines kommunalen Steuersystems in Frage kommt, weil "... der überwiegende Teil der Gemeindeleistungen den Gemeindeeinwohnern mehr oder weniger gleichmäßig zugutekommt oder in Transferzahlungen besteht. Bei dieser Steuer müssen die Gemeinden das Belastungsniveau in Abstimmung mit den Präferenzen ihrer Einwohner bestimmen können, also das Hebesatzrecht besitzen. Die individuelle Steuerbelastung muß sich am Einkommen und den sonstigen für die Einkommensbesteuerung relevanten Tatbestănden orientieren, wobei alle Einkommen, also auch die bei Körperschaften thesaurierten, heranzuziehen sind." (Haller, 1987, 70)

Hans-Georg Napp - 978-3-631-75263-0 
ten dienen. Die Einkommensteuer wird also im Sinne einer Einwohnersteuer als fiskalisches Äquivalent der der betroffenen Gruppe (hier der Einwohnerschaft) zugeflossenen Gemeindeleistungen angesehen. Diesem Vorgehen liegt die Annahme zugrunde, daß zwischen Einkommensentstehung und gemeindlichem Finanzbedarf ein Zusammenhang besteht. Einschränkend bleibt jedoch anzumerken, daß Einkommen auch außerhalb der Gemeindegrenzen erworben werden können (Problem reiner "Wohngemeinden") und somit die Korrelation zwischen der Bemessungsgrundlage der Gemeindeeinkommensteuer und dem kommunalen Finanzbedarf insgesamt gesehen eher schwächer sein dürfte.

Die Bemessungsgrundlage einer Gemeindeeinkommensteuer wird sich in der Regel etwa in Richtung und Ausmaß des Sozialprodukts entwickeln. Wachstumsreagibilität kann also im Prinzip als gegeben angesehen werden, denn die Steigerungsraten des Bruttosozialprodukts, an denen das Wachstum der Steuerkraft ausgerichtet sein sollte, unterscheiden sich kaum von denen des Volkseinkommens. Der in die gemeindliche Besteuerung einbezogene Teil des Volkseinkommens dürte sich daher im Zeitablauf in Richtung und Ausmaß nur unwesentlich anders entwickeln als die Gesamtgröße.

Zur Realisierung einer größeren Breitenwirkung wird man die Frage, wer steuerfähig ist, auf der kommunalen Entscheidungsebene anders beantworten als auf der staatlichen. Die Bestimmung von Ausnahmen von der Steuerpflicht, die Festlegung der Bemessungsgrundlage, der Freibetrags- sowie Freigrenzenregelungen sind von entscheidendem Einfluß auf diese Breitenwirkung. Weicht das kommunale Einkommensteuerrecht deutlich vom staatlichen ab, ist nicht nur ein Zielkonflikt mit den staatlichen Verteilungsvorstellungen zu erwarten, sondern wohl auch ein solcher bezüglich der steuerrechtlichen und steuertechnischen Grundprinzipien.

Auch ein für die kommunalen Steuern in der Regel geforderter proportionaler Tariftyp tangiert die Verteilung steuerlicher Lasten und damit an bestimmten Distributionszielsetzungen orientierte gesamtstaatliche Vorstellungen. Im Idealfall müßte der Steuertarif einer kommunalen Einkommensteuer so ausgestaltet werden, daß die im Sinne der kommunalspezifischen Zielsetzungen liegende Aufkommensentwicklung erreicht und ein nicht mehr tolerierbarer Konflikt mit der Steuerpolitik der staatlichen Ebene vermieden werden kann. Die gleichzeitige Realisierung beider Vorstellungen dürfte aber nahezu unmöglich sein. 
Bezüglich der eigenständigen Entwicklung der gemeindlichen Einkommensbesteuerung bleibt abschließend festzuhalten, daß eine rechtliche Abtrennung ${ }^{212}$ der kommunalen von der staatlichen Steuer im wesentlichen vermeiden könnte, daß die Gemeindeeinkommensteuer zum Instrument der staatlichen Wirtschaftspolitik wird bzw. ein unerwünschter Einfluß des Staates auf das kommunale Steueraufkommen durch Änderungen der Rechtsvorschriften erfolgt. Eine solche Steuer dürfte aber gesamtwirtschaftlich gesehen sehr aufwendig in ihrer konkreten Ausgestaltung sein, denn es wäre ein gesondertes Veranlagungsverfahren erforderlich, welches sowohl für den Steuerzahler (Entrichtungsbilligkeit) als auch für den Fiskus (Erhebungsbilligkeit) recht hohe Kosten mit sich bringen würde. Darüber hinaus würden wichtige Zielsetzungen der staatlichen Einkommensteuer konterkariert. Beispielsweise wäre die bei beiden Steuern - der staatlichen und der kommunalen - sich ergebende addierte Progressionswirkung nicht mehr exakt abschätzbar, etwa weil die Tarife differieren oder die Behandlung des Familienstandes unterschiedlich ausfiele. Gerade weil die Einkommensteuer so zahlreiche Ziele der Wirtschafts- und Sozialpolitik berücksichtigt, eignet sie sich nicht für eine solche zusätzliche Erhebungsform.

Unter dem Eindruck dieser Argumente läge es daher näher, einen andersgelagerten Weg zu gehen und für eine gemeindliche Steuer auf private Haushalte vereinfachte Formen zu wählen. Hierzu zählen Beispiele und Vorschläge für Bürgersteuern (vgl. Bickel, 1956, 410; Institut "Finanzen und Steuern", 1966, 44ff) ebenso wie die nur kurzlebige britische "Community Charge" ("Poll Tax"), die auf die Anlehnung an Einkommen oder an einkommensnahe Indikatoren generell verzichtete.

\subsubsection{Einwohner- bzw. Bürgersteuer}

Weitergehende Möglichkeiten bei der Realisierung des Ziels, "... eine möglichst breite Schicht von Gemeindebürgern in die Steuerpflicht einzubeziehen, um auf diese Weise ihr Interesse und ihr Verantwortungsbewußtsein gegenüber der Gemeindepolitik und den Gemeindefinanzen zu wecken" (Wissenschaftlicher Beirat, 1974, 180), bietet also möglicherweise die Einführung einer "Gemeindepersonalsteuer" in der Form einer Gemeindeeinwohner- oder Bürgersteuer. Unter dem Eindruck der Argumente hinsichtlich der Praktikabilität einer wie auch immer ausgestalteten gemeindlichen Einkommensteuer(-beteiligung) läge es wohl näher, den Weg in Richtung Gemeindepersonalsteuer zu gehen. So wäre eine gemeindliche Steuer auf private Haushalte in einer ver-

212 Eine umfassende Absicherung der erörterten Gemeindesteuer von staatlichen Einflüssen wird jedoch nur schwer zu verwirklichen sein, denn Änderungen der Einkommensteuergesetzgebung liegen infolge der sinnvollerweise einzuräumenden Gesetzgebungshoheit (Wahrnehmung der Distributionsaufgabe) stets im Ermessen der staatlichen Ebene. 
einfachten Form unter Beibehaltung der Vorzüge hinsichtlich Merklichkeit, Aufkommensvariation, Verantwortungsbewußtsein und Flexibilität ohne negative Folgen für die staatliche Einkommensteuer mit ihren distributiven Elementen kreierbar. Eine Gemeindepersonalsteuer (als Einwohner- oder Bürgersteuer) ist - weil sie im Prinzip alle Gemeindebürger erfaßt und in Gestalt gleicher absoluter Beträge je Steuerpflichtigen erhoben wird - infolgedessen geeignet, das Interesse breiter Schichten an den Gemeindeangelegenheiten und damit auch die Selbstverantwortung der Gemeindeparlamente bei der Bewilligung von Ausgaben zu stärken (vgl. Bickel, 1956, 410; Institut "Finanzen und Steuern", 1966 oder auch Wissenschaftlicher Beirat, 1974, 182).

\subsubsection{Das Konzept der Kopfsteuer als Basis einer kommunalen Einwohnersteuer}

\subsection{Allokationswirkungen einer nationalen Kopfsteuer}

In Steuerwirkungsanalysen - vor allem im Rahmen der sogenannten "optimal taxation"213 - dient die Kopfsteuer in der Regel als Referenzgröße bei der Untersuchung steuerlich induzierter Wohlfahrtseinbußen. Ausgehend von einer Wirtschaft im "steuerfreien Zustand" werden im Rahmen dieser Analysen die Wirkungen verschiedener aufkommensgleicher Steuern betrachtet (vgl. etwa Atkinson/Stiglitz, 1980, $23 \mathrm{ff}$ ). Anschließend werden die Auswirkungen auf bestimmte endogene Größen (beispielsweise Einkommen, Ersparnis, Güterpreise) ermittelt und verglichen. Ein Wohlfahrtsverlust, der über den durch die Besteuerung verursachten Aufkommenseffekt (Einkommenseffekt) hinausgeht, liegt dann vor, wenn die jeweilige Steuer zu einer Veränderung der relativen Preise, damit zu einer Verzerrung der Rahmenbedingungen für die individuellen Entscheidungen und folglich zu Substitutionsvorgängen (-effekten) führt. Folge ist eine Veränderung der Allokation der im privaten Sektor verbliebenen Ressourcen (vgl. Krause-Junk, 1988, 347f). Die beschriebene Wohlfahrtseinbuße wird in der Regel als sogenannte "Zusatzlast" oder auch "excess burden" bezeichnet. ${ }^{214}$

Eine Kopfsteuer knüpft nicht an wirtschaftliche Tatbestände des Steuerpflichtigen an und bietet diesem daher keine Möglichkeit, ihr durch ökonomische Reaktionen zu ent-

213 Der Beginn der "optimal taxation"-Debatte kann im angelsächsischen Sprachraum in den Arbeiten von Mirrlees (1971) sowie Diamond/Mirrlees (1971) gesehen werden. An diese Ansätze schloß sich rasch eine rege Diskussion an, die vor allem mit Namen wie Atkinson, Boadway, Fair, Sandmo und Stiglitz verbunden ist. Geeignete Überblicke der steuertheoretischen und -politischen Ansätze liefern Sandmo (1976) und Kay (1990).

${ }^{214}$ Betrachtet man in einer solchen Analyse das Arbeitsangebot als variabel, so wirken die wichtigsten heute üblichen Steuern - Einkommen- und Verbrauchsteuern - als spezielle Steuern auf den Produktionsfaktor Arbeit. Lediglich eine "lump-sum tax" ist allokationsneutral (vgl. Krause-Junk, 1988, 348), da sie die Wahl zwischen Arbeit und Freizeit unbeeinflußt läßt (vgl. auch Wiegard, 1984, 141). 
gehen. ${ }^{215}$ Er kann den Umfang seiner Steuerschuld weder durch eine Variation seines Ausgabenniveaus bzw. seiner Ausgabenstruktur (vgl. Pohmer, 1977, 210) noch durch Umstrukturierung seiner Arbeitsangebots-Freizeit-Wahl beeinflussen (vgl. Rosen, $1980,171 \mathrm{ff})$.

Die angesprochene Allokationsneutralität kann freilich nur dann ein wesentliches Kriterium in der faktischen Steuerpolitik sein, wenn das Steuersystem tatsächlich von einer Kopfsteuer dominiert werden würde. Ein solcher Zustand ist aber vor allem aus distributionspolitischen Gründen weder wünschbar noch politisch realisierbar. ${ }^{216}$ Alle anderen Steuern, die eine solche dominante Rolle spielen könnten, lösen aber Substitutionseffekte aus. Daraus folgert Schmidt (1980, 154f), daß die excess-burden-Diskussion für die praktische Steuerpolitik generell wenig hergibt. Es wird im folgenden zu überprüfen sein, ob diese Schlußfolgerung auch für eine lokale Abgabe, die in Anlehnung an die Pauschsteueridee ausgestaltet wird, in einer solchen Allgemeinheit zutrifft.

\subsection{Allokationswirkungen einer "lokalen Kopfsteuer"}

Während bei den vorstehenden Bemerkungen zu den Allokationswirkungen einer (nationalen) Kopfsteuer von einer landesweit erhobenen Abgabe ausgegangen wurde, soll nunmehr eine lokal differenzierte Steuer untersucht werden. Die für eine nationale Kopfsteuer nachgewiesene Neutralität läßt sich nämlich nicht ohne weiteres auf eine "lokale Kopfsteuer" - hier exakter als Einwohnersteuer bezeichnet - übertragen (vgl. Brümmerhoff, 1987, 440). Substitutionseffekte und folglich Wohlfahrtseinbußen bzw. Mehrbelastungen treten in diesem Zusammenhang auf, wenn lokale Steuern die optimale räumliche Allokation der Produktionsfaktoren verzerren. Mit einem Modell von King (1984, 220ff) sollen die Auswirkungen auf die räumliche Allokation untersucht werden.

Wir nehmen an, daß es zehn Gemeinden (A, B, C, D, E, F, G, H, I, J) gibt, die in aufsteigender Reihenfolge verstärkt lokale öffentliche Güter anbieten. Die Gesamtkosten dieses Angebots $(\mathrm{K})$ verhalten sich sowohl zum Niveau der angebotenen öffentlichen

215 Von der Möglichkeit der Emigration wird hier zunächst abgesehen; später (gerade im lokalen Kontext) wird diese jedoch in Form der steuerlich induzierten Wanderungsbewegungen wieder aufgegriffen.

216 So schreibt etwa Timm (1981, 192), daß die Kopfsteuer in fortgeschrittenen Gesellschaften in der Besteuerung keinen Platz habe, während Pohmer $(1977,210)$ von der Kopfsteuer als einer für die modernen Kulturstaaten wirklichkeitsfremden Abgabeart spricht. Treffend faßt Schmidt $(1980,155)$ zusammen: "Die Vorstellungen über die steuerliche Gerechtigkeit mögen dunkel und kontrovers sein, aber über die Ablehnung von Pauschsteuern besteht weitgehend Einigkeit." 
Leistung (z) als auch zur Einwohnerzahl $(\mathrm{N})$ vollkommen proportional. Daher kann folgende Beziehung (Gleichung 9.1) gebildet werden, wobei "l" hier einen konstanten Parameter darstellt.

$$
K=l * z * N
$$

Abbildung 9.1: Steuerbelastung durch lokale öffentliche Güter

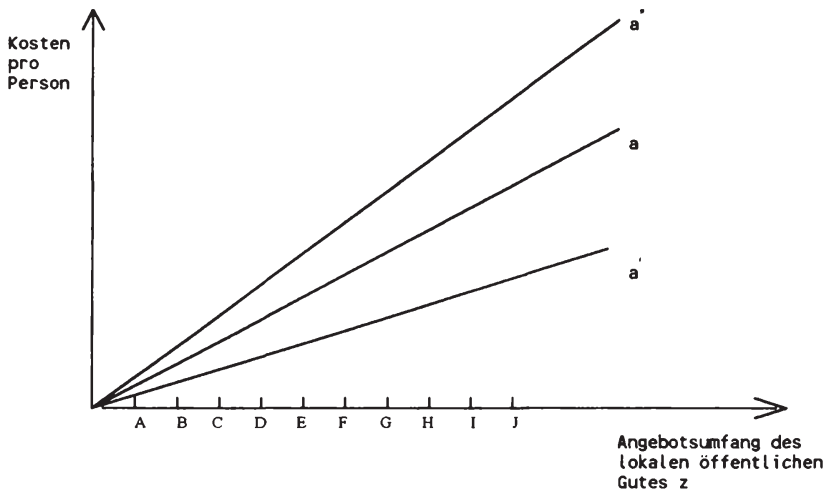

Die Gerade 0a in Abbildung 9.1 beschreibt diesen Zusammenhang, wobei auf der Ordinate die Kosten pro Einwohner $(l * z)$ abgetragen sind. Wenn nun unterstellt wird, daß jede Gemeinde eine "Kopfsteuer" nach Maßgabe der ihr entstehenden Kosten pro Person für die Bereitstellung lokaler öffentlicher Güter erhebt, so stellt 0a gleichfalls die (Kopf-)Steuerbelastung dar, der sich der einzelne Gemeindeeinwohner (natürlich je nach Wohnsitz) gegenübersieht. Diese Steuerbelastung steigt, wenn das Wirtschaftssubjekt etwa von Gemeinde C nach Gemeinde D zieht. Die Grenzkosten sind jedoch bei einer Erhöhung der angebotenen (und damit beanspruchten) Menge der lokalen öffentlichen Leistungen - d.h. beim Umzug von A nach B oder von E nach F - stets konstant. Diese Grenzkosten werden durch die Gerade bb (Parallele zur Abzisse) in Abbildung 9.2 wiedergegeben. Die Geraden b'b' sowie b"b" zeigen alternative Grenzkostenverläufe.

Betrachten wir nun zwei Wirtschaftssubjekte (Gemeindeeinwohner) $E_{1}$ und $E_{2}$, die den Nutzen der lokalen öffentlichen Güter nach Maßgabe ihrer Grenznutzenfunktionen $\mathrm{GN}_{\mathrm{E}_{1}}$ bzw. $\mathrm{GN}_{\mathrm{E}_{2}}$ in Abbildung 9.2 einschätzen und vollständig mobil sind. Wird folglich von Mobilitäts- und Informationskosten abgesehen, so wählen die Individuen $E_{1}$ und $\mathrm{E}_{2}$ die für sie optimalen Wohnsitzgemeinden $\mathrm{C}$ bzw. $F$. Wohnte $\mathrm{E}_{1}$ beispielsweise in Gemeinde B, so kann er durch einen Umzug in die Gemeinde $C$ eine bessere Ver- 
sorgung mit öffentlichen Gütern erlangen. Die mit diesem Umzug verbundene höhere Kopfsteuerbelastung (Kostenanteil) in Gemeinde $C$ wird durch den erlangten Nutzenzuwachs überkompensiert. Ein Umzug von $B$ nach $A$ würde für Individuum $E_{1}$ umgekehrt bedeuten, daß die Kopfsteuerersparnis vom entgangenen Nutzen überkompensiert wird. Nur in Gemeinde $C$ entsprechen sich Grenznutzen und Grenzkosten für das Individuum $\mathrm{E}_{1}$. Eine an der Kopfsteueridee orientierte Einwohnersteuer führt also bei Mobilität unter den zugrunde liegenden Modellprämissen zu einer optimalen Allokation (vgl. auch die Ausführungen in Abschnitt 4.4 sowie in Kapitel 5).

Abbildung 9.2: Grenznutzen/-kosten lokaler öffentlicher Güter

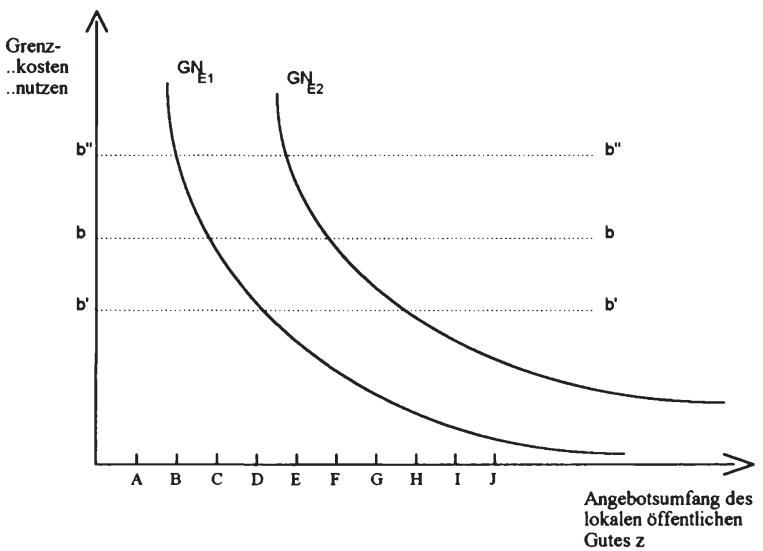

Betrachten wir nunmehr zum Vergleich die Wirkungen einer proportionalen (Gemeinde-)Einkommensteuer, wie sie in Abschnitt 9.2.1.2 bereits diskutiert worden ist. Über die für die modellmäßige Betrachtung der Wirkungen einer Kopfsteuer getroffenen Annahmen hinaus soll angenommen werden, daß die Durchschnittseinkommen in allen Gemeinden gleich sind und daß sich die Ausgaben für das lokale öffentliche Leistungsangebot proportional zur Einwohnerzahl entwickeln. Daraus folgt, daß bei gleichem Angebotsniveau die Gemeinden identische Steuersätze festlegen. Bieten die Gemeinden hingegen - wie vorab unterstellt - öffentliche Leistungen in unterschiedlicher Größenordnung an, variieren die Steuersätze proportional. Bei einer interkommunalen Wanderung hängen die Grenzkosten der Wirtschaftssubjekte $E_{1}$ und $E_{2}$ nunmehr von ihrem Einkommen ab.

Verfugt $E_{1}$ beispielsweise über ein niedrigeres Einkommen als Individuum $E_{2}$, bedeutet ein Umzug von Gemeinde B nach Gemeinde C, daß der Steuersatz für beide Wirt- 
schaftssubjekte gleichermaßen ansteigt, die Steuerlast sich aber absolut für Steuerzahler $E_{2}$ stärker erhöht als für $E_{1}$.

Die Geraden b'b' bzw. b"b" in Abbildung 9.2 geben die Grenzkosten für $E_{1}$ bzw. $E_{2}$ an, die ihnen bei einer lokalen, proportionalen Einkommensteuer entstehen. Im Ergebnis wird sich nunmehr $\mathrm{E}_{1}$ in Gemeinde $\mathrm{D}, \mathrm{E}_{2}$ in Gemeinde $\mathrm{E}$ niederlassen. Individuen ohne Einkommen siedeln sich unter diesen Rahmenbedingungen stets in Gemeinde $\mathrm{J}$ an.

Es stellt sich ceteris paribus eine ineffiziente Allokation ein, denn $E_{1}$ und $E_{2}$ maximieren ihren Nutzen gemäß der ihnen auferlegten (Steuer-)Lasten. Die jeweilige Steuerbelastung gibt aber nicht die tatsächlichen (Mehr-)Kosten wieder, die in den Gemeinden bei einem Umzug beispielsweise des $E_{1}$ von $C$ nach $D$ entstehen, denn die Kosten verhalten sich nach wie vor proportional zur Einwohnerzahl. Die lokale Einkommensteuer führt somit zu einer Zusatzlast. Ein identisches Resultat erhielte man, wenn statt einer Einwohnersteuer eine Grund- oder Vermögensteuer eingeführt wird und $E_{1}$ weniger Vermögen besitzt als $\mathrm{E}_{2}$.

Die im Vergleich zur gerade behandelten Einkommensteuer nicht vorhandene Zusatzlast spricht also zugunsten einer an der Kopfsteueridee orientierten Einwohnersteuer. Diese verliert allerdings ihre allokative Überlegenheit, wenn sich die Kosten für die Bereitstellung lokaler öffentlicher Güter nicht mehr konstant pro Person (Kopf), sondern beispielsweise proportional zum Einkommen (Y) oder zum Angebotsniveau des lokalen öffentlichen Gutes z verhalten. Damit würde dann gelten:

$$
K=l * z * Y
$$

Die Geraden 0a' und 0a" in Abbildung 9.1 geben nunmehr die Kosten pro Person an, die der jeweiligen Gemeinde entstehen, wenn eine Person mit niedrigem Einkommen (Gerade 0a') bzw. mit hohem Einkommen (Gerade 0a") ihr Leistungsangebot in Anspruch nimmt. Die tatsächlichen Grenzkosten bei einer Veränderung des lokalen Angebots an öffentlichen Gütern können jetzt beispielsweise durch die Geraden b'b' bzw. $b " b "$ in Abbildung 9.2 abgebildet werden. Unter dieser Voraussetzung wählt $E_{1}$ wieder die Gemeinde $\mathrm{D}$ und $\mathrm{E}_{2}$ wieder die Gemeinde $\mathrm{E}$ als Wohnsitz. Eine optimale Allokation wird jetzt durch eine proportionale kommunale Einkommensteuer, die sich unter den zuvor gemachten Annahmen als allokativ ineffizient erwiesen hatte, verwirklicht. 
Eine Einwohnersteuer hätte unter diesen Rahmenbedingungen $\mathrm{zu}$ den ineffizienten Wohnsitzen $C$ und $F$ für die Wirtschaftssubjekte $E_{1}$ bzw. $E_{2}$ geführt. ${ }^{217}$

Eine Zusatzlast wird also nicht schon dadurch hervorgerufen, daß lokale Steuern von Ort zu Ort variieren. Vielmehr hängen mögliche Substitutionseffekte davon ab, ob eine lokale Steuer (oder eine Kombination lokaler Steuern) die ortsansässigen Bürger (bzw. Vermögen, Unternehmen etc.) exakt nach Maßgabe der Ausgaben, die diese der Gemeinde direkt oder indirekt verursachen, belastet. Anders ausgedrückt bedeutet dies, daß (idealtypischerweise) die effektive Steuerinzidenz den Beitrag eines Wirtschaftssubjekts (Vermögensbesitzers, Grundstückinhabers, Unternehmens) zum Entstehen lokaler Ausgaben genau widerspiegeln sollte, um eine optimale Allokation zu gewährleisten.

Die Stärke des beschriebenen Modells liegt darin, daß infolge der Mobilitätsannahme die explizite Offenbarung der Präferenzen für lokale öffentliche Güter nicht notwendig ist. Die Relevanz des Ansatzes wird aber dadurch eingeschränkt, daß Mobilitätskosten, spillover-Effekte und economies bzw. diseconomies of scale bei der Bereitstellung lokaler öffentlicher Güter in diesem Modell unberücksichtigt bleiben. Gerade den spillover-Effekten und dem Ausmaß der Mobilität kommt aber bei der Diskussion um ein effizientes Gemeindefinanzsystem sicherlich eine nicht zu vernachlässigende Bedeutung zu. Außerdem erfaßt das Modell nur eine Form möglicher Präferenzäußerung, nämlich die Abstimmung mit den Füßen ("exit"). Unberücksichtigt bleibt also die Wahlentscheidung des Steuerzahlers per Stimmzettel ("voice").

So wird letztendlich die Entstehung einer Zusatzlast bei Realisierung kommunaler Finanzautonomie nie zu verhindern sein, allein schon aufgrund der erwähnten spillovers und der Schwierigkeit, Kostenverursacher zweifelsfrei zu identifizieren. Dennoch liefert die vorstehende Diskussion wichtige Hinweise, welche Größen als Bemessungsgrundlage einer kommunalen Steuer geeignet sein könnten. Daher kann sie durchaus ein Anhaltspunkt bzw. ein Orientierungsmaßstab für die praktische Steuerpolitik sein.

\subsubsection{Einwohnersteuer und Distribution}

Die Inzidenz der lokalen Kopfsteuer (Einwohnersteuer) erscheint zunächst offensichtlich. Jeder Einwohner einer Gemeinde zahlt den gleichen Betrag und kann die Bela-

${ }^{217}$ In ähnlicher Weise garantiert eine Grundsteuer eine effiziente Allokation nur, wenn die Kosten der Bereitstellung lokaler offentlicher Güter sich proportional zur Bemessungsgrundlage dieser Steuer in einer Kommune entwickeln (vgl. auch Abschnitt 9.4). 
stung nicht abwälzen bzw. vermeiden. Diese These ist jedoch so nicht haltbar, denn eine lokal differenzierte Kopfsteuer ist möglicherweise hinsichtlich ihrer Abweichungen vom Durchschnitt überwälzbar. Es ist vorstellbar, daß sich eine lokal überdurchschnittliche Kopfsteuer in erhöhten Lohnforderungen und geringerer Zahlungsbereitschaft für Mieten im betroffenen Gebiet niederschlägt, also auf Arbeitgeber und Vermieter überwälzt wird.

Sieht man von dieser möglichen Überwälzbarkeit ab, so wird jeder Einwohner unabhängig von seiner Einkommens- und Vermögenslage gleich hoch belastet. Demnach wirkt die Einwohnersteuer regressiv. Dies scheint den üblichen Gerechtigkeitsvorstellungen und dem Leistungsfähigkeitsprinzip zu widersprechen. Aber nicht allein die regressiven oder progressiven Effekte einer einzelnen Steuer, sondern die Wirkungen des gesamten Steuer- und Transfersystems sind auf ihre Verteilungswirkungen hin zu beurteilen (vgl. Kay/King, 1986, 223ff).

Daher sind mögliche kompensatorische Maßnahmen mit einzubeziehen, wenn über die Einführung einer kommunalen Kopfsteuer und ihre Wirkungen diskutiert wird. Der Zentralstaat als verteilungspolitisch zuständige Instanz könnte Maßnahmen ergreifen, die die Belastung für Bezieher niedriger Einkommen reduziert. Sinnvollerweise sollten diese Entlastungen durch zentralstaatliche Transfers erfolgen. Ein aufeinander abgestimmtes Steuer- und Transfersystem mit der Sicherung eines Existenzminimumeinkommens könnte der regressiven Tendenz einer "kommunalen Kopfsteuer" (sprich Einwohnersteuer) entgegenwirken.

\subsubsection{Die Eignung der Einwohnersteuer als Gemeindesteuer}

Die zuletzt behandelten distributiven Wirkungen einer Einwohnersteuer als "örtlicher Aufwandsteuer" müssen zwar im Zusammenhang mit möglichen kompensierenden Maßnahmen der für die Distributionsaufgabe zuständigen obersten gebietskörperschaftlichen Ebene und damit der Ausgestaltung des gesamten Steuer- und Transfersystem gesehen werden, doch eine Einführung einer solchen Abgabe als Gemeindesteuer würde in jedem Falle die unteren Einkommensgruppen neuen Belastungen aussetzen. Damit fällt die distributive Beurteilung der Einwohnersteuer eindeutig negativ aus. So deutlich dieses Resultat unter Distributionsgesichtspunkten auch erscheint; ein abschließendes Urteil kann nur im Zusammenspiel distributiver und allokativer Aspekte und einer systematischen Abwägung aller Argumente erfolgen. Die finanzwissenschaftlichen Kriterien einer geeigneten Gemeindesteuer sind weiter oben herausgearbeitet worden. Diese Grundsätze sollen nunmehr benutzt werden, um Entscheidungshilfen für diese abschließende Beurteilung zu finden. 
Eine Einwohnersteuer mit der entsprechenden Ausgestaltung weist unter Autonomiegesichtspunkten günstige Eigenschaften auf. Abgesehen von möglichen - seitens der Zentralregierung ausgesprochenen - Höchstbetragsregeln und Ausnahmetatbeständen kommt eine eigenständige lokale Einwohnersteuer notwendigen Finanzierungserfordernissen in angemessener Weise nach. Die Kommunen können deren Höhe selbständig festlegen und somit eine autonome Finanzierung ihres örtlichen Leistungsangebots realisieren. "Sie ist infolgedessen geeignet, das Interesse breiter Schichten an den Gemeindeangelegenheiten und damit auch die Selbstverantwortung der Gemeindeparlamente bei der Bewilligung von Ausgaben zu stärken. Infolge der großen Zahl der Steuerpflichtigen besteht die Möglichkeit, die Einwohnersteuer zu einer ergiebigen Abgabe auszugestalten" (Wissenschaftlicher Beirat, 1974, 182).

Wie die intensive Diskussion in Großbritannien bezüglich der dort eingeführten (aber sehr kurzlebigen) "poll tax"218 bewiesen hat, ist die Fühlbarkeit bzw. Merklichkeit einer solchen Einwohnersteuer garantiert. ${ }^{219}$ Die Fühlbarkeit kann durch eine entsprechende Erhebungsform noch unterstützt werden. Diese könnte so aussehen, daß ein gesonderter Steuerbescheid ergeht, der die jährlich tatsächlich zu zahlende Einwohnersteuer ausweist und durch die Angabe der Steuerbelastung des Vorjahres dem Zensiten darüber hinaus vor Augen führt, welche Veränderung sich ergeben hat. Eine gewünschte Beeinflussung privater Entscheidungen - im Sinne der Gegenüberstellung von kommunalem Leistungsangebot und eigenem Finanzierungsbeitrag - und daraus folgende Konsequenzen (beispielsweise bei der Wohnortwahl oder politischen Entscheidungen auf lokalem Niveau) dürfte angesichts solcher Rahmenbedingungen eher gewährleistet sein als bei weniger merklichen Abgabeformen. Es ist somit möglich, die "fiscal responsibility" bzw. "fiscal (local) accountability" - also die Verantwortlichkeit

218 Die britische Kopfsteuer wurde wie folgt ausgestaltet: Von jedem in einer Gemeinde ansăssigen Bürger über achtzehn Jahren konnte eine pauschale Abgabe erhoben werden, über deren Höhe die jeweilige Kommune autonom entscheiden durfte. Die durchschnittliche Steuerbelastung lag dabei bei $£ 360$, wobei allerdings die Bandbreite von $£ 93$ bis $£ 782$ als beträchtlich zu bezeichnen ist. Von der Erhebung der Steuer konnten u.a. Bewohner von Pflege- und Altenheimen, Insassen von Gefängnissen, Mitglieder religioser Orden, Mitglieder von stationierten ausländischen Streitkräften sowie Obdachlose ausgenommen werden. Für Bezieher sehr niedriger Einkommen konnte ein Rabatt von höchstens achtzig Prozent der Steuerschuld gewăhrt werden. Vgl. in diesem Zusammenhang Mennel (1980, Länderteil Großbritannien, 39f).

219 Es darf jedoch nicht vernachlässigt werden, daß die Zielsetzung der englischen Gemeindesteuerreform mit der Einführung einer solchen kopfsteuerähnlichen Abgabe ("poll tax") etwas anders ausgerichtet war. Die in Großbritannien vorgesehene Residual-("Lückenbüßer-") und Signalfunktion bei "überdurchschnittlichen" Ausgaben ist nämlich unter allokationspolitischem Blickwinkel eher als verfehlt einzustufen (vgl. dazu Diekmann/Schütz, 1989, 250). Daneben hat es keine hinreichende Abfederung der bekanntermaßen sehr weitgehenden negativen Verteilungskonsequenzen gegeben. Dies spiegelt sich auch in den innenpolitischen Unruhen, deren Anlaß u.a. die Reform des kommunalen Finanzsystems (in deren Rahmen an Stelle der bis zum 1. Januar 1990 erhobenen Grundsteuer privater Haushalte die "poll tax" eingeführt wurde) ist, wider. Letztlich hat diese unzureichende verteilungspolitische Absicherung sowie auch die verfehlte allokationspolitische Zielsetzung in Großbritannien zur Einsicht geführt, die Kopfsteuer auf kommunaler Ebene wieder zur Disposition zu stellen. 
für kommunale Leistungen - über die Realisierung der fiskalischen Äquivalenz und des damit zusammenhängenden Interessenausgleichs zu verstärken, da der Kreis der Steuerpflichtigen sehr weit geschnitten wäre und so die entsprechende Breitenwirkung verspricht; also praktisch alle Wahlberechtigten umfaßt. Dies heißt im Ergebnis jedoch nicht, daß die Einwohnersteuer mit einer (exakten) individuellen Äquivalenz begründbar wäre und daß alle Bürger die kopfsteuerfinanzierten Leistungen wirklich gleichermaßen in Anspruch nehmen. Bei den in Frage kommenden Leistungen ist daher wegen ihrer Besonderheit vielmehr nur die schwächere Form der Gruppenäquivalenz realisierbar. Die Summe aller kommunalen Leistungen, deren Kosten von der Einwohnerzahl abhängen und mit denen keine distributiven Ziele verfolgt werden, läßt sich demnach durch das Aufkommen aus einer kopfsteuerfundierten Einwohnersteuer näherungsweise herstellen. Die Verwandtschaft von Gebühren und Beiträgen mit äquivalenzorientierten Steuern wird damit deutlich. Vor diesem Hintergrund wird leicht verständlich, warum die britische Regierung ihre Kopfsteuer als "Kommunal-" bzw. "Gemeinschaftsbeitrag" ("community charge") deklariert hatte (vgl. Diekmann/Schütz, $1989,248 f)$.

Unter dem Aspekt der räumlichen Streuung ist eine Einwohnersteuer in der Lage (bei gleicher Steueranspannung und annähernd gleichem Leistungsstandard), ein relativ gleichmäßiges Pro-Kopf-Aufkommen zu erbringen. Gemeinden mit gleicher Einwohnerzahl können ein gleiches, Gemeinden mit unterschiedlicher Einwohnerzahl ein entsprechend unterschiedliches Aufkommen erwarten. Diese Eigenschaft ist wünschenswert, solange keine (gesetzmäßigen) economies oder diseconomies of scale bei den lokalen Ausgaben in Abhängigkeit von der Einwohnerzahl in einer Gemeinde unterstellt werden. Aber selbst die Existenz steigender oder abnehmender Skalenerträge bei bestimmten lokalen öffentlichen Leistungen kann toleriert werden, denn die Beziehung zwischen Gemeindegröße und Finanzbedarf pro Einwohner ist dann nicht eindeutig, wenn das gesamte Bündel der durch eine Einwohnersteuer finanzierbaren Leistungen betrachtet wird.

$\mathrm{Da}$ die Bemessungsgrundlage der Einwohnersteuer im Konjunkturverlauf praktisch unverändert bleibt, erfüllt sie in nahezu idealer Weise das Kriterium der Konjunkturunabhängigkeit bzw. Stetigkeit. Die Einwohnersteuer ist also als im Grunde genommen konjunkturunelastische Abgabe eindeutig positiv zu bewerten. Denkbar erscheint allerdings, daß bei sehr schlechter wirtschaftlicher Lage untere Einkommensgruppen die Steuer nicht mehr aufbringen können. Eine solche Situation müßte gegebenenfalls korrigierende Maßnahmen des Zentralstaates nach sich ziehen.

Da die Einwohnersteuer als quasi Kopfsteuer an eine Bestandsgröße (dem einzelnen Individuum) anknüpft, folgt ihr Aufkommen nicht der allgemeinen Wirtschaftsentwick- 
lung. Diese fehlende Wachstumsreagibilität wird in der Regel zwar als mögliches Problem (vgl. etwa Fischer, 1990, 568) gesehen, ist jedoch vor dem Hintergrund der fiskalischen Äquivalenz und der somit einwohnersteuerfinanzierten lokalen öffentlichen Leistungen nahezu vernachlässigbar, da zumindest einige der auf diese Weise finanzierten öffentlichen Aufgaben (z.B. Bildung) als superiore Güter positiv mit dem Wachstum korreliert sind.

Unter kommunalspezifischen Besteuerungsgrundsätzen und dem Aspekt der Einfachheit (z.B. infolge der niedrigen Erhebungskosten) scheint eine solche Einwohnersteuer prinzipiell eine hohe Eignung als kommunale Abgabe zu besitzen. Doch ein gewichtiges Gegenargument bleibt. Wie alle kopfsteuerähnlichen Abgaben wirkt die Einwohnersteuer ebenfalls stark regressiv. Diesem Effekt kann jedoch das Steuersystem des Zentralverbandes so entgegenwirken, daß die Progressivität des gesamten Steuersystems (zumindest im Bereich der Personalbesteuerung) gewahrt bleibt (beispielsweise durch eine progressivere Ausgestaltung des Einkommensteuertarifs).

Diesen Aspekten wird aber die bei vielen Ansätzen Vorbildfunktion besitzende "poll tax" und damit das britische Steuer- und Transfersystem nicht gerecht. Die geringe verteilungspolitische Kompensationsfunktion des britischen Steuer- und Transfersystems kann bestenfalls im Landesdurchschnitt die Regressivität der lokalen Kopfsteuer ausgleichen, so daß bei lokal stark divergierenden Kopfsteuern unerwünschte Verteilungswirkungen erhalten bleiben (vgl. Smith, 1988, 22f) Eine abschließende Bewertung im übernächsten Kapitel soll diese Argumentation nochmals aufgreifen und die oftmals geäußerten Urteile in der Finanzwissenschaft überprüfen, ob kopfsteuerähnliche Abgaben mit all ihren allokativen Vorteilen wirklich keinen Platz in einem Steuersystem moderner, entwickelter Volkswirtschaften (vgl. etwa Fischer, 1990, 568 oder auch Milbradt, 1981, 524) haben.

\subsection{Produktionsbezogene Steuerformen}

Mit den folgenden Ausführungen sollen die Allokationseffekte relevanter Gemeindesteuern für die Nutzergruppe "Unternehmen" (den Produktionsfaktor Kapital) präzisiert werden. Dazu wird vorab ein neoklassisches Investitionsmodell skizziert, das eine relativ einfache Behandlung der allokativen Wirkungen der unterschiedlichen Abgabeformen zuläßt. Im Grunde genommen sind die nachfolgend abgeleiteten Ergebnisse im Einzelfall bereits bekannt (vgl. etwa Sinn 1984a; 1984b; 1985; 1987; Sievert/ Naust/ Jochum/Peglow/Glumann, 1989; Gutting, 1987 sowie Richter/Wiegard, 1990a), doch für die abschließende Beurteilung unterschiedlicher Besteuerungsalternativen sollen 
sie hier noch einmal im Kontext der zugrunde liegenden Fragestellung vorgestellt werden.

\subsubsection{Der Analyserahmen: Ein neoklassisches Investitionsmodell}

Zunächst sollen die grundlegenden real- und finanzwirtschaftlichen Vorgänge dieses Investitionsmodells beschrieben werden (vgl. dazu auch King, 1987, 380 oder Feldhoff, 1989, 56ff). Die für die weitere Untersuchung relevante Investitionsentscheidung eines repräsentativen Unternehmens soll im Rahmen eines partial-analytischen "ZweiPerioden-Modells" analysiert werden (vgl. Richter/Wiegard, 1990a). $\mathrm{K}_{0}$ bezeichnet den Bestand an Kapitalgütern zu Beginn der Periode 0 und stellt die vorhandene Anfangsausstattung dar, die in der Produktion derselben Periode zum Einsatz kommen kann. Der entsprechende Preis des Kapitalgutes $q_{t}$ wird wie alle anderen Marktpreise $\left(p_{t}\right)$ exogen vorgegeben. Alle diese Preise werden vom Unternehmen korrekt antizipiert.

Der vorhandene Kapitalstock unterliegt in jeder Periode einem zum jeweiligen Kapitalbestand proportionalen Verschleiß mit einer Rate $\delta$. Darüber hinaus wird in der Periode 0 der Produktionsfaktor Arbeit im Umfang von $\mathrm{L}_{0}$ (zum Nominallohnsatz $\mathrm{w}_{0}$ ) in der Produktion eingesetzt. Die Unternehmung produziert dabei mit Hilfe einer Produktionsfunktion $\mathrm{F}\left(\mathrm{K}_{0}, \mathrm{~L}_{0}\right)$. Die erzielbaren Umsatzerlöse belaufen sich auf $\mathrm{p}_{0} \mathrm{~F}\left(\mathrm{~K}_{0}, \mathrm{~L}_{0}\right)$.

In der Periode 0 werden Ausgaben für Bruttoinvestitionen in Höhe von $\mathrm{q}_{0} \mathrm{I}_{0}$ getätigt. Sie setzen sich aus den Aufwendungen zur Kompensation des Kapitalverschleißes (Reoder Ersatzinvestitionen) $q_{0} \delta K_{0}$ und für Nettoinvestitionen $q_{0}\left(K_{1}-K_{0}\right)$ zusammen. Der Kapitalstock $K_{1}$ wird in der Periode 0 aufgebaut, wirft aber erst in der Periode 1 einen Ertrag ab, kann also im Rahmen der Produktion des entsprechenden Outputs in dieser Periode erstmals benutzt werden.

Unterstellt wird ferner ein vollkommener Kapitalmarkt. Die Nettoinvestitionen werden durch Aufnahme von Fremdkapital auf diesem Kapitalmarkt finanziert. Das in Periode 0 aufgenommene Fremdkapital ist in Periode 1 zusammen mit der marktüblichen Verzinsung zurückzuzahlen. Die Produktionsvorgänge in der Periode 1 entsprechen denen der Vorperiode; allerdings werden keine Investitionsgüter mehr erworben. Die Unternehmung wird stattdessen nach Ablauf des Produktionsprozesses liquidiert. Die Ausschüttungen an die Anteilseigner des Unternehmens werden mit $\mathrm{A}_{1}$ bezeichnet.

Die folgende Tabelle spiegelt noch einmal die Herkunft und die Verwendung von Finanzmitteln des repräsentativen Unternehmens wider (vgl. Richter/Wiegard, 1990a, 2). 
In der ersten Zeile stehen dabei die realwirtschaftlichen, in den anderen Zeilen die finanzwirtschaftlichen Zahlungsströme.

Tabelle 9.1: Zusammenstellung der Zahlungsströme

\begin{tabular}{|c|c|c|c|}
\hline \multicolumn{2}{|c|}{ Zuflüsse } & \multicolumn{2}{|c|}{ Abflüsse } \\
\hline Periode 0 & Periode 1 & Periode 0 & Periode 1 \\
\hline \multicolumn{2}{|c|}{$\begin{array}{c}\text { Einnahmen aus dem Verkauf von Gütern, abzüglich } \\
\text { Lohnkosten }\end{array}$} & $\begin{array}{c}\text { Ausgaben für Bruttoinve- } \\
\text { stitionen }\end{array}$ & Liquidationserlöse \\
\hline$p_{0} F\left(K_{0}, L_{0}\right)-w_{0} L_{0}$ & $p_{1} F\left(K_{1}, L_{1}\right)-w_{1} L_{1}$ & $q_{0}\left[K_{1}-(1-\delta) K_{0}\right]$ & $-q_{1}(1-\delta) K_{1}$ \\
\hline $\begin{array}{l}\text { Kreditaufnahme } \\
q_{0}\left(K_{1}-K_{0}\right)\end{array}$ & - & - & $\begin{array}{l}\text { Kredittilgung } \\
q_{0}\left(K_{1}-K_{0}\right)\end{array}$ \\
\hline \multirow[t]{3}{*}{$\begin{array}{l}\text { Eigenkapitaleinlage } \\
\qquad q_{0} K_{0}\end{array}$} & - & - & $\begin{array}{c}\text { geleistete Zinszahlungen } \\
r_{1} q_{0}\left(K_{1}-K_{0}\right) \\
\end{array}$ \\
\hline & & \multicolumn{2}{|c|}{ (Brutto-)Ausschüttungen } \\
\hline & & $A_{0}$ & $A_{1}$ \\
\hline
\end{tabular}

Aus der Investitionstheorie (vgl. dazu den Grundlagentext von Jorgenson, 1967) ${ }^{220}$ ist bekannt, daß man den optimalen Kapitalstock und somit die Investitionsnachfragefunktion über die Maximierung des als Gegenwartswert der Einnahmenüberschüsse ("Cash-flow") definierten Unternehmenswertes erhält. Diese Einnahmenüberschüsse $C_{t}$ wiederum ergeben sich in jeder Periode als Differenz der Einnahmen aus dem Verkauf von Gütern (also den Erlösen) sowie den Ausgaben für die Produktionsfaktoren (also Löhnen und Bruttoinvestitionen). Folglich gilt für unser einfaches Zwei-Perioden-Modell:

$$
C_{0}=p_{0} F\left(K_{0}, L_{0}\right)-w_{0} L_{0}-q_{0} I_{0}=p_{0} F\left(K_{0}, L_{0}\right)-w_{0} L_{0}-q_{0}\left[K_{1}-(1-\delta) K_{0}\right]
$$

sowie

$$
C_{1}=p_{1} F\left(K_{1}, L_{1}\right)-w_{1} L_{1}-q_{1} I_{1}=p_{1} F\left(K_{1}, L_{1}\right)-w_{1} L_{1}-q_{1}(1-\delta) K_{1}
$$

Als Diskontierungsfaktor wird der Marktzinssatz $\mathbf{r}_{\mathrm{i}}$ benutzt, so daß die Zielfunktion für den Unternehmer lautet:

220 Vgl. in diesem Zusammenhang auch Hax (1972), Schleiter (1985) sowie den Sammelband von Funke (1989). 


$$
\max _{L_{0}, L_{1}, K_{1}}\left\{C_{0}+\frac{1}{1+r_{1}} C_{1}\right\}
$$

Als notwendige Bedingungen erster Ordnung ergeben sich für das Maximum des Unternehmenswertes die Gleichungen

$$
\begin{aligned}
& p_{0} \frac{\partial F}{\partial L_{0}}\left(K_{0}, L_{0}\right)=w_{0} \\
& p_{1} \frac{F}{\partial L_{1}}\left(K_{1}, L_{1}\right)=w_{1}
\end{aligned}
$$

und

$$
p_{1} \frac{\partial F}{\partial K_{1}}\left(K_{1}, L_{1}\right)=q_{0} r_{1}+q_{1} \delta-\left(q_{1}-q_{0}\right)
$$

Die vorstehenden Gleichungen sind im wesentlichen aus der Literatur bekannt (vgl. etwa Sievert/Naust/Jochum/Peglow/Glumann, 1989). Genauer zu erläutern bleibt aber vor allem Gleichung (9.6). Die rechte Seite der Gleichung dokumentiert die sogenannten Kapitalnutzungskosten ("user costs of capital"). Diese werden im folgenden mit $c_{1}$ abgekürzt. Wie ihr Name schon andeutet, stellen die Kapitalnutzungskosten die Opportunitätskosten dar, die mit der Nutzung einer Kapitaleinheit in Periode 1 verbunden sind. ${ }^{221}$ Diese Einheit wurde bekanntlich in der Periode 0 zum Preis $\mathrm{q}_{0}$ erworben. Der erste Summand $\left(\mathrm{q}_{0} \mathrm{r}_{1}\right)$ gibt folglich die kalkulatorischen Kosten in Form entgangener Zinsen an, die bei der Anlage von $\mathrm{q}_{0}$ Geldeinheiten auf dem Kapitalmarkt hätten erzielt werden können; der zweite Ausdruck $\left(q_{1} \delta\right)$ entspricht den Aufwendungen, die erforderlich sind, um den Kapitalverschleiß auszugleichen ${ }^{222}$; der dritte Term $\left(\mathrm{q}_{1}-\mathrm{q}_{0}\right)$ steht für den Wertzuwachs oder den Wertverlust, der erzielt wird, wenn die Kapitaleinheit in Periode 1 verkauft wird. ${ }^{223}$ Im Ergebnis muß bei positivem Wertgrenzprodukt des Faktors Kapital für eine Lösung des Planungsproblems (der Maximierung des Unternehmenswertes) für eine endliche Investitionsnachfrage $q_{0} r_{1}+q_{1} \delta>\left(q_{1}-q_{0}\right)$ gelten.

\footnotetext{
221 Man könnte $c_{1}$ auch als den Mietpreis für eine Kapitalstockeinheit verstehen ("rental price of capital").

$222 \mathrm{Da}$ sich dieser Vorgang in der Periode 1 abspielt, sind dementsprechend die Abschreibungen mit Wiederbeschaffungspreisen zu bewerten.

223 Steigende Investitionsgüterpreise vermindern demnach die Kosten des Kapitaleinsatzes.
} 
Nach Umformung der vorab beschriebenen Gleichung (9.6) zu

$$
r_{1}=\frac{p_{1} \frac{F}{\partial K_{1}}-q_{1} \delta+\left(q_{1}-q_{0}\right)}{q_{0}}
$$

eröffnet sich eine alternative Interpretationsmöglichkeit. Die rechte Seite der Gleichung gibt nunmehr die interne Ertragsrate einer marginalen Investition an. Um dies zu verdeutlichen, wird der Einfluß einer Änderung der Investitionshöhe auf die Einnahmenüberschüsse in den Perioden 0 und 1 bei jeweils optimal angepaßter Arbeitsnachfrage $\left(L_{0}^{*}, L_{1}^{*}\right)$ betrachtet. Es ergeben sich:

$$
\begin{aligned}
\frac{d C_{0}}{d K_{1}} & =-q_{0} \\
\frac{d C_{1}}{d K_{1}} & =p_{1} \frac{\partial F}{\partial K_{1}}\left(K_{1}, L_{1}^{*}\right)+\left[p_{1} \frac{\partial F}{\partial L_{1}}\left(K_{1} L_{1}^{*}\right)-w_{1}\right] \frac{d L_{1}^{*}}{d K_{1}}+q_{1}(1-\delta) \\
& =p_{1} \frac{\partial F}{\partial K_{1}}\left(K_{1}, L_{1}^{*}\right)+q_{1}(1-\delta) .
\end{aligned}
$$

Die interne Ertragsrate einer marginalen Kapitalstockerhöhung bestimmt sich nunmehr durch den Quotienten $\left(d C_{1}+d C_{0}\right) /\left(-d C_{o}\right)$. Bei Berücksichtigung der beiden letzten Gleichungen wird deutlich, daß die interne Ertragsrate gerade dem Ausdruck auf der rechten Seite der Gleichung (9.7) entspricht. Der Marktzins $r$ auf der linken Seite gibt den Ertrag einer in Wertpapieren angelegten Geldeinheit an. Folglich wird solange in Sachkapital investiert, bis die Erträge von Real- und Finanzinvestitionen übereinstimmen.

Weil $\mathrm{K}_{0}$ vorgegeben ist, ergibt sich die Arbeitsnachfrage der Periode 0 aus der Gleichung (9.5a) nur als Funktion des Preises $p_{0}$ und des Nominallohnes $w_{0}$. Kapital- und Arbeitsnachfrage der zweiten Periode $\left(t_{1}\right)$ bestimmen sich simultan aus den Gleichungen $(9.5 b)$ und $(9.6)$ und sind allgemein durch

$$
L_{1}=L_{1}\left(w_{1}, c_{1}, p_{1}\right) \quad \text { mit } \quad \frac{\partial L_{1}}{\partial w_{1}} \leq 0
$$

und

$$
K_{1}=K_{1}\left(w_{1}, c_{1}, p_{1}\right) \quad \text { mit } \quad \frac{\partial K_{1}}{\partial c_{1}} \leq 0
$$


gegeben. Wegen $I_{0}=K_{1}-(1-\delta) K_{0}$ ist damit über $d_{0} / \partial_{1} \leq 0$ zugleich die Richtung des Einflusses der Kapitalnutzungskosten auf die Investitionsentscheidung determiniert.

Damit sind die wesentlichen Zusammenhänge eines partial-analytischen (neoklassischen) Investitionsmodells vorgestellt. Anhand dieses Instrumentariums sollen in den nächsten Abschnitten die allokativen Wirkungen unterschiedlicher kommunaler (Unternehmens-)Steuern auf die betrieblichen Entscheidungen verdeutlicht werden. Die Marginalbedingungen in den Gleichungen (9.5a), (9.5b), (9.6) und (9.7) stellen dabei den normativen Hintergrund für die Beurteilung der allokativen Effekte dar. Bei Gültigkeit der Marginalbedingungen liegt eine effiziente Produktionsentscheidung vor. Wir sprechen daher dann auch von Produktionseffizienz.

In dem vorgestellten Modellrahmen hat der Effizienzbegriff eine statische und eine intertemporale Dimension. Erstere betrifft die periodenweise Wahl des Faktoreinsatzverhältnisses, letztere die intertemporale Investitionsentscheidung, welche den Kapitaleinsatz in den einzelnen Perioden miteinander verbindet. Investitionseffizient ist ein Steuersystem demnach, wenn es die Marginalbedingungen (9.6) und (9.7) unverändert läßt. Bei gegebenen Preisen und Arbeitseinsätzen hätte eine Besteuerung unter diesen Rahmenbedingungen keinerlei Einfluß auf die Investitionsentscheidungen der Unternehmung. Abschließend sei angemerkt, daß Produktionseffizienz zwar Investitionseffizienz einschließt, dies aber umgekehrt nachvollziehbarerweise nicht gilt.

\subsubsection{Die Gewerbesteuer}

\subsubsection{Skizzierung der Gewerbesteuer}

Die Gewerbesteuer (als Beispiel wird wegen der im Grunde genommen gegebenen Einmaligkeit 224 die bundesdeutsche Erhebungsform skizziert) besteht aus zwei Teilen, nämlich der Gewerbeertrag- und der Gewerbekapitalsteuer. Besteuerungsgrundlage ist für die Gewerbeertragsteuer der einkommensteuer(körperschaftsteuer-)rechtliche Gewinn jeweils korrigiert um Hinzurechnungen und Kürzungen. Auf diese Besteuerungsgrundlage wird die Steuermeßzahl angewendet und so der Steuermeßbetrag nach dem Gewerbeertrag berechnet. Besteuerungsgrundlage für die Gewerbekapitalsteuer ist der Einheitswert des gewerblichen Betriebsvermögens, korrigiert durch Hinzurechnungen und Kürzungen. Durch Anwendung der Steuermeßzahl wird der Steuermeßbetrag nach dem Gewerbekapital berechnet. Die Steuermeßbeträge nach Gewerbeertrag und Ge-

224 Gewerbesteuern gibt es in ähnlicher Art nur noch in Österreich (nur Besteuerung des Gewerbeertrags) sowie Luxemburg (vgl. Mennel, 1980, Lănderteil Österreich, 47ff; Lănderteil Luxemburg, 40ff). 
werbekapital werden addiert und darauf schließlich von der jeweiligen Kommune ein gemeindlicher Hebesatz angewendet, der dann die letztliche Steuerschuld für den einzelnen Betrieb bestimmt.

Jede Gemeinde hat das Recht, den Hebesatz für die in ihrem Gebiet angesiedelten Betriebe festzusetzen. Im einzelnen streuen die Hebesätze zwischen den Gemeinden beträchtlich (vgl. dazu Institut "Finanzen und Steuern", 1986; 1992b). Bei der Gewerbeertragsteuer gilt seit dem 01. Januar 1980 ein Freibetrag für Einzelunternehmen und Personengesellschaften von 36.000 DM. ${ }^{225}$ Seit dem 01. Januar 1983 werden Dauerschuldzinsen nur noch zu 60 Prozent, ab 01. Januar 1984 nur noch zu 50 Prozent dem Gewerbeertrag hinzugerechnet. ${ }^{226}$ Bei der Gewerbekapitalsteuer wurde mit Wirkung vom 01. Januar 1981 zunächst ein Freibetrag für Dauerschulden in Höhe von 50.000 DM eingeführt und der allgemeine Freibetrag für das Gewerbekapital von $60.000 \mathrm{DM}$ auf 120.000 DM heraufgesetzt. ${ }^{227}$ Seit dem 01. Januar 1983 wird die Hinzurechnung der Dauerschulden zum Gewerbekapital begrenzt, und zwar für 1983 zunächst auf 60 Prozent, ab 1984 auf 50 Prozent. ${ }^{228}$

\subsubsection{Allokative Wirkungen der Gewerbesteuer}

a) Die Gewerbekapitalsteuer

Bemessungsgrundlage der Besteuerung des Gewerbekapitals ist in der Periode 0 der Einheitswert der vorangegangenen Periode $\left(t_{-1}\right)$, denn in dieser Vorperiode wurde der in Periode 0 in der Produktion einsetzbare Kapitalstock gebildet. Für steuerliche Zwecke ist dieser Kapitalbestand mit dem Faktorpreis $\mathrm{q}_{-1}$ zu bewerten. Da zu Beginn der Periode 0 annahmegemäß keine Verschuldung existieren soll, ist die Bemessungsgrundlage der Gewerbekapitalsteuer am relevanten Stichtag also durch $\mathrm{q}_{1} \mathrm{~K}_{0}$ gegeben. Der entsprechende Wert des Gewerbekapitals (und damit die Bemessungsgrundlage für Periode 1) beträgt

$$
\left[q_{0} K_{1}-0,5 q_{0}\left(K_{1}-K_{0}\right)\right]=0,5 q_{0}\left(K_{0}+K_{1}\right)
$$

\footnotetext{
225 Dieser wird ab dem 01. Januar 1993 auf 48.000 DM erhöht (vgl. Steueränderungsgesetz 1992 vom 25. Februar 1992, BGBI. I, S. 297).
}

226 Vgl. Haushaltsbegleitgesetz 1983 vom 20. Dezember 1982 (BGBl. I, S. 1857).

227 Vgl. Steueränderungsgesetz 1979 vom 30. November 1978 (BGBl. I, S. 1849).

228 Vgl. Haushaltsbegleitgesetz 1984 vom 22. Dezember 1983 (BGBI. I, S. 1532). 
Dieser Wert ergibt sich durch Hinzurechnung von $50 \%$ der Dauerschulden zum Einheitswert des Betriebsvermögens.

Den Steuersatz der Gewerbekapitalsteuer erhält man durch Multiplikation von Steuermeßzahl und kommunalem Hebesatz. Für das der Modellbetrachtung zugrundegelegte repräsentative Unternehmen sei er allgemein durch $\tau_{k}$ gegeben. ${ }^{229}$ Freibeträge sollen aus Vereinfachungsgründen vernachlässigt werden.

Die aus der Besteuerung des Gewerbekapitals resultierende Steuerschuld beläuft sich somit für Periode 0 auf

$$
T_{0}^{k}=\tau_{k} q_{-1} K_{0}
$$

und für Periode 1 auf

$$
T_{1}^{k}=0,5 \tau_{k} q_{0}\left(K_{0}+K_{1}\right)
$$

b) Die Gewerbeertragsteuer

Bei der Gewerbeertragsteuer ist bekanntlich der Steuerbetrag der Gewerbekapitalsteuer als Betriebsausgabe abziehbar. Die Bemessungsgrundlage der Gewerbeertragsteuer geht aus dem Gewinn hervor, der der Einkommen- bzw. Körperschaftsteuerveranlagung zugrunde liegt, wird aber durch bestimmte Hinzurechnungen und Kürzungen modifiziert. In die hier vorliegende Modellbetrachtung soll lediglich die Hinzurechnung (analog zur Gewerbekapitalsteuer) der bei der Ermittlung des steuerlichen Gewinns abzuziehenden Dauerschuldzinsen einbezogen werden. Alle übrigen Hinzurechnungen und Kürzungen werden aus Vereinfachungsgründen außer acht gelassen. Wichtig ist aber die Berücksichtigung der Tatsache, daß neben der Gewerbekapitalsteuer auch die Gewerbeertragsteuer selbst die Bemessungsgrundlage mindert.

Da die Dauerschuldzinsen hier erst in der Periode 1 anfallen, stimmt der Gewerbeertrag der Periode 0 mit dem steuerlichen Gewinn (hier: Bilanzgewinn) überein. Aufbauend auf dem eingangs geschilderten Investitionsmodell (Abschnitt 9.3.1) ergibt sich als Gewinn für die einzelnen Perioden:

$$
G_{0}=p_{0} F\left(K_{0}, L_{0}\right)-w_{0} L_{0}-q_{0} \delta K_{0}
$$

229 Bei einer Steuermeßzahl von 2 vT des Gewerbekapitals und einem durchschnittlichen Hebesatz von $340 \%$ ergábe sich folglich ein Steuersatz von $0,68 \%$. 


$$
G_{1}=p_{1} F\left(K_{1}, L_{1}\right)-w_{1} L_{1}-q_{1} \delta K_{1}-r q_{0}\left(K_{1}-K_{0}\right)
$$

Der entsprechende Steuersatz der Gewerbeertragsteuer (vgl. dazu Brümmerhoff, 1987, 317) sei $\tau_{e}$. Unter Vernachlässigung (wie bei der Gewerbekapitalsteuer) der Freibeträge ergibt sich als Steuerschuld der Gewerbeertragsteuer in Periode 0

$$
\begin{aligned}
T_{0}^{e} & =\tilde{\tau}_{e}\left[p_{0} F\left(K_{0}, L_{0}\right)-w_{0} L_{0}-q_{0} \delta K_{0}-T_{0}^{k}-T_{0}^{e}\right] \\
& =\tau_{e}\left[p_{0} F\left(K_{0}, L_{0}\right)-w_{0} L_{0}-q_{0} \delta K_{0}-\tau_{k} q_{-1} K_{0}\right] .
\end{aligned}
$$

Dabei ist $\tau_{e}=\tilde{\tau}_{e} /\left(1+\tilde{\tau}_{e}\right)$ der "effektive" Steuersatz.

In der Periode 1 wird dann die obige Hinzurechnungsvorschrift wirksam. Die Steuerschuld beläuft sich demnach auf:

$$
T_{1}^{e}=\tau_{e}\left[p_{1} F\left(K_{1}, L_{1}\right)-w_{1} L_{1}-q_{1} \delta K_{1}-0,5 r_{1} q_{0}\left(K_{1}-K_{0}\right)-0,5 \tau_{k} q_{0}\left(K_{0}+K_{1}\right)\right]
$$

Nach diesen vorbereitenden Ausführungen und Modellierungen läßt sich jetzt der Einfluß der Gewerbesteuer auf den optimalen Arbeits- und Kapitaleinsatz durch Lösung der Optimierungsaufgabe (in Anlehnung an die in Gleichung (9.4) formulierte Zielfunktion)

$$
\max _{L_{0}, L_{1}, K_{1}}\left\{\left(C_{0}-T_{0}^{k}-T_{0}^{e}\right)+\frac{1}{1+r_{1}}\left(C_{1}-T_{1}^{k}-T_{1}^{e}\right)\right\}
$$

nachweisen, wobei darüber hinaus noch die Gleichungen (9.3a), (9.3b), (9.12a), (9.12b), (9.14a) und (9.14b) zu beachten sind. Als Diskontierungsfaktor gilt weiterhin der Marktzinssatz $r_{1}$, da sich die Gewerbesteuer gemäß ihrer Zielsetzung (vgl. Bundesministerium der Finanzen, 1992a, 89ff) nicht auf Finanzanlagen erstreckt.

Die üblichen Ableitungen zur Formulierung der Optimalitätsbedigungen führen zu:

$$
\begin{aligned}
& p_{0} \frac{\partial F}{\partial L_{0}}\left(K_{0}, L_{0}\right)=w_{0} \\
& p_{1} \frac{\partial F}{\partial L_{1}}\left(K_{1}, L_{1}\right)=w_{1}
\end{aligned}
$$




$$
p_{1} \frac{\partial F}{\partial K_{1}}\left(K_{1}, L_{1}\right)=r_{1} q_{0} \frac{1-0,5 \tau_{e}}{1-\tau_{e}}+q_{1} \delta+0,5 \tau_{k} q_{0}-\frac{1}{1-\tau_{e}}\left(q_{1}-q_{0}\right)=c_{1}\left(\tau_{e}, \tau_{k}\right)
$$

Bei $\tau_{k}=\tau_{e}=0$ reduziert sich die letzte Gleichung auf die ursprüngliche Gleichung (9.6).

Die abgeleiteten Marginalbedingungen verdeutlichen, daß die Arbeitsnachfrageentscheidungen von der Gewerbesteuer nicht direkt tangiert werden. Allerdings hängen die Kapitalnutzungskosten jetzt sowohl vom Gewerbekapital- als auch vom Gewerbeertragsteuersatz ab. Dies hat einen unmittelbaren Einfluß auf die Investitionsentscheidung. Bevor darauf näher eingegangen wird, sollen die in der Gleichung (9.16c) im Vergleich zur Gleichung (9.6) zusätzlich auftretenden Ausdrücke erläutert werden. Dazu ist es jedoch hilfreich, die Gleichung (9.16c) in eine zur Gleichung (9.7) vergleichbare Form zu bringen.

$$
r_{1}=\frac{\left[p_{1} \frac{\partial F}{\partial K_{1}}-q_{1} \delta+\left(q_{1}-q_{0}\right)\right]-\tau_{e}\left[p_{1} \frac{\partial F}{\partial K_{1}}-q_{1} \partial\right]-\left(1-\tau_{e}\right) 0,5 \tau_{k} q_{0}}{q_{0}\left(1-0,5 \tau_{e}\right)}
$$

Die interne Ertragsrate einer (zusätzlichen Kapitalstockeinheit wird durch die Gewerbesteuer in zweifacher Weise beeinflußt. Die gegenüber der Gleichung (9.7) hinzutretenden Summanden bewirken für sich genommen eine Verminderung der internen Ertragsrate und damit eine Dämpfung der Investitionsnachfrage. Zu den Faktoren im einzelnen. Der erste zusätzliche Ausdruck erfaßt den Einfluß der Gewerbeertragsteuer auf den Produktionswert, wobei die Abzugsfähigkeit der "Abnutzung" des Faktors Kapital Berücksichtigung findet. Im nächsten Term symbolisiert $0,5 \tau_{k} q_{0}$ eine Reduktion der Kapitalrendite infolge der Besteuerung des Gewerbekapitals. Der Faktor 0,5 erklärt sich bekanntlich über die Hinzurechnung der Hälfte der Dauerschulden zur Bemessungsgrundlage. Wegen der Absetzbarkeit der Gewerbekapitalsteuer von der Bemessungsgrundlage der Gewerbeertragsteuer wird dieser Effekt in einem um den Faktor $\left(1-\tau_{e}\right)$ verringerten Ausmaß wirksam.

Den vorab beschriebenen investitionsdämpfenden Einflüssen steht die durch den Ausdruck $\left(1-0,5 \tau_{e}\right)$ hervorgerufene Erhöhung der internen Ertragsrate entgegen. Dieser Effekt ist über die Abzugsfähigkeit der Hälfte der Fremdkapitalzinsen im Rahmen der Gewerbeertragsbesteuerung erklärbar. Schuldzinsen sind (zur Hälfte) abzugsfähig, während Habenzinsen aus Finanzanlagen gewerbesteuerlich unerfaßt bleiben. Durch diese asymmetrische Behandlung von Zinszahlungen kommt es zu einer Senkung der Finanzierungskosten (vgl. etwa Gutting, 1987, 34). Bei isolierter Betrachtung führt 
dieser Effekt aufgrund der unterstellten Modellannahmen (die Nettoinvestitionen werden durch Aufnahme von Fremdkapital finanziert) zu einer Ausweitung der realen Investitionstätigkeit. Allerdings ist im Ergebnis dieser Effekt in der Regel schwächer als die zuvor beschriebenen investitionsdämpfenden Einflußfaktoren. Per Saldo kommt es folglich durch die Gewerbekapital- und die Gewerbeertragsbesteuerung zu einem Rückgang der Investitionsnachfrage (vgl. auch Richter/Wiegard, 1990b, 41). Dies wird bei näherer Betrachtung der Differentialquotienten

$$
\frac{\partial x_{0}}{\partial c_{1}} \frac{\partial c_{1}}{\partial \tau_{k}} \quad \text { und } \quad \frac{\partial_{0}}{\partial c_{1}} \frac{\partial c_{1}}{\partial \tau_{e}}
$$

deutlich. Die Differentiation der rechten Seite der Gleichung (9.17) liefert

$$
\frac{\partial c_{1}}{\partial \tau_{k}}=0,5 q_{0} \quad ; \quad \frac{\partial c_{1}}{\partial \tau_{e}}=\frac{q_{0}\left(0,5 r_{1}-\pi\right)}{\left(1-\tau_{e}\right)^{2}},
$$

wobei $\pi=\left(q_{1}-q_{0}\right) / q_{0}$ die Inflationsrate für Kapitalgüterpreise bezeichnet. Bei Nichtvorhandensein von Inflation (d.h. $q_{1}=q_{0}$ ) wirken beide Gewerbesteuerkomponenten eindeutig investitionsdämpfend.

Die vorstehenden Ausfuihrungen reihen sich in die umfassende wirtschaftstheoretische Auseinandersetzung um die Gewerbesteuer ein (vgl. auch Gutting, 1987, 25ff). Resümierend bleibt für die Gewerbesteuer festzuhalten, daß sie die Finanzierungsstruktur verzerrt, die Investitionsneigung hemmt und arbeitsintensive Produktionsverfahren begünstigt. Bei der Gewerbeertragsteuer führt der hälftige Abzug der Schuldzinsen zu Verzerrungen, denn bei fremdfinanzierten Investitionsprojekten verringert sich der Nettozinssatz um die Hälfte des Gewerbesteuersatzes. Bei der Eigenfinanzierung bleibt dagegen die Diskontierungsrate ("Alternativzinssatz") konstant, weil die Anlage von Geldern am Kapitalmarkt nicht der Gewerbesteuer unterliegt. Dies fuihrt zu Verzerrungen der Finanzierungsentscheidungen bei der Sachkapitalbildung, indem eine Präferenz für Fremdfinanzierung der Investitionen erzeugt wird (vgl. Gutting, 1987). Die Gewerbekapitalsteuer trifft die Fremdkapitalaufnahme - wegen der hälftigen Hinzurechnung des langfristigen Fremdkapitals - weniger stark als die Eigenkapitalerhöhung. Daher wird auch hier die Kreditfinanzierung begünstigt.

Daß durch die Gewerbesteuer arbeitsintensive Produktionsverfahren begünstigt werden, hängt mit der Diskriminierung der Sachkapitalinvestitionen und der neutralen Wirkung in bezug auf den Arbeitseinsatz zusammen. Der Fiskus beteiligt sich im Grunde genommen bei der Gewerbeertragsteuer gleichmäßig an den Kosten und Erträgen der Arbeit; die Gewerbekapitalsteuer berührt den Arbeitseinsatz überhaupt nicht. 


\subsubsection{Die Eignung der Gewerbesteuer als Gemeindesteuer}

Die Gewerbesteuer schneidet also unter Effizienzgesichtspunkten schlecht ab. Über die konkreten Ergebnisse des vorstehenden Modells hinaus gibt es eine Reihe weiterer Kritikpunkte. Das die Gewerbesteuer nicht allokationsneutral ist, wurde bereits im Rahmen der vorstehenden Modellbetrachtung erkennbar. Des weiteren verursacht die Gewerbesteuer intersektorale Allokationsverzerrungen, einerseits durch die hohen Freibeträge, andererseits durch den engen Begriff des Gewerbes im Sinne des Gewerbesteuergesetzes. Die vergleichsweise hohen Freibeträge sowohl bei der Gewerbeertrag- als auch bei der Gewerbekapitalsteuer haben zur Folge, daß nur noch mittlere und vor allem große Betriebe gewerbesteuerpflichtig sind ("Großbetriebsteuer"). ${ }^{230}$ Der enge Gewerbebegriff führt dazu, daß aufgrund der Abgrenzung des Gewerbebetriebes im Sinne des Gewerbesteuergesetzes beispielsweise die freien Berufe ebenso unbesteuert bleiben wie die sogenannten Hoheitsbetriebe der öffentlichen Hand. Auch die Land- und Forstwirtschaft ist von der Gewerbesteuerpflicht ausgenommen, unterliegt dafür jedoch zumindest der Grundsteuer. Unter Äquivalenzgesichtspunkten erfüllt die Gewerbesteuer damit nur in unzureichender Form die an eine Gemeindesteuer geknüpften Erwartungen. Schließlich können noch die Unzulänglichkeiten der Einheitsbewertung des betrieblichen Eigenkapitals und eine Reihe daraus resultierender Probleme gegen die Gewerbebesteuerung ins Feld geführt werden (vgl. dazu Wissenschaftlicher Beirat, 1989, 15).

Als verteilungsneutral wird die Gewerbesteuer - trotz ihrer sogenannten "Mittelstandsfreundlichkeit" (vgl. Marcus, 1987, 69), die durch bestimmte Befreiungen von der Steuerpflicht sowie existierende Freibeträge zum Ausdruck kommt - aufgrund einiger der vorab erwähnten Tatbestände wohl ebenfalls kaum angesehen werden können. Auch stabilitätspolitische Wirkungen gehen von der Gewerbesteuer aus. Thr Beitrag zur automatischen Flexibilität des Steuersystems - also zur automatischen Reaktion des Steueraufkommens auf Wachstumsschwankungen, ist nicht sehr hoch zu veranschlagen, da sie einen reagiblen (Ertragsteuer) und einen relativ starren (Kapitalsteuer) Teil umfaßt. Es wird hier sogar eine ungünstige Wirkung vermutet, denn "(d)ie relative Zahllast, ausgedrückt als Verhältnis der Steuerschuld zum Gewinn, nimmt ... regelmäßig während einer Rezessionsperiode zu und vice versa während einer Aufschwungphase ab" (Littmann, 1980, 625).

${ }^{230}$ Diese Entwicklungen haben sich durch die laufenden Eingriffe des Gesetzgebers in das Gewerbesteuergesetzes und die Gewerbesteuer-Durchführungsverordnung eher noch verstärkt. Letztes Glied in einer Kette von Eingriffen, die im Grunde genommen die Gewerbesteuer immer weiter pervertiert haben, ist das Steuerănderungsgesetz 1992 (BGBI. I, S. 297), mit dem eine weitere Freibetragsanhebung für Einzelunternehmen und Personengesellschaften sowie eine Streckung der Steuermeßzahlen für Einzelunternehmen und Personengesellschaften ab 01. Januar 1993 verankert wurde. 
Auch aus der Sicht der Gemeinden (neben der entsprechenden Kritik der Wirtschaft) erfüllt die Gewerbesteuer die Funktionen einer "echten" Gemeindesteuer nur (noch) unzureichend. Ziel der Besteuerung des örtlichen Gewerbes (der örtlichen Unternehmen) war und ist die Herstellung eines Bindegliedes ("Interessenverbund") zwischen den Städten und Gemeinden auf der einen sowie der heimischen Wirtschaft auf der anderen Seite. Die Gewerbesteuern zählen zwar zu den Steuerquellen - die in den Ländern, in denen sie zur Erhebung gelangen - traditionsgemäß den Gemeinden zur alleinigen Ausschöpfung überlassen bleiben; überdies haben die Gemeinden durchweg die Möglichkeit, Aufkommensvariationen durch ihre Entscheidungen herbeizuführen. Doch es stellt sich die Frage, ob man davon ausgehen kann, daß jene gemeindliche Teilgruppe, die die Abgabe tragen soll, in genügender Breite getroffen wird. Wenn man argumentiert, es seien letztlich die Gewerbetreibenden, die Nutzen aus bestimmten (lokalen) öffentlichen Leistungen ziehen bzw. kommunale Lasten verursachen, und wenn man weiterhin berücksichtigt, daß die in einem Gewerbesteuermodell vorgesehene Fassung des Begriffs "Gewerbebetrieb" einen Kreis an Pflichtigen festlegen würde, der den zur Zeit in der Bundesrepublik Deutschland einbezogenen übertrifft, ließe sich im Gegensatz zur real existierenden Situation von einer genügend großen Breitenwirkung der Steuer in bezug auf die hier relevante Teilgruppe sprechen.

Der Staat besitzt die Gesetzgebungskompetenz über die Gewerbesteuer und über das gesamte Feld der Einkommensteuer. Daher kann er durch Änderungen von Rechtsvorschriften zur Regelung der Gewerbesteuer, aber auch durch Änderung von Vorschriften, welche die mit der Gewerbesteuer verknüpfte Einkommen- und Körperschaftsteuer betreffen, auf das kommunale Gewerbesteueraufkommen einwirken. Beispiele dafür gibt es zur Genüge und gerade die bundesdeutsche Entwicklung macht die angesprochene Problematik nicht nur mehr als deutlich, sondern zeigt, daß diese Änderungen der Rechtsetzung selbst die Ursache von Fehlentwicklungen sein können.

Mit dem Steueränderungsgesetz 1992 und seinen Regelungen wurde im Bereich der Gewerbebesteuerung eine Kette von Entscheidungen vorläufig abgeschlossen, die die Gewerbesteuer in ihrer Eigenschaft als Gemeindesteuer - gerade auch hinsichtlich ihres eigentlichen Charakters als Objektsteuer - im Zeitablauf sukzessiv ausgehöhlt haben. Aus heutiger Sicht besitzt die Gewerbesteuer bei der Erfuillung ihrer Funktion unter anderem deshalb grundlegende Schwächen. Doch die Bewertung dieser Entwicklung ist unterschiedlich. Unter steuersystematischen Gesichtspunkten wird man diese Maßnahmen insofern begrüßen, als sie die Bedeutung dieser Abgabe mildern, die teils eine nicht personalisierte Sondersteuer auf eine Gruppe von Einkommensempfängern, teils eine Sollertragsteuer auf eine Klasse von Vermögensbesitzern (Gewerbekapitalvermögen) ist, die infolge ihrer spezifischen Ausgestaltung nur noch in einem sehr losen Zusammenhang mit den lokalen öffentlichen Leistungen steht und damit weder 
nach dem Äquivalenz- (wie für eine kommunale Steuer üblich) noch nach dem Leistungsfähigkeitsprinzip Rechtfertigung erfahren kann (vgl. Rehm, 1981, 185). Die Beseitigung der Lohnsummensteuer, die Heraufsetzung der Freibeträge nach Ertrag und Kapital sowie die neue Staffelung der Meßzahlen nach dem Gewerbeertrag oberhalb des Freibetrags für Einzelunternehmen und Personengesellschaften haben aber auch nachhaltige Differenzierungen der Gewerbesteuerbelastung bewirkt, die nicht nur an sich wieder neue allokative Verwerfungen ausgelöst haben, sondern darüber hinaus auch die Streuung des örtlichen Gewerbesteueraufkommens verstärken, zumal die Abgabe durch die erwähnten Maßnahmen sich noch stärker in die Richtung einer "Großbetriebsteuer" entwickelt hat.

Bei allen kritischen Einwänden gegenüber dieser kommunalen Steuer sollte dennoch nicht übersehen werden, daß sie eine besondere Qualität für die gemeindliche Finanzpolitik besitzt. Sind die Betriebe Verursacher gemeindlicher Lasten, so werden sie sich in der Regel an der Finanzierung derselben auch dann beteiligen, wenn sie nicht als "Direkt"-Verursacher (via Gebühren- oder Beitragszahlung) identifizierbar sind. Sie dürften grundsätzlich ein nicht unerhebliches Interesse an der Durchführung kommunaler Aufgaben (etwa Infrastrukturinvestitionen) wegen des damit für sie verbundenen Vorleistungscharakters besitzen. Die Gemeinden wiederum haben ein Interesse an der Existenz und dem Florieren des in ihrem Raum ansässigen Gewerbes. Mit Hilfe der Gewerbesteuer (beispielsweise) läßt sich ein "elastisches Band" (so zumindest Marcus, 1986, 175) zwischen Gewerbebetrieben und Gemeinden knüpfen. "Fehlt eine in welcher Form auch immer erhobene Gewerbebetriebsabgabe, so ist die beschriebene Verknüpfung nicht vorhanden." (Marcus, 1986, 175)

Doch Marcus zielt auf eine zu eng gefaßte Kausalität ab. Einmal sind es nicht die Gewerbebetriebe allein, die kommunale Infrastruktur im Sinne von Vorleistungen bei ihrer eigenen Leistungserstellung nutzen, sondern etwa auch freie Berufe und öffentliche Einrichtungen. Zum anderen kann sicherlich auch eine andere Form der Unternehmensbesteuerung als "elastisches Band" zwischen Gemeinde und örtlicher Wirtschaft dienen und einen Interessenausgleich in der vorgeschlagenen Form bewirken. Welche anderen Steuerformen sich dabei anbieten, soll nunmehr diskutiert werden.

\subsubsection{Die Wertschöpfungsteuer}

Schon Anfang der sechziger Jahre fand die Wertschöpfungsteuer als "neue" Kommunalabgabe Eingang in die Reformdiskussion kommunaler Finanz- bzw. Steuersysteme (vgl. etwa Oberhauser, 1964, 241ff). "Eine derartige Steuer hätte den Vorteil, daß ihr Aufkommen pro Kopf der Bevölkerung in Orten gleicher Größe weit stärker nivelliert 
wäre, als das bei den heutigen Gemeindesteuern der Fall ist" (Oberhauser, 1964, 241). Mit dieser Abgabe wird eine weitgehend gleichmäßige Besteuerung der Einkommen auf indirektem Wege ermöglicht, und zwar mittels einer Steuer, "... die die gesamte Wertschöpfung proportional erfaßt" (Oberhauser, 1964, 244).

\subsubsection{Skizzierung der Wertschöpfungsteuer}

Die Bemessungsgrundlage einer solchen kommunalen Abgabe (die betriebliche Wertschöpfung) kann dabei sowohl von der Entstehungsseite als auch von der Verwendungsseite des Produktionskontos ermittelt werden. In der Volkswirtschaftlichen Gesamtrechnung ist die (Netto-)Wertschöpfung (WS) eines Unternehmens von der Entstehungsseite definiert als Differenz zwischen dem (Brutto-)Produktionswert (BPW) ${ }^{231}$ und den von anderen Wirtschaftseinheiten bezogenen Vorleistungen (Vor), der Wertminderung (Kapitalverzehr) des Anlagevermögens - also den Abschreibungen (D) sowie dem Saldo aus gezahlten indirekten Steuern ( $\left.T^{\text {ind }}\right)$ und erhaltenen staatlichen Subventionen (Zu). Es ergibt sich somit fuir die Entstehungsseite (subtraktive Methode)

$$
\mathrm{WS}=\mathrm{BPW}-\text { Vor }-\mathrm{D}-(\text { Tind }-\mathrm{Zu})
$$

Von der Verteilungsseite her wäre die einzelwirtschaftliche Bemessungsgrundlage einer derartigen Steuer (additive Methode) die Summe der den Produktionsfaktoren zufließenden Erträge, also

$$
W S=G+L_{A}+Z_{A}-B_{E}-Z_{E}+T^{\text {ind }}-Z u
$$

wobei

sind.

$$
\begin{aligned}
& \mathrm{G}=\text { Gewinn } \\
& \mathrm{L}_{\mathrm{A}}=\text { Lohn- und Gehaltsaufwand } \\
& \mathrm{Z}_{\mathrm{A}}=\text { Zinsaufwand } \\
& \mathrm{B}_{\mathrm{E}}=\text { Beteiligungserträge }{ }^{232} \\
& \mathrm{Z}_{\mathrm{E}}=\text { Zinserträge }
\end{aligned}
$$

Gleichung (9.18b) entspricht der teilweise bereinigten Nettowertschöpfung zu Marktpreisen, Gleichung (9.18a) der unbereinigten Nettowertschöpfung zu Faktorkosten. Bei

\footnotetext{
231 Dieser ergibt sich als Summe der Verkäufe, des Eigenverbrauchs und der Zunahme des Sachvermögens (Lagerbestandsverănderungen, selbsterstellte Anlagen).

${ }^{232}$ Soll die Wertschöpfung an der verursachenden Stelle erfaßt werden, so ist die Wertschøpfungsrechnung von der Verwendungsseite her um die Beteiligungserträge zu korrigieren. Andernfalls würden sie doppelt oder gar mehrfach erfaßt werden.
} 
der Ermittlung der Bemessungsgrundlage, die auf eine vollständige Bereinigung der Wertschöpfung abstellt, müßte ein Vorsteuerabzug bei den Investitionen zugelassen werden. Dies müßte geschehen, weil durch den Investitionsvorgang selbst noch keine Wertschöpfung stattfindet (vgl. Rehm, 1982, 107). Auf die damit zusammenhängenden Probleme geht im Rahmen einer Erörterung von Einzelfragen der Abgrenzung der Bemessungsgrundlage der Wertschöpfungsteuer Rehm (1982, $111 \mathrm{ff})$ ausführlich ein (vgl. auch Klaus-Dieter-Arndt-Stiftung, 1986a).

Ausgehend von diesen einzelwirtschaftlichen Bemessungsgrundlagen kann die Wertschöpfungsbesteuerung nur mit "gewissen Einschränkungen als eine 'indirekte Einkommensbesteuerung' charakterisiert werden" (Rehm, 1982, 107). Die betriebliche (Netto-)Wertschöpfung stellt den Beitrag eines Unternehmens zum Nettoinlandsprodukt zu Faktorkosten und nicht zum Nettosozialprodukt (oder zum Volkseinkommen) dar (vgl. Pohmer, 1980, 704). Da zur inländischen Einkommenserzeugung auch die Exportleistungen (nicht aber die Importe) zählen, entspricht es dem Konzept der Belastung der betrieblichen Wertschöpfung, die Exporte zu belasten, die Importe dagegen (abgesehen natürlich von der inländischen Wertschöpfung des Importeurs) von der Steuer zu befreien. Diese Form der Belastung betrieblicher Wertschöpfung verzichtet also auf einen Grenzausgleich (vgl. Biehl, 1988, 695f).

Für das gesamtwirtschaftliche Belastungskonzept einer Wertschöpfungsteuer wäre zu entscheiden, ob das Nettoinlandsprodukt zu Marktpreisen oder zu Faktorkosten Grundlage einer Besteuerung sein soll. In erstgenannten Fall wären die Gleichungen (9.18a) und (9.18b) um den Saldo aus indirekten Steuer und Subventionen zu korrigieren. Steuerpolitischer Vorteil einer solchen Vorgehensweise wäre, daß die Wertschöpfung zu Marktpreisen einen optisch niedrigeren Steuersatz als eine Belastung der Wertschöpfung zu Faktorkosten erfordert, wenn mit beiden Steuerarten das gleiche Steueraufkommen angestrebt würde. Die angesprochenen Zahlungsunterschiede dieser beiden Varianten einer Wertschöpfungsbesteuerung können allerdings in Abhängigkeit von der regionalen Wirtschaftsstruktur und von der konkreten Gestaltung des Abgabensystems die interregionale Streuung des Aufkommens einer solchen Abgabe beeinflussen. Neben diesem raumordnungspolitischen Aspekt wäre auch unter steuersystematischen Gesichtspunkten, d.h. im Hinblick auf eine äquivalenztheoretisch begründete Belastung der Faktorerträge, die Besteuerung der Wertschöpfung zu Faktorkosten vorzuziehen.

Zur Abgrenzung der Steuerpflicht einer solchen Abgabe ist anzumerken, daß die Gleichungen (9.18a) und (9.18b) lediglich ein Grundschema darstellen, das in Abhängigkeit von dem konkreten Besteuerungsziel einer Wertschöpfungsabgabe differenziert werden kann. Eine solche Differenzierung könnte im Zusammenhang mit dem Begriff 
"steuerpflichtige Unternehmen" erforderlich sein, denn es müßte beispielsweise geklärt werden, ob die Vermietung und/oder Verpachtung von Grund und Boden oder Gebäuden als unternehmerische Tätigkeit gelten oder auf eine Integration in die Bemessungsgrundlage wegen der Belastung dieser Erträge durch andere Abgaben (beispielsweise die Grundsteuer) verzichtet werden sollte.

Im Sinne einer Allgemeinheit der Besteuerung ist es sinnvoll, auch die Wertschöpfung der Landwirtschaft und der freien Berufe in die Steuerpflicht einzubeziehen. Darüber hinaus wäre zu überlegen, ob auch die Wertschöpfung der nicht-kommunalen öffentlichen Institutionen der Steuerpflicht unterworfen werden sollte, um die "Dienstleistungszentren" oder "Verwaltungsstädte" im Hinblick auf die interlokale Verteilung des Steueraufkommens infolge unterschiedlicher Wirtschaftsstrukturen nicht zu benachteiligen. ${ }^{233}$

Die Ermittlung der einzelbetrieblichen Wertschöpfung wäre für die Unternehmen im Grunde genommen kein prinzipiell neues Rechnungsziel, weil diese Größe im Rahmen einer Erweiterung der betrieblichen Rechnungslegung zu Ergebnisdarstellungen in Form von Sozialbilanzen teilweise bereits ausgewiesen wird (vgl. Goetzke, 1979, 419ff; Reichmann/Lange, 1980, 518ff; Dierkes, 1981, 901ff).

\subsubsection{Allokative Wirkungen der Wertschöpfungsteuer}

Die Bemessungsgrundlage dieser Steuer - die Wertschöpfung - kann also entweder auf additivem oder auf subtraktivem Weg ermittelt werden. Allgemein wird der additiven Ermittlung der Vorzug gegeben. Danach erhält man die Bemessungsgrundlage als Summe der Löhne, Gewinne, Mieten und Zinsen (vgl. auch Gleichung (9.18b)). Unter den für das vorgestellte neoklassische Investitionsmodell (vgl. Abschnitt 9.3.1) getroffenen Annahmen bestimmt sich die Steuerschuld des Unternehmens dann über die Tariffunktionen (je nach Periode):234

$$
\begin{aligned}
& T_{0}^{w s}=\tau_{w s}\left(w_{0} L_{0}+G_{0}\right) \\
& T_{1}^{w s}=\tau_{w s}\left[w_{1} L_{1}+G_{1}+r_{1} q_{0}\left(K_{1}-K_{0}\right)\right]
\end{aligned}
$$

233 Oberhauser $(1964,248)$ stellt in diesem Zusammenhang fest, daß "... die Bediensteten des Staates ebenfalls zur volkswirtschaftlichen Wertschöpfung beitragen" und es somit durchaus konsequent erscheint, "... daß die nicht-kommunalen öffentlichen Institutionen an die Gemeinden Übertragungen in einer Höhe vornehmen, die der Belastung der privatwirtschaftlichen Wertschöpfung entspricht".

${ }^{234}$ Dabei steht der Index "ws" für die Wertschöpfung. 
Bei der subtraktiven Methode sind von den Unternehmensumsätzen die Ausgaben für die von anderen Unternehmen bezogenen Vorleistungen und darüber hinaus die Aufwendungen für den Kapitalverschleiß abzuziehen. In diesem Fall lauten die Steuerschuldgleichungen für die jeweilige Periode wie folgt:

$$
\begin{aligned}
& T_{0}^{w s}=\tau_{w s}\left[p_{0} F\left(K_{0}, L_{0}\right)-q_{0} \delta K_{0}\right] \\
& T_{1}^{w s}=\tau_{w s}\left[p_{1} F\left(K_{1}, L_{1}\right)-q_{1} \delta K_{1}\right]
\end{aligned}
$$

Unter Berücksichtigung der Gleichungen (9.13a) und (9.13b) wird offenkundig, daß die Gleichungen (9.19a) und (9.20a) sowie (9.19b) und (9.20b) jeweils äquivalent sind. Beim einem Vergleich der Gleichungen (9.20a) und (9.20b) mit den Gleichungen (9.25a) und (9.25b) wird ebenfalls klar, daß sich die Bemessungsgrundlagen von Umsatz- (s. Abschnitt 9.3.5) und Wertschöpfungsteuer im wesentlichen nur um die Nettoinvestitionen unterscheiden. Darauf wird später noch einmal näher eingegangen werden müssen (vgl. die Abschnitte 9.3.4 und 9.3.5).

Die optimale Arbeits- und Kapitalnachfrage erhält man jetzt aus den Marginalbedingungen (9.21a), (9.21b) und (9.22).

$$
\left(1-\tau_{w s}\right) p_{0} \frac{\partial F}{\partial L_{0}}=w_{0}
$$

$$
\left(1-\tau_{w s}\right) p_{1} \frac{\partial F}{\partial L_{1}}=w_{1}
$$

$$
\frac{\left(1-\tau_{w s}\right)\left[p_{1} \frac{\partial F}{\partial K_{1}}-q_{1} \delta\right]+\left(q_{1}-q_{0}\right)}{q_{0}}=r_{1}
$$

Aus diesen Gleichungen ist ersichtlich, daß bei in der Zeit konstanten Kapitalgüterpreisen zwar die relativen Faktorpreise und damit die Faktoreinsatzverhältnisse von der Wertschöpfungsteuer an sich nicht betroffen sind, daß allerdings Investitionseffizienz nicht gewährleistet ist, denn die Wertschöpfungsteuer belastet zwar die Produzentenrente und die Leistungseinkommen aller Produktionsfaktoren zu gleichen Anteilen (sie ist also neutral hinsichtlich Finanzierungsform und Arbeitseinsatz), sie diskriminiert aber eindeutig die Sachinvestition gegenüber einer Finanzinvestition (also einer Geldmarktanlage) und beeinflußt damit die Investitionsneigung (vgl. Richter/Wiegard, 
1990b, 41). Das liegt daran, daß die Steuer einerseits die Nettoeinnahmen verringert und andererseits die Fremdkapitalzinsen und die Zinserträge aus Wertpapieren nicht berührt (Konstanz der Diskontierungsrate). Richter und Wiegard (1990a, 12) widersprechen aufgrund dieser Ergebnisse der Auffassung des Wissenschaftlichen Beirats beim Bundesministerium der Finanzen $(1982,75)$, daß "... es beim Einsatz der Produktionsfaktoren zwischen kapital- und arbeitsintensiven Unternehmen oder zwischen Konsum und Investition kaum zu Verzerrungen kommen" kann. Eine Wertschöpfungsteuer ist in ihren Augen keineswegs als weitgehend allokativ neutral anzusehen; vielmehr verzerrt "(e)ine Besteuerung der Wertschöpfung ... die marginale (Sach-)Investitionsentscheidung im Prinzip ebenso wie die Gewerbesteuer. A priori kann nicht einmal gesagt werden, welche Steuer den Einsatz von Sachkapital stärker diskriminiert." (Richter/Wiegard, 1990a, 12) Gleichwohl bleibt anzumerken, daß die Wertschöpfungsteuer im "realen" Sektor aufgrund der breiten Bemessungsgrundlage und der gleichmäßigeren Belastungsstruktur eindeutige Vorzüge im Vergleich zur Gewerbesteuer des aktuellen Typs besitzt.

Als weiterer Kritikpunkt an der Wertschöpfungsteuer wird häufig die Identität der Bemessungsgrundlage dieser Abgabe mit der Bemessungsgrundlage der Nettoumsatzsteuer vom Einkommenstyp bzw. einer Einkommensteuer an sich angefuihrt (vgl. Richter/Wiegard, 1990a, 12f). Es wird argumentiert, daß die Wertschöpfungsteuer im Grunde genommen einer zusätzlichen proportionalen Einkommensteuer oder einer gleichmäßigen Anhebung aller Einkommensteuersätze entspräche. Daraus wird gefolgert, daß damit die leistungshemmenden Wirkungen des Steuersystems zunähmen.

\subsubsection{Die Eignung der Wertschöpfungsteuer als Gemeindesteuer}

Das von Oberhauser (1964) seinerzeit präferierte Konzept einer kommunalen Wertschöpfungsteuer stellt auf die indirekte Erfassung der Wertschöpfung ab. D.h. für die Verteilung der Steuererträge auf die einzelnen Gemeinden ist nicht der Ort der Wertschöpfung, sondern der Ort der "verteilten" Wertschöpfung heranzuziehen. "Da in gleicher Höhe wie die Wertschöpfung Einkommen anfallen, müßten die Steuererträge den Kommunen zufließen, deren Gemeindemitglieder die Einkommen erhalten. Entscheidend für die Aufteilung des Steueraufkommens müßte also der Wohnsitz der Einkommensempfänger und nicht der Sitz der Unternehmen sein." (Oberhauser, 1964, 245) Damit wird infolge der Tatsache, daß der Ort der Wertschöpfung mit dem Wohnsitz des Einkommensempfängers keineswegs identisch sein muß23s, ein Verfah-

${ }^{235}$ Elsner $(1978,102 \mathrm{ff})$ zeigt auf, daß es gerade in den kreisfreien Städten zu teilweise recht hohen Abweichungen der Wohn- von der sogenannten Wirtschaftsbevolkerung kommt. 
ren zur Aufteilung der Steuererträge auf die verschiedenen Gemeinden, deren Bewohner Wertschöpfungsbeiträge via Einkommen von anderen als ihren Wohnsitzgemeinden beziehen, benötigt (vgl. Marcus, 1986, 177).

Einen anderen Weg der Zuteilung des Aufkommens der Wertschöpfungsteuer geht der Wissenschaftliche Beirat $(1982,68)$. Er schlägt vor, daß das Aufkommen der Wertschöpfungsteuer den Betriebsgemeinden (Wahrung eines Interessenausgleichs) zustehen sollte. Für Unternehmen mit Betriebsstätten in mehreren Gemeinden ist dann eine Zerlegung des Steueraufkommens nach der Belegenheitsgemeinde anhand geeigneter Schlüssel - etwa der Lohnsumme - vorzunehmen (vgl. auch Littmann, 1983, 178ff).

Die bisherigen Überlegungen gingen von einem einheitlichen (nationalen) Steuersatz für die Kommunen aus. Die Gemeinden müßten jedoch im Sinne des Beweglichkeitspostulats zur Realisierung einer tatsächlichen Einnahmenautonomie die Möglichkeit besitzen, unmittelbaren Einfluß auf die Höhe des ihnen zufließenden Steueraufkommens auszuüben. Vor diesem Hintergrund und zur Anpassung der eigenen Einnahmen an den unterschiedlichen Finanzbedarf ist es daher notwendig, im Rahmen der Wertschöpfungsbesteuerung den Gemeinden ein Hebesatzrecht einzuräumen (vgl. Oberhauser, 1964, 249). Von derartigen gemeindlichen Steuersatzvariationen würden selbstverständlich Standortwirkungen und Wettbewerbsverschiebungen ausgehen. Eine gemeindliche Finanzautonomie ist aber notwendigerweise mit solchen Effekten verbunden und kann, wenn die Signale richtig sind, diese Steuersatzdifferenzierungen über die entsprechende Äquivalenzbeziehung zu den damit finanzierten Ausgaben im Rahmen des interlokalen Standortwettbewerbs durchaus sinnvoll nutzen.

Problematisch werden mögliche Steuersatzdifferenzen, wenn die "Entstehungsgemeinden" auch für jene Teile der Wertschöpfung ein Hebesatzrecht erhalten, die sie verlassen (vgl. Oberhauser, 1964, 249). Dann kann das Steueraufkommen einer Kommune Teile enthalten, die dem eigenen politischen Entscheidungsrahmen direkt nicht mehr zugänglich sind. Dies ist für jene "Überweisungen" von anderen Kommunen, welche für Wertschöpfungsbeiträge anfallen, die von Einwohnern der Empfangsgemeinde dort geleistet wurden, der Fall. Außerdem würde die Überweisungsgemeinde Steueraufkommmen der Empfangsgemeinde mit verändern können. Die durch politische Entscheidung einer Gemeinde bewirkte Aufkommensänderung tangiert dann nicht mehr ausschließlich den Haushalt derselben (vgl. Marcus, 1986, 178). Dieser Einwand verliert jedoch an Bedeutung, wenn das Aufkommen der Wertschöpfungsteuer den Betriebsgemeinden zusteht (vgl. Wissenschaftlicher Beirat, 1982, 68).

Grundsätzlich könnte die Wertschöpfungsteuer eine langfristige Lösung zur Sicherung der Finanzautonomie der Gemeinden bei Aufrechterhaltung eines finanziellen Bandes 
zwischen Kommunen und örtlicher Wirtschaft darstellen. Infolge ihrer Allgemeinheit und Merklichkeit ist sie gut geeignet für einen entsprechenden "Interessenausgleich" (vgl. Wissenschaftlicher Beirat, 1982, 32ff); dies insbesondere dann, wenn es gelingt, die Wohnungswirtschaft in die Abgabe einzubeziehen. Auf diese Weise wären dann Wohntatbestand - soweit er Produktion bedeutet - und Gewerbe der gleichen Steuer mit gleicher Höhe (innerhalb einer Gemeinde) unterworfen. Eine einseitige Belastung einzelner Gruppen innerhalb der Gemeinden durch Hebesatzänderungen würde vermieden. Durch eine Einbeziehung der freien Berufe und staatlicher Behörden zum kommunalen Steueraufkommen würde das einseitige fiskalische Interesse der Kommunen an gewerblichen Groß- und Mittelbetrieben (beispielsweise bedingt durch eine entsprechende Ausgestaltung einer Gewerbesteuer) abgebaut (vgl. Roloff, 1987, 103). W. Ritter (1983) befürchtet allerdings ein nachlassendes Interesse an der Industrieansiedlung. "Vor allem aber fördert sie [die Wertschöpfungsteuer] weniger die Industrieansiedlung, sondern begünstigt die Ansiedlung von Behörden und öffentlichen Einrichtungen. Im einem Wettlauf zwischen Fabrik und Behörde, Hochofen und Universität muß unter den Prämissen einer solchen Steuer die gewerbliche Ansiedlung zum Schaden unserer Volkswirtschaft zu kurz kommen." (Ritter, W., 1983, 392) Diese Vermutung erscheint jedoch vorschnell, wenn auf der anderen Seite festgestellt wird, "(d)ie Wertschöpfungsteuer würde die Unternehmen auch deshalb besonders treffen, weil sie außer von den Kosten auch vom Gewinn zu zahlen wäre, während die öffentliche Hand nur mit einer Steuer von einer Kostenart belastet würde. Von einer gleichmäßigen Verteilung der Last auf die private und die öffentliche Wertschöpfung kann bei diesem Zuschnitt keine Rede sein." (Ritter, W., 1983, 392) Insgesamt betrachtet ist daher kaum einzusehen, warum dem höheren Beitrag der Industrie zum kommunalen Steueraufkommen nicht auch ein höheres (oder zumindest nicht nachlassendes) fiskalisches Interesse an der Industrieansiedlung entsprechen sollte.

Die Wertschöpfungsteuer dürfte langfristig in gleicher Richtung und gleichem Ausmaß wie das Sozialprodukt wachsen, also eine Aufkommenselastizität von annähernd eins besitzen. Dem Kriterium der Wachstumsproportionalität würde damit entsprochen. Kurzfristig dürfte die Aufkommenselastizität allerdings etwas über eins liegen, weil etwa im Vergleich zu einer allgemeinen Verbrauchsbesteuerung im Sinne der Mehrwertsteuer die zusätzliche Einbeziehung der Investitionen in die Bemessungsgrundlage eine stärkere Konjunkturabhängigkeit ergibt. Im Vergleich zur Gewerbesteuer dürfte aber eine deutliche Reduzierung der Konjunkturreagibilität die Folge sein, da der ertragsabhängige Anteil der Bemessungsgrundlage, der bekanntlich besonders stark auf konjunkturelle Entwicklungen reagiert, bei der Wertschöpfungsteuer von geringerem Gewicht ist. Die Gefahr eines prozyklisch wirkenden Verhaltens der unteren gebietskörperschaftlichen Ebene (Parallelpolitik) ist also im Falle der Wertschöpfungsteuer deutlich geringer. 
Die breite Streuung der Steuerlast erlaubt eine relative Verringerung der Belastung des einzelnen Zensiten. Damit wäre dem Grundsatz der Allgemeinheit der Besteuerung sowie dem Streben nach einer Breitenwirkung Genüge getan. In diesem Sinne muß die Wertschöpfungsteuer positiv beurteilt werden; ihre größere Reichweite der Bemessungsgrundlage führt dazu, ein selektives fiskalisches Interesse nur am Gewerbe bzw. an Unternehmen des Einzelhandels zu vermeiden. Gleichzeitig wird das Steueraufkommen unabhängiger von der Wirtschaftsstruktur.

Auch auf die Standortwahl von Unternehmen und sonstigen steuerpflichtigen Institutionen wirkt sich die Wertschöpfungsteuer durchaus günstig aus. Zum einen reduziert die breitere Streuung der Steuerlast die Belastungshöhe für den einzelnen Betrieb und damit die Gefahr rein steuerlich bedingter Abwanderungen von Unternehmen aus den Kernstädten in die Randzonen. Zum anderen zwingt die steuerliche Belastung von bisher steuerfreien Institutionen diese dazu, die Steuer bei der Standortwahl zu berücksichtigen. Dieser Tatbestand würde dann einer Entwicklung entgegenwirken (wie sie in den USA durchaus schon beobachtbar ist), nämlich daß steuerfreie Institutionen als Standort zunehmend die Kernstädte wählen und kommunale Vorleistungen in hohem Maße in Anspruch nehmen, ohne selbst zum Steueraufkommen beizutragen, während Unternehmen vor den hohen kommunalen Steuerlasten in die Randzonen der Ballungsgebiete (umliegende Gemeinden) ausweichen. Daraus ergibt sich für die Kernstädte möglicherweise eine Erosion der steuerlichen Basis, folglich steigt die Notwendigkeit höhere Steuersätze zu etablieren, und ein sich selbst immer weiter verstärkender "circulus vitiosus" kommt in Gang. Damit diese Gefahren vermieden werden, wird die umfassende Einbeziehung staatlicher, teilstaatlicher und privater Organisationen ohne Erwerbscharakter in die Wertschöpfungsteuer gefordert.

"Die Wertschöpfungsteuer soll als Objektsteuer die betriebliche Wertschöpfung ohne Differenzierung der Steuersätze nach Produktionsbereichen oder Wertschöpfungsbestandteilen und ohne sozial- und wettbewerbspolitisch begründete Steuerermäßigungen erfassen" (Strauß, 1984, 78). Damit soll eine weitestgehende Neutralität und Breitenwirkung dieser Abgabe sichergestellt werden, womit eine Ungleichbehandlung von Personen- und Kapitalgesellschaften genauso vermieden werden kann wie eine Diskriminierung einzelner Produktionsfaktoren oder die Existenz bzw. Herausbildung von Wettbewerbsverzerrungen aufgrund entsprechender Belastungsunterschiede. Regionale Steuerlastunterschiede würden allerdings - bei unterschiedlicher Ausschöpfung der Steuerbasis infolge abweichender Finanzbedarfe - bestehen bleiben. Diese sind jedoch vor dem Hintergrund der Realisierung fiskalischer Äquivalenz sowie der Herstellung eines Interessenausgleichs als Standortfaktor in der Lage, entsprechende Signale für die wirtschaftlichen Entscheidungen zu geben. 
Die Wertschöpfungsteuer weist von der Bemessungsgrundlage her nicht nur Ähnlichkeit mit den Realsteuern (einschließlich der Lohnsummensteuer) auf, sondern zeichnet sich auch durch gewisse Parallelen mit der Nettoumsatzsteuer ${ }^{236}$ aus. Rehm (1981, 193) stellt fest, daß der entscheidende Unterschied zwischen den Konzeptionen der betrieblichen Wertschöpfung und des Nettoumsatzes in der Art und Weise der Periodisierung des "Mehrwerts" und damit in der unterschiedlichen Behandlung der Nettoinvestitionen liegt (vgl. auch Rahmann, 1989, 23ff). Nur für die Totalperiode, d.h. den Zeitraum von der Gründungseinlage bis zur Ausschüttung des Liquidationsüberschusses sind Nettoumsatz und betriebliche Nettowertschöpfung zu Marktpreisen identisch (vgl. Strauß, 1984, 79f); bei periodischer Wertermittlung ergeben sich jedoch eine Reihe von Abweichungen. Der bedeutendste davon ist die Tatsache, daß die Wertschöpfungsteuer auf die Belastung der Produktion ohne Berücksichtigung der Verwendung abstellt, also auch die Nettoinvestitionen belastet, während die Mehrwertsteuer allein den privaten Verbrauch (Umsatzerlöse) erfaßt und einer Belastung unterwirft (vgl. Rau/Rieger, 1981, 63ff sowie Rehm, 1981, 199f). Die Wertschöpfungsteuer ist daher genau wie die Umsatzsteuer als ertragsunabhängige, umsatz- bzw. verbrauchsorientierte Abgabe aufzufassen (vgl. dazu Strauß, 1984, 33f).

Bei den angesprochenen Steuerformen wird in der Regel davon ausgegangen, daß die Unternehmen die Steuerlast überwälzen. Für den Erfolg der Überwälzung spielt es dabei keine Rolle, daß die Wertschöpfungsteuer gedanklich an die Produktion anknüpft, die Mehrwertsteuer aber an den Verbrauch. Vielmehr zählt allein die Frage, ob der Markt die Überwälzung zuläßt. Zwischen Wertschöpfung- und allgemeiner Umsatzsteuer (Mehrwertsteuer) bleibt jedoch in diesem Zusammenhang ein wichtiger Unterschied, denn die Mehrwertsteuerschuld entsteht zu dem Zeitpunkt, an dem ein Umsatz getätigt wird; Investitionen werden also erst belastet, wenn sie als Abschreibungen Preisbestandteil geworden sind. Die Wertschöpfungsteuer ist hingegen schon zum Zeitpunkt der Erstellung der Anlageinvestitionen fällig und somit auch dann, wenn eine Unternehmung bei mangelnder Nachfrage auf Lager produziert. Die Wertschöpfungsteuer bringt also beispielsweise im Vergleich mit einer Nettoumsatzbesteuerung aufgrund der anders gearteten Periodisierung der Wertschöpfungsbestandteile stärkere Liquiditätsbelastungen für Unternehmen mit sich. Diese sollten allerdings nicht überschätzt werden, denn in der angesprochenen Situation eines nicht umgesetzten Produktionsergebnisses verringert sich schließlich auch die Wertschöpfung der Unternehmung um die buchmäßigen Verluste.

\footnotetext{
${ }^{236}$ Diese erfaßt die Wertschöpfung bekanntlich nicht als Summe der Faktorentgelte, sondern ermittelt die Steuerschuld auf dem Wege des Vorsteuerabzugs; einer Mehrwertermittlung gemå der subtraktiven Methode (vgl. Pohmer, 1980, 688ff).
} 
Die Einbeziehung der Nettoinvestitionen in die Bemessungsgrundlage einer Wertschöpfungsteuer führt darüber hinaus auch zu einer höheren "built-in-flexibility", da die Investitionen im Konjunkturverlauf stärkeren Schwankungen unterworfen sind als der Verbrauch. Die Wertschöpfungsteuer reagiert damit auch auf die betriebliche Zahlungsfähigkeit. ${ }^{237}$

Eine Entlastung der Exporte ist bei der Wertschöpfungsbesteuerung nicht vorgesehen. Dies stieße zum einen auf technische Schwierigkeiten und widerspräche zum anderen sowohl dem angestrebten Belastungskonzept der Wertschöpfungsteuer als einer Abgabe auf den Beitrag der Unternehmen zum Nettoinlandsprodukt (vgl. Pohmer, 1980, 701) als auch ihrem Charakter als kommunale Objektsteuer.

Das Kriterium der Wachstumsorientierung hängt natürlich eng mit den vorhergehenden kommunalspezifischen Steuergrundsätzen zusammen, ist aber nicht damit identisch. Unter Wachstumsorientierung sollen hier in erster Linie allokative Wirkungen der Besteuerung verstanden werden, also die Einflüsse einer Wertschöpfungsteuer auf die Investitionsneigung bzw. die Investitionsmöglichkeiten. Bevor später diese Wirkungen bezüglich der einzelnen Unternehmensteuerarten auf der kommunalen Ebene modellhaft noch einmal gegenüberstellt werden sollen, werden an dieser Stelle die wesentlichen Grundzüge und Argumentationsmuster dieser Diskussion präsentiert. Aussagen über die Wirkungen einzelner Steuern gehen dabei in der Regel von Plausibilitätsannahmen aus; ein empirischer Nachweis der jeweiligen Wirkungen ist schwierig.

In der steuerpolitischen Diskussion hat sich im Grunde genommen die Grundüberzeugung herausgebildet, da $B$ die direkten Steuern zu hoch und damit leistungshemmend sind. Eine Umschichtung zu indirekten Besteuerungsformen (also beispielsweise der Verbrauchsbesteuerung) wird daher unter Leistungsanreizgesichtspunkten befürwortet. Diese Argumente spielen natürlich auch auf der lokalen Ebene eine entscheidende Rolle. Daraus ergeben sich dann Argumente, die den Wegfall der Gewerbesteuer fordern, aber auch die Wertschöpfungsteuer (trotz ihrer Nähe zur Mehrwertsteuer) wegen der Belastung der Nettoinvestitionen negativ beurteilen. ${ }^{238}$

Der Wissenschaftliche Beirat $(1982,80)$ schätzt die Gefahren ernsthafter Rückwirkungen der Wertschöpfungsteuer auf die Investitionstätigkeit eher gering ein. Die Wert-

${ }^{237}$ Dies ist allerdings dann kein Vorteil, wenn Betriebe, wie in den gegenwărtig in verschiedenen Branchen zu beobachtenden Strukturkrisen, trotz schlechter Ertragslage hohe Investitionen zur Sicherung der Zukunft leisten müssen (vgl. Strauß, 1984, 81).

${ }^{238}$ Es wird eine Verteuerung der Investitionsgüter um die auf ihnen ruhende Wertschöpfungsteuerlast befürchtet und somit ein gestiegenes Investitionsrisiko attestiert (vgl. etwa Rehm, 1981, 194).

Hans-Georg Napp - 978-3-631-75263-0 
schöpfungsteuer als Kostensteuer sei in ihrer Form und Ausgestaltung vielmehr auf Überwälzung angelegt, so daß es abgesehen von partiellen Überwälzungsschwierigkeiten und Sondersituationen in einzelnen Wirtschaftsbereichen kaum Nettogewinneinbußen durch die Wertschöpfungsteuer gäbe.

Der steuertechnische Aufwand einer Wertschöpfungsteuer muß unterschieden werden nach dem einmaligen Aufwand verbunden mit ihrer Einführung und dem laufenden Aufwand ihrer regelmäßigen Erhebung. Die Frage, ob eine Komplizierung der laufenden Erhebung eintritt, ist schwierig zu beantworten. Für die im Rahmen anderer Steuern (beispielsweise Grund- oder Gewerbesteuern) jetzt bereits Besteuerten gilt, $\mathrm{da} B$ die für die Anwendung der additiven Methode erforderlichen Unterlagen aus der Einkommens- und Gewinnbesteuerung im allgemeinen vollständig vorliegen. Bei neu hinzukommenden Steuerpflichtigen hält sich die zu erwartende Zusatzbelastung in Grenzen, da die erhebungstechnischen Vorgänge im Zusammenhang mit einer Besteuerung des Einkommens erledigt werden könnten. Für die Finanzverwaltung treten aber bei Einführung einer kommunalen Wertschöpfungsteuer durchaus zusätzliche Belastungen und damit Kosten auf, die aber kaum in einem nicht zu vertretenden Umfang anfallen dürften. ${ }^{239}$

\subsubsection{Die Cash-flow-Steuer}

Die Einführung von Cash-flow-Steuern auf Unternehmensebene wird international seit längerem intensiv diskutiert (vgl. Brown, 1948; Meade Committee, 1978; Kay/King, 1986; King, 1987; Bradford, 1987). Im deutschen Sprachraum hat sich in erster Linie Sinn (1984a; 1984b; 1985; 1987; 1989a; 1989b) mit dieser Idee und den verschiedenen Varianten einer Cash-flow-Besteuerung beschäftigt. Mit der Cash-flow-Steuer hat die Finanzwissenschaft eine sehr interessante neue Unternehmensteuer erdacht, die zwar als Ergänzung zu einer persönlichen Konsumausgabensteuer vorgesehen ist, die aber auch als "Gewerbesteuer" (Unternehmensteuer im Sinne einer Äquivalenzabgabe auf der kommunalen Ebene) durchaus Perspektiven besitzen könnte (vgl. auch Cansier, 1990)

\footnotetext{
239 Littmann $(1983,183)$ weist in diesem Zusammenhang auf die Erfahrungen mit einer nach der additiven Methode erhobenen Wertschöpfungsteuer im US-Bundesstaat Michigan hin, die Aufwand und Praktikabilităt dieser Steuer in positivem Licht erscheinen lassen.
} 


\subsubsection{Skizzierung der Grundzüge der Cash-flow-Besteuerung}

Die neuen Wege, die durch die seit einiger Zeit in der Steuerwissenschaft diskutierte Cash-flow-Steuer aufgezeigt werden, erklären sich im wesentlichen aus der Tatsache, daß nicht - wie bei der üblichen Einkommensbesteuerung - der Gewinn zur Bemessungsgrundlage der Betriebsbesteuerung erhoben wird, sondern sich diese Form der Besteuerung je nach rechentechnischer Variante als Bemessungsgrundlage unterschiedlich ausgestaltete Zahlungsstromsalden herausgreift. Das zentrale Argument für die Cash-flow-Steuer gilt für sämtliche rechentechnischen Varianten; nämlich die effektive Freistellung der Investitionen von der Steuer. Die Cash-flow-Steuer entlastet die Investitionen, indem sie ab ihrem Einführungszeitpunkt sämtliche mit den betrieblichen Investitionen zusammenhängenden Zahlungsströme als Abzug von der Bemessungsgrundlage zuläßt und die darüber hinaus auflaufenden Zahlungsüberschüsse besteuert.

Bezeichnet man das Gegenteil von Investition als Desinvestition, so läßt sich die Cashflow-Steuer auch als "Desinvestitionsteuer" charakterisieren. Es bleibt bei der Besteuerung, sofern die auflaufenden Zahlungsüberschüsse einer nicht-investiven - also konsumtiven - Verwendung zugeführt werden; die Cash-flow-Steuer wird dagegen gar nicht erst erhoben bzw. zurückerstattet, wenn die Zahlungsüberschüsse in demselben oder in einem anderen Betrieb reinvestiert werden und die damit verbundenen Zahlungen die Bemessungsgrundlage mindern. Im Falle eines negativen Cash-flow hat der Fiskus eine Steuererstattung zu leisten (vgl. auch Tabelle 9.1).

Es gibt verschiedene Arten der Cash-flow-Steuer. Die sogenannte Grundvariante (Brown-Steuer) stellt ausschließlich auf realwirtschaftliche Transaktionen ab (vgl. Brown, 1948). Bemessungsgrundlage sind die Einnahmen aus dem Verkauf von Gütern und Diensten (einschließlich des Eigenverbrauchs) abzüglich der laufenden Ausgaben (ohne Zinszahlungen) und der Investitionsausgaben. Besteuert wird also der Saldo der Zahlungsströme aller realwirtschaftlichen Transaktionen. Der Steuertarif der Cash-flow-Steuer muß aus naheliegenden Gründen streng proportional ausgestaltet werden, d.h. mit konstantem Steuersatz und ohne Freibeträge.

Es handelt sich bei der "R-base-tax" folglich um eine Art Nettoumsatzsteuer, bei der allerdings nur das Vorumsatzverfahren angewendet werden kann. Gegenüber der Wertschöpfungsteuer vom Konsumtyp müßten zusätzlich zu den Vorleistungen und Bruttoinvestitionen die Löhne und Gehälter sowie die Mieten und Pachten abzugsfähig sein. Der Nachteil der Brown-Steuer liegt darin, daß sie nur Produktionsunternehmen erfaßt. Betriebe mit einem hohen Anteil von Finanzinvestitionen im Portefeuille - also Banken beispielsweise - weisen eine permanent negative Bemessungsgrundlage auf 
und zahlen entweder keine Steuern oder bekommen sogar (wegen der speziellen Ausgestaltung der Cash-flow-Steuer) ständig Steuererstattungen.

Zur Lösung dieses Problems gibt es zwei Auswege. Entweder man führt für den finanziellen Sektor eine besondere Steuer ein - dies ist der Vorschlag von King (1987, $377 \mathrm{ff}$ ) -, oder man weitet die Bemessungsgrundlage auf Einnahmen aus finanziellen Transaktionen aus. Diese Lösung schlägt die Meade-Kommission (1978) vor. Der Vorteil der zweiten Variante ist, daß an einer allgemeinen einheitlichen Unternehmensteuer festgehalten werden kann. Hinzu kommt, daß diese Steuer in ihren Wirkungen auf die Finanzierungs- und Investitionsentscheidungen völlig äquivalent der Steuer auf den Cash-flow aus realwirtschaftlichen Transaktionen ist.

Die zweite Version der Cash-flow-Steuer erfaßt also auch die finanziellen Transaktionen, daher auch die Bezeichnung " $\mathrm{R}+\mathrm{F}$-base tax". Damit können also auch die Banken und andere Finanzintermediäre "regulär" der Cash-flow-Steuer unterworfen werden. Die Bemessungsgrundlage der "Brown-Steuer" wird um den Saldo der Zahlungsströme, die die Fremdfinanzierung betreffen, erweitert (vgl. Meade Committee, 1978, 233). Die Bemessungsgrundlage setzt sich zusammen aus den Nettoeinnahmen aus dem Verkauf von Gütern und Diensten und den Nettokrediteinnahmen abzüglich der Investitionsausgaben und der Nettozinszahlungen (direkte Ermittlung der Bemessungsgrundlage). Weil Ein- und Auszahlungen immer übereinstimmen müssen, läßt sich der real- und finanzwirtschaftliche Cash-flow auch indirekt als Saldo von Gewinnausschüttung und Nettoeigenkapitaleinzahlung (Beteiligungsfinanzierung) ermitteln. Man spricht hinsichtlich dieser indirekten Form der Bemessungsgrundlage auch von einer sogenannten Ausschüttungsteuervariante (vgl. Cansier, 1989a, 50f). Bemessungsgrundlage ist der Saldo der Zahlungsströme, die die Beteiligungsfinanzierung betreffen (vgl. Bach, 1992, 326). Damit sind empfangene Zinsen mitsamt der Tilgung der Forderung ebenso wie die Kreditaufnahme selbst steuerpflichtig, während Zinsauszahlungen mitsamt der zugehörigen Tilgung der Verbindlichkeit wie auch die Kreditvergabe abgezogen werden dürfen.

Im deutschsprachigen Schriftum hat sich die Finanzwissenschaft in der jüngsten Vergangenheit ebenfalls intensiver mit der Idee und den unterschiedlichen Varianten der Cash-flow-Besteuerung auseinandergesetzt (vgl. Sinn, 1984a; 1984b; 1985; 1987; 1989a; 1989b; Cansier, 1989a; 1989b; 1990; Feldhoff, 1989; Schneider, 1987 sowie Bach, 1992). Auf einen weiteren Überblick und/oder eine systematische Auseinandersetzung mit den unterschiedlichen in der Literatur vorgestellten Ansätzen soll in diesem Kontext jedoch verzichtet werden, weil mit der Konzentration auf das Wesentliche die Rolle der Cash-flow-Steuer als kommunale Abgabe untersucht werden soll (so auch bei Richter/Wiegard, 1990a). 


\subsubsection{Allokative Wirkungen der Cash-flow-Steuer}

Die von Kay und King (1986) favorisierte "R-base-tax" besteuert - wie gesehen - die realwirtschaftlichen Zahlungsüberschüsse eines Unternehmens. Diese sind durch die Gleichungen (9.3a) und (9.3b) gegeben. Weil im Grunde genommen die Maximierung des Gegenwartswertes des Cash-flow angestrebt wird, wird folgerichtig leicht offenkundig, daß eine (proportionale) Abgabe auf die Zielfunktion

$$
\max \left(1-\tau_{c}\right)\left\{C_{0}+\frac{1}{1+r_{1}} C_{1}\right\}
$$

die notwendigen Bedingungen [Gleichungen (9.5a), (9.5b) und (9.6)] unverändert läßt. Die Besteuerung des realwirtschaftlichen Cash-flow ist produktionseffizient und damit insbesondere auch investitionseffizient (weil investitionsneutral). Darüber hinaus läßt sich auch nachweisen, daß eine proportionale Cash-flow Steuer finanzierungsneutral ist (vgl. Sinn, 1984b). ${ }^{240}$ Die Begründung dieser Neutralität liegt darin, daß diese Steuerform ausschließlich funktionslose Produzentenrenten besteuert; alle mit dem Erwerb der Produktionsfaktoren Kapital und Arbeit verbundenen Kosten sind (im Idealfall) von der Bemessungsgrundlage abziehbar. Im vorliegenden partial-analytischen Modell würde also die Cash-flow-Steuer die Investitionsnachfrage überhaupt nicht beeinflussen. Diese Investitionsneutralität kommt zustande, weil die Cash-flowSteuer den Ertragswert einer Investition und die Investitionsausgaben gleichmäßig kürzt. Die für die Investitionsnachfrage relevanten Preise $p_{1}, w_{1}$, und $c_{1}$ ändern sich zwar durch die Besteuerung um den Faktor $\left(1-\tau_{c}\right.$,), da aber die Faktornachfragefunktionen homogen vom Grade Null in allen Preisen sind, bleibt die Arbeits- und Kapitalnachfrage unverändert. "Aber selbst bei Berücksichtigung von Marktinterdependenzen und den daraus resultierenden Faktorpreisanpassungen bleiben die Effizienzeigenschaften der Cash-flow-Besteuerung gewahrt" (Richter/Wiegard, 1990, 13).

Die vorab betrachtete Besteuerung realwirtschaftlicher Zahlungsüberschüsse würde Banken und andere Finanzintermediäre, die ihre Profite im finanzwirtschaftlichen Bereich erzielen, wenig oder gar nicht treffen. Die Meade-Kommission (1978) hat daher eine Variante der Cash-flow-Besteuerung erwogen, die eine Abgrenzung realwirtschaftlicher von finanzwirtschaftlichen Zahlungsvorgängen überflüssig macht. Dieser Vorschlag läßt sich äquivalent entweder als "R+F-base" oder als "S-base"-Steuer charakterisieren (vgl. Sinn, 1987, 14ff). "R+F" bedeutet dabei, daß real- und finanzwirt-

\footnotetext{
240 Finanzierungsneutralităt heißt, daß Fremd-, Selbst- und Beteiligungsfinanzierung steuerlich gleichbehan-
} delt werden (vgl. Cansier, 1989a, 51). 
schaftliche Zahlungsströme gemeinsam die Bemessungsgrundlage dieser Cash-flowSteuer-Variante bilden. $\mathrm{Zu}$ den in den Gleichungen (9.3a) und (9.3b) aufgeführten realwirtschaftlichen Zahlungskomponenten müßten also die Kreditaufnahme des Unternehmens sowie erhaltene Zinszahlungen addiert und Kreditvergabe bzw. Kredittilgung sowie geleistete Zinszahlungen subtrahiert werden. Im vorliegenden Modellrahmen ist in der ersten Periode die Kreditaufnahme in Höhe von $\mathrm{q}_{0}\left(\mathrm{~K}_{1}-\mathrm{K}_{0}\right)$ zu berücksichtigen, in der zweiten Periode die Kredittilgung nebst Schuldendienst im Umfang $\left(1+r_{1}\right) q_{0}\left(K_{1}-K_{0}\right)$. Es läßt sich relativ schnell nachvollziehen, daß die Bemessungsgrundlage der " $\mathrm{R}+\mathrm{F}$ "-Steuer wegen

$$
\begin{aligned}
& C_{0}^{R+F}=C_{0}+q_{0}\left(K_{1}-K_{0}\right) \\
& C_{1}^{R+F}=C_{1}-\left(1+r_{1}\right) q_{0}\left(K_{1}-K_{0}\right)
\end{aligned}
$$

denselben Gegenwartswert wie die Bemessungsgrundlage einer "R-base"-Steuer aufweist. Damit ist sie ebenfalls produktionseffizient. Beiden Cash-flow-Steuervarianten unterscheiden sich also lediglich im Hinblick auf die zeitliche Verteilung der Steuer-

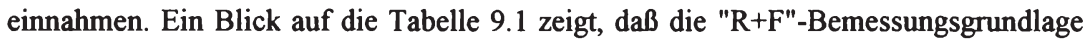
bei Abwesenheit von Steuern mit den unter Abzug der Eigenkapitalein- bzw. -rückzahlungen gebildeten Nettoausschüttungen übereinstimmt. Der Unterschied zwischen "R+F"-Steuer einerseits und "S"-Steuer andererseits besteht eigentlich nur darin, daß die Bemessungsgrundlage der " $\mathrm{R}+\mathrm{F}$ "-Steuer die Steuerschuld selbst einschließt, während dies bei der "S-base"-Steuer nicht der Fall ist (vgl. Meade Committee, 1978, 235f).

Die Cash-flow-Besteuerung erfüllt also die Forderung, daß eine Unternehmensteuer die Faktorallokation nicht beeinträchtigen soll, in idealtypischer Weise. Ihre besonderen Vorteile bestehen ja gerade darin, daß sie neutral auf Finanzierungsform, Investitionsneigung und Arbeitseinsatz wirkt (vgl. Richter/Wiegard, 1990b, 41f). Ein einfaches Beispiel soll dies nochmals verdeutlichen. Eine selbstfinanzierte Investition von 100 Geldeinheiten (GE) mit einer Lebensdauer von einer Periode erbringt Nettoeinnahmen von $120 \mathrm{GE}$. Der Kapitalmarktzins sei $10 \%$. Bei der Besteuerung gehen wir von der direkten Ermittlungsmethode der Bemessungsgrundlage aus. Der Steuersatz solle $40 \%$ betragen. Auf die Einnahmen entfallen somit $48 \mathrm{GE}$ Steuern; die Investitionsausgaben führen zu einer Gutschrift von $40 \mathrm{GE}$; an Steuern zu zahlen ist also insgesamt ein Betrag von $8 \mathrm{GE}$ (das sind zwei Fünftel vom Ertrag). Der Unternehmer erhält außerdem wegen der Sofortabschreibung einen (nicht zu versteuernden) Zinsvorteil von $4 \mathrm{GE}$. Seine Effektivbelastung ist also $4 \mathrm{GE}$, die exakt der Besteuerung des Überschusses der (Netto-)Erträge über die Kapitalkosten ( $40 \%$ von $10 \mathrm{GE}$ ) entspricht. 
Da die Steuer offensichtlich nur diesen Überschuß trifft, wirkt sie neutral auf die Investitionstätigkeit. Wesentlich ist - das sei noch angemerkt - die Unterscheidung von Effektivbelastung (4 GE) und Steuerzahlung (8 GE). Die Steuerzahlungen sind eine proportionale Funktion der Investitionserträge.

\subsubsection{Die Eignung der Cash-flow-Steuer als Gemeindesteuer}

Neben diesen generellen allokativen Erwägungen sind vor allem auch ökonomische Aspekte aus lokaler Sicht und spezifische Anforderungen an kommunale Steuern zu beachten. Vorab ließe sich zunächst festhalten, daß infolge der möglichst allgemeinen Form einer kommunalen Steuer (vor dem Hintergrund der Idee des Äquivalenzprinzips, daß alle Betriebe die kommunale Leistungen in Anspruch nehmen, an deren Kosten zu beteiligen sind) die erweiterte Variante der Cash-flow-Steuer - die "R+F"Steuer - als geeigneterer Kandidat für ein Gemeindesteuersystem anzusehen ist. Auf den ersten Blick macht aber auch in dieser Ausgestaltungsform der Cash-flow äquivalenztheoretisch keinen großen Sinn. Denn je mehr ein Unternehmen investiert, um so weniger Steuern zahlt es, obwohl es nicht weniger (lokale) öffentliche Leistungen in Anspruch nimmt. Bei solchen Überlegungen wird jedoch in der Regel auf die einzelne Periode abgestellt. Man kann aber auch von einer langfristigen Durchschnittsbetrachtung ausgehen und dabei berücksichtigen, daß die Inanspruchnahme öffentlicher Leistungen letztlich immer private Investitionen voraussetzt. Somit könnte man postulieren, daß über die Lebensdauer eines Investitionsgutes hinweg periodendurchschnittlich eine Äquivalenz zwischen Steuerzahlungen und öffentlichen Leistungen (oder besser deren Nutzung) bestehen soll. Auf diese Weise ließe sich ein gewisser Bezug zum Äquivalenzgedanken herstellen. Bei der R-Steuer sind die Steuerzahlungen eine proportionale Funktion der internen Erträge. Diese Basis enthält neben dem Gewinn die vollen Fremdkapitalkosten und ist daher breiter als beispielsweise der Gewerbeertrag. Die ausschließlich an realwirtschaftlichen Zahlungsströmen orientierte Cash-flowSteuer ist insofern zwar vorteilhafter (in bezug auf fiskalische Äquivalenz) als die Gewerbeertragsteuer, läßt aber wichtige Wirtschaftsbereiche (vor allem Banken) aus der Besteuerung heraus und besitzt daher die ebenfalls für die fiskalische Äquivalenz erforderliche Breitenwirkung nicht oder erfült sie zumindest nur unzureichend.

Für die erweiterten Formen der Cash-flow-Steuer ("R+F-base-tax" oder "S-base-tax") gilt, daß bei eigenfinanzierten Investitionsprojekten die internen Erträge ebenfalls proportional besteuert werden. Dies gilt jedoch ebenso für die Gewerbeertragsteuer, aber nur, wenn von den begrenzten Abschreibungs- und Verlustausgleichsmöglichkeiten abgesehen wird. Bei fremdfinanzierten Investitionsvorhaben sind die Steuerzahlungen hingegen eine Funktion des Überschusses der Erträge über die Zinskosten, d.h. des 
(durchschnittlichen) Gewinns. Diese Basis ist aber enger als der Gewerbeertrag. Die erweiterten Formen der Cash-flow-Steuer schneiden also hinsichtlich des Äquivalenzprinzips eher schlechter ab als beispielsweise die Gewerbesteuer oder die Wertschöpfungsteuer.

Eine Gemeindesteuer sollte darüber hinaus - wie dies vor dem Hintergrund von Steuerpostulaten wie Einfachheit und Billigkeit im übrigen für alle Steuern gelten sollte - möglichst einfach zu erheben sein. Die Cash-flow-Steuer erfüllt diese Anforderungen gut; die Zahlungsgrößen sind leicht festzustellen und es entfallen Bewertungsschwierigkeiten. Ermittlung und Kontrolle setzen im wesentlichen ähnliche Daten voraus wie beispielsweise die Gewerbesteuer. Ein gewisser Mehraufwand tritt auf, weil die Ansätze aus den Einkommen- und Vermögensteuererklärungen wegen der relevanten Zahlungsgrößen nicht immer übernommen werden können. Am einfachsten läßt sich wohl die (Netto-)Ausschüttungsteuer erheben, denn bei dieser Erhebungsform müssen nur die Nettozahlungen (einschließlich Sachentnahmen) an die Unternehmens(Anteils-)eigner für die Ermittlung der Bemessungsgrundlage bekannt sein.

Unproblematisch ist - wie weiter oben beschrieben - die Erfassung der Kreditinstitute. Schwierigkeiten, die bei der Verwendung der Brown-Steuer ("R-base-tax") auftreten, werden mit der Wahl der Steuer auf real- und finanzwirtschaftliche Transaktionen vermieden. Die Ausgestaltung als "R+F"-Steuer garantiert, daß im Sinne der gewünschten Allgemeinheit der gemeindlichen Besteuerung auch die Kreditgeschäfte, für die ebenfalls lokale öffentliche Leistungen in Anspruch genommen werden, der Besteuerung unterworfen werden. Problematisch könnte aber sein, daß bei einer Erhebung einer Steuer auf Gewinne, Löhne, Mieten und Pachten bei den Banken man zwar dem Äquivalenzgedanken Rechnung trägt, aber eine teilweise Doppelbesteuerung von Wertschöpfungskomponenten in Kauf nimmt. ${ }^{241}$

Für Unternehmen mit mehreren Betriebsstätten in verschiedenen Gemeinden muß eine Zerlegung des Steuermeßbetrages vorgenommen werden. Die gleiche Aufgabe stellt sich heute jedoch bei der Gewerbesteuer und würde sich im übrigen auch bei einer

\footnotetext{
241 Wenn eine Bank aufgrund ihrer Einlagen einen Kredit an ein Produktionsunternehmen gewăhrt und dafür 100 Geldeinheiten (GE) Zinsen erhalt, sie andererseits an ihre Einlagen 80 GE Zinsen zahlt und außerdem Löhne und Gewinne in Höhe von $20 \mathrm{GE}$ anfallen, dann betrăgt die Wertschøpfung nicht $200 \mathrm{GE}$, sondern nur $100 \mathrm{GE}$. Die Zinseinnahmen dürfen nur einmal Berücksichtigung finden, entweder bei der Produktionsunternehmung oder bei der Bank. Es ist üblich, die Entstehung den Produktionsunternehmen zuzurechnen. Dann dürfte aber von der Bank keine Steuer erhoben werden, da im anderen Falle eine Doppelbesteuerung von Wertschöpfungskomponenten erfolgte. Da aber die Banken auch Nebenleistungen (Abwicklung des Zahlungsverkehrs, Depotverwaltung u.a.) erbringen, die teils direkt über Gebühren und teils indirekt über die Zinsspanne (durch relativ niedrige Depositenzinsen) finanziert werden, wăre eine generelle Freistellung aber ebenso problematisch. Eine konfliktlose Lösung ist daher kaum möglich (vgl. auch Cansier, 1990, 254).
} 
Wertschöpfungsteuer stellen. Sie stellt also kein spezifisches Problem der Cash-flowBesteuerung dar. Lösungen dieses Problems bietet die Zurechnung nach Maßgabe der Arbeitseinkommen. Besser - aber wohl auch komplizierter - wäre die direkte Aufteilung entsprechend des Anteils der einzelnen Betriebsstätte an der Bemessungsgrundlage.

Hinsichtlich der Postulate der steuerlichen Aufkommensentwicklung läßt sich für die Cash-flow-Steuer folgendes festhalten. Um die konjunkturellen Eigenschaften dieser Steuer aufzuzeigen, soll (wie auch schon weiter oben) von der Variante der Ausschüttungsteuer ausgegangen werden. Der ausgeschüttete Gewinn entspricht dem Gewinn abzüglich Selbstfinanzierung. Die Bemessungsgrundlage läßt sich folglich auch definieren als Gewinn minus Beteiligungs- und Selbstfinanzienung. Der Grad der Eigenfinanzierung der Investitionen soll mit e bezeichnet werden. Bezogen auf das Volkseinkommen (Y) erhält man dann für die Bemessungsgrundlage der Cash-flow-Steuer: G/Y - eI/Y. Im Aufschwung nehmen bekanntlich nicht nur die Gewinne, sondern auch die Investitionen überproportional zu. Daneben erhöht sich regelmäßig der Grad der Eigenfinanzierung. Im Abschwung ist es umgekehrt. Dies führt dazu, daß insgesamt gesehen die Bemessungsgrundlage der Cash-flow-Steuer deutlich weniger konjunkturreagibel ist als beispielsweise die Gewerbeertragsteuer. Die Aufkommenselastizität hängt letztlich von den Schwankungen der Gewinnquote im Verhältnis zu den Schwankungen der Investitionsquote (gewichtet mit dem Selbstfinanzierungsanteil) ab. Geht man davon aus, daß die Gewinne im Konjunkturverlauf in der Regel stärker schwanken als die Investitionen liegt die Aufkommenselastizität einer Cash-flowSteuer über 1. Der Wert verringert sich jedoch noch um mögliche Finanzierungsänderungen. Insgesamt gesehen dürfte sich das Aufkommen der Cash-flow-Steuer daher etwa - ähnlich wie die Wertschöpfungsteuer - proportional zur Konjunktur entwickeln. Besonders starke Aufkommensschwankungen - wie etwa bei der Gewerbeertragsteuer oder auch bei Einkommen- und Körperschaftsteuern - würden vermieden.

Daß die Cash-flow-Steuer auch das Postulat der Wachstumsproportionalität gut erfüllt, ist offensichtlich. Im Wachstumstrend erhöhen sich, dies wurde schon mehrfach betont, Gewinne und Investitionen relativ gleichmäßig.

Erwünscht ist für kommunale Steuern auch eine möglichst gleichmäßige Verteilung des Steueraufkommens (oder zumindest der Bemessungsgrundlagen) pro Kopf zwischen den Gemeinden. Dadurch soll eine überproportionale Auseinanderentwicklung steuerstarker und steuerschwacher Gebiete durch zunehmende Unterschiede in der Steueranspannung und Infrastruktur vermieden werden. In diesem Zusammenhang läßt sich bisher zur Cash-flow-Steuer relativ wenig sagen. Man müßte erkunden, wie sich Gewinn-, Investitions- und Finanzierungsunterschiede im Raum zueinander verhalten. 
Darüber könnten nur empirische Untersuchungen Aufschluß geben, die in dieser Form bisher noch nicht vorliegen. Es kann aber vermutet werden, daß hinsichtlich dieser Forderung die Cash-flow-Steuer kaum schlechter abschneidet als mögliche andere Besteuerungsvarianten.

\subsubsection{Die Umsatzsteuerbeteiligung der Gemeinden}

Unter den zur Diskussion stehenden Alternativen zur Reform der Gewerbesteuer besitzt in der Bundesrepublik Deutschland die Beteiligung der Gemeinden an der Umsatzsteuer die meisten Befürworter (vgl. auch die aktuelle Diskussion und in diesem Zusammenhang vor allem Karrenberg, 1992a; 1992b; Schäfer, 1992). Nach vorsichtigen Schätzungen (vgl. Richter/Wiegard, 1990a, 10) müßten die Mehrwertsteuersätze bei Aufkommensneutralität um etwa 2 bis 3 Prozentpunkte erhöht und die Gemeinden zur Kompensation einer Abschaffung der Gewerbesteuer mit etwa $16 \%$ am Aufkommen beteiligt werden. Bei teilweiser Abschaffung vermindert sich demzufolge der Kompensationsbedarf.

\subsubsection{Die Grundkonzeption}

Eine Beteiligung der Gemeinden an der Umsatzsteuer wird in verschiedenen Varianten diskutiert. Von den entsprechenden Vorschlägen sollen zunächst nur die Modelle betrachtet werden, die durch ihre spezielle Ausgestaltung und die Verwendung entsprechender Verteilungsschlüssel - wenn auch nur indirekt - einen Interessenausgleich zwischen der Gemeinde als Wirtschaftsstandort und den Unternehmen vor Ort garantieren. Dies erklärt auch, warum die Umsatzsteuerbeteiligung der Gemeinden unter der Rubrik der produktionsbezogenen Gemeindesteuern diskutiert wird. ${ }^{242}$

Eine prozentuale Beteiligung der Gemeinden an der Umsatzsteuer läßt sich auf den ersten Blick betrachtet technisch scheinbar relativ einfach gestalten. Es bleibt jedoch die entscheidende Frage, und damit ist die Verwendbarkeit und der Grad der Zielrealisierung der Umsatzsteuerbeteiligung als (implizit) produktionsbezogene Abgabe entscheidend verknüpft, nach welchen Schlüsseln das Steueraufkommen auf die einzelnen Gemeinden verteilt werden soll. Dies könnte zugegebenermaßen analog zur Beteiligung der Gemeinden an der Einkommensteuer nach dem örtlichen Aufkommen - gege-

\footnotetext{
242 Die Idee der Zuweisung der Mehrwertsteuer der letzten Stufe an die Gemeinden (möglicherweise auch verbunden mit einem Hebesatz- bzw. Zuschlagsrecht) wird daher auch später, nămlich bei den "exportbezogenen" Abgabeformen Beachtung finden (vgl. Rau/Rieger, 1981, 25ff).
} 
benenfalls in modifizierter Form - geschehen. Eine solche Modifizierung sah der Vorschlag des Wissenschaftlichen Beirats beim Bundesministerium der Finanzen in seinem Gutachten zum Gemeindesteuersystem vom 16. März 1968 (Wissenschaftlicher Beirat, 1974, 424) vor. Demnach sollte den Gemeinden die Mehrwertsteuer der letzten Stufe zugewiesen werden (vgl. auch Rau/Rieger, 1981, 18ff).

In der Regel werden aber hinsichtlich der Beteiligung der Gemeinden an der Umsatzsteuer eine Reihe von Verteilungsschlüsseln diskutiert, die vor allem die angesprochene Funktion als (implizit) produktionsbezogene Abgabeform erfüllen helfen sollen. Solche produktionsbezogenen Verteilungsschlüssel können die Anzahl der Beschäftigten (vgl. Wissenschaftlicher Beirat, 1982, 55), die örtliche Wertschöpfung bzw. der Nettoumsatz (Steuerreformkommission, 1971, 738f; Rau/Rieger, 1981, 95ff), die Kombination aus Lohnsumme und Betriebskapital (Steuerreformkommission 1971, 739f; Karrenberg, 1992b, 194ff) bzw. die Lohnsumme und die materiellen Wirtschaftsgüter (Institut "Finanzen und Steuern", 1982, 22ff) oder das Anlagevermögen (Wissenschaftlicher Beirat, 1982, 55) sein. Im Gegensatz zu den Vorschlägen solcher produktionsorientierter Verteilungsschlüssel wird aus raumordnungspolitischer Sicht gefordert, eine Verteilung nach Einwohnern (Recker, 1978, 568; 1979, 689ff) oder veredelten Einwohnern (Tetsch, 1979, 88) vorzunehmen.

In der wissenschaftlichen und politischen Auseinandersetzung um eine Reform der Gewerbesteuer hat die Umsatzsteuerbeteiligung der Gemeinden eine umfassende Erörterung erfahren (vgl. Deutscher Industrie- und Handelstag, 1982; Institut "Finanzen und Steuern", 1982; Ritter, W., 1983; Bundesverband der Deutschen Industrie, 1985; Milbradt, 1982; Niedersächsischer Landtag, 1988; Landtag Rheinland-Pfalz, 1986; Wissenschaftlicher Beirat, 1982; Karrenberg/Münstermann, 1992; Schäfer, 1992). Dabei standen jedoch immer wieder die Verteilungswirkungen aus der Sicht der Gemeinden bzw. der Wirtschaft oder Verfassungsaspekte (vgl. etwa Geske, 1980, 247) im Vordergrund. In Analogie zur Vorgehensweise bei den anderen produktionsbezogenen Abgaben sollen nunmehr auch für die Umsatzsteuer allokative Aspekte sowie die Eignung der Umsatzsteuerbeteiligung für das gemeindliche Steuersystem erörtert werden.

\subsubsection{Allokative Wirkungen der Umsatzsteuer(-beteiligung)}

Im gewählten Kontext interessieren also vor allem die allokativen Wirkungen möglicher Umsatzsteuererhöhungen, die als solche bei Konstanz der Steueranteile anderer Ebenen eine Beteiligung der Gemeinden an der Umsatzsteuer fiskalisch erst realisierbar werden lassen. 
Annahmegemäß gebe es (für unsere folgende Modellbetrachtung) nur einen einzigen (Mehrwert-)Steuersatz, der mit $\tau_{m}$ bezeichnet werden soll. Bei einheitlichem Steuersatz fuihren Vorsteuer- und Vorumsatzabzugsverfahren zu identischen Ergebnissen, so daß ohne Beschränkung der gewonnenen Ergebnisse das letztere Verfahren für die Analysezwecke genutzt werden kann. Dann erhält man die Bemessungsgrundlage der Mehrwertsteuer, indem die Ausgaben für Vorleistungen und Bruttoinvestitionen von den Erlösen abgezogen werden. Die Steuerschuld erhält man also über die Gleichungen

$$
\begin{aligned}
& T_{0}^{m}=\tau_{m}\left[p_{0} F\left(K_{0}, L_{0}\right)-q_{0}\left(K_{1}-(1-\delta) K_{0}\right)\right] \\
& T_{1}^{m}=\tau_{m}\left[p_{1} F\left(K_{1}, L_{1}\right)+q_{1}(1-\delta) K_{1}\right]
\end{aligned}
$$

Die Maximierung des Unternehmenswertes, d.h. die Lösung der Optimierungsaufgabe

$$
\max \left\{\left(C_{0}-T_{0}^{m}\right)+\frac{1}{1+r_{1}}\left(C_{1}-T_{1}^{m}\right)\right\}
$$

liefert jetzt die Marginalbedingungen

$$
\begin{aligned}
& \left(1-\tau_{m}\right) p_{0} \frac{\partial F}{\partial L_{0}}=w_{0} \\
& \left(1-\tau_{m}\right) p_{1} \frac{\partial F}{\partial L_{1}}=w_{1} \\
& p_{1} \frac{\partial F}{\partial K_{1}}=q_{0} r_{1}+q_{1} \delta-\left(q_{1}-q_{0}\right) .
\end{aligned}
$$

Die Mehrwertsteuer ist also im vorher definierten Sinne investitionseffizient, sie diskriminiert aber den Einsatz des Faktors Arbeit. Eine Erhöhung des Mehrwertsteuersatzes führt in jeder Periode zu einer geringeren Arbeitsnachfrage. Wie schon erwähnt, bedeutet Investitionseffizienz nicht, daß die Umsatzsteuer auch die Höhe des Investitionsvolumens unbeeinflußt läßt. Die niedrigere Arbeitsnachfrage in Periode 1 beeinflußt nämlich die Grenzproduktivität des Faktors Kapital. Damit beeinflußt die Mehrwertsteuer sehr wohl die Höhe der Investitionsnachfrage, sie ist aber neutral im Hin- 
blick auf die marginale Entscheidung zwischen einer Sach- und einer Finanzinvestition. 243

Bedeutender und offenkundiger ist jedoch der Einfluß der Mehrwertsteuer auf die Arbeitsnachfrage; der Produktionsfaktor Arbeit wird nämlich diskriminiert, weil die Mehrwertsteuer die Produzentenrente und das Leistungseinkommen des Faktors Arbeit belastet (vgl. auch Richter/Wiegard, 1990b, 41). Diese allokativen Verwerfungen sind zwar generell kritisch einzuschätzen, aber besonders in Zeiten hoher Arbeitslosigkeit dürte eine stärkere Benachteiligung des Faktors Arbeit kaum erwünscht sein.

9.3.5.3 Die Umsatzsteuerbeteiligung als Finanzierungskomponente des kommunalen Steuersystems

\subsection{Generelle Beurteilung}

Zunächst soll bei der Überprüfung der Eignung einer Umsatzsteuerbeteiligung für die Gemeinden auf das allen Modellvarianten Gemeinsame eingegangen werden. Mögliche Unterschiede innerhalb der Beurteilung aufgrund alternativer Verteilungsschlüssel sollen anschließend diskutiert werden. Diese ergeben sich in erster Linie hinsichtlich der Frage des Interessenausgleichs und der räumlichen Wirkungen.

Die Einbeziehung der Gemeinden in den Umsatzsteuerverbund ist mit einem geringeren $\mathrm{Ma} \beta$ an finanzieller Autonomie der Gemeinden verbunden, sofern nicht ein Hebesatzrecht oder andere Beeinflußungsmöglichkeiten des Beteiligungsvolumens eingeräumt werden (vgl. etwa Krause-Junk, 1989a, 380f). Befürworter der Umsatzsteuerbeteiligung betonen jedoch, daß zur Gemeindeautonomie mehr als nur das Hebesatzrecht zu zählen sei. Sie betonen, daß gerade auch stetige und verläßliche Steuereinnahmen für die Kommunen von entscheidender (finanzieller) Bedeutung sind. Daher sollten kommunale (Steuer-)Einnahmen im wesentlichen ertragsunabhängig und darüber hinaus nicht andauernden staatlichen Korrekturen unterworfen sein. Diesen Anforderungen, so der weitere Argumentationsgang, entspräche gerade eine Umsatzsteuerbeteiligung am besten. Wie folglich unter kommunalspezifischen Gesichtspunkten eine abschließende Beurteilung ausfällt, hängt von der konkreten Ausgestaltung einer Umsatz-

243 Betrachtet man das existierende Mehrwertsteuersystem in der Bundesrepublik Deutschland, so ist die Mehrwertsteuer nicht einmal in diesem Sinn neutral. Ein Blick auf die Input-Output-Tabellen des Statistischen Bundesamtes zeigt, daß nur ca. drei Fünftel der nichtabzugsfăhigen Umsatzsteuer auf den Konsum fallen, ein Fünftel dagegen auf den Investitionen und das restliche Fünftel auf den Vorleistungen bestimmter Produktionsbereiche liegen (vgl. Statistisches Bundesamt, Volkswirtschaftliche Gesamtrechnungen, verschiedene Jahrgănge). 
steuerbeteiligung, d.h. von der Stetigkeit und Langfristigkeit einer solchen Regelung einschließlich des Verteilungsschlüssels, ab. Eine angemessene Bewertung der Umsatzsteuerbeteiligung erfordert also mehr als nur die Feststellung, daß den Gemeinden das Hebesatzrecht genommen wird. Wenn aber trotzdem die Umsatzsteuerbeteiligung unter dem Aspekt der Gemeindeautonomie negativ beurteilt werden muß, so deshalb, weil der Verlust an eigenverantwortlichem finanzpolitischen Handeln und an fiskalischer Flexibilität vor dem Hintergrund der Effizienzvorteile fiskalischer Äquivalenz mit ihren differenzierten Finanzbedarfen auf der lokalen Ebene schwerer gewichtet werden muß.

Darüber hinaus koppelt eine schlüsselmäßige Beteiligung der Gemeinden an der Umsatzsteuer die örtlichen Einnahmen vom örtlichen Aufkommen bzw. der Traglast der Steuer ab. Die erhofften allokativen Vorteile der Fühlbarkeit bzw. Merklichkeit und der Förderung der optimalen Allokation der Produktivkräfte im Raum kommen folglich nicht zur Geltung.

Der private Verbrauch schwankt im Konjunkturverlauf weniger stark als das Sozialprodukt und entwickelt sich langfristig parallel zu diesem. Die Aufkommenselastizität der Umsatzsteuer ist daher vergleichsweise geringen Schwankungen unterworfen und liegt im langfristigen Durchschnitt knapp unter eins (vgl. Körner, 1974, 35). Die Beteiligung an der Umsatzsteuer entspricht damit in besonderer Weise den Kriterien der Konjunkturabhängigkeit und Wachstumsproportionalität. Auch die räumliche Neutralität bleibt gewahrt, so daß Bedenken, wie sie bei einer kommunalen Endverbrauchsteuer (vgl. Abschnitt 9.5) mit Hebesatzrecht aus regionalpolitischer Sicht vorgebracht werden, entfallen; zumal wenn zum einen innerhalb des Umsatzsteuerverbundes auf ein kommunales Hebesatzrecht verzichtet wird und zum anderen aufgrund der gewählten Verteilungsschlüssel anders geartete fiskalische Anreize auf das kommunalpolitische Verhalten ausgehen als bei der Endverbrauchsteuer.

\subsection{Die Beurteilung alternativer Verteilungsschlüssel}

Für die abschließende Beurteilung der Umsatzsteuerbeteiligung der Gemeinden ist die Wahl des entsprechenden Verteilungsschlüssels von grundlegender Bedeutung. Eine wesentliche Voraussetzung für die Auswahl geeigneter Verteilungsschlüssel ist deren Eignung in bezug auf den Interessenausgleich zwischen örtlicher Wirtschaft und der Gemeinde. Verteilungsschlüssel sind demnach so zu konstruieren, daß das Interesse an Industrieansiedlung erhalten und der Wirtschaftsstandort Gemeinde funktionstüchtig bleibt. 
- Die "Beschäftigtenzahl" am Arbeitsort ist ein einfacher und leicht handhabbarer Schlüssel, der die Lasten der Gemeinde aus ihrer Funktion als Arbeitsort berücksichtigt, nicht aber die Belastungen bei weitgehend automatisierter kapitalintensiver Produktion. Das Interesse der Gemeinden wird also auf die Attrahierung arbeitsintensiver Produktionen gelenkt. Der Schlüssel wirkt damit nicht neutral in dem Sinne, daß für jede Art von Produktion ein angemessener Interessenausgleich stattfindet.

- Ähnlich wie die Anzahl der Beschäftigten ist auch die "Lohnsumme" als alleiniger Verteilungsschlüssel zu beurteilen. Allerdings ergibt sich eine andere räumliche Streuung, da das Aufkommen neben der Arbeitszentralität auch vom regionalen Lohn- und Gehaltsniveau bestimmt wird.

- Die "örtliche Wertschöpfung" bzw. der "Nettoumsatz" enthalten neben Kostenbestandteilen auch den Ertrag. Dieser ist als Verteilungskomponente nach den Vorstellungen der Steuerreformkommission $(1971,738)$ ungeeignet, da zwischen den Gewinnen der örtlichen Industrie und den kommunalen Lasten kein enger Zusammenhang bestehe.

- Die Diskussion konzentriert sich daher zunehmend auf einen kombinierten Schlüssel aus "örtlicher Lohnsumme und örtlichem Kapitaleinsatz" (Gewerbekapital bzw. Rohbetriebsvermögen), wobei beide Schlüsselelemente gleich gewichtet werden. Während die Lohnsumme nach den Maßstäben, die der Lohnsummensteuer zugrunde lagen, ermittelt werden könnte, erscheint es fraglich, welches der maßgebende Kapitalwert (Kapitaleinsatz) der Betriebe ist, der als Indikator für Aufwendungen der Gemeinden für örtliche Betriebsanlagen gelten könnte.

Die verschiedenen produktionsbezogenen Verteilungsschlüssel unterscheiden sich also in den Fragen der räumlichen Streuung, des Interessenausgleichs (der fiskalischen Äquivalenz) und des Aufwandes bei der Erstellung bzw. Berechnung der Schlüssel. Dabei ist die Funktion des Interessenausgleichs bei allen Verteilungsschlüsseln geschwächt, da es am direkten Zusammenhang zwischen den kommunalen Leistungen und den produktionsbezogenen Steuerlasten fehlt. ${ }^{244}$

244 Im Rahmen von Modellrechnungen (vgl. Strauß, 1984; Schmitt, 1985; Micosatt/Junkernheinrich, 1991; Junkernheinrich, 1991) für die răumliche Streuung einer Beteiligung der Gemeinden an der Umsatzsteuer für die einzelnen Verteilungsschlüssel sind kurz skizziert folgende wesentliche Wirkungsmuster nachgewiesen worden. Wenn - vor allem aus raumordnungspolitischen Gründen - der Verteilungsschlüssel Einwohner Verwendung fände, treten unter allen Varianten die extremsten Nivellierungseffekte in bezug auf die Steuerkraft auf. Verlierer wären vor allem die Großstädte, Profiteure die ländlichen Zonen sowie Ballungsrandzonen. Der Verteilungsschlüssel Beschătigte liegt überall dort über dem Schlüssel Einwohner, wo eine überdurchschnittliche Erwerbsbeteiligung vorliegt und/oder die Wirtschaftsbevölkerung aufgrund von Einpendlerüberschüssen die Wohnbevölkerung übersteigt. Beim Verteilungsschlüssel Lohnsumme zeigt sich, daß die Anteile der kreisfreien Städte bzw. der Ballungskerne über dem Anteil der Beschäftigten liegen. Dies ist ein deutliches Zeichen für das höhere Lohn- und Gehaltsniveau in diesen Regionen. Der

Hans-Georg Napp - 978-3-631-75263-0 
Vorschläge, das Umsatzsteueraufkommen nach Einwohnern oder veredelten Einwohnern auf die einzelnen Gemeinden zu verteilen, entsprechen nicht dem Kriterium des Interessenausgleichs. Eine Berücksichtigung der Produktion und damit der gewünschten Beziehung zwischen örtlicher Wirtschaft und Gemeinde fände dann im kommunalen Finanzsystem praktisch nicht mehr statt, es sei denn, eine andere produktionsbezogene Abgabe nimmt eine die fiskalische Äquivalenz herstellende Rolle ein.

9.3.6 Der Vorschlag einer Umsatzsteuerbeteiligung mit modifiziertem Hebesatzrecht ${ }^{245}$

\subsubsection{Skizzierung des Vorschlags}

Eine Vielzahl von Vorschlägen zur Reform des kommunalen Steuersystems zielt auf die gerade behandelte Beteiligung der Gemeinden am Umsatzsteueraufkommen ab (vgl. Deutscher Industrie- und Handelstag, 1982; Institut "Finanzen und Steuern", 1982; Ritter, W., 1983; Bundesverband der Deutschen Industrie, 1985; Milbradt, 1982; Niedersächsischer Landtag, 1988; Landtag Rheinland-Pfalz, 1986; Wissenschaftlicher Beirat, 1982; Karrenberg/Münstermann, 1992; Schäfer, 1992). Diese Lösung kommt zwar den Vorstellungen der Wirtschaft entgegen, stößt aber - wie auch die obigen Ausführungen deutlich machen - bei den Gemeinden und auch der Mehrzahl der Finanzwissenschaftler auf Bedenken, weil das Hebesatzrecht entfiele und damit die kommunale Finanzautonomie stark eingeschränkt würde (vgl. Scherf, 1989, 572). Auf der anderen Seite würde für ein Hebesatzrecht der Gemeinden im Rahmen eines globalen Umsatzsteuerverbundes mit einer interkommunalen Verteilung nach Maßgabe eines entsprechenden Schlüssels kein Raum sein, weil es zum einen keinen sinnvollen Ansatzpunkt für ein Hebesatzrecht gibt (vgl. Rau/Rieger, 1981, 99f) und zum anderen unter Harmonisierungsgesichtspunkten der Umsatzbesteuerung administrative Probleme zu erwarten sind (vgl. Strauß, 1984, 95; Rau/Rieger, 1981, 25ff).

Unter diesen Rahmenbedingungen hat Krause-Junk (1989a; 1989b) einen Vorschlag entwickelt, der den vorgebrachten Einwänden Rechnung tragen soll. Es schlägt als Form der Umsatzsteuerbeteiligung ein sogenanntes "Beteiligungsmodell" vor, das den Gemeinden einen einnahmepolitischen Spielraum beläßt. In Kurzform läßt sich seine Idee (für die bundesdeutsche Situation und die Diskussion um die Gewerbesteuer) wie folgt umschreiben:

kombinierte Schlüssel Lohnsumme und örtlicher Kapitaleinsatz führt dazu, daß die Konzentration der Einnahmen auf die Ballungskerne zunimmt. Dieser kombinierte Schlüssel ist daher eher "ballungsraumfreundlich", wăhrend ländlich strukturierte Regionen eher benachteiligt sind.

245 Vgl. dazu Krause-Junk (1989a; 1989b), Scherf (1989) sowie Richter/Wiegard (1990a, 14f). 
- Die Gewerbesteuer (als produktionsbezogene Abgabe) wird abgeschafft und zur Kompensation werden die Umsatzsteuersätze so erhöht, daß die daraus resultierenden Mehreinnahmen ungefähr doppelt so hoch sind wie das bisherige Gewerbesteueraufkommen.

- Das zusätzliche Umsatzsteueraufkommen wird nach der örtlichen Lohnsumme ${ }^{246}$ der umsatzsteuerpflichtigen Betriebe an die Gemeinden überwiesen.

- Der Gesamtbetrag wird zwischen Gemeinde und ortsansässiger Wirtschaft aufgeteilt. Der Aufteilungsschlüssel hat die Funktion eines Hebesatzes, d.h. die Gemeinde kann die Aufteilung nach eigenem Ermessen ändern. Auch die den Unternehmen zurückerstattete Umsatzsteuer wird nach der Lohnsumme verteilt.

Das Krause-Junk-Modell zeichnet sich dadurch aus, daß ein aus der Sicht der Unternehmen akzeptabler Reformvorschlag auch für die Gemeinden an Attraktivität gewinnt. Die Hebesatzkonstruktion kann durchaus als zweckmäßig angesehen werden, denn sie ermöglicht den Gemeinden eine Variation ihrer Einnahmen aus produktionsbezogenen Steuern und zwingt sie dabei zur Rücksichtnahme auf die ortsansässigen Unternehmen. ${ }^{247}$

\subsubsection{Allokative Beurteilung}

Um zu einer Bewertung dieses Vorschlags zu gelangen, sollen zunächst anhand des eingangs formulierten Investitionsmodells die allokativen Wirkungen überprüft und darüber hinaus die Einordnung in ein kommunales Finanzsystem hinterfragt werden. Für die Modellbetrachtung wird angenommen, daß $\tau_{m}$ den erhöhten Umsatzsteuersatz und $\sigma$ den Proportionalitätsfaktor, der sich als Quotient von zusätzlichem Umsatzsteueraufkommen und gesamtwirtschaftlicher Lohnsumme ergibt und als "Lohnsummen-Subventionssatz" (Richter/Wiegard, 1990a, 15) interpretiert werden kann. Schließlich wird durch $\alpha^{B}$ und $\alpha^{G}$ ( mit $\alpha^{B}+\alpha^{G}=1$ ) die Aufteilung des insgesamt an eine Gemeinde überwiesenen Anteils am Umsatzsteueraufkommen auf die örtlichen Betriebe und die Gemeinde selbst angegeben. Folglich ergibt sich der unternehmerische Netto-Cash-flow für die jeweiligen Perioden als

246 Krause-Junk zieht auch in Betracht, die Lohnsumme mit der örtlichen Produktivităt zu gewichten. Auf diese Weise könnte der Faktor Kapital bei der Verteilung des Steueraufkommens indirekt berücksichtigt werden (vgl. Krause-Junk, 1989a, 381f).

${ }^{247}$ Der Vorschlag hebt sich insofern vorteilhaft von dem Anrechnungsmodell des Deutschen Industrie- und Handelstages (1982) ab, der die Gewerbesteuer mit Hebesatzrecht beibehalten will, aber eine Verrechnung mit der Umsatzsteuer vorsieht. Die Folge wăre, daß sich die Gemeinden zu Lasten von Bund und Lăndern, nicht aber zu Lasten der ortsansässigen Wirtschaft Mehreinnahmen verschaffen könnten. 
(9.29) $C_{t}-T_{t}^{M}+\sigma \alpha^{B} w_{t} L_{t}=\left[p_{t} F\left(K_{t}, L_{t}\right)-w_{t} L_{t}-q_{t} I_{t}\right]-\dot{\tau}_{M}\left[p_{t} F\left(K_{t}, L_{t}\right)-q_{t} I_{t}\right]+\sigma \alpha^{B} w_{t} L_{t}$.

Nach entsprechender Umformung und für $\tau_{c}=\sigma \alpha^{B}$ kann man stattdessen auch schreiben:

$(9.30) C_{t}-T_{t}^{M}+\sigma \alpha^{B} w_{t} L_{t}=\left(1-\tau_{c}\right)\left[p_{t} F\left(K_{t}, L_{t}\right)-w_{t} L_{t}-q_{t} I_{t}\right]-\left(\tau_{m}^{\prime}-\tau_{c}\right)\left[p_{t} F\left(K_{t}, L_{t}\right)-q_{t} I_{t}\right]$.

Es läßt sich erkennen, daß Krause-Junks Vorschlag letztendlich auf die Kombination einer Cash-flow-Steuer mit dem Satz $\tau_{c}$ und einer mit dem effektiven Satz $\left(\tau_{m}-\tau_{c}\right)$ ausgestatteten Mehrwertsteuer hinausläuft. Richter und Wiegard (1990b) haben verdeutlicht, daß man die Bemessungsgrundlage der Cash-flow-Steuer aus derjenigen der Mehrwertsteuer ermitteln kann, wenn man letztere um die Lohnsumme kürzt. Dieses Ergebnis ist dann mit der Erhebung einer Mehrwertsteuer bei gleichzeitiger Subventionierung der Lohnsumme identisch. Daher stimmt bezüglich der allokativen Wirkungen dieser Vorschlag im wesentlichen mit den Ergebnissen der Cash-flow-Steuer überein. Ein wesentlicher Unterschied ist jedoch die Tatsache, daß mit einem örtlich differenzierten Cash-flow-Steuersatz $\sigma \alpha^{B}$ im Rahmen dieser Besteuerungsvariante auch eine lokale Variation des Mehrwertsteuersatzes $\left(\tau_{m}-\sigma \alpha^{B}\right)$ einhergeht.

Mit einigen Einwänden und Kritikpunkten, die sein Vorschlag hervorgerufen hat, setzt sich Krause-Junk selbst auseinander. Hervorzuheben sind in dieser Hinsicht vor allem die negativen Verteilungswirkungen, die bereits diskutierte Verteilungsschlüsselproblematik sowie die lokal differierenden Steuersätze, die (wie bei anderen "Hebesatzvarianten" auch) im Widerspruch zu einem EG-einheitlichen Umsatzsteuerrecht stehen könnten (vgl. Rau/Rieger, 1981, 25ff).

9.3.6.3 Die Eignung des Vorschlags hinsichtlich der Einordnung in ein Gemeindesteuersystem

Diesen doch erheblichen Nachteile stehen die Vorzüge des Modells gegenüber, die vor allem im Bereich der Wahrung und Stärkung der kommunalen Finanzautonomie liegen. Wenn nun die Wahrung der kommunalen Finanzautonomie vor dem Hintergrund des Interessenausgleichs bzw. der fiskalischen Äquivalenz hohe Priorität genießt, ist es den Gemeinden durch diese Modellvariante einer "Umsatzsteuerbeteiligung" möglich, das Niveau der öffentlichen Leistungen besser an den Wünschen der Gemeindebürger zu orientieren. Im Idealfall könnten die Bürger wählen, ob sie ein Mehr oder Weniger an Steuern und damit auch ein Mehr oder Weniger an (lokalen) öffentlichen Leistun- 
gen wollen. Dies ist jedenfalls, wie schon mehrfach betont, der Sinn kommunaler Finanzautonomie, wie er von der Finanzwissenschaft gesehen und hervorgehoben wird. Vor diesem Hintergrund mußten die bisherigen Diskussionsalternativen einer Umsatzsteuerbeteiligung verworfen werden; hier liegt der entscheidende Vorteil des KrauseJunk-Vorschlags. Hinsichtlich der übrigen kommunalspezifischen Erfordernisse stimmen die Argumente mit den Ausführungen bei der Cash-flow-Besteuerung und einer Umsatzsteuerbeteiligung der Gemeinden weitgehend überein.

\subsection{Bodenbezogene Steuerformen}

Die Besteuerung des Faktors Boden stellt mit Grund- und (Grund-)Vermögensabgaben einen zentralen Bereich kommunaler Besteuerung dar. Es stellt sich in diesem Kontext die Frage, ob zwischen den Grundstücken bzw. ihren Werten und den verursachten gemeindlichen Flächenkosten oder damit zusammenhängenden lokalen öffentlichen Leistungen ein Zusammenhang besteht, der im Sinne eines Interessenausgleichs zwischen Grundstücksbesitzer und Gemeinde eine Abgabenerhebung in Form von "Bodensteuern" rechtfertigt.

Der räumlich immobile Faktor Boden wird in der Regel für Wohn- und für Produktionszwecke verwendet. Dabei ist hinsichtlich der Nutzung als Produktionsfaktor zu unterscheiden. Bei ländlichen Gemeinden wird der überwiegende Teil der Gemeindefläche landwirtschaftlich (forstwirtschaftlich) genutzt, bei städtischen Gemeinden bis hin zu den Großstädten wird ein erheblicher Teil der Gemeindeflächen für Produktionszwecke verschiedenster Art (Handwerk, Industrie, freie Berufe, Einzelhandel, Dienstleistungen) verwendet. Unter der Zielsetzung einer entsprechenden Breitenwirkung gemeindlicher Besteuerung müssen selbstverständlich alle genutzten Grundstücke (ob Betriebsgrundstück oder Wohngrundstück) in eine Grundbesteuerung einbezogen werden. Am Beispiel der bundesdeutschen Grundsteuer sollen kurz die Vorzüge und Nachteile einer Grundsteuer im kommunalen Einnahmespektrum verdeutlicht werden.

\subsection{1 "Traditionelle" Grundsteuer}

\subsubsection{Skizzierung}

Die Grundsteuer - die man als klassische Gemeindeabgabe bezeichnen kann - wird in der Regel als eine Ertragsteuer auf den Faktor Boden angesehen (vgl. etwa Marcus, 1986, 165). Daher rechnet man sie steuersystematisch zu den Ertragsteuern, denn bei ihrer Ausgestaltung wird auf die Erfassung des Ertrags aus dem Produktionsfaktor Bo- 
den abgestellt. In der Bundesrepublik Deutschland ist sie als Sollertragsteuer eingerichtet. Die Besteuerung geht also den Umweg über die den Ertrag abwerfenden Objekte. Dabei werden zwei Arten des Grundbesitzes und damit der Grundabgaben unterschieden (vgl. Hessler, 1976, 91):

- land- und forstwirtschaftliches Vermögen (Boden, Betriebsgebäude, Maschinen, Betriebsmittelbestände, Wohngebäude) werden erfaßt von der Grundsteuer A;

- Grundvermögen (Wohngrundstücke, nicht land- und forstwirtschaftliche Betriebsgrundstücke) werden erfaßt von der Grundsteuer B.

Das zentrale Problem der Grundbesteuerung ist die Einheitsbewertung. Zum einen ist die unmittelbare Bewertungsmethode problembehaftet (vgl. Marcus, 1987, 72f), zum anderen aber die Periodizität der Bewertung (vgl. Hessler, 1976, 96 sowie Moxter, 1980, 234). Diese "erhebungstechnischen" Faktoren sind wohl in erster Linie dafür verantwortlich, daß die fiskalische Bedeutung der Grundbesteuerung sehr stark zurückgegangen ist. Daneben dürften aber auch strukturelle Entwicklungen, wie die nahezu bedeutungslos gewordene Grundsteuer A für land- und forstwirtschaftliche Betriebe zu diesem Bedeutungsverlust geführt haben. Die geringe Aufkommenselastizität ist letztlich für die nur geringe Konjunkturreagibilität der Grundsteuern (im Vergleich zur Gewerbesteuer) verantwortlich.

\subsubsection{Bewertung}

Die Grundsteuer wird in der Regel den Gemeinden zur alleinigen Ausschöpfung überlassen und ist somit in bezug auf autonome Einnahmeerzielung, Aufkommensvariation und Belastungsveränderungen eine recht geeignete kommunale Abgabeform. Durch die Besteuerung des Faktors Boden werden darüber hinaus örtliche Tatbestände erfaßt und es erscheint durchaus realistisch, daß eine Beziehung zwischen dem Ertrag aus Grundvermögen und dem kommunalen Finanzbedarf besteht. ${ }^{248}$

Die Einrichtung eines proportionalen Tariftyps dürfte sich bei dieser Abgabe problemlos bewerkstelligen lassen, doch auch hier resultiert möglicherweise wieder ein Konflikt mit staatlichen Besteuerungszielsetzungen, d.h. einer dem Leistungsfähigkeitspostulat entsprechenden Lastverteilung (vgl. dazu Marcus, 1986, 167). Außerdem ließe

\footnotetext{
248 Vgl. die umfangreichen Diskussionen um die "Kapitalisierung" von Vermögens- oder Grundsteuern einerseits sowie die Wertsteigerungen von Grundstücken durch ein entsprechendes kommunales Leistungsangebot andererseits. Eine umfangreiche theoretische Betrachtung der Allokationswirkungen der Bestandsbesteuerung (unter besonderer Berücksichtigung der Vermőgensteuer, der Gewerbekapitalsteuer und der Grundsteuer in der Bundesrepublik Deutschland) liefert Nachtkamp (1986).
} 
sich mit einer Anpassung der Soll- an die Ist-Ertragswerte, die sich permanent und nicht nur in größeren Abständen vollziehen müßte, eine Entwicklung der Bemessungsgrundlage erreichen, die - bei jährlicher Betrachtung - der des Sozialprodukts in Richtung und $A u s m a ß$ nahe käme.

Geht man davon aus, daß die Grundsteuer nicht überwälzt wird, werden über die Grundsteuer alle Gemeindeeinwohner, die entweder Nutzen aus kommunalen Leistungen ziehen, die das in der Gemeinde vorhandene Grundvermögen betreffen, oder aber als Eigentümer oder Mieter von Gundvermögen Verursacher kommunaler Lasten sind, als diejenige gemeindliche Teilgruppe aufgefaßt, welche von der Grundsteuer tangiert werden soll. Bei entsprechender Ausgestaltung werden also die Zensiten die Grundsteuer als Last bemerken und sie in ihr Entscheidungskalkül einbeziehen (Realisierung fiskalischer Äquivalenz). Auch wenn Grundstücksbesitzer ihren Wohnsitz selbst nicht dort haben, wo sich ihr ertragbringendes Objekt befindet, erhalten sie diese Last von einer anderen als ihrer Wohnsitzgemeinde aufgebürdet. Dies kann jedoch auch ein Problem darstellen.

Eine Grundsteuer als Alleinsteuer garantiert eine effiziente Allokation nur dann, wenn die Kosten der Bereitstellung lokaler öffentlicher Güter sich proportional zur Bemessungsgrundlage dieser Steuer in einer Kommune entwickeln. Eine Zusatzlast wird also nicht schon dadurch hervorgerufen, daß lokale Steuern von Ort zu Ort variieren. Vielmehr hängen mögliche Substitutionseffekte davon ab, ob eine lokale Steuer die ortsansässigen Bürger (bzw. Unternehmen) exakt nach Maßgabe der Ausgaben, die diese der Gemeinde direkt oder indirekt verursachen, belastet. Anders ausgedrückt bedeutet dies, daß die effektive Steuerinzidenz den Beitrag eines Wirtschaftssubjekts (Vermögensbesitzers, Grundstückinhabers, Unternehmens) zum Entstehen lokaler Ausgaben genau widerspiegeln muß, um eine optimale Allokation zu gewährleisten. Daneben sind Substitutionseffekte in der Regel nicht möglich, weil der Faktor Boden immobil ist.

Entgegen der bisherigen Annahme der Nichtüberwälzbarkeit der Grundsteuer soll nunmehr der Fall betrachtet werden, bei dem die Grundsteuer als Kostenfaktor in die Mieten eingeht. Durch Überwälzungsvorgänge erweitert sich der Kreis der betroffenen Gemeindebürger und somit würde ein kommunales Steuersystem, das nur aus einer Grundsteuer bestehen würde, allein durch diese Überwälzung die erwünschte Breitenwirkung der gemeindlichen Besteuerung erzielen. Fraglich ist aber, ob aufgrund stattgefundener Überwälzungsprozesse, die dann zum Großteil indirekt (über höhere Mieten oder niedrigere Vermögenswerte) wirken, den belasteten Gemeindeeinwohnern das Tragen einer steuerlichen Last für "ihre" Gemeinde" noch offensichtlich werden läßt. Daraus folgt, daß der Überwälzungsvorgang als solcher dem Steuerträger ersicht- 
lich gemacht werden muß, damit die Merklichkeit bzw. Spürbarkeit solcher kommunaler Abgaben gewahrt bleibt.

Das der Zentralstaat die Grundsteuer als konjunkturpolitisches Instrument verwendet, dürfte wenig wahrscheinlich sein. Des weiteren ist sie (als Sollertragsteuer ausgestaltet) wenig konjunkturreagibel und daher im Zeitablauf bezüglich ihrer Entwicklung relativ kontinuierlich. Lediglich über die Einheitswertfestsetzung ist es dem Staat möglich, Einfluß auf das kommunale Steueraufkommen via Änderungen von Rechtsvorschriften zu nehmen. Da zumeist die Einheitsbewertung Grundlage mehrerer staatlicher Abgaben ist, kann es passieren, daß Einheitswertveränderungen im Hinblick auf irgendeine Steuer (Vermögen-, Erbschaft- oder Schenkungsteuer) auf die ebenfalls mit Einheitswerten operierende Grundbesteuerung durchschlagen.

Im großen und ganzen (das zeigt auch ihre praktische Bedeutung) ist die Grundsteuer ein brauchbares Einnahmeinstrument auf lokaler Ebene. Bei einer Betrachtung der spezifischen kommunalen Erfordernisse wurde ihre weitgehende Eignung verdeutlicht. Hauptnachteil ist die zu selten durchgeführte Veränderung und Anpassung der Einheitswerte (es wird auf der Basis überalterter Einheitswerte besteuert) und ihre in der Regel geringe Aufkommenskraft, wenn nicht sehr hohe Steuerbelastungen in Kauf genommen werden sollen. Daher kommt sie zwar als ergänzende Abgabe für ein geeignetes Gemeindesteuersystem in Betracht, sollte aber keine tragende Säule eines solchen Systems darstellen.

\subsubsection{Ein alternativer Ansatz: Die (äquivalenzorientierte) "Grundsteuer neuer Art"}

In Analogie zu den produktionsbezogenen und den einwohnerbezogenen Abgabeformen steht - wie bereits verdeutlicht - auch bei den über Grundsteuern zu finanzierenden Gemeindeleistungen der Äquivalenzgedanke im Vordergrund. Folglich sollte es sich bei den durch Grundsteuern zu finanzierenden Gemeindeleistungen um flächenbezogene Kosten handeln, die dafür sorgen, daß die innerhalb eines Gemeindegebiets gelegenen, von Wohnbürgern und Produzenten jeder Art genutzten Flächen Indikator und Anknüpfungspunkt bei der Bemessung der Steuerbeträge (-belastung) sind. Flächenbezogen sind sämtliche Aufwendungen für Straßen und Plätze sowie für das Versorgungs- und Entsorgungsnetz (Strom- und Gasleitungen, Abwasserkanalisation). Bei diesen Aufwendungen ist zu unterscheiden zwischen denjenigen für die Neuanlage und denjenigen für die laufende Unterhaltung und Verbesserung. Bei Neuanlagen ist eine Kostendeckung über die Anliegerbeiträge (s. auch Kapitel 8) möglich, wobei eine Differenzierung angemessen erscheint, je nachdem, ob es sich um Teilstücke eines durchgehenden Netzes oder um Endstücke (Sackstraßen) handelt. Das bedeutet, daß bei 
Endstücken volle Kostendeckung, bei Teilstücken (infolge der Mitnutzung durch Anlieger sich daran anschließender Teilstïcke) partielle Kostendeckung angestrebt werden sollte. Die laufenden Aufwendungen für Erhaltung und Verbesserung sind jedoch durch periodische (Zwangs-)Abgaben zu decken, da ihnen häufig die Charakteristika der Gebühren- und Beitragsfähigkeit fehlen.

Eine stärker auf diese Äquivalenzgesichtspunkte abzielende Grundsteuer soll in zwei Szenarien diskutiert werden (vgl. auch Haller, 1987, 92ff). Sieht man zunächst von einer Motorisierung und den damit verbundenen Belastungen ab und nimmt an, daß die gesamte Fläche einer Gemeinde für Wohnzwecke genutzt wird, so könnte man von den Grundeigentümern zur Deckung der laufenden Ausgaben eine Grundsteuer in mäßiger Höhe erheben. Als geeigneten Maßstab für die Höhe der Grundsteuer im Einzelfall könnte man die Größe des Grundstücks (also die Grundstücksfläche) benutzen. Zwar gibt es keine Proportionalität zwischen Grundstücksgröße und anteiliger Verursachung gemeindlicher flächenbezogener Kosten, doch verursacht ein größeres Grundstück tendenziell höhere Kosten dieser Art als ein kleineres, da ein längeres Straßen- und Leitungsnetz um dieses herumgeführt werden muß. Einen anderen brauchbaren Indikator könnte die Länge der Straßenfront eines Grundstücks darstellen, doch schon bei langgezogenen Grundstücken mit relativ kleiner Straßenfront erscheint dieser Maßstab unbefriedigend. Seine Verwendung könnte auch dazu führen, daß die Grundstücke entsprechend geschnitten werden (Ausweichreaktionen). Bei der Verwendung der Grundstücksgröße als Bemessungsgrundlage kann der Steuer dagegen nur durch Nutzung kleinerer Wohngrundstücke ausgewichen werden.

Diese Form einer Grundsteuer (hier als "Grundsteuer neuer Art" bezeichnet) knüpft also nicht wie die aktuelle Grundsteuer an Wertgrößen, sondern an physische Größen an. Wertgrößen erscheinen nicht nur wegen der ganzen Bewertungsproblematik mit ihren Ungereimtheiten (Wissenschaftlicher Beirat, 1989) weniger geeignet, sondern vor allem auch, weil kein generell gültiger Zusammenhang zwischen Grundstückswerten und verursachten gemeindlichen Flächenkosten gesehen werden kann. Kleine, zentral gelegene oder sonst wegen ihrer Lage sehr begehrte Grundstücke können hohe Werte aufweisen, an der Verursachung von Flächenkosten im obigen Sinne aber nur geringfügig beteiligt sein.

Reine Wohngemeinden als selbständige Kommunen gibt es vermutlich in der Realität kaum, weil zumindest Ladengeschäfte und Restaurants zur Grundversorgung "beigemischt" sein werden. Folglich werden auch immer für "Geschäftszwecke" genutzte Grundstücke der Grundsteuer unterworfen werden müssen. Darüber hinaus wird bei normalen ländlichen Gemeinden der überwiegende Teil der Gemeindefläche landwirtschaftlich (und forstwirtschaftlich) genutzt, bei städtischen Gemeinden bis hin zu 
den Großstädten wird ein erheblicher Teil der Gemeindeflächen für Produktionszwecke verschiedenster Art (Handwerk, Industrie, freie Berufe, Einzelhandel, Dienstleistungen) verwendet. Selbstverständlich müssen alle so genutzten Grundstücke (Betriebsgrundstücke) ebenso in die Grundbesteuerung einbezogen werden, es sei denn über die produktionsbezogene Abgabe ist für von dieser Nutzergruppe veranlaßte Gemeindeleistungen bereits eine äquivalente Finanzierung erfolgt (beispielsweise über die Wertschöpfungsteuer). Da zunächst nicht das Zusammenspiel unterschiedlicher Abgabeformen im Gesamtsystem analysiert wird, wird hier eine umfassende Grundsteuerlösung vorgestellt. Systemaspekte und das Zusammenwirken der einzelnen Abgabeformen werden in Kapitel 11 diskutiert. Somit gelten bei Betriebsgrundstücken die gleichen Anforderungen wie für die Wohngrundstücke, so daß die Grundsteuer sich zum großen Teil (bei Landgemeinden sogar überwiegend) auf Betriebsgrundstücke erstreckt.

Bei Nutzung von Flächen für die Produktion stellt sich die Frage, ob nicht die mit der Produktion verbundenen "Belastungen" bzw. Anforderungen an die Kommunen eine höhere Grundsteuerbelastung rechtfertigen als sie für Wohngrundstücke vorzusehen ist. Für jede Art von Produktion ergeben sich sehr verschiedenartige Anforderungen; bei der Landwirtschaft der Verkehr mit Fuhrwerken und der Transport landwirtschaftlicher Geräte und Maschinen, bei gewerblicher Produktion der Straßentransport von Rohstoffen und Produkten sowie das $\mathrm{Zu}$ - und Abströmen der Belegschaften, beim Handel der Transport der Waren und der Kundenverkehr usw. Hinzu kommt bei gewerblicher Produktion häufig eine Lärmentwicklung, die Verschmutzung der Luft und des Wassers durch entsprechende Emissionen. Es ergeben sich also zusätzliche (Umwelt-)"Belastungen", die jedoch teilweise auch über Vorschriften baulicher Art und solche, die den Einbau von Filtern und die Errichtung betrieblicher Kläranlagen erzwingen, unterbunden oder zumindest reduziert werden.

Gäbe es, wie zunächst angenommen, keine Motorisierung, so bliebe, auch wenn die Lärmentwicklung und die Verschmutzung von Luft und Wasser unterbunden bzw. durch spezielle Gebühren abgegolten wird, noch immer eine zusätzliche Verkehrsbelastung durch die betriebliche Nutzung eines Teils der Gemeindefläche. Es würde aus diesen Gründen angemessen erscheinen, die Grundsteuer auf Betriebsgrundstücke höher anzusetzen als diejenige auf Wohngrundstück, wobei an eine gewisse Differenzierung je nach Art der Produktion gedacht werden könnte. Der "Zuschlag" könnte sich jedoch in relativ engen Grenzen halten.

Berücksichtigen wir nunmehr in unserer Betrachtung die Motorisierung, die heute einen solchen Grad erreicht hat, daß unterstellt werden kann, die Masse der Beschäftigten und der Einkaufenden lege den Weg zum Arbeitsplatz und zur Einkaufsstätte mit 
dem Kraftfahrzeug zurück. Das Kraftfahrzeug wird ferner fast ausschließlich dafür benutzt, innerörtliche Warentransporte aller Art durchzuführen. Daneben ist die Landwirtschaft ebenfalls motorisiert. Je nach Beschäftigtenzahlen, Kundenzahlen oder ähnlich gelagerten Faktoren tragen die einzelnen Betriebe unterschiedlich zur Erhöhung des Verkehrsvolumens bei. Zumindest bei Produktionsbetrieben (mit Ausnahme der Landwirtschaft) könnte man daran denken, die Beschäftigtenzahl in einer Weise zu berücksichtigen, daß die Grundsteuer je Quadratmeter Fläche nach der "Beschäftigungsintensität" gestaffelt würde. ${ }^{249}$ Die Gestaltung der Staffelung nach "Beschäftigungsintensitäten" würde allerdings ein nicht unerhebliches Willkürelement enthalten. Die Berücksichtigung von Kundenzahlen (etwa bei Betrieben des Einzelhandels) dürte daran scheitern, daß die benötigten Zahlen nicht zu ermitteln sind.

Der Gedanke, irgendwie noch die Größe des "Produktionsapparates" neben der Grundstücksgröße, die ja auch hierfür relevant ist, zu berücksichtigen (etwa anhand des Realkapitals, das in einem Betrieb Verwendung findet und das man wieder auf die Fläche "projizieren" könnte), liegt zwar nahe, doch es ist wohl eher zweifelhaft, ob die Höhe des Realkapitals einen zuverlässigen Indikator für die durch einen Betrieb verursachten besonderen Verkehrskosten darstellt. ${ }^{250}$

Eine praktikable - wenn auch keineswegs ideale - Lösung zur Berücksichtigung der Beschäftigten- und Kundenzahlen sowie der entsprechenden besonderen Verkehrskosten könnte folgendermaßen aussehen. Die Grundsteuer je Quadratmeter sollte unterschiedlich festgesetzt werden je nach Art der Nutzung von Grundstücken. Bei Wohngrundstücke könnte generell ein bestimmter Satz (Betrag) Verwendung finden, doch könnte man überlegen, ob nicht von einer bestimmten Stockwerkzahl an (z.B. ab dem dritten Stockwerk) ein höherer Satz festzulegen wäre, weil mit Wohngebäuden, die mit mehr Mietern belegt sind, ein stärkerer Kraftfahrzeugverkehr verbunden ist. Selbstverständlich wäre es, daß die Grundsteuer den Mietern weiterbelastet (überwälzt) wird. Bei der Nutzung der Grundstücke für Produktionszwecke sollte nach der Art der Produktion differenziert werden. So könnte man für freie Berufe einen Satz festlegen, der nur wenig über demjenigen für Wohnungsnutzung liegt, weil die zusätzliche Verkehrsbelastung hier nur relativ geringe Bedeutung hat. Bei der gewerblichen Produktion könnte man grob nach Betriebsgrößen, gemessen an der Beschäftigtenzahl, differenzieren. Generell sollte dieser Satz erheblich über demjenigen für Wohngrundstücke lie-

${ }^{249}$ Man könnte beispielsweise unterstellen, daß auf $10 \mathrm{~m}^{2}$ genutzter Fläche ein Beschăftigter kommt. Zwei Betriebe mit 1.000 bzw. $10.000 \mathrm{~m}^{2}$ genutzter Fläche würden dann je $\mathrm{m}^{2}$ gleich (normal) besteuert, wenn ihre Belegschaften $100 \mathrm{im}$ einen und 1.000 Arbeitnehmer im anderen Fall betrüge. Bei stărkerer flăchenbezogener Belegung (etwa bei $1.000 \mathrm{~m}^{2}$ Fläche 150 Arbeitnehmer) könnte man eine höhere Steuer je $\mathrm{m}^{2}$ festlegen.

${ }^{250}$ Gemeindliche Kosten im Zusammenhang mit der Schaffung der Produktionskapazităten können schließlich auch durch Sonderabgaben (beispielsweise Anliegerbeiträge) abgegolten werden. 
gen. Bei Einzelhandelsgeschäften könnte man nach Umsatzzahlen differenzieren, die als Behelfsindikator für den Kundenverkehr dienen würden. Ähnlich könnte man verfahren bei Gaststätten und Dienstleistungsbetrieben. Einen Sonderfall stellt auch die landwirtschaftliche Nutzung dar.

Selbstverständlich ist die hier zur Diskussion gestellte Lösung mit zahlreichen Definitions- und Abgrenzungsproblemen verbunden; insofern also keineswegs einfach. Daher soll das Verfahren hier nur seiner Art nach vorgeführt werden, nicht jedoch in den Einzelheiten, für die ein weiter (je nach örtlichen Erfordernissen) Gestaltungsspielraum bliebe. Technisch könnte man also so vorgehen, daß man die für Wohngrundstücke (also bei Gebäuden bis zu beispielsweise zwei Etagen) je Quadratmeter Grundstücksfläche festgesetzte Steuer als Basis (Normsteuer) verwendet, sie als gleich 100 setzt, und die höheren Steuern für betrieblich genutzte Grundstücke je nach Nutzungsart mit über 100 liegenden Sätzen der Normalsteuer festlegt. Alternativ kann man natürlich auch die Steuerbeträge je Quadratmeter direkt in unterschiedlicher Höhe ansetzen. Die Grundsteuer neuer Art sollte zwar nach einheitlichen Grundsätzen zentralstaatlich geregelt, jedoch mit entsprechenden Gestaltungsmöglichkeiten auf der kommunalen Ebene variabel ausgestaltbar sein (Steuersatz- bzw. -betragsvariation oder Hebesatzrecht). Nur so kann sie als äquivalenzbezogene Steuer ihren Sinn haben. ${ }^{251}$

\section{5 "Exportbezogene" Steuerformen}

\subsubsection{Wirkungsweise einer kommunalen Einzelhandelsumsatzsteuer}

Aus der Gruppe von allgemeinen Verbrauchsteuern (vgl. Rau/Rieger, 1981), die für das gemeindliche Steuersystem geeignet sind (vgl. verschiedene Varianten bei Rehm, 1980, 36f), soll im folgenden die sogenannte "Einzelhandelsumsatzsteuer" (auch als kommunale Endverbrauchsteuer bezeichnet) herausgegriffen werden. Pohmer (1980, 684) hält sie für "... eine der ganz wenigen Steuern, die als wirklich ergiebige Kommunalabgaben in Betracht kommen". Hierbei handelt es sich jedoch um eine sehr umstrittene Aussage, wie es auch Pohmer $(1980,684)$ selbst konstatiert. Die Idee, den Gemeinden eine Steuer auf den Endverbrauch einzuräumen, ist nicht neu. Er ist seit Beginn der fünfziger Jahre immer wieder diskutiert worden, auch mit dem Hinweis auf die us-amerikanischen "municipal taxes" (vgl. Due, 1957, 318f) sowie auf die bis 1967

251 Die hier vorgestellte "Grundsteuer neuer Art" steht natürlich mit anderen Säulen den kommunalen Finanzsystems in Beziehung. Je nachdem, ob eine betriebsbezogene oder verkehrsbezogene Abgabe existiert, wird ihre Rolle sich verändern. Im Regelfall wird sie dann eine Nebensteuer mit weit geringerem Gewicht sein, deren Funktion aber die Abgeltung der nicht über Produktion und Verkehr verursachten flachenbezogenen Gemeindekosten darstellt. 
in Frankreich geltende Regelung, bei der eine "taxe locale" neben der bis zur Großhandelsstufe reichenden Nettoumsatzsteuer erhoben wurde. ${ }^{252}$ So forderte bereits Noltenius (1952, 31), der Bund solle sich im Rahmen einer Neuordnung der Finanzverfassung auf die Umsatzsteuer der Industrie, der Landwirtschaft und des Großhandels beschränken und die Erhebung der Umsatzsteuer auf die Umsätze der letzten Stufe den Gemeinden überlassen.

Der besondere Vorzug einer gemeindlichen Verbrauchsteuer (beispielsweise im Vergleich zur vorab diskutierten Umsatzsteuerbeteiligung) liegt in der Zuweisung einer autonomen Steuerquelle und der Möglichkeit, diese je nach Finanzbedarf ausschöpfen zu können. Die Realisierung einer fiskalischen Äquivalenz wird folglich erst durch die autonome Festlegung von Steuer- bzw. Hebesätzen möglich und erlaubt auf diese Weise eine Verknüpfung des kommunalen Leistungsangebots und seiner Finanzierung.

Die Belastung des Verbrauchs soll über die Besteuerung der (Einzelhandels-)Umsätze erfolgen. Folglich wird diese Abgabe auch Einzelhandelsteuer genannt. ${ }^{253}$ Pohmer (1980, 681ff) diskutiert sie in seiner Abhandlung zur Umsatzbesteuerung unter der Rubrik "Einphasen-Umsatzsteuern". Wenn es bei dieser Abgabe letztlich darum geht, daß die Konsumausgaben lückenlos belastet werden (vgl. Pohmer, 1980, 681), dann müßte, falls die Einzelhandelsumsätze die Bemessungsgrundlage darstellen, die Summe derselben genau dem gesamten privaten Konsum entsprechen. Diese Übereinstimmung dürfte jedoch nicht gegeben sein, denn zum einen betrifft ein Teil der Einzelhandelsumsätze Verkäufe an das Ausland, zum anderen wird ein weiterer Teil nicht durch inländische Einzelhandelsumsätze erfaßt, wie der Eigenverbrauch der Unternehmen ${ }^{254}$, "Käufe" der Konsumenten beim Staat, Direktimporte der inländischen Konsumenten sowie den Konsum der nicht erfaßten Wertschöpfung der privaten Haushalte. Jener Teil der Umsätze, der ausländische Abnehmer betrifft, müßte von der Steuer ausgenommen, die Direktimporte durch inländische Konsumenten müßten dagegen einbezogen werden (vgl. Marcus, 1986, 196). Wird aber ein solcher Grenzausgleich gewährt, gibt es aber unter Umständen steuerrechtliche Probleme, die der eingeleiteten Harmonisierung der Umsatzbesteuerung innerhalb der Europäischen Gemeinschaft zuwiderlaufen (vgl. Karl-Bräuer-Institut, 1984, 97f). Daher soll für die hier be-

252 Die "taxe locale" wurde mit der Einführung der "taxe sur la valeur ajoutée", d.h. einer alle Stufen umfassenden Mehrwertsteuer, zum 1. Januar 1968 aufgehoben.

253 Zwilling (1971) unterscheidet eine Einzelhandelsumsatzsteuer und eine Endverbrauchsteuer. Letztere entspricht der hier behandelten Abgabe, die erstgenannte ist identisch mit der vom Wissenschaftlichen Beirat, 1982, 82ff) vorgeschlagenen "Mehrwertsteuer auf der letzten Stufe".

254 Dies stellt aber einen umsatzsteuerpflichtigen Tatbestand im Rahmen der staatlichen Umsatzbesteuerung dar (vgl. Pohmer, 1980, 691). 
trachtete Variante auf die Berücksichtigung der Käufe der privaten Haushalte im Ausland ebenso verzichtet werden, wie auf die Entlastung der Exporte (vgl. auch Rehm, $1980,42 f)$.

Hingegen soll der Eigenverbrauch der Unternehmer (wie auch bei Pohmer, 1980, 685) in die Bemessungsgrundlage einer kommunalen Einzelhandelsteuer einbezogen werden, nicht jedoch (vor allem unter Praktikabilitätsgesichtspunkten) der Verbrauch der nicht erfaßten Wertschöpfung durch die Haushalte. Da darüber hinaus weder die Transaktionen zwischen Unternehmen und Staat noch die "Käufe" von Staatsleistungen durch private Haushalte Einzelhandelsumsätze darstellen, wäre somit sämtlicher Konsum staatlicher Leistungen steuerfrei. Um dies zumindest für einen Teil des öffentlichen Leistungsangebots zu vermeiden, schlägt Pohmer (1980, 682f) die Einbeziehung der entgeltlich abgegebenen Leistungen der öffentlichen Hand in die Bemessungsgrundlage einer Einzelhandelsteuer vor (ebenso Rehm, 1980, 42).

9.5.2 Allokative und raumwirtschaftliche Wirkungen einer kommunalen Einzelhandelsumsatzsteuer

Wichtiger als diese steuerrechtlichen und steuertechnischen Probleme sind die ökonomischen (allokativen) Aspekte und raumwirtschaftlichen Wirkungen einer kommunalen Endverbrauchsteuer. In diesem Zusammenhang sei nochmals an die Aufgabenstellung der Kommunalfinanzen im Hinblick auf die Allokationsfunktion des öffentlichen Gesamthaushalts erinnert. Danach sind den Gemeinden diejenigen Aufgaben zuzuordnen, die auf einer örtlich radizierbaren "Nachfrage" beruhen; oder anders ausgedrückt, bei denen der Nutzen- und Kostenradius sowie der Kreis der Träger einer finanzpolitischen Entscheidung kongruent sind (vgl. Williams, 1966; Litvak/Oates, 1970 und Pauly, 1970a). Dadurch können interlokale Nutzen- und Kosten-spillovers vermieden, die Versorgung mit öffentlichen Leistungen am ehesten der "Nachfrage" angepaßt und auch im Hinblick auf die Entscheidungskosten wirtschaftlich gestaltet werden (Rothenberg, 1970, 31ff). Daraus resultiert die Maxime, die Steuerfinanzierung der kommunalen Haushalte nach dem Prinzip einer gruppenmäßigen Äquivalenz im lokalen Sinn zu gestalten (vgl. Olson, 1977, 66ff; Frey, 1977, 93ff und Hanusch, 1978, 129ff). Dieser im Verlauf der vorstehenden Analyse geeignet erscheinender Gemeindesteuern benutzten Forderung würde eine kommunale Endverbrauchsteuer offenkundig nicht genügen, denn

- die räumliche Streuung der sich aus dieser Abgabe ergebenden Steuerkraft wäre relativ hoch, 
- selbst bei gleicher hypothetischer Steuerkraft, d.h. bei gleichem örtlichen Steuerpotential, würden unterschiedliche Steuersätze angesichts der Mobilität der Kaufkraft Aufkommensverlagerungen auslösen,

- die Abgabe könnte auf die Einwohner bzw. Produzenten in anderen Gemeinden überwälzt werden (vgl. Rehm, 1980, 46f).

Zunächst zum ersten Argument. Da eine Endverbrauchsteuer in der Form einer kommunalen Einzelhandelumsatzsteuer nicht am Ort des Verbrauchs, sondern der Einkommensverausgabung erhoben würde, käme es voraussichtlich zu einem ausgeprägten Steuerkraftgefälle zwischen Stadtgemeinden einerseits und Landgemeinden andererseits. Empirische Untersuchungen von Rehm (1980, 47ff) zeigen, daß der Wareneinzelhandelsumsatz der Großstädte - bedingt durch den großräumigen Kaufkraftzufluß aus dem Umland - um rund vierzig Prozent höher ist, als es der Einwohnerzahl dieser Städte entspricht. Ähnliches dürfte auch für Dienstleistungen, insbesondere im Banken- und Versicherungssektor gelten. Dem könnte entgegengehalten werden, daß eine gewisse räumliche Konzentration der Finanzkraft in größeren Gemeinwesen insofern gerechtfertigt sein könnte, weil ihr häufig die "spillover"-Effekte der zentralörtlichen Leistungen gegenüberstehen (vgl. Tiebout, 1961, 81; Hirsch, 1973, 46; Mielke, 1978, 33). Diesem Aspekt könnte wiederum entgegengehalten werden, daß mit einer solchen Lösung die Zentralität lediglich in ihrer Ausprägung als Handelszentralität dotiert würde (vgl. Kloten/Höpfner, 1967, 355). Dies gilt auch unter Berücksichtigung der Tatsache, daß die Auspendler aus den Zentren einen Teil der Kaufkraft, die in den Agglomerationsgebieten erworben wird, in den Umlandgemeinden für konsumtive Zwecke verwenden. Empirische Untersuchungen bestätigen denn auch, daß für die Oberzentren der Kaufkraftzufluß aus dem Umland deutlich höher ist als der durch Pendler-Effekte bedingte Kaufkraftabfluß. Mit anderen Worten heißt dies, daß es selbst bei gleicher Steueranspannung, d.h. bei einem gleichen Grad der Ausschöpfung der Steuerquelle "Endumsatz", zu Abweichungen vom Prinzip der gruppenmäßigen Äquivalenz käme.

Das Ausmaß dieser Abweichungen - hervorgerufen durch eine ungleichmäßige interlokale Verteilung des Steuerpotentials einer lokalen Endverbrauchsteuer - ist a priori schwer abzuschätzen. Allerdings spricht sowohl das differierende Verbraucherpreisniveau (vgl. Rostin, 1979, 403ff) als auch die unterschiedliche Kaufkraft je Einwohner zwischen und innerhalb der einzelnen Gemeindegrößenklassen dafür, daß das örtliche Aufkommen einer kommunalen Endverbrauchsteuer (etwa bezogen auf die Einwohnerzahl) sehr unterschiedlich wäre. 
In diesem Zusammenhang sind weiterhin die durch die wesentlich höhere Mobilität der Kaufkraft in Großstädten möglicherweise eintretenden längerfristigen stadtentwicklungspolitischen Konsequenzen einer kommunalen Endverbrauchsteuer zu beachten, nämlich die Entleerung der Innenstädte durch Umlandwanderungen (vgl. Carlberg, 1978, 98ff; v. Audenhove, 1979, 4f). Vermutlich würde die Bevölkerungsbewegung hin zur Peripherie der Großgemeinden durch die Abgabe noch verstärkt. $\mathrm{Zu}$ dem mit der Abwanderung der Einwohner aus den Kernstädten in das Umland verbundenen zunehmendem Kaufkraftüberschuß der Randgemeinden (vgl. Neenan, 1970, 117ff; Bradford/Oates, 1974, 51) träten dann gleichgerichtete steuerbedingte Kaufkraftverlagerungen ${ }^{255}$, die - mit einem gewissen time lag - auch die Standortwahl der Distributionsund Dienstleistungsunternehmen beeinflussen würden. Diese Verlagerungen des Besteuerungspotentials blieben längerfristig sicherlich nicht ohne Rückwirkungen auf den "tax effort" der Randgemeinden. Dadurch würden dann die angedeuteten negativen stadtentwicklungspolitischen Konsequenzen noch potenziert (vgl. Rehm, 1980, $53 \mathrm{ff} .{ }^{236}$

Jedoch nicht nur infolge der vermutlich relativ ungleichmäßigen Verteilung des Steuerpotentials würde eine gemeindliche Endverbrauchsteuer kaum dem Prinzip der gruppenmäßigen Äquivalenz entsprechen. Die Verwirklichung dieser Maxime würde bei jener Abgabe auch durch die Steuerausweichung erschwert werden, da insbesondere in verdichteten Regionen (Ballungsräumen wie etwa das Ruhr- oder das RheinMain-Gebiet) auch die interlokale Mobilität der Kaufkraft aufgrund der relativ geringen Translokationskosten gro $B$ ist und entsprechende steuerbedingte Verschiebungen der Nachfrage zu erwarten sind.

Schließlich ist darauf zu verweisen, daß eine kommunale Einzelhandelsumsatzsteuer dem Prinzip der gruppenmäßigen Äquivalenz bei der Finanzierung kommunaler Leistungen insofern unzureichend Rechnung trüge, als in Abhängigkeit von den Elastizitäten von Angebot und Nachfrage, der interlokalen Differenz zwischen den Steuersätzen

255 Dies wird durch die Ergebnisse einer Studie von Mikesell $(1970,206 \mathrm{ff})$ verdeutlicht. Mikesell weist anhand einer ökonometrischen Studie für 173 us-amerikanische Großstådte nach, daß relativ geringe Steuersatzdifferenzen bei der "sales tax" zwischen den Zentren und ihren Vororten deutliche Wanderungen der Kaufkraft auslösen. Vgl. auch Smith/Shapiro $(1979,135 \mathrm{ff})$.

256 Die Umlenkung von Kaufkraft aus den Kernstădten in die Randgemeinden würde darüber hinaus einer Entwicklung Vorschub leisten, der mit dem Stopp der Ansiedlung weiterer Einkaufszentren auf der "grünen Wiese" in der letzten Zeit gerade entgegengewirkt werden soll: Der Zerstörung lebensfahiger Strukturen und die Gefährdung der Revitalisierung innerstädtischer Zentren durch die Sogwirkung der Verbrauchermärkte (vgl. Mielenhausen, 1976, 98ff). Die stadtentwicklungspolitisch höchst bedenkliche Vision von großstädtischen Agenturen, die lediglich die Verkăufe von höherwertigen Produkten aus dem niedrig besteuerten Umland vermitteln und damit auch die entsprechenden kommunalen Umsatzsteuereinnahmen in die Randzonen lenken, könnte bei Einführung einer Einzelhandelsumsatzsteuer mit differierenden Steuersătzen nicht ausgeschlossen werden (vgl. Rehm, 1980, 55). 
sowie der räumlichen Verteilung von Angebot und Nachfrage nach den besteuerten Gütern eine auf dem kommunalen Endverbrauch lastende Steuer zumindest teilweise in eine (oder mehrere) Gemeinde(n) "exportiert" werden kann (vgl. dazu McLure, 1964, 187ff; 1967, 49ff; 1969, 457ff).

Diese Aussage soll anhand eines Beispiels verdeutlicht werden. Betrachtet wird ein Gut, das bei vollkommener Konkurrenz in zwei Gemeinden nachgefragt wird, und dessen Angebot in Gemeinde 2 nicht nur auf deren Produktion, sondern auch auf Importe aus der Gemeinde 1 zurückgeht. Dabei seien

$$
\begin{array}{ll}
N_{1}^{1}: & p_{1}^{1}=f_{1}\left(x_{1}^{1}\right) \\
N_{2}^{1}: & p_{2}^{1}=f_{2}\left(x_{2}^{1}\right)
\end{array}
$$

die Nachfragefunktion der Einwohner in Gemeinde 1 bzw. in Gemeinde 2;

$$
\begin{aligned}
& A_{1}^{1}: \quad p_{1}^{1}=g_{1}\left(x_{1}^{1}\right) \\
& A_{2}^{1}: \quad p_{2}^{1}=g_{2}\left(x_{2}^{1}\right)
\end{aligned}
$$

die Angebotsfunktion in der jeweiligen Gemeinde.

Wird nun in Gemeinde 1 eine Endverbrauchsteuer $\tau_{E V}$ erhoben, während Gemeinde 2 auf die Erhebung einer Endverbrauchsteuer verzichtet, gilt:

$$
A_{1}^{2}: \quad p_{1}^{2}=g_{1}\left(x_{1}^{1}\right)+\tau_{E V}
$$

Will man die Preisänderungen ermitteln, die durch die Besteuerung jeweils ausgelöst worden sind, ist zweckmäßigerweise von den Umkehrfunktionen der Nachfrage bzw. des Angebots auszugehen. Dann folgt für die Nachfrage

$$
\begin{aligned}
& N_{1}^{1}: \quad x_{1}^{1}=m_{1}\left(p_{1}^{1}\right) \\
& N_{2}^{1}: \quad x_{2}^{1}=m_{2}\left(p_{2}^{1}\right)
\end{aligned}
$$

und für das Angebot

$$
A_{1}^{1}: \quad x_{1}^{1}=n_{1}\left(p_{1}^{1}\right)
$$




$$
A_{2}^{1}: \quad x_{2}^{1}=n_{2}\left(p_{2}^{1}\right)
$$

Unter Berücksichtigung der Erhebung einer Endverbrauchsteuer in der Gemeinde $1 \mathrm{mit}$ dem Satz $t_{1}$ folgt für das Angebot:

$$
A_{1}^{2}: \quad x_{1}^{2}=n_{1}\left(p_{1}^{1}\right)-t \cdot n_{1}^{2}\left(p_{1}^{1}\right)
$$

Vor Besteuerung galt für das (interlokale) Gleichgewicht :

$$
m_{1}\left(p_{G}^{1}\right)+m_{2}\left(p_{G}^{1}\right)-n_{1}\left(p_{G}^{1}\right)-n_{2}\left(p_{G}^{1}\right)=0
$$

Die Endverbrauchsteuer verschiebt - wie betont - die Angebotskurve in Gemeinde 1 nach $A_{1}^{2}$, der Gleichgewichtspreis ist nunmehr $p_{G}^{2}=p_{G}^{1}+\Delta p_{t_{1}}$. Daher gilt nach Besteuerung in Gemeinde 1

$$
m_{1}\left(p_{G}^{1}+\Delta p_{t_{1}}\right)+m_{2}\left(p_{G}^{1}+\Delta p_{t_{1}}\right)-n_{1}\left(p_{G}^{1}+\Delta p_{t_{1}}\right)+t_{1} \cdot n_{1}^{2}\left(p_{1}^{1}\right)-n_{2}\left(p_{G}^{1}+\Delta p_{t_{1}}\right)=0
$$

Beachtet man, daß für lineare Angebots-/Nachfragefunktionen gilt:

$$
m_{1}\left(p_{G}^{1}+\Delta p_{t_{1}}\right)=m_{1}\left(p_{G}^{1}\right)+\Delta p_{t_{1}} m_{1}^{2}\left(p_{1}^{1}\right)
$$

so erhält man aus Gleichung (9.38) schließlich

$$
\frac{\Delta p_{t_{1}}}{t_{1}}=\frac{n_{1}^{2}\left(p_{1}^{1}\right)}{n_{1}^{2}\left(p_{1}^{1}\right)+n_{2}^{2}\left(p_{2}^{1}\right)-m_{1}^{2}\left(p_{1}^{1}\right)-m_{2}^{2}\left(p_{2}^{1}\right)}
$$

Gleichung (9.40) gibt an, welcher Teil der in der Gemeinde 1 erhobenen Endverbrauchsteuer von den Konsumenten in der Gemeinde 2 getragen wird. Der Term $\Delta p_{t_{1}} / t_{1}$ quantifiziert also den Teil der Steuerlast, der aus der Gemeinde 1 in die Gemeinde 2 "exportiert" wird. Mithin verdeutlicht dieser Ausdruck die interlokale Steuerinzidenz. Das Steueraufkommen in der Gemeinde 1 ist folglich höher als deren Steuerleistung; die Differenz stellt den angesprochenen Steuerexport dar (vgl. Peffekoven, 1975, 4). 
Abbildung 9.3: Wirkungen einer kommunalen Endverbrauchsteuer

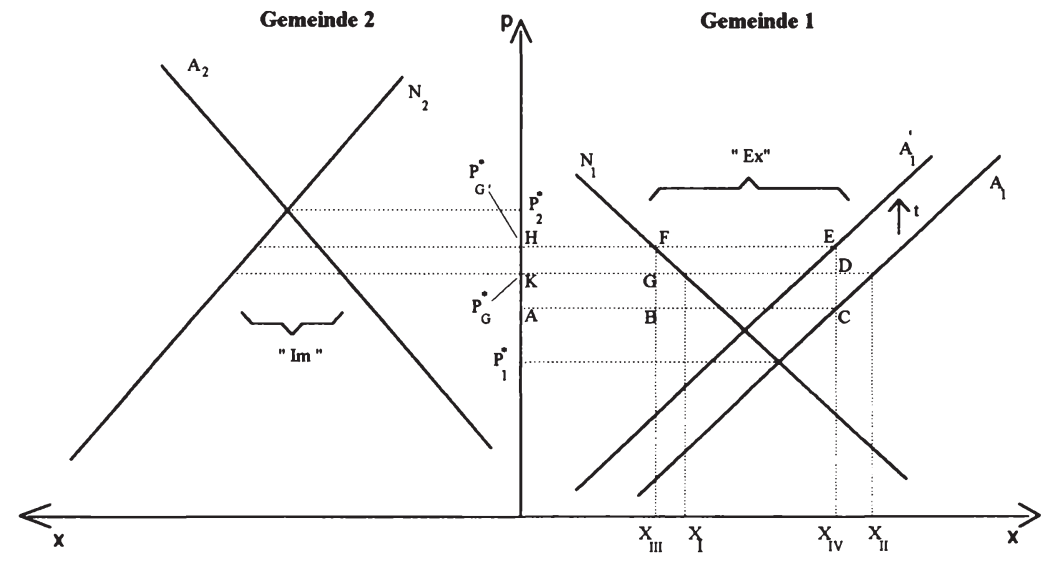

Diese Zusammenhänge werden graphisch in der Abbildung 9.3 verdeutlicht. Dabei wird angenommen, daß in der Ausgangssituation der Satz der Endverbrauchsteuer in den Gemeinden 1 und 2 gleich Null ist. Die Gemeinde 2 soll weiterhin Waren aus Gemeinde 1 "importieren", d.h. in der Gemeinde 1 ist die angebotene größer als die nachgefragte Menge. Der Gleichgewichtspreis vor Besteuerung liegt bei $p_{G}^{*}$; Gemeinde 1 exportiert die Menge $\overline{x_{l} x_{I l}}$.

Erhebt die Gemeinde 1 eine Endverbrauchsteuer mit dem Steuersatz $t_{1}$, so steigt der Gleichgewichtspreis auf $p_{G^{\prime}}^{*}$ und der Export sinkt auf $\overline{x_{I I} x_{I V}}$. Die Produktion (Angebot) in Gemeinde 1 sinkt auf $\overline{0 x_{I V}}$, die Steuereinnahmen belaufen sich auf $\overline{0 x_{I V}} \cdot t_{1}$. Dieses Aufkommen wird aber nur teilweise von den Konsumenten der Gemeinde 1 selbst getragen, nämlich im Umfang von $x_{I I I}\left(p_{G^{\prime}}^{*}-p_{G}^{*}\right)=H F G K$ von den Konsumenten und im Umfang $x_{I V}\left[t_{1}-\left(p_{G^{*}}^{*}-p_{G}^{*}\right)\right]=A C D K$ von den Produzenten. Der übrige Teil des Endverbrauchsteueraufkommens in Höhe von DEFG wird in die Gemeinde 2 exportiert. $p_{G^{\prime}}^{*}-p_{G}^{*}$ entspricht der Preisänderung $\Delta p_{t_{1}}$ aufgrund der Steuererhebung; $\mathrm{t}_{1}$ ist der Steuersatz der Endverbrauchsteuer, $x_{\mathrm{IV}}$ umfaßt die Produktion (Angebot) in Gemeinde 1 nach Besteuerung und $x_{\mathrm{IV}}-\mathrm{x}_{\mathrm{III}}$ stellt den Export der Gemeinde 1 in die Gemeinde 2 dar. Für die Quantifizierung der interlokalen Steuerinzidenz erhält man dann

$$
E=\frac{x_{I V}-x_{I I I}}{x_{I V}} \cdot \frac{\Delta p_{t_{1}}}{t_{1}}
$$


die sogenannte "Rate des Steuerexports", die den Anteil der exportierten Steuer am gesamten Steueraufkommen angibt.

Unter Verwendung der Gleichungen (9.40) und (9.41) ergibt sich damit:

$$
\text { Steuerexport }=\text { Exportrate nach Steuer * interlokale Steuerinzidenz }
$$

Der interlokale Steuerexport ist ceteris paribus um so größer, je elastischer das Angebot und je unelastischer die Nachfrage nach dem betreffenden Gut ist. Der gesamte Steuerexport ist darüber hinaus um so höher, je stärker die Marktstellung der Produzenten in der steuererhebenden Gemeinde (bzw. in der Gemeinde mit der positiven Steuersatzdifferenz) ist, je stärker die Produktion des Gutes in dieser Gemeinde konzentriert ist und je mehr sich die Nachfrage in der (den) Nachbargemeinde(n) konzentriert.

\subsubsection{Die Eignung der kommunalen Einzelhandelsumsatzsteuer als Gemeindesteuer}

Unter allokativen Gesichtspunkten und vor dem Hintergrund des Äquivalenzgedankens ist festzuhalten, daß der für die Erfüllung dieses Kriteriums anzustrebende Zusammenhang zwischen der Bemessungsgrundlage einer Steuer einerseits und der gemeindlichen Bereitstellung öffentlicher Güter andererseits bei einer kommunalen Endverbrauchsteuer kaum gegeben ist. Der gemeindliche Endverbrauch ist vielmehr - ganz abgesehen von den diskutierten Fällen der Steuerausweichung, der Standortwirkungen und der interlokalen Steuerüberwälzung - allenfalls insofern mit den durch die Gemeindebürger verursachten örtlichen Ausgaben verknüpft, als deren Einkommen, das auf diese Weise zusätzlich (indirekt) belastet wird, Umfang und Struktur der Gemeindeausgaben (mit-)bestimmt (vgl. Pagenkopf, 1978, 151). Die Erfassung des örtlichen Verbrauchs ist aber nur dann unproblematisch, wenn der Verkaufsort und der Wohnort des Abnehmers identisch sind. Für alle anderen Fälle gilt es zu klären, ob der Wohnsitz des Käufers oder der Betriebsstättensitz des Verkäufers die Steuerpflicht begründet; mithin das "Bestimmungsort-" oder das "Ursprungsortprinzip" Anwendung finden soll (vgl. Rehm, 1980, 61).

Unter den Gesichtspunkten einer gruppenmäßigen Äquivalenz und der Verringerung von Unterschieden im Pro-Kopf-Steueraufkommen zwischen den Gemeinden gleicher (tendenziell aber auch zwischen den Gemeinden verschiedener) Größenklassen wäre ein Verfahren vorzuziehen, bei dem das Steueraufkommen derjenigen Gemeinde zufließt, in welcher der Käufer seinen Wohnsitz hat. Dieses Verfahren wäre wohl kaum praktikabel, da bei jedem Kauf der Wohnsitz des Käufers festzustellen und dorthin die 
vom Verkäufer einbehaltene Steuer abzuführen wäre. Unter Praktikabilitätsgesichtspunkten wäre nur das "Ursprungsort"-Prinzip realistisch, mit der Folge, daß zentrale Einkaufsorte ein höheres Pro-Kopf-Aufkommen erzielten.

Ferner wird von gemeindlichen Steuern verlangt, daß Aufkommensvariationen (die seitens der Gemeinde etwa durch Steuersatz- oder Hebesatzänderungen hervorgerufen werden können) nur zu Belastungsänderungen für die Bürger der Gemeinde führen, deren Entscheidungen die Belastungsänderung bewirkt haben. Diese Forderung, daß die Aufkommens- sowie die Belastungsänderungen auf das Gebiet der Entscheidungsgemeinde beschränkt bleiben, ist im Rahmen einer Modellbetrachtung, kaum aber für die Realität erfüllbar. Wie weiter oben bereits angedeutet, muß mit einer "interlokalen Mobilität der Kaufkraft" (Rehm, 1980, 53) gerechnet werden. Diese Kaufkraftmobilität wird sowohl von Belastungsdifferenzen zwischen Wohn- und potentiellen Kaufgemeinden hinsichtlich der Einzelhandelsteuer als auch von möglichen "Ausweichkosten" (für das Kaufen außerhalb der Wohngemeinde) beeinflußt. Rehm (1980) berichtet von empirischen Beobachtungen bei der amerikanischen "sales tax" (vgl. auch Peffekoven, 1969, 415ff). Diese haben gezeigt, daß "... selbst relativ geringe Steuersatzdifferenzen das räumliche Kaufverhalten der Verbraucher ... beeinflussen" (Rehm, $1980,53) .257$

Diese unter allokativen Gesichtspunkten auf den ersten Blick eindeutigen Nachteile (in Form fehlender gruppenmäßiger Äquivalenz bzw. des Auftretens räumlicher Verzerrungen und Ausweichreaktionen) der kommunalen Einzelhandelsumsatzsteuer haben wie bereits angedeutet - aber auch einen gewissen Reiz. Um insbesondere - wenn auch nicht ausschließlich - dem Tatbestand Rechnung zu tragen, daß es Nutznießer gemeindlicher Leistungen gibt, die ihren Wohnsitz nicht innerhalb einer die Leistung anbietenden Gemeinde haben, könnte die Einzelhandelsumsatzsteuer die Funktion einer sogenannten "exportbezogenen" Abgabe wahrnehmen (vgl. Marcus, 1987, 130). Damit gelänge möglicherweise schon über das gemeindliche Steuersystem an sich eine gewisse Internalisierung räumlicher spillovers. Wie leistungsfähig dabei Endverbrauchsteuern sein können, müßte empirisch jedoch noch eingehend geprüft werden.

Bezüglich der örtlichen Radizierbarkeit wird die kommunale Einzelhandelsteuer in der Regel positiv eingeschätzt (vgl. etwa Neumark, 1979, 40). Nicht so eindeutig wird das Urteil ausfallen, wenn es um die Würdigung möglicher Korrelationen zwischen der

${ }^{257}$ Eine Untersuchung für den Staat Washington, der 1958 eine "sales tax" (mit einem Satz von 3,5\%) einführte, während die beiden Anrainerstaaten Oregon und Idaho keine "sales tax" erhoben, zeigt, daß sich die Kaufkraft deutlich in diese "Steueroasen" verlagerte (vgl. McAllister, 1961, 362ff). Ähnliche Reaktionen zeigten sich in den sechziger Jahren auch im Staat Massachusetts, dessen Nachbarstaaten Vermont und New Hampshire (damals) keine "sales tax" erhoben (vgl. Due, 1968, 273).

Hans-Georg Napp - 978-3-631-75263-0 
Bemessungsgrundlage dieser Abgabe und dem gemeindlichen Finanzbedarf geht. Es fällt schwer, solche auf den ersten Blick zu identifizieren. Dennoch dürften Zusammenhänge zwischen beiden Größen durchaus bestehen. Es ist zu vermuten, daß diese zwischen den Einzelhandelsumsätzen und der Inanspruchnahme gemeindlicher Infrastrukturleistungen vorhanden sind.

Die Einzelhandelsteuer ist eine Abgabe, die durch eine große Breitenwirkung gekennzeichnet ist. Steuerdestinatare sollen die Konsumenten sein, Steuerpflichtige die Verkäufer von Konsumgütern. Soll erreicht werden, daß die mit der Einzelhandelsteuer letztlich belasteten Konsumenten (Gemeindebürger) diese auch bemerken, müßte darauf im Rahmen der Ausgestaltung dieser Steuer Rücksicht genommen werden. In diesem Zusammenhang wird vorgeschlagen, daß ein gesonderter Ausweis der Steuer auf jedem Kassenzettel (jeder Rechnung) erfolgen sollte. Durch eine solche Publizitätsvorschrift bezüglich der Rolle sowie der möglichen Aktivitäten der Gemeinden bei dieser Steuer ließe sich die Spürbarkeit dahingehend erweitern, daß die Träger gemeindlicher Steuerlasten zur Kenntnis nehmen, daß sie einerseits Lasten für ihre Gemeinde tragen und daß ihre Gemeinde die individuellen Steuerlasten beeinflussen kann. Diese Argumente gelten jedoch nur unter Berücksichtigung der entsprechenden Einschränkungen hinsichtlich der Möglichkeiten des Steuerexports der Einzelhandelsteuer.

Unter Verteilungsgesichtspunkten ist vor allem darauf hinzuweisen, daß eine zusätzliche Belastung des privaten Konsums durch eine kommunale Endverbrauchsteuer die Regressionswirkung der Mehrwertsteuer - die intendierte Abwälzung auf die Verbraucher unterstellt - verstärken würde. Wie Untersuchungen, die auf Ergebnissen von Einkommens- und Verbrauchsstichproben basieren, zeigen, tragen in der Bundesrepublik Deutschland - entgegen einer anderen mitunter geäußerten Auffassung (vgl. Bedau/Göseke, 1977, 377ff) - gemessen am Netto-Haushaltseinkommen (d.h. am verfügbaren Einkommen der privaten Haushalte) die niedrigen und mittleren Einkommen nach wie vor eine relativ stärkere Belastung mit indirekten Steuern als die höheren Einkommen (vgl. auch Huppertz/Wartenberg, 1978, 395ff sowie Kitterer, 1978, 263ff).

Im Hinblick auf die Stabilisierungsfunktion einer kommunalen Endverbrauchsteuer für die Gemeindehaushalte ist zunächst daran zu erinnern, daß eine solche Abgabe nicht nur aus fiskalischen, sondern auch aus steuersystematischen Gründen neben dem eigentlichen Einzelhandelsumsatz auch alle übrigen Lieferungen und Leistungen an den Endverbraucher umfassen sollte. Mithin wäre die Frage der kurz- und langfristigen Entwicklung der Bemessungsgrundlage dieser Steuer in Abhängigkeit von Sozialprodukt nicht nur die konjunkturell bzw. wachstumsbedingte Abhängigkeit der Einzelhandelsumsätze, sondern auch die der Umsätze des produzierenden Handwerks, des 
Dienstleistungsbereichs sowie der Endumsätze im Verkehrs-, Kredit- und Versicherungswesen zu untersuchen (vgl. Rehm, 1980, 60). Vernachlässigt man die zuletzt genannten Bereiche, da bei diesen eine klare Erfassung besonders schwierig ist, und nimmt man für die Umsätze der übrigen genannten Sektoren wegen des leichteren statistischen Zugriffs den Produktionswert ${ }^{258}$, zeigt sich folgendes: Die Elastizität der so definierten Umsätze in bezug auf das Bruttosozialprodukt zu Marktpreisen lag in den zurückliegenden Jahrzehnten bei 1, so daß sich für eine kommunale Endverbrauchsteuer eine Aufkommenselastizität von ebenfalls annähernd 1 ergeben hätte. Einen weiteren Anhaltspunkt für die Aufkommenselastizität einer solchen Abgabe kann die Veränderung des privaten Konsums in Abhängigkeit von Veränderungen des Sozialprodukts liefern. Hier offenbart ein Rückblick, daß längerfristig der Anteil des privaten Verbrauchs am Bruttosozialprodukt zu Marktpreisen im wesentlichen konstant ist, die längerfristige Aufkommenselastizität einer kommunalen Abgabe (ebenso wie bei der Mehrwertsteuer) also auch aus dieser Sicht bei 1 liegen dürfte.

Beurteilt man eine Einzelhandelsumsatzsteuer hinsichtlich ihrer Eignung als gemeindliche Abgabe, so ist trotz einer Reihe von Vorbehalten gegen die Etablierung einer solchen Steuer durchaus auch ihre Bedeutung für die kommunale Finanzwirtschaft (vor allem im Hinblick auf die Einbeziehung zentralörtlicher Funktionen) deutlich geworden. Daher kann einer kommunalen Endverbrauchsteuer durchaus Bedeutung beigemessen werden, wenn es um die Herleitung eines geeigneten Finanzierungssystems für die lokale Ebene geht (vgl. auch Marcus, 1986, 196ff).

258 Der Produktionswert unterscheidet sich vom Umsatz darin, daß er auch die Lagerinvestitionen und die selbsterstellten Anlagen enthallt. Diese beiden Komponenten fallen aber in den angesprochenen Bereichen nicht ins Gewicht (vgl. Statistisches Bundesamt, Volkswirtschaftliche Gesamtrechnung, Fachserie 18, Reihe 1: Konten und Standardtabellen). 
Hans-Georg Napp - 978-3-631-75263-0

Downloaded from PubFactory at 01/11/2019 06:33:05AM

via free access 


\section{Finanzzuweisungen als Einnahmekategorie der Kommunen}

Es sind im wesentlichen zwei Faktoren, die eine Einbeziehung der Finanzzuweisungen ("grants") in eine Betrachtung der Effizienzaspekte kommunaler Finanzautonomie und deren Implikationen für die Ausgestaltung eigenständiger Finanzierungssysteme rechtfertigen. Zunächst ist es die quantitative Bedeutung der Finanzzuweisungen in real existierenden (auch föderal gegliederten) Staatswesen ${ }^{259}$; daneben - und im Rahmen der hier durchgeführten theoretischen Argumentation von größerem Interesse - sind es die Einflüsse der Finanzzuweisungen auf das ökonomische und politische Entscheidungsverhalten auf lokalem Niveau (vgl. Livesey, 1987 sowie Peacock/Ricketts, 1983), die Aufmerksamkeit und Beachtung verlangen.

\section{1 Ökonomische Begründungen}

Die Notwendigkeit von zentralstaatlichen bzw. Landes-"Zuschüssen" zur Deckung des kommunalen Finanzbedarfs wird mit einer Reihe von Argumenten belegt. Im folgenden sollen die Begründungen für die Etablierung von Finanzzuweisungen ${ }^{260}$ in föderativ gegliederten Gemeinwesen in drei Gruppen eingeteilt werden.

Als wohl entscheidendster Bereich kann - daher an erster Stelle - die Internalisierung räumlicher spillovers durch Finanzzuweisungen genannt werden ("allocation objective"). Diese Argumentation beruht auf der Annahme, daß in föderativen Systemen eine optimale Allokation der Ressourcen im allgemeinen wegen auftretender räumlicher Externalitäten (spillovers) nur mit Hilfe von "gebundenen" Finanzzuweisungen möglich erscheint.

Zweiter Begründungsrahmen für staatliche Zuweisungen ist die Sicherung und Garantierung bestimmter Versorgungsniveaus bzw. die Gewährleistung von Mindeststan-

259 Für die Bundesrepublik Deutschland liegt der Anteil der Finanzzuweisungen an den gesamten kommunalen Einnahmen immerhin bei ca. dreißig Prozent (vgl. Tabelle 12.8). Selbst in ebenfalls stark foderativ ausgestalteten Gemeinwesen wie der Schweiz oder den USA liegt der Anteil der staatlichen Zuweisungen am gesamten kommunalen Einnahmespektrum ebenfalls bei etwa zwanzig bzw. über zwanzig Prozent (vgl. Reischauer, 1975, 40ff).

${ }^{260}$ Die Etablierung von Finanzzuweisungen unterschiedlichster Ausrichtung und Orientienung kann als ganzes in einem sogenannten "Finanzausgleich" geschehen, wie er in der Bundesrepublik Deutschland institutionalisiert ist. Der Finanzausgleich ist dabei das "Gesamtsystem" staatlicher Zuweisungen und Zuschüsse. Vgl. in diesem Zusammenhang zu den wirtschaftstheoretischen Grundlagen des Finanzausgleichs Peffekoven (1988), zum Finanzausgleich in der Bundesrepublik Deutschland Ehrlicher (1988) sowie dem System der USA beispielsweise Break (1967, 123ff). 
dards kommunaler Leistungen aus meritorischen Gründen. Auf diese Weise soll vor allem bei einer sehr unterschiedlichen Finanzausstattung der einzelnen Gebietskörperschaften einer Ebene eine angemessene Versorgung mit öffentlichen Gütern und Leistungen sichergestellt werden.

Dritter Bereich zur Rechtfertigung von Finanzzuweisungen sind mögliche fiskalische Ungleichgewichte zwischen den einzelnen Ebenen eines Staatsgebildes aufgrund abweichender Ausgaben- und Einnahmenentwicklungen (vertikale Komponente) bzw. eine notwendige Anpassung der Finanzausstattung (horizontale Komponente) an den gemeindespezifischen Finanzbedarf ("equity objective"). Mit sogenannten "revenuesharing grants" (King, 1984, 121) soll eine Korrektur solcher Divergenzen erfolgen. ${ }^{261}$

\subsection{Arten und Zielsetzungen}

\subsubsection{Zuweisungsarten}

Bekannteste und gebräuchlichste Unterscheidung der Zuweisungen ist die Einteilung in die beiden Hauptgruppen, nämlich die allgemeinen Zuweisungen ("general grants") und die Zweck- bzw. zweckgebundenen Zuweisungen ("specific", "functional" oder auch "conditional grants").

Die allgemeinen Zuweisungen dienen dem Ausgleich der finanziellen Ausstattung der einzelnen Ebenen, daher spricht man häufig auch von sogenannten Ausgleichszuweisungen ("balancing grants"). Von der Zielsetzung her haben solche vertikalen Zuweisungen keine Zweckbindung und sind daher weder mit Auflagen noch mit Kontrollen der zahlenden Gebietskörperschaft verbunden. Da diese allgemeinen Zuweisungen in der Regel als "lump-sum grants" geleistet werden, erhöhen sie je nach der Einkommenselastizität der Nachfrage nach dem privaten bzw. dem öffentlichen Gut - unter Beibehaltung der "Ausgabeprioritäten" - die kommunalen Ausgaben und/oder mindern die eigene Steueranspannung, sofern man vereinfachend im Sinne des "community preference models" unterstellt, daß eine örtliche Gemeinschaft (Kommune) wie ein einzelner privater nutzenmaximierender Haushalt (oder zumindest eine Gruppe identischer Haushalte) betrachtet werden kann. Allgemeine Zuweisungen haben also ledig-

\footnotetext{
${ }^{261}$ Daneben nennt Seiler $(1988,518)$ noch zwei weitere Aspekte, die Aufgaben bzw. Begründungen für die Etablierung eines Zuweisungssystems bzw. eines Finanzausgleichs darstellen. Dies ist zum einen die Unterstützung der gesamtstaatlichen Wirtschaftspolitik ("stabilization objective") und die speziell dem kommunalen Finanzausgleich zufallende fiskalische Funktion der vertikalen Anreicherung des kommunalen Finanzierungsvolumens ("fiscal objective"), weil rein horizontale Ausgleiche zwischen den Gemeinden auf freiwilliger Basis nur im Ausnahmefall realisierbar sind. Es wăre allerdings denkbar, bei ausreichender Steuerausstattung Umlagesysteme bezüglich der Wahrnehmung dieser fiskalischen Funktion einzurichten.
} 
lich einen "Einkommenseffekt", der zu bestimmten Wirkungsmustern führt. Diese werden anschließend (nach Vorstellung der Zweckzuweisungen) im Rahmen unterschiedlicher ökonomischer Modellansätze diskutiert.

Zweckzuweisungen sind - wie der Name schon andeutet - an bestimmte Auflagen gebunden. In der Regel wird mit der Zahlung einer solchen Zuweisung die Aufforderung an die empfangende Gebietskörperschaft verbunden sein, eine bestimmte Aktivität auszuführen bzw. gewisse Aufgaben (zusätzlich) wahrzunehmen. Dabei reicht die Zweckbindung grundsätzlich jedoch noch nicht aus, um sicherzustellen, daß die empfangende Körperschaft auch tatsächlich das erwartete Mehrangebot einer öffentlichen Leistung erbringt, also die Ausgaben entsprechend ausweitet. Entscheidend sind vielmehr die Reaktionen der betroffenen Entscheidungsträger auf den Zufluß der Zuweisungen. So kann sich eine Gemeinde veranlaßt sehen, wegen der Zuweisungen etwa ihre eigenen Einnahmen zu senken, so daß die Ausgaben eben nicht im gewünschten Ausma $\beta$ steigen. Dieser "(Einnahmen-)Substitutionseffekt" steht offenbar im Widerspruch zum angestrebten Ziel der Zuweisungen. ${ }^{262}$

Die beschriebene Form der Zweckzuweisungen (sie stellt in dieser Form eine "lumpsum specific grant" dar) garantiert also keineswegs das gewünschte und durch die $\mathrm{Zu}$ weisung angestrebte Verhalten der empfangenden Körperschaft. Dieses ließe sich hingegen sicherstellen, wenn die Zweckzuweisungen eine Ausgestaltung erfahren würden, die Eigenbeteiligungen - durch die die Empfänger solcher Zuweisungen (man spricht dann von "matching specific grants") verpflichtet werden, sich aufgrund einer bestimmten Formel entweder selbst an der Finanzierung der Aufgabe zu beteiligen oder aber auf die Zuweisung zu verzichten - vorsehen. Hierbei wäre im Idealfall die Beteiligung so zu gestalten, daß die Relation von Zuweisung zu Gesamtausgaben gleich dem Verhältnis von externem Nutzen zu Gesamtnutzen ist.

Eine solche Zuweisung kann in der Höhe unbegrenzt ("open-end-type of grant" bzw. "open-ended grant") oder begrenzt ("fixed-sum grant", "closed-end-type of grant" bzw. "close-ended grant") sein. Dabei ist für die Wahl einer finanziellen Begrenzung letztlich die beabsichtigte Zielsetzung einer solchen Zweckzuweisung von Bedeutung, wie weiter unten noch aufzuzeigen sein wird.

262 Denkbar wăre aber auch, daß das empfangende Gemeinwesen sich entscheidet, für den "geforderten" Zweck eigene Mittel im bisherigen oder gar noch höherem Umfang bereitzustellen. In diesem Fall können die Ausgaben erhöht werden; man spricht deshalb von einem "(Ausgaben-)Anreizeffekt" (vgl. Waldauer, 1973). 
Tabelle 10.1: Zuweisungsarten

\begin{tabular}{|c|c|c|c|c|}
\hline Zuweisungsart: & $\begin{array}{c}\text { allgemeine Zuwei- } \\
\text { sungen ("general } \\
\text { grants") }\end{array}$ & \multicolumn{2}{|c|}{ Zweckzuweisungen ("functional grants") } \\
\hline Ausgestaltung: & $\begin{array}{c}\text { pauschale Zuwei- } \\
\text { sungen ("lump-sum } \\
\text { grants") }\end{array}$ & $\begin{array}{c}\text { pauschale Zuwei- } \\
\text { sungen für be- } \\
\text { stimmte Zwecke } \\
\text { ("lump-sum specific } \\
\text { grants") }\end{array}$ & $\begin{array}{c}\text { Zuweisungen mit } \\
\text { konkreten Auflagen } \\
\text { ("conditional } \\
\text { grants") }\end{array}$ & $\begin{array}{c}\text { Zuweisungen mit } \\
\text { ("matching grants") }\end{array}$ \\
\hline
\end{tabular}

\subsubsection{Zielsetzungen}

10.2.2.1 Finanzzuweisungen als Instrument zur Internalisierung räumlicher externer Effekte

Zentralstaatliche oder andere Zuschüsse übergeordneter gebietskörperschaftlicher Ebenen zur Finanzierung kommunaler Ausgaben können gewährt werden, um damit Einfluß auf die Aufgabenwahrnehmung und folglich die Ausgabengestaltung vor Ort zu nehmen. Wie bereits in Kapitel 6 im Rahmen der Behandlung der räumlichen externen Effekte und ihrer Allokationswirkungen angedeutet, führt fehlende bzw. nicht zu realisierende fiskalische Äquivalenz infolge von Nutzen-spillovers dazu, daß nachgeordnete Körperschaften die öffentliche Leistung in einem sub-optimalen Umfang anbieten. Die übergeordnete Gebietskörperschaft kann dann - statt selbst das Angebot dieser Leistungen zu übernehmen oder sofern die anderen Internalisierungsmöglichkeiten nicht erwünscht bzw. nicht realisierbar sind - Zuweisungen gewähren, die die untere Ebene (also beispielsweise Städte und Gemeinden) veranlassen sollen, die entsprechende Aufgabe im gewünschten Ausmaß zu erfüllen. ${ }^{263}$ Die Zuweisungen würden demnach für solche Aktivitäten gezahlt, bei deren Bereitstellung spillover-Effekte entstehen. Die Höhe der Zuweisungen müßte idealtypisch exakt dem jeweiligen Ausmaß des externen Effekts entsprechen (vgl. Helm/Smith, 1987, 12 sowie King, 1984, 122ff).

Zweckzuweisungen mit allokativer Zielrichtung - nämlich der Internalisierung von räumlichen Externalitäten - sind also nur bei entsprechender Ausgestaltung ein erfolgversprechendes Rezept. Zweiter gewichtiger Einwand gegen einen umfangreichen und unspezifizierten Gebrauch von Zweckzuweisungen zur Finanzierung nachgeordneter

263 Vgl. dazu auch die Ausführungen in Abschnitt 6.1.5.3 (Vertikale Transfers als Internalisierungskonzept răumlicher externer Effekte). 
gebietskörperschaftlicher Ebenen sind neben ihren häufig nicht exakt vorhersehbaren Wirkungen die notwendigerweise mit ihnen verbundenen Auflagen und Kontrollen. Diese stehen einer umfangreichen Verwirklichung autonomer Finanzgestaltung auf der kommunalen Ebene entgegen. Dieses Argument gewinnt auch besonders dann an Gewicht, wenn eine Vielzahl von Zuweisungen gezahlt wird, so daß übergeordnete Körperschaften bei nahezu allen Aktivitäten ein Mitsprache- oder sogar Entscheidungsrecht bekommen. Jedoch ist dieser Konflikt zwischen weitgehender Dezentralisierung und dem ökonomischen Ziel der Wohlstandssteigerung dann nicht existent, wenn sich die Zweckzuweisungen wirklich auf die Internalisierung räumlicher spillovers beschränken. Unter Wohlfahrtsgesichtspunkten ist dann eine Einschränkung der kommunalen Autonomie durchaus sinnvoll, sofern die mit der Zuweisung erzielten allokativen Ergebnisse den Erfordernissen gerecht werden. Sollte dies nicht der Fall sein, ist zu prüfen, inwieweit andere Strategien eine ökonomisch effizientere Internalisierung räumlicher Externalitäten ermöglichen. ${ }^{264}$

10.2.2.2 Finanzzuweisungen zur Sicherung eines bestimmten Versorgungsniveaus sowie zur Gewährleistung von Mindeststandards

Wenn dezentrale Entscheidungseinheiten danach streben, die Wohlfahrt der örtlichen Gemeinschaft zu maximieren und ihnen mit Hilfe von Zweckzuweisungen eine Internalisierung räumlicher externer Effekte ermöglicht wird, ist unter Allokationsgesichtspunkten bei exakter Zuweisungshöhe und entsprechenden Wirkungen der (wirtschafts-)theoretische Rahmen für die Erreichung pareto-optimaler Ergebnisse vorgegeben. Doch darüber hinaus können durchaus weitere Rechtfertigungen für die Etablierung zusätzlicher Zuweisungen gegeben werden. Ein Grund kann die unzureichende Finanzausstattung einer lokalen Körperschaft sein, die eine (von der "Zentrale") als "ausreichend" definierte Versorgung ihrer Einwohner mit öffentlichen Leistungen nicht möglich macht.

Musgrave/Musgrave $(1984,512)$ stellen fest, daß der Wunsch zur Beeinflussung des örtlichen Leistungsangebots vor allem deshalb existiert, weil eine, mehrere oder alle lokalen öffentlichen Leistungen "... from a national point of view ... are considered in the nature of merit goods". Daher verbindet die übergeordnete Gebietskörperschaft mit der Gewährung einer Zuweisung das Interesse, daß sich infolge der "Bezuschussung" ein höheres Bereitstellungs- und damit Konsumtionsniveau einstellt als ohne die Ge-

$264 \mathrm{Vgl}$. in entsprechender Ausführlichkeit auch die Bemerkungen in Abschnitt 6.1.5 (Internalisierungskonzepte räumlicher Externalitäten). 
währung von Zuweisungen. ${ }^{265}$ Es stellt sich die Frage, warum der Zentralstaat (Oberverband) als Zuweisungsgeber eine Meritorisierung bestimmter lokaler öffentlicher Leistungen für notwendig erachtet. Oder anders ausgedrückt, worin könnten Rechtfertigungstatbestände für diese Vorgehensweise gesehen werden. Zuweisungen mit der Zielsetzung einer Meritorisierung bestimmter Leistungen können zum einen an Zwecke gebunden sein, deren Nutzen nicht der Wahlbevölkerung, sondern den Nichtwählern zugute kommen. "The most plausible scenario for this argument is one where the majority of the nation's adults do take school children's interests into account, but where only a minority do in some areas; in this case the median central voter may well demand action for the benefit of school children in areas whose median voters ignore them" (King, 1984, 131). In eine ähnliche Richtung gehen die Argumente von Dafflon (1977). Mindeststandards dienen - so die Begründung - dem Schutz von Minderheiten, die "... may not have a proper migration alternative" (Dafflon, 1977, 39).

King $(1984,131)$ führt als Begründung für Zuweisungen zum Zwecke der Beeinflussung des öffentlichen Leistungsangebots vor Ort ebenfalls aus, daß es sich hierbei häufig um die Präferenzen von Minderheiten handele. ${ }^{266}$ Zuweisungen sind in diesem Sinne folglich notwendig, um eine angemessene Versorgung mit den betreffenden Leistungen sicherzustellen. Zuweisungen dieser Art dürten jedoch eher problematisch sein, denn die Mehrheit der Wähler auf lokalem Niveau (die eine Finanzierung solcher Dienste in angemessenem Umfang ablehnt) ist auch die Wählerschaft auf nationalem Niveau und damit existieren ähnlich gelagerte Präferenzstrukturen. Daher stellt sich die Frage, warum sich die Präferenz für die angesprochenen Leistungen und deren Finanzierung auf zentralem Niveau eher durchsetzen sollte als auf lokalem Level; oder steckt hinter der Meritorisierung etwa doch der Wunsch nach Durchsetzung einer bestimmten außermarktlichen sowie außerdemokratischen Allokations- und/oder Distributionsentscheidung? ${ }^{267}$

Auf der anderen Seite kann aber hinsichtlich der Rechtfertigung einer solchen Meritorisierung und des beabsichtigten Minderheitenschutzes mit King (1984, 132) auch vermutet werden, da $\beta$ "... a national majority of voters are concerned with a problem

265 Vgl. auch Abschnitt 10.2.2.1, wobei dort aber die Zuweisung aus der Internalisierungsabsicht răumlicher externer Effekte und nicht aus meritorischem Interesse heraus gerechtfertigt wurde. Die Verwischung der Grenzen allokativer (Internalisierungs-) und distributiver (meritorischer) Komponenten bei der Begründung der Notwendigkeit von Zuweisungen werden mehr als deutlich.

266 Entsprechende offentliche Leistungen sind vor allem Museen, Büchereien bzw. Kunst und Kultur im allgemeinen (vgl. auch Musgrave/Musgrave, 1984, 511ff).

${ }^{267}$ Die Meritorisierungsidee begegnet auch hier ihrer schărfsten Kritik, nămlich dem Vorwurf des "weisen (wohlmeinenden) Diktators", der "seine" Präferenz als Meritorisierung der Konsumentscheidung auf Kosten der Mehrheit durchzusetzen imstande wăre. 
that does not concern a majority in every area ...". Ein (empirischer) Nachweis für eine solche Hypothese fehlt hingegen noch.

Mit dieser unterschiedlichen Sichtweise ist nur ein Teil der Problematik innerhalb dieses Themenkomplexes angesprochen. Denn Zuweisungen müssen zwar nicht auf der jeweiligen lokalen Ebene (selbst) finanziert werden, insgesamt gesehen (d.h. auf nationalem Niveau) müssen sie aber ebenso wie andere Kostenbeiträge aus Steuermitteln der Allgemeinheit aufgebracht werden. Häufig werden Zuweisungen aus politischpragmatischen Gründen dennoch vorgezogen, weil mit ihnen eine geringere Merklichkeit infolge des Fehlens einer nachvollziehbaren fiskalischen Äquivalenz verbunden ist. Damit sind sie zwar ein politisch verlockendes Finanzierungsinstrument der lokalen Ebene, aber infolge unsicherer Wirkungen sehr häufig unter ökonomischen Gesichtspunkten eher problematisch und damit effizienzmindernd. Das gilt besonders dann, wenn der Einfluß der Bürokratie im öffentlichen Entscheidungsfindungsprozeß recht bedeutend ist.

Außerdem agieren die Kommunen unter dem Regime eines funktionierenden und umfangreichen Zuweisungssystems zur Realisierung eines angemessenen Versorgungsniveaus bzw. zur Sicherstellung bestimmter Mindeststandards in der Regel demnach nur noch als lokale (unselbständige) Agenten für den zentralen Prinzipal (vgl. Abschnitt 6.3.2). Eine autonome Aufgabenerfüllung ist dann nur noch bei solchen lokalen öffentlichen Leistungen möglich, die aufgrund der lokalen Entscheidung allein schon oberhalb sogenannter Mindeststandards liegen. Dies macht deutlich, daß sich eine Begründung von Finanzzuweisungen als Finanzierungsinstrument im Rahmen der Meritorisierung des lokalen Leistungsangebots nur auf die zwingend gebotenen Sachverhalte beziehen darf, wenn keine Aushöhlung der finanziellen (kommunalen) Autonomie erfolgen soll. In der Regel wird aber diese Möglichkeit von der "Zentrale" eher über das Mindestmaß hinaus ausgeschöpft werden, um damit eine (politische) Kontrolle über die lokale(n) Entscheidungsinstanz(en) zu erhalten bzw. zu gewinnen.

Zweiter Problembereich der auf die Erreichung von Mindeststandards ausgerichteten Zuweisungsbegründungen ist die häufig enge Verflechtung meritorischer und distributiver Elemente. So hängen Zuweisungen zum Zwecke der Garantie bestimmter Versorgungsniveaus in der Regel von der finanziellen Ausstattung und damit der Steuerkraft vor Ort ab und sind damit im Grunde genommen nichts anderes als Zuweisungen mit dem Ziel, fiskalische Ungleichgewichte zu korrigieren und damit eine Anpassung von Finanzkraft und Finanzbedarf zu gewährleisten. Da sich aber solche Verteilungsaspekte sehr viel schwieriger durchsetzen lassen, wird häufig mit dem Argument der Gewährleistung von Mindeststandards bzw. eines angemessenen Versorgungsniveaus allokationspolitisch argumentiert. 


\subsubsection{Fiskalische Ungleichgewichte}

Dritte wesentliche Zielsetzung von Zuweisungen ist also ihr Einsatz zur Kompensation fiskalischer Ungleichgewichte. Solche Ungleichgewichte ergeben sich zum einen, wenn zwischen dem Ausgabenbedarf und seiner Entwicklung und der Entwicklung der Einnahmemöglichkeiten eine Abweichung zwischen den einzelnen gebietskörperschaftlichen Ebenen resultiert (vertikale fiskalische Ungleichgewichte). Zweite Möglichkeit für das Auftreten sogenannter fiskalischer Ungleichgewichte sind speziell auf der lokalen Ebene zu beobachtende und aus Gleichheitsgründen nicht erwünschte tiefgreifende Abweichungen zwischen der Finanzausstattung der jeweiligen Gemeinde und einem normierten Finanzbedarf, der im Sinne einer "Einheitlichkeit der Lebensverhältnisse" als angemessen angesehen wird (horizontale fiskalische Ungleichgewichte). ${ }^{268}$

\subsection{Vertikale fiskalische Ungleichgewichte}

Ein Blick auf die Entwicklung der Einnahmenstrukturen der einzelnen gebietskörperschaftlichen Ebenen in den wichtigsten westlichen Volkswirtschaften verdeutlicht, daß sich vertikale fiskalische Ungleichgewichte in nicht unerheblichem Maße einstellen. Diese sind letztlich Resultat einer unterschiedlichen Zuteilung von Finanzquellen und ihrer Entwicklung sowie einer davon unabhängigen Entwicklung der Ausgaben. Darum ist es möglich, daß sich zwischen den einzelnen Ebenen eines föderativ gegliederten Staatswesens fiskalische Ungleichgewichte ergeben. ${ }^{269}$

Der Zentralstaat als oberste gebietskörperschaftliche Ebene hat jetzt mehrere Möglichkeiten, auf eine solche Situation zu reagieren. Zunächst könnte er die nachgeordneten Ebenen unterstützen bzw. bevollmächtigen, beispielsweise mehr und höhere Gebühren oder andere Einnahmekategorien zur Ausdehnung der eigenen Einnahmen zu erheben. Eine weitere Möglichkeit wäre die Zuweisung neuer Steuern für die kommunale, die regionale oder die Länderebene. Soweit den nachgeordneten Körperschaften solche Steuerquellen nach dem Trennsystem zugestanden worden sind oder zugestanden werden, erzielen sie folglich entsprechende Steuer(mehr-)einnahmen nach dem Prinzip des

\footnotetext{
268 Mit dieser Problematik setzen sich am Beispiel der Bundesrepublik Deutschland Kuhn und Hanusch (1990) auseinander.

269 An solchen fiskalischen Ungleichgewichten entzünden sich bei Steuergesetzgebungsverfahren mit Auswirkungen auf die gemeinsamen Steuern der gebietskörperschaftlichen Ebenen (Gemeinschaftsteuern) immer wieder die Diskussionen. Letztes Beispiel in einer langen Kette solcher Auseinandersetzungen zwischen Bund, Ländern und Gemeinden in der Bundesrepublik Deutschland war das Vermittlungsverfahren zum Steueränderungsgesetz 1992 (BGB1. I, S. 297) im Februar 1992.
} 
örtlichen Aufkommens. Drittens wäre eine höhere Beteiligung am gesamten staatlichen Steueraufkommen zu nennen; also beispielsweise höhere kommunale Anteile an den Gemeinschaftsteuern. Vierte Möglichkeit wäre die Gewährung von Zuweisungen zur Anhebung der kommunalen oder regionalen Finanzausstattung (vgl. King, 1984, 138).

Häufig wird in föderal gegliederten Staatswesen die letzte Möglichkeit bevorzugt, zumal sie dem Zentralstaat gewisse Einflußmöglichkeiten auf die kommunale Ebene ermöglicht. Wird mittels Zuweisungen ein Ausgleich finanzieller Ungleichgewichte angestrebt, geschieht dies in der Regel mit allgemeinen Zuweisungen, da schließlich keine spezielle Förderung bestimmter Güter und Leistungen vorgesehen ist. Vielmehr geht es ausschließlich darum, eine Angleichung der Aufteilung von Finanzquellen und Einnahmekompetenzen im föderalen Staat an die durch die administrative Organisation gebundene Aufgaben- und Ausgabenentwicklung zu sichern.

Je dezentraler jedoch Einnahmekompetenzen verteilt sind und je größer die Finanzierungsspielräume auf einer autonomen lokalen Ebene, je weniger notwendig sind solche mit unsicheren Wirkungen sowie Einflußmöglichkeiten der "Zentrale" verbundenen Zuweisungen. Sind alle gebietskörperschaftlichen Ebenen mit ausreichenden Autonomierechten auf der Einnahmeseite ausgestattet, entfällt die Notwendigkeit zur Beseitigung vertikaler fiskalischer Ungleichgewichte weitgehend, da jede Ebene flexibel auf unterschiedliche Anpassungserfordernisse reagieren kann.

\subsection{Horizontale fiskalische Ungleichgewichte}

Zweiter Bereich möglicher Begründungen für Zuweisungen im Rahmen von gesamtstaatlichen Verteilungszielsetzungen ist die Beseitigung bzw. Vermeidung horizontaler fiskalischer Ungleichgewichte. Zur Zielerreichung innerhalb dieses Aufgabenfeldes werden ebenfalls vorwiegend allgemeine Zuweisungen eingesetzt, um die innerhalb der lokalen Ebene möglicherweise recht ungleichen Entwicklungen zwischen Finanzbedarf und Finanzausstattung (Finanzkraft) zu korrigieren. Hintergrund dieser Begründung ist die Zielsetzung einer "Einheitlichkeit der Lebensverhältnisse" und die Vermeidung fiskalisch motivierter Wanderungen, was häufig dazu führt, auch diese Zuweisungen wieder allokativ zu rechtfertigen. Der Oberverband versucht also mittels Zuweisungen fiskalische Ungleichgewichte zu vermeiden und damit über diesen Ausgleich dafür zu sorgen, daß fiskalische Faktoren für die Standort- bzw. Wohnsitzwahl nicht wirksam werden, also neutral sind.

Wie diese Zuweisungen sinnvollerweise ausgestaltet werden müßten, läßt sich nicht generell sagen. Entscheidend ist, auf welchem Weg der Oberverband das Ziel - die 
Vermeidung sogenannter "fiscal residua" (Peffekoven, 1988, 624) - erreichen will. Ein Ausgleich kann über die Beeinflussung der Finanzkraft (mit allgemeinen Zuweisungen) oder die Steuerung des Niveaus der öffentlichen Leistungen (mit Zweckzuweisungen) angestrebt werden.

Die Verwirklichung einer fiskalischen Gleichheit ("fiscal equity") innerhalb eines föderativen Staatswesens gilt also als eine Aufgabe, die durch den Einsatz von Finanzzuweisungen realisiert werden soll. ${ }^{270}$ Was jedoch unter dem Begriff der fiskalischen Gleichheit zu verstehen ist, wird unterschiedlich definiert. Einmal kann der Terminus auf einzelne Wirtschaftssubjekte, zum anderen auf Körperschaften der gleichen Ebene bezogen werden. Einen ersten Ansatz hat Buchanan (1950) vorgetragen. Er geht von dem Grundsatz gerechter Besteuerung aus, wonach Wirtschaftssubjekte, die sich in gleichen wirtschaftlichen Verhältnissen befinden, steuerlich gleich zu behandeln sind. Dieses Prinzip wird auf die Ausgabentätigkeit des Staates ausgeweitet. "Fiscal equity" ist für Buchanan dann erreicht, wenn für alle Wirtschaftssubjekte in gleicher ökonomischer Lage - also bei gleich hohem Einkommen - in den nachgeordneten Gebietskörperschaften (beispielsweise Gemeinden) eines Staates der gleiche fiskalische Restwert 271 ("fiscal residuum") gilt (vgl. Buchanan, 1950, 588).

Sind die fiskalischen Restwerte für Wirtschaftssubjekte in gleichen wirtschaftlichen Verhältnissen von Region zu Region oder von Kommune zu Kommune unterschiedlich, dann wird dies - so Buchanan (1950, 588f) - zu allokationspolitisch unerwünschten Wanderungen der Produktionsfaktoren führen. Die Wirtschaftssubjekte werden ceteris paribus allein aus fiskalischen Überlegungen in die Gebietskörperschaften mit niedrigen "fiscal residua" wandern, wodurch die optimale Allokation der Ressourcen beeinträchtigt wird. ${ }^{272}$ Der so begründete allokationspolitisch erforderliche Ausgleich der fiskalischen Restwerte erfolgt in der Weise, daß Gemeinden mit hohen Restwerten

${ }^{270}$ Im Regelfall geschieht dies im Rahmen von Finanzausgleichssystemen, innerhalb derer Abweichungen zwischen Finanzbedarf und Finanzkraft ermittelt und mittels eines entsprechenden vertikalen Einnahmenausgleichs mit horizontaler Wirkung oder eines echten bzw. reinen horizontalen Einnahmenausgleichs mittels Zuweisungen egalisiert oder zumindest reduziert werden (vgl. auch Peffekoven, 1988, 425f).

${ }^{271}$ Dieser fiskalische Restwert ergibt sich als Differenz zwischen der von einem Wirtschaftssubjekt zu tragenden Steuerbelastung und den ihm aus den Staatsausgaben zufließenden Nutzen. Der Saldo kann positiv, negativ oder gleich Null sein (vgl. Peffekoven, 1988, 628).

272 Außerdem ergeben sich Einflüsse auf die Einkommensverteilung. Die nachgeordneten Gebietskorperschaften kőnnen somit auf die Verteilung einwirken, obgleich die Kompetenz für Distributionsmaßnahmen beim Oberverband liegen sollte. 
höhere Zahlungen erhalten als Gemeinden mit niedrigeren Restwerten. ${ }^{273}$ Im Ergebnis sollen die Restwerte ausgeglichen sein.

Ökonomisch gesehen kann es aber gerade sinnvoll sein, regional bzw. lokal unterschiedliche fiskalische Restwerte zuzulassen bzw. sie gar bewußt zu initiieren. Das würde bedeuten, daß letztlich den einzelnen Gebietskörperschaften die Entscheidung über die Höhe der Besteuerung und der Ausgaben und damit über die Residuen überlassen bleiben müßte. Interlokale Wanderungen im Tiebout'schen Sinne (vgl. Abschnitt 4.4) würden dann gerade die unter Allokationsgesichtspunkten erwünschten Ergebnisse produzieren.

Diese Sichtweise steht der Zuweisungsbegründung aus der Existenz horizontaler fiskalischer Ungleichgewichte gemäß Buchanan (1950) konträr entgegen. Der Ansatz von Buchanan ist infolgedessen in der Literatur auch ausgiebig diskutiert worden (vgl. vor allem Musgrave, 1961; Tiebout, 1961; Scott, 1964). Auf der einen Seite wird bezweifelt, ob der interregionale Ausgleich der fiskalischen Restwerte in einem föderativen Staatsgebilde überhaupt erstrebenswert sei oder ob nicht vielmehr den einzelnen Gebietskörperschaften die Entscheidung über die Höhe der Besteuerung und der Ausgaben und damit über die Residuen überlassen bleiben müsse. Daneben ist die Praktikabilität des Konzepts umstritten. Die Residuen und damit die zum Ausgleich erforderlichen Transfers können exakt nur bestimmt werden, wenn die personelle und interregionale Inzidenz der Besteuerung und der Nutzen, den die Staatsausgaben verschaffen, bekannt sind. Diese Annahme wird zwar bei nahezu allen nutzentheoretischen Ansätzen in der "Theorie des Finanzausgleichs" (beispielsweise zum Ausgleich räumlicher Externalitäten) getroffen, ihre praktische Relevanz ist jedoch umstritten. Schließlich wird auch die von Buchanan behauptete allokative Neutralität seines Konzepts bezweifelt (vgl. dazu Scott 1952b, 1964). Ein bestimmtes fiskalisches Residuum ist mit vielen Steuer-Ausgaben-Kombinationen zu vereinbaren. Auf der anderen Seite können die einzelnen Wirtschaftssubjekte Steuer-Ausgaben-Kombinationen als gleichwertig erachten, die unterschiedliche Residuen ergeben. Mit dem Ausgleich der Residuen könnten daher sogar allokativ unerwünschte Wanderungen initiiert werden, so daß Wohlfahrtsverluste entstehen, die doch eigentlich mittels Zuweisungen zum Ausgleich horizontaler fiskalischer Ungleichgewichte gerade vermieden werden sollten.

273 Die gleiche Zielsetzung kann auch mit horizontalen Ausgleichszahlungen (vgl. etwa den bundesdeutschen Lănderfinanzausgleich) angestrebt werden. Vgl. dazu vor allem Ehrlicher (1988, 684ff) sowie Peffekoven (1988, 625ff) und Seiler (1988, 518ff). Scott (1964) setzt sich mit der Problematik des Ausgleichs fiskalischer Restwerte anhand von "revenue sharing"- oder Finanzausgleichssystemen in einem allgemeinen Kontext auseinander. 


\subsection{Wirkungsweise}

\subsubsection{Zuweisungen mit allokativer Zielsetzung}

\subsubsection{Modellrahmen}

Für die Bestimmung geeigneter Zuweisungssysteme und damit die Gewährleistung einer funktionsgerechten Wirkungsweise ist es bedeutsam, die einzelnen Wirkungen der unterschiedlichen Zuweisungsarten zu analysieren. Ökonomische Modelle, die sich mit den Wirkungen von Finanzzuweisungen auseinandersetzen, werden in der Regel im Rahmen von Indifferenzkurvensystemen formuliert, wobei diese Indifferenzkurven die Präferenzen bezüglich eines lokalen öffentlichen Gutes $\mathrm{z}$ und alternativer Verwendungsmöglichkeiten der finanziellen Mittel (also etwa des Konsums eines privaten Gutes x) abbilden. Dabei gibt es einige unterschiedliche Betrachtungsweisen. Wilde (1968) spricht bei der Wahl der Indifferenzkurven von der Abbildung der Präferenzen der politischen Entscheidungsinstanz der die Zuweisung empfangenden Ebene; Romer/ Rosenthal $(1980,453)$ bilden im Indifferenzkurvensystem die Präferenz des sogenannten Medianwählers ab (vgl. Abschnitt 4.3.2) und Boadway $(1979,424)$ stellt die Präferenzen aller Wähler im Sinne von "community indifference curves" dar. Der letztgenannte Ansatz ist im Grunde genommen die Übertragung der individuellen Wahlhandlungs- oder Nutzentheorie auf den öffentlichen Bereich. "The advantage of using community indifference curves is that, by reflecting the welfare of the community as a whole, they enable some normative conclusions to be reached as well as positive ones" (King, 1984, 89).

Diese "community indifference curves" werden für das weitere Vorgehen auch hier zugrunde gelegt (vgl. auch Oates, 1972, 75f). Dabei wird unterstellt, daß eine örtliche Gemeinschaft (Gemeinde) ähnlich handelt wie ein einzelnes Individuum, d.h. bei gegebenem Einkommen (I) entscheidet die Gemeinschaft über die Verwendung zwischen zwei möglichen Alternativen, nämlich der Konsumtion des privaten Gutes $\mathbf{x}$ und der Konsumtion des lokalen öffentlichen Gutes z. Das Entscheidungsproblem der Gemeinde stellt sich somit als Maximierung einer Nutzenfunktion $U(x, z)$ unter Beachtung der Budgetrestriktion $p_{x} * x+p_{z} * z=I$ dar, die determiniert ist durch das gesamte Einkommen der Haushalte der Gemeinde. Mit diesem Instrumentarium sollen nunmehr die unterschiedlichen Wirkungen der einzelnen Zuweisungsarten analysiert werden. Dabei wird das private Gut als "Numéraire" verwendet, der Preis dieses Gutes $x$ ist $p_{x}=1$, so daß die jeweilige Zuweisungshöhe in Einheiten dieses Numéraire-Gutes gemessen werden kann. 


\subsubsection{Wirkungsanalyse}

\subsubsection{1 "Klassische" Ansätze}

Eine (allokative) Zielsetzung bei der Gewährung von Zuweisungen an nachgeordnete Gebietskörperschaften ist die Beeinflussung des Angebotsverhaltens bezüglich bestimmter öffentlicher Leistungen. Ist trotz eigenständiger ebenenspezifischer Besteuerung keine fiskalische Äquivalenz gegeben bzw. realisierbar - weil beispielsweise räumliche spillovers vorliegen - bieten die nachgeordneten Körperschaften die öffentliche Leistung in der Regel in sub-optimalem Umfang an (vgl. Abschnitt 6.1.4). In einem solchen Fall werden dann beispielsweise "lump-sum specific grants" eingesetzt, um seitens der übergeordneten Körperschaft das Angebot der entsprechenden öffentlichen Leistung zu beeinflussen bzw. die nachgeordnete Ebene zu veranlassen, die entsprechende Aufgabe in gewünschtem und damit effizientem Ausmaß zu erfüllen (vgl. dazu Abschnitt 10.2.2). Die Wirkung einer solchen Zweckzuweisung kann in Abbildung 10.1 verdeutlicht werden.

Abbildung 10.1: Die Wirkung einer Zweckzuweisung sowie einer allgemeinen Zuweisung im Vergleich - Fall 1

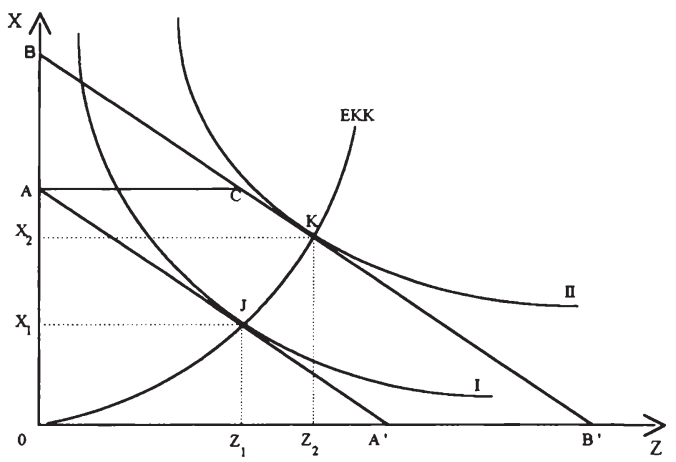

Die Ordinate mißt in Mengeneinheiten das für Konsumtionszwecke verfügbare private Gut $\mathbf{x}^{274}$, die Abzisse in Mengeneinheiten das lokale öffentliche Gut z. AA'

274 In einigen Analysen wird statt einer alternativen Konsumtionsmöglichkeit (hier des privaten Gutes $\mathrm{x}$ ) eine Vielzahl bzw. ein Bündel weiterer Alternativen der entsprechenden öffentlichen Gütermenge z gegenüber gestellt. Dabei können die alternativen Verwendungsmöglichkeiten neben privaten Zwecken auch andere öffentliche Leistungen, deren Bereitstellungsniveau nicht durch Zuweisungen beeinflußt werden soll, umfassen (vgl. etwa King, 1984, 86ff; Musgrave/Musgrave, 1984, 538ff). Aus Vereinfachungsgründen wird hier von einer "Zwei-Güter-Welt" ausgegangen, zumal sich die gewonnenen Ergebnisse dadurch nicht verändern (vgl. etwa auch Fisher, 1987, 366). 
repräsentiert die Budgetgerade - die die Gesamtheit der Einkommen aller Einwohner (also der lokalen Gemeinschaft) abzüglich der an andere gebietskörperschaftlichen Ebenen gezahlten Steuern (also etwa Bundes- und/oder Landessteuern) und zuzüglich der von diesen möglicherweise erhaltenen Zuweisungen abbildet - und damit die unter gegebenem Einkommen ${ }^{275}$ für den Konsum realisierbaren Mengenkombinationen des privaten sowie des lokalen öffentlichen Gutes. Wir nehmen zunächst an, daß diese Budgetgerade ohne Zuweisungsströme in der Form AA' verläuft; die Steigung ist wegen der Annahme eines exogen vorgegebenen "Steuerpreises" des lokalen öffentlichen Gutes $\mathrm{z}$ durch das jeweilige Preisverhältnis $\left(\mathrm{p}_{z} / \mathrm{p}_{\mathrm{x}}\right)$ determiniert. Entsprechend der durch die Nutzenfunktion ausgedrückten Präferenzen wird sich unter diesen Rahmenbedingungen ein Gleichgewicht $\mathrm{J}$ einstellen, wobei das lokale öffentliche Gut in Höhe von $0 \mathrm{z}_{1}$ und das private Gut in der Größenordnung $0 \mathrm{x}_{1}$ (aufgrund des gegebenen Einkommens bei den jeweiligen Preisen $p_{z}$ und $p_{x}$ ) für Konsumzwecke vorhanden sind.

Wenn jetzt eine Zweckzuweisung in Form einer "lump-sum grant" in Höhe von AB Einheiten des privaten Gutes eingeführt wird, die es erlaubt, bei gleichem Steuerpreis und damit identischem Preisverhältnis $\mathrm{A}^{\prime} \mathrm{B}^{\prime}$ bzw. AC Einheiten des Gutes z zu finanzieren, ergibt sich eine neue Budgetbeschränkung in Form von ACB'276. Aufgrund der gegebenen Präferenzen ergibt sich letztlich ein "Konsumtionspunkt" $\mathrm{K}$ mit $0 \mathrm{z}_{2}$ Einheiten des lokalen öffentlichen Gutes und $0 \mathrm{x}_{2}$ Einheiten für andere Konsumzwecke (hier des privaten Gutes $\mathbf{x}$ ). Die angestrebte Zielsetzung, eine Ausdehnung der Konsummenge und damit des Versorgungsgrades des lokalen öffentlichen Gutes $z$, ist somit realisiert worden; gleichzeitig sind aber auch Ausgabenspielräume für den Konsum des privaten Gutes geschaffen worden. Unter Beibehaltung der Ausgabeprioritäten (wegen des unveränderten Preisverhältnisses) ergibt sich also das Ergebnis in Abhängigkeit der Elastizitäten der Nachfrage nach dem lokalen öffentlichen Gut z bzw. dem privaten Gut x. Solange z ein normales (superiores) Gut - bezogen auf die Einkommenselastizität der Nachfrage - darstellt, werden "lump-sum grants" einen stimulierenden Effekt auf die Konsumtionsmenge dieses Gutes ausüben und damit wird die sogenannte Einkommens-Konsum-Kurve der Gemeinde(-Einwohner) eine positive Steigung aufweisen.

${ }^{275}$ Das Einkommen ist also sozusagen die gesamte Kaufkraft einer Kommune, sprich die für die Konsumzwecke (hier hinsichtlich des privaten Gutes $x$ und des lokalen offentlichen Gutes $\mathrm{z}$ ) vorhandenen finanziellen Mittel.

${ }^{276}$ Die Budgetbeschränkung wird nicht automatisch durch die Gerade BCB' abgebildet, weil bei weniger als AC Konsumeinheiten des lokalen offentlichen Gutes die Gemeinde nicht in den Genuß des vollen Zuweisungsbetrages kommen wird; wenn keine zusătzlichen Einheiten von z "gekauft" werden, wird demnach keine Zweckzuweisung gezahlt und ergibt sich daher bei $z=0$ für den Konsum des privaten Gutes $x$ eher Punkt A als Punkt B. 
In Zusammenhang mit Wirkungsanalysen von Finanzzuweisungen wird häufig argumentiert, daß allgemeine und zweckgebundene Zuweisungen (sofern sie als "lump-sum grants" ausgestaltet sind) identische Ergebnisse aufweisen können. Das liege daran, so die Argumentation, daß diese Zuweisungsform (lump-sum grants) keine Substitutionseffekte aufweist (also das Preisverhältnis und damit die Ausgabeprioritäten unverändert läßt) und somit unter den entsprechenden Rahmenbedingungen zu einem identischen Konsumtionspunkt (hier K) führt. Dies wird durch die Abbildung 10.1 zunächst auch belegt. Einziger Unterschied ist der abweichende Verlauf der Budgetgerade, die bei Zweckzuweisungen ACB' entspricht, während eine allgemeine Zuweisung (an keinerlei Auflagen gebunden) auch im Falle einer Nichtveränderung des Konsumniveaus von Gut $\mathrm{z}$ gewährt wird (Budgetgerade $\mathrm{BCB}$ ).

Es kann jedoch nachgewiesen werden, daß allgemeine und zweckgebundene Zuweisungen bei gleicher Ausgestaltung (als lump-sum grant) nicht in jedem Fall einheitliche Wirkungen aufweisen. Dies soll in Abbildung 10.2 veranschaulicht werden. Ausgehend von Konsumtionspunkt $\mathrm{J}$ und der gegebenen Budgetbeschränkung $\mathrm{AA}^{\prime}$ werden nunmehr wieder "lump-sum grants" (in Höhe von $\mathrm{AB}$ ) als allgemeine bzw. als zweckgebundene Zuweisungen eingeführt. Es ergeben sich als Budgetlinien für den Fall der "lump-sum general grant" BCB' und für den Fall der "lump-sum specific grant" ACB'. Es können - wie unschwer zu erkennen ist - in dieser Konstellation unterschiedliche Konsumtionspunkte resultieren, nämlich $\mathrm{K}$ bei der allgemeinen Zuweisung und $\mathrm{C}$ bei der Zweckzuweisung. Aus Sicht der empfangenden Gemeinde wird die allgemeine Zuweisung folglich vorgezogen, da sie aufgrund der dominierenden Präferenzen für alternative Verwendungen (hier den Konsum des privaten Gutes $\mathbf{x}$ ) anstelle des Konsum des lokalen öffentlichen Gutes $z$ ein höheres Nutzen(Wohlfahrts-)niveau ermöglicht. ${ }^{277}$ Die Zuweisungen "zahlende" Körperschaft hingegen verfolgt bekanntermaßen die Zielsetzung, das Konsumtionsniveau von $\mathrm{z}$ anzuheben. Daher wird hinsichtlich der Zielfestlegung der übergeordneten Gebietskörperschaft (Steigerung des Konsums des lokalen öffentlichen Gutes) die zweckgebundene Form der lump-sum-Zuweisung vorgezogen, weil mit dieser ein höheres Konsumtionsniveau von Gut $\mathrm{z}$ auch tatsächlich realisiert werden kann. Unter Wohlfahrtsgesichtspunkten ist damit aber ein niedrigeres Nutzenniveau des lokalen Gemeinwesens verbunden, was letztlich zur angedeuteten Interessendisharmonie führt.

${ }^{277}$ Diese Nutzenposition für die Gemeinde als solche (bzw. für die Gesamtheit ihrer Einwohner und damit das "Kollektiv") ist aber lediglich ein lokales Wohlfahrtsmaximum. Gesamtwirtschaftlich kann infolge vorhandener răumlicher spillovers oder economies of scale eine andere Güterkombination effizienter und damit für die Gesamtwohlfahrt der Volkswirtschaft vorzuziehen sein. 
Abbildung 10.2: Die Wirkung einer Zweckzuweisung und einer allgemeinen Zuweisung im Vergleich - Fall 2

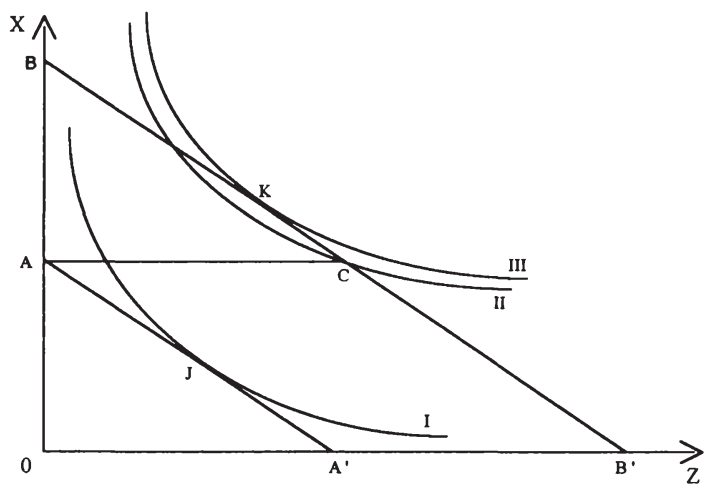

Hinsichtlich der angestrebten Wirkungen (Steigerung des Versorgungsgrades des lokalen öffentlichen Gutes z) ist eine alternative Ausgestaltungsform der Zweckzuweisung noch geeigneter. Hierbei handelt es sich um die sogenannten "matching grants", also die an eine Eigenbeteiligung geknüpften und für einen bestimmten Verwendungszweck gewährten Zuweisungen. Deren Wirkungen werden anhand der Abbildung 10.3 analysiert.

Ausgangspunkt der Wirkungsanalyse einer solchen zweckgebundenen Zuweisung mit Eigenbeteiligung sei wieder die Budgetgerade $\mathrm{AA}^{\prime}$ und der als Tangentialpunkt mit der höchsten erreichbaren Indifferenzkurve mögliche nutzenmaximale Konsumtionspunkt J. Die Einführung der angesprochenen "matching grant", d.h. die Kostenbeteiligung bei der Bereitstellung des lokalen öffentlichen Gutes $\mathrm{z}$ durch die übergeordnete Gebietskörperschaft (z.B. in Höhe von $A^{\prime} B / 0 B$ ) führt zu einer entsprechenden Veränderung der Preisrelationen und damit zu einer Drehung der Budgetgerade, deren Verlauf jetzt durch $\mathrm{AB}$ dargestellt wird. Der nutzenmaximale Konsumtionspunkt des betrachteten Gemeinwesens liegt nunmehr bei $\mathrm{K}$. Erhöht sich die Kostenbeteiligung in Form der Zweckzuweisung beispielsweise auf $\mathrm{A}^{\prime} \mathrm{C} / 0 \mathrm{C}$ resultiert die neue Budgetgerade $\mathrm{AC}$; das Gleichgewicht repräsentiert jetzt der Konsumtionspunkt L. Die Punkte A, J, K und L skizzieren den Verlauf der sogenannten "Preis-Konsum-Kurve" (PKK); einer Art "Nachfragekurve" des die Finanzzuweisung empfangenden Gemeinwesens in Abhängigkeit von "Preisänderungen" des Gutes $\mathrm{z}$ (hier dokumentiert durch die unterschiedlichen Finanzierungsbeteiligungen an den Bereitstellungskosten). Ist also das bereitzustellende lokale öffentliche Gut $\mathrm{z}$ kein Giffen-Gut, führt jede Ausdehnung der Zweckzuweisung zu einem höheren Konsumtionsniveau dieses Gutes. Somit führt eine 
zweckgebundene Zuweisung mit Eigenbeteiligung zu einem höheren Konsumtionsniveau des Gutes $z$ und - zumindest zunächst (die konkrete Wirkung hängt vom jeweiligen Verlauf der Preis-Konsum-Kurve ab) - gleichzeitiger Reduktion der Ausgabemöglichkeiten für andere Verwendungen.

Abbildung 10.3: Die Wirkung einer Zweckzuweisung mit Eigenbeteiligung der empfangenden Körperschaft

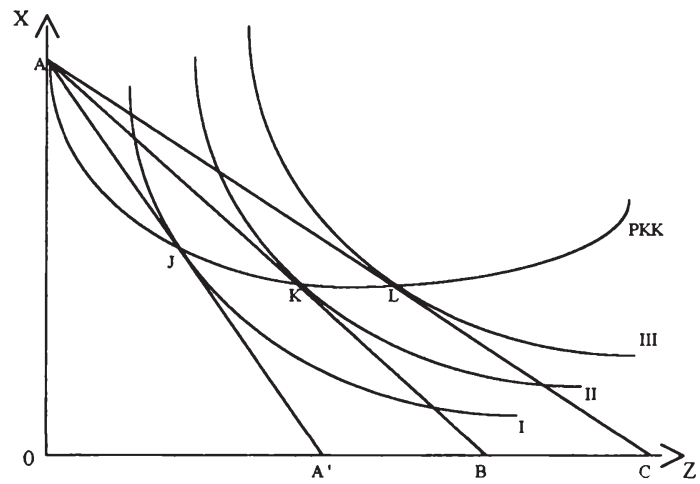

In Abbildung 10.4 werden schließlich noch einmal die beiden Formen einer zweckgebundenen Zuweisung und eine allgemeine Zuweisung bezüglich ihrer Wirkungen verglichen. Eine mit Eigenbeteiligung verbundene Zweckzuweisung (in Höhe von $\left.A^{\prime} D / 0 D\right)$ führt zur Veränderung der Komsumtionsentscheidung durch das empfangende Gemeinwesen vom Ausgangspunkt J hin zu Punkt K. Realisiert wird das Nutzenniveau $\mathrm{I}_{\mathrm{II}}$. Die Gemeinde finanziert dabei mit ihrer eigenen Finanzkraft (Gesamteinkommen) ein Güterbündel $K^{\prime}$ und deckt darüber hinaus die Kosten für K'K (oder auch $A^{\prime} B^{\prime}$ ) Einheiten des Gutes $\mathrm{z}$ durch die erhaltene Zuweisung. Auf der anderen Seite führt eine allgemeine Zuweisung ("lump-sum general grant") zur Budgetgerade BCB', da die "Preisrelationen" und damit die "Ausgabeprioritäten" unverändert bleiben. Eine solche allgemeine Zuweisung wird unter Nutzengesichtspunkten von der empfangenden Körperschaft präferiert, weil sie jetzt einen Konsumtionspunkt $L$ realisieren kann, der mit einem Nutzenniveau $\mathrm{I}_{\mathrm{III}}$ verbunden ist. Eine Zweckzuweisung ohne Eigenbeteiligung ("lump-sum specific grant") führt bei entsprechender Ausgestaltung zum gleichen Resultat, nämlich dem Konsumtionspunkt L, nur die Budgetgerade hat im Vergleich zur allgemeinen Zuweisung mit ACB' den bereits weiter oben angesprochenen geänderten Verlauf. 
Abbildung 10.4: Zuweisungsarten im Vergleich

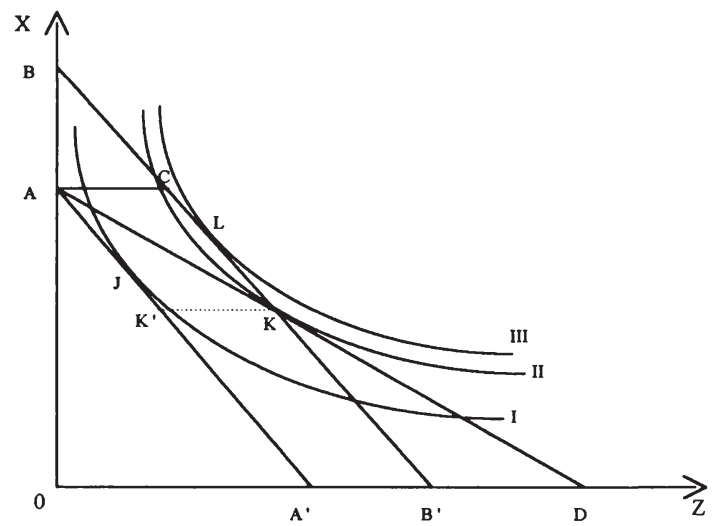

Während also unter Nutzengesichtspunkten die Gemeinde selbst eine allgemeine $\mathrm{Zu}$ weisung einer Zweckzuweisung und im Rahmen von Zweckzuweisungen die ohne Eigenbeteiligung und ohne Auflagen der mit Eigenbeteiligung und entsprechenden Konditionen vorzieht (weil sich auf diese Weise aus der Zuweisung die gesamten Ausgaben infolge der unveränderten Preisrelationen bei dann konstanten "Ausgabeprioritäten" ausdehnen lassen), ist die übergeordnete Körperschaft unter der Zielsetzung einer Beeinflussung des Bereitstellungs- und damit des Konsumtionsniveaus eines bestimmten lokalen öffentlichen Gutes unter gesamtgesellschaftlichen Gesichtspunkten und damit im Rahmen der Wohlfahrtssteigerung der Volkswirtschaft daran interessiert, eine möglichst eingeschränkte Verwendungsfreiheit der Zuweisungsmittel zu erlauben. Sie wird daher - um eben beispielsweise räumliche spillovers zu internalisieren - die "matching grant" wegen ihres höheren Zielrealisierungsgrades (die Konsumtionsmenge von $\mathrm{z}$ ist bei $\mathrm{K}$ größer als bei $\mathrm{L}$ ) den anderen Zuweisungsarten vorziehen.

Abschließend sollen schließlich die Unterschiede einer begrenzten bzw. einer unbegrenzten Zuweisungshöhe diskutiert werden. Dahinter steckt folgendes Argumentationsmuster. Eine unbegrenzte Zuweisung wird in der Regel dann als angebracht angesehen, wenn bei der beabsichtigten Zielsetzung (Internalisierung räumlicher spillovers) davon ausgegangen wird, daß die spillover-Effekte mit wachsendem Ausgabenvolumen ebenfalls (absolut) steigen. Obwohl dieser Fall sicherlich realistisch ist, werden $\mathrm{Zu}$ weisungen im allgemeinen nicht unbegrenzt gewährt, weil sich gegen diese Handhabung Widerstände bei den zahlenden Körperschaften ergeben, denen die tatsächliche Belastung nicht von vornherein bekannt ist. 
Daher werden Zuweisungen häufig als begrenzte Zuweisungen ("fixed-sum grants") gewährt. Deren Wirkungen sollen im Vergleich zu unbegrenzten Zuweisungen in Abbildung 10.5 demonstriert werden. Ausgangssituation ist die Budgetgerade $\mathrm{AA}^{\prime}$ und das nutzenmaximale Konsumtionsniveau K. Dabei wird auf die Darstellung der Indifferenzkurven verzichtet, um den Blick für das wesentliche zu erleichtern. Es wird angenommen, daß eine Zweckzuweisung (mit Eigenbeteiligung) gewährt wird ( $\mathrm{A}^{\prime} \mathrm{F} / \mathrm{OF}$ )

Abbildung 10.5: Begrenzte und unbegrenzte Zweckzuweisungen mit Eigenbeteiligung - Fall 1 und 2

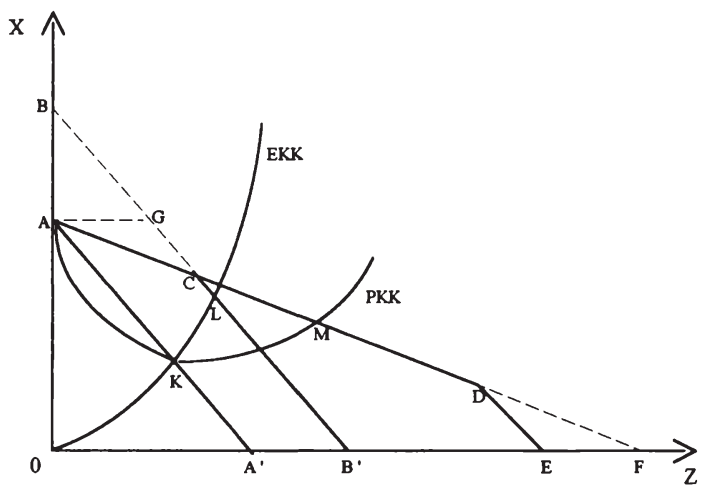

Drei mögliche Ergebnisse sind denkbar. Zwei davon werden zunächst in Abbildung 10.5 vorgestellt. Gibt es bezüglich der gewährten Zuweisung keinen finanziellen Höchstbetrag, resultiert folglich die Budgetgerade AF. Dies bedeutet, daß bei ausschließlicher Bereitstellung und Konsumtion des lokalen öffentlichen Gutes z sich die übergeordnete Gebietskörperschaft in Höhe von $\mathrm{A}^{\prime} \mathrm{F}$ an den Gesamtkosten beteiligt. Gibt es hingegen einen Höchstbetrag für die Zweckzuweisung - beispielsweise in Höhe der Kosten vom A'B' Einheiten des Gutes z, weist die Budgetgerade einen Knick auf und verläuft in der Form ACB'. Im Ergebnis führt dies - wiederum bei ausschließlicher Verwendung des Einkommens zur Konsumtion des Gutes z - zur Erlangung zusätzlicher Einheiten dieses Gutes in Höhe von A'B'. Beträgt die Höchstsumme für die $\mathrm{Zu}$ weisung $A^{\prime} E$ Einheiten des Gutes z, resultiert wieder eine geknickte Budgetgerade, diesmal in der Form ACDE.

Die Wirkungen eines finanziell begrenzten Zuweisungsvolumens hängen von der jeweiligen Form der Budgetbeschränkung und den Verläufen der Preis-Konsum-Kurve (PKK) und der Einkommens-Konsum-Kurve (EKK) ab. Liegt der entsprechende Knick der Budgetgeraden oberhalb der Preis-Konsum- sowie der Einkommens-Konsum- 
Kurve (also im Punkt C) resultiert das optimale Konsumtionsniveau im Schnittpunkt der Budgetgerade ACB' und der Einkommens-Konsum-Kurve als Güterbündel L. Dies liegt daran, daß der relevante Teil der Budgetgerade (CB') parallel zu $\mathrm{AA}^{\prime}$ verläuft (quasi Einkommensausweitung) und somit ein Tangentialpunkt im Schnittpunkt mit der Einkommens-Konsum-Kurve resultiert. In diesem Fall ist die begrenzte Zweckzuweisung in ihren Wirkungen identisch sowohl zur allgemeinen Zuweisung (die mit einer Budgetbeschränkung in der Form BGCB' verbunden wäre) als auch zur Zweckzuweisung ohne Eigenbeteiligung der empfangenden Kommune (Budgetlinie AGCB'). In allen drei Fällen resultiert als nutzenmaximaler Konsumtionspunkt die Güterkombination L. Sowohl die übergeordnete Gebietskörperschaft als Zahler als auch das nachgeordnete Gemeinwesen als Empfänger sind folglich bezüglich der drei alternativen Zuweisungsformen unter Zielrealisierungsaspekten (übergeordnete Körperschaft) bzw. lokalen Nutzengesichtspunkten (Kommune) indifferent.

Als zweite Möglichkeit wird eine begrenzte Zuweisung mit Eigenbeteiligung angenommen; der Knick der Budgetgerade liegt also im Punkt D, also unterhalb der Einkommens-Konsum- und der Preis-Konsum-Kurve. Die zugrunde liegende Budgetbeschränkung ist ACDE. Ein Nutzenmaximum stellt sich jetzt dort ein, wo die Budgetgerade die Preis-Konsum-Kurve schneidet. Verantwortlich dafür ist der Verlauf des relevanten Teils der Budgetgerade, die im gleichen Punkt die Ordinate schneidet wie die Ausgangsgerade AA' (quasi verändertes Preisverhältnis) und daher als möglicher Tangentialpunkt der Punkt M im Schnittpunkt zwischen Preis-Konsum-Kurve und Budgetgerade resultiert. Mit Rückgriff auf die weiter oben diskutierten Ergebnisse läßt sich feststellen, daß eine solche begrenzte Zweckzuweisung das gleiche Resultat liefert wie eine unbegrenzte "matching grant". Wieder sind - jetzt bezüglich dieser beiden Alternativen - Empfänger und Zahler der Zweckzuweisung unter Nutzen- bzw. Zielrealisierungsgesichtspunkten indifferent.

Eine dritte Möglichkeit soll in Abbildung 10.6 demonstriert werden. Der Knick der Budgetgerade AEB' liegt jetzt im Punkt E und damit zwischen Einkommens-Konsumund Preis-Konsum-Kurve. In diesem Fall ist keine Tangentiallösung denkbar, vielmehr wird es zu einer Ecklösung kommen; d.h. der Punkt E ist der unter Nutzengesichtspunkten optimale Konsumtionspunkt bei einer begrenzten Zweckzuweisung mit Eigenbeteiligung. Daraus folgt, daß eine Zuweisung geleistet wird, die den Kosten von A'B' Einheiten des Gutes z entspricht. Der Empfänger der Zuweisung würde in dieser Situation eine allgemeine Zuweisung oder eine Zweckzuweisung vom "lump-sumTyp" gleicher Größenordnung vorziehen, weil im Punkt L ein höheres Nutzenniveau erreichbar wird (Tangentialpunkt im Schnittpunkt zwischen den Budgetgeraden BCB' bzw. ACB' und der Einkommens-Konsum-Kurve). Der Zuweisungsgeber dagegen präferiert eine unbegrenzte Zweckzuweisung mit einer Eigenbeteiligung des Empfängers 
("matching grant"), weil dadurch ein höheres Konsumniveau von Gut $z$ und damit ein höherer Zielrealisierungsgrad (gemessen am Versorgungsniveau des Gutes z) möglich wird. Dies wird in Abbildung 10.6 deutlich, denn der Punkt M als Schnittpunkt zwischen der Budgetgerade AMD und der Preis-Konsum-Kurve repräsentiert ein höheres Konsumtionsniveau des Gutes $\mathrm{z}$ als der Punkt $\mathrm{E}$ bei der begrenzten $\mathrm{Zweckzuweisung}$.

Abbildung 10.6: Begrenzte und unbegrenzte Zweckzuweisungen mit Eigenbeteiligung - Fall 3

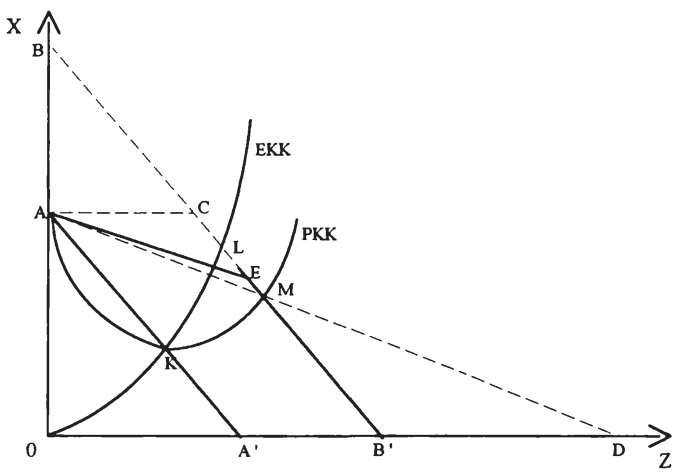

Deutlich wurde aus den entsprechenden Wirkungsanalysen (vgl. auch Scott, 1952a, 381ff; King, 1984, 86ff bzw. den spieltheoretischen Ansatz von Barrow, 1986, 155ff), daß für den jeweiligen Einsatz der Zuweisungen im Rahmen der eingangs angesprochenen Funktionen und Zielsetzungen die abweichenden Resultate von großer Bedeutung sind, denn für die Gewährung einer Zuweisung ist die gewählte Form hinsichtlich einer Realisierung angestrebter Ziele sehr bedeutsam.

In bezug auf die empirische Relevanz der vorgestellten Wirkungsmuster sind zwei Anmerkungen von Bedeutung. Einerseits hat eine Reihe von Arbeiten die "klassischen" Wirkungsanalysen und ihre Ergebnisse durchaus empirisch bestätigt (vgl. etwa Gramlich, 1968; 1977; Sacks/Harris, 1964; Bishop, 1964; O'Brien, 1971), andererseits sind diese Grundmodelle in bezug auf spezielle Auswirkungen weiterentwickelt und verfeinert worden. ${ }^{278}$

278 Speziell zur Frage der Zielerreichung hat es umfangreiche Erklärungsversuche gegeben, ob sich in bezug auf das angestrebte Ziel der Ausgabensteigerung für einen bestimmten Zweck letztlich tatsăchlich ein (Ausgaben-)Anreizeffekt (höhere Bereitstellung) oder ein (Einnahmen-)Substitutionseffekt (Senkung der anderen eigenen Einnahmen) durchsetzt, denn der letztgenannte Effekt steht natürlich in krassem Widerspruch zum angestrebten Ziel der Zuweisung. Wenn solche Wirkungen - (Einnahmen-)Substitutionseffekte - die Regel wären, würde das Instrument der Zuweisungen für bestimmten ökonomische Zwecke folglich 
Von Bedeutung ist in diesem Zusammenhang vor allem die Finanzierungsfrage. Die Übertragung der vorstehenden Ergebnisse führt unter der Annahme einer "eigenen" Finanzierung (Mitfinanzierung) allgemeiner Zuweisungen durch die Einwohner der empfangenden Gemeinde in Form von Steuerzahlungen an den Zentralstaat als zuweisungsgebende Körperschaft zu der Folgerung, daß sich die einzelnen Effekte der entsprechenden Maßnahmen (unter den getroffenen Annahmen wohlgemerkt) aufheben (können). ${ }^{279}$

Diese theoretisch zunächst einleuchtende Schlußfolgerung hat Gramlich (1977) unter etwas anderer Aufgabenstellung für die USA empirisch überprüft. Dabei kommt er zu dem Ergebnis (ausgehend von einem "community preference model", wie vorstehend bei der Wirkungsanalyse verwendet), daß allgemeine Zuweisungen des Zentralstaats langfristig höhere (Budget-)Ausgaben (für das lokale öffentliche Gut) implizieren als Steuersenkungen. ${ }^{280}$ Dieses Resultat ist als der sogenannte "flypaper effect"281 (Gramlich, 1977, 226) bekannt geworden. ${ }^{282}$

\subsection{Bürokratiemodelle}

Ein bisher weitgehend vernachlässigter Aspekt soll nunmehr aufgegriffen werden. Dies ist (im Rahmen dieser durchgeführten Wirkungsanalyse noch nicht problematisiert) das mögliche Auseinanderklaffen der Interessen von Politikern, Bürokraten und Wählern. Bisher ist davon ausgegangen worden, da $B$ im Sinne eines "community preference models" die gemeinsame Zielsetzung der örtlichen Gemeinschaft die Wohlfahrts(Nut-

ungeeignet erscheinen. Eine Feststellung also, die auf die praktische Ausgestaltung eines foderativen Staatswesens und speziell der Verteilung der Finanzierungsquellen sehr bedeutsam sein dürfte.

279 Die vorher durch Gewährung einer allgemeinen Zuweisung nach "außen" verschobene Budgetgerade (vgl. etwa Abbildung 10.1) weist durch den Aufkommenseffekt der Steuererhebung wieder den ursprünglichen Verlauf auf (Kompensation).

280 Gramlichs Studie $(1977,225)$ zeigt, daß eine Ausdehnung des Nettoeinkommens der Einwohner um $100 \$$ (beispielsweise durch eine Steuersenkung) die Ausgaben für das lokale offentliche Leistungspaket um 5 bis 10 S erhöht, wăhrend eine allgemeine Zuweisung in gleicher Hobe diese um 40 bis $100 \$$ vergrößert.

281 Unter dem "flypaper effect" versteht man "... the proposition that grants, since they are given to government, tend to stick with budgetary use and thus result in a higher level of services than would be the case if they were made directly to individuals." (Musgrave/Musgrave, 1984, 545)

282 Gramlich $(1977,226)$ begründet den sogenannten "flypaper effect" damit, weil eine Zuweisung "sticks where it hits". Eine Zuweisung wird - so seine Argumentation - nicht dazu verwendet, in Form einer Kürzung der Steuerzahlung vor Ort die Entscheidung den Individuen zu überlassen, in welcher Form sich die Konsumstruktur verăndert. Es kommt vielmehr durch politische bzw. bürokratische Entscheidungen zu einer überproportionalen Zunahme des Versorgungsgrades des lokalen offentlichen Gutes. Bei einer "normalen" Einkommenserhöhung durch Steuersenkung hingegen können die Konsumenten (Gemeindeeinwohner) "selbst" zwischen einer Erhőhung des Konsums des privaten und des lokalen offentlichen Gutes entscheiden. 
zen-)maximierung dieses Gemeinwesens darstellt. Das erlaubte eine Übertragung der individuellen Wahlhandlungs- und Nutzentheorie auf den öffentlichen Bereich (vgl. auch nochmals Abschnitt 4.2).

Das Problem bei Vorliegen von Diskrepanzen zwischen dem, was Wähler wünschen und dem, was sie letztlich durch den Staat erhalten, ist in den Modellen der "Ökonomischen Theorie der Politik" und der Bürokratietheorie behandelt und analysiert worden. Im Abschnitt 4.3.3 wurde dieser Aspekt in Zusammenhang mit der Behandlung der Präferenzoffenbarung für lokale öffentliche Güter durch politische Abstimmungen bereits in Grundzügen betrachtet. An dieser Stelle soll das Problem daher noch einmal aus einem anderen Blickwinkel betrachtet werden; und zwar in bezug auf den speziellen Zusammenhang zwischen Zuweisungen als kommunaler Finanzierungsquelle und den Zielsetzungen von Bürokraten.

Unter Bezugnahme auf die Grundmodelle des Verhalten der Bürokraten (vgl. dazu etwa Niskanen, 1968; Breton/Wintrobe, 1975) und die Hypothese, daß Bürokraten eher die eigene Wohlfahrt als die der Wähler und damit der örtlichen Gemeinschaft maximieren, sollen die damit verbundenen Auswirkungen einer Zuteilung der Finanzmittel aus zentralen "Töpfen" nachgezeichnet werden.

In den Abbildungen 10.7 und 10.8 wird ein auf den Annahmen der Bürokratietheorie (vgl. Abschnitt 4.3.3) aufbauendes Modell zur Analyse der Auswirkungen von Zuweisungen benutzt. Die Bürokratie stellt annahmegemäß als Monopolist das lokale öffentliche Gut $\mathrm{z}$ bereit und kennt dabei die Präferenzen der Mitglieder der örtlichen Gemeinschaft (also der Einwohner) und ihre jeweilige (Steuer-)Zahlungsbereitschaft. Der Grenznutzen der örtlichen Gemeinschaft aus der Konsumtion des Gutes z wird durch die Grenznutzenkurve GN ("Pseudo-Nachfrage") abgebildet. Die Kurve DN gibt den durchschnittlichen Nutzen der jeweiligen Outputmengen an; DK gibt die minimalen Durchschnittskosten jedes Outputniveaus an und GK bildet die entsprechenden Grenzkosten (Angebotskurve für das lokale öffentliche Gut z) ab. Die Bürokratie nutzt ihre Monopolstellung dadurch aus, daß sie ihr Leistungsangebot auf einer sogenannten "alles-oder-nichts" Basis ${ }^{283}$ anbietet. Dies bedeutet, daß das Bereitstellungsniveau des Gutes $\mathrm{z}$ ausgedehnt werden kann bis die Gesamtnutzen den Gesamtkosten entsprechen. Dies wird in Abbildung 10.7 durch den Schnittpunkt zwischen DN und DK verdeutlicht und somit ein Ausbringungsniveau $0 z_{1} z u$ Durchschnittskosten in Höhe von 0B realisiert. Ein niedrigeres Outputniveau seitens der Bürokratie wird nicht gewählt, weil damit ein geringerer Gesamtnutzen, somit geringe Einnahmen und letztlich ein geringeres Budget die Folge wären. Ein höheres Outputniveau würde dazu führen, daß die 
Gesamtkosten die Gesamtnutzen übersteigen und so nicht genügend Einnahmen resultieren. Das vorgeschlagene Outputniveau $0 \mathrm{z}_{1}$ wird zu den geringsten Durchschnittskosten $0 \mathrm{~B}$ produziert. Die Gesamtkosten bzw. -nutzen betragen $0 \mathrm{BCz}_{1}$. Abschließend muß betont werden, daß das Outputniveau $0 z_{1}$ über dem effizienten und damit wohlfahrtsoptimalen Bereitstellungsniveau ( $\left.z^{*}\right)$ liegt, wo Grenznutzen und Grenzkosten gleich sind (vgl. Niskanen, 1968, 295f; Breton/Wintrobe, 1975, 197).

Abbildung 10.7: Die Bereitstellung öffentlicher Leistungen unter Berücksichtigung von Eigeninteressen der Bürokratie

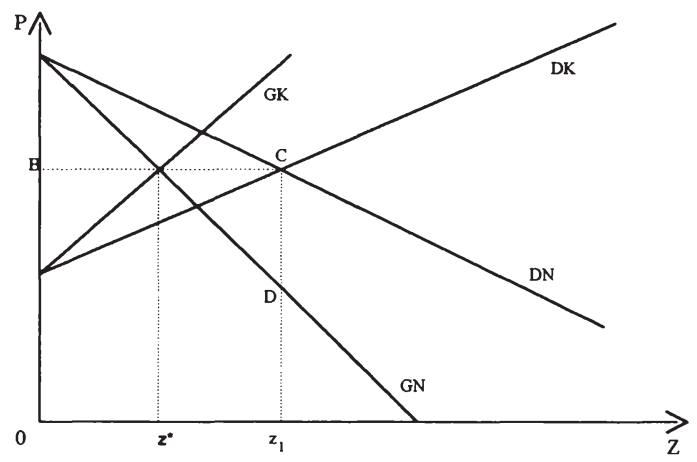

Wir nehmen nunmehr an, daß die Bürokratie auf lokalem Niveau ihr Leistungsangebot - also das lokale öffentliche Gut $\mathrm{z}$ - bereitstellt und zur Finanzierung vom übergeordneten Gemeinwesen eine Zweckzuweisung mit Eigenbeteiligung der empfangenden Kommune (in Höhe von einem Drittel der Bereitstellungskosten) gewährt wird. Diese Zuweisung reduziert die Durchschnittskosten und führt in Abbildung 10.8 zur Verlagerung der Durchschnittskostenkurve von DK auf DK'. Die Grenznutzenkurve GN ist aus Abbildung 10.7 übernommen worden. Die angesprochene Zuweisung führt zu folgenden Effekten. Der Output des Gutes $z$ steigt von $0 z_{1}$ auf $0 z_{2}$ und das Budgetvolumen steigt von $0 \mathrm{BCz}_{1}$ auf $0 \mathrm{EFz}_{2}$. Das höhere Outputniveau läßt den Gesamtnutzen von $0 \mathrm{ADz}_{1}$ auf $0 \mathrm{AGz}_{2}$ ansteigen und ist verbunden mit einer Finanzierung durch die Gemeindeeinwohner (lokale Besteuerung) zu einem Drittel und durch die übergeordnete Gebietskörperschaft (in Form der gewährten Zuweisung) zu zwei Dritteln. Insgesamt steigt also das Budgetvolumen um mehr als die reine Zuweisungshöhe. 
Abbildung 10.8: Bürokratieverhalten und die Wirkungen von Zuweisungen

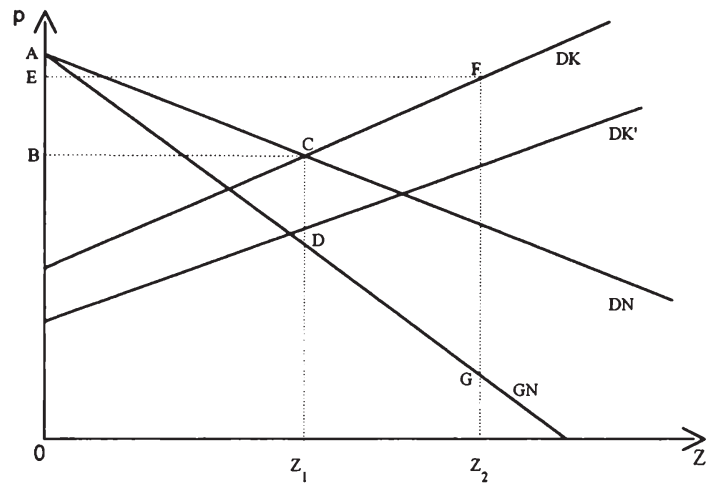

Die vorstehenden Ausführungen (vgl. auch Niskanen, 1968, 293ff) zeigen, wie Zuweisungen zu einen Anstieg des Budgetvolumens der empfangenden Gebietskörperschaft (Kommune) führen können. Um auch hier die Bedeutung des mit Zuweisungen verbundenen "flypaper effect" zu verdeutlichen, ist es sinnvoll, aufzuzeigen, daß ein Anstieg des Einkommens der örtlichen Gemeinschaft in der Regel zu einem geringeren Budgetanstieg führt als eine erhaltene Zuweisung in gleicher Größenordnung. Ein Einkommensanstieg führt lediglich zu Auswirkungen bezüglich der Grenznutzen- bzw. Durchschnittsnutzenkurve der Einwohner. Bleiben diese unverändert, dann ergeben sich keinerlei Effekte auf das Outputniveau des lokalen öffentlichen Gutes und damit das Budgetvolumen (vgl. Abbildung 10.7). In der Regel wird sich jedoch auf der Basis gestiegener Einkommen eine Ausweitung der Nachfrage nach dem Gut z einstellen, wenn es sich bei diesem um ein superiores Gut handelt. Die Grenznutzenkurve GN und die Durchschnittsnutzenkurve DN verschieben sich also nach rechts. Dabei wird aber ein Einkommensanstieg zu einem wesentlich geringeren Outputzuwachs und damit einer Budgetausdehnung führen, als die betrachtete Zuweisung, weil eben die Verwendung des Einkommens bei konstanten Ausgabeprioritäten infolge des unveränderten Preisverhältnisses für verschiedene Alternativen (hier auch das private Gut) erfolgen kann. Durch Zweckzuweisungen einer übergeordneten Gebietskörperschaft kommt es folglich zu einer Unterstützung des Budgetmaximierungsverhaltens der Bürokraten und damit zu Wohlfahrtsverlusten durch ein zu hohes Outputniveau der betroffenen lokalen öffentlichen Leistungen.

Breton und Wintrobe (1975) stehen diesen Ergebnissen kritisch gegenüber. Sie argumentieren, daß Bürokraten nicht zwangsläufig Budgetmaximierung betreiben müssen und darüber hinaus die zuweisungsgewährende Körperschaft sich solchen Fehlent- 
wicklungen gegenüber nicht passiv verhalten wird, wie das Modell unterstellt. Sicherlich ist Niskanens Position extrem, aber sie liefert weitere Erklärungen für die Existenz des sogenannten "flypaper effect", der aber zugegebenermaßen nicht in jedem Fall in der beschriebenen Weise auftreten muß.

Weitere Modellansätze zur Erklärung des "flypaper effect" sind auf den bisherigen Erkenntnissen aufbauend formuliert worden. Romer und Rosenthal (1979a; 1979b) haben sich einerseits besonders mit der Rolle des Medianwählers und dessen Implikationen sowie andererseits der Bedeutung der Bürokratie bei Wahlentscheidungen als Verfahren zur Präferenzoffenbarung für öffentliche Güter beschäftigt (vgl. Abschnitt 4.3.3). Aufbauend auf den Ergebnissen aus der Betrachtung dieses Problemkomplexes im Kapitel 4, sollen an dieser Stelle ebenfalls noch die besonderen Implikationen für die Wirkungen von Zuweisungen analysiert werden. Dazu werden die Abbildungen 10.9 und 10.10 benutzt. ${ }^{284}$

Die Abbildungen zeigen die Auswirkungen einer Ausdehnung des Einkommens auf der einen bzw. der Gewährung einer "lump-sum grant" gleicher Größenordnung auf der anderen Seite für die Nutzenentscheidung des Medianwählers. In beiden Fällen ist die Budgetgerade $\mathrm{AA}^{\prime}$ die Ausgangslage und das seitens der Bürokratie angestrebte Bereitstellungsniveau ${ }^{285} 0 \mathrm{z}_{\mathrm{B}}$ ist höher als das optimale Konsumtionsniveau (Schnittpunkt zwischen Angebots- und Nachfragekurve) des lokalen öffentlichen Gutes z. Die sich ergebende Bereitstellungsmenge des Gutes $\mathrm{z}$ unter den gegebenen Umständen (Einfluß der Bürokratie auf die Wahlentscheidung) ist somit eben die Menge $0 z_{B}$, so daß der Punkt E auf der Budgetgerade des Medianwählers das zu konsumierende Güterbündel dokumentiert. In Abbildung 10.9 führt die Ausdehnung des Einkommens zur Verschiebung der Budgetgerade auf BB', jedoch wird sich bei Konstanz des "reversion level" am "Bürokratie-Output" des Gutes z nichts ändern. Statt dessen wird das zusätzliche Einkommen ausschließlich für andere Konsumtionsalternativen (hier des privaten Gutes $x$ ) verwendet. Folglich resultiert als Güterbündel der Punkt $F$ auf der Budgetgerade BB'. Die Einkommensänderung hat also keinerlei Einflüsse auf die Outputhöhe des Gutes $z$ und damit das Budgetvolumen, sehr wohl aber Wirkungen auf die Nutzenposition des Medianwählers.

284 Anders als bisher wird im Rahmen der Modellbetrachtung in Anlehnung an Romer und Rosenthal (1979a; 1979b) nicht mehr vom sogenannten "community preference model" (mit einer gemeinsamen Nutzenfunktion der ortlichen Gemeinschaft) ausgegangen. Infolge der Kritik an diesen Übertragungen der individuellen Wahlhandlungs- und Nutzentheorie auf die Allokation offentlicher Güter verwenden Romer und Rosenthal die Nutzenfunktion des Medianwăhlers als Repräsentant der Entscheidung der ortlichen Gemeinschaft zwischen dem Konsum des privaten Gutes $x$ und dem des lokalen offentlichen Gutes z (vgl. auch die Abschnitte 4.3.2 und 4.3.3).

285 Vgl. dazu die ausführliche Diskussion im Abschnitt 4.3.3, wo die Rolle der Bürokratie für die Bereitstellung offentlicher Güter verdeutlicht und das sogenannte "reversion level" definiert wird. 
Abbildung 10.9: Wirkungen von Zuweisungen bei Beachtung bürokratietheoretischer Implikationen - Fall 1

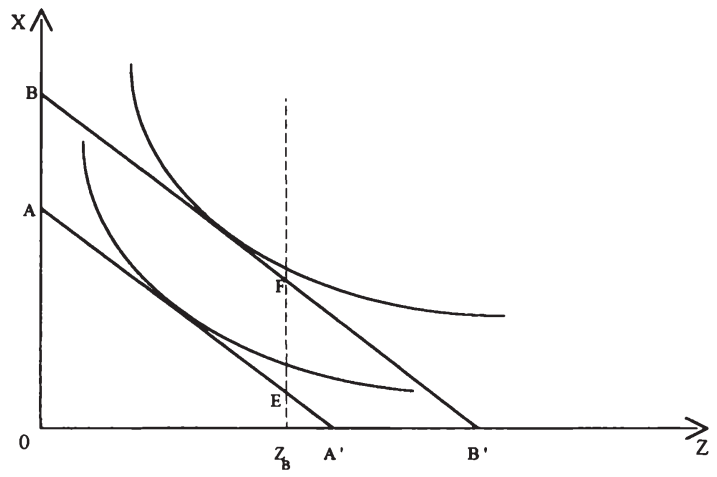

Abbildung 10.10: Wirkungen von Zuweisungen und bürokratietheoretische Implikationen - Fall 2

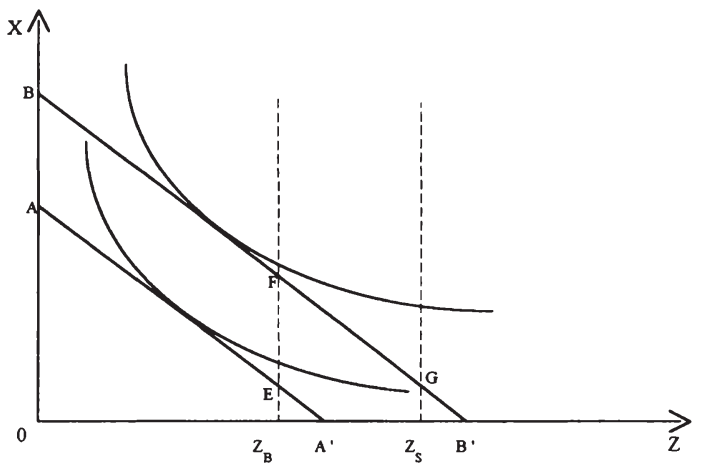

In der Abbildung 10.10 wird nunmehr der Fall einer Zuweisung untersucht. Diese führt zunächst zu den gleichen Auswirkungen, nämlich einer Verschiebung der Budgetgerade nach BB'. Gleichzeitig - so argumentieren Romer und Rosenthal (1980) - ergibt sich aber in Folge der erhaltenen Zuweisung eine Veränderung des Bereitstellungsvolumens (die Bürokraten nutzen ihre Position für die Durchsetzung eines höheren Bereitstellungsniveaus), das sich um die Höhe der Zuweisung nach rechts verschiebt, also erhöht $\left(z_{s}\right)$. Dadurch stellt sich das neue Outputniveau von $0 z_{s}$ für Gut $z$ ein, was einen entsprechenden Anstieg des Budgetvolumens mindestens um die Zuweisungshöhe wahrscheinlich aber über die eigentliche Höhe der Zuweisung hinaus - zur Folge hat. 
Diese - wenn auch unter sehr rigiden Modellannahmen - gewonnenen Ergebnisse verdeutlichen, welche Wohlfahrtsverluste sich aus der Gewährung von Zuweisungen ergeben können. Dies wird bei einem Vergleich der Abbildungen 10.9 und 10.10 und der sich aus den unterschiedlichen Rahmenbedingungen ergebenden Abweichungen des jeweiligen Bereitstellungsniveaus $\left(\mathrm{z}_{\mathrm{B}}\right)$ bzw. $\left(\mathrm{z}_{\mathrm{s}}\right)$ vom Optimum des Medianwählers $\left(\mathrm{z}^{*}\right)$ deutlich. Durch die Zahlung der Zuweisung - egal ob es sich um eine allgemeine oder eine Zweckzuweisung unterschiedlicher Ausgestaltung handelt - vergrößert sich diese Abweichung im Vergleich zu einer "innerkommunalen (Steuer-)Lösung". Mit der größer werdenden Abweichung zwischen dem optimalen Konsumtionspunkt und dem jeweils von der Bürokratie präferierten und aufgrund ihrer ("Markt-")Macht durchsetzbaren Bereitstellungsniveau steigt somit der Grad der Sub-Optimalität der entsprechenden Allokationsentscheidung.

\subsubsection{Zuweisungen mit "distributiver" Zielsetzung - "Equalization grants" und lokale Effizienz}

Das grundlegende Problem einer distributionsorientierten Begründung ("equity objective") von Finanzzuweisungen ist die Frage, ob Zuweisungen mit der Zielsetzung einer Angleichung der fiskalischen Verhältnisse die Erreichung effizienter Ergebnisse erschweren oder gar verhindern oder ob die Vermeidung (Unterdrückung) fiskalisch motivierter interlokaler Wanderungen ökonomisch sinnvoller ist.

Die Produktion privater Güter in einer Volkswirtschaft erfolgt (so die idealisierte modellhafte Betrachtungsweise) effizient und erzielt optimale Ergebnisse, wenn der Produktionsfaktor Arbeit sowie die anderen Inputs in einer Weise eingesetzt werden, die dazu führt, daß für den Faktor Arbeit das gleiche Grenzprodukt in jeder Region (Kommune) der Volkswirtschaft erreicht wird. Ist hingegen das Grenzprodukt - sagen wir eines Maschinenschlossers - in der Kommune A höher als in der Kommune B, würde der Output und damit das Produktionsergebnis steigen können, wenn Maschinenschlosser aus der Kommune B in die Kommune A abwandern würden. In einer idealisierten Wettbewerbsökonomie ist bekanntermaßen das Wertgrenzprodukt der Arbeit gleich dem Lohnsatz und folglich würde der Wanderungsprozeß andauern, bis schließlich für einen bestimmten Typ des Faktors Arbeit (hier: Maschinenschlosser) gleiche Lohnsätze und damit das gleiche Wertgrenzprodukt innerhalb aller Regionen vorliegen. ${ }^{286}$ Dieser Migrationsproze $B$ wird jedoch beeinflußt und verzerrt, sobald Hemmnisse und Kosten für interregionale Wanderungen existieren (vgl. auch Abschnitt 4.4). 
Nehmen wir also an, daß sich die Kommunen $A$ und $B$ in einer ungleichgewichtigen Ausgangssituation befinden, also Lohnsatzdifferentiale für gleiche Arbeitsleistungen existieren. Dieser Tatbestand führt zur Migration von Haushalten aus der NiedriglohnKommune B in die Hochlohn-Kommune A. Jede der angesprochenen Kommunen ist mit Autonomierechten bezüglich ihrer Ausgaben- und Einnahmengestaltung ausgestattet und bietet auf ihrem Niveau das lokale öffentliche Gut $\mathrm{z}$ an. Diese Leistung wird jeweils durch eine Einkommensteuer finanziert. Ferner wird davon ausgegangen, daß infolge der Eigenschaft der gemeinsamen Konsumierbarkeit (Nicht-Rivalität) der öffentlichen Leistung die durch Migration verursachten Zuzüge in eine der beiden Regionen nicht zu einem Anstieg der Bereitstellungskosten in Form des Ressourcenverzehrs führen, da das (lokale) öffentliche Gut $\mathrm{z}$ noch nicht kapazitätsbeschränkt ist, also eine kritische Gemeindegröße noch nicht erreicht wird. ${ }^{287}$ Wenn nun also die Löhne in der Kommune A höher sind als in B, kann die Gebietskörperschaft A ihren Einwohner ein effektiveres Leistungsangebot bezüglich des Gutes $\mathrm{z}$ garantieren, denn es ist für $\mathrm{A}$ entweder möglich ein bestimmtes Bereitstellungsniveau von $\mathrm{z}$ zu einem niedrigeren Steuersatz der Einkommensteuer oder ein höheres Bereitstellungsniveau von z zu gleichen Steuersätzen wie in B anzubieten. Unter diesen Rahmenbedingungen ergeben sich zusätzliche Anreize für interregionale Wanderungen von B nach A. Wenn nunmehr über Finanzzuweisungen des Zentralstaats (eines übergeordneten Gemeinwesens) ein Ausgleich dieser unterschiedlichen Ausgangssituation zwischen den Gebietskörperschaften A und B angestrebt wird, würde dies je nach Ausgestaltung der Finanzzuweisungen zu einer Verringerung oder gar einem Verschwinden der Wanderungsbewegungen führen, da entsprechende Anreize nicht mehr wirksam würden.

Unter ökonomischen Gesichtspunkten sind also Zuweisungen mit dem Ziel der Egalisierung fiskalischer Ungleichgewichte eher negativ zu bewerten, denn die dezentrale öffentliche Leistungserstellung ohne "equalization grants" ist immer dann der geeignete Weg zur Setzung von Wanderungsanreizen bei lokalen öffentlichen Gütern, wenn diese keine räumlichen Externalitäten aufweisen (vgl. dazu Scott, 1950, 419).288

287 Wenn die "optimale Gemeindegröße" (vgl. dazu Gilbert/Picard, 1990) überschritten wăre, würden interregionale Wanderungen weniger wünschenswert, da sie zu verstärkten "congestion"-Effekten führen und möglicherweise unter Allokationsgesichtspunkten nachteilig wirken könnten (vgl. auch Abschnitt 2.3).

${ }^{288} \mathrm{Zu}$ einem ähnlichen Ergebnis gelangt man auch, wenn sich infolge der unterschiedlichen fiskalischen Ausstattung der Regionen der Zentralstaat selbst zur Übernahme der Bereitstellung der öffentlichen Leistung z entschließt. Ziel dieser Maßnahme ist ein identisches Angebotsniveau der öffentlichen Leistung innerhalb aller Regionen und folglich auch ein annähernd gleicher Finanzierungsbeitrag über die Besteuerung. Folge dieser Vorgehensweise wird wiederum die Reduzierung der Migrationsanreize mit entsprechenden Wirkungen auf die Wohlfahrtsoptimalităt möglicher Lösungen sein (vgl. im Gesamtzusammenhang Scott, 1950; 1952a; 1952b). 
Es ist anzumerken, daß diese Schlußfolgerung weniger klar ausfällt, wenn die Gebietskörperschaften A und B eine andere Finanzierungsform als die Einkommensbesteuerung wählen. So ist es möglich, daß die Niedriglohn-Kommune B bei einer anderen Bemessungsgrundlage (beispielsweise einer Vermögen- bzw. Grundsteuer oder einer allgemeinen Verbrauchsteuer) eine größere Steuerbasis als Kommune A vorfindet. Ohne die Etablierung eines unter Ausgleichsgesichtspunkten konstruierten Finanzzuweisungssystems würde diese Situation zu Wanderungsanreizen aus der Kommune $\mathrm{A}$ in die Kommune B führen; also genau in die entgegengesetzte Richtung und damit wohlfahrtsmindernde Wanderungsbewegungen mit sich bringen. Die Einführung von $\mathrm{Zu}-$ weisungen würde in diesem Fall die Anreize für die Individuen in die Kommune mit der geringeren Arbeitsproduktivität zu ziehen, reduzieren bzw. eliminieren.

Buchanan (1952a, 208f) hält der vorstehenden Sichtweise Scott's vor allem zwei Argumente entgegen. Zunächst führt er aus, daß keineswegs eindeutig ist, daß bei identischen Wertgrenzprodukten und damit identischen Lohnsätzen für gleiche Arbeit auf "equalization grants" völlig verzichtet werden könne. Denn bei identischen Lohnsätzen in Kommune $\mathrm{A}$ und Kommune B kann sich beispielsweise der sogenannte Besatz in den unterschiedlichen Lohngruppen oder Beschäftigungszweigen dergestalt unterscheiden, daß die durchschnittlichen Einkommen in A höher als in B sind. In einer solchen Situation könnte folglich ein Zuweisungssystem mit der Zielsetzung eines fiskalischen Ausgleichs zwischen den Regionen positive Effekte dergestalt mit sich bringen, daß Wanderungsbewegungen von B nach A - die wohlfahrtsmindernd (weil outputreduzierend) wirken - verhindert werden.

Zweites Argument Buchanans ist der Hinweis, daß ein Zuweisungssystem zur Beseitigung fiskalischer Ungleichgewichte keineswegs zwangsläufig eine ökonomisch ineffiziente Lösung mit sich bringen muß. Er stimmt zwar zu, daß die Abschaffung von $\mathrm{Zu}$ weisungssystemen sich stimulierend auf Wanderungsbewegungen auswirkt, gibt aber zu bedenken, daß eine Angleichung der Lohnsätze zwischen den Regionen und damit die sich über Migration des Produktionsfaktors Arbeit einstellende Outputerhöhung auch von anderen Faktoren unterstützt wird, die wiederum ihrerseits mit der Zuweisungsgewährung positiv zusammenhängen (vgl. Buchanan, 1952a, 209f). Er nennt vor allem den Zusammenhang zwischen den Produktionsfaktoren Arbeit und Kapital, beispielsweise einen hohen Anteil von ungelernten Arbeitern in Gemeinde B und damit eine hohe Arbeitsintensität in Relation zum Faktor Kapital. Daraus resultierende Wanderungsbewegungen von ungelernten Arbeitern reduzieren zwar Lohnsatzdifferentiale, sofern die Migrationsanreize in deren Existenz begründet sind; aber infolge möglicherweise günstigerer Rahmenbedingungen für den Faktor Kapital (beispielsweise einer höheren Kapitalrentabilität) könnte es zu diesen allokativ erwünschten Wanderungen auch kommen, wenn statt der angesprochenen Wanderung des Faktors Arbeit 
von B nach A der Faktor Kapital von A nach B gehen würde. Wenn nun existierende Finanzzuweisungen mit der Zielsetzung eines Ausgleichs möglicher fiskalischer Ungleichgewichte abgeschafft würden, könnte die Gebietskörperschaft B beispielsweise ihre Vermögensteuern erhöhen oder ihre Infrastrukturausgaben reduzieren, mit dem Ergebnis eines Rückgangs der "Einwanderung" des Faktors Kapital. Folglich könne auch nicht endgültig entschieden werden, ob nun die Abschaffung bzw. Nicht-Etablierung von Zuweisungen den Angleichungsproze $B$ zwischen Regionen mittels Migration behindern oder unterstützen würde. Ein positiver Nettoeffekt (Unterstützung der Wanderungsbewegungen) ist um so wahrscheinlicher, wenn die niedrige Arbeitsproduktivität und damit die Lohnsätze in B zum Großteil infolge der schlechten Ausstattung dieser Region mit natürlichen Ressourcen (vgl. Scott, 1952b, 534ff) sowie anderer natürlicher Standortnachteile existieren.

In Anlehnung an das erste Argument gibt es einen Ansatz von Buchanan und Wagner (1970), der aufzeigt, daß der Produktionsfaktor Arbeit mittels seiner Mobilität nicht zwangsläufig Ergebnisse "produziert", die zu einer Outputmaximierung führen (müssen). Das angesprochene Modell basiert dabei auf folgenden Annahmen (vgl. Buchanan/Wagner, 1970, 143ff). Der Wert der öffentlichen Leistungen wird als Nettonutzen angesehen, der sich aus der Wertschätzung einer solchen Leistung im Rahmen der individuellen Bedürfnisbefriedigung abzüglich der entsprechenden Steuerzahlungen ergibt. Weiterhin wird angenommen, daß jede nachgeordnete Gebietskörperschaft ein bestimmtes Niveau an öffentlichen Leistungen bereitstellt. Wenn nun die Bevölkerung einer Gebietskörperschaft wächst, sinkt bei unterstellter gemeinsamer Konsumtionsmöglichkeit (Nicht-Rivalität) zunächst die Steuerlast pro Kopf und somit resultieren erhöhte Nettonutzen. Da aber bei lokalen öffentlichen Gütern (vgl. Abschnitt 2.3) Überfüllung und Übernutzung (also "crowding" und "congestion") bzw. Kapazitätseffekte die Regel sind, kann es bei auftretenden "congestion effects" auch zu einem Rückgang der Nettonutzen der einzelnen Individuen und somit der bisherigen Einwohner kommen, weil eine wachsende Einwohnerzahl zunehmend zu Übernutzung führen kann (vgl. Buchanan/Wagner, 1970, 151ff). Aus dieser Tatsache, die bei der individuellen Entscheidung des einzelnen Haushalts (im Sinne externer Effekte) unberücksichtigt bleibt und somit zu Wohlfahrtsverlusten führt, folgern Buchanan und Wagner $(1970,154 f)$, daß ein Zuweisungssystem benötigt wird, das unterbevölkerte Regionen (Gemeinden) attraktiver und überbevölkerte Regionen (Gemeinden) weniger attraktiv macht. Zuweisungen würden also in diesem Sinne nicht nur eine distributive Funktion erfüllen, sondern infolge der Reduzierung unerwünschter Wanderungen auch allokative Effekte haben. Man könnte in Anlehnung an Buchanan/Wagner $(1970,154)$ daher auch von der Möglichkeit einer "fiscal equalization as a substitute for exclusion rights" mittels Zuweisungen reden. 
Abschließend bleibt festzuhalten, daß die Wirkungen von Zuweisungen mit der Zielsetzung einer Beseitigung möglicher fiskalischer Ungleichgewichte in erheblichen Maße von den jeweiligen Rahmenbedingungen abhängen. Es ist einerseits möglich, daß Zuweisungen sich eher hemmend auf die Mobilitätsbereitschaft der Individuen auswirken und damit möglicherweise unter Allokationsgesichtspunkten erwünschte Wanderungen nicht zustande kommen; andererseits können Zuweisungen aber auch Kapitalbewegungen mobilisieren und damit unter ökonomischen Gesichtspunkten das Entwicklungspotential einer Volkswirtschaft als Ganzes verbessern helfen (vgl. King, 1984, 159ff).

\subsection{Gesamtbeurteilung}

Ein Gesamtfazit muß - in Anlehnung an die vorstehenden Ausführungen - sehr differenziert ausfallen. In einem Gemeindefinanzsystem spielen auch bei einer wesentlichen Orientierung an Autonomiegesichtspunkten Zuweisungen übergeordneter Gebietskörperschaften eine nicht zu vernachlässigende Rolle. Gleichwohl - dies hat die (zugegebenermaßen ausschließlich theoretische) Betrachtung mehr als deutlich werden lassen - sind Zuweisungen unter Effizienzgesichtspunkten prinzipiell kritisch zu beurteilen, denn ihr Einsatz und ihr Gebrauch können von einer Reihe von Unwägbarkeiten begleitet sein, die im Ergebnis eher zu gegenteiligen und eben nicht zu den gewünschten Effekten und Wirkungen führen.

Besonders problematisch ist eine generelle "Alimentierung" der lokalen Ebene durch Zuweisungsströme übergeordneter Gemeinwesen, denn hier dürften unter Wohlfahrtsgesichtspunkten die gravierendsten Nachteile offenbar werden, zumal Effizienzpotentiale durch die besonderen Merkmale der lokalen öffentlichen Leistungsbereitstellung und ihrer Finanzierung nur unzureichend oder gar nicht ausgeschöpft würden. Kommunale Autonomie ist kein Selbstzweck, sondern kann bei entsprechender Ausgestaltung Wohlfahrtsgewinne garantieren, weil Effizienzvorteile realisiert werden können. Wichtig für das Gesamtverständnis der Problematik ist dabei, daß kommunale Finanzautonomie Bedeutung für die Effizienz lokaler Finanzwirtschaften hat (und nicht umgekehrt, also Effizienz gewissermaßen eine Voraussetzung für kommunale Autonomie ist). So läßt sich schließlich die Eigenverantwortlichkeit für Nutzen und Kosten politischer Budgetentscheidungen (politische Autonomie) für das ökonomische Ziel der Minimierung des Aufwandes (effiziente Allokation) für eine gegebene Aufgabe instrumentalisieren.

$\mathrm{Da}$ aber auch Zuweisungen durchaus noch eine Bedeutung zukommt, bedarf wohl kaum einer besonderen Erwähnung. Doch wird die quantitative und qualitative Bedeu- 
tung von Finanzzuweisungen in einem unter Effizienzgesichtspunkten konstruierten "optimalen" Gemeindefinanzsystems eine wesentlich andere sein als die, die wir in den meisten föderalen Staatsgebilden heute vorfinden (vgl. dazu Reischauer, 1975, 40ff; Kuhn/Hanusch, 1990 oder auch Peffekoven, 1988, 623ff). 
Hans-Georg Napp - 978-3-631-75263-0

Downloaded from PubFactory at 01/11/2019 06:33:05AM

via free access 
"Worum Stadtparlamente und Kommunalpolitiker ringen und ringen werden, bis sie es erreicht haben, ist ... die Möglichkeit ... auch die Einnahmeseite ihres Budgets nach den besonderen Gesichtspunkten der eigenen Stadt, unter eigener Verantwortung - und zwar lediglich vor der eigenen Bürgerschaft und vor sonst niemand - stddtisch-individuell zu gestalten. (Dieser) Wille der Stadte (ist) restlos berechtigt ... er ist nichts anderes als die finanzpolitische Seite ihres Lebenswillens selbst."

Joseph A. Schumpeter (1928)

\section{Grundstrukturen eines kommunalen Finanzsystems}

Die vorstehende Analyse einer kommunalen Finanzautonomie und ihrer Bedeutung für eine effizientere Wahrnehmung lokaler öffentlicher Aufgaben hat konstitutive Elemente für ein kommunales Finanzsystem erkennen lassen, die vorhanden sein sollten, "... damit das Wohl aller Bürger nachhaltig gefördert ... wird" (Wust, 1981, 154). Die Berücksichtigung dieser Elemente bei der Ausgestaltung kommunaler Finanzierungssysteme könnte als ein "raumordnungspolitisch wirksames Signal" (Littmann, 1968, 28) für mehr Wirtschaftlichkeit bei der (lokalen) öffentlichen Leistungsbereitstellung und ihrer Finanzierung sorgen. In diesem Kapitel sollen daher die bisher abgeleiteten Grundstrukturen kommunaler Finanzierungssysteme zu einer geschlossenen Konzeption zusammengefügt werden.

11.1 Die Vorteilhaftigkeit kommunaler Finanzautonomie - Zusammenfassung wesentlicher Ergebnisse

Viele öffentliche Güter stiften einen räumlich begrenzten Nutzen oder - anders ausgedrückt - haben einen (lokal) begrenzten Wirkungskreis. Sie können daher nicht von allen Bürgern einer Nation gemeinsam und ohne Rivalität konsumiert werden. Die potentielle Gruppe der Verbraucher ergibt sich aus der spezifischen Reichweite der möglichen Nutzung. Folglich erscheint es sinnvoll, nur die Nutznießer über das öffentliche Leistungsangebot entscheiden $\mathrm{zu}$ lassen, denn diese sollen schließlich auch die (gesamten) Kosten dieser Leistungsbereitstellung tragen und letztlich in "voller" Kenntnis ihrer finanziellen Belastung den (subjektiven ) "Wert" der Güter mitbestimmen. Aus vertikaler Sicht hieße dies aber dann, daß so viele Gemeinwesen entstehen, wie es Leistungen mit unterschiedlicher Nutzenstreuung gibt. Diese Lösung ist natürlich weder praktikabel noch wünschenswert. Unter pragmatischen Gesichtspunkten werden daher im Rahmen der Arbeiten zur Föderalismusproblematik vereinfachend internationale, nationale, regionale und lokale Güter und dazu korrespondierende geographische Systeme (föderale Ebenen) unterschieden. 
Um zu gewährleisten, daß die Bürger die (lokalen) öffentlichen Leistungen nicht verschwenderisch nutzen bzw. die "Anbieter" (Politiker und Bürokraten) diese nicht unwirtschaftlich bereitstellen, sollte grundsätzlich jedes Gemeinwesen seine Güter selbst finanzieren. Die Aufteilung der Einnahmehoheiten hat sich also an den Entscheidungserfordernissen über das Angebot der Leistungen zu orientieren. Dabei sollte namentlich die untere gebietskörperschaftlichen Ebene (also die Kommunen) die Lasten eher nach der Inanspruchnahme der Dienste (Äquivalenzgedanke) und weniger nach der Leistungsfähigkeit ihrer Bürger verteilen (vgl. Oates, 1977c, 15ff).

Dieser Tatbestand erfordert, daß man auf der lokalen Ebene im Rahmen der autonomen Bestimmung möglicher Einnahmequellen und ihrer Verteilung die Zurechnung öffentlicher Leistungen auf den Einzelnen (bei Gebühren und Beiträgen) bzw. auf eine Gruppe (bei Steuern) versuchen und den Einzelnen (die Gruppe) mit den Kosten belasten sollte, die durch die Bereitstellung der von ihm/ihr konsumierten Leistungen entstehen. Bei der Lösung dieses Problems gilt es also, bestimmte Nutzer(-kreise) für lokale öffentliche Leistungen zu identifizieren und schließlich geeignete Abgaben zu finden, die den Einzelnen (die Gruppe) an der Finanzierung der jeweils konsumierten Leistung beteiligen. Um die Vorteile dieser Argumentation (sprich der Herstellung eines Interessenausgleichs zwischen Nutzern, Zahlern und Entscheidern) zu begreifen, bedarf es keiner weiteren Überlegung. Es ist eine historische Grunderfahrung, daß der Mensch Güter und Dienste, die er wirklich oder vermeintlich kostenlos nutzt, verschwendet. Verliert der Einzelne bei der Nutzung der öffentlichen Leistungen den Bezug zu ihrer Finanzierung, glaubt er, er könne eine solche Leistung als "Trittbrettfahrer" quasi kostenlos ("zum Nulltarif") konsumieren. Er wird daher eine solche Leistung so lange beanspruchen, bis ihm eine zusätzliche Einheit dieser Leistung wirklich keinen Nutzen mehr stiftet. Das kann aber im Hinblick auf die Gesamtwohlfahrt einer Volkswirtschaft nur wenig sinnvoll sein, weil eine Fehlallokation knapper Ressourcen die Folge wäre.

Eine "lastorientierte" Verteilung der Finanzierungserfordernisse hat zwei zusätzliche Vorteile:

- Die Allokationsentscheide in der privaten Wirtschaft werden weniger stark verzerrt, da regionale Unterschiede in der Steuerlast logischerweise letztendlich nur die differierenden lokalen öffentlichen Leistungsangebote in den Gemeinwesen abbilden.

- Die Umverteilungspolitik (also die Wahrnehmung der Distributionsaufgabe) gewinnt an Effizienz, weil sie ausschließlich Aufgabe der zentralen Regierung ist.

Dezentrale Einnahmekompetenzen haben auch Auswirkungen auf die Erfüllung der Stabilitätsaufgabe der öffentlichen Haushalte in einer Volkswirtschaft. Viel zu häufig 
wird in diesem Zusammenhang die Notwendigkeit ausschließlich zentraler Einnahmekompetenzen betont. Gemeinsame Verhandlungen anhand objektiver Kriterien könnten jedoch auf einen stabilitätsgerechten Umfang aller öffentlichen Haushalte auch bei autonomen (dezentralen) Finanzierungssystemen hinwirken. Die Kommunen könnten aber beispielsweise auch in der Verfassung zu konjunkturgerechtem Verhalten verpflichtet werden und - falls sie dieser Aufgabe nicht nachkommen - mit Sanktionen "bestraft" werden. Ausschließliche zentrale Einnahmekompetenzen in Verbindung mit der Zusicherung von Hoheitsrechten für alle wesentlichen Steuern sind für diesen Zweck jedenfalls nicht zwingend erforderlich.

Eine entsprechende föderale Ordnung (finanzielle Autonomie der Städte und Gemeinden) gemäß des Leitgedankens der Herstellung eines Verbundes zwischen Nutzer, Zahler und Entscheider - oder verkürzt nach den Grundsätzen der fiskalischen Äquivalenz bzw. des Interessenausgleichs - hat den großen Vorzug, daß nur die Entscheidenden selbst von den Folgen des Angebots und dessen Finanzierung getroffen werden. Die Versorgung mit (lokalen) öffentlichen Leistungen ist somit stärker an Effizienzgesichtspunkten ausgerichtet, da jede(r) Einzelne/Gruppe über Menge und Qualität der jeweils von ihm/ihr konsumierten und finanzierten Güter befinden kann. Bezüglich der Wahrnehmung der Allokationsaufgabe braucht man sich also nicht mit einem regional einheitlichen Standard oder einem "nationalen Durchschnitt" zufrieden zu geben.

Der Grundsatz der fiskalischen Verknüpfung (Äquivalenz) bzw. des Interessenausgleichs kann in der Realität in bestimmten Fällen aber auch durchbrochen werden, ohne daß man ihn selbst in Frage stellen muß. Die zwei bedeutendsten Abweichungen (vgl. auch Kapitel 6) lassen sich relativ einfach an die formulierten Grundsätze kommunaler Autonomie anpassen bzw. in das vorliegende Konzept integrieren:

- Sind etwa die Stückkosten eines lokalen öffentlichen Gutes von der Betriebsgröße abhängig, liegen also natürliche Skalenerträge vor, so kann die Produktion - exakter die Bereitstellung - je nach Situation entweder zentraler (bei zunehmenden Skalenerträgen) oder dezentraler (bei abnehmenden Skalenerträgen) organisiert werden. Die Anbieter entsprechender Leistungen erhalten dann im Wege des Finanzausgleichs via Zuweisungen von potentiellen Nutzergruppen eine Rückvergütung. Lassen sich "brachliegende" Skalenerträge nur nutzen, wenn der Bedarf mit Hilfe eines weiträumigen Kollektivgutes befriedigt wird (Fall der steigenden Skalenerträge), kann es sich lohnen, auf ein lokales/regionales Angebot zu verzichten und die Aufgabe der nächsthöheren Gebietskörperschaft zu übertragen. Eine andere Möglichkeit wäre die Verwirklichung eines solchen Leistungsangebots innerhalb eines horizontalen Verbundes von gleichrangigen Körperschaften; also die Bildung kom- 
munaler Zweckverbände (wie beispielsweise in der Abwasser- oder Abfallbeseitigung bzw. der Energieversorgung üblich).

- In der Realität sind die Gemeinwesen nicht hermetisch voneinander getrennt. Aus vielerlei Gründen treten räumliche Überlappungen der Kosten und Nutzen lokaler Leistungen zwischen den Kommunen auf. Da verständlicherweise jede Gemeinde bei ihren Angebotsentscheidungen nur die Nutzen- und Kostenströme erfaßt, die in ihren eigenen Grenzen anfallen, stellt sich aufgrund räumlicher externer Effekte ein "falsches" Angebotsniveau und damit eine Fehlallokation von Ressourcen ein. Am einfachsten wäre es, wenn die "externen" Nutzer gezwungen werden könnten, für die Inanspruchnahme der externen Vorteile ein direktes Entgelt (Gebühr) zu entrichten. Dies entspräche den Gedanken der Äquivalenz bzw. des Interessenausgleichs am ehesten. Da diese Möglichkeit infolge der Besonderheiten des öffentlichen Leistungsangebots in der Regel nicht zur Verfugung steht, verbleibt - neben freiwilligen (dezentralen) Verhandlungen der beteiligten Kollektive über einen finanziellen Ausgleich - die Ausschöpfung der Möglichkeiten des Finanzausgleichs mit der Etablierung von Zuweisungsströmen, die räumliche externe Effekte internalisieren sollen. Auch in einem an den Grundsätzen fiskalischer Äquivalenz und des Interessenausgleichs ausgerichteten (eigenständigen) kommunalen Finanzierungssystem verbleibt nicht nur Raum für Finanzzuweisungen; vielmehr bekommen diese Finanzzuweisungen innerhalb eines entsprechenden Finanzausgleichs instrumentellen Charakter, jedoch nur im beschriebenen (allokativen) Sinne und nicht aus rein fiskalisch orientierten Motiven heraus. Denn ein in erster Linie auf Finanzzuweisungen aufgebautes kommunales Finanzierungssystem bringt eine Reihe von (mit solchen zentralen Einnahmekompetenzen verbundenen) negativen Auswirkungen mit sich. Dies ist im wesentlichen die Tatsache, daß die Nutzung und die Kostenübernahme (Zahlung) von öffentlichen Gütern getrennt wird. Das Prinzip der fiskalischen Äquivalenz wird durchbrochen und ein entsprechender Interessenausgleich nicht möglich. Die kollektive Entscheidung (politische Abstimmung) kann das fehlende Plebiszit der Nachfrager nach öffentlichen Leistungen immer weniger ersetzen, da die Fähigkeiten und Leistungen der Anbieter einseitig an den Ausgaben gemessen werden, nicht aber daran, inwieweit sie die knappen Ressourcen tatsächlich effizient einsetzen.

Bei der Verhandlung um die Aufteilung der gemeinschaftlichen Finanzmittel im föderalen Staat wird sich keine Gruppe (gebietskörperschaftliche Ebene) zugunsten einer anderen mit ihren Forderungen zurückhalten. Warum sollte sich beispielsweise eine Gemeinde unter diesen Gesichtspunkten mit einem "unterdurchschnittlichen" oder nur "normalen" Angebot an kollektiven Leistungen zufriedengeben, wenn die damit verbundenen Einsparungen die eigenen Bürger nicht spürbar entlasten? Mitnahmeeffekte 
und Eigeninteressen bestimmen also die kommunalpolitischen Belange, weil eine Kommune, die im wesentlichen von der übergeordneten Ebene alimentiert wird, bei der Festsetzung ihres Leistungsangebots ohne finanzielle Autonomie ein "free rider"Verhalten offenbart. Sie kann kommunale Leistungen veranlassen, die vornehmlich den Mitgliedern "ihrer" Kommune Vorteile verschaffen, gleichzeitig aber hinsichtlich der Finanzierung auf "nationale" (überregionale) Steuertöpfe zurückgreifen und so dazu beitragen, daß "Nichtnutzer" in einem nicht unerheblichen Ausmaß an der Finanzierung dieser Leistungen beteiligt sind. Ein solches Trittbrettfahrerverhalten läßt sich prinzipiell (bei entsprechend ausgestaltetem Finanzierungssystem) bei allen Kommunen vermuten, so daß eine nicht-effiziente Mittelverwendung in erheblichem Ausmaß die Folge wäre. Die Bedeutung fiskalischer Äquivalenz bzw. des angesprochenen Interessenausgleichs für die Allokationsentscheidungen in einer Volkswirtschaft werden nochmals mehr als deutlich. Bedeutsam ist folglich auch ein "vertikaler Interessenausgleich" zwischen den Ebenen, der sich durch eigenständige lokale Finanzierungssysteme ebenfalls realisieren ließe.

Populär und plakativ ausgedrückt hieße das für ein kommunales Finanzierungssystem unter den Zielsetzungen von Allokationseffizienz und fiskalischer Äquivalenz bzw. einem Interessenausgleich: So viele Gebühren und Beiträge wie möglich und so wenige Finanzzuweisungen wie nötig. Dazwischen bliebe genügend Raum für am Prinzip des Interessenausgleichs ausgerichtete Gemeindesteuern, die - trotz der geforderten Ausschöpfung der Gebührenpotentiale und der (vor allem aus allokativen Erwägungen heraus) nach wie vor notwendigen Zuweisungen (vgl. Kapitel 10) - weiterhin die bedeutendste Einnahmekategorie eines kommunalen Finanzsystems darstellen.

\subsection{Grundstruktur eines kommunalen Finanzsystems}

Der Aufbau des kommunalen Finanzsystems im föderativen Staat ist demnach eine wesentliche Voraussetzung für die Realisierung der mit staatlicher Dezentralisierung verbundenen Effizienzvorteile. In welchem Ausmaß dabei der lokalen Ebene finanzielle Ressourcen zur Verfügung stehen bzw. gestellt werden sollen, hängt ab von

- dem Umfang der Tätigkeit (d.h. Niveau und Struktur kommunaler Aufgaben),

- dem Ausmaß der Effizienzvorteile, die durch die dezentralisierte Entscheidungsfindung erreichbar sind sowie

- der Bedeutung distributionspolitischer Maßnahmen auf der lokalen Ebene.

Unter Autonomiegesichtspunkten und zur Realisierung einer möglichst effizienten Ressourcenallokation sollte nach einer möglichst vollständigen Ausschöpfung der Ge- 
bührenpotentiale 289 der Anteil der Steuern an der kommunalen Finanzmasse so groß sein, wie es die Allokationseffizienz (oder abgeschwächt die fiskalische Äquivalenz) erfordert und andere Ziele wie Korrespondenz ${ }^{290}$ und Kompatibilitä ${ }^{291}$ es zulassen. Ein genügend großer Steueranteil an der kommunalen Finanzmasse stärkt die Einnahmeautonomie und erlaubt so im Sinne einer allgemeinen fiskalischen Äquivalenz "Steuerpreissignale" soweit wie möglich fühlbar werden zu lassen. Dadurch können die angestrebten Zielsetzungen dezentraler öffentlicher Leistungserstellung und ihrer Finanzierung weitestgehend realisiert werden. Über- oder unterdurchschnittliche Steueranspannungen sollten zur Wahrung der Einnahmenautonomie nicht durch gegenläufige Maßnahmen des Finanzausgleichs kompensiert werden. Je nach Steuersystem und Fühlbarkeit der Steuerbelastung wird sogar eine Unterstützung der Unterschiede in der Steueranspannung für erforderlich gehalten. ${ }^{292}$

Der Anteil der zweckgebundenen Zuweisungen an der Finanzausgleichsmasse sollte zur Wahrnehmung der "Verwendungsautonomie" nur so hoch sein, wie dies zur Abgeltung - also Internalisierung - von räumlichen Externalitäten und zur Gewährleistung von notwendigen Standards (Mindestversorgung) in wichtigen Aufgabenbereichen notwendig ist. Durch eine solche "Selbstbeschränkung" wird eine Unterstützung der Allokationseffizienz erreicht.

Insgesamt gesehen soll das kommunale Finanzierungssystem also die Aufgabenerfüllung der Gemeinden nicht nur unterstützen, sondern eben erst gewährleisten (Äquivalenzgedanke), sich dabei aber in das gesamtstaatliche (finanzpolitische) Zielsystem so einfügen (Kompatibilität), daß es keine Aushöhlung verteilungs- bzw. stabilitätspolitischer Aufgabenbereiche gibt. Tabelle 11.1 liefert einen kurzen Überblick der Finanzquellen lokaler Gemeinwesen. Diese sind dabei nach dem Grad der fiskalischen Autonomie geordnet.

289 Ihnen kommt bei der Gegenüberstellung von Finanzbedarf und Finanzkraft Bedeutung zu, denn die Ausschöpfung vorhandener Gebührenpotentiale liefert nicht nur eine Basis für autonome Finanzierungsspielräume, sondern sichert auch die effiziente Leistungsbereitstellung über individuelle "(Steuer-)Preise".

290 Unter Korrespondenz versteht man die möglichst weitgehende Entsprechung von Finanzausstattung und Finanzbedarf bzw. die Minimierung möglicher Abweichungen (vgl. dazu Seiler, 1988, 515).

${ }^{291}$ Kompatibilität verlangt die Einordnung des kommunalen Finanzierungssystems in das gesamtstaatliche Steuer-Transfer-System und die Beachtung gesamtwirtschaftlicher Zielsetzungen wie Distribution und Stabilisierung. Diesem Aspekt wird vor allem im năchsten Kapitel noch weitergehende Beachtung geschenkt.

292 Ein Beispiel sind die "tax incentives" in den Zuweisungsformeln des Steuerverbundes in den Vereinigten Staaten (vgl. Mennel, 1980, USA, 7ff). 
Tabelle 11.1: Rangfolge der Finanzquellen der kommunalen Ebene gemäß des jeweiligen Grades fiskalischer Autonomie 293

\begin{tabular}{|l|l|}
\hline Finanzquelle & Kennzeichen \\
\hline Leistungsentgelte & $\begin{array}{l}\text { Die lokale Ebene ist in der Lage, für bestimmte individuell zurechen- } \\
\text { bare Leistungen Gebühren und Beiträge zu erheben. }\end{array}$ \\
\hline Eigene Steuern & $\begin{array}{l}\text { Bemessungsgrundlagengestaltung und Steuersatzvariation in kommu- } \\
\text { naler Eigenverantwortung. }\end{array}$ \\
\hline Zuschlagsfähige Steuern & $\begin{array}{l}\text { Es existiert eine bestimmte nationale Steuerquelle mit entsprechender } \\
\text { Bemessungsgrundlage, auf die die kommunale Ebene durch Festle- } \\
\text { gung eines Steuer- oder Hebesatzes einen Zuschlag erhebt. }\end{array}$ \\
\hline Gemeinschaftsteuern & $\begin{array}{l}\text { Gesamtstaatliche Festlegung von Steuerbemessungsgrundlagen und } \\
\text { Steuersätzen; das Aufkommen solcher Abgaben fließt jedoch allen ge- } \\
\text { bietskörperschaftlichen Ebenen in bestimmter Aufteilung zu. Auf die } \\
\text { Verteilung kann die kommunale Ebene in möglichen Verhandlungen } \\
\text { Einfluß nehmen. }\end{array}$ \\
\hline $\begin{array}{l}\text { Allgemeine Finanzzuwei-- } \\
\text { sungen }\end{array}$ & $\begin{array}{l}\text { Finanzierungsbeitrag zur kommunalen Finanzausstattung von einer } \\
\text { übergeordneten Gebietskörperschaft, der von dieser gemäß bestimmter } \\
\text { Verteilungsschlüssel festgelegt wird. Die Verwendung dieser Finanz- } \\
\text { mittel ist auf der kommunalen Ebene frei. }\end{array}$ \\
\hline Zweckzuweisungen & $\begin{array}{l}\text { Zuweisung einer übergeordneten Gebietskörperschaft, deren Auszah- } \\
\text { lung aber an die Durchführung einer bestimmten Aktivität } \\
\text { (möglicherweise auch mit Eigenbeteiligung) seitens der empfangenden } \\
\text { Kommune gebunden ist. Ein fiskalischer Freiheitsgrad ist somit kaum } \\
\text { mehr vorhanden. }\end{array}$ \\
\hline
\end{tabular}

\subsubsection{Ausschöpfung der Gebührenpotentiale}

Bei Abwägung der Frage, ob die Gebühr der Steuer und den anderen Finanzierungsalternativen vorzuziehen sei oder nicht, kann man sich auf vier wesentliche Aspekte beschränken. Wie in Kapitel 8 offenkundig wurde, kann sich die öffentliche Hand durch die Gebühren- und Beitragserhebung die Vorzüge des Preismechanismus zunutze machen, wodurch sich die Ressourcen im öffentlichen Sektor an sich und im Verhältnis zum privaten Sektor weit effizienter ausnutzen ließen. Auch die aus der föderativen Ausgestaltung vieler Gemeinwesen resultierenden "Verteilungs-"probleme zwischen den einzelnen gebietskörperschaftlichen Ebenen (so etwa die Auseinandersetzung der Gebietskörperschaften um einen entsprechenden Anteil am Steueraufkommen) ließen sich durch eine Ausweitung des Gebührenprinzips beträchtlich reduzieren. Das komplizierte System des Finanzausgleichs könnte durchsichtiger und vereinfacht werden.

Der Einwand, eine intensivere Nutzung der Gebührenpotentiale würde den Verwaltungsaufwand (Identifikation gebührenfähiger Tatbestände, Abgrenzung der Nutzer,

293 Die kommunale Verschuldung wird infolge ihrer Besonderheiten (vgl. etwa Rakers, 1979) in dieser Betrachtung der Finanzierungsquellen der Kommunen nicht gesondert behandelt. Außerdem würde eine Betrachtung hinsichtlich der Zielsetzung dieser Studie keine grundlegenden Erkenntnisgewinne liefern.

Hans-Georg Napp - 978-3-631-75263-0 
Zuordnung des Leistungsempfangs, Durchsetzung des Gebührenanspruchs) beträchtlich erhöhen, verliert zum einen für die kommunale Ebene mit ihren äquivalenzorientierten Vorteilen infolge der Präferenznähe und der möglichen Radizierbarkeit öffentlicher Leistungen und ihrer Finanzierung und zum anderen durch die Einführung moderner Erhebungstechniken entscheidend an Bedeutung. Vergleicht man den damit verbundenen Aufwand schließlich mit den beim Finanzausgleich und in der Steuerverwaltung möglichen Einsparpotentialen, werden die Argumente für eine Ausschöpfung der Gebührenpotentiale eher noch verstärkt.

Ähnlich verhält es sich mit den alten Bedenken, die auf die unsozialen Folgen der Gebühr hinweisen. Wie im achten Kapitel erkennbar, sind diese Einwände aus zwei Gründen nicht stichhaltig. Zum einen lassen sich mit Realleistungen nur sehr schwer (auf Personen oder Gruppen zurechenbare) Verteilungseffekte realisieren. Zum anderen stehen heute Methoden für eine monetäre Umverteilung zur Verfügung, die einen wesentlich höheren Zielrealisierungsgrad aufweisen und mehr Genauigkeit bei der Redistribution besitzen, als dies mit Realtransfers möglich ist. Die personelle Verteilung der Realnutzen staatlicher Dienste ist nur indirekt und auch nur näherungsweise erfaßbar, solange die Finanzierung durch allgemeine Deckungsmittel des Gesamthaushalts erfolgt. Dies liegt auch daran, daß die Zahl der Begünstigten sehr groß ist und die jeweilige Nutzungsmöglichkeit nicht erfaßt werden kann. Das free-rider-Problem führt folglich dazu, daß auch bei den lokalen öffentlichen Gütern, sofern sie über allgemeine - nicht äquivalenz-orientierte - Abgaben finanziert werden, weder ein effizientes noch ein gerecht verteiltes Leistungsangebot realisierbar ist.

Zusammenfassend kann bis hierher festgehalten werden, daß aktuelle Fehlentwicklungen der Kommunalfinanzen häufig darauf zurückzuführen sind, daß finanzpolitische Verantwortung und lokale finanzwirtschaftliche Kompetenz nicht (mehr) deckungsgleich sind. Deshalb sollten Vorschläge für eine effektivere Ausgestaltung des Gemeindefinanzsystems darauf abzielen, diese beiden Elemente wieder zur Deckung zu bringen. Ein intensiver Rückgriff auf das Instrumentarium der Gebühren und Beiträge würde diesem Ziel nicht zuletzt deshalb entsprechen, weil dadurch eine stärkere Dezentralisation der finanzpolitischen Entscheidungen möglich würde.

\subsubsection{Erhebung äquivalenzorientierter Steuern}

\subsubsection{Von der einzelsteuerlichen Beurteilung zur Konstruktion eines Steuersystems}

Die in Kapitel 9 beispielhaft durchgeführte "Eignungsprüfung" von einzelnen für ein kommunales Steuersystem als relevant angesehenen Abgaben stellte - neben der Be- 
trachtung der Gebühren und Beiträge - den ersten Schritt zur Ableitung der Grundstrukturen eines geeigneten Gemeindefinanzsystems dar. Es wurde erkennbar, welche allokativen Auswirkungen die einzelne Abgabe bei ihrer Verwendung als Kommunalsteuer und welche Bedeutung diese Abgabe in bezug auf die Realisierung des der gemeindlichen Besteuerung vorgebenen Zielsystems hätte.

Die weiteren Anwendungsschritte haben das Ziel, die Zusammensetzung eines kommunalen Steuersystems aus mehreren Einzelabgaben zu verdeutlichen. Es muß also eine Auswahl aus den überprüften Einzelabgaben getroffen werden. Dabei spielen die Verzahnungen innerhalb des Systems eine wichtige Rolle, denn nunmehr kann die einzelne Abgabe nicht mehr isoliert betrachtet, sondern muß in ihrem Zusammenspiel mit den anderen Steuern gesehen werden.

\subsubsection{Zur Notwendigkeit eines mehrgliedrigen gemeindlichen Steuersystems}

Bereits den Ausführungen Adolph Wagners $(1890,414)$, daß gerade für die gemeindliche Besteuerung "... eine Combination verschiedenartiger Steuern zweckmäßig und geboten .. " sei, falls die kommunale Steuerpolitik "gerecht" und "wirthschaftlich richtig" sein solle, kann entnommen werden, daß die Notwendigkeit eines mehrsäuligen kommunalen Steuersystems existiert. Es wird sich in der finanzwissenschaftlichen Literatur auch kaum eine Stimme finden lassen, die das physiokratische Ideal der "Alleinsteuer" auf den gemeindlichen Sektor übertragen sehen möchte.

Die Forderung nach einem mehrgliedrigen Gemeindesteuersystem bedeutet aber nicht nur, daß ein kommunales System mehrere Einzelabgaben enthalten soll. Sie hat auch einen "dynamischen" Aspekt. Bei der Konstruktion des Systems muß darauf geachtet werden, daß letzteres nicht zu einer "Monokultur" aufgrund systemimmanenter Mängel wird. ${ }^{294}$ Nachfolgend aufgeführte Aspekte werden in erster Linie zur Unterstützung und Rechtfertigung von Forderungen nach einem mehrgliedrigen Gemeindesteuersystem genannt:

- Herstellen teiläquivalenter Beziehungen

Wenn zum einen erkannt wird, daß kommunale Teilgruppen in unterschiedlichem Maße gemeindliche Leistungen verursachen bzw. direkt beanspruchen und zum anderen verlangt wird, daß keine Umverteilungen von Lasten auf Nichtnutznießer

294 Gerade dies dürfte die große Schwäche des bundesdeutschen Gemeindesteuersystems der fünfziger und sechziger Jahre gewesen sein, in denen eine starke Anspannung der Gewerbesteuer festgestellt und als wesentlicher Mangel des Systems hervorgehoben wurde (vgl. etwa Institut "Finanzen und Steuern", 1966, $310 \mathrm{ff}$ sowie zusammenfassend Napp, 1993). 
bzw. Nicht-Lastenverursacher erfolgen sollen, um einen effizienten Interessenausgleich sicherzustellen, so hat dies zur Konsequenz, daß diesen Anforderungen nur ein mehrgliedriges Gemeindesteuersystem gerecht wird. Folglich muß in Anlehnung an den Grundsatz des Interessenausgleichs auch zwangsläufig die Forderung der Schaffung mehrerer Säulen für ein gemeindliches Steuersystem erhoben werden. Will man also eine bedarfsorientierte (äquivalente) Verteilung der steuerlichen Lasten gewährleisten, müssen sich die unterschiedlichen Bemessungsgrundlagen und damit die unterschiedlichen Abgabeformen an verschiedenen Anknüpfungstatbeständen orientieren.

- Erreichen der gewünschten Breitenwirkung

Ein mehrgliedriges Steuersystem ist viel eher dazu geeignet, einen möglichst breiten Kreis an Gemeindebürgern in die Besteuerung einzubeziehen, als ein "System", das im Extremfall nur eine Abgabe umfaßt. Es sei nur daran erinnert, daß die staatliche Ebene den Kommunen bezüglich der Abgrenzung des Kreises der Steuerpflichtigen - wenn überhaupt - allenfalls bei einzelnen Steuern freie Hand lassen wird.

- Reduzierung der räumlichen Streuung

Bei einem mehrgliedrigen Steuersystem der gemeindlichen Ebene kann man eher erwarten, daß sich die negativen Folgen regional stark streuender Steuerobjekte insgesamt ausgleichen. 295

- Förderung der Flexibilität des Systems

Ein mehrgliedriges System eröffnet Möglichkeiten für eine flexible Steuerpolitik. So kann je nach kommunaler Grundstruktur jeweils die eine oder die andere Steuerquelle stärker ausgeschöpft werden; je nachdem ob es sich beispielsweise um eine Wohngemeinde oder einen Produktionsstandort, eine Einkaufsstadt oder ein touristisches Zentrum handelt. Diese Flexibilität erfordert die Möglichkeit seitens der Gemeinden, Aufkommensvariationen bei den einzelnen Abgaben durchzuführen und damit dem Grundsatz der Flexibilität erst nachkommen zu können.

295 In der Bundesrepublik Deutschland ist die als Mangel des praktizierten Systems der fünfziger und sechziger Jahre apostrophierte starke Streuung letztlich Ergebnis einer Entwicklung gewesen bzw. ist sie immer noch, $\mathrm{daB}$ das gemeindliche Steuersystem im Zeitablauf de facto ein "Ein-Steuer-System" wurde. Man spricht in diesem Zusammenhang auch von der Kopflastigkeit der Gewerbesteuer (vgl. Marcus, 1986, $210 \mathrm{f}$ ). 
- Vermeidung von Überbeanspruchungen einzelner Steuerquellen

Wenn ein Steuersystem aus mehreren Säulen besteht, aber im Grunde genommen faktisch nur auf einer Säule ruht, weil die übrigen Abgaben kaum eine budgetäre Bedeutung besitzen und/oder diese zunehmend verloren haben, so ist es wenig verwunderlich, wenn diese zunächst sehr ergiebige Steuerquelle eine zunehmende Ausschöpfung (Überbeanspruchung) erfährt. Die Tatsache, daß es mehrere - wirklich ergiebige und steuersystematisch intakte - Steuerquellen gibt, beugt solchen Fehlentwicklungen (Beispiel Bundesrepublik Deutschland) vor.

- Vermeidung übermäßiger Verknüpfungen mit dem staatlichen Steuersystem

Es ist zu erwarten, daß die Abkoppelung des kommunalen vom staatlichen Steuersystem (also die Vermeidung von direkten und indirekten Einflußmöglickeiten der staatlichen Ebene auf das kommunale Steueraufkommen) bei einem mehrgliedrigen System ceteris paribus in größerem Umfang möglich ist als bei einem "Ein-SteuerSystem". Man kann davon ausgehen, daß sich der staatliche Regelungseifer nicht auf alle kommunalen Abgaben in gleicher Weise erstreckt. Ebenso dürfte der instrumentelle Charakter des kommunalen Steuersystems bei einer mehrgliedrigen Ausgestaltung geringer werden. Der Hang der staatlichen Ebene, gemeindliche Abgaben auf indirektem Wege mit in ihre Politik einzubeziehen, wird sich vornehmlich auf diejenigen beschränken, welche eine enge Verwandtschaft zu staatlichen Abgaben besitzen (beispielsweise Gewerbeertrag- und Einkommensteuer). Dieses Argument wird bei der abschließenden Würdigung geeigneter Abgaben noch eine Rolle spielen.

\subsubsection{Teilkomponenten eines äquivalenzorientierten Gemeindesteuersystems}

Bei der Untersuchung geeigneter Gemeindesteuern ist davon ausgegangen worden, daß die gemeindlichen Leistungen in erster Linie den in der Gemeinde wohnenden Bürgern und den dort ansässigen Unternehmen zugute kommen. Eine weitere Nutzergruppe, die sich aber teilweise mit den vorgenannten deckt, sind die Grundstücksbesitzer. Anknüpfend an diese drei Faktoren Arbeit, Kapital und Boden (in Verbindung mit dem Vorleistungscharakter der gemeindlichen Güter und Dienstleistungen) sollte ein an Effizienzgesichtspunkten ausgerichtetes - d.h. fiskalische Äquivalenz bzw. einen Interessenausgleich garantierendes - Gemeindesteuersystem zunächst aus einer einwohnerbezogenen, einer produktionsbezogenen und einer grundbesitz- bzw. bodenbezogenen Abgabe bestehen. 
Weil es nur im Idealfall möglich sein wird, die Nutzen aus den Leistungen einer Gemeinde auf ihren Raum begrenzen zu können (Kongruenzprinzip), gibt es auch Leistungsempfänger außerhalb der Grenzen jener Gemeinde, die diese Leistungen bereitstellt. Neben den in diesem Zusammenhang zur Internalisierung räumlicher spillovers erforderlichen Finanzzuweisungen (aber auch teilweise an deren Stelle) ist auch innerhalb des kommunalen Steuersystems an sich ein (Teil-)Ausgleich solcher räumlicher Überlappungen denkbar. Ein an Allokationsaspekten orientiertes kommunales Steuersystem könnte also neben den bereits genannten einwohner-, produktions- und grundbesitzbezogenen Abgaben als vierte Säule eine "exportbezogene" Abgabe enthalten. Dies ist um so notwendiger, je stärker der Grad der Zentralörtlichkeit und damit die Existenz räumlicher spillovers aus der Funktion des Oberzentrums als Einkaufsort erklärbar wird. Ist dies der Fall, könnte eine "exportbezogene" Steuer diejenigen, die zum Einkauf von Sachgütern oder zur Inanspruchnahme von Dienstleistungen mehr oder weniger oft einpendeln und dafur kommunale Infrastruktur in Form von Verkehrswegen, Parkplätzen etc. nutzen, an der Finanzierung des kommunalen Leistungsangebots beteiligen. 296

\subsection{Einwohnerbezogene Komponente}

Als geeignet erscheinende einwohnerbezogene Abgabeformen können

- eine gemeindliche Einkommensteuer in Anlehnung an die bestehende staatliche Einkommensteuer (aber mit einem kommunalen Hebesatzrecht),

- eine gesondert konzipierte Einkommensteuer der Gemeinden oder

- vereinfachte auf den Bürger bezogene Steuern (Einwohner- bzw. Bürgersteuern)

296 Als fünftes Standbein werden hăufig ergănzende spezifische Lenkungsabgaben oder andere ortliche Verbrauch- und Aufwandsteuern auf der kommunalen Ebene gesehen. Angesichts der seitens der Kommunen immer wieder beklagten finanziellen Probleme - insbesondere auch aufgrund der gestiegenen Belastungen auf der Ausgabenseite - sind Städte und Gemeinden immer hăufiger dazu übergegangen, von der Möglichkeit Gebrauch zu machen, sich die notwendigen Finanzmittel durch eigene kommunale Einnahmen, u.a. auch neue Steuern, zu beschaffen. Die kommunale Zweitwohnungsteuer war bislang das bekannteste Beispiel für den eingeschlagenen Lósungsweg. Zur Zeit stellt sich die Frage, ob durch Ausübung des kommunalen Steuerfindungsrechts - d.h. der den Kommunen zustehenden Befugnis zur Erhebung selbstentwickelter Steuern - weitere Einnahmequellen zu erschließen sind. Die Einfuhrung neuer kommunaler Steuertypen, beispielsweise der Reitpferdesteuer, der Getrănkeverpackungsteuer oder der Bodenwertzuwachssteuer, ist Gegenstand rechtspolitischer Diskussionen. Häufig werden zur Rechtfertigung der neuen kommunalen Steuern außerfiskalische Ziele genannt, beispielsweise ordnungs- oder umweltpolitische Ziele. Mohl (1992) hat eine rechtliche Analyse der Einführung entsprechender neuer Abgaben im Rahmen der ortlichen Verbrauch- und Aufwandsteuern durchgeführt. Er kommt zu dem Ergebnis, daß die Einführung und Erhebung bestimmter Steuern als rechtlich zulăssig anzusehen ist. Unter okonomischen Gesichtspunkten, speziell auch vor dem Hintergrund der administrativen Einfachheit sowie der Erhebungs- und Entrichtungsbilligkeit der Steuern ist aber eine umfangreiche Ausschöpfung dieser juristischen Möglichkeiten eher negativ zu beurteilen. 
angesehen werden. Die größere Merklichkeit bzw. Fühlbarkeit einer Steuer führt in der Regel gleichzeitig zu einer stärkeren Einbindung der Bürger in die gemeindlichen Entscheidungen. Die Merklichkeit der Aufgabenerfüllung und ihrer Finanzierung ist von besonderer Bedeutung, denn der Bürger muß bei Forderungen an die Kommune spüren, daß deren Erfüllung nur umzusetzen ist durch den Einsatz von Kräften und Mitteln, die er selbst aufzubringen hat. Das Bewußtsein wächst, daß das "eigene" Geld für entsprechende Projekte bzw. bereitzustellende lokale öffentliche Leistungen Verwendung finden soll; dies kann insbesondere in kleineren Gemeinden eine stärkere politische Betätigung bewirken. Beide Aspekte, die erhöhte Merklichkeit und die stärkere Einbeziehung der Bürger, sind komplementäre Faktoren für die Erfüllung der bedeutendsten kommunalspezifischen Steuerzielsetzung, der Sicherung der fiskalischen Äquivalenz. Diese Forderung besagt bekanntlich, daß der Entscheidungsträger, der über Ausgaben und ihre Vorteile für seine Wähler beschließt, auch verpflichtet sein muß, diese (seine) Wähler zugleich mit den entsprechenden Abgaben zu belasten. Diese unter der Allokationszielsetzung wichtige Wirkung ist neben der Erhebung von Gebühren und Beiträgen im Bereich der Besteuerung nur mit beweglichen Abgaben möglich.

Nur mit einer "beweglichen" Einkommensbesteuerung (vgl. Hansmeyer/Zimmermann, 1991; 1992) auf Gemeindeebene ist prinzipiell die Ausrichtung der öffentlichen Tätigkeit nach Art und Umfang an den Präferenzen der Bürger zu sichern, und zwar auch in der Grenzbetrachtung, also bei laufenden Entscheidungen schon während der Wahlzyklen (beispielsweise via Mobilität). Diese Ausrichtung der kommunalen Aufgaben und Ausgaben einerseits und der dafür erforderlichen Einnahmen andererseits an den Präferenzen der Bürger ist die zentrale allokative bzw. ordnungspolitische Forderung bei der Ausgestaltung kommunaler Finanzierungssysteme.

Wenn man von den Zielen für ein gemeindliches Steuersystem ausschließlich diejenigen heranzieht, die sich auf die Gemeindefinanzen selbst beziehen, so erscheint es sinnvoll, eine gesonderte Einkommensteuer für die Gemeinden zu konzipieren (vgl. Zwilling, 1971; Marcus, 1986, 150ff). Für eine solche kommunale Einkommensteuer sprechen neben ihrer Eignung zur Realisierung fiskalischer Äquivalenz vor allem ihre distributiven Eigenschaften (etwa im Vergleich zur - an die Kopfsteueridee angelehnten - Bürger- bzw. Einwohnersteuer) und die entsprechende Einordnung in bestehende Steuer-Transfer-Systeme. Nachteilig wirken sich die Interdependenzen zwischen staatlicher und kommunaler Einkommensbesteuerung (wichtige distributive Ziele der staatlichen Einkommensteuer werden möglicherweise konterkariert) ${ }^{297}$, die zentralstaatliche

297 Beispielsweise wăre die bei beiden Steuern - dèr staatlichen und der kommunalen - sich ergebende addierte Progressionswirkung nicht mehr abschätzbar, weil beispielsweise die Tarife differieren oder die Behand- 
Beeinflußbarkeit und technische Schwierigkeiten (etwa wegen des gesonderten Veranlagungsverfahrens) aus. Dies gilt ähnlich auch für die Installierung eines kommunalen Hebesatz- oder Zuschlagsrechts zur staatlichen Einkommensteuer, wie sie etwa Hansmeyer/Zimmermann (1991; 1992) oder Fromme (1992) fordern.

Unter dem Eindruck dieser kritischen Argumente liegt es nahe, über einen alternativen Weg nachzudenken und für eine gemeindliche Steuer auf private Haushalte vereinfachte Formen zu wählen, wie etwa eine Bürger- bzw. Einwohnersteuer. Diese bietet eine weitgehende Unabhängigkeit von der staatlichen Einkommensteuer und damit auch von distributionspolitischen Erfordernissen. Die distributiven Wirkungen einer Einwohnersteuer müssen zwar auch in Zusammenhang mit dem gesamten Steuer- und Transfersystem gesehen werden, aber infolge ihrer besonderen Ausgestaltung tangiert sie dieses nicht (direkt). Insgesamt gesehen muß aber die Einwohnersteuer unter Verteilungsgesichtspunkten eindeutig negativ beurteilt werden. ${ }^{298}$ Ihre Vorzüge liegen hingegen - ebenso eindeutig - in ihrer Eignung, Fühlbarkeit und Transparenz des kommunalen Steuersystems und dem Tatbestand, die Verantwortlichkeit ("fiscal responsibility") innerhalb der Gemeinde zu stärken. Allokativ ist eine Einwohnersteuer mit konstanten Steuerbeträgen pro Kopf allerdings nur dann effizient, wenn die Kosten der Bereitstellung lokaler öffentlicher Güter ebenfalls konstant pro Person sind. Unter solchen Rahmenbedingungen kann man ihr aufgrund ihrer Vorzüge und unter Berücksichtigung ihrer distributiven Nachteile grundsätzlich eine (untergeordnete) Rolle in einem Gemeindefinanzsystem zubilligen. Das ändert aber nichts daran, daß sie als alleinige residuale Finanzquelle ungeeignet ist, denn bei einer Marginalbetrachtung werden die ausschließlich einwohnerinduzierten zusätzlichen Bedarfe nie hundert Prozent ausmachen. ${ }^{299} \mathrm{Ganz}$ abgesehen davon werden sich diese Bedarfe kaum präzise genug anteilmäßig angeben lassen.

lung des Familienstandes unterschiedlich ausfiele. Gerade weil die Einkommensteuer so zahlreiche Ziele der Wirtschafts- und Sozialpolitik berücksichtigt, eignet sie sich kaum für eine solche zusătzliche Erhebungsform.

298 "Dies trifft möglicherweise gesamtwirtschaftlich nicht zu, weil ein gewünschter Umverteilungsgrad mittels der staatlichen Einkommensteuer erreicht worden sein kann und vor diesem Hintergrund eine hierbei bereits berücksichtigte kommunale Kopfsteuer (oder annähernde Kopfsteuer) verteilungspolitisch durchaus angemessen erscheinen mag." (Hansmeyer/Zimmermann, 1991, 644)

299 Die in Großbritannien mit der "Poll Tax" vorgesehene Restfinanzierungs- (Residual- bzw. Lückenbüßer-) und Signal-(Indikator-)funktion bei überdurchschnittlichen Ausgaben ist dann aber unter allokationspolitischem Blickwinkel verfehlt (vgl. Diekmann/Schütz, 1989, 250). 


\subsection{Produktionsbezogene Komponente}

Mit den produktionsbezogenen Abgaben soll eine (direkte) finanzielle Beteiligung der Empfänger (Nutzer) gemeindlicher Infrastrukturleistungen für Produktionszwecke bewirkt werden. Im Rahmen der Einzelanalyse geeigneter Steuern sind fünf Vorschläge diskutiert worden. Grundsätzlich hat jede dieser Alternativen ihre Nachteile. Das gilt in besonderem Maße für die Gewerbesteuer (strukturelle und steuersystematische Mängel) und die Umsatzsteuerbeteiligung mit einem produktionsbezogenen Verteilungsschlüssel (infolge der nur indirekten fiskalischen Äquivalenzbeziehung und der mit der Schlüsselermittlung verbundenen technischen Probleme), aber auch für die neueren Modelle einer Wertschöpfungsteuer bzw. einer Cash-flow-Steuer.

Die Gewerbesteuer ist der Wertschöpfungsteuer bezüglich ihrer Allokationsneutralität unterlegen. Weil die von der Gewerbeabgabe einbezogenen Teilerträge nach unterschiedlichen Verfahren ermittelt werden (neben der direkten noch die indirekte Ertragsermittlung), wird sich eine ungleiche Belastung derselben wohl kaum vermeiden lassen. Die Wertschöpfungsteuer hingegen bezieht die Erträge sämtlicher Faktoren ein und belastet diese gleich. Das derzeitige Realsteuersystem (als praktisches Beispiel einer Gewerbebesteuerung) umfaßt weder sämtliche Teilerträge, noch arbeitet es mit einheitlichen Sätzen. Zwar könnte durch Modifizierung (etwa "Revitalisierung") hier einiges verbessert werden, dennoch dürfte das Wertschöpfungsteuermodell unter allokativen Zielsetzungen die überlegene Alternative darstellen. Selbst wenn man nicht in Abrede stellen kann, daß die exakte Berechnung der Wertschöpfung im Einzelfall sowie ihre umfassende Ermittlung generell Probleme aufwerfen könnte, dürfte eine Wertschöpfungsabgabe gegenüber der Gewerbesteuer auch Vorteile bei Erfüllung von Forderungen nach einer Vereinfachung der Besteuerung besitzen. Gemäß diesem allgemeinen Grundsatz der Besteuerung wird vor allem Transparenz verlangt. Die direkt Form der Erfassung (über die Wertschöpfungsermittlung) der steuerlichen Bemessungsgrundlage verdeutlicht diese Vorzüge gegenüber dem komplizierten und kaum noch überschaubaren Verfahren der praktizierten ("indirekten") Bestimmung (man denke etwa an die Hinzurechnungen und Kürzungen) der Erträge bei der Gewerbesteuer.

Die Cash-flow-Steuer ist der Gewerbesteuer ebenfalls in wichtigen Punkten überlegen. Sie wirkt investitionsfreundlich (weil finanzierungsneutral) und effizient (sie verzerrt die Entscheidungsstrukturen nicht), fördert ein konjunkturgerechtes Verhalten der Gemeinden und führt zu einer gleichmäßigeren Streuung des gemeindlichen Steueraufkommens. Andererseits steht sie weniger gut in Einklang mit dem Äquivalenzprinzip als maßgeblichem gemeindlichen Steuerpostulat. Gegenüber der Wertschöpfungsteuer liegen ihre ökonomischen Vorteile in der größeren Effizienz (keine Diskriminierung 
zwischen Sach- und Finanzanlage) und der leichteren und allgemeineren Erhebungsform. Die Zinsproblematik, die sich im Rahmen der Wertschöpfungsermittlung ergibt, stellt sich bei der Cash-flow-Steuer nicht. Eventuelle Ausnahmen für Kreditinstitute und andere Kapitalsammelstellen sind nicht erforderlich. Ein Nachteil der Cash-flowSteuer besteht möglicherweise in der stärkeren Streuung des Steueraufkommens zwischen den Gemeinden. Hier müßten aber (bislang noch nicht vorhandene) Aufkommensberechnungen erst Aufschluß über tatsächliche Entwicklungen geben.

Aus politischer Perspektive erweckt die Wertschöpfungsteuer einen günstigen Eindruck, weil wegen der breiteren Bemessungsgrundlage (etwa im Vergleich zu Gewerbesteuer) der Steuersatz niedriger sein könnte und steuerpolitische Widerstände somit eine andere Relevanz besäßen. Gegenüber der Cash-flow-Steuer scheint sie wegen der noch fehlenden praktischen Erfahrungen mit dieser (neuen) Steuerform ebenfalls politisch eher durchsetzbar zu sein.

Sowohl die Wertschöpfungsteuer als auch die Cash-flow-Steuer sind mit gewissen technischen und steuersystematischen Komplikationen verbunden, weil sie in bestehende Einkommen-, Körperschaft- und Vermögensteuersyteme integriert werden müßten.

Die Cash-flow-Steuer stellt sicherlich von allen betrachteten Alternativen die theoretisch eleganteste Lösung dar. Dabei sollte man sich zwar bewußt sein, daß die exakte Einbettung der Cash-flow-Steuer in ein Gemeindesteuersystem noch einer entsprechenden Klärung bedarf. Dennoch erscheint die neue Steueridee bedeutend genug, um in die Diskussion um die Ausgestaltung kommunaler Finanzierungs- und Steuersysteme aufgenommen zu werden, zumal die Wertschöpfungsteueridee nach ihrer "Blütezeit" zu Beginn der achtziger Jahre in der gegenwärtigen wissenschaftlichen und vor allem politischen Diskussion ${ }^{300}$ eine geringere Rolle spielt und daher (zumindest gegenwärtig) ebenfalls Durchsetzungsschwierigkeiten offenbart.

\subsection{Bodenbezogene Komponente}

Mit den bodenbezogenen Abgaben soll erreicht werden, daß auch flächenbezogene Kosten (Leistungen) der Gemeinde mit einer äquivalenzorientierten Abgabe finanziert werden können. Ergänzend zu einer einwohner- und einer produktionsbezogenen Ab-

300 Vgl. etwa Karrenberg (1992a; 1992b), Grünewald (1992) oder die Kommission zur Verbesserung der steuerlichen Bedingungen für Investitionen und Arbeitsplătze (1991). In seinem "Gutachten zur Reform der Unternehmensbesteuerung" ist hingegen der Wissenschaftliche Beirat $(1990,45)$ nach wie vor "... mehrheitlich der Auffassung, daß die Wertschöpfungsteuer ... die beste Lősung ist." 
gabe sollten im Rahmen eines unter Effizienzgesichtspunkten abgeleiteten Gemeindesteuersystems die von den Einwohnern und den Produzenten genutzten Flächen sinnvollerweise als Bemessungsgrundlage herangezogen werden. Flächenbezogen sind sämtliche Aufwendungen für Straßen und Plätze sowie für das Versorgungs- und Entsorgungsnetz (Strom-, Wasser- und Gasleitungen, Abwasserkanalisation). Bei den in diesem Zusammenhang anfallenden Aufwendungen ist zu unterscheiden zwischen denjenigen für die Neuanlage und denjenigen für die laufende Unterhaltung und Verbesserung. Bei Neuanlagen ist eine Kostendeckung über Anliegerbeiträge möglich, wobei eine Differenzierung angemessen erscheint, je nachdem, ob es sich um Teilstücke eines durchgehenden Netzes oder um Endstücke (Sackstraßen) handelt. Volle Kostendeckung ist bei Endstücken, teilweise Kostendeckung wegen der Mitnutzung durch Anlieger der sich anschließenden Teilstrecken bei "Durchgangsstraßen" geboten. Die laufenden Aufwendungen für Erhaltung und Verbesserung sind schließlich durch periodische Abgaben allgemeiner Art (also eine äquivalenzorientierte Grundsteuer) zu decken.

Die geeignetste Variante dieser bodenbezogenen Abgabe stellt eine Grundsteuer dar, die an physische Größen und nicht - wie bei der heutigen Grundbesteuerung - an Wertgrößen anknüpft. Wertgrößen sind nicht nur wegen der Bewertungsproblematik wenig geeignet, sondern vor allem auch deswegen, weil kein generell gültiger Zusammenhang zwischen Grundstückswerten und verursachten gemeindlichen Flächenkosten gesehen werden kann (vgl. Abschnitt 9.4.2). Das vorgeschlagene Modell einer äquivalenzorientierten Grundsteuer ist zwar mit einigen Definitions- und Abgrenzungsproblemen verbunden (insofern also keineswegs einfach), doch eine solche "Grundsteuer neuer Art" könnte auf der gemeindlichen Ebene als äquivalenzbezogene Abgabe eine wichtige Funktion einnehmen. Daher sollte man eigentlich nicht auf sie verzichten, denn zum einen ist ihre praktische Eignung in Abschnitt 9.4.2 dargelegt worden, und zum anderen handelt es sich vom Gewicht her um eine Art Nebensteuer (Ergänzungsteuer), denn diese Grundsteuer besitzt in der Regel eine geringere fiskalische Bedeutung als die beiden Hauptsäulen kommunaler Steuersysteme (nämlich die einwohner- und die produktionsbezogene Abgabe). Somit könnte man nach einigen Erfahrungen mit dieser neuartigen Abgabeform auch Korrekturen anbringen, deren Auswirkungen immer beschränkt blieben und die Grundkonzeption als solche nicht in Frage stellten.

\subsubsection{4 "Exportbezogene" Komponente}

Um auch dem Tatbestand Rechnung zu tragen, daß es Nutznießer gemeindlicher Leistungen gibt, die ihren Wohnsitz außerhalb einer die Leistung jeweils anbietenden 
Gemeinde haben, könnte eine "exportbezogene" Abgabe als vierte Säule eingerichtet werden. Dazu könnte unter bestimmten Rahmenbedingungen eine kommunale Endverbrauchsteuer geeignet sein. Zwar haben die entsprechenden Ausführungen (vgl. Abschnitt 9.5) auch eine Reihe von Vorbehalten gegen die Einführung einer kommunalen Endverbrauchsteuer verdeutlicht, doch bleibt die Frage, mit welchen Alternativen die fiskalischen Auswirkungen räumlicher spillovers auf der Gemeindeebene kompensiert werden können. Eine Antwort auf diese Frage könnte zwar die Gewährung von Finanzzuweisungen zur Internalisierung räumlicher Externalitäten sein, doch deren Analyse in Kapitel 10 zeigt auch die Problematik einer umfangreichen Zuweisungsgewährung übergeordneter an nachgeordnete Gebietskörperschaften und die Schwierigkeiten, die angestrebten ökonomischen, versorgungs- und/oder regionalpolitischen Ziele tatsächlich auch zu erreichen.

\subsubsection{Ergänzende Gewährung von Finanzzuweisungen}

Auch in einem an Äquivalenzgesichtspunkten und dem Grundsatz des Interessenausgleichs ausgerichteten Gemeindefinanzsystem hat das Instrumentarium der Finanzzuweisungen eine Bedeutung. Doch wie soll diese Rolle konkret aussehen und welche Formen von Finanzzuweisungen helfen bei der Realisierung der angestrebten Wirkungen, kompensieren dabei aber nicht vollends die positiven Eigenschaften eines ansonsten dezentral ausgerichteten Einnahmesystems?

Im Regelfall wird die Notwendigkeit zentralstaatlicher (Bund- oder Länder-) "Zuschüsse" zur Deckung des gemeindlichen Finanzbedarfs mit einer Reihe von Argumenten belegt. Die bedeutendste Begründung für die Notwendigkeit von Finanzzuweisungen wird in der Existenz räumlicher externer Effekte gesehen ("allocation objective"). Zweiter Begründungsrahmen für staatliche Zuweisungen ist das Ziel der Sicherung bestimmter Versorgungsniveaus bzw. die Gewährleistung von Mindeststandards kommunaler Leistungen aus meritorischen Gründen. Drittens werden Finanzzuweisungen wegen möglicher fiskalischer Ungleichgewichte gefordert. Mit sogenannten "revenue-sharing grants" (King, 1984, 121) soll eine Korrektur solcher Divergenzen erfolgen.

In der Praxis kommt zu diesen drei Begründungen (aus allokativer, meritorisch-distributiver oder regional- bzw. versorgungspolitischer Sicht) zumindest eine vierte hinzu, nämlich die fiskalische Zielsetzung von Finanzzuweisungen, die im Rahmen der kommunalen Finanzierungssysteme je nach konkreter Ausgestaltung einen bedeutenden Anteil der Gesamteinnahmen ausmachen. Doch gerade die generelle "Alimentierung" der lokalen Ebene durch Zuweisungsströme übergeordneter Gemeinwesen birgt unter 
Wohlfahrtsgesichtspunkten die gravierendsten Unwägbarkeiten. Daher sollten Zuweisungen auf ihre offenkundigen Aufgaben in allokativer Richtung beschränkt bleiben. Dabei ist aber vor allem auch die Wahl der Zuweisungsart von erheblicher Bedeutung. So sollten nicht allgemeine Zuweisungen eingesetzt werden, sondern Zweckzuweisungen mit möglichst eng auslegbaren Handlungsspielräumen für die Kommunen und gegebenenfalls entsprechende Eigenbeteiligungen bei zu fördernden bzw. gewünschten lokalen Aktivitäten vorgesehen werden, um die Realisierung der gewünschten Zielsetzungen zu garantieren.

\subsection{Zusammenfassende Darstellung der Säulen eines kommunalen Finanzsystems}

Die kommunale Selbstverwaltung steht und fällt mit der finanziellen Eigenverantwortung der Gemeinden. Zum Wesenskern der kommunalen Selbstverwaltung gehört folglich das Recht, daß die Städte und Gemeinden alle Angelegenheiten der örtlichen Gemeinschaft im Rahmen der Gesetze in eigener Verantwortung regeln können. Zur Eigenverantwortlichkeit in den entscheidenden Sachfragen gehört jedoch nicht nur die Autonomie in der Entscheidung über die Verwendung der vorhandenen Mittel, sondern ebenso unverzichtbar auch die Eigenverantwortlichkeit in der Beschaffung der für notwendig erachteten Einnahmen. Um die Gemeinden nicht zu "Kostgängern" der übergeordneten gebietskörperschaftlichen Ebenen werden zu lassen bzw. sie aus dieser Rolle herauszulösen, müssen die notwendigen Einnahmen der Gemeinden zum überwiegenden Teil entweder aus Gebühren und Beiträgen und/oder gemeindeeigenen Steuern kommen. Staatliche Zuweisungen sind kein Ersatz für eigene Steuern der Gemeinden.

Aus kommunaler Sicht ist auch eine verstetigte Einnahmeentwicklung notwendig, um die Einnahmeseite der kommunalen Haushalte von Konjunkturschwankungen unabhängiger zu machen und damit den Gemeinden die Möglichkeit zu geben, durch eine verstetigte Investitionspolitik ihrer Versorgungsaufgabe gleichbleibend und dauerhaft nachzukommen.

Um ein den beschriebenen Anforderungen gerecht werdendes Gemeindefinanzsystem zu schaffen, müssen die kommunalen Einnahmequellen (insbesondere die Steuern) auf möglichst breiter Grundlage angelegt werden. Neben strukturellen Verbesserungen eines existierenden Systems an sich (vor allem unter allokativen Gesichtspunkten), hätte ein solcher Vorschlag (sprich eine entsprechende Gemeindefinanzreform) vor allem qualitative (mehr kommunale (Finanz-)Autonomie) und quantitative (breitere Steuerbasis) Verbesserungen der gemeindlichen Ebene bzw. des kommunalen Finanz- 
gefüges zur Folge. Ein aufbauend auf diesen Überlegungen konzipiertes "optimales" Gemeindefinanzsystem hätte dann etwa folgendes Aussehen:

Tabelle 11.2: Struktur eines kommunalen Finanzsystems

\begin{tabular}{|c|c|}
\hline $\begin{array}{l}\text { Gebühren und Bei- } \\
\text { träge: }\end{array}$ & $\begin{array}{l}\text { Ansatzpunkte sollten lokale öffentliche Leistungen sein, die auf der einen Seite } \\
\text { den Charakter eines Mischgutes besitzen (also kollektive und zugleich private } \\
\text { Aspekte aufweisen) und bei denen auf der anderen Seite gewährleistet werden } \\
\text { kann, daß die Leistungsempfanger identifiziert und abgegrenzt werden } \\
\text { können (wobei die Abgrenzung wirtschaftlich vertretbar und gesellschaftlich } \\
\text { akzeptabel sein muß). }\end{array}$ \\
\hline Gemeindesteuern: & $\begin{array}{l}\text { Ansatzpunkte sollten (sofern sich die entsprechenden lokalen öffentlichen Lei- } \\
\text { stungen im vorgenannten Sinne als nicht gebührenfähig erwiesen haben) in } \\
\text { erster Linie die besonderen Belastungsfaktoren für eine Gemeinde sein. Als } \\
\text { solche Faktoren sind insbesondere zu nennen: } \\
\text { - die Einwohner mit ihren zahlreichen Ansprüchen an die kommunale Da- } \\
\text { seinsvorsorge: Einwohnersteuer } \\
\text { die vorhandenen Produktionsbetriebe mit den besonderen Belastungen und } \\
\text { Anforderungen für den Ausbau und Erhalt der Infrastruktur: Cash-flow- } \\
\text { bzw. Wertschסpfungsteuer } \\
\text { - der Haus- und Grundbesitz mit seinen Anforderungen an Ver- und Entsor- } \\
\text { gung: "Grundsteuer neuer Art" } \\
\text { die Nutznießer gemeindlicher Leistungen, die ihren Wohnsitz nicht inner- } \\
\text { halb einer die Leistung jeweils anbietenden Gemeinde haben: kommunale } \\
\text { Endverbrauchsteuer }\end{array}$ \\
\hline Finanzzuweisungen: & $\begin{array}{l}\text { Diesen kommt folglich nur noch eine ergänzende fiskalische Funktion } \\
\text { (Sicherung einer finanziellen Mindestversorgung in Form einer fiskalischen } \\
\text { "Grundausstattung") sowie die Aufgabe zu, für eine Internalisierung răumli- } \\
\text { cher externer Effekte zu sorgen. }\end{array}$ \\
\hline
\end{tabular}

\subsection{Praktikabilität des dargestellten Lösungsvorschlags}

Der bisherige Schwerpunkt der Überlegungen galt der theoretischen Ableitung eines unter Allokationsgesichtspunkten geeignet erscheinenden Gemeindefinanzsystems. Auf dieser theoretischen Basis

- können für die praktische Steuerpolitik verwertbare Steuerbuketts konstruiert werden,

- lassen sich praktizierte Systeme daraufhin beurteilen, ob sie der steuerpolitischen "Idealvorstellung" entsprechen und

- auf diese Art und Weise beurteilte und nicht als optimal angesehene Systeme reformieren. 
Das theoretisch entwickelte System könnte also zum Wegweiser und zur Richtschnur für die praktische Steuerpolitik werden. Es könnte als Maßstab im Rahmen von Steuerreformdiskussionen (wie etwa der bundesdeutschen Auseinandersetzung um die Gewerbesteuer und ihre Zukunft) Verwendung finden. Reformen, die sich an solchen objektiven Maßstäben orientieren, könnten im Gegensatz zur oft ideologisierten und interessenbezogen geführten politischen Diskussion eher zu brauchbaren und längerfristig akzeptierten Ergebnissen führen, weil durch mehr Entscheidungstransparenz haltbarere Kompromisse möglich erscheinen.

Die zentrale These der vorliegenden Untersuchung ist die Existenz spezifischer Zielsetzungen für die gemeindliche Finanzwirtschaft (abgeleitet aus der Besonderheit des lokalen öffentlichen Leistungsangebots und der damit verbundenen Finanzierungserfordernisse) und der daraus folgenden Notwendigkeit eigenständiger kommunaler Finanzierungskomponenten. Wegen dieser spezifischen Ziele einerseits und infolge vielfältiger Konflikte mit den (zentral-)staatlichen Interessen andererseits kann das staatliche Finanz- und Steuersystem nicht auch die Rolle eines (nach den resultierenden Ergebnissen als ideal zu beurteilenden) gemeindlichen Finanz- und Steuersystems übernehmen. In der Erhaltung und Stärkung der hier wirtschaftstheoretisch interpretierten kommunalen Selbstverwaltung ist das herausragende Ziel zu sehen, dem auch die gemeindliche Finanz- und Steuerpolitik dienen soll.

Es dürfte den Leser einer Arbeit, wie sie die vorliegende darstellt, kaum zufriedenstellen, wenn er nicht auch erfährt, wie sich der Autor die Umsetzung seiner Überlegungen, die er in entsprechender Breite vorgeführt hat, in real existierenden Systemen vorstellt. Dies wird daher abschließend erfolgen, wobei neben der bisherigen (wirtschaftstheoretischen) Orientierung nunmehr auch der Praktikabilität und politischen Relevanz der gewonnenen Ergebnisse Beachtung geschenkt werden soll. 
Hans-Georg Napp - 978-3-631-75263-0

Downloaded from PubFactory at 01/11/2019 06:33:05AM

via free access 
"Irgendwann muß einmal Schluß sein mit dem sachlichen Argumentieren, dann muß die Politik entscheiden; und dann ist endlich Ruhe."

Erich Küpker (1975)

\section{Zur Frage der politischen Durchsetzbarkeit und praktischen Realisierbarkeit neu gestalteter kommunaler Finanzierungssysteme}

Bisher wurde versucht, die Gestalt von auf die Bedürfnisse der Gemeinden zugeschnittenen Finanzierungssystemen generell zu erörtern. Da für die Zielsetzung dieser Untersuchung und als Motivation einer entsprechenden Themenstellung die Situation in der Bundesrepublik Deutschland mit der jahrzehntelangen Diskussion über die Gemeindefinanzen und ihre Reform eine zentrale Rolle gespielt hat (vgl. etwa zusammenfassend Haller, 1987), sollen zum Schluß die gewonnenen Ergebnisse der (wirtschafts-)theoretischen Überlegungen auf die Bundesrepublik "projiziert" werden.

\subsection{Das Gemeindefinanzsystem der Bundesrepublik Deutschland}

\subsubsection{Die verfassungsrechtliche Stellung der Gemeinden}

Die Bundesrepublik Deutschland ist ein zweistufiger Bundesstaat, bestehend aus dem Gesamtstaat (Bund) und den Gliedstaaten (Bundesländer). Die Gemeinden bilden also keine dritte staatliche Ebene, sondern sind Teile der Länder. Dennoch nehmen Städte, Gemeinden und Kreise einen herausragenden Platz im bundesdeutschen Verwaltungsaufbau ein. Die Gemeinden sind dezentrale Entscheidungskollektive, weil sie mit dem Recht auf Selbstverwaltung ${ }^{301}$ ausgestattet sind, also über dezentrale Entscheidungsbefugnisse verfügen. Diese herausgehobene Stellung der Gemeinden innerhalb der Länder gründet sich auf das in Art. 28 Abs. 2 GG verankerte kommunale Selbstverwaltungsrecht.

301 Die kommunale Autonomie markierte zunăchst einmal als Begriff des Verwaltungs- und Staatsrechts die Position der Gemeinde im foderativen Staatsaufbau. Die Entwicklung der kommunalen Selbstverwaltung (vgl. zur historischen Entwicklung auch Spang, 1968, 240) hat dabei nicht unwesentlich zur Durchsetzung demokratischer Staatsformen beigetragen. So wurde die Gemeinde als "Keimzelle" der demokratischen Regierungsform gedeutet, da die kommunale Ebene die Möglichkeit der "... praktischen Selbsterziehung durch Teilnahme der Meisten an konkreten Aufgaben ..." (Jaspers, 1957, 163) erlaubte. "Daher ist die freie und verantwortliche Gemeindeverwaltung unerlaßlich für die Entstehung eines demokratischen Ethos. Nur was im kleinsten Umfang in nächster Nähe jederzeit im Leben praktisch geübt wird, kann die Menschen reif machen zu dem, was sie in größeren und größten Räumen demokratisch verwirklichen sollen." (Jaspers, 1957, 163) 
Die Gemeinden können ihre kommunalen und die ihnen übertragenen staatlichen Aufgaben nur dann ordnungsgemäß erfüllen, wenn sie mit ausreichenden Haushaltsmitteln ausgestattet sind. Dabei haben die Finanzreformen der Jahre 1956 und 1969 - aus einem gewachsenen Verständnis für die Forderungen der Gemeinden nach Stärkung ihres Selbstverwaltungsrechts - die finanzverfassungsrechtliche Stellung der Kommunen und ihren damit verbundenen finanziellen Handlungsspielraum (gegenüber ihrer ursprünglichen Rechtsposition im Grundgesetz) erheblich verbessert.

Die Stellung der Gemeinden im gegenwärtigen Finanzverfassungssystem des Grundgesetzes (GG) wird im wesentlichen durch drei Merkmale gekennzeichnet (vgl. Frey, 1982, 67):

- den Gemeinden stehen nach Art. 106 Abs. 5 und 6 GG eigene Steuereinnahmen zu;

- soweit eigene Steuereinnahmen der Gemeinden zur Erfüllung ihrer Aufgaben nicht ausreichen, tragen die Länder die Hauptverantwortung für die kommunale Finanzausstattung (Installierung eines kommunalen Finanzausgleichs aufgrund Art. 106 Abs. 7 GG);

- zwischen dem Bund und den Gemeinden bestehen keine unmittelbaren Finanzbeziehungen; der Bund trägt zwar eine gesamtpolitische Mitverantwortung für die Gemeinden, seine Mitwirkung an der Finanzausstattung ist jedoch auf einige wenige Einflußmöglichkeiten begrenzt (ausgenommen die durch den Einigungsvertrag vom 31. August 1990 (BGBI. II, S. 889) und seine Regelungen möglich gewordene besondere Rolle des Bundes bei der Finanzierung der deutschen Einheit). ${ }^{302}$

Da sämtliche Einnahmenverteilungssysteme ${ }^{303}$ in föderalen Gemeinwesen Nachteile offenbaren, versucht man häufig, sie in der Praxis zu kombinieren. Dann spricht man von sogenannten Mischsystemen. Innerhalb dieser Mischsysteme werden die Einnahmen den einzelnen gebietskörperschaftlichen Ebenen teilweise nach dem

302 Unmittelbare Finanzbeziehungen zwischen dem Bund und einzelnen Gemeinden können sich nur aufgrund der Ausnahmevorschrift des Art. 106 Abs. 8 GG ergeben. Veranlaßt der Bund in einzelnen Gemeinden besondere Einrichtungen, die diesen Gemeinden unmittelbar Mehrausgaben oder Mindereinnahmen verursachen, so erhalten die betroffenen Gemeinden den erforderlichen Ausgleich ("Sonderbelastungsausgleich") vom Bund, wenn und soweit den Gemeinden nicht zugemutet werden kann, die Sonderbelastungen zu tragen. Diese Verfassungsvorschrift spielt im Verteidigungsbereich eine wichtige Rolle, denn zahlreiche Gemeinden werden durch die verschiedenen militărischen Einrichtungen des Bundes (beispielsweise Kasernen, Flugplătze) mit zusătzlichen Ausgaben (z.B. für Schulen und Kanalisation) belastet.

303 Die Aufteilung der Einnahmekompetenzen und Finanzquellen im foderativen Staat unterscheidet sich in erster Linie nach dem Grad der finanziellen Autonomie, den man nachgeordneten gebietskorperschaftlichen Ebenen einrăumen möchte. Mit sinkendem Autonomiegrad der unteren Ebenen ergibt sich folgende Reihenfolge denkbarer Systeme der vertikalen Steuerverteilung: Zuweisungssystem mit Umlagen bzw. Beiträgen, Freies Trennsystem, Gebundenes Trennsystem, Zuschlagssystem, Verbundsystem, Zuweisungssystem mit Dotationen. 
Trennsystem und teilweise nach dem Verbund- oder Zuschlagssystem zugewiesen. Auch das im Grundgesetz verankerte bundesdeutsche "Einnahmenverteilungssystem" ist ein solcher Mischtyp. Aufgrund des Trennsystems steht nicht nur dem Bund und den Ländern das Aufkommen bestimmter Steuern jeweils zur ausschließlichen Verfügung zu, sondern auch den Gemeinden (vgl. Schaubild 12.1).

Schaubild 12. 1: Steuerverteilung nach Art. 106 GG

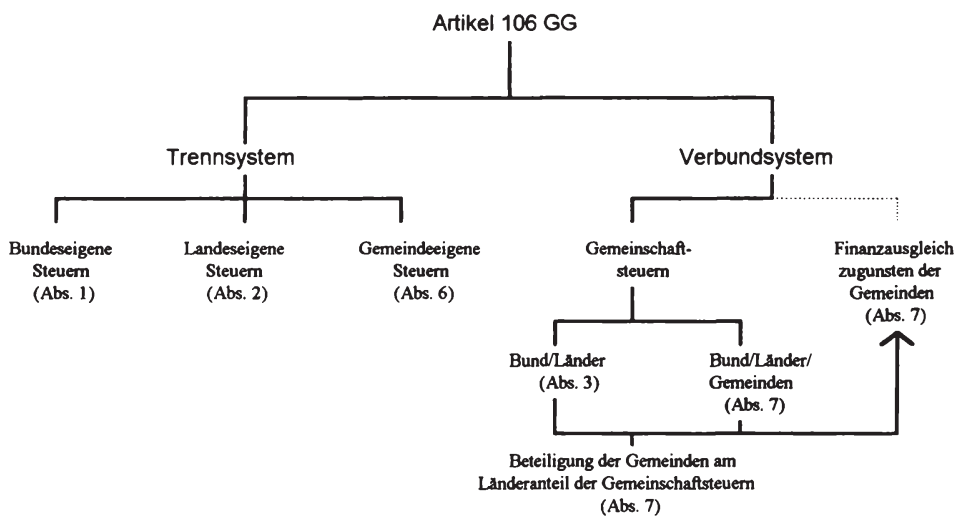

Nach Art. 106 Abs. 6 Satz 1 GG steht den Gemeinden das Aufkommen der Realsteuern und der örtlichen Verbrauch- und Aufwandsteuern unmittelbar zu. Diese Regelung bedeutet jedoch keine Bestandsgarantie für diese Abgaben, sondern sichert den Gemeinden lediglich das Aufkommen aus diesen Steuern jeweils in dem Umfang, der sich aus der entsprechenden gesetzlichen Regelung ergibt. Neben den Realsteuern und den örtlichen Verbrauch- und Aufwandsteuern, die den Gemeinden unmittelbar zustehen, haben die Kommunen nach Art. 106 Abs. 5 Satz 1 GG einen verfassungsrechtlichen Anspruch auf eine Beteiligung am Aufkommen der Einkommensteuer (Verbundsystemkomponente). ${ }^{304}$

${ }^{304}$ In der Bundesrepublik Deutschland sind im sogenannten Steuerverbund die Lohnsteuer, die veranlagte Einkommensteuer, nicht veranlagte Steuern vom Ertrag, die Körperschaftsteuer, die Umsatzsteuer sowie die Einfuhrumsatzsteuer enthalten. Außerdem sind über die Gewerbesteuerumlage Bund und Länder an dieser Gemeindesteuer beteiligt (vgl. zur Aufteilung dieser Verbund- oder auch Gemeinschaftsteuern auf die einzelnen Ebenen Seiler, 1988, 515 sowie Bundesministerium der Finanzen, 1992a, 42f). Auch in Österreich gibt es beispielsweise einen Verbund der wichtigsten Steuern, wobei der gemeinschaftliche Ertrag nach Bedarfskriterien anhand bestimmter Schlüssel verteilt wird (redistributiver Verbund). 
Tabelle 12.1: Die Steuereinnahmen des Bundes, der Länder und der Gemeinden (1988) in Mrd. DM

\begin{tabular}{|c|c|c|c|c|}
\hline & $\begin{array}{c}\text { Gesamtes } \\
\text { Steueraufkommen } \\
\end{array}$ & \multicolumn{3}{|c|}{$\begin{array}{l}\text { Steueraufkommen der } \\
\text { Gebietskörperschaften }\end{array}$} \\
\hline Ebene: & & Bund & Lănder & Gemeinden \\
\hline \multicolumn{5}{|l|}{ Gemeinschaftsteuern } \\
\hline 1. Lohnsteuer & 181072,8 & 76955,9 & 76955,9 & 27160,9 \\
\hline 2. Veranlagte Einkommensteuer & 36519,4 & 15520,7 & 15520,7 & 5477,9 \\
\hline 3. Nicht veranlagte Steuern vom Ertrag & 10838,7 & 5419,3 & 5419,3 & - \\
\hline 4. Korperschaftsteuer & 30090,2 & 15045,1 & 15045,1 & - \\
\hline 5. Umsatzsteuer (MWSt) & 84649,0 & 55015,4 & 29623,7 & - \\
\hline 6. Einfuhrumsatzsteuer & 69949,1 & 45466,9 & 24482,2 & - \\
\hline 7. Summe: & 416390,2 & 213423,3 & 167046,9 & 32638,8 \\
\hline 8. Gewerbesteuerumlage & 5571,8 & 2785,9 & 2785,9 & $-5571,8$ \\
\hline 9. Steuerverbund insgesamt: & 418691,0 & 216209,2 & 169832,8 & 27067,0 \\
\hline \multicolumn{5}{|l|}{ Bundessteuern } \\
\hline 10. Ergănzungsabgabe & 1,1 & 1,1 & & \\
\hline 11. Tabaksteuer & 18287,3 & $18.287,3$ & & \\
\hline 12. Kaffeesteuer & 1966,9 & 1966,9 & & \\
\hline 13. Zuckersteuer & 159,5 & 159,5 & & \\
\hline 14. Schaumweinsteuer & 974,7 & 974,7 & & \\
\hline 15. Branntweinabgaben & 4515,1 & 4515,1 & & \\
\hline 16. Mineralolsteuer & 36637,9 & 36637,9 & & \\
\hline 17. Kapitalverkehrsteuern & 1578,5 & 1578,5 & & \\
\hline 18. Versicherungsteuer & 4484,3 & 4484,3 & & \\
\hline 19. Wechselsteuer & 350,3 & 350,3 & & \\
\hline 20. Sonstige Bundessteuern & 279,7 & 279,7 & & \\
\hline 21. Summe Steuereinnahmen Bund: & & 285444,7 & & \\
\hline \multicolumn{5}{|l|}{ Lăndersteuern: } \\
\hline 22. Vermőgensteuer & 6333,1 & & 6333,1 & \\
\hline 23. Krafffahrzeugsteuer & 8422,3 & & 8422,3 & \\
\hline 24. Biersteuer & 1413,1 & & 1413,1 & \\
\hline 25. Sonstige Lăndersteuern & 9422,9 & & 9422,9 & \\
\hline 26. Summe Steuereinnahmen Länder: & & & 195424,2 & \\
\hline \multicolumn{5}{|l|}{ Gemeindesteuern } \\
\hline 27. Gewerbesteuer E und $\mathrm{K}$ & 38795,6 & & & 38795,6 \\
\hline 28. Grundsteuer $A$ & 440,7 & & & 440,7 \\
\hline 29. Grundsteuer B & 8282,8 & & & 8282,8 \\
\hline 30. Sonstige Gemeindesteuern & 1120,9 & & & 1120,9 \\
\hline 31. Summe Steuereinnahmen Gemeinden: & & & & 75707,0 \\
\hline 32. Gesamtsumme aller Steuern: (Anteile) & 562157,7 & $50,8 \mathrm{vH}$ & $34,8 \mathrm{vH}$ & $13,5 \mathrm{vH}$ \\
\hline 33.9 in vH von 32 : & $74,5 \mathrm{vH}$ & $38,5 \mathrm{vH}$ & $30,2 \mathrm{vH}$ & $4,8 \mathrm{vH}$ \\
\hline
\end{tabular}

Quelle: Bundesministerium der Finanzen (1992b), eigene Berechnungen. 
Es liegt in der Verantwortung der Länder, welche Finanzmittel ihre Gemeinden darüber hinaus erhalten und wie hoch demgemäß letztlich die Finanzausstattung ihrer Gemeinden ist (vgl. dazu ausführlich Marcus, 1987, 80ff).

Die Länder kommen ihrer verfassungsrechtlichen Verpflichtung - nämlich für eine ausreichende Finanzausstattung ihrer Gemeinden zu sorgen - im Rahmen des kommunalen Finanzausgleichs nach. Die Hauptaufgaben des kommunalen Finanzausgleichs bestehen darin, die Finanzkraft der Gemeinden insgesamt zu erhöhen, weil die kommunalen Steuereinnahmen nicht zur Deckung des gemeindlichen Finanzbedarfs ausreichen, sowie die Unterschiede in der Finanzkraft der Gemeinden untereinander zu verringern.

Die bundesstaatliche Verfassung garantiert den Kommunen einen Anspruch auf eine landesinterne Finanzausgleichsregelung, die eine prozentuale Beteiligung am Länderanteil an den Gemeinschaftsteuern vorsieht (Verbundquote). Danach haben die Länder einen bestimmten Anteil ihres Aufkommens aus den Gemeinschaftsteuern an die Gemeinden und die Gemeindeverbände weiterzuleiten (obligatorischer Steuerverbund). Der Landesgesetzgeber selbst bestimmt die Höhe des Anteilssatzes sowie darüber hinaus, ob und inwieweit das Aufkommen der reinen Landessteuern (vgl. Art. 106 Abs. 2 GG) ebenfalls den Gemeinden und Gemeindeverbänden zufließen soll (fakultativer Steuerverbund). Der kommunale Finanzausgleich ist innerhalb des durch das Grundgesetz vorgegebenen Rahmens von Land zu Land sehr unterschiedlich ausgestaltet (vgl. dazu Ehrlicher, 1988, 684ff sowie Haverkamp, 1988, 69ff).

\subsubsection{Die gegenwärtige Finanzsituation der Gemeinden}

\subsubsection{Die Finanzsituation der Gemeinden im alten Bundesgebiet}

Die kommunalen Ausgaben stiegen seit 1980 mit einer durchschnittlichen jährlichen Zuwachsrate von 4 v.H. Zwischen 1981 und 1984 stand deutlich die Konsolidierung im Vordergrund; die Zunahme der Ausgaben lag im Jahresdurchschnitt nur bei 1,5 v.H. und damit niedriger als die der Einnahmen. Das Finanzierungsdefizit konnte 1984 erstmals im Betrachtungszeitraum in einen Überschuß umgewandelt werden. 1985 bis 1987 hat sich an die Phase der strikten Konsolidierung, die insbesondere zu Lasten der Sachinvestitionen ging, eine neue Phase mit im Vergleich zu den Einnahmen stärkeren Ausgabenzuwächsen angeschlossen. Die Bemühungen der Kommunen um eine $\mathrm{Zu}$ rückführung des Ausgabenanstiegs hielten jedoch auch weiterhin an. Dabei wurde deutlich, daß erstmals die Konsolidierungsbemühungen nicht zu Lasten der Sachinvestitionen gingen, da die Kommunen strukturelle Verbesserungen in ihren Haushalten erzielt hatten. Dagegen stiegen die Ausgaben der Gemeinden und Gemeindeverbände 
1989 erstmals wieder stärker an als im Vorjahr, allerdings in geringerem Maße als die Einnahmen. So konnten 1988 und 1989 Finanzierungsüberschüsse erzielt werden. Diese guten Ergebnisse wurden 1990 und 1991 nicht wiederholt (vgl. Tabelle 12.2).

Tabelle 12.2: Ausgaben, Einnahmen und Finanzierungssalden der Gemeinden (GV) in den alten Länderna)

\begin{tabular}{|l|r|r|r|r|r|r|r|r|r|r|r|r|}
\hline \multicolumn{1}{|c|}{ Jahr } & 1980 & 1981 & 1982 & 1983 & 1984 & 1985 & 1986 & 1987 & 1988 & 1989 & 1990 & 1991 \\
\hline $\begin{array}{l}\text { Ausgaben } \\
\text { in Mrd. DM }\end{array}$ & 145,6 & 152,1 & 153,0 & 151,7 & 154,7 & 162,9 & 172,5 & 179,2 & 184,4 & 194,3 & 208,2 & 227,5 \\
\hline $\begin{array}{l}\text { Veränderung } \\
\text { gegenüber } \\
\text { Vorjahr in vH }\end{array}$ & $+11,6$ & $+4,5$ & $+0,6$ & $-0,9$ & $+2,0$ & $+5,3$ & $+5,9$ & $+3,9$ & $+2,9$ & $+5,4$ & $+7,1$ & $+9,3$ \\
\hline $\begin{array}{l}\text { Einnahmen } \\
\text { in Mrd. DM }\end{array}$ & 139,9 & 142,0 & 145,8 & 150,3 & 155,8 & 163,6 & 170,8 & 176,7 & 185,1 & 196,0 & 204,7 & 222,0 \\
\hline $\begin{array}{l}\text { Veränderung } \\
\text { gegenüber } \\
\text { Vorjahr in vH }\end{array}$ & $+11,9$ & $+1,5$ & $+2,7$ & $+3,1$ & $+3,7$ & $+5,0$ & $+4,4$ & $+3,5$ & $+4,8$ & $+5,9$ & $+4,4$ & $+8,4$ \\
\hline $\begin{array}{l}\text { Finanzie- } \\
\text { rungssaldo } \\
\text { in Mrd. DM }\end{array}$ & $-5,7$ & $-10,1$ & $-7,3$ & $-1,3$ & $+1,1$ & $+0,7$ & $-1,7$ & $-2,6$ & $+0,6$ & $+1,7$ & $-3,6$ & $-5,5$ \\
\hline
\end{tabular}

a) Bereinigte Einnahmen/Ausgaben ohne besondere Finanzierungsvorgänge

Quelle: Bundesministerium der Finanzen (1992b, 133).

Für die kommenden Jahre sind die Prognosen bezüglich der Einnahmenentwicklung zwar nicht ungünstig, jedoch auch mit einigen Unsicherheiten behaftet. Neben den beschriebenen strukturellen (qualitativen) Problemen auf der Einnahmeseite ${ }^{305}$ könnte auch in quantitativer Hinsicht Reformdruck erwachsen; dies vor allem vor dem Hintergrund gestiegener Aufgabenverantwortungen der Kommunen beispielsweise in $\mathrm{Zu}$ sammenhang mit der Verlagerung von Folgekosten der Arbeitslosigkeit vom Bund auf strukturschwache Gemeinden oder in Zusammenhang mit Sozial-306 oder Umweltschutzausgaben ${ }^{307}$ als finanzielle Zusatzlasten für die Städte und Gemeinden.

305 Dies sind die zunehmende Konjunkturanfalligkeit der kommunalen Einnahmen und starke Aufkommensschwankungen zwischen den Kommunen; speziell bei der Gewerbesteuer.

306 In zunehmendem Maße werden die kommunalen Haushalte durch wachsende Überwălzung der mit dem modernen Sozial- und Interventionsstaat verbundenen Ausgabeverantwortungen belastet. Durch die politische, wirtschaftliche und soziale Vereinigung Deutschlands erlangt dieser Problemkomplex zusătzliche Bedeutung (man denke nur an die Finanzierungsnotwendigkeiten der Transfers in die neuen Bundesländer über den Fonds "Deutsche Einheit", an dessen Finanzierung auch die Kommunen (West) mit 40 v.H. des Lănderanteils beteiligt sind).

307 Wahrend der vergangenen beiden Jahrzehnte haben umweltpolitische Ziele innerhalb der politischen Entscheidungsskala einen zunehmend höheren Rang erhalten. Durch staatliche Anforderungen an den Umweltschutz werden auch kommunale Handlungs- und damit Finanzbedarfe begründet. Diese berühren die einzelnen Gemeinden noch dazu in unterschiedlichem Maße, da in der Regel Gemeinden mit vergleichsweise starkem Besatz an umweltbelastenden Industrien, mit besonderen răumlichen Funktionen, mit hoher 
Tabelle 12.3: Struktur der kommunalen Einnahmen (Kommunen West) in Mrd. DM

\begin{tabular}{|c|c|c|}
\hline & 1991 & 1992 \\
\hline \multicolumn{3}{|l|}{ Verwaltungshaushalt } \\
\hline - Steuern & 74,0 & 77,9 \\
\hline - Gebühren & 48,7 & 53,1 \\
\hline - Zuweisungen von Land/Bund & 44,4 & 47,0 \\
\hline - Sonstige & 26,3 & 28,8 \\
\hline - Zusammen: & 193,4 & 206,8 \\
\hline \multicolumn{3}{|l|}{ Vermögenshaushalt } \\
\hline - Überschuß des Verwaltungshaushalts & 17,8 & 18,9 \\
\hline - Zuweisungen von Land/Bund & 13,4 & 13,1 \\
\hline - Kredite & 14,0 & 14,5 \\
\hline - Sonstige & 18,7 & 18,1 \\
\hline - Zusammen: & 63,9 & 64,6 \\
\hline
\end{tabular}

Quelle: Karrenberg/Münstermann, 1992, 62.

\subsubsection{Die Finanzsituation der Gemeinden in den neuen Ländern}

Für 1991 ergab sich bei den ostdeutschen Kommunen ein kassenmäßiger Finanzierungsüberschuß von 1,5 Mrd. DM. Die Entwicklung im Jahre 1991 zeigte (trotz der besonderen Einflüsse im ersten Jahr des Aufbaus einer kommunalen Selbstverwaltung), daß den ostdeutschen Kommunen ein Einstieg zur Schaffung und Ausschöpfung eigener Finanzierungsquellen (vor allem im Gebührenbereich) gelungen ist.

Durch die Aufstockung der Mittel des Fonds "Deutsche Einheit" (vgl. Gesetz zur Aufhebung des Strukturhilfegesetzes und zur Aufstockung des Fonds "Deutsche Einheit" vom 16. März 1992 (BGBl. I, S. 674) um 2,2 Mrd. DM in 1992, 4,2 Mrd. DM in 1993 und 5,1 Mrd. DM in 1994 (Anteil der Kommunen ohne Berlin) und die im Bundeshaushalt veranschlagten Projektmittel zur Förderung des Aufbaus der kommunalen Infrastruktur ist eine gute Ausgangsbasis vorhanden, die aber von den ostdeutschen Kommunen durch sparsames Wirtschaften, insbesondere durch den Abbau überhöhter Personalbestände in kommunalen Einrichtungen, abzusichem ist. Nur so wird es möglich sein, den großen Investitionsbedarf der ostdeutschen Kommunen im Rahmen einer geordneten Haushaltswirtschaft umzusetzen. Problematisch für die Entwicklung eigenständiger Einnahmen könnte mittelfristig vor allem die mangelnde Ergiebigkeit der Gewerbesteuer sein, die vor allem infolge der zunächst nur spärlichen Gewinnerwartungen (Gewerbeerträge), aber auch infolge der Befreiung der in Ostdeutschland

Vorbelastung und bisher geringen Leistungen im Bereich des eigenen Umweltschutzes in Zukunft mehr Finanzmittel aufwenden müssen als andere Gemeinden. 
ansässigen Unternehmen von der Gewerbekapitalsteuer (zunächst bis Ende 1994)308 zutage tritt. Es wären also auch vor dem spezifischen Hintergrund der Situation der Kommunen in den neuen Bundesländern grundlegende Gedanken (sowohl in quantitativer als auch in qualitativer Sicht) über Reformen des Gemeindesteuersystems sinnvoll.

Tabelle 12.4: Kommunale Einnahmen in den neuen Ländernª)

\begin{tabular}{|c|c|c|c|c|c|c|}
\hline & 1991 & $1992^{\mathrm{b})}$ & 1991 & $1992^{\mathrm{b})}$ & 1991 & 1992b) \\
\hline Einnahmeart: & \multicolumn{2}{|c|}{ Mrd. DM } & \multicolumn{2}{|c|}{ DM/Einwohner } & \multicolumn{2}{|c|}{$\begin{array}{c}\% \text { des West- } \\
\text { niveaus }{ }^{\text {) }}\end{array}$} \\
\hline - Steuern & 2,5 & 4,0 & 169 & 270 & 13,5 & 20,5 \\
\hline - Laufende Zuweisungen & 21,0 & 19,5 & 1415 & 1314 & 188,5 & 165,0 \\
\hline - Investitionszuweisungen & 7,5 & 10,0 & 506 & 674 & 223,0 & 304,0 \\
\hline - Gebühren & 3,0 & 4,0 & 202 & 270 & 24,5 & 30,0 \\
\hline - Sonstige Einnahmen & 5,0 & 6,0 & 337 & 404 & 50,5 & 57,0 \\
\hline Einnahmen insgesamt: & 39,0 & 43,5 & 2629 & 2932 & 70,5 & 74,5 \\
\hline
\end{tabular}

a) Für das 2. Halbjahr 1991 und für 1992 Schätzungen.

b) Ohne Aufstockung des Fonds "Deutsche Einheit".

c) Jeweilige Einnahmen und Ausgaben der Kommunen im alten Bundesgebiet je Einwohner $=100 \%$.

Quelle: Karrenberg/Münstermann, 1992, 69.

\subsection{Die einzelnen Elemente des bundesdeutschen Gemeindefinanzsystems}

\subsubsection{Gemeindesteuern}

Für das Haushaltsjahr 1992 werden insgesamt etwa 90 Mrd. DM (nach Abzug der Gewerbesteuerumlage $84 \mathrm{Mrd}$. DM) an Steuereinnahmen bei den Gemeinden erwartet. Die einzelnen Komponenten des gemeindlichen Steuersystem erbringen dabei folgende Anteile:

- Realsteuern (ca. 52,5\%);

- Gemeindeanteil an der Einkommensteuer (ca. 45,8\%);

- örtliche Verbrauch- und Aufwandsteuern (ca. 1,7\%).

308 Mit der geplanten zweiten Stufe einer Unternehmensteuerreform, die gerade mit dem Referentenentwurf des "Gesetzes zur Verbesserung der steuerlichen Bedingungen des Wirtschaftsstandorts Deutschland im Europäischen Binnenmarkt" (Standortsicherungsgesetz) auf den Gesetzgebungsweg gebracht worden ist, sollen die für die neuen Bundeslănder geltenden Steuervergünstigungen in Form der Aussetzung der Gewerbekapital- und der Vermögensteuer bis Ende 1995 verlăngert werden. 
$\mathrm{Zu}$ den Realsteuern zählen die Grundsteuer A (0,5 Mrd. DM und damit 0,6\% des erwarteten Steueraufkommens in 1992), Grundsteuer B (9,0 Mrd. DM = 10,7\%) und die Gewerbesteuer nach Ertrag und Kapital (brutto: 40,5 Mrd. DM, nach Abzug der Gewerbesteuerumlage: $34,6 \mathrm{Mrd}$. DM=41,2\%). Der Anteil der Gemeinden an der Einkommensteuer ist für das Jahr 1992 mit 39,3 Mrd. DM veranschlagt worden; er wird damit 45,8 \% der gesamten gemeindlichen Steuereinnahmen erbringen. Die örtlichen Verbrauch- und Aufwandsteuern sind nahezu bedeutungslos geworden. Zwar können die Gemeinden 1992 mit 0,9 Mrd. DM einen ähnlichen Betrag ansetzen wie in den vergangenen Jahren; allerdings sind dies gegenwärtig lediglich noch 1,7\% der gesamten kommunalen Steuereinnahmen.

Die Steuereinnahmen der Gemeinden insgesamt belaufen sich gegenwärtig auf etwa $12 \%$ des gesamten Steueraufkommens der gebietskörperschaftlichen Ebenen in der Bundesrepublik Deutschland.

Tabelle 12.5: Struktur und Zusammensetzung der gemeindlichen Steuereinnahmen

\begin{tabular}{|c|c|c|c|c|c|c|c|c|c|c|c|c|}
\hline Jahr & 1980 & 1981 & 1982 & 1983 & 1984 & 1985 & 1986 & 1987 & 1988 & 1989 & 1990 & 1991 \\
\hline \multicolumn{13}{|l|}{$\begin{array}{l}\text { Aufkommen in } \\
\text { Mrd DM }\end{array}$} \\
\hline $\begin{array}{l}\text { Gemeindeanteil an } \\
\text { der Einkommen- } \\
\text { steuer }\end{array}$ & 20,7 & 20,9 & 21,3 & 21,7 & 22,5 & 24,3 & 25,5 & 27,1 & 28,2 & 30,5 & 29,4 & 34,6 \\
\hline $\begin{array}{l}\text { Gewerbesteuer } \\
\text { netto }^{\text {a) }}\end{array}$ & 19,7 & 18,1 & 18,2 & 19,9 & 22,2 & 23,9 & 25,0 & 24,7 & 27,2 & 28,9 & 30,8 & 31,8 \\
\hline $\begin{array}{l}\text { Gewerbesteuer- } \\
\text { umlage }\end{array}$ & 5,9 & 5,7 & 5,6 & 4,0 & 3,8 & 4,1 & 4,2 & 4,1 & 4,5 & 4,9 & 5,0 & 5,4 \\
\hline Grundsteuer A & 0,4 & 0,4 & 0,4 & 0,4 & 0,5 & 0,5 & 0,4 & 0,4 & 0,5 & 0,5 & 0,4 & 0,5 \\
\hline Grundsteuer B & 4,9 & 5,0 & 5,3 & 5,7 & 6,0 & 6,2 & 6,5 & 6,7 & 7,0 & 7,3 & 7,5 & 7,9 \\
\hline \multicolumn{13}{|l|}{$\begin{array}{l}\text { Anteil an den } \\
\text { Steuereinnahmen } \\
\text { in v.H. }\end{array}$} \\
\hline $\begin{array}{l}\text { Gemeindeanteil an } \\
\text { der Einkommen- } \\
\text { steuer }\end{array}$ & 43,7 & 45,4, & 45,3 & 44,0 & 42,8 & 43,1 & 43,3 & 45,2 & 44,2 & 44,8 & 42,6 & 45,6 \\
\hline $\begin{array}{l}\text { Gewerbesteuer } \\
\text { netto }{ }^{\text {a) }}\end{array}$ & 41,7 & 39,3 & 38,8 & 40,4 & 42,2 & 42,5 & 42,5 & 41,2 & 42,7 & 42,5 & 44,5 & 42,0 \\
\hline $\begin{array}{l}\text { Grundsteuer A } \\
\text { und B }\end{array}$ & 11,2 & 11,8 & 11,2 & 12,5 & 12,3 & 11,9 & 11,8 & 12,0 & 11,8 & 11,3 & 11,4 & 11,0 \\
\hline
\end{tabular}

a) Gewerbesteuer nach Ertrag und Kapital zuzüglich Lohnsummensteuer (bis 1980) abzüglich Gewerbesteuerumlage

Quelle: Bundesministerium der Finanzen (1992b, 138)

\subsubsection{Die Realsteuern}

Der Begriff "Realsteuern" ist ein rechtlicher Terminus. In der Finanzwissenschaft reiht man die Realsteuern in die sogenannten Ertragsteuern ein. Dies sind Abgaben, "deren 
Steuergegenstand ertragbringende Objekte oder aus diesen fließende Erträge sind" (Kolms, 1976, 83). Letztendlich geht es bei den Realsteuern um die Erfassung von Erträgen im volkswirtschaftlichen Sinn, denn der Ertrag ist eine "... objektbezogene Größe einer warenproduzierenden Wirtschaftseinheit" (Littmann, 1980, 565f). Damit wird zugleich auch eine Besonderheit - die den Realsteuern häufig als ihre Schwäche zugeschrieben wird (vgl. Marcus, 1987, 65) - offenbar, denn die Realsteuern abstrahieren von den jeweiligen persönlichen Verhältnissen der Zensiten. Dies wird jedoch nur dann problematisch sein, wenn als Zielsetzung einer Realsteuer die Besteuerung nach der individuellen Leistungsfähigkeit angesehen wird. Wie aber bereits angedeutet sind Realsteuern Objektsteuern, die gerade auf der kommunalen Ebene unter Äquivalenzgesichtspunkten kommunale Einnahmen erbringen sollen.

In der Finanzwissenschaft wird daher auch nur der Teil der Ertragsteuern als Realsteuern bezeichnet, der auf die Erfassung eines Sollertrages ausgerichtet ist. Man spricht von Realsteuern im engeren Sinn, wenn der Ertrag über den Umweg des Wertes des den Ertrag abwerfenden Gutes gewonnen wird ("Ertragswertsteuern"). Damit rechnen im engen Sinn eigentlich nur die Grundsteuern und die Gewerbekapitalsteuer zu den Realsteuern (vgl. Littmann, 1980). Die Gewerbeertragsteuer sowie die inzwischen abgeschaffte Lohnsummensteuer knüpfen direkt an die Erträge an ("Reinertrag-" bzw. "Arbeitsertragsteuern"). Ein vollständiges Ertragsteuersystem müßte alle drei Produktionsfaktoren (Arbeit, Kapital und Boden) einbeziehen.

In der Bundesrepublik Deutschland besteht gegenwärtig folgendes System (vgl. auch Littmann, 1980, 574):

Schaubild 12.2: Struktur und Aufbau der Realsteuern

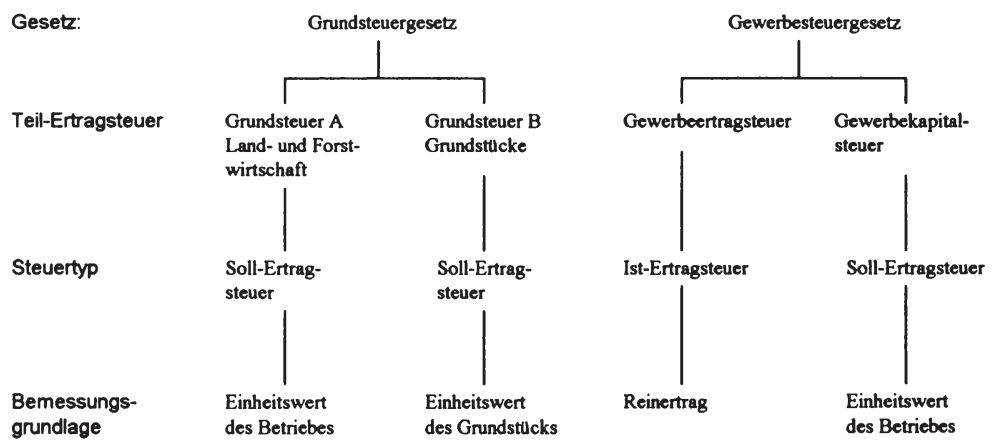


Schaubild 12.3: Bemessungsgrundlagen und Bewertungsmaßstäbe der Realsteuern

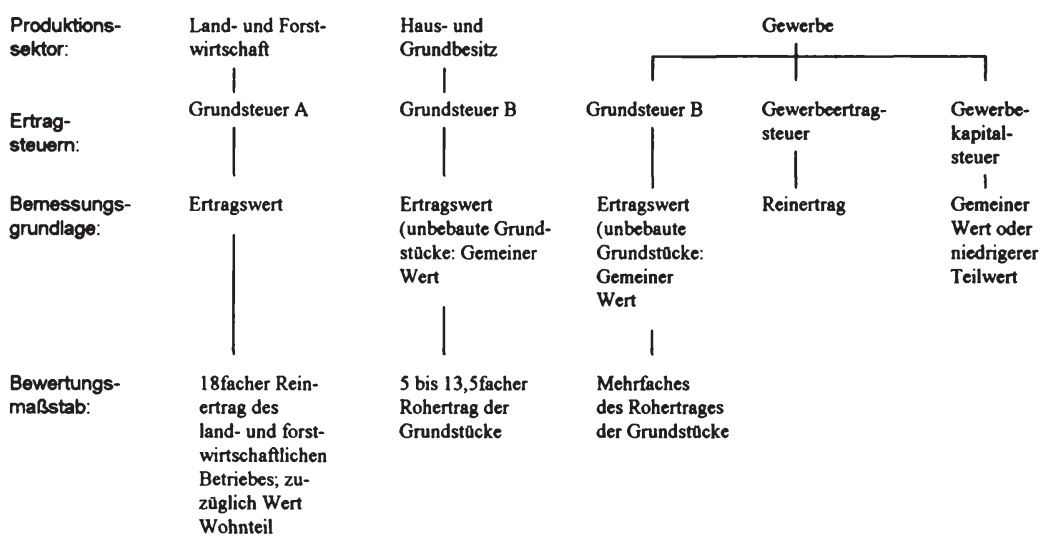

\subsection{Gewerbesteuern}

Es lassen sich nur noch wenige Länder finden, in denen die Gewerbesteuer eine derartige fiskalische Rolle spielt wie in der Bundesrepublik Deutschland. Eine ähnliche Stellung haben Gewerbesteuern nur noch in Österreich sowie Luxemburg und - eingeschränkt - in Frankreich, wo im Rahmen einer Reform 1976 die alte "contribution des patentes" durch die "taxe professionnelle" ersetzt worden ist.

In Deutschland besitzt die Gewerbesteuer eine nahezu zweihundertjährige Tradition. Als kommunale Steuer wurde sie allerdings erst im Zuge der Miquel'schen Steuerreform (1890/91) verankert. Thre gesetzliche Grundlage für die heutige Ausgestaltung reicht in das Jahr 1936 zurück. Im Rahmen der allgemeinen Zentralisierungstendenzen während der Zeit des Nationalsozialismus wurde die Gewerbesteuer mit einer reichseinheitlichen gesetzlichen Basis versehen (Gewerbesteuergesetz 1936). Die Gemeinden erhielten die Ertragshoheit. Bis zur Gegenwart - wenn man von einer Zwischenperiode von 1949 bis 1956 einmal absieht (während dieser Zeit war die Gewerbesteuer Ländersteuer) - ist dieser Zustand erhalten geblieben. Die heutige Ausgestaltung der Steuer hat ihre rechtliche Grundlage im Gewerbesteuergesetz 1978 vom 22. September 1979 (BGBl. I, S. 1557), das im wesentlichen auf dem zuvor erwähnten Reichsgesetz aufbaut. Steuerpflichtig sind demnach die sogenannten Gewerbebetriebe; öffentliche Hoheitsbetriebe wie Bundesbahn, Bundespost und Bundesbank sind genauso befreit wie viele Freiberufler. Veränderungen hat das Gewerbesteuerrecht durch das 
Steueränderungsgesetz 1979 erfahren, mit dem zum 01. Januar 1980 die Lohnsumme als Teilkomponente der Gewerbesteuer abgeschafft wurde.

Entlastungen für die von der Gewerbesteuer betroffenen Betriebe brachten

- das Haushaltsbegleitgesetz 1983 vom 20. Dezember 1982 (BGBl. I, S. 1857) mit der Festlegung, daß ab $198340 \%$ und ab $198450 \%$ der Hinzurechnungen von Dauerschulden (im Rahmen der Gewerbekapitalsteuer) sowie Dauerschuldzinsen (im Rahmen der Gewerbeertragsteuer) entfallen;

- das Steueränderungsgesetz 1991 vom 24. Juli 1991 (BGBl. I, S. 1322) mit der Festlegung, daß nach der deutschen Vereinigung in den neuen Ländern zunächst (1991/1992) auf eine Erhebung der Gewerbekapitalsteuer verzichtet und eine Staffelung der Steuermeßzahl bei der Gewerbeertragsteuer für Einzelunternehmen und Personengesellschaften vorgesehen wird (d.h. es gelten für Gewerbeerträge bis 84.000 DM ermäßigte Steuermeßzahlen);

- das Steueränderungsgesetz 1992 vom 25. Februar 1992 (BGBl. I, S. 297) mit der Festlegung, daß im gesamten Bundesgebiet für die Gewerbeertragsteuer bei Einzelunternehmen und Personengesellschaften der Freibetrag ab 1. Januar 199348.000 DM beträgt und ermäßigte Steuermeßzahlen für Gewerbeerträge bis $144.000 \mathrm{DM}$ gelten. Darüber hinaus wurde die Aussetzung der Gewerbekapitalsteuer in den ostdeutschen Ländern bis Ende 1994 verlängert (vgl. Fußnote 308 (Standortsicherungsgesetz) in diesem Kapitel).

Als kommunale Steuer kommt der Gewerbesteuer eine zentrale Bedeutung zu, weil sie das notwendige finanzielle Band zwischen Gewerbetreibenden und Gemeinden darstellt und somit letztlich zum Interessenausgleich auf der lokalen Ebene beiträgt. Selbstverständlich hängt ihre hervorragende Bedeutung auch mit ihrer fiskalischen Ergiebigkeit zusammen (ca. $41 \%$ der Gemeindesteuereinnahmen).

Seit 1970 (geregelt durch das Gemeindefinanzreformgesetz vom 08. September 1969 (BGBl. I, S. 1587) müssen die Gemeinden einen Teil des Gewerbesteueraufkommens als sogenannte Gewerbesteuerumlage an Bund und Länder entrichten. ${ }^{309}$ Die ursprünglich einmal auf ca. 40 \% des Aufkommens bemessene Umlage hat nach mehreren Veränderungen - zuletzt durch das Steueränderungsgesetz 1992 - stark an Bedeutung ver-

309 Durch die Einführung einer Gewerbesteuerumlage sollte das Übergewicht der Gewerbesteuer im gemeindlichen Einnahmespektrum beseitigt und mit der parallel dazu vorgesehen Einkommensteuerbeteiligung der Gemeinden erreicht werden, daß die Steuerkraft der Gemeinden ohne ertragstarke Industrien und insbesondere die Steuerkraft der zentralen Orte mit ihren auch für die Versorgung des Umlands wesentlichen Funktionen entscheidend gestărkt und damit auch in diesen Gemeinden eine ausreichende Grundlage für eine eigenverantwortliche kommunale Selbstverwaltung geschaffen werden konnte (vgl. Elsner/Schüler, $1970,81 \mathrm{ff})$. 
loren. Sie beträgt ab 01. Januar 1993 nur noch etwa 8 \% des gesamten Gewerbesteueraufkommens. ${ }^{310}$

\subsection{Grundsteuern}

Die Grundsteuern zählen zu den ältesten Formen der öffentlichen Abgaben überhaupt (vgl. Andreae, 1980, 579). In der Bundesrepublik Deutschland besitzen die Gemeinden die Ertragshoheit für die Grundsteuer. Ihre gesetzliche Grundlage geht - wie bei der Gewerbesteuer - auf die Realsteuerreform von 1936 zurück. Das nunmehr geltende Grundsteuerrecht, das im Gesetz zur Reform des Grundsteuerrechts vom 07. August 1973 (BGBl. I, S. 965) enthalten ist, baut darauf auf.

Steuersystematisch rechnet man die Grundsteuer zu den Ertragsteuern, da bei ihrer Ausgestaltung auf die Erfassung des Ertrags aus dem Produktionsfaktor Boden abgestellt wird. In der Bundesrepublik Deutschland ist sie als Sollertragsteuer eingerichtet. Die Besteuerung geht also den Umweg über die den Ertrag abwerfenden Objekte. Dabei werden zwei Arten des Grundbesitzes und damit der Grundabgaben unterschieden (vgl. Hessler, 1976, 91):

- land- und forstwirtschaftliche Vermögen (Boden, Betriebsgebäude, Maschinen, Betriebsmittelbestände, Wohngebäude) werden erfaßt von der Grundsteuer A;

- das übrige Grundvermögen (Wohngrundstücke, nicht land- und forstwirtschaftliche Betriebsgrundstücke) wird erfaßt von der Grundsteuer B.

Das zentrale Problem der Grundbesteuerung ist die Einheitsbewertung. Zum einen ist die unmittelbare Bewertungsmethode problembehaftet (vgl. Marcus, 1987, 72f), zum anderen aber auch die Periodizität der Bewertung (vgl. Hessler, 1976, 96 sowie Moxter, 1980, 234). Diese "erhebungstechnischen" Faktoren sind wohl in erster Linie dafür verantwortlich, daß die fiskalische Bedeutung der Grundbesteuerung stark zurückgegangen ist. Entstammten 1960 noch etwa $17 \%$ der gesamten kommunalen Steuereinnahmen dieser Abgabe, so sind es 1990 lediglich noch etwas mehr als $11 \%$ gewesen (Bundesministerium der Finanzen, 1992b, 138). Daneben dürften aber auch struktu-

${ }^{310}$ Durch das sogenannte "Gesetz zur Verbesserung der steuerlichen Rahmenbedingungen zur Sicherung des Wirtschaftsstandorts Deutschland im Europäischen Binnenmarkt" (Standortsicherungsgesetz), der Referentenentwurf befindet sich gerade im Gesetzgebungsverfahren, soll jedoch die Gewerbesteuerumlage wieder angehoben werden. Da die Gemeinden von den Entlastungen bei den Ertragsteuern im Vergleich zu Bund und Lăndern kaum betroffen sind, aber von der Gegenfinanzierung (Änderung der Abschreibungsbedingungen) insbesondere durch Gewerbesteuermehreinnahmen wesentlich stärker als Bund und Länder profitieren, soll ein Ausgleich durch eine Anhebung der Gewerbesteuerumlage vorgenommen werden. Die Umlage soll mit der vorgesehenen Änderung dann etwa 12,5\% des Gewerbesteueraufkommens betragen.

Hans-Georg Napp - 978-3-631-75263-0 
relle Entwicklungen, wie die nahezu bedeutungslos gewordene Grundsteuer A für land- und forstwirtschaftliche Betriebe, zu diesem Bedeutungsverlust beigetragen haben.

\subsubsection{Der Gemeindeanteil an der Einkommensteuer}

Im Rahmen der großen Haushalts- und Finanzreform 1968/69 wurde den Gemeinden durch eine entsprechende Verfassungsänderung eine Beteiligung am Aufkommen der Einkommensteuer (Lohn- und veranlagte Einkommensteuer) eingeräumt. ${ }^{311}$ Anfänglich erhielten die Gemeinden $14 \%$, inzwischen ist dieser Anteil durch das Steueränderungsgesetz 1979 vom 20. November 1979 (BGBl. I, S. 1849) auf $15 \%$ angehoben. Im Rahmen der "Neuregelung der Zinsbesteuerung" - Zinsabschlaggesetz vom 9. November 1992 (BGB1. I, S. 1853) - wurde zum 01. Januar 1993 mit einer Beteiligung der Gemeinden am Zinsabschlag der Einkommensteueranteil in seiner Zusammensetzung verändert (vgl. auch Karrenberg, 1992c, 266ff). In Abkehr von der bisherigen Rechtslage, wonach die Gemeinden an den nicht veranlagten Steuern vom Ertrag nicht beteiligt waren, werden sie ab 1993 einen Anteil von $12 \%$ am Zinsabschlag erhalten. Mit dieser Neuregelung wird vermieden, daß infolge der Berücksichtigung der erhöhten Freibeträge im Zuge der Veranlagung und der danach erfolgenden Erstattung zuviel einbehaltener Kapitalertragsteuer durch Reduzierung des Aufkommens der veranlagten Einkommensteuer Mindereinnahmen bei den Kommunen auftreten.

Die konkrete Ausgestaltung - d.h. wie und in welchem Umfang die Gemeinden an der Einkommensteuer zu beteiligen sind - bestimmt das Gemeindefinanzreformgesetz vom 08. September 1969 (BGB1. I, S. 1587). Es sieht den erwähnten Anteilssatz vor und regelt auch das Verfahren zur Aufteilung des Anteils auf die einzelnen Gemeinden. Dabei ist zunächst einmal festzuhalten, daß es sich um einen landesbezogenen Anteil handelt, denn die Gemeinden erhalten $15 \%$ des örtlichen Aufkommens aus der Lohn-312 sowie der veranlagten Einkommensteuer (bzw. $12 \%$ des Zinsabschlagsteuer-

311 Die Beteiligung der Gemeinden an der Einkommensteuer sollte das Übergewicht der Gewerbesteuer im gemeindlichen Einnahmespektrum beseitigen. Durch die Einkommensteuerbeteiligung sollte gleichzeitig erreicht werden, daß die Steuerkraft der Gemeinden ohne ertragstarke Industrien und insbesondere die Steuerkraft der zentralen Orte mit ihren auch für die Versorgung des Umlands wichtigen Funktionen entscheidend gestărkt wurde. Neben dieser qualitativen Komponente hatte diese Maßnahme auch quantitative Auswirkungen, denn die Beteiligung an der Einkommensteuer sollte den Gemeinden mehr Einnahmen bringen als die Ausfalle infolge der Einführung der Gewerbesteuerumlage ausmachten. Dieses Ziel wurde erreicht, denn die Steuermehreinnahmen der Gemeinden beliefen sich im Jahre 1970, dem ersten Jahr nach Inkraftreten der Gemeindefinanzreform, auf mehr als 2,4 Mrd. DM (vgl. Napp, 1993, 6ff).

312 Für die Lohnsteuer findet eine Zerlegung statt. Nach Art. 107 Abs. 1 S. 2 GG sind durch zustimmungsbedürftiges Bundesgesetz für die Lohnsteuer (wie auch für die Korperschaftsteuer) năhere Bestimmungen über die Abgrenzung sowie Art und Umfang der Zerlegung des ortlichen Aufkommens zu treffen. Aufgrund 
aufkommens ${ }^{313}$ ) des jeweiligen Bundeslandes. Dieser Bundesländeranteil wird dann weiter auf die einzelnen Gemeinden verteilt. Das Gemeindefinanzreformgesetz bestimmt, daß für jede Gemeinde eines Bundeslandes zunächst eine sogenannte "Schlüsselzahl" zu errechnen ist. Sie gibt den Anteil an einem speziell abgegrenzten Einkommensteueraufkommen ${ }^{314}$ eines Bundeslandes an, der in einer Gemeinde dieses Landes anfällt (vgl. ausführlich Elsner/Schüler, 1970, 81ff).

Der Einkommensteueranteil ist neben der Gewerbesteuer zum zweiten bedeutenden Faktor des gemeindlichen Steuersystems geworden. In seiner relativen und absoluten Bedeutung entspricht er der Netto-Gewerbesteuer.

Art. 106 Abs. 5 Satz 3 GG sieht vor, daß den Gemeinden ein eigenes Hebesatzrecht für die Einkommensteuer durch Bundesgesetz zugesprochen werden kann. Von dieser Möglichkeit hat der Gesetzgeber bisher jedoch keinen Gebrauch gemacht.

\subsubsection{3 Örtliche Verbrauch- und Aufwandsteuern}

Örtliche Verbrauch- und Aufwandsteuern sind dadurch charakterisiert, daß

- der Steuergegenstand ausschließlich örtlich bestimmbar sein muß und

- die Steuerwirkungen sich im Gebiet der steuererhebenden Gemeinde als Hoheitsträger erschöpfen.

des "Gesetzes über die Steuerberechtigung und die Zerlegung bei der Einkommensteuer und der Körperschaftsteuer (Zerlegungsgesetz) vom 25. Februar 1971 (BGBI. I, S. 146) erfolgt die Verteilung der Lohnsteuer unter den Ländern (somit auch für den Gemeindeanteil) durch Steuerzerlegung nach dem Wohnsitzprinzip. Das Wohnsitzprinzip besagt, daß die Lohnsteuer dem Land zufließt, in dem der Arbeitnehmer seinen Wohnsitz hat. Insoweit ist für die Lohnsteuer die Bezeichnung ortliches Aufkommen irreführend, denn es handelt sich nach der Zerlegung lediglich um ein korrigiertes ortliches Aufkommen.

313 Auch für den Zinsabschlag ist aufgrund der Tatsache, daß infolge der Bankenkonzentration das ortliche Aufkommen zu einer nicht sachgerechten Verteilung führt, für den Lănder- und Gemeindeanteil eine Zerlegungsregelung vorgesehen worden. Die Zerlegung wird anhand eines kombinierten Verteilungsschlüssels durchgeführt, der sich aus drei unterschiedlich gewichteten Komponenten, nămlich der regionalen Verteilung der Einkünfte aus Kapitalvermögen, dem regionalen Aufkommen der Einkommensteuer sowie der Körperschaftsteuer nach Zerlegung zusammensetzt.

314 Speziell abgegrenzt bedeutet, daß nicht das gesamte Aufkommen Berücksichtigung findet, sondern nur der Teil, der innerhalb von Höchstbeträgen ("Sockel") liegt. So wird im Rahmen der augenblicklich gültigen Fassung des Gemeindefinanzreformgesetzes für die erwähnte Relation (Schlüsselzahl) nur die Einkommensteuer einbezogen, die bei einem steuerpflichtigen Einkommen bis zu 32.000 DM (Ledige) bzw. 64.000 DM (Verheiratete) anfallt. Die von den Zensiten für über die Höchstbetrăge hinausreichende pflichtige Einkommen entrichtete Steuer bleibt außer Betracht. Gemeinden, in denen ein hoher Anteil "Besserverdienender" ansässig ist, wird somit ein geringeres Steueraufkommen zugerechnet als effektiv dort aufkommt. Diese nivellierende Maßnahme, welche im Rahmen der Schlüsselberechnung vollzogen wird, soll der Abmilderung der (Aufkommens-)Streuung dienen (vgl. Marcus, 1987, 74f). 
Das Recht zur Gesetzgebung im Bereich der örtlichen Verbrauch- und Aufwandsteuern steht gemäß Art. 105 Abs. 2a GG den Ländern zu. Die einzelnen Bundesländer haben in entsprechenden (Steuer-)Gesetzen bzw. den jeweiligen Kommunalabgabengesetzen unterschiedlichen Gebrauch von dieser Möglichkeit gemacht. Liegen keine entsprechenden landesrechtlichen Bestimmungen vor, können die Gemeinden und Kreise im Rahmen ihrer Selbstverwaltungsmöglichkeiten sonstige (örtliche) Steuerquellen ausschöpfen. Beispiele für örtliche Verbrauch- und Aufwandsteuern sind die Vergnügungsteuer, die Hundesteuer, die Jagd- und Fischereisteuer oder die Zweitwohnungsteuer. ${ }^{315}$

Quantitativ spielen die örtlichen Verbrauch- und Aufwandsteuern im gemeindlichen Finanzsystem kaum noch eine Rolle. Sie erbringen noch etwa $1,7 \%$ der gesamten gemeindlichen Steuereinnahmen.

\subsubsection{Zuweisungen}

Als zweite große Einnahmegruppe neben den Steuern werden für die gemeindlichen Haushalte die "Zuweisungen von öffentlichen Stellen und die allgemeinen Umlagen" (Marcus, 1987, 76) angegeben. Sie erbrachten im Jahr 1991 etwa ein Drittel der gesamten kommunalen Einnahmen.

Ein Großteil der Zuweisungen zählt finanzwissenschaftlich zum weiten Feld des Finanzausgleichs. Die Zuweisungen resultieren zum überwiegenden Teil aus der Umverteilung von Steuereinnahmen, die aus zugewiesenen Steuerquellen entnommen werden. Ein weiterer Teil hat "Entgeltcharakter", d.h. die finanziellen Transfers sind Gegenleistung an die gemeindliche Ebene fur von ihr jeweils erbrachte Leistungen.

Die Rechtsgrundlagen für die öffentlichen Transferleistungen an die Gemeinden umfassen ein weites Feld. An erster Stelle sind verfassungsrechtliche Regelungen zu nennen. Diese betreffen den kommunalen Finanzausgleich, den sie teilweise obligatorisch, teilweise fakultativ regeln (vgl. auch Abschnitt 12.1.1). Darüber hinaus sind noch die Regelungen hinsichtlich der Bundeshilfen an die Gemeinden nach Art. 104 a Abs. 4

315 Vgl. zur Einführung und Erhebung neuer Steuern aufgrund des kommunalen Steuererfindungsrechts Mohl (1992), der unter juristischen Aspekten prüft, ob die Einführung weiterer ortlicher Verbrauch- und Aufwandsteuern (wie etwa einer Bodenwertzuwachssteuer, einer Steuer auf Spielapparate und pornographische Darbietungen oder einer Getränkeverpackungsteuer) möglich ist. 
GG anzuführen. Danach kann der Bund unter bestimmten Rahmenbedingungen ${ }^{316}$ Finanzhilfen für besonders bedeutsame Investitionen der Gemeinden gewähren. Des weiteren sind bundes- und landesrechtliche Regelungen für öffentliche Transferleistungen relevant. $\mathrm{Zu}$ den letzteren zählen vor allem die länderweise unterschiedlichen Gesetze zur Regelung des kommunalen Finanzausgleichs (Gemeindefinanzierungsgesetze) und die kommunalen Abgabengesetze. Im gemeindlichen Bereich sind Satzungsregelungen anzuführen, die Einzelheiten der Umlagengestaltung sowie weiterer interkommunaler Leistungen bestimmen.

Die Zuweisungen werden von der Finanzstatistik wie folgt eingeteilt:

Tabelle 12.6: Struktur der staatlichen Zuweisungen (1989)

\begin{tabular}{|l|r|}
\hline Zuweisungsart: & Betrag in Mrd. DM \\
\hline Allgemeine Zuweisungen & 28,2 \\
\hline - Schlüsselzuweisungen & 22,3 \\
\hline - Bedarfszuweisungen & 0,5 \\
\hline - sonstige allgemeine Zuweisungen & 5,4 \\
\hline & 22,9 \\
\hline Zweckgebundene Zuweisungen & 5,4 \\
\hline - Erstattung von Ausgaben für staatliche Aufgaben & 4,9 \\
\hline - Zuweisungen für laufende Zwecke & 0,2 \\
\hline - Schuldendiensthilfen & 51,1 \\
\hline
\end{tabular}

Quelle: Bundesministerium der Finanzen (1992b, 132ff), eigene Berechnungen

\subsubsection{Der kommunale Finanzausgleich}

Die vorangegangenen Ausführungen (Abschnitt 12.1.1) haben bereits in Umrissen das System des kommunalen Finanzausgleichs erkennen lassen. Seine Ausgestaltung geht historisch im wesentlichen auf Popitz (1932) zurück, der mit seinem fundamentalen Gutachten wesentliche Grundzüge des Finanzausgleichs zwischen den gebietskörperschaftlichen Ebenen aufgezeigt hat. Die verschiedenen - aber dennoch in ihrer Grundstruktur einheitlichen - Finanzausgleichssysteme der deutschen Bundesländer weisen die Zweiteilung in zweckgebundene und allgemeine Zuweisungen auf. Finanziert werden die Zuweisungen an die kommunale Ebene aus der sogenannten "Finanzaus-

316 An der Finanzierung entsprechender Investitionen kann sich der Bund mit Zuschüssen oder Darlehen beteiligen, wenn sein Eingreifen aus bestimmten konjunkturpolitischen oder strukturpolitischen Gründen erforderlich ist und es sich um besonders bedeutsame Investitionen handelt. 
gleichsmasse". Diese gliedert sich in die "Steuerverbundmasse" und in weitere Mittel außerhalb des Steuerverbundes. Die Steuerverbundmasse wird durch die Rahmenvorschriften des Art. 106 Abs. 7 GG und die sie näher ausführenden Regelungen der Gemeindefinanzierungsgesetze der Länder bestimmt. Die Mittel, die außerhalb des Steuerverbundes in die Ausgleichsmasse fließen, können Gelder aus den Landeshaushalten, Bundesmittel sowie verschiedene Umlagen (Schul-, Krankenhaus- oder Finanzausgleichsumlage), die von der gemeindlichen Ebene selbst aufgebracht werden (interkommunale Transfers), umfassen (vgl. Haverkamp, 1988, 55ff).

\subsubsection{Interkommunale Transfers}

In der Bundesrepublik Deutschland gibt es eine bedeutende Anzahl von finanziellen Leistungen, die innerhalb der kommunalen Ebene anfallen. Hierzu zählen in erster Linie die sogenannten "Umlagen". Die bedeutendsten sind die Kreis- und die Verbandsumlagen.

Die Kreisumlage wird von den kreisangehörigen Gemeinden aufgebracht und zählt zu den wichtigsten Einnahmequellen der Kreise. Sie ist jedoch nicht nur Einnahmebeschaffungsinstrument, sondern nimmt auch eine Ausgleichsfunktion als "... Maßnahme des ergänzenden Finanzausgleichs, d.h. eine zum Ausgleich der unterschiedlichen Einnahmen-(Abgaben-)Verteilung, insbesondere Steuerquellenverteilung nachfolgende Korrekturmaßnahme" (Günther, 1980, 51) wahr. Die Kreise besitzen das Recht, die Umlagesätze von ihren Organen (Kreistagen) eigenverantwortlich im Rahmen der gesetzlichen Bestimmungen festzulegen. Die Berechnung der jeweiligen Kreisumlage orientiert sich dabei an der gemeindlichen Finanzkraft und dem jeweils festgelegten Umlagesatz.

Neben der Kreisumlage sind vielfältige Verbandsumlagen üblich, die von Zweckverbänden bzw. den in einigen Bundesländern vorhandenen Verbandsgemeinden erhoben werden (vgl. Marcus, 1987, 91).

\subsubsection{Gebühren und Beiträge}

Die Gesetzgebungskompetenz im Bereich der kommunalen Gebühren und Beiträge (der sogenannten Leistungsentgelte) besitzen die Bundesländer (Art. $70 \mathrm{GG}$ ). Dies führt dazu, daß die Bundesländer mittels spezifischer Vorschriften, zumeist kommunale Abgabengesetze, den Gemeinden das Recht übertragen, Gebühren und Beiträge zu erheben und diesen Bereich satzungsmäßig zu regeln. Sie setzen somit einen Rahmen 
fest, innerhalb dessen sich die von den Gemeinden entsprechend der Bedürfnisse und der unterschiedlichen örtlichen Gegebenheiten zu erlassenden Satzungen bewegen. Das gemeindliche Satzungsrecht bezieht sich auf die Festlegung der Gebühren- und Beitragshöhe, auf Stundungs-, Niederschlagungs- sowie Erlaßmöglichkeiten.

Die Kompetenzausstattung der kommunalen Ebene im Bereich der Gebühren und Beiträge ist sehr hoch anzusetzen; sie erscheint höher als bei den Gemeindesteuern. Allerdings gibt es bei den letzteren eine verfassungsmäßige (Aufkommens-)Garantie für die Kommunen ("Realsteuergarantie")317, bei den Gebühren und Beiträgen fehlt diese.

Tabelle 12.7: Einnahmen der Gemeinden aus Gebühren und Beiträgen

\begin{tabular}{|c|c|c|c|c|}
\hline Jahr & $\begin{array}{c}\text { Gebühren } \\
\text { in Mrd. DM }\end{array}$ & $\begin{array}{c}\text { Anteil der Gebühren } \\
\text { an den Einnahmen } \\
\text { in vH }\end{array}$ & $\begin{array}{c}\text { Beiträge und ähnli- } \\
\text { che Entgelte } \\
\text { in Mrd. DM }\end{array}$ & $\begin{array}{c}\text { Anteil der Beitrăge } \\
\text { an den Einnahmen } \\
\text { in vH }\end{array}$ \\
\hline 1980 & 25,3 & 18,1 & 4,1 & 2,9 \\
\hline 1981 & 27,3 & 19,2 & 4,3 & 3,0 \\
\hline 1982 & 29,4 & 20,1 & 4,3 & 2,9 \\
\hline 1983 & 31,4 & 20,9 & 4,3 & 2,8 \\
\hline 1984 & 32,6 & 20,9 & 3,7 & 2,4 \\
\hline 1985 & 33,7 & 20,6 & 3,5 & 2,1 \\
\hline 1986 & 35,6 & 20,8 & 3,3 & 1,9 \\
\hline 1987 & 37,5 & 21,2 & 3,4 & 1,9 \\
\hline 1988 & 39,1 & 21,1 & 3,6 & 1,9 \\
\hline 1989 & 41,0 & 20,9 & 3,6 & 1,8 \\
\hline 1990 & 43,9 & 21,5 & 3,8 & 1,8 \\
\hline 1991 & 49,0 & 22,1 & 4,1 & 1,9 \\
\hline
\end{tabular}

Quelle: Bundesministerium der Finanzen (1992b, 140).

Gebühren (so definiert sie beispielsweise das Kommunalabgabengesetz NordrheinWestfalen) sind Geldleistungen, die als Gegenleistung für eine besondere Leistung Amtshandlung oder sonstige Tätigkeit - der Verwaltung (Verwaltungsgebühr) oder für die Inanspruchnahme öffentlicher Einrichtungen und Anlagen (Benutzungsgebühr) erhoben werden. Beiträge sind hingegen Geldleistungen, die dem Ersatz des Aufwandes für die Herstellung, Anschaffung und Erweiterung von öffentlichen Einrichtungen und Anlagen dienen. Bei Straßen, Wegen und Plätzen umfassen Beiträge auch die Aufwendungen für deren Verbesserung, jedoch ohne die laufende Unterhaltung und Instandsetzung. Beitragszahler sind die Grundstückseigentümer, die wirtschaftliche Vorteile aus der gemeindlichen Maßnahme erlangen. Bei Beiträgen erfolgt also (im Gegensatz zu den (Benutzungs-)Gebühren, mit denen sämtliche betriebswirtschaftli-

${ }^{317}$ Die Zuweisung der Realsteuern gemäß Art. 106 Abs. 6 S. 1 GG bedeutet jedoch keine Bestandsgarantie für diese Steuern. Die Regelung garantiert den Gemeinden das Aufkommen aus den Realsteuern nur in dem Umfang, der sich aus der jeweiligen gesetzlichen Regelung der Steuern ergibt. Der Fortbestand der Realsteuergesetze ist also nicht garantiert. 
chen Kosten einer öffentlichen Einrichtung oder Anlage abgegolten werden) eine Abdeckung von Investitionsaufwendungen für eine öffentliche Einrichtung oder Anlage. Daher erfolgt die Vereinnahmung dieser einmalig erhobenen Abgabe (Beitrag) auch im Vermögenshaushalt, während die Gebühr als laufend erhobene Abgabe im Verwaltungshaushalt vereinnahmt wird (vgl. Bernhardt/Schünemann/Schwingeler, 1991, 243f).

Die Einnahmen aus den Gebühren und Beiträgen sind seit 1980 im Jahresdurchschnitt um 5,5\% gestiegen. Für diese Einnahmenzuwächse zeichnen in erster Linie Gebührenerhöhungen verantwortlich, die aus Kostensteigerungen und Erhöhungen der Kostendeckungsgrade resultierten (vgl. Karrenberg/Münstermann, 1992). Einnahmen aus Beiträgen sind abhängig vom Investitionsverhalten der Gemeinden und daher in der Regel häufigeren und stärkeren Schwankungen unterworfen als die Gebühreneinnahmen.

\subsubsection{Weitere Einnahmen}

Die beiden bedeutendsten nicht einzeln dargestellten Einnahmearten sind die kommunalen Einnahmen aus wirtschaftlicher Tätigkeit und die Erlöse aus Vermögensveräußerungen. $\mathrm{Zu}$ den Einnahmen aus wirtschaftlicher Tätigkeit gehören (das Zahlenmaterial bezieht sich auf das Jahr 1989) vor allem die Mieten und Pachten (2,8 Mrd. DM), Gewinnablieferungen von Unternehmen (0,6 Mrd. DM) sowie die Konzessionsabgaben (3,7 Mrd. DM). Die Einnahmen aus Vermögensveräußerungen beliefen sich 1991 auf 6,8 Mrd. DM (vgl. Bundesministerium der Finanzen, 1992b, 140).

\subsubsection{Kommunale Verschuldung}

Da im Rahmen dieser Arbeit die Analyse der kommunalen Verschuldung keine Rolle gespielt hat, soll auch hier auf eine qualitative Bewertung verzichtet werden. Zur Abrundung der kommunalen Einnahmesituation wird daher lediglich ein kurzer Blick auf die quantitative Dimension gerichtet.

Die Kommunen erhöhten ihren Schuldenstand aus Kreditmarktmitteln seit 1980 um $38,3 \%$. Die durchschnittliche jährliche Zuwachsrate im Betrachtungszeitraum liegt mit

$3 \%$ aber sowohl unter der Zuwachsrate der Steuern als auch unter der der Einnahmen insgesamt. Die Gemeinden und Gemeindeverbände nehmen hauptsächlich Kredite am Kreditmarkt und bei Verwaltungen auf. Der Schuldenstand aus Schulden bei Verwaltungen betrug Ende 1991 10,3 Mrd. DM. Diese öffentlichen Mittel werden den kom- 
munalen Gebietskörperschaften zu erheblich günstigeren Konditionen als die Kreditmarktmittel gewährt. 1991 betrug der Verhältnis von Zinsausgaben für öffentlichen Darlehen zum Schuldenstand aus öffentlichen Darlehen 3,5\%; dagegen betrug die entsprechende Relation bei den Kreditmarktmitteln 7,1\%.

Tabelle 12.8: Kommunale Verschuldung

\begin{tabular}{|c|c|c|c|c|c|}
\hline Jahr & $\begin{array}{c}\text { Schulden aus } \\
\text { Kreditmarkt- } \\
\text { mitteln } \\
\text { in Mrd. DM }\end{array}$ & $\begin{array}{l}\text { Schulden bei } \\
\text { Verwaltungen } \\
\text { in Mrd. DM }\end{array}$ & $\begin{array}{l}\text { Schulden zu- } \\
\text { sammen } \\
\text { in Mrd. DM }\end{array}$ & $\begin{array}{c}\text { Schulden } \\
\text { in } \mathrm{DM} \text { je Einwoh- } \\
\text { ner }\end{array}$ & $\begin{array}{c}\text { Nettokreditauf- } \\
\text { nahme } \\
\text { in Mrd. DM }\end{array}$ \\
\hline 1980 & 86,9 & 8,3 & 95,2 & 1661 & 4,4 \\
\hline 1981 & 92,6 & 8,4 & 101,0 & 1758 & 6,1 \\
\hline 1982 & 99,0 & 8,5 & 107,5 & 1872 & 6,4 \\
\hline 1983 & 101,5 & 8,4 & 109,9 & 1920 & 2,7 \\
\hline 1984 & 102,6 & 8,5 & 111,1 & 1947 & 1,2 \\
\hline 1985 & 103,6 & 8,7 & 112,3 & 1973 & 1,1 \\
\hline 1986 & 105,1 & 9,3 & 114,4 & 2009 & 1,8 \\
\hline 1987 & 108,0 & 9,4 & 117,4 & 2066 & 3,2 \\
\hline 1988 & 109,6 & 9,9 & 119,5 & 2092 & 2,3 \\
\hline 1989 & 111,7 & 10,4 & 122,0 & 2117 & 2,0 \\
\hline 1990 & 114,5 & 10,4 & 124,9 & 2126 & 2,8 \\
\hline 1991 & 120,2 & 10,3 & 130,4 & 2191 & 5,6 \\
\hline
\end{tabular}

Quelle: Bundesministerium der Finanzen (1992b, 140)

Bund, Länder und Gemeinden haben sich seit 1980 in sehr unterschiedlichem Umfang verschuldet. Der Anteil der Gemeinden an den Schulden der Gebietskörperschaften verringerte sich von $19,9 \%$ in 1980 auf $11,5 \%$ in 1991. Im gleichen Zeitraum erhöhten sich der Anteil des Bundes von rund 50 auf $56 \%$ und der der Länder von rund 30 auf $33 \%$ (vgl. Bundesministerium der Finanzen, 1992b, 140).

Die Kommunen haben insgesamt betrachtet andere Verschuldungsmöglichkeiten als Bund und Länder (vgl. dazu auch Littmann, 1968, 18; Bernhardt/Schünemann/ Schwingeler, 1991, 23). Dazu gehört zunächst die Vorschrift, daß Kredite nur für investive Zwecke Verwendung finden dürfen. Konsolidierungsphasen mit rückläufigen Ausgaben für Sachinvestitionen spiegeln sich daher auch in der Entwicklung der Kreditaufnahme wider. Hinzu kommen die restriktiven Auswirkungen einer rückläufigen Wirtschaftsentwicklung auf die Verschuldungsmöglichkeiten, da die Schuldendienstgrenzen bei geringer eingehenden laufenden Einnahmen automatisch nach unten gedrückt werden (vgl. Postlep, 1979).

Schließlich spielen die Besonderheiten der kommunalen Investitionsfinanzierung eine Rolle. Obwohl die Städte und Gemeinden etwa zwei Drittel der öffentlichen Sachinvestitionen tätigen, trifft die Finanzierungslast nur zu einem weit geringeren Teil die 
kommunalen Haushalte selbst. Einen erheblichen Finanzierungsbeitrag leisten die Länder und der Bund mit Hilfe staatlicher (Investitions-)Zuweisungen (vgl. Tabelle 12.6). Außerdem erheben die Kommunen für die Benutzung ihrer (kostenrechnenden) Einrichtungen in beträchtlichem Umfang Gebühren und Beiträge. Diese Mittel sollen nach den Kommunalabgabengesetzen auch der Refinanzierung kommunaler Investitionen dienen (vgl. Bernhardt/Schünemann/Schwingeler, 1991, 209ff sowie 244ff).

12.3 Zur Notwendigkeit einer Gemeindefinanzreform in der Bundesrepublik Deutschland

\subsubsection{Problemaufriß}

Die umfangreiche und ausführliche Diskussion in Wissenschaft und Politik (vgl. auch Kapitel 1) zur Frage der Notwendigkeit einer Reform des Gemeindesteuersystems im besonderen bzw. des Gemeindefinanzsystems im allgemeinen zeigt die Bedeutung dieses Problemkomplexes auf. Der Diskussionsgang konzentriert sich dabei auf die Frage der Reform, Revitalisienung, Substituierung bzw. Abschaffung der Gewerbesteuer (vgl. Albers, 1988). Dieser Steuer - die bestimmte Einkünfte (aus Gewerbebetrieb) und bestimmte Vermögensteile (Gewerbekapital) belastet - werden in der Regel eine Vielzahl steuersystematischer Mängel vorgeworfen. Dabei sind die Argumentationsmuster der Betroffenen (nämlich Kommunen und Wirtschaft) aber recht unterschiedlich.

Für die örtliche Wirtschaft wird die Gewerbesteuer infolge ihres Charakters einer reinen Unternehmensteuer als erhebliche Belastungskomponente gesehen, denn

- die Gewerbesteuer diskriminiert das Einkommen des gewerblichen Unternehmens und drängt anlagesuchendes Kapital aus diesem volkswirtschaftlich wichtigen Bereich heraus;

- die Gewerbesteuer setzt noch einmal dort an, wo die Unternehmen bereits durch andere Steuern Belastungen erfahren haben und verstößt damit gegen das Gebot, übermäßige Besteuerung zu vermeiden;

- die Gewerbesteuer nimmt kaum Rücksicht auf die Leistungsfähigkeit der Unternehmen, weil sie - zu wesentlichen Teilen - unabhängig von der wirtschaftlichen Lage des Unternehmens und der Eigentümer gezahlt werden muß;

- die Gewerbesteuer verzerrt den Wettbewerb auf dem nationalen Markt und verschlechtert die Wettbewerbsposition deutscher Unternehmen auf dem internationalen Markt. 
Die vorstehende Kritik fürt zu entsprechenden Forderungen seitens der Wirtschaft, mit einer "Reform" des (Gemeinde-)Steuersystems die Gewerbebesteuerung entweder gänzlich abzuschaffen oder zumindest erheblich zu reduzieren. Die besondere Problematik dieser Diskussion ist jedoch, daß auf der anderen Seite Städte und Gemeinden die Gewerbesteuer als traditionelle sowie durch das Grundgesetz garantierte Einnahmequelle erhalten wollen und die Gewerbesteuer für die Kommunen als Hauptstandort der Wirtschaft die bedeutendste Steuerquelle darstellt.

Doch auch aus der Sicht der Gemeinden erfüllt die Gewerbesteuer die Funktion einer echten Gemeindesteuer nur (noch) unzureichend. Ziel der Besteuerung des örtlichen Gewerbes war und ist die Herstellung eines Bindegliedes zwischen den Städten und Gemeinden sowie der örtlichen Wirtschaft. Aus heutiger Sicht besitzt die Gewerbesteuer bei der Erfüllung dieser Funktion jedoch grundlegende Schwächen:

- Die Gewerbesteuer fließt nicht stetig genug, um den Gemeinden eine gesamtwirtschaftlich sinnvolle und versorgungspolitisch verläßliche Ausgabenpolitik zu ermöglichen.

- Die Gewerbesteuer (speziell die Gewerbeertragsteuer) ist sehr eingriffsanfällig ${ }^{318}$, wie auch die bisherige Entwicklung bewiesen hat.

- Die Gewerbesteuer vertieft die Kluft zwischen armen und reichen Gemeinden; die resultierenden Unterschiede (Aufkommensstreuung) sind in der Regel gravierend.

- Die Gewerbesteuer entspricht durch ihre (jetzige) Form ("Großbetriebsteuer") längst nicht mehr dem ursprünglichen Prinzip von Leistung und Gegenleistung (Äquivalenzprinzip) zwischen Gemeinde und Gewerbe. Die "Reformen" der vergangenen Jahre haben diese Nachteile eher noch verstärkt.

Vor diesem Hintergrund sehen die Kommunen und ihre Spitzenverbände ebenfalls die Notwendigkeit für eine Reform des Gemeindesteuersystems, wenn auch mit (im Vergleich zur Wirtschaft) unterschiedlicher Akzentuierung. Die wesentlichen Argumente aus dem kommunalen Forderungskatalog sind:

- Abbau der großen Steuerkraftunterschiede zwischen Kommunen gleicher Funktion und Größe und damit Schaffung einer bedarfsgerechten Steuerbasis auch für strukturschwache Städte;

318 Diese Eingriffsanfalligkeit hinsichtlich gesetzgeberischer Aktivitäten im Bereich der Gewerbesteuer selbst, aber auch im Rahmen der mit der Gewerbesteuer (über die Bemessungsgrundlage) zusammenhăngenden Körperschafts-, Einkommens-, Vermögens- sowie Grundbesteuerung wird bei einem Blick auf die Entwicklung des bundesdeutschen gemeindlichen Einnahmensystems mehr als deutlich. Die häufigen Steuerrechtsănderungen haben sich nicht immer reformierend und damit positiv auf die Gestalt der Gewerbesteuer ausgewirkt (Stichwort "Großbetriebsteuer"). Vgl. dazu auch Napp (1993, 2ff). 
- Reduzierung der starken Einnahmeschwankungen im Zeitablauf;

- Korrektur der dem geltenden Gemeindesteuersystem immanenten Umverteilungstendenzen zu Lasten der Städte;

- Stärkung des steuerlichen Bindegliedes zwischen Kommunen und ortsansässiger Wirtschaft;

- Bewahrung eines funktionsfähigen Hebesatzrechts für die wirtschaftsbezogene Gemeindesteuer und damit auch Erhalt der Finanzautonomie.

Die vorstehende Liste der Mängel und Kritikpunkte der Gewerbesteuer hat im Zuge der umfangreichen Diskussion zur Entwicklung einer größeren Zahl von Gutachten und wissenschaftlichen Arbeiten geführt, die mit der Zielsetzung der Neu-, Um- bzw. effektiveren Ausgestaltung der Gemeindefinanzen angetreten waren bzw. sind.

Aus der "Frühzeit" der Diskussion über eine Reform der Gemeindesteuern sind vor allem zwei Beiträge zu nennen. Zum einen sind dies die Ausführungen des Wissenschaftlichen Beirats beim Bundesministerium der Finanzen in seinem "Bericht über eine organische Steuerreform" von 1953, zum anderen der Bericht der Studienkommission "Neuordnung des bundesstaatlichen Finanzausgleichs" von 1954. Während der Wissenschaftliche Beirat sich im wesentlichen darauf beschränkte, die Lohnsummensteuer im Rahmen der Gewerbesteuer zu kritisieren und ihre Abschaffung zu empfehlen, findet sich im Bericht der Studienkommission der bemerkenswerte Vorschlag, eine breite Kreise erfassende Gemeindeeinwohnersteuer einzuführen und bei den Realsteuern eine Senkung vorzunehmen.

In der Folgezeit kamen die wichtigsten Reformvorschläge vom Wissenschaftlichen Beirat in seinen Gutachten von 1959 ("Gutachten zur gegenwärtigen Problematik der Gemeindefinanzen"), von 1968 ("Gutachten zum Gemeindesteuersystem und zur Gemeindesteuerreform") und von 1982 ("Gutachten zur Reform der Gemeindesteuern"); weiterhin von der Kommission für die Finanzreform ("Gutachten über die Finanzreform in der Bundesrepublik Deutschland" - sogenanntes Troeger-Gutachten - von 1966) und von der Steuerreformkommission ("Gutachten der Steuerreformkommission 1971").

Seit Beginn der achtziger Jahre ist eine größere Zahl von Modellen zur Abschaffung der Gewerbesteuer bzw. zur Neuordnung des Gemeindesteuersystems in die Diskussion eingebracht worden (einen ausführlichen Überblick liefert Napp, 1993). Die diskutierten Reformalternativen lassen sich grob in fünf Lösungsansätze unterteilen: 
- Anrechnungsmodelle: Die Gewerbesteuer wird in ihrer derzeitigen Form beibehalten; die gezahlte Steuer kann jedoch mit der Steuerschuld einer anderen Steuer (Umsatz-, Einkommen- oder Körperschaftsteuer) verrechnet werden.

- Beteiligungsmodelle: Die Gewerbesteuer wird abgeschafft; zum Ausgleich werden die Gemeinden in stärkerem Umfang am Aufkommen der großen Verbundsteuern beteiligt.

- Kombinationsmodelle: Hier gibt es zwei Versionen. Die erste sieht eine Abschaffung der Gewerbekapitalsteuer und eine Senkung der Gewerbeertragsteuer vor. Der daraus resultierende Steuerausfall soll durch eine Beteiligung der Gemeinden an der Umsatzsteuer ausgeglichen werden. Die zweite Version sieht eine teilweise Anrechnung der Gewerbesteuer (bis zu einem bestimmten (Norm-)Hebesatz ) auf die Einkommensteuer- und Körperschaftsteuerschuld vor.

- Substitutionsmodelle: Die Gewerbesteuer wird abgeschafft und durch eine neue Gemeindesteuer ersetzt.

- Revitalisierungsmodelle: Die Gewerbesteuer wird beibehalten; der Kreis der Steuerpflichtigen und die Bemessungsgrundlage werden jedoch erweitert.

Anrechnungsmodelle sind schon steuersystematisch verfehlt. Die Gewerbesteuer wird nicht beseitigt und daher auch keiner der wesentlichen Nachteile - nicht die Konjunkturempfindlichkeit der Gewerbesteuer, nicht ihre starke Streuung und auch nicht ihre Begrenztheit in bezug auf den Kreis der Steuerpflichtigen und der damit verbundenen Unzulänglichkeiten für den Interessenausgleich zwischen Gemeinden und örtlicher Wirtschaft. Ferner ist nicht auszuschließen, daß über eine unbegrenzte Anrechnungsmöglichkeit die staatlichen Steuern ausgehöhlt werden. Vermieden werden kann eine solche Tendenz nur durch eine (dann aber wieder die gemeindliche Finanzautonomie gefährdende) Einschränkung des kommunalen Hebesatzrechts.

Allen Beteiligungsmodellen gemeinsam ist die stärkere Eingliederung der Kommunen in den Steuerverbund. Der Vorteil einer solchen Lösung ist die Teilhabe an den großen und ergiebigen Steuern des bundesdeutschen Steuersystems. Gegen eine Beteiligung an der Umsatzsteuer spricht der damit verbundene Wegfall bzw. die Reduktion des Hebesatzrechts (denn dies wäre nicht vereinbar mit europäischen Harmonisierungstendenzen) und die Unsicherheit über die künftige Verteilung des Umsatzsteueraufkommens zwischen der Europäischen Gemeinschaft und den Mitgliedsstaaten. Eine Ausweitung der Beteiligung der Gemeinden an der Einkommensteuer (diese ließe sich prinzipiell auch mit einem Hebesatzrecht einrichten) hätte vor allem den Nachteil, daß kein finanzielles Band zwischen Gemeinde und lokaler Wirtschaft (Unternehmen) mehr 
existieren würde, wenn im Gegenzug die Gewerbesteuer abgeschafft oder stark reduziert würde.

Bei den Kombinationsmodellen blieben, soweit die Gewerbesteuer beibehalten werden soll, ihre Mängel ebenfalls bestehen. Bei einer Beteiligungsversion gelten zudem die Bedenken, die gegen eine Umsatzsteuerbeteiligung bereits vorgebracht worden sind. Bei der Anrechnungsversion käme es zu einer (zusätzlichen) Beteiligung der Gemeinden an der Einkommen- und an der Körperschaftsteuer. Der Gemeindeanteil würde insoweit in Abhängigkeit von der Bemessungsgrundlage, insbesondere der Gewerbeerträge, schwanken. Bund und Länder könnten daher nicht mehr mit festen Anteilen am Aufkommen dieser Steuern rechnen.

Im Rahmen der Substitutionsmodelle wird im Grunde genommen zumeist der Ersatz der Gewerbesteuer durch eine Wertschöpfungsteuer diskutiert. In eine ähnliche Richtung zielen die Vorschläge der kommunalen Spitzenverbände (Revitalisierungsmodelle) hinsichtlich einer Reform der Gewerbesteuer durch eine Verbreiterung der Bemessungsgrundlage und eine Ausweitung des Kreises der Steuerpflichtigen.

Hinsichtlich der politischen Durchsetzbarkeit ${ }^{319}$ möglicher Modellvarianten ist anzumerken, daß alle Substitutions-, Anrechnungs-, Beteiligungs- und Kombinationsmodelle Verfassungsänderungen erfordern. Darüber hinaus standen sich in der Vergangenheit prinzipiell sehr kontroverse Standpunkte der Beteiligten gegenüber, die politisch tragbare Konzepte nicht möglich machten. Während sich die Wirtschaft im wesentlichen für Anrechnungs-, Beteiligungs- oder Kombinationsmodelle aussprach (vgl. Deutscher Industrie- und Handelstag, 1982; Ritter, W., 1983; Bundesverband der Deutschen Industrie, 1985), wurden aus Sicht der Kommunen und ihrer Spitzenverbände Revitalisierungsmodelle eindeutig bevorzugt (vgl. etwa Karrenberg, 1986). In der wissenschaftlichen Auseinandersetzung standen dagegen die Substitutionsmodelle eindeutig im Vordergrund (vgl. Wissenschaftlicher Beirat, 1982; 1990; Sachverständigenrat, 1983/84, Rz. 399ff; 1989/90, Rz. 342ff; Klaus-Dieter-Arndt-Stiftung, 1986a; Rahmann, 1989). Diese Interessenkonstellation führte dazu, daß auf dem Weg zu einer Reform des Gemeindesteuersystems zwar viele Vorschläge in der Diskussion auftauchten, diese aber infolge der Interessengegensätze wenig Realisierungschancen versprachen. So wurde und wird beispielsweise die vom Wissenschaftlichen Beirat beim Bun-

319 Bei Beantwortung dieser Frage spielen auch die haushaltsmaßigen Auswirkungen sowie die finanzausgleichspolitischen Folgewirkungen bei den einzelnen Modellvarianten eine große Rolle. Gemeinsames Merkmal aller Reformmodelle ist, daß unvermeidbare Aufkommenswirkungen den Bundesgesetzgeber dazu zwingen werden, erheblich mehr finanzielle Mittel auf die kommunale Ebene umzuschichten, als insgesamt gesehen bei ihr an Gewerbesteuereinnahmen ausfallt, um bei den "Verlustgemeinden" zu tragbaren (wenn auch nicht zu befriedigenden) Lösungen hinsichtlich der Aufkommenswirkungen zu kommen ("Lohnsummensteuereffekt"). 
desministerium der Finanzen (1982) vor gut zehn Jahren vorgeschlagene und vom Sachverständigenrat zur Begutachtung der gesamtwirtschaftlichen Situation (1983/84, Rz. 399ff; 1989/90, Rz. 342ff) übernommene gemeindliche Wertschöpfungsteuer von der Wirtschaft vehement abgelehnt; andere von der Wirtschaft initiierte oder präferierte Vorschläge (wie etwa der der Kommission zur Verbesserung der steuerlichen Bedingungen für Investitionen und Arbeitsplätze, 1991) für Änderungen des geltenden Gemeindesteuersystems sind von den Städten und Gemeinden abgelehnt worden.

Politisch durchsetzbar erscheint also realistischerweise nur ein Kompromißmodell, das trotz bestehender Interessengegensätze zwischen Steuerschuldnern und -gläubiger die Erwartungen beider Seiten berücksichtigt. In diese Richtung scheint sich die Diskussion nunmehr auch tatsächlich zu bewegen.. Mittlerweile existiert ein Vorschlag des Deutschen Städtetages zur unmittelbaren Beteiligung der Gemeinden am Umsatzsteueraufkommen (Ergänzung des Art. $106 \mathrm{GG}$ ), der mit einer Reduzierung des Volumens der Gewerbesteuer (aber nicht deren vollständige Abschaffung) verknüpft ist (vgl. Karrenberg, 1992b, 194ff). Diese neue Entwicklung in der Gewerbesteuerdiskussion wird von den Beteiligten (Städte und Gemeinden bzw. örtliche Wirtschaft) - wie auch von seiten des Bundesgesetzgebers (vgl. auch Grünewald, 1992) - als Möglichkeit einer dauerhaften Lösung des Gewerbesteuerproblems angesehen. ${ }^{320}$

In der bundesdeutschen Diskussion geht es heute also praktisch nur um die Art und Weise der Besteuerung der Produktionseinheiten zugunsten der Gemeinden, die "entschädigt" werden müssen für ihre Vorleistungen und die eine ins Gewicht fallende steuerliche Beziehung zu "ihren" Betrieben für erforderlich halten. Die Besteuerung der Gemeindebürger wird nicht mehr diskutiert, seit der Einkommensteuerverbund geschaffen worden ist. Auch um die Grundsteuer ist es ruhig geworden. Im internationalen Vergleich gesehen erscheint die Gemeindesteuerproblematik in der Bundesrepublik Deutschland mit dem Generalthema Unternehmensbesteuerung daher recht einseitig, denn in den meisten vergleichbaren westlichen Industrienationen stehen die Einkommensteuer und die Grundsteuer auf der lokalen Ebene im Vordergrund. ${ }^{321}$

320 Dabei ist die Haltung der kommunalen Spitzenverbände nicht einheitlich. Wăhrend der Deutsche Landkreistag (vgl. Recker, 1992) den Städtetags-Vorschlag unterstützt, setzt sich der Deutsche Städte- und Gemeindebund eher für den Erhalt der Gewerbesteuer ein, indem er fordert, die Gewerbesteuer in Europa als Finanzierungsquelle für die lokalen Gebietskörperschaften abzusichern, weil sie nach wie vor ein unverzichtbares Band zwischen Kommune und Wirtschaft darstellt. Daher favorisiert man seitens des Stădteund Gemeindebundes ein Reformmodell, daß eine revitalisierte Gewerbesteuer zum Ziel hat und betont, daß die vom Deutschen Städtetag geforderte Beteiligung der Gemeinden an der Umsatzsteuer erst nach eingehender Prüfung (beispielsweise der Aufkommenswirkungen) als diskussionswürdige Reformalternative angesehen werden kann.

321 Der Anteil der Gemeinden an den Steuereinnahmen insgesamt fallt in nahezu allen Industriestaaten relativ gering aus. Er liegt zwischen etwa 2 v.H. (Griechenland) und 36,5 v.H. (Japan). Der Durchschnitt betrăgt 14,6 v.H.. In der Bundesrepublik Deutschland partizipieren die Gemeinden am Steueraufkommen mit etwa Hans-Georg Napp - 978-3-631-75263-0 
Somit greift die Diskussion um die Gewerbesteuer und ihre Reform an sich zu kurz. Bei der Erörterung der Gestalt von auf die Bedürfnisse der Gemeinden zugeschnittenen Steuern wird schnell erkennbar, daß eine ("Quasi-")Alleinsteuer allokationspolitisch nicht sinnvoll ist. Daher muß ein bewertender Blick auch auf die anderen Komponenten des Gemeindesteuersystems gerichtet werden. Auch wenn diese nicht Kernpunkte aktueller Auseinandersetzungen sind (vgl. Karrenberg, 1992b, 195f), so sind sie doch vor dem Hintergrund entsprechender Anforderungen an kommunale Steuern mit Mängeln behaftet (vgl. Kapitel 9).

So läßt sich die Grundsteuer in ihrer derzeitigen Ausgestaltung kaum mit dem Äquivalenzprinzip rechtfertigen. Infolge der mangelnden Anpassung der Einheitswerte an die Marktentwicklung ist zudem die notwendige Wachstumsproportionalität nicht gegeben. Der im Vergleich zur Gewerbesteuer enorme Rückgang der fiskalischen Bedeutung der Grundsteuer im Einnahmespektrum der Gemeinden verdeutlicht diese Mängel. Der Einkommensteueranteil (ohne Hebesatzrecht) ist sehr eingriffsanfallig (die Vergangenheit hat dies deutlich gezeigt), für die Gemeindeeinwohner nicht spürbar und im allgemeinen zu konjunkturempfindlich. Die mangelnde Spürbarkeit und die unzureichende Einnahmenautonomie könnten jedoch durch das verfassungsrechtlich mögliche kommunale Hebesatzrecht ausgeräumt werden.

\subsubsection{Lösungswege}

\subsubsection{Vorbemerkungen}

Abschließend stellt sich nunmehr die Frage, welche Wege für das bundesdeutsche Gemeindesteuersystem gegangen werden sollten. Gutachten- und Kommissionsvorschläge gibt es in Fülle, doch sind diese oft interessenbezogen determiniert. Daher erscheint es

12 v.H. Damit liegt dieser Wert unter dem internationalen Durchschnitt. Die Struktur der kommunalen Steuereinnahmen zeigt ein hohes Gewicht der direkten Steuern. Im Industrielanderdurchschnitt machen sie 77,5 v.H. der kommunalen Steuereinnahmen aus, die Bundesrepublik Deutschland liegt mit einer 99 v.H.Quote deutlich über dem Industrielănderdurchschnitt. Nur in wenigen Lăndern wird eine Gemeindesteuer erhoben, die mit der deutschen Gewerbesteuer vergleichbar ist. In Österreich und Luxemburg gibt es die Gewerbesteuer (nur als Gewerbeertragsteuer) ahnlich dem deutschen Muster; unter den großßeren Industriestaaten sind Frankreich ("taxe professionnelle") und Japan ("enterprise tax") zu nennen, in denen die Betriebe (Unternehmen) mit einer lokalen Steuer belastet werden (vgl. Institut "Finanzen und Steuern", 1992a). Schließlich gibt es in den Bundesstaaten USA und Kanada in einzelnen Gliedstaaten (Provinzen) gewerbesteuerartige lokale Abgaben, die teilweise ertrags-, teilweise kapital- und teilweise lohnsummenbezogen sind. Eine dominierende Rolle spielen gemeindliche Einkommensteuern (in der Regel als Zuschlag zu Bundessteuern) in Bundesstaaten wie der Schweiz und den USA; erhebliche Bedeutung kommt gemeindlichen Einkommensteuern auch in den skandinavischen Ländern zu. Auch in Japan, Italien und Belgien gibt es ein gemeindliches Element bei der Einkommensbesteuerung. Grundsteuern als Gemeindesteuern finden sich in den meisten Ländern, doch kommt ihnen unterschiedliche Bedeutung zu (vgl. Haller, $1987,49 f)$. 
sinnvoll, Vorschläge zu unterbreiten und damit Untersuchungen durchzuführen, die sich zunächst von der rein "deutschen Sicht" des Problems ${ }^{322}$ lösen und aufzeigen, wie das gemeindliche Steuer- bzw. Finanzsystem - denn natürlich müssen Zuweisungen und Leistungsentgelte (Gebühren und Beiträge) in eine Betrachtung einbezogen werden - aussehen könnte. Erst wenn eruiert worden ist, welche besonderen Anforderungen an Abgaben zu stellen sind, die von Städten und Gemeinden erhoben werden, können Überlegungen angestellt werden, die die ungefähre Gestalt eines effizienzorientierten, zielgerichteten gemeindlichen Finanzsystems zum Ziel haben.

Bei der Ableitung der geeignet erscheinenden Steuern muß zwar - dies versteht sich von selbst - der Gesichtspunkt der Praktikabilität beachtet werden, doch sollten beispielsweise verfassungsrechtliche Schranken, die häufig bei den Kommissions- und Gutachtenvorschlägen zur Einschränkung des Kreises verwertbarer Ergebnisse führen, vorübergehend außer acht gelassen werden. Diese Herangehensweise läßt zunächst volle Gestaltungsfreiheit zu. Daran anschließend lassen sich dann die Ergebnisse mit der in der Bundesrepublik Deutschland gegebenen verfassungsrechtlichen Situation konfrontieren, die bekanntlich schwer veränderbar ist. Auf verfassungsrechtliche Schranken stoßen aber auch die meisten der gegenwärtig diskutierten Reformvorschläge (vgl. Abschnitt 12.3.1), so daß neue und möglicherweise auch völlig andersartige Lösungen nicht ausgeschlossen werden sollten, auch wenn sie ein höheres $\mathrm{Maß}$ an Grundgesetzänderungen erfordern. Wenn eine Grundgesetzänderung letztlich unvermeidlich ist, dann besteht Anlaß, mit aller Sorgfalt zu prüfen, wie man zu einem adäquaten System der Gemeindebesteuerung bzw. -finanzierung kommt. Es sollte grundsätzlich nicht die Lösung mit dem kleinsten verfassungsrechtlichen Eingriff gewählt werden, sondern die am besten begründete und den Zielvorstellungen am nächsten kommende Alternative, selbst wenn der Eingriff dabei stärker sein müßte. Kommt man auf diese Weise zu überzeugenden Lösungen, kann insgesamt gesehen die Hemmschwelle für Grundgesetzänderungen vielleicht eher überwunden werden.

\subsubsection{Grundstrukturen eines reformierten kommunalen Finanzsystems}

Bei der anschließenden Diskussion sollen die im theoretischen Kontext formulierten Vorschläge hinsichtlich einer effektiven Ausgestaltung eines Gemeindefinanz- bzw. Gemeindesteuersystems mit den besonderen verfassungsrechtlichen sowie institutionellen Rahmenbedingungen in der Bundesrepublik Deutschland konfrontiert und auf ihre Eignung und ihre politischen Erfolgsaussichten hin überprüft werden. Dabei sol-

322 "Den Konflikt zwischen den Interessen der Wirtschaft, u.a. ihre Belastung durch Gemeindesteuern zu begrenzen, und den Interessen der Stădte, diese Steuerquellen zu sichern und zu verstărken, hat noch niemand lösen können. Vermutlich ist das auch nicht möglich. Einigkeit besteht aber darüber, daß es eine steuerliche Klammer zwischen Wirtschaft und Stadt geben muß." (Schăfer, 1992a, 57) 
len auch die besonderen Rahmenbedingungen der Städte und Gemeinden in den neuen Bundesländern und die Entwicklung auf europäischer Ebene Berücksichtigung finden.

Die steuerliche Basis der ostdeutschen Kommunen ist nach Auslaufen bzw. Rückführung der Sonderfinanzierung (beispielsweise über den Fonds "Deutsche Einheit") im Hinblick auf ihre Aufgabenfülle völlig unzureichend. Der kommunale Finanzausgleich wird auf Dauer nicht in der Lage sein, diese Mängel an fehlender eigener Steuerbasis zu ersetzen. Eine Gemeindefinanzreform muß daher die Stärkung der eigenen Steuerquellen der ostdeutschen Städte und Gemeinden besonders im Auge haben. Vor dem Hintergrund der europäischen Integration sollten nur solche Steuerarten Gegenstand von Erörterungen und daraus abgeleiteten Reformvorschlägen sein, deren Bestand auch in Zukunft gesichert ist und die in einem "Europa der Regionen" den bundesdeutschen Kommunen ihre Aufgabenerfüllung unter größer gewordenem Konkurrenzdruck sichern und gewährleisten.

Entsprechend der im Rahmen der theoretischen Analyse abgeleiteten Erkenntnis, daß ein geeignetes kommunales Steuersystem mehrere Steuerquellen umfassen sollte, werden nunmehr in analoger Vorgehensweise die einzelnen Elemente und ihre Eignung für die bundesdeutsche föderale Einnahmenverteilung analysiert. Noch einmal zur Erinnerung. Um ein gemeindliches Steuersystem zu schaffen, das den Zielen kommunaler Besteuerung gerecht wird, müssen die kommunalen Steuerquellen auf möglichst breiter Grundlage angelegt werden. Ansatzpunkte dafür sind in erster Linie besondere Belastungsfaktoren, so daß ein kommunales Finanz- und Steuersystem an die Besteuerung der vorhandenen Produktionsbetriebe, der Einwohner bzw. Einkommen, des Haus- und Grundbesitzes sowie des Einzelhandelsumsatzes anknüpfen sollte.

\subsection{Produktionsbezogene Komponente}

Das existierende bundesdeutsche Gemeindefinanzsystem - die vorstehenden Ausführungen belegen dies - ist durch eine zunehmende und nicht bedarfsgerechte Streuung der Gewerbesteuereinnahmen gekennzeichnet. Angesichts dieses empirischen Befundes (vgl. Held/Hötker/Junkernheinrich, 1992) wird eine Reform des Gemeindesteuersystems im wesentlichen als eine Reform der Gewerbesteuer (also der produktionsbezogenen Komponente des kommunalen Steuersystems) gesehen. Die Beurteilung der Vor- und Nachteile der Gewerbesteuer und ihrer Alternativen (vgl. Abschnitt 9.3) hängt natürlich von den Zielvorstellungen ab, die an eine (kommunale) Unternehmensteuer gerichtet werden. Im Lichte der in der einschlägigen Literatur diskutierten Kriterienkataloge konzentrierte sich die vorstehende Analyse in erster Linie auf die allokativen Aspekte des Problems. Diese hängen zwar eng mit der Forderung nach einer 
wettbewerbsneutralen Unternehmensbesteuerung zusammen, doch sind die allokativen Aspekte auf lokalem Level (wenn es um eine effizienz-orientierte Besteuerung geht) unter den Gesichtspunkten der Herstellung einer fiskalischen Äquivalenz bzw. der Realisierung eines Interessenausgleichs mehr als nur die Forderung nach einer weitestgehenden Neutralität der Besteuerung, .

Der Vorschlag einer kommunalen Cash-flow-Steuer als produktionsbezogene Teilabgabe eines gemeindlichen Steuersystems stellt wohl die theoretisch eleganteste Alternative der diskutierten Steuern in diesem Feld dar (vgl. Richter/Wiegard, 1990b, 40f und Cansier, 1990, 253ff); wenn man allerdings Überlegungen bezüglich der Praktikabilität sowie der politischen Durchsetzbarkeit mit in die Beurteilung einbezieht, wird man dieses Ergebnis skeptischer beurteilen müssen (so auch Cansier, 1990, 256). Wird das Modell derart zugeschnitten, daß es praktikabel und auch politisch durchsetzbar erscheint, dürfte es vermutlich viel von seinen Vorzügen einbüßen. In ähnlicher Weise argumentiert Marcus $(1986,215)$ auch fuir die Wertschöpfungsteuer. Diese Auffassung kann jedoch nicht geteilt werden. In Anbetracht aller Aspekte erscheint die Wertschöpfungsteuer gegenüber der Gewerbesteuer (auch in einer revitalisierten bzw. modifizierten Form) und auch gegenüber einer Beteiligung der Gemeinden an der Umsatzsteuer mit produktionsorientiertem Verteilungsschlüssel ${ }^{323}$ ) (immer noch) als die praktikabelste und auch der Zielsetzung des Interessenausgleichs am nächsten kommende Lösung (vgl. Wissenschaftlicher Beirat, 1982, 52ff).

Die Wertschöpfungsteuer soll in umfassender Weise an der örtlichen Wertschöpfung der Volkswirtschaft ansetzen, d.h. an den Einkommen der Produktionsfaktoren Arbeit, Boden und Kapital. ${ }^{324}$ Die Bemessungsgrundlage ergibt sich bekanntlich als Summe der Löhne und Gehälter, Zinsen, Mieten und Pachten, zuzüglich der Gewinne und abzüglich der Verluste. Weil der größte Teil der Wertschöpfung auf gewerbliche Unternehmen entfällt, schließt die Wertschöpfungsteuer direkt an die Gewerbesteuer an. Durch die Einbeziehung der freien Berufe, des Gesundheitswesens und des Staates,

${ }^{323}$ Hinsichtlich der Auswahl geeigneter Verteilungsschlüssel gibt es zwar mit der Beschäftigtenzahl, der Lohnsumme, der örtlichen Wertschöpfung, dem Nettoumsatz sowie einer Kombination von Lohnsumme und ortlichem Kapitaleinsatz eine Reihe von Alternativen, doch allen Verteilungsschlüsseln ist gemein, daß sie die Funktion des Interessenausgleichs nur in abgeschwächter Form wahrnehmen können, da es an einem direkten Zusammenhang zwischen kommunalen Leistungen und gewerblichen Steuerlasten fehlt.

${ }^{324}$ Eine Substitution der Gewerbesteuer nach Ertrag und Kapital betrifft nicht nur die Gewerbesteuer selbst. So würde der Vorschlag des Wissenschaftlichen Beirats (1982), die Gewerbesteuer durch eine Wertschöpfungsteuer zu ersetzen, in seiner ursprünglichen Fassung auch eine Abschaffung der beiden anderen Realsteuern (Grundsteuer A und B) bedeuten. In den übrigen Făllen und bei einer Wertschöpfungsteuer, die auf die Berücksichtigung der Land- und Forstwirtschaft verzichtet, ist allein die Gewerbesteuer von einer Reform betroffen. 
möglicherweise auch der Landwirtschaft und der Wohnungswirtschaft, besitzt sie jedoch eine wesentlich breitere Bemessungsgrundlage.

Dies führt kommunal und konjunkturell zu einem ausgeglichenerem Steueraufkommen. Zudem wird die Steuerzahllast auf eine größere Anzahl von "Schultern" verteilt. Während die Gewerbesteuer heute tendenziell zu einer "Sondersteuer auf Gewinne" großer Unternehmen degeneriert ist, werden durch die Verbreiterung der Bemessungsgrundlage praktisch alle Betriebe erfaßt. Auf diese Weise wird berücksichtigt, daß jede wirtschaftliche Tätigkeit, auch wenn sie nicht $\mathrm{zu}$ einer Gewinnerzielung führt, für eine Gemeinde mit Kosten verbunden ist, die von den "Verursachern" getragen werden sollte. Vor diesem Hintergrund bleibt unter gemeinsamer Betrachtung (allokations-)theoretischer und praktischer Gesichtspunkte die Wertschöpfungsteuer eine Reformalternative, die für die Realisierung einer bedarfsgerechten und effizienz-orientierten Finanzausstattung der Städte und Gemeinden ist Ost und West konkurrenzlos erscheint. ${ }^{325}$ Auch der Wissenschaftliche Beirat beim Bundesministerium der Finanzen (1990, 45) ist nach wie vor (nach sorgfältiger Prüfung der Gegenargumente und anderer Reformvorschläge) "... mehrheitlich der Auffassung, daß die Wertschöpfungsteuer ... die beste Lösung ist."

Die Einführung einer Wertschöpfungsteuer ließe sich auch schrittweise bewerkstelligen. So könnte, um die örtliche Produktion zunächst einmal zu entlasten, in einem ersten Schritt die Gewerbesteuerumlage abgeschafft werden. Dabei müßte natürlich sichergestellt werden, daß die Gemeinden die Gewerbesteuer in gleicher Höhe auch tatsächlich senken. Ein weiterer Zwischenschritt zur Einführung einer Wertschöpfungsteuer wären Änderungen, die den Kreis der Steuerpflichtigen erweitern und im Sinne des Interessenausgleichs (vgl. Wissenschaftlicher Beirat, 1982) von örtlicher Produktion und den dabei entstehenden Lasten auch die öffentlichen Institutionen (Behörden) einschließen. In die gleiche Richtung würde eine Abschaffung der Gewerbekapitalsteuer zielen; stattdessen müßte die Lohnsumme (wieder) generell besteuert werden. Auch ein Verzicht auf Kürzungen und Hinzurechnungen bei Ermittlung der Bemessungsgrundlagen für die Gewerbebesteuerung würde sich in ein solches Konzept einfügen. Nicht angestrebt werden sollte hingegen eine Differenzierung von Steuermeßzahlen und Hebesätzen in bezug auf einzelne Teile der Bemessungsgrundlage (vgl. auch Wissenschaftlicher Beirat, 1990, 45f).

Vorschläge für ein reformiertes Gemeindesteuersystem, das keine produktionsbezogene Abgabe beinhaltet, weil eine solche beispielsweise als nicht konform mit staatsspe-

325 Held/Hotker/Junkernheinrich $(1992,90)$ konstatieren im Lichte kommunalspezifischer Besteuerungspostulate sogar, daß die Wertschöpfungsteuer "... den Charakter einer "First-Best-Losung aufweist". 
zifischen Zielen der Besteuerung angesehen wird, sind in keinster Weise mit den kommunalspezifischen Zielsetzungen zur Realisierung fiskalischer Äquivalenz bzw. eines Interessenausgleichs vereinbar. Nur wenn ein Interessenverbund zwischen Steuergläubiger (Kommune) und Steuerschuldner (Produzent bzw. Unternehmen) gegeben ist, werden sich die Gemeinden auch weiterhin bemühen, Flächen für die Gewerbeansiedlung bereitzustellen und wirtschaftsfördernde Maßnahmen zu ergreifen. Wenn es keine Gegenleistung für die daraus resultierenden Folgelasten gibt, werden die Gemeinden zu wenig oder eventuell sogar nichts mehr tun, um als Produktionsstandort attraktiv zu sein.

\subsection{Einwohnerbezogene Komponente}

Als ideale einwohnerbezogene Abgabe wurde in der theoretischen Analyse eine Einwohner- bzw. Bürgersteuer angesehen. Wegen ihrer beschriebenen distributiven Wirkungen dürte sie allerdings politisch kaum durchsetzbar sein. Daher sollte - trotz aller steuersystematischen Einschränkungen - eine (eigenständige) kommunale Einkommensteuer als realistischeres Ziel dienen.

Die Beteiligung der Gemeinden an der Einkommensteuer durch die Finanzreform des Jahres 1969 war an sich ein Vorstoß in die "richtige Richtung". Weil man sie aber in Form eines Steuerverbundes installierte, wurde die "richtige" Lösung (eine bewegliche kommunale Einkommensbesteuerung) blockiert. $\mathrm{Da}$ die im sogenannten "TroegerGutachten" (Sachverständigenkommission für die Finanzreform, 1966), vorgesehene (bescheidene) Hebesatzregelung nicht zustandekommen würde, war beinahe voraussehbar. Im Grunde genommen wurde das ganze Problem viel zu sehr unter dem Gesichtspunkt gesehen, die Streuung der gemeindlichen Steuereinnahmen zu verringern. ${ }^{326}$ Es wird dabei leider völlig übersehen, daß nur eine echte Gemeindeeinkommensteuer diejenige Lenkungs- und Abstimmungsfunktion für den Interessenausgleich erfüllt, auf die es ankommt, wenn die Städte und Gemeinden über eigene Steuern den lokalen Bedürfnissen Rechnung tragen sollen. Nur wenn alle Bürger direkt und spürbar zu den Lasten der Gemeinschaft beitragen, werden sie sich dafür interessieren, was mit "ihrem" Geld geschieht. Genau dies sind die gewünschten Aspekte.

Gerade auf der kommunalen Ebene ist (vgl. die Ausführungen in Abschnitt 9.2) die Merklichkeit der Finanzierung der lokalen (öffentlichen) Aufgabenerfüllung besonders wichtig (vgl. auch Fromme, 1992, 202). Der Bürger muß bei Forderungen an die öf-

${ }^{326}$ Dies galt und gilt übrigens auch für die verschiedenen Plăne, bei denen die Gewerbesteuer umgestaltet oder durch einen (teilweisen) Verbund ersetzt werden soll. 
fentlichen Hände spüren, daß deren Erfüllung nur umzusetzen ist, wenn Mittel und Kräfte eingesetzt werden, die letztlich von ihm selbst (unter Beachtung des Äquivalenzgedankens) aufzubringen sind. Solange dies nicht der Fall ist, werden die Forderungen ohne Maß gestellt. Daher muß es eine direkte finanzielle Verbindung zwischen Bürgern (Gemeindeeinwohnern) und der kommunalen Ebene (Gemeinde) geben. Der Bürger muß die Auswirkungen einer eigenen Forderung deutlich spüren. Eine solche Verbindung besteht über die Steuern und Abgaben zwischen Bürgern und Gebietskörperschaft aber nur dann, wenn die Gemeinde in wesentlichen Teilen das Maß der Abschöpfung selbst beeinflussen kann.

Diesen Anforderungen wird das gegenwärtige bundesdeutsche Gemeindesteuersystem nicht oder zumindest nur unzureichend gerecht. Der Gemeindeanteil an der Einkommensteuer erfüllt eine direkte Merklichkeitsfunktion nicht, da die Gemeinden ihn nicht beeinflussen können und er somit nicht als "Sanktion" für "überzogene" Forderungen eingesetzt werden kann. Er wird von den Bürgern als Bestandteil der staatlichen Einkommensteuer angesehen und nicht mit der Gemeinde in Verbindung gebracht. Solange keine Hebesatzrecht (bzw. eine Steuersatzvariationsmöglichkeit) besteht, wird sich daran auch nichts ändern.

Das Anknüpfen am Bürger direkt soll auch dazu führen, daß sich wieder mehr Einwohner für die Belange der Gemeinschaft interessieren und beispielsweise mit der Arbeit der gemeindlichen Gremien auseinandersetzen oder - was ebenfalls bedeutungsvoll sein kann - für eine entsprechende Arbeit zur Verfügung stellen und auch Mandate annehmen. Das führt auch dazu, daß Politik wieder bürgernäher wird und die Gesellschaft vor mancher "Fehlinvestition" bewahrt wird. ${ }^{327}$

Die Einführung einer Gemeindeeinkommensteuer von wirklichem Gewicht bedingt selbstverständlich eine gravierende Änderung des Tarifs der staatlichen Einkommensteuer und führt zu fiskalischen Konsequenzen für den Bund und die Länder. Diese Aufkommenswirkungen, die damit verbundenen distributiven Aspekte und schließlich der Verwaltungsmehraufwand werden als Kritikpunkte eines "beweglichen" gemeindlichen Einkommensteueranteils genannt. Der zu erwartende Verwaltungsmehraufwand (dieser dürfte im Zeitalter der elektronischen Datenverarbeitung aber überschaubar sein) sollte jedoch unbedingt mit dem gesellschaftspolitisch zu erwartenden "Ertrag" in Relation gesetzt werden, um sich ein abschließendes Urteil zu bilden.

${ }^{327}$ Das die Kommunen selbst die Umsetzung eines derartigen Hebesatzrechts nicht mit mehr Nachdruck fordern, hăngt mőglicherweise damit zusammen, daß insbesondere grőere Stădte Durchsetzungsprobleme befürchten und erheblichen Widerstand gegen kommunale Maßnahmen erwarten. 
Als zweitbeste Lösung wäre auch eine verknüpfte Einkommensteuer, d.h. die Beibehaltung des bisher praktizierten Steuerverbundes bei der Einkommensteuer mit kommunaler Beteiligung - allerdings bei Etablierung eines (verfassungsrechtlich möglichen) Hebesatzrechts - denkbar. Hansmeyer und Zimmermann (1992) unterbreiten einen Vorschlag, wie ein solches Hebesatzrecht in die bundesdeutsche Praxis aufgenommen werden kann, ohne dabei die Herleitung der individuellen Einkommensteuerbelastung gegenüber der jetzigen Ausgangslage unnötig zu erschweren.

Grundgedanke dabei ist, daß sich das mit der Anwendung eines kommunalen Hebesatzrechts durch eine Gemeinde erzielbare Mehr- oder Minderaufkommen ausschließlich auf diese Gemeinde beschränkt. Zusätzliche Steuereinnahmen sollten daher insbesondere nicht auf Kosten des Bundes oder der Länder, aber gleichfalls auch nicht zu Lasten anderer Gemeinden erzielt werden können, da ansonsten ein exzessives "free rider"-Verhalten einzelner Kommunen die mit einer solchen Regelung angestrebten Effizienzgewinne gefährden könnte. Darüber hinaus darf die Attraktivität des Hebesatzrechts für die einzelne Gemeinde auch nicht dadurch reduziert werden, daß die Mehreinnahmen aus erhöhten Hebesätzen durch kompensierende Einnahmekürzungen des Landes (beispielsweise im Rahmen des kommunalen Finanzausgleichs) zugunsten anderer Gebietskörperschaften aufgezehrt werden (vgl. Hansmeyer/Zimmermann, 1992, 491).

Gemäß der soeben skizzierten Bedingungen bliebe als Basis das bestehende Einkommensteuerrecht zur Bemessung der individuellen Steuerlast. Vor der individuellen Steuerschuld fließen - wie bisher - 42,5\% an den Bund, 42,5\% an die Länder und 15 $\%$ an die Gesamtheit aller Gemeinden. Genau auf diesen $15 \%$-Anteil soll nun ein Hebesatzrecht angewendet werden können; die durch den Hebesatz verursachte Änderung der Einnahmen soll zur Gewährleistung der "fiskalischen Äquivalenz" auf die jeweilige Gemeinde begrenzt sein.

Formal besteht die individuelle Einkommensteuerschuld aus drei Bestandteilen. Teil 1 fließt Bund und Ländern zu und ist unabhängig von den gemeindespezifischen Hebesätzen. Teil 2 umfaßt die $15 \%$ der individuellen Einkommensteuerschuld für die Gesamtheit aller Gemeinden und Teil 3 drückt die durch gemeindeindividuelle Hebesätze (diese dürfen natürlich nur an Teil 2 anknüpfen) verursachten Mehr- bzw. Minderbelastungen aus. Es zeigt sich durch dieses einfache Beispiel, daß die Herleitung der individuellen Einkommensteuerbelastung gegenüber üblichen Verfahren nur unwesentlich erschwert worden ist und darüber hinaus durch den offenen Ausweis der Aufteilung im Steuerbescheid des Pflichtigen der Vorteil der besseren Fühlbarkeit der gemeindespezifischen Steuerbelastung erreicht werden könnte (vgl. Hansmeyer/Zimmermann, 1992, 492). 
Um den Einfluß der gemeindespezifischen Hebesätze zu veranschaulichen, bieten Hansmeyer/Zimmermann $(1992,492)$ eine einfache algebraische Darstellung an:

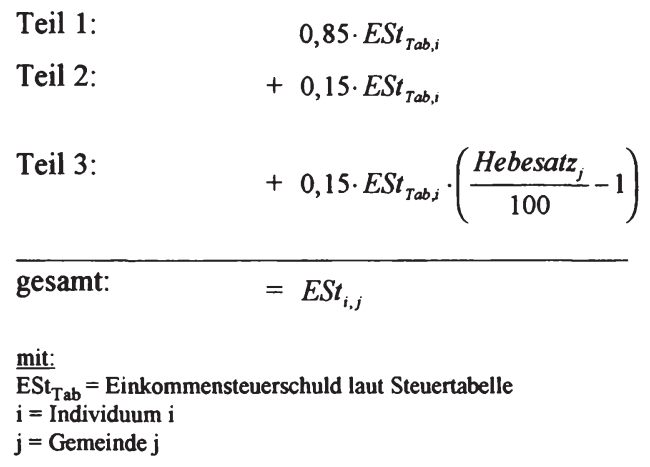

\subsection{Bodenbezogene Komponente}

Die Grundsteuer wird in der Regel den Gemeinden zur alleinigen Ausschöpfung überlassen und ist somit in bezug auf autonome Einnahmeerzielung, Aufkommensvariation und Belastungsveränderungen eine geeignete kommunale Abgabeform. So sollen auch im bundesdeutschen Realsteuersystem durch die Besteuerung des Faktors Boden örtliche Tatbestände erfaßt und finanziert werden, indem eine Beziehung zwischen dem Ertrag aus Grundvermögen und dem kommunalen Finanzbedarf unterstellt wird. Die Grundsteuer läßt sich jedoch in ihrer derzeitigen Ausgestaltung kaum mit dem Äquivalenzprinzip rechtfertigen. Infolge der mangelnden Anpassung der Einheitswerte an die Marktentwicklung basiert ihre Erhebung auf unrealistischen (verzerrten) Größen.

Die Realisierung der vorgeschlagenen "Grundsteuer neuer Art" (vgl. Abschnitt 9.4.2) stellt naturgemäß einen Eingriff dar, der weiter geht, als die Eingriffe, die gegenwärtig bezüglich eines Umbaus der Gewerbesteuer oder der Realisierung der gewerbesteuerlichen "Ersatzlösungen" diskutiert werden. Doch infolge der angesprochenen Einheitswertproblematik und der Zielsetzung einer besseren Erfassung der zugrunde liegenden Äquivalenzbeziehungen über qualitative Faktoren des Grund und Bodens erscheint sie jedoch für ein effektives kommunales Steuersystem trotz gewisser Praktikabilitätshemmnisse unumgänglich. Eine Teilalternative (ergänzende Komponente) könnte jedoch die als produktionsbezogene Abgabe vorgeschlagene Wertschöpfungsteuer darstellen. Diese hat nicht nur gegenüber der Gewerbesteuer sondern auch gegenüber dem gesamten gegenwärtig praktizierten Realsteuersystem den steuertechnischen Vorteil, die Erträge direkt zu erfassen und nicht über den Umweg von (Soll-)Ertragswertbe- 
rechnungen. Sie vermeidet damit die Problematik der weder einfachen noch besonders transparenten Einheitsbewertung, die gegenwärtig sowohl bei der gesamten Grundsteuer als auch für Teile der Gewerbebesteuerung (Gewerbekapital) zur Anwendung gelangt. Dann müßte nur der Bereich der nicht unter die Wertschöpfungsteuer fallenden Grundstücke, also die privat genutzten, einer (zusätzlichen) Grundbesteuerung unterworfen werden. Diese "Rest"-Grundsteuer hätte dann eine fiskalisch geringe Bedeutung, folglich könnte die Zurückhaltung vor umfangreichen Eingriffen zur Umgestaltung weniger gravierend sein und damit eine erfolgversprechende Umsetzung wahrscheinlicher werden.

\subsubsection{4 "Exportbezogene" Komponente}

Um insbesondere, wenn auch nicht ausschließlich, dem Tatbestand Rechnung zu tragen, daß es Nutznießer gemeindlicher Leistungen gibt, die ihren Wohnsitz nicht innerhalb einer die Leistung jeweils anbietenden Gemeinde haben, sollte eine "exportbezogene" Abgabe eingerichtet werden. In diesem Kontext wird ein Vorgehen in mehreren Schritten vorgeschlagen. In einem ersten Schritt kann in Anlehnung an die Lösung, die ein Mitglied des Wissenschaftliches Beirats beim Bundesministerium der Finanzen (Wissenschaftlicher Beirat, 1982, 143) vorgeschlagen hat, eine Beteiligung der Gemeinden an der Umsatzsteuer vorgesehen werden. Als Verteilungsschlüssel fungiert der Endverbrauchsumsatz in einer Abgrenzung, wie er im Abschnitt 9.5 dieser Arbeit bereits ausführlich beschrieben worden ist. Damit können die Städte und Gemeinden auf die Erhebung von sogenannten örtlichen Verbrauch- und Aufwandsteuern verzichten, die als "Bagatellsteuern" ohnehin zur Disposition stehen. ${ }^{328}$ Diese Tendenz entspräche auch dem Bestreben, die Einfachheit, Transparenz und Erhebungsbilligkeit des Steuersystems an sich zu erhöhen. Langfristig kann man dann eine "echte" kommunale Einzelhandelumsatzsteuer mit Hebesatzrecht an die Stelle dieses Steuerverbundes bei der Umsatzsteuer treten lassen.

328 Anders sieht dies jedoch Mohl (1992). Er schlägt angesichts "... der seit mehr als einem Jahrzehnt bestehenden kommunalen Finanznot ..." vor, daß die "... Städte und Gemeinden immer hăufiger dazu übergehen [sollten], die notwendigen Finanzmittel durch eigene kommunale Einnahmen, u.a. auch neue Steuern, bereitzustellen" (Mohl, 1992, LX). 
12.3.2.3 Mögliche Ergänzungsteuern eines effizienz-orientierten kommunalen Steuersystems

\subsection{Weitere aktuelle Vorschläge}

Kühn (1992) unterbreitet im Zusammenhang mit der Gewerbesteuerdiskussion den Vorschlag, die Kraftfahrzeugsteuer zusammen mit der Einführung eines Hebesatzrechts den Gemeinden zu übertragen (vgl. auch Marcus, 1986, 216f). Begründung erfährt dieser Vorschlag dadurch, daß ein enger Zusammenhang zwischen dem gemeindlichen Kraftfahrzeugbestand und den gemeindlichen Infrastrukturleistungen gesehen wird. Man kann den Zusammenhang übrigens auch zu den kommunalen Leistungen für den Umweltschutz sehen. Diese Leistungskategorie dürfte in Zukunft noch an Bedeutung gewinnen und damit beachtliche Mittel beanspruchen. Zur Wahrnehmung kommunaler Lenkungsmöglichkeiten ist daher den Gemeinden die Kraftfahrzeugsteuer als eigene Steuer zuzuweisen. Damit besteht für die Kommunen die Möglichkeit mittels Steuersatz- bzw. Hebesatzvariationen Lenkungswirkungen herbeizuführen. Diese könnten beispielsweise darin zum Ausdruck kommen, daß Ermäßigungen bei der Kraftfahrzeugsteuer insbesondere von großflächigen und dünnbesiedelten $\mathrm{Ge}$ meinden vorgenommen werden, in denen das Auto mangels anderer günstiger Verkehrsmöglichkeiten für die Mobilität unabdingbar ist. Zuschläge zur Kraftfahrzeugsteuer wären unter folgenden Gesichtspunkten denkbar:

- Spitzenfinanzierung des öffentlichen Personennahverkehrs,

- Abgeltung von Belastungen durch den ruhenden (stehenden) Verkehr,

- Heranziehung von Kraftfahrzeugbesitzern ohne Einstellplätze,

- Heranziehung von Zweitwohnungsinhabern am Sitz der Zweitwohnung,

- Heranziehung von Inhabern mehrerer Personenkraftwagen.

Die Kraftfahrzeugsteuer ist bisher eine Ländersteuer und mit einem Aufkommen von etwa 13 Mrd. DM kein vernachlässigbarer Einnahmeposten. Zwar ist zu berücksichtigen, daß die Städte und Gemeinden in einzelnen Ländern über den obligatorischen Steuerverbund am Aufkommen dieser Steuer beteiligt sind, doch müßte bei einem Wegfall der Kraftfahrzeugsteuereinnahmen den Ländern zwangsläufig ein finanzieller Ausgleich gewährt werden. Dieser Ausgleich könnte etwa darin bestehen, daß die Mineralölsteuer in die Gemeinschaftsteuern einbezogen wird. Dies entspricht im übrigen auch den Vorstellungen einer Reihe von Ländern, gerade auch vor dem Hintergrund der Regionalisierung des schienengebundenen Personennahverkehrs, in Zukunft an der Mineralölsteuer beteiligt zu werden. Mit dieser Einbeziehung der Mineralölsteuer in die Gemeinschaftsteuern würde ferner erreicht, daß diese Steuerquelle Gegenstand des 
obligatorischen Steuerverbundes wird, denn nach Art. 106 Abs. 7 GG haben die Länder die Gemeinden mit einem bestimmten Vomhundertsatz am Aufkommen der Gemeinschaftsteuern zu beteiligen. Eine Einbeziehung der Mineralölsteuer in das Aufkommen der Gemeinschaftsteuern würde gleichzeitig die Stetigkeit und Kontinuität des kommunalen Finanzsystems erhöhen.

In diesem Zusammenhang unterbreitet Fromme $(1992,207)$ einen ähnlichen Vorschlag, der jedoch auf eine gemeindliche Beteiligung an der Mineralölsteuer abzielt. Er betont, daß "(i)m Gegenzug für die Übernahme neuer Aufgaben des Öffentlichen Personennahverkehrs und der Abwälzung vom Bund auf die Länder und Landkreise bzw. Städte und Gemeinden ... ein Anteil an der Mineralölsteuer" erforderlich würde.

\subsection{Beurteilung dieser Vorschläge}

Die vorstehenden Ausführungen zeigen, da $B$ auch in der Gegenwart innerhalb des breiten Spektrums der Steuern, die den Aufwand und Verbrauch von einzelnen Gütern und Diensten belasten, vor allem diese zwei Abgaben immer wieder Gegenstand intensiver Diskussionen bezüglich der tatsächlichen Ausgestaltung kommunaler Finanzierungssysteme sind. Als sogenannten "Äquivalenzsteuern" 329 wird den (zu den Verbrauchsteuern gerechneten) Kraftfahrzeug- und Mineralölsteuern (vgl. Hansmeyer/Caesar/Koths/Siedenberg, 1980, 719) partiell eine Eignung für gemeindliche Belange zugesprochen (vgl. Marcus, 1986, 180).

In den USA partizipieren die lokalen Gebietskörperschaften über das "tax sharing" am Aufkommen der "motor fuel taxes" (vgl. Torres, 1967, 78 bzw. Maxwell/Aronson, 1977, 172); in anderen Ländern wie beispielsweise Großbritannien (vgl. Hepworth, 1984, 290) oder auch der Bundesrepublik Deutschland (vgl. Wissenschaftlicher Beirat, $1974,176)$ hat es Reformbestrebungen gegeben, deren Zielsetzungen entweder eine gemeindliche Beteiligung am Aufkommen aus den Mineralölsteuern oder aber die Einführung einer lokalen Mineralölabgabe ("fuel duty") waren. Hepworth $(1984,90)$ stellt fest, daß gerade bei dieser Form der Besteuerung "... a closer correlation between taxation and expenditure" gesehen werden kann. Auch der Wissenschaftliche Beirat (1974, 185f) erwähnt die Möglichkeit, eine eigenständige (lokale) Kfz-Abgabe einzu-

${ }^{329}$ Maxwell/Aronson $(1977,98)$ sprechen von "benefit taxes", zu denen sie ausdrücklich die Mineralölsteuern rechnen. Für solche Abgaben soll gelten, daß "... they are a quid pro quo for public services that yield particular and measurable benefits to individuals" (Maxwell/Aronson, 1977, 98) 
führen. ${ }^{330}$ In den Vereinigten Staaten werden die "motor vehicle licenses" in das "revenue sharing" zwischen Bundesstaaten und lokaler Ebene einbezogen (vgl. Maxwell/ Aronson, 1977, 81); daneben werden die Kraftfahrzeuge im Rahmen der Besteuerung des Vermögens durch die sogenannte "special property tax" erfaßt (vgl. Torres, 1967, 58). ${ }^{331}$ Die Kraftfahrzeugsteuer wird von Hansmeyer/Caesar/Koths/Siedenberg (1980, 719) als Abgabe auf den "Gebrauch spezieller Güter" angesehen; Neumark (1961, 358f) zählt sie zu den sogenannten "Aufwand-Besitzsteuern", wobei der steuerliche Zugriff dem "Besitz oder Genuß dauerhafter Wirtschaftsgüter" (Neumark, 1961, 367) gilt, egal ob diese konsumtiver oder produktiver Verwendung fähig sind.

Es scheint in erster Linie die fiskalische Ergiebigkeit zu sein, welche die beiden vorgenannten Abgaben für ihre praktische Verwendung interessant erscheinen läßt. ${ }^{332}$ Daneben schreibt man der Mineralöl- und der Kraftfahrzeugsteuer auch allokative Funktionen zu, was im Kontext dieser Arbeit von besonderer Bedeutung ist. ${ }^{333} \mathrm{Um}$ das private Gut "Kraftfahrzeug" nutzen zu können, bedarf es zum einen öffentlicher Komplementärgüter in Form von Verkehrswegen, Parkmöglichkeiten u.a.; zum anderen kommen mit einer zunehmenden Berücksichtigung der "tatsächlichen" Kosten des Individualverkehrs (in immer größerem Maße auch der unter umweltpolitischen Gesichtspunkten notwendigen Internalisierung mit der Kraftfahrzeugnutzung verbundener externer Effekte) zusätzliche Anforderungen auf diese Abgaben zu. In beiden Fällen ist es unter Allokationsgesichtspunkten erforderlich, entweder die Kosten für die Bereitstellung öffentlicher Komplementärgüter oder die tatsächliche Inanspruchnahme der Umwelt

330 Bereits 1961 wollte der damalige bayerische Finanzminister erreichen, daß das Aufkommen aus dieser Steuer in der Bundesrepublik Deutschland voll den Gemeinden zukommt. Sein Vorschlag wurde in Bayern bei der Ausgestaltung des kommunalen Finanzausgleichs berücksichtigt (vgl. Weinberger, 1969, 828).

331 In einigen us-amerikanischen Bundesstaaten werden die Kraftahrzeuge als Bestandteile des "personal tangible property" auch in die Bemessungsgrundlage der Vermögensteuer ("general property tax") aufgenommen (vgl. Maxwell/Aronson, 1977, 142ff), wenn auch im großen und ganzen gilt, daß die Vermögensteuer "... has become largely a tax on real estate" (Torres, 1967, 58).

332 Hansmeyer/Caesar/Koths/Siedenberg $(1980,722)$ bemerken, daß in der politischen Auseinandersetzung um solche Abgaben "die Dominanz des fiskalischen Ziels" zu erkennen ist.

333 Bei allokativen Zielsetzungen im Rahmen der speziellen Verbrauchsbesteuerung ist die Verănderung der relativen Preise bestimmter Güter mit Hilfe der Besteuerung Instrument der Politik. Der Staat kann folglich versuchen, mit Hilfe von Steuern auf spezielle Güter die Kosten derjenigen Staatsleistungen, die als Vorleistungen oder öffentliche Komplementärgüter zur Produktion oder beim Konsum dieser privaten Güter anfallen, bei den Nachfragern zu internalisieren. Maßgeblich ist in diesem Zusammenhang die allokative Überlegung, daß der relative Preis dieser Güter am Markt ohne die Kosten der betreffenden Staatsleistungen zu gering ausfalle, so daß eine Fehlallokation beispielsweise durch eine überhöhte Nachfrage die Folge ist. Daneben können Steuern auf spezielle Güter dazu benutzt werden, in den gesamtwirtschaftlichen Allokationsprozeß mit dem Ziel einzugreifen, vorhandene oder vermutete negative externe Effekte, die im Verlauf der Produktion oder des Konsums einzelner Güter auftreten, bei den jeweiligen Verursachern zu internalisieren. Dies ist vornehmlich bei Umweltabgaben der Fall (vgl. Hansmeyer/Caesar/Koths/Siedenberg, $1980,726 f$ ). 
als Ressourcenspender (Erdöl) bzw. Schadstoffaufnahmemedium (Abgase) über die Steuern (sofern dies nicht im Zuge individuell zurechenbarer Gebühren möglich erscheint) zu "internalisieren", also der potentiellen Nutzergruppe zuzurechnen. Die zugrundeliegende allokationspolitisch orientierte Hypothese lautet folglich, daß der Marktpreis bestimmter privater Güter zu niedrig ausfällt, weil er kein realistisches Äquivalent der tatsächlichen volkswirtschaftlichen Kosten - einschließlich der komplementären öffentlichen Leistungen bzw. der möglichen externen Effekte - enthält. Folge würde eine Fehlallokation von Ressourcen sein.

Um die beiden angesprochenen Steuerarten abschließend beurteilen zu können, soll in Anlehnung an die im Rahmen dieser Arbeit durchgeführte effizienz-theoretische "Eignungsprüfung" kommunaler Steuern (vgl. Kapitel 9) eine kurze Bewertung dieser Abgaben erfolgen.

12.3.2.3.2.1 Kommunale Mineralölsteuer(-beteiligung) und deren Eignung als Komponente eines Gemeindesteuersystems

Die Mineralölsteuer ist in nahezu allen westlichen Volkswirtschaften eine der ergiebigsten Einzelsteuerquellen (vgl. etwa Bundesministerium der Finanzen, 1992b, 216f). Dieser Aspekt darf nicht übersehen werden, wenn die Möglichkeiten einer kommunalen Beteiligung an dieser Steuerquelle diskutiert werden. Vor dem Hintergrund dieser fiskalischen Gegebenheiten könnte eine mögliche Lösung wie folgt aussehen.

Die bestehende Mineralölsteuer wird aufgeteilt in eine (Rest-)Bundesabgabe (mit Ertragshoheit beim Bund) und in eine neu einzurichtende "kommunale Mineralölsteuer" (Ertragshoheit bei den Gemeinden). Dabei wird zunächst von einer aufkommensneutralen Lösung ausgegangen, d.h. die Bundesabgabe wird so gesenkt, daß die Gesamtbelastung (vor Veränderung des Aufkommens durch die Gemeinden) unverändert bleibt.

Eine derartige Ausgestaltung ließe kommunale Aufkommensvariationen zu und ermöglicht somit eine autonome Finanzierungsentscheidung durch die jeweilige Gemeinde. Als Instrumente für die Aufkommensvariation kämen Hebesätze in Frage. Die Forderung, daß Aufkommensvariationen einer Gemeindesteuer nur die Bürger der betreffenden Gemeinde berühren sollten, dürfte allerdings kaum realisierbar sein. Finden Überwälzungsvorgänge ${ }^{334}$ statt, würde nur im Ausnahmefall der Identität von Gemein-

${ }^{334}$ Die Mineralölsteuer kann in der Regel entweder direkt auf den Endverbraucher oder indirekt infolge der Weitergabe durch die Hersteller der betroffenen Produkte an andere Hersteller und letztlich die Verbraucher Hans-Georg Napp - 978-3-631-75263-0 
de- und Marktgrenzen diese Forderung erfüllt werden. Der Regelfall dürfte aber so aussehen, daß Käufer der Güter, deren Preise überwälzte Mineralölsteuern beinhalten, auch außerhalb der Gemeinde, in denen die steuerabführenden Unternehmen ihren Sitz haben, wohnen werden. Die Folge wäre ein Lasttransfer über Gemeindegrenzen hinweg, der um so größer ausfällt, je stärker die betroffene Kommune mit anderen Kommunen verflochten ist ("Zentraler Ort" oder "Oberzentrum").

Fraglich ist damit auch die Merklichkeit der mit der Mineralölsteuer verbundenen Finanzierungslast für den einzelnen Haushalt bzw. das einzelne Individuum. Das Kriterium der Spürbarkeit bzw. Merklichkeit verlangt von kommunalen Abgaben, daß sie dem Steuerpflichtigen verdeutlichen sollen, daß er zum einen eine bestimmte Last trägt und zum anderen diese Last für "seine" Gemeinde aufbringt. Beides dürfte infolge der Überwälzungsmöglichkeiten sowie des Kostensteuercharakters der Mineralölbesteuerung kaum realisierbar sein.

Gleichgültig, wem das Aufkommen zufließt, die Mineralölsteuer ist zweifellos Instrument staatlicher Wirtschaftspolitik (vgl. Hansmeyer/Caesar/Koths/Siedenberg, 1980, 722f; Tait/Morgan, 1980, 7ff). Der mit der Gesetzgebungsbefugnis über die kommunale Abgabe ausgestattete Zentralstaat wird in der Regel danach streben, zusätzlich zu seiner Steuer auch die Abgaben der gemeindlichen Ebene in den Dienst seiner Politik zu stellen. Eine entsprechende energie-, umwelt- oder versorgungspolitisch motivierte Änderung des die kommunale Abgabe regelnden Gesetzeswerkes wäre der Normalfall. Auf diese Weise gerät das gemeindliche Steueraufkommen aus einer Mineralölsteuer in eine Abhängigkeit entsprechender wirtschaftspolitischer Maßnahmen des Zentralstaats. Je höher dabei die instrumentelle Eignung der betroffenen Abgabe (hier der Mineralölsteuer), je höher ist die Wahrscheinlichkeit für entsprechende Rechtsänderungen.

Vor allem die geringere Merklichkeit der Mineralölsteuerlast als indirekte Abgabeform, die starke Beeinflußbarkeit seitens der obersten gebietskörperschaftlichen Ebene und das Problem der Aufkommensvariation sind als Kritikpunkte zu nennen, wenn über die Tauglichkeit der Mineralölsteuer als Kommunalabgabe entschieden werden soll. So ist vom (gruppen-)äquivalenztheoretischen Standpunkt aus betrachtet eine regional unterschiedliche Belastung der Verbraucher unter Umständen zwar zu rechtfertigen, dennoch sollte nicht verkannt werden, daß das Problem einer Internalisierung von Kosten weder für öffentliche Komplementärgüter noch für die Vermeidung oder Beseitigung von Umweltbelastungen über die lokale Ausgestaltung dieser Steuer befriedigend lösbar ist. Es muß vielmehr damit gerechnet werden, daß sowohl Nutzen- 
bzw. Kostentransfers über die Gemeindegrenzen hinweg erfolgen als auch Umweltbelastungen beispielsweise nicht nur den Einwohnern der jeweiligen Kommune zugerechnet werden können. Unter allokativen Gesichtspunkten eignet sich also die (fiskalisch sehr ergiebige) Mineralölsteuer kaum für eine kommunale Beteiligung mit Autonomierechten (etwa Hebesatzvariation).

\subsection{Kommunale Kraftfahrzeugsteuer und deren Eignung als Komponente eines Gemeindesteuersystems}

Eine eigenständige lokale Abgabe auf den Besitz und Betrieb von Kraftfahrzeugen ist zunächst unter Autonomiegesichtspunkten von Vorteil, denn sie erlaubt der lokalen Ebene eine eigenständige Festlegung der entsprechenden Steuerbelastung entsprechend ihres jeweiligen Finanzbedarfs. Es läßt sich kaum bezweifeln, daß ein Zusammenhang zwischen der Bemessungsgrundlage der Kraftfahrzeugsteuer und dem gemeindlichen Finanzbedarf besteht. ${ }^{335}$ Ein Bezug zum Ort kann bei einer gemeindlichen Kraftfahrzeugsteuer als gegeben angesehen werden, so daß sich technische und rechtliche Radizierbarkeit problemlos herstellen lassen könnten. Die Folge wäre eine "ursachengerecht" ausgestaltete Finanzierung durch Belastung der potentiellen "Benutzer" kommunaler Verkehrswege. Auf der Basis dieser Finanzierung nach dem Äquivalenzprinzip tragen die Bürger als Kraftfahrzeughalter im Ausmaß ihrer Nutzung (oder besser Nutzungsmöglichkeit) zur Finanzierung der lokalen öffentlichen Leistungen bei.

Die Möglichkeiten für die kommunale Ebene, Aufkommensvariationen vorzunehmen, ließen sich einrichten. Dann wird es infolge der eintretenden regionalen Belastungsdifferenzen möglicherweise zu Standort- bzw. Wohnsitzverlagerungen kommen. ${ }^{366} \mathrm{Je}$ effektiver aber auch hier eine fiskalische Äquivalenz bei der Teilgruppe Kraftfahrzeug-

335 Kritisch wird einer kommunalen Kraftfahrzeugsteuer entgegengehalten, daß sie zwar im Sinne der fiskalischen Äquivalenz Präferenznähe garantiert, aber beispielsweise Ballungsräume mit einem besonders hohen Verkehrsaufkommen infolge der Pendlerbewegungen aus dem Umland anteilig ein zu geringes Aufkommen erhielten, als es ihrem (tatsăchlichen) anteiligen Bedarf entsprechen würde, wenn die Kraftfahrzeugsteuer weiterhin nach dem Zulassungsort des Kraftfahrzeugs verteilt würde. Dadurch entstünden von vornherein Verzerrungen zwischen der Verteilung des Bedarfs an kommunalen Straßen bzw. Parkraum und dem Kraffahrzeugsteueraufkommen. Darüber hinaus würden - so die Argumentation der Kritiker - Ausweichreaktionen der Kraftfahrzeughalter (und damit Verzernungen) provoziert; durch Wohnsitzmeldungen in Gebieten mit niedrigen Steuer- bzw. Hebesätzen könnte die Kraftfahrzeugsteuerbelastung für die Bürger reduziert werden. Ferner, so die Kritiker einer kommunalen Kraffahrzeugsteuer weiter, hätten die Gemeinden fiskalisch gesehen ein Interesse an der "Maximierung" der Anzahl der Kraftahrzeughalter (Forderung des Individualverkehrs). Sollte die Kraftfahrzeugsteuer zu einem Instrument der Umweltpolitik ausgestaltet werden, würden sich daher erhebliche Konflikte, Widersprüche und Probleme ergeben.

336 Als Steuergläubiger kommt in der Regel die Gemeinde in Frage, in der der Kraftfahrzeughalter seinen Hauptwohnsitz hat (bei Personenkraftwagen oder Motorrădern) oder in der die überwiegende Nutzung des Fahrzeugs (beispielsweise bei gewerblichen Lastkraftwagen) erfolgt. 
betreiber Nutzen und Kosten für öffentliche Komplementärgüter wie Verkehrswege oder Parkraum angleicht, desto weniger nachteilig werden solche Standortverlagerungen bei Kraftfahrzeugen sein.

Die Frage, ob die kommunalen Steuerbelastungsänderungen nur die Bürger der Gemeinde treffen, welche eine Änderung ihres Aufkommens herbeigeführt hat, läßt sich ohne Überlegungen hinsichtlich möglicher Überwälzungsvorgänge nicht abschließend beantworten. Für den Bereich der privaten Kraftfahrzeugnutzung sind diese zwar in der Regel fast gänzlich auszuschließen, doch auch hier verändert sich die Situation, wenn die Kraftfahrzeugsteuer fuir Fahrzeuge mit betrieblicher Nutzung den Charakter eine Kostensteuer annimmt. In diesem Fall geht sie über die Kalkulation in den Preis der erzeugten Produkte ein. ${ }^{337}$

Im Hinblick auf die interkommunale Streuung und die Breitenwirkungen dieser Abgabe sollte eine gemeindliche Kraftfahrzeugsteuer möglichst wenig Ausnahmetatbestände aufweisen. Die bei der bisherigen Ausgestaltung als Landessteuer beispielsweise aus sozialpolitischen oder anderen Gründen gewährten Befreiungen sollten weitestgehend vermieden und auf andere Weise durch die übergeordneten Gebietskörperschaften entsprechende Kompensationen gewährt werden.

Insgesamt gesehen fallt das Urteil bezüglich der Verwendbarkeit der Kraftfahrzeugsteuer als Gemeindeabgabe ähnlich aus wie das der Mineralölsteuer. Wenn man jedoch ein bisher noch nicht behandeltes kommunalspezifisches Besteuerungspostulat - die Merklichkeit bzw. Spürbarkeit - hinzunimmt, erscheint die Kraftfahrzeugsteuer die überlegene Alternative zu sein. So werden die privaten Kraftfahrzeughalter die Kraftfahrzeugsteuer als für die Gemeinde zu tragende und von dieser variierbare Last bemerken und empfinden. Hier liegt der eindeutige Vorteil gegenüber der prinzipiell weniger merklichen Mineralölsteuer.

Unter bestimmten Voraussetzungen kann eine kommunale Kraftfahrzeugsteuer als Ergänzungsteuer Eingang in ein Gemeindesteuersystem finden. Sie bekommt aber lediglich vor dem besonderen Hintergrund des Individualverkehrs und seiner Belastungen sowie der Finanzierung des öffentlichen Personennahverkehrs (möglicherweise auch nur vorübergehende) Relevanz und ist daher auch nicht als eine der tragenden Säulen in der theoretischen Diskussion des Kapitels 9 vorgestellt worden.

\footnotetext{
${ }^{337}$ Man könnte versuchen, die sich damit einstellenden Probleme zu umgehen, indem man die gewerbliche Kraftahrzeughaltung von der Besteuerung ausnimmt. Das würde möglicherweise aber andere Probleme (mögliche Hinterziehung, fehlende Breitenwirkung) hervorrufen.
} 
Ist also die Hypothese verifizierbar, daß ein enger Zusammenhang zwischen dem gemeindlichen Kraftfahrzeugbestand und kommunalen Infrastrukturleistungen (Gemeindestraßen, Parkraum, Verkehrszeichen) existiert, kann eine kommunale Kraftfahrzeugbesteuerung mit entsprechendem Hebesatzrecht ein weiteres Stück gemeindlicher Finanzautonomie im Sinne einer fiskalischen Äquivalenz bzw. eines Interessenausgleichs verwirklichen. ${ }^{338}$ Dieser Interessenausgleich könnte im Sinne stadtentwicklungs- sowie verkehrspolitischer Zielsetzungen bei (zweckgebundener) Verwendung des Aufkommens zur Bewältigung der Aufgaben im öffentlichen Nahverkehr weiter ausgedehnt werden und so über die Besteuerung des (lastverursachenden) Individualverkehrs und die Förderung (finanzielle "Unterstützung") des öffentlichen Personennahverkehrs im Resultat möglicherweise auch Verhaltensänderungen der Betroffenen bewirken.

Die vorgeschlagene Zweckbindung ist jedoch vor dem Hintergrund des (im bundesdeutschen Haushaltsrecht verankerten) Nonaffektationsprinzips problematisch, aber nach dessen "Aufweichung" (vgl. die späteren Ausführungen im Abschnitt 12.5) nicht nur realisierbar, sondern infolge der besonderen Finanzierungsnotwendigkeiten (Stichwort: Regionalisierung des schienengebundenen Personennahverkehrs in der Bundesrepublik Deutschland im Zuge der sogenannten Bahnreform) durchaus ein auch kurzfristig realisierbares Konzept, das neben dem Gemeindeverkehrsfinanzierungsgesetz (das zweckgebundene und bedarfsorientierte Finanzzuweisungen des Bundes bei komplementärem Mitteleinsatz der Kommunen für die Finanzierung genehmigungspflichtiger Projekte vorsieht) die besonderen Anforderungen der nächsten Jahre bewältigbar (zumindest von der fiskalischen Seite) machen könnte. Durch diese ergänzende Komponente erscheint über eine gemeindliche Mitverantwortung eine bedarfsorientierte öffentliche Verkehrsinfrastruktur bei effizientem Mitteleinsatz möglich. Dies muß nicht unbedingt, wie Kritiker oft vorschnell argumentieren, in einem möglichst gleichmäßigen Versorgungsniveau bestehen, sondern kann nach Abdeckung eines Grundbedarfs durchaus auch an lokalen/regionalen Besonderheiten ausgerichtete Differenzierungen aufweisen.

338 Wichtig ist jedoch eine Beobachtung möglicher Ausweichreaktionen der Kraftfahrzeughalter, die durch Wohnsitzmeldungen in Gebieten mit niedrigen Hebesätzen eine Reduktion ihrer individuellen Steuerbelastung anstreben können. Dieses Problem dürfe jedoch insofern kaum gravierende Ausmaße annehmen, wenn, wie vorgeschlagen, eine kommunale Kraftfahrzeugsteuer lediglich einen ergănzenden Charakter bekăme. Darüber hinaus ist die besondere Situation der zentralen Orte und der Ballungsräume zu beachten, die starke Einpendleranteile (mit Kraftahrzeugen) aufweisen und bei ausschließlicher Finanzierung durch heimische Kraftfahrzeugbesitzer die Verkehrsinfrastrukturlasten "ungerecht" verteilen würden. 


\subsubsection{Abschließende Bewertung des vorgestellten Gesamtkonzepts}

Die fiskalischen Auswirkungen von Reformkonzepten (wie sie vorstehend erörtert worden sind) können zwischen den Ebenen dadurch reduziert werden, daß eine entsprechende Umgestaltung zwischen den gebietskörperschaftlichen Ebenen weitestgehend aufkommensneutral erfolgt. Eine geringfügige auch quantitative Aufstockung der kommunalen Steuereinnahmen auf der einen Seite wird durch geringere Zuweisungsbedarfe auf der andere Seite für die übergeordneten Ebenen kompensiert. Gleichwohl ergeben sich aber auf der lokalen Ebene erhebliche interkommunale Verteilungswirkungen. Diese Aufkommensdifferenzen (bei Umstellungen gibt es auf der Gemeindeebene "Gewinner" und "Verlierer") können in einer Übergangszeit beispielsweise durch einen "Spitzenausgleich" abgefedert werden; später stellen sie jedoch einen durchaus gewünschten Anreiz- und Sanktionsindikator für ein an Effizienzgesichtspunkten und auf Wanderungsanreize abzielendes (wettbewerbliches) Gemeindefinanzsystem dar. Selbstverständlich setzt die Umstrukturierung des Systems auch erhebliche Verfassungsänderungen voraus.

Daher sei abschließend nochmals angemerkt, daß angesichts der Unumgänglichkeit von Grundgesetzänderungen bei Neuregelungen der Gemeindefinanzen in der aktuellen Reformdiskussion auch solche Vorschläge nicht von vornherein ausgeschlossen werden sollten, die mehr an Grundgesetzänderungen implizieren. Wenn man sich zu einer Grundgesetzänderung entschließen muß, besteht sicherlich Anlaß, mit aller Sorgfalt zu überlegen, wie man zu einem adäquaten kommunalen Finanz- und Steuersystem kommt. Nicht die Lösung mit dem kleinsten Eingriff ist dann zu wählen, sondern die unter den zugrundeliegenden Kriterien am besten begründete, auch wenn der Eingriff dabei stärker sein muß. Kommt man zu wirklich überzeugenden Lösungen, so kann vielleicht die Hemmschwelle für Grundgesetzänderungen eher überwunden werden.

\subsection{Ergänzende politisch-institutionelle Aspekte}

Unberücksichtigt bei der Urteilsfindung blieb bisher die für die gesamtstaatliche Steuerpolitik bedeutsame Frage, welche Probleme der Einbau des aufgrund kommunalspezifischer Erfordernisse als ideal ausgewiesenen Finanz- bzw. Steuersystems in das Gesamtsteuersystem eines Staates aufwirft. Konkret heißt dies, wenn das kommunale Steuersystem neu gestaltet wird, dann ist zu berücksichtigen, daß dieses reformierte System zum staatlichen - also das von Bund und Ländern beispielsweise - hinzutritt. Welches Bukett an Einzelabgaben letztlich zum praktizierten Kommunalsteuersystem in der Realität wird, hängt auch von der Lösung dieses Interessenkonflikts ab; konkret also von der Bereitschaft, ob überhaupt und gegebenenfalls in welchem Ausmaß 
Konflikte (Divergenzen) zwischen kommunaler und staatlicher Steuerpolitik toleriert werden.

Die Würdigung einzelner Steuern sowie die Ableitung eines als ideal zu klassifizierenden Systems ist aber bisher bewußt nicht vermischt worden mit der Frage, ob auch eine Eignung für das Gesamtsystem vorliegt, weil sonst kaum erkennbar sein dürfte, was als theoretisch gewonnene Lösung und was als politischer Kompromiß aufzufassen ist. Insofern dienen diese Bemerkungen auch als quasi letzter Anwendungsschritt, der einerseits die angesprochene "Einbaufahigkeit" des kommunalen Teils in ein gesamtstaatliches Finanz- bzw. Steuersystem beinhaltet, andererseits aber auch die generellen politischen Implikationen äquivalenzorientierter Gemeindefinanzierungssysteme (am Beispiel der Bundesrepublik Deutschland) aufzeigen soll.

Wer das angesprochene Problem der Einbaufähigkeit kommunaler Finanzierungssysteme in die gesamtstaatlichen lösen will, bewegt sich zwischen zwei Polen. Auf der einen Seite hat er zu beachten, daß mit Hilfe des gemeindlichen Steuersystems eine adäquate Wahrnehmung kommunaler Belange - d.h. der Bereitstellung lokaler öffentlicher Leistungen und ihrer Finanzierung - gewährleistet wird. Auf der anderen Seite darf der Konstrukteur des kommunalen Steuersystems mögliche Konflikte mit den zentralstaatlichen Interessen nicht übersehen. Eine Lösung, wie sie der Wissenschaftlichen Beirat beim Bundesministerium der Finanzen $(1974,405)$ in seinem "Gutachten zum Gemeindesteuersystem und zur Gemeindesteuerreform in der Bundesrepublik Deutschland" vom 16. März 1968 formuliert hat, nämlich daß in Fällen von Interessenkonflikten stets den kommunalen Belangen Priorität einzuräumen sei, wird sich vermutlich kaum realisieren lassen. In seinem jüngeren "Gutachten zur Reform der Gemeindesteuern" (Wissenschaftlicher Beirat, 1982, 44) gibt er diese Vorstellung daher auch auf und stellt die gemeindespezifischen Prinzipien den staatlichen gleich. Das würde bedeuten, daß im Einzelfall bei Vorliegen entsprechender Zielkonflikte einmal der zentralstaatlichen Steuerpolitik der Vorzug gegeben wird (etwa bei Verteilung der steuerlichen Lasten), ein anderes Mal kann und wird man sich zugunsten der gemeindlichen Steuerpolitik entscheiden (etwa wenn es um das Problem der Wettbewerbsneutralität geht). 
12.5 Beurteilung der aktuellen finanz- und steuerpolitischen Lage aus kommunaler Sicht

Statt einer Reform des Gemeindesteuersystems ist mit dem Steueränderungsgesetz 1992 die Demontage der Gewerbesteuer fortgesetzt worden. ${ }^{339}$ Für die Zukunft kann nach den Erfahrungen mit dem Steueränderungsgesetz 1992 nicht ausgeschlossen werden, daß weitere Eingriffe in die Gewerbesteuer erfolgen (müssen).

Konkrete Ansätze für eine Reform des Gemeindesteuersystems, die diesen Namen verdient, sind bisher bei der Bundesregierung und den sie tragenden Parteien nicht erkennbar. Auch auf der Länderebene sind keine nennenswerten Aktivitäten in Sicht, eine dauerhafte Lösung des Gewerbesteuerproblems im Rahmen einer grundlegenden Reform des Gemeindesteuersystems in Angriff zu nehmen. ${ }^{340}$

Angesichts der auf Jahre hinaus außerordentlich geringen Steuerkraft der Städte und Gemeinden in den neuen Ländern ${ }^{341}$ hat sich die Notwendigkeit noch verstärkt, so schnell wie möglich auch den strukturschwachen Kommunen mit gewinnschwacher Wirtschaft zu einer bedarfsgerechten steuerlichen Basis zu verhelfen. Die Stärkung gewinnunabhängiger Elemente der produktionsbezogenen Gemeindesteuer ist also durch die deutsche Einheit notwendiger denn je geworden, zumal die ostdeutschen Städte und Gemeinden, die überwiegend zu den strukturschwachen Kommunen zählen dürften und daher in besonderer Weise auf gewinnunabhängige Steuereinnahmen angewiesen sind, in den nächsten Jahren (voraussichtlich bis Ende 1995) die Gewerbe-

339 Mit dem Steuerănderungsgesetz 1992 vom 25. Februar 1992 (BGBl. I, S. 297) wurden weitere Änderungen der Gewerbesteuer (vor allem auch vor dem Hintergrund der deutschen Einheit) beschlossen. Dieses sind im einzelnen: Anhebung des Freibetrags bei der Gewerbeertragsteuer von 36.000 auf 48.000 DM, Staffelung der Meßzahlen nach dem Gewerbeertrag oberhalb des Freibetrags für Einzelunternehmen und Personengesellschaften in fünf Schritten von 1 bis 5 v.H. je zusătzlich 24.000 DM Gewerbeertrag, Übernahme der Steuerbilanzwerte in die Vermögensaufstellung, Erhø̆hung des Freibetrags für Betriebsvermogen von 125.000 auf 500.000 DM, Verlăngerung der Aussetzung der Gewerbekapitalsteuer und der Vermögensteuer in den ostdeutschen Ländern bis Ende 1994 (in den alten Lăndern bleibt es derzeit bei der Gewerbekapitalsteuer), keine Abführung der Gewerbesteuerumlage durch die Gemeinden in den jungen Lăndern bis einschließlich 1992, Senkung des Vervielfaltigers zur Ermittlung der Gewerbesteuerumlage auf 28 v.H. ab 1. Januar 1993.

340 Die bisherige Diskussion einer Umsatzsteuerbeteiligung zeigt, daß zwar auch die Lănderfinanz- und -innenminister durchaus der Auffassung sind, daß der Städtetagsvorschlag năher geprüft und bewertet werden sollte; den Anforderungen der Länder an ein Gemeindefinanzsystem entspricht, so die Argumentation, aber eher die vom Wissenschaftlichen Beirat beim Bundesministerium der Finanzen vorgeschlagene Wertschöpfungsteuer und die von den kommunalen Spitzenverbänden bisher vertretenen Vorschläge einer Revitalisierung der bestehenden Gewerbesteuer.

341 Infolge der zunächst noch geringen Steuerkraft der Städte und Gemeinden in den neuen Lăndern sowie wegen ihrer kurzfristig kaum überbrückbaren Probleme bei der Durchsetzung hoherer und kostengerechter Gebühren kommt den Zuweisungen der neuen Lăder an die Kommunen eine zentrale finanzpolitische Bedeutung zu. 
kapitalsteuer nicht erheben dürfen. Eine vorübergehende Lösungsmöglichkeit - die bis zu einer "echten" Gemeindefinanzreform Bestand haben könnte, wäre eine Umlenkung $^{342}$ der von den (West-)Gemeinden an Bund und Länder abzuführenden Gewerbesteuerumlage an die Kommunen der neuen Länder. Diese Zwischenfinanzierung könnte nach Auslaufen des Fonds "Deutsche Einheit" und bei Inkrafttreten der neuen (Länder-)Finanzausgleichsregelungen ab 1995 für eine Übergangszeit helfen, die finanzielle Basis der ostdeutschen Städte und Gemeinden zu sichern, bis ein Reformkonzept für das Gemeindefinanzsystem auf den Weg gebracht worden ist, das die neuen Rahmenbedingungen ausreichend berücksichtigt und darüber hinaus die $\mathrm{Be}$ steuerungsbasis der jungen Länder sich an die der alten Länder angenähert hat.

Den kommunalen Interessen stehen Anforderungen an die Steuerpolitik gegenüber, die angesichts der Diskussion um Unternehmensteuerreformen und die internationale Wettbewerbsfähigkeit deutscher Unternehmen vorgetragen werden. Gerade die Substanzsteuerbelastung der Unternehmen in der Bundesrepublik erscheint (so etwa die Kommission zur Verbesserung der steuerlichen Bedingungen für Investitionen und Arbeitsplätze, 1991; Fischer, 1989, Deutsches Institut für Wirtschaftsforschung, 1989) im internationalen Vergleich insgesamt deutlich zu hoch. Als Ursache dafür wird der Tatbestand gesehen, daß die (betriebliche) Vermögensteuer und die Gewerbekapitalsteuer in vielen Ländern nicht erhoben wird (vgl. Bundesministerium der Finanzen, 1989). Dies zeigt deutlich den Zielkonflikt zwischen gemeindespezifischen und unternehmensspezifischen Interessen bei der Frage um die Reform des Steuersystems im allgemeinen bzw. der Gemeindesteuern (Gewerbesteuer) im besonderen.

Andererseits hat die deutsche Einheit zu einer massiven Verengung der Finanzierungsspielräume geführt. ${ }^{343}$ Dies wirkt sich für eine grundlegende Reform des Gemeindesteuersystems, bei der es neben Gewinnern zweifellos auch Verlierer geben würde, um so restriktiver aus, als im Interesse der politischen Durchsetzbarkeit zusätzliche Mittel zur "Abfederung" von Verlusten ("Spitzenausgleich") erforderlich wären.

342 Damit nicht nur Bund und Länder an der Finanzierung dieses Transferstromes beteiligt wăren, ließe sich (ăhnlich wie bei der Beteiligung der Finanzierung des Fonds "Deutsche Einheit" über die sogenannte Erhöhungszahl bei der Vervielfáltigermethode zur Ermittlung der Gewerbesteuerumlage) eine Beteiligung der Kommunen (West) mit einem bestimmten Anteil festlegen, indem die Gewerbesteuerumlage um diesen Prozentanteil erhöht würde. Die Kommunen in den neuen Bundeslăndern müßten selbstverstăndlich (wie zunăchst mit dem Steuerănderungsgesetz 1991 [BGBI. I, S. 1322]auch vorgesehen) wieder von der Abführung einer Gewerbesteuerumlage befreit werden.

343 Recker (1992) bemerkt zutreffend: "Angesichts der unvereinbaren Positionen auf beiden Seiten - Kommunen hier, Wirtschaft und Politik da - kam es zu einer Blockade der von Regierung und Kommunen für dringend notwendig gehaltenen Fortsetzung der Gemeindefinanzreform. Damit wurde [in den achtziger Jahren] kostbare und, wie wir heute wissen, finanzpolitisch vergleichsweise 'goldene' Zeit vertan." 
Die Diskussion über Änderungen des Grundgesetzes und insbesondere der Finanzverfassung legt es darüber hinaus nahe, jetzt die Vorstellungen einer auf einen breiten politischen Konsens ausgerichteten Reform des Gemeindesteuersystems zu konkretisieren, insbesondere wenn hierfür Verfassungsänderungen erforderlich wären.

Infolge der schwierigen haushaltspolitischen Lage und der finanzpolitischen Anforderungen (beispielsweise Neuregelung des Länderfinanzausgleichs) erscheint es kaum wahrscheinlich, in absehbarer Zeit eine Reform der Gemeindefinanzen in einer auch nur annähernd in der Breite der hier dargelegten Vorschläge adäquaten Form zu realisieren.

Mit diesen Darlegungen zur bundesdeutschen Gemeindesteuerproblematik sollten die theoretisch gewonnenen Ergebnisse auf eine reale Situation projiziert werden. Damit soll auch angestrebt werden, daß die (scheinbar fortwährende Aktualität besitzende) Gemeindefinanzreformproblematik nicht nur erneut überdacht wird, sondern auch tatsächlich in absehbarer Zeit einer Lösung näher gebracht werden kann. Dazu sind jedoch bei allen Beteiligten nicht nur interessenbezogene Meinungsäußerungen und daraus abgeleitete Reformvorschläge gefragt, sondern vielmehr konstruktive gemeinsame Schritte in eine Richtung, die - wie gesehen - am Ende zu mehr Effizienz auch im öffentlichen Sektor fuihrt. Dabei kommt, das sollte im Verlaufe der Arbeit mehr als deutlich geworden sein, der kommunalen Ebene eine entscheidende Bedeutung zu.

Welche steuerlichen Ausgleichsmaßnahmen erforderlich sein werden, wenn ein Gemeindefinanzsystem so grundlegend umgestaltet würde, und welche Rechnungen aufzumachen sind, wenn Bund und Länder nicht "verlieren" sollen, lag außerhalb dieser Themenstellung. Dies ist ein Feld, auf dem noch wissenschaftlicher Forschungsbedarf (vor allem in empirischer Hinsicht) besteht. Auch in diesem Kontext sollte man jedoch vermeiden, von vornherein aufgrund entsprechender "Umverteilungsbedarfe" echte Reformen abzulehnen, denn diese Aufkommenswirkungen in Form räumlicher Streuungen und ihre "Kosten" sind mit den "Erträgen" der reformierten Systeme zu verrechnen. Solche (ökonomischen und politischen) "Ertragskomponenten" können die größere Präferenznähe, die äquivalenzorientierte lokale öffentliche Leistungserstellung (die kostensparend, ressourcenschonend und bedarfs-/nachfrageorientiert ist), deren adäquate Finanzierung sowie das Vorhandensein von mehr basisdemokratischen Elementen (Bürgernähe, -beteiligung) darstellen.

In der Finanzordnung der Bundesrepublik Deutschland können Länder und Gemeinden ihre Aufgaben (bisher) nur in höchst beschränktem Maße aus Einnahmen finanzieren, deren Art und Höhe sie autonom zu gestalten vermögen. So stammen etwa $60 \%$ aller 
Einnahmen der Kommunen und fast $80 \%$ aller Einnahmen der Länder ${ }^{344}$ aus dem Steuerverbund sowie aus Zuweisungen übergeordneter Gebietskörperschaften. Der Großteil des zur Verfügung stehenden Finanzierungsvolumens stammt also aus Quellen, auf deren Gestaltung und Ertrag kein direkter Einfluß möglich ist. Es stellt sich zwangsläufig die Frage, wie unter solchen Bedingungen Einwohner (Wähler), Politiker und Bürokraten eines Gemeinwesens vernünftig (und eben nicht verschwenderisch bzw. ineffizient) über den Einsatz der Mittel entscheiden, wenn diese Mittel zum weitaus größten Teil von zentraler Stelle ohne Kenntnis der Zahler zur Verfügung gestellt werden. ${ }^{345}$

In gleicher Weise wirkt der (legalisierte) Haushaltsgrundsatz der "Nonaffektation" Er verbietet, Steuern gezielt für bestimmte Zwecke zu erheben, trennt also eigentlich bewußt Zahler und Nutzer öffentlicher Leistungen. Man gewinnt den Eindruck, daß zumindest in Deutschland das Nonaffektationsprinzip (also die Nichtbindung einer Einnahme an die Ausgabe) so sehr im finanzwissenschaftlichen Denken und in den Entscheidungen des Alltags verhaftet bzw. verwurzelt ist, daß es kaum jemandem in den Sinn kommt, die generelle Finanzierung öffentlicher Dienste vor dem Hintergrund der Struktur und Reichweite der einzelnen Leistung neu zu überdenken. Im Gegenteil, es werden laufend Argumente zusammengetragen, die für eine unentgeltliche Abgabe öffentlicher Leistungen sprechen und die begründen, welche Vorteile eine Steuerfinanzierung (orientiert an Leistungsfähigkeitsgesichtspunkten) gegenüber einer direkten individuellen Abgabe bzw. äquivalenzorientierten Abgaben für bestimmte Nutzergruppen besäße. Dabei läge es mehr als nahe zu fragen, ob es in einem hochentwickelten (föderalen) Gemeinwesen nicht erforderlich ist, die Einnahmen und die Ausgaben in einem Budget nicht nur global einander gegenüberzustellen, sondern sie im Bedarfsfall nach Einzelprojekten geordnet miteinander zu verzahnen. Auf diese Weise könnte man ökonomische Effizienz auch im öffentlichen Sektor stärker als bisher - wenn auch in Grenzen - messen und sichern. Gerade auf der lokalen Ebene - aber durchaus nicht nur auf dieser - ist diese Vorgehensweise der eigentliche "Schlüssel zum Erfolg".

\footnotetext{
344 Die Kreditaufnahme ist nicht berücksichtigt worden.

345 Weitere eher technische und organisatorische Problembereiche sind sogenannte Mitnahmeeffekte von $\mathrm{Zu}$ schüssen und Zuweisungen, eine Art "Gießkannenprinzip" bei der Fördermittelvergabe sowie die Belohnung und Bevorzugung politisch opportunen Verhaltens durch die Zentrale. Diese Schwierigkeiten erschweren eine effektive Ausgestaltung eines solchen "Alimentationssystems". Bestimmte Machtkonstellationen und ihre möglichen Auswirkungen (also ihr Mißbrauch) verzerren entsprechende Resultate und sprechen so ebenfalls gegen ein zentrales "Einnahmenerzielungsmonopol" und der damit verbundenen Alimentierung untergeordneter Gebietskörperschaften.
} 
Hans-Georg Napp - 978-3-631-75263-0

Downloaded from PubFactory at 01/11/2019 06:33:05AM

via free access 
"Federalism means different things to different people, and so do its fiscal implications. No wonder then that there is no distinct theory of fiscal federalism. Rather, we deal with a composite of theories or models, pointed at various facets of the problem."

Richard A. Musgrave (1969b, 521)

\section{Abschließende Bemerkungen}

Eine Analyse, die wie die vorstehende nicht nur innerhalb eines geschlossenen Modells argumentiert, sondern versucht, zwischen theoretischen Einzelerkenntnissen und der Realität eine Brücke zu schlagen, kann nicht zu völlig werturteilsfreien Ergebnissen gelangen. Es besteht bei einer derartigen Vorgehensweise immer die Gefahr, daß man beim Abwägen unterschiedlicher Argumente gelegentlich die Gewichtung unter einengenden (partialen) Aspekten vornimmt oder die Modellkonstruktion in den Vordergrund treten läßt.

Mit dieser Arbeit sollte der Blick nicht nur auf reine Modellbetrachtungen und die daraus ableitbaren Ergebnisse gerichtet werden, denn der Wert der Wissenschaft erschöpft sich nicht nur in der reinen Logik des Modells, sondern wird vielmehr auch und gerade daran gemessen, welchen Beitrag die Wissenschaft leistet, um den Menschen und seine Umwelt besser zu verstehen und sein Wirken zu erleichtern. Dazu ist es erforderlich, daß auch ökonomische und soziale Zusammenhänge sichtbar gemacht und durchleuchtet werden, für die bisher noch keine endgültigen Erklärungen zur Verfügung stehen, die aber andererseits politisch beeinflußt werden (sollen).

Die Gefahr einer analytischen Sterilität ist zwar in der Finanzwissenschaft geringer als etwa in der theoretischen Volkswirtschaftslehre, aber es gelingt trotzdem nicht immer, rechtzeitig zu erkennen, welche Grenzen, gemessen am Bezug zum realen Phänomen, einigen Konzeptionen gesetzt sind. Weit schwieriger, als einen "Modellplatonismus" zu vermeiden, scheint es manchmal zu sein, auch sogenannte alte Fragen wieder aufzugreifen und neu zu durchleuchten, für die es scheinbar seit langem "gesicherte" Antworten gibt.

So wurde auch im Verlauf dieser Untersuchung deutlich, daß der Konstrukteur eines (ebenfalls) für die steuerpolitische Praxis gedachten Systems die Ebene rein theoretischer Überlegungen verlassen muß; nämlich in dem Moment, in dem eine Lösung nicht mehr ohne subjektive Wertungen auskommt. Dies ist dann der Fall, wenn die angestrebte Lösung mit einer Stellungnahme zu vorgefundenen Zielkonflikten verbunden ist. Mit der Bezeichnung "praktikabel" ist dann letztlich (vgl. speziell Kapitel 12) auch 
auf diesen Tatbestand aufmerksam gemacht worden. Daher ist sich der Autor durchaus der Tatsache bewußt, daß der eigene Lösungsvorschlag nur ein Diskussionsbeitrag sein kann, der sich zu den vielen Vorschlägen hinzugesellt, die schon zum gleichen Anliegen vorgetragen worden sind.

Aus dieser doppelten Sicht hat sich der Untersuchungsgegenstand dieser Arbeit, die kommunale Finanzautonomie und ihre Implikationen für die Ausgestaltung eigenständiger lokaler Finanzierungssysteme, als fruchtbar erwiesen. Es wurde erkennbar, daß sich der Staat gerade auf der lokalen Ebene (durch die Gemeinden) einige Vorzüge des Marktmechanismus zunutze machen könnte und sich damit knappe Ressourcen im öffentlichen Sektor und im Verhältnis zum privatwirtschaftlichen Bereich weit effizienter ausnutzen ließen. Auch die aus der föderativen Finanzstruktur der Bundesrepublik Deutschland resultierenden Probleme ließen sich durch eine Neukonzipierung des kommunalen Finanzsystems verringern, so etwa in der Auseinandersetzung der gebietskörperschaftlichen Ebenen um einen höheren Anteil am Steueraufkommen. ${ }^{346}$ Das komplizierte System des Finanzausgleichs sowohl in vertikaler Sicht zwischen Bund, Ländern und Gemeinden als auch horizontal auf Länder- bzw. Gemeindeebene könnte durchsichtiger und vereinfacht werden, wenn ein an Äquivalenzgesichtspunkten und dem Grundsatz des Interessenausgleichs orientiertes (effizienzförderndes) kommunales Finanzsystem Platz greifen würde.

Die üblichen Einwände hinsichtlich der politischen Nichtdurchsetzbarkeit solch weitreichender Vorschläge, deren Nichtpraktikabilität und das Festhalten an bestimmten verkrusteten Prinzipien der öffentlichen Finanzwirtschaft - wie dem Nonaffektationsprinzip (vgl. Kapitel 12) - blockieren und verhindern zwar häufig wirkliche Reformen, können und sollten jedoch nicht als objektive Einwände gegen bessere Alternativen allgemeine, immerwährende bzw. ausschlaggebende Geltung besitzen.

Insgesamt gesehen sind daher im Verlauf dieser Arbeit sowohl die normativen Ergebnisse der an der individualistischen Wohlfahrtstheorie angelehnten Modellansätze als auch das allzu starre Festhalten an bestimmten kameralistischen Grundsätzen der Haushalts- und Finanzpolitik kritisch unter die Lupe genommen worden. Dabei zeigte sich, daß einzelne (gängige) Hypothesen längst überholt sind und ältere Ansätze nicht mehr befriedigen können. Eine kritische Überprüfung der neueren (föderalismustheoretischen) Literatur hat ergeben, daß trotz nachdrücklicher Forderung, die Produktivität in Staat und Verwaltung zu verbessern, der Frage nach der jeweils effizien-

346 Letztes Beispiel in einer Reihe von entsprechend abgelaufenen Verteilungskonflikten ist das Steuerănderungsgesetz 1992; die năchsten Auseinandersetzungen zeichnen sich im Zusammenhang mit der Finanzierung der deutschen Einheit, der Neuregelung des Lănderfinanzausgleichs sowie der Diskussion um eine Reform der Gemeindefinanzen (Beteiligung der Gemeinden an der Umsatzsteuer) bereits mehr als deutlich ab. 
ten Finanzierung bestimmter (hier lokaler) öffentlicher Leistungen noch keineswegs die Aufmerksamkeit zuteil wird, die ihr heute (erneut) gebührt.

Die aufgezeigten Umrisse für die Ausgestaltung kommunaler Finanzsysteme (sowohl in ihrer rein theoretischen Ausformung als auch in ihrer für die Realität bestimmten Gestalt) sind raum- und zeitbezogen. Es läßt sich nämlich, wie Haller $(1971,3)$ zutreffend bemerkt hat, keine "... zweckmäßige Gestaltung der Besteuerung ..." ermitteln, die "... für alle Zeiten und Völker gelten ..." kann. Nicht zuletzt deshalb wird die Suche nach einem idealen/optimalen Gemeindefinanz- bzw. Gemeindesteuersystem Daueraufgabe der Finanzwissenschaft bleiben. Dies bedeutet ganz generell, daß der Prozeß der "Vervollkommnung" von praktizierten Systemen eine Dauererscheinung in der finanzwirtschaftlichen und -politischen Wirklichkeit sein wird. Diesen permanenten Reformdruck und seine möglichen Ergebnisse auf dem Weg zu einer solchen "Vervollkommnung" soll abschließend ein - beispielhafter, aber nicht ganz ernst gemeinter historischer Exkurs verdeutlichen. Diese Ausführungen sollen eine Arbeit beschließen, die für ihren zugrundeliegenden Untersuchungsgegenstand gerade auch solche (Fehl-) Entwicklungen zu vermeiden versucht. Dieser Blick in die Historie illustriert aber auch, daß Steuerreformbestrebungen wohl so alt sind wie die Besteuerung selbst, und zeigt darüber hinaus den Umgang der politischen Realität mit all den bedeutenden, theoretisch fundierten "Idealen" der Finanzwissenschaft. Doch diese Diskussion böte reichlich "Stoff" für eine neue Arbeit.

Schon zu Zeiten des Kaisers Probus (232-282) wurde $282 \mathrm{n}$. Chr. im alten Rom eine Steuerreform durchgeführt. Finanzsenator war Scaefarius, der vom römischen Senator Casparius mit folgenden Worten ausgezeichnet wurde:

"Lobend gleichzustellen ist diese deine Steuerreform, Scaefarius, allen Steuerreformen, die da waren, sind oder je kommen werden. Sie ist modern, gerecht, entlastend und kunstvoll:

- modern, weil jede der alten Steuern einen neuen Namen trägt,

- gerecht, weil sie alle Bürger des Römischen Reiches gleichbenachteiligt,

- entlastend, weil sie keinem Steuerzahler mehr einen vollen Beutel laßt,

- kunstvoll, weil du in vielen Worten ihren kurzen Sinn versteckst: dem Kaiser zu geben, was des Kaisers ist - und dem Bürger zu nehmen, was des Bürgers ist" (zitiert nach Ulrich, 1989, 261f). 
Hans-Georg Napp - 978-3-631-75263-0

Downloaded from PubFactory at 01/11/2019 06:33:05AM

via free access 


\section{Literaturverzeichnis}

Acheson, K. (1988), Bureaucratic Theory: Retrospect and Prospect, in: Breton, A.; Galeotti, G.; Salmon, P.; Wintrobe, R. (Eds.), Villa Colombella Papers on Bureaucracy (Proceedings of the Seminar held at Saint Marc sur Richelieu, Canada, September 1986), Regensburg, S. 17-46

Albers, W. (1962), Die Aufgaben- und Einnahmenverteilung auf die öffentlichen Gebietskörperschaften und die gemeindliche Selbstverwaltung, in: Archiv für Kommunalwissenschaften, 1. Jg., S. 65-92

Albers, W. (1964), Das Popitzsche Gesetz der Anziehungskraft des übergeordneten Haushalts, in: Neumark, F. (Hrsg.), Strukturwandlungen einer wachsenden Wirtschaft (Schriften des Vereins fuir Socialpolitik, Neue Folge, Bd. 30/II), Berlin, S. 835-858

Albers, W. (1988), Reform ist überfällig, in: Wirtschaftswoche, 42. Jg., Heft 28, S. 64-66

Alchian, A.A.; Demsetz, H. (1972), Production, Information Costs, and Economic Organization, in: American Economic Review, Vol. 62, S. 777-795

Alter, R.; Stegmann, H. (1984), Die Praktikabilität einer kommunalen Wertschöpfungsteuer, in: Wirtschaftsdienst, 64. Jg., Heft 2, S. 90-94

Alter, R.; Stegmann, H. (1985), Gestaltungsmöglichkeiten des Modells einer kommunalen Wertschöpfungsteuer und ihre räumlichen Auswirkungen, in: Raumforschung und Raumordnung, 43. Jg., Heft 5, S. 201-208

Alvermann, F.; Gebert, G. (1979), Die Behandlung von Fehlbeträgen und Überschüssen bei kostenrechnenden Einrichtungen, in: Der Gemeindehaushalt, 80. Jg., S. 12-13

Andel, N. (1980), Einkommensteuer, in: Handbuch der Finanzwissenschaft, Tübingen, 3. Aufl., Bd. II, S. 331-401

Ando, A.; Blume, M.E.; Friend, I. (1985), The Structure and Reform of the U. S. Tax System, Cambridge, Mass./London

Andreae, C.-A. (1980), Grundsteuern, in: Handbuch der Finanzwissenschaft, Tübingen, 3. Aufl., Bd. II, S. 575-606

Arians, I. (1980), Kommunaler Finanz- und Lastenausgleich - Berücksichtigung überdurchschnittlich hoher Arbeitslosigkeit, in: Städte- und Gemeinderat, 34. Jg., Heft 9, S. 323

Arnott, R.J. (1979a), Optimal City Size in a Spatial Economy, in: Journal of Urban Economics, Vol. 6, S. 65-89

Arnott, R.J. (1979b) Optimal Taxation in a Spatial Economy with Transport Costs, in: Journal of Public Economics, Vol. 11, S. 307-334

Arnott, R.J.; Stiglitz, J. E. (1979), Aggregate Land Rents, Expenditure on Public Goods, and Optimal City Size, in: Quaterly Journal of Economics, Vol. 93, S. 471-500

Aronson, J.R.; Schwartz, E. (1973), Financing Public Goods and the Distribution of Population in a System of Local Governments, in: National Tax Journal, Vol. 26, S. 137-160

Arrow, K.J. (1950), A Difficulty in the Concept of Social Welfare, in: The Journal of Political Economy, Vol. 58, S. 328-346 
Arrow, K.J. (1963), Social Choice and Individual Values (2. ed.), New Haven/London

Arrow, K.J. (1980), Wo Organisation endet - Management an den Grenzen des Machbaren, Wiesbaden

Arrow, K.J.; Debreu, G. (1954), Existence of an Equilibrium for a Competitive Economy, in: Econometrica, Vol. 22, S. 265-290

Aschinger, G. (1985), Das Coase-Theorem, in: Das Wirtschaftsstudium (WISU), Heft 2, S. 97-102

Atkinson, A.B.; Stiglitz, J.E. (1980), Lectures on Public Economics, Maidenhead

Audenhove, M. von (1979), The Financial Consequences of the Position and Tasks of Cities, in: Local Finance, Nr. 2, S. 3-9

Bach, H.W. (1978), Planungswertausgleich und Raumordnungspolitik, München

Bach, S. (1992), Cash-flow-Steuern - Ein Weg zu einem konsumorientierten Steuersystem, in: Wirtschaftsdienst, 72. Jg., Heft 6, S. 325-332

Badelt, C. (1980), Sozioökonomie der Selbsthilfeorganisation, Frankfurt a.M.

Bätz, K. (1979), Administrative Preispolitik öffentlicher Unternehmen - Gebühren und Tarife als Mittel zur Lenkung der Nachfrage nach öffentlichen Leistungen, Baden-Baden

Bahl, R.W.; Vogt, W. (1975), Fiscal Centralization and Tax Burdens: State and Regional Financing of City Services, Cambridge, Mass.

Balser, W. (1981), Räumliche Aufkommensdisparitäten beim Gemeindeanteil an der Einkommensteuer: Dargestellt am Beispiel der Stadtregion Ludwigshafen, in: Raumforschung und Raumordnung, 39. Jg., Heft 5/6, S. 247-253

Barrow, M.M. (1986), Central Grants to Local Governments - A Game Theoretic Approach, in: Environment and Planning C: Government and Policy, Vol. 4, S. 155-164

Bator, F.M. (1958), The Anatomy of Market Failure, in: Quaterly Journal of Economics, Vol. 72, S. 351-379

Baumol, W.J. (1964), External Economies and Second Order Optimality Conditions, in: American Economic Review, Vol. 54, S. 358-372

Bayer, H.-W. (1989), Die Einwohnersteuer als örtliche Aufwandsteuer - Zum Einwohnersteuerurteil des VG Sigmaringen vom 13. April 1989, in: Kommunale Steuerzeitschrift, 38. Jg., S. 167-169

Becker, H. (1990), Finanzwissenschaftliche Steuerlehre - Steuerwirkung, Steuerfinanzierung, Steuerpolitik, München

Bedau, K.D.; Göseke, G. (1977), Die Belastung der privaten Haushalte mit indirekten Steuern, in: DIW-Wochenbericht, 44. Jg., S. 377-384

Bennett, J. (1987), The Second-Best Lump-Sum Taxation of Observable Characteristics, in: Public Finance, Vol. 42, Nr. 2, S. 227-235

Berglas, E. (1976), Distribution of Tastes and Skills and the Provision of Local Public Goods, in: Journal of Public Economics, Vol. 6, S. 409-423

Berglas, E. (1982), User Charges, Local Public Services, and Taxation of Land Rents, in: Public Finance, Vol. 37, S. 178-188 
Berglas, E. (1984), Quantities, Qualities, and Multiple Public Services in the Tiebout Model, in: Journal of Public Economics, Vol. 25, S. 299-321

Berglas, E.; Pines, D. (1981), Clubs, Local Public Goods and Transportation Models: A Synthesis, in: Journal of Public Economics, Vol. 15, S. 141-162

Bergstrom, T.C.; Goodman, R.P. (1973), Private Demands for Public Goods, in: American Economic Review, Vol. 63, S. 280-296

Berkenhoff, H.A. (1982), Modell für die Ablösung der Gewerbesteuer durch einen Gemeindeanteil an der Umsatzsteuer, in: Kommunalwirtschaft (Zeitschrift des Vereins fur Kommunalwirtschaft und Kommunalpolitik), Heft 9, S. 333-337

Bernhardt, H.; Schünemann, H.; Schwingeler, R. (1991), Kommunales Finanz- und Abgabenrecht NW - Lehrbuch mit praktischen Übungen und Lösungen (4. Aufl.), Witten

Bernholz, P. (1972), Grundlagen der Politischen Ökonomie (1. Band), Tübingen

Bernholz, P. (1975), Grundlagen der Politischen Ökonomie (2. Band), Tübingen

Bertelsmann, B.; Postlep, R.-D. (1979), Eine kommunale Einzelhandelsumsatzsteuer und ihre räumliche Verteilung, in: Informationen zur Raumentwicklung, Heft 11/12, S. 721-732

Bewley, T.F. (1981), A Critique of Tiebout's Theory of Local Public Expenditures, in: Econometrica, Vol. 49, S. 713-740

Bickel, W. (1956), Ertragsteuern, in: Handbuch der Finanzwissenschaft, Tübingen, 2. Aufl., Bd. II, S. 403-446

Biehl, D. (1979), Dezentralisierung als Chance für größere Effizienz und mehr soziale Gerechtigkeit, in: Schuster, F. (Hrsg.), Dezentralisierung des politischen Handelns II - Konzeptionen und Positionen, Melle, S. 85-132

Biehl, D. (1988), Finanzausgleich IV: Internationaler Finanzausgleich, in: Handbuch der Wirtschaftswissenschaften (HdWW), Stuttgart/Tübingen/Göttingen, Bd. 2, S. 689-713

Bird, R.M. (1976), Charging for Public Services - A New Look at an Old Idea (Canadian Tax Paper, No. 59), Toronto

Bishop, G.A. (1964), Stimulative versus Substitute Effects of State School Aid in New England, in: National Tax Journal, Vol. 17, S. 133-143

Black, D. (1948), On the Rationale of Group Decision-Making, in: Journal of Political Economy, Vol. 56, S. 23-34

Black, D. (1958), The Theory of Committees and Elections, Cambridge

Blankart, Ch.B. (1979), Die wirtschaftspolitische Bedeutung von Skalenerträgen öffentlicher Unternehmen - Eine theoretische und empirische Betrachtung, in: Zeitschrift für öffentliche und gemeinwirtschaftliche Unternehmen, 2. Jg., S. 1-25

Blinder, A.S.; Break, G.F.; Netzer, D.; Solow, R.M.; Steiner, P.O. (1974), The Economics of Public Finance, Washington D.C.

Blümel, W. (1987), Die Allokation öffentlicher Güter in unterschiedlichen Allokationsverfahren - Eine vergleichende theoretische Untersuchung, Berlin

Blümel, W.; Pethig, R.; von dem Hagen, O. (1986), Theory of Public Goods: A Survey of Recent Issues, in: Journal of Institutional and Theoretical Economics (Zeitschrift fur die gesamte Staatswissenschaft), Vol. 142, S. 241-309 
Boadway, R.W. (1979), Public Sector Economics, Cambridge, Mass.

Boadway, R.W. (1982), On the Method of Taxation and the Provision of Local Public Goods: Comment, in: American Economic Review, Vol. 72, S. 846-851

Boadway, R.W.; Flatters, F.R. (1982), Equalization in a Federal State - An Economic Analysis, Ottawa

Boadway, R.W.; Wildasin, D.E. (1984), Public Sector Economics (2. ed.), Boston/Toronto

Böckels, L. (1989), Möglichkeiten einer Reform der Gewerbesteuer, in: Wirtschaftsdienst, 69. Jg., Heft 2, S. 82-86

Bös, D. (1971), Eine ökonomische Theorie des Finanzausgleichs, Wien/New York

Bös, D. (1980), The Democratic Decision on Fees versus Taxes, in: Kyklos (Internationale Zeitschrift für Sozialwissenschaften), Vol. 33, S. 76-99

Bössmann, E. (1988), Information, in: Handbuch der Wirtschaftswissenschaften (HdWW), Stuttgart/Tübingen/Göttingen, Bd. 4, S. 184-200

Bohley, P. (1977), Gebühren und Beiträge - Ihre wirtschaftspolitischen Funktionen und ihr Platz im System der öffentlichen Einnahmen, Tübingen

Bohley, P. (1980), Gebühren und Beiträge, in: Handbuch der Finanzwissenschaft, Tübingen, 3. Aufl., Bd. II, S. 915-947

Bonus, H. (1978), Verzauberte Dörfer, oder: Solitarität, Ungleichheit und Zwang, in: Jahrbuch für die Ordnung von Wirtschaft und Gesellschaft (ORDO), Bd. 29, S. 49-82

Borcherding, T.E. (1970), Liability in Law and Economics: Note, in: American Economic Review, Vol. 60, S. 946-948

Borda, J.-Ch. de (1781), Mémoire sur les élections au scrutin - Histoire de l'Académie Royale des Sciences, Paris

Borell, R.; Schemmel, L. (1991), Steuern in Deutschland - Zu den Aufgaben der Steuerpolitik nach der Einigung (Schriftenreihe des Karl-Bräuer-Instituts des Bundes der Steuerzahler e.V., Heft 72), Wiesbaden

Bowen, H.R. (1943), The Interpretation of Voting in the Allocation of Economic Resources, in: Quarterly Journal of Economics, Vol. 58, S. 27-48

Bowen, H.R. (1948), Toward Social Economy, New York

Bowman, J. (1974), Tax Exportability, Intergovernmental Aid, and School Finance Reform, in: National Tax Journal, Vol. 27, S. 163-173

Bradford, D.F. (1987), On the Incidence of Consumption Taxes, in: Walker, C.E.; Bloomfield, M.A. (Eds.), The Consumption Tax - A better Alternative?, Cambridge, Mass., S. 243261

Bradford, D.F.; Oates, W.E. (1971a) Towards a Predictive Theory of Intergovernmental Grants, in: American Economic Review, Vol. 61, S. 440-448

Bradford, D.F.; Oates, W.E. (1971b), The Analysis of Revenue Sharing in a New Approach to Collective Fiscal Decisions, in: Quaterly Journal of Economics, Vol. 85, S. 416-439

Bradford, D.F.; Oates, W.E. (1974), Suburban Exploitation of Central Cities and Governmental Structure, in: Hochman, H.; Peterson, G. (Eds.), Redistribution Trough Public Choice, New York/London, S. 43-90 
Brainard, W.C.; Dolbear, F.T (1967), The Possibility of Oversupply of Local "Public" Goods A Critical Note, in: Journal of Political Economy, Vol. 75, S. 86-90

Break, G.F. (1967), Intergovernmental Fiscal Relations in the United States, Washington D.C.

Break, G.F. (1980), Financing Government in a Federal System, Washington D.C.

Breton, A. (1965), A Theory of Government Grants, in: Canadian Journal of Economics and Political Science, Vol. 31, S. 175-187

Breton, A. (1970), Public Goods and the Stability of Federalism, in: Kyklos (Internationale Zeitschrift für Sozialwissenschaften), Vol. 23, S. 882-902

Breton, A. (1977), Eine Theorie staatlicher Finanzzuweisungen, in: Kirsch, G. (Hrsg.), Föderalismus, Stuttgart/New York, S. 77-89

Breton, A.; Scott, A.D. (1978), The Economic Constitution of Federal States, Toronto

Breton, A.; Wintrobe, R. (1975), The Equilibrium Size of a Budget-Maximizing Bureau: A Note on Niskanen's Theory of Bureaucracy, in: Journal of Political Economy, Vol. 83, S. 195-220

Breton, A.; Wintrobe, R. (1982), The Logic of Bureaucratic Conduct, New York

Brown, E.C. (1948), Business-Income Taxation and Investment Incentives, in: Hansen, A.H. (Ed.), Income, Employment and Public Policy, New York, S. 300-316

Brümmerhoff, D. (1987), Finanzwirtschaft (2. Aufl.), München/Wien

Buchanan, J.M. (1950), Federalism and Fiscal Equity, in: American Economic Review, Vol. 40, S. 583-599

Buchanan, J.M. (1952a), Federal Grants and Resource Allocation, in: Journal of Political Economy, Vol. 60, S. 208-217

Buchanan, J.M. (1952b), A Reply, in: Journal of Political Economy, Vol. 60, S. 536-538

Buchanan, J.M. (1965a), An Economic Theory of Clubs, in: Economica, Vol. 32, S. 1-14

Buchanan, J.M. (1965b), The Public Finances (2.ed.), Homewood, Illinois

Buchanan, J.M. (1967), Public Finance in Democratic Process - Fiscal Institutions and Individual Choice, Chapel Hill

Buchanan, J.M. (1968), Demand and Supply of Public Goods, Chicago

Buchanan, J.M. (1972), Who Should Pay for Common-Access Facilities?, in: Public Finance, Vol. 27, S. 1-8

Buchanan, J.M. (1977), Wer sollte was in einem föderativen System verteilen?, in: Kirsch, G. (Hrsg.), Föderalismus, Stuttgart/New York, S. 51-65

Buchanan, J.M.; Flowers, M.R. (1975), The Public Finances - An Introductory Textbook (4. ed.), Homewood, Illinois

Buchanan, J.M.; Goetz, C.J. (1972), Efficiency Limits of Fiscal Mobility - An Assessment of the Tiebout-Model, in: Journal of Public Economics, Vol. 1, S. 25-43

Buchanan, J.M.; Kafoglis, M.Z. (1963), A Note on Public Goods Supply, in: American Economic Review, Vol. 53, S. 403-414

Buchanan, J.M.; Stubblebine, W.C. (1962), Externality, in: Economica, Vol. 29, S. 371-384 
Buchanan, J.M.; Tullock, G. (1971), The Calculus of Consent - Logical Foundations of Constituional Democracy (4. ed.), Ann Arbor

Buchanan, J.M.; Wagner, R.E. (1970), An Efficiency Basis for Federal Fiscal Equalization, in: Margolis, J. (Ed.), The Analysis of Public Output, New York, S. 139-158

Bucovetsky, S. (1981), Optimal Jurisdictional Fragmentation and Mobility, in: Journal of Public Economics, Vol. 16, S. 171-191

Budäus, D. (1978), Finanzierungspotential einer kostendeckenden Gebührenpolitik öffentlicher Einrichtungen aufgrund von Spielräumen bei der Kostenerfassung und -bewertung, in: Verwaltungsarchiv, 69. Jg., S. 361-376

Buhr, W. (1987), Empircal Analysis of Allocation - On the State of the Art in Urban Development Modeling, in: Zeitschrift für Wirtschafts- und Sozialwissenschaften, 107. Jg., S. 169-199

Bullinger, M.; Rincke, G.; Oberhauser, A.; Schmidt, R.-B. (1974), Das Verursacherprinzip und seine Instrumente - Eine interdisziplinäre Untersuchung, Berlin

Bulutoglu, K. (1976), Fiscal Decentralization - A Survey of Normative and Positive Contributions, in: Finanzarchiv, N.F., Vol. 35, S. 1-34

Bundesministerium der Finanzen (1989), Informationsdienst zur Finanzpolitik des Auslands Die wichtigsten Steuern im internationalen Vegleich, Nr. 1/89

Bundesministerium der Finanzen (1990), Unsere Steuern von A-Z, Bonn

Bundesministerium der Finanzen (1991), Finanzbericht 1992, Bonn

Bundesministerium der Finanzen (1992a), Unsere Steuern von A-Z, Bonn

Bundesministerium der Finanzen (1992b), Finanzbericht 1993, Bonn

Bundesministerium der Justiz (Hrsg.) (verschiedene Jahrgänge); Bundesgesetzblatt, Teil I und II, Bonn

Bundesverband der Deutschen Industrie (1985), Zukunftsorientierte Steuerpolitik, Köln

Bush, W.C.; Denzau, A.T. (1977), The Voting Behavior of Bureaucrats and Public Sector Growth, in: Borcherding, T.E. (Ed.), Budgets and Bureaucrats, Durham, S. 90-99

Caesar, R.; Kops, M. (1983), Abbau des Dotationswesens zwischen Ländern und Gemeinden, in: Archiv für Kommunalwissenschaften, 22. Jg., S. 50-73

Calabresi, G. (1968), Transaction Costs, Resource Allocation an Liability Rules: A Comment, in: Journal of Law and Economics, Vol. 11, S. 67-73

Cansier, D. (1989a), Cash-flow-Steuern - Neue Wege der Unternehmensbesteuerung?, in: Wirtschaftsdienst, 69. Jg., Heft 1, S. 49-56

Cansier, D. (1989b), Eine steuersystematische Beurteilung der Cash-flow-Steuern - Antwort auf ein Replik, in: Wirtschaftsdienst, $69 \mathrm{Jg}$., Heft 5, S. 252-256

Cansier, D. (1990), Ersatz der Gewerbesteuer durch die Cash-Flow-Steuer?, in: Der Betriebsberater (Zeitschrift fur Recht und Wirtschaft), 45. Jg., S. 253-256

Carlberg, M. (1978), Stadtökonomie - Ökonomische Analyse der Stadt, besonders in der Bundesrepublik, Göttingen 
Clausen, G. (1978), Das gebührenrechtliche Kostendeckungsprinzip, Frankfurt a.M./Bern/Las Vegas

Clemens, R.; Held, T. (1986), Gewerbesteuerreform im Spannungsfeld von Unternehmenssteuerbelastung und kommunaler Finanzautonomie, Stuttgart

Coase, R.H.(1937), The Nature of the Firm, in: Economica, Vol. 4, S. 386-405

Coase, R.H. (1960), The Problem of Social Cost, in: Journal of Law an Economics, Vol. 3, S. $1-44$

Colm, G. (1965), National Goals Analysis and Marginal Utility Economics, in: Finanzarchiv, N.F., Vol. 24, S. 209-224

Condorcet, M.J. de (1785), Essai sur l'application de l'analyse à la probabilité des décisions rendues à la pluralité des voix, Paris

Conn, D. (1978), Economic Theory and Comparative Economic Systems: A Partial Literature Survey, in: Journal of Comparative Economics, Vol. 2, S. 355-381

Cornes, R.; Sandler, T. (1986), The Theory of Externalities, Public Goods and Club Goods, Cambridge

Courant, P.N.; Gramlich, E.M.; Rubinfeld, D.L. (1979), Public Employee Market Power and the Level of Government Spending, in: American Economic Review, Vol. 69, S. 806817

Craig, S.G.; Inman, R.P. (1982), Federal Aid and Public Education - An Empirical Look at the New Fiscal Federalism, in: Review of Economics and Statistics, Vol. 64, S. 541-552

Cyert, R.M.; March, J. (1963), A Behavioural Theory of the Firm, Prentice Hall, N. J.

Dafflon, B. (1977), Federal Finance in Theory and Practice with Special Reference to Switzerland, Bern/Stuttgart

Dammroff, E. (1970), Die Finanzierung der Infrastruktur, Zürich

Davis, O.H.; Haines, G.A. (1966), A Political Approach to a Theory of Public Expenditures The Case of Municipalities, in: National Tax Journal, Vol. 19, S. 259-275

Davis, O.A.; Whinston, A. (1962), Externalities, Welfare, and the Theory of Games, in: Journal of Political Economy, Vol. 70, S. 241-262

Debreu, G. (1959), Theory of Value - An Axiomatic Analysis of Economic Equilibrium, New Haven/London

Deitmer, M.; Sauerborn, W. (1986), Systemkrise der Gemeindesteuern: gewerkschaftliche Anforderungen und Lösungsansätze, in: WSI-Mitteilungen, 39. Jg., Heft 12, S. 798-805

Demsetz, H. (1967), Toward a Theory of Property Rights, in: American Economic Review, Papers and Proceedings, Vol. 57, S. 347-359

Deutscher Industrie- und Handelstag (1982), Gewerbesteuer auf neuem Kurs - Mängel beseitigen, Vorteile erhalten (DIHT-Broschüre, Nr. 201), Köln

Deutscher Industrie- und Handelstag u.a. (1984), Kommunale Wertschöpfungsteuer - Der falsche Weg: Gemeinsame Stellungnahme des Deutschen Industrie- und Handelstages, des Bundesverbandes der Deutschen Industrie, des Bundesverbandes des Deutschen Großund Außenhandels, der Hauptgemeinschaft des Deutschen Einzelhandels, des Zentralver- 
bandes des Deutschen Handwerks, der Arbeitsgemeinschaft Selbständiger Unternehmer, des Bundesverbandes Deutscher Banken und des Gesamtverbandes der Deutschen Versicherungswirtschaft, Bonn/Köln

Deutsches Institut für Urbanistik (Hrsg.) (1979), Möglichkeiten und Probleme einer angemessenen Steuer- und Finanzreform (Bericht über die Sitzung des Kommunalwissenschaftlichen Arbeitskreises am 24. Nov. 1978 in Köln), Berlin

Deutsches Institut furr Wirtschaftsforschung (1989), Die Besteuerung der Unternehmensgewinne - sieben Industrieländer im Vergleich (Beiträge zur Strukturforschung, Heft 111), Berlin

Deutscher Städtetag (1986), Vorschlag des Deutschen Städtetages zur Umgestaltung der Gewerbesteuer, in: Kommunale Korrespondenz (Pressedienst des Deutschen Städtetages), Nr. 467, Köln

Diamond, P.A.; Mirrlees, J.A. (1971), On Optimal Taxation and Public Production I: Production Efficiency; II: Tax Rules, in: American Economic Review, Vol. 61, S. 827, S. 261-278

Dick, G.; Tiepelmann, K. (1988), Optimal Taxation - Optimale Besteuerung, Duisburg

Diekmann, B.; Schütz, D. (1989), Die Kopfsteuer als Komponente eines Gemeindesteuersystems? Das britische Beispiel, in: Archiv für Kommunalwissenschaften, 28. Jg., S. 228251

Dierkes, M. (1981), Sozialbilanzen bei Kreditinstituten - Perspektiven für die weitere Forschung, in: Zeitschrift für Betriebswirtschaft, 51. Jg., S. 901-909

Donges, J.B. (1985), Marktversagen und Staatsversagen - Was überwiegt?, in: Zeitschrift für Wirtschaftspolitik, 34. Jg., S. 121-130

Doose, U. (1981), Bemessungsgrundlagen für Entwässerungsgebühren, in: Der Städtetag (Zeitschrift für kommunale Praxis und Wissenschaft) 34. Jg., Heft 4, S. 277-283

Downs, A. (1960), Why Government Budget is Too Small in a Democracy, in: World Politics, Vol. 12, S. 541-563

Downs, A. (1967), Inside Bureaucracy, Boston

Downs, A. (1968), Ökonomische Theorie der Demokratie, Tübingen

Dudenhöffer, F.; Gebauer, H. (1982), Die Allokation lokaler öffentlicher Güter bei Konsumentenmobilität - Einige Anmerkungen zum Tiebout-Theorem, in: Siebert, H. (Hrsg.), Umweltallokation im Raum, Frankfurt a.M., S. 93-144

Due, J.F. (1957), Sales Taxation, London

Due, J.F. (1961), Studies of State-Local Tax Influences on Location of Industry, in: National Tax Journal, Vol. 14, S. 163-173

Due, J.F. (1968), The New State Sales Taxes 1961-68, in: National Tax Journal, Vol. 21, S. 266-287

Due, J.F.; Friedlaender, A.F. (1973), Government Finance - Economics of the Public Sector (5. ed.), Homewood, Illinois

Dziadkowski, D. (1987), Umgestaltung, Revitalisierung oder Ersatz der Gewerbesteuer?, in: Steuer und Wirtschaft, Heft 4, S. 330-342 
Edel, M.; Sclar, E. (1974), Taxes, Spending, and Property Values: Supply Adjustment in a Tiebout-Oates-Model, in: Journal of Political Economy, Vol. 82, S. 941-954

Ehle, D. (1962), Die verfassungsrechtliche Bedeutung des Kostendeckungsprinzips im Gebührenrecht, in: Die öffentliche Verwaltung, 15. Jg., S. 45-50

Ehrlicher, W. (1988), Finanzausgleich III: Der Finanzausgleich in der Bundesrepublik Deutschland, in: Handwörterbuch der Wirtschaftswissenschaften (HdWW), Stuttgart/ Tübingen/Göttingen, Bd. 2, S. 662-689

Einem, E. von (1981), Rückzug aus der Bodenwertabschöpfung - Ein Lehrstück der Reformpolitik?, in: Die öffentliche Verwaltung, 34. Jg., S. 252-262

Elsner, H. (1978), Gemeindehaushalt, Konjunktur und Finanzausgleich - Die Notwendigkeit einer wirtschafts-, zentralitäts- und aufgabenpolitischen Fortsetzung der Gemeindefinanzreform (Schriftenreihe zur öffentlichen Verwaltung und öffentlichen Wirtschaft, Bd. 24), Baden-Baden

Elsner, H. (1979) Das Gemeindefinanzsystem - Geschichte, Ideen, Grundlagen (Neue Schriften des Deutschen Städtetages, Heft 36), Stuttgart/Berlin/Köln/Mainz

Elsner, H.; Schüler, M. (1970), Das Gemeindefinanzreformgesetz - Einführung in die Gemeindefinanzreform und Erläuterungen zum Gemeindefinanzreformgesetz, Hannover

Endres, A. (1976), Die pareto-optimale Internalisierung externer Effekte, Frankfurt a.M.

Engelhardt, G.; Brockmann, G.; Rosenfeld, M.; Thiede, W. (1986), Finanzwissenschaftliche Folgen kommunaler Gebiets- und Funktionalreform - Problembereiche und Hypothesen im Überblick, Baden-Baden

Engelken, K. (1974), Abschöpfung planungsbedingter Bodenwertsteigerungen - Ziele und Konsequenzen der vorliegenden Vorschläge, in: Die öffentliche Verwaltung, 27. Jg., Heft 20, S. 685-699

Engels, W. (1983), Strittige Fragen bei der Gewerbesteuerreform, in: Die Wirtschaftsprüfung, Heft 23/24, S. 665-671

Epple, D.; Zelenitz, A. (1981a), The Implications of Competition among Jurisdictions - Does Tiebout Needs Politics?, in: Journal of Political Economy, Vol. 89, S. 1197-1217

Epple, D.; Zelenitz, A. (1981b), The Roles of Jurisdictional Competition and of Collective Choice Institutions in the Market for Local Public Goods, in: American Economic Review, Papers and Proceedings, Vol. 71, S. 87-92

Färber, G. (1988), Probleme der Finanzpolitik bei schrumpfender Bevölkerung, Frankfurt a.M./New York

Fama, E. (1980), Agency Problems and the Theory of Firm, in: Journal of Political Economy, Vol. 88, S. 288-307

Feldhoff, M. (1989), Die Cash-flow-Besteuerung und ihre Problematik, in: Steuer und Wirtschaft, 66. Jg., S. 53-63

Feldman, A.M. (1980), Welfare Economics and Social Choice Theory, Boston

Feldstein, M.S. (1975), Wealth Neutrality and Local Choice in Public Education, in: American Economic Review, Vol. 65, S. 75-89 
Feldstein, M.S.; Metcalf, G.E. (1987), The Effect of Federal Tax Deductibility on State and Local Taxes and Spending, in: Journal of Political Economy, Vol. 95, S. 710-736

Fiedler, K.P. (1981), Kommunale Strukturen in den USA, in: Der Städtetag (Zeitschrift für Kommunale Praxis und Wissenschaft), 34. Jg., S. 341-346

Finanzminister-Konferenz (1992), Plädoyer für Reform der Gewerbesteuer, in: Handelsblatt vom 2. November 1992, S. 1

Fisch, O. (1975), Optimal City Size: The Economic Theory of Clubs and Exclusionary Zoning, in: Public Choice, Vol. 24, S. 59-70

Fischer, H. (1990), Die Kopfsteuer - Eine "gute" Gemeindesteuer?, in: Wirtschaftswissenschaftliches Studium (WiSt), Heft 11, S. 567-569

Fischer, L. (1988), Die ertragsunabhängige Besteuerung der Unternehmen - Eine Spezialität des deutschen Steuersystems?, in: Finanzarchiv, N.F., Vol. 46, S. 299-322

Fischer-Menshausen, H. (1988), Finanzausgleich II: Grundzüge des Finanzausgleichsrechts, in: Handwörterbuch der Wirtschaftswissenschaften (HdWW), Stuttgart/Tübingen/Göttingen, Bd. 2, S. 636-662

Fisher, R.C. (1987), State and Local Public Finance, Glenview/London

Flatters, F.; Henderson, V.; Mieszkowski, P. (1974), Public Goods, Efficiency and Regional Fiscal Equalization, in: Journal of Public Economics, Vol. 3, S. 99-112

Forte, F. (1977), Binnenwanderung als Problem der Wohlfahrtsökonomie, in: Kirsch, G. (Hrsg.), Föderalismus, Stuttgart/New York, S. 90-108

Franke, S.F. (1981), Entwicklung und Begründung der Einkommensbesteuerung, Darmstadt

Frankfurter Institut für wirtschaftspolitische Forschung (1988), Die Reform des Gemeindesteuersystems - Vorschläge des Kronberger Kreises (Argumente zur Wirtschaftspolitik, Nr. 17), Frankfurt

Frey, B.S. (1988a), Ökonomische Theorie der Politik, in: Handwörterbuch der Wirtschaftswissenschaften (HdWW), Stuttgart/Tübingen/Göttingen, Bd. 5, S. 658-667

Frey, B.S. (1988b), Wohlfahrtsökonomik III: Wahlverfahren, in: Handwörterbuch der Wirtschaftswissenschaften (HdWW), Stuttgart/Tübingen/Göttingen, Bd. 9, S. 494-502

Frey, D. (1982), Die Finanzverfassung des Grundgesetzes, in: Bundesministerium der Finanzen (Hrsg.), Die Finanzbeziehungen zwischen Bund, Ländern und Gemeinden aus finanzverfassungsrechtlicher und finanzwirtschaftlicher Sicht, Bonn, S. 13-86

Frey, R.L. (1977), Zwischen Föderalismus und Zentralismus - Ein volkswirtschaftliches Konzept des schweizerischen Bundesstaates, Bern/Frankfurt a.M

Fromme, J.-K. (1985), Folgen der überdurchschnittlichen Arbeitslosigkeit auf die Finanzlage der Kommunen, in: Der Gemeindehaushalt, 86. Jg., Heft 12, S. 273-274

Fromme, J.-K. (1992), Fortsetzung der Gemeindefinanzreform ist notwendiger denn je, in: Kommunale Steuer-Zeitschrift (Zeitschrift für das gesamte Gemeindeabgabenwesen), 41. Jg., Heft 11, S. 201-207

Fürst, D.; Klein, R.R. (1972), Finanzierungsalternativen bei der Abfallbeseitigung, in: Der Städtetag (Zeitschrift für kommunale Praxis und Wissenschaft), 25. Jg., Heft 5, S. 241245

Funke, M. (Hrsg.) (1989), Factors and Business Investments, Berlin/Heidelberg/New York 
Ganter, R.L. (1980), Die Stellung der "Sonstigen Einnahmen" im konjunkturneutralem Haushalt, in: Finanzarchiv, N.F., Vol. 38, S. 110-118

Gatzweiler, H.P. (1975), Zur Selektivität interregionaler Wanderungen - Ein theoretisch- empirischer Beitrag zur Analyse und Prognose altersspezifischer interregionaler Wanderungen (Forschungen zur Raumentwicklung, Bd. 1), Bonn-Bad Godesberg

Gawel, E. (1992), Finanzausgleichsprobleme eines ökologieorientierten Steuer- und Abgabensystems, in: Wirtschaftsdienst, 72. Jg., Heft 8, S. 428-434

George, H. (1955), Progress and Poverty, New York

Geske, O.-E. (1980), Verstetigung durch Umsatzsteuerbeteiligung?, in: Wirtschaftsdienst, 60. Jg., Heft 5, S. 242-247

Gewerkschaft "Öffentliche Dienste, Transport und Verkehr" (1987), Für eine Reform des Gemeindefinanzsystems - Gewerkschaftliche Forderungen angesichts der Strukturkrise des kommunalen Finanzsystems, Stuttgart

Giersch, H. (1961), Allgemeine Wirtschaftspolitik - Grundlagen (Bd. 1), Wiesbaden

Gifford, A.; Stone, C.C. (1973), Externalities, Liability and the Coase Theorem: A Mathematical Analysis, in: Western Economic Journal, Vol. 11, S. 260-269

Gilbert, G.; Picard, P. (1990), Incentives and the Optimal Size of Local Government: A Model, (Diskussionspapier, vorgelegt auf dem 46. Kongreß des "International Institute of Public Finance" (IIPF) in Brüssel vom 27.-30. August 1990)

Gläser, M. (1981), Die staatlichen Finanzzuweisungen an die Gemeinden - Gestaltungskriterien, Effektivität, Reform, Frankfurt a.M.

Goetz, Ch.J. (1972), What is Revenue Sharing?, Washington D.C.

Götz, F.J. (1978), Kommunale Jahresrechnung - Beurteilung der neugeordneten westdeutschen kommunalen Jahresrechnung in betriebswirtschaftlicher Sicht, München

Goetzke, W. (1979), Zur Kritik an der einzelwirtschaftlichen Wertschöpfungsrechnung, in: Zeitschrift für Betriebswirtschaft, 49. Jg., S. 419-428

Goodspeed, T.J. (1989), A Re-examination of the Use of Ability to Pay Taxes by Local Government, in: Journal of Public Economics, Vol. 38, S. 319-342

Gordon, R.H. (1983), An Optimal Taxation Approach to Fiscal Federalism, in: Quaterly Journal of Economics, Vol. 98, S. 567-586

Gornas, J. (1976), Gründzüge einer Verwaltungskostenrechnung - Die Kostenrechnung als Instrument zur Planung und Kontrolle der Wirtschaftlichkeit in der öffentlichen Verwaltung, Baden-Baden

Gramlich, E.M. (1968), Alternative Federal Policies for Stimulating State and Local Expenditures: A Comparison of Their Effects, in: National Tax Journal, Vol. 21, S. 119-129

Gramlich, E.M. (1977), Intergovernmental Grants: A Review of the Empirical Literature, in: Oates, W.E. (Ed.), The Political Economy of Fiscal Federalism, Lexington/Toronto, S. 219-240

Gramlich, E.M.; Rubinfeld, D.L. (1982), Voting on Public Spending: Differences between Public Employees, Transfer Recipients, and Private Workers, in: Journal of Policy Analysis and Management, Vol. 1, S. 516-533 
Greenwald, B.C.; Stiglitz, J.E. (1986), Externalities in Economics with Imperfect Information and Incomplete Markets, in: Quaterly Journal of Economics, Vol. 101, S. 229-264

Gründger, F. (1977), Zum Problem der Bedarfsermittlung bei Investitionen im Bildungs- und Gesundheitswesen - Eine Vergleichende Untersuchung unter besonderer Berücksichtigung des Schul- und Krankenhaussektors, Berlin

Grünewald, J. (1992), Gemeindefinanzreform - eine wichtige Zukunftsaufgabe, in: Kommunale-Steuerzeitschrift, 41. Jg., Heft 10, S. 181-182

Günther, A. (1980), Probleme des Kreisfinanzsystems, Berlin

Gutting, B. (1987), Der Einfluß der Gemeindesteuern auf die Finanzierungs- und Investitionsentscheidungen von Unternehmen, in: Finanzarchiv, N.F., Vol. 45, S. 25-44

Hadermann, J.; Käppli, J.; Koller, P. (1975), Räumliche Mobilität: Theoretische Grundlagen und empirische Untersuchungen in der Planungsregion St. Gallen, St. Gallen

Häuser, K. (1967), Über Ansätze zur Theorie der Staatsausgaben, in: Timm, H.; Haller, H. (Hrsg.), Beiträge zur Theorie der öffentlichen Ausgaben (Schriften des Vereins für Socialpolitik, Bd. 47), Berlin, S. 36-65

Haller, H. (1961), Die Bedeutung des Äquivalenzprinzips für die öffentliche Finanzwirtschaft, in: Finanzarchiv, N. F., Vol. 21, S. 248-260

Haller, H. (1966), Das Gutachten zur Finanzreform, in: Konjunkturpolitik, 12. Jg., Heft 2, S. 69-105

Haller, H. (1967), Bemerkungen zur sogenannten Parallelpolitik der öffentlichen Finanzwirtschaft, in: Jahrbücher für Nationalökonomie und Statistik, Bd. 180, S. 164-178

Haller, H. (1971), Die Steuern (2. Aufl.), Tübingen

Haller, H. (1972), Finanzpolitik - Grundlagen und Hauptprobleme (5. Aufl.), Tübingen

Haller, H. (1980), Rationale Steuersysteme und Bestimmungsgründe empirischer Steuerverfassưngen, in: Handbuch der Finanzwissenschaft, Tübingen, 3. Aufl., Bd. II, S. 173-201

Haller, H. (1987), Zur Frage der zweckmäßigen Gestalt gemeindlicher Steuern - Ein Diskussionsbeitrag zur Gemeindesteuerreform, Frankfurt a.M./Bern/New York/Paris

Hamilton, B.W. (1983), A Review: Is the Property Tax a Benefit Tax, in: Zodrow, G.R. (Ed.), Local Provision of Public Services - The Tiebout Model after Twenty-Five Years, New York, S. 85-108

Hansen, A.; Perloff, H. (1944), State and Local Finance in the National Economy, New York

Hansmeyer, K.-H. (1966), Zur Theorie der kommunalen Finanzwirtschaft, in: Haus, W. (Hrsg.), Kommunalwissenschaftliche Forschung, Stuttgart/Berlin/Köln/Mainz, S. 161190

Hansmeyer, K.-H. (1967), Das Popitzsche Gesetz von der Anziehungskraft des zentralen Etats, in: Timm, H.; Haller, H. (Hrsg.), Beiträge zur Theorie der öffentlichen Ausgaben (Schriften des Vereins für Socialpolitik, Bd. 47) Berlin, S. 197-229

Hansmeyer, K.-H. (1979), Der kommunale Finanzausgleich als Instrument zur Förderung Zentraler Orte, in: Pohmer, D. (Hrsg.), Probleme des Finanzausgleichs II (Schriften des Vereins für Socialpolitik, Bd. 96/II), Berlin, S. 83-150 
Hansmeyer, K.-H.; Caesar, R.; Koths, D.; Siedenberg, A. (1980), Steuern auf spezielle Güter in: Handbuch der Finanzwissenschaft, Tübingen, 3. Auf., Bd. II, S. 709-885

Hansmeyer, K.-H.; Fürst, D. (1968), Die Gebühren - Zur Theorie eines Instrumentariums der Nachfragelenkung bei öffentlichen Leistungen, Stuttgart/Berlin/Köln/Mainz

Hansmeyer, K.-H.; Zimmermann, H. (1991), Bewegliche Einkommensbesteuerung durch die Gemeinden, in: Wirtschaftsdienst, 71. Jg., Heft 12, S. 639-644

Hansmeyer, K.-H.; Zimmermann, H. (1992), Einführung eines Hebesatzrechts beim gemeindlichen Einkommensteueranteil, in: Wirtschaftsdienst, 72. Jg., Heft 9, S. 490-496

Hanusch, H. (1978), Tendencies in Fiscal Federalism, in: Recktenwald, H.C. (Ed.), Secular Trends of the Public Sector (Proceedings of the 32nd Congress of the International Institute of Public Finance), Paris, S. 129-149

Hanusch, H. (1979), Privatisierung einer öffentlichen Tätigkeit: Das Beispiel Theater, in: Weizsäcker, C.C. von (Hrsg.), Staat und Wirtschaft (Schriften des Vereins für Socialpolitik, Bd. 102) Berlin, S. 171-193

Hanusch, H.; Roskamp, K.W.; Wiseman, J. (Hrsg.) (1985), Staat und Politische Ökonomie heute - Public Sector and Political Economy Today, Stuttgart/New York

Haus, W. (Hrsg.) (1966), Kommunalwissenschaftliche Forschung (Schriftenreihe des Vereins für Kommunalwissenschaft e.V. Berlin, Bd. 12), Stuttgart/Berlin/Köln/Mainz

Hax, H. (1972), Investitionstheorie (2. Aufl.), Würzburg/Wien

Haverkamp, F. (1988), Die Finanzbeziehungen zwischen Ländern und Gemeinden, in: Arnold, V.; Geske, O.-E. (Hrsg.), Öffentliche Finanzwirtschaft, München, S. 55-120

Head, J.G. (1974), Public Goods and Public Welfare, Durham

Head, J.G. (1983), Intergovernmental Fiscal Relations in Australia, Canada and the United States since World War II, in: Handbuch der Finanzwissenschaft, Tübingen, 3. Aufl., Bd. 4, S. $187-216$

Heady, E.O. (1952), Economics of Agricultural Production and Resource Use, New York/Prentice-Hall (zitiert nach Olson, 1985)

Hedtkamp, G. (1961), Das ökonomisch rationale Steuersystem, in: Weltwirtschaftliches Archiv, Bd. 86, S. 232-285

Hedtkamp, G. (1967), Bestimmungsgründe für Umfang und Struktur der öffentlichen Ausgaben, in: Timm, H.; Haller, H. (Hrsg.), Beiträge zur Theorie der öffentlichen Ausgaben (Schriften des Vereins für Socialpolitik, Bd. 47) Berlin, S. 66-103

Heilbrun, J. (1974), Urban Economics and Public Policy, New York

Held, F.W.; Hötker, D,; Junkernheinrich, M. (1992), Altindustrielle Problemregionen, kommunale Selbstverwaltung und Gemeindesteuerreform, in: WSI-Mitteilungen, 45. Jg., Heft 2, S. 88-98

Helm, D.; Smith, S. (1987), The Assessment: Decentralisation and the Economics of Local Government, in: Oxford Review of Economic Policy, Vol. 3, S. 1-21

Helpman, E.; Pines, D.; Borukhov, E. (1976), The Interaction between Local Government and Urban Residential Location: Comment, in: American Economic Review, Vol. 66, S. 961967 
Henckel, D. (1981), Einwohnerveränderungen und Gemeindeanteil an der Einkommensteuer, in: Raumforschung und Raumordnung, 39. Jg., Heft 5/6, S. 241-247

Henderson, J.M. (1979), Local Government Expenditures: A Social Welfare Analysis, in: Review of Economics and Statistics, Vol. 50, S. 156-163

Henderson, J.V. (1985), Economic Theory and the Cities (2. ed.), Orlando

Hepworth, N.P. (1984), The Finance of Local Government (7. ed.), London

Hermsdörfer, W. (1986), Die allgemeine kommunale Verbrauchsteuer - Vorschlag zur Neugestaltung des Gemeindesteuersystems, in: Kommunale Steuer-Zeitschrift (Zeitschrift für das gesamte Gemeindeabgabenwesen), 35. Jg., Heft 9, S. 161-164

Hesse, J.-J.; Klein, R.R. (1980), Der Lohnsummensteuer-Konflikt - Anlaß zu einer Neuinterpretation der Beziehungen zwischen Bund, Land und Gemeinde?, in: Zeitschrift für Parlamentsfragen, 11. Jg., Heft 1, S. 73-72

Hessler, H.D. (1976), Finanzwissenschaftliches System der Besteuerung, Tübingen/Düsseldorf

Hessler, H.D. (1983), Die Fundamentalprinzipien der Besteuerung I und II, in: Das Wirtschaftsstudium (WISU), Heft, 6, S. 281-285 und Heft 7, S. 329-334

Hettlage, K.M. (1964), Die Gemeinden in der Finanzverfassung, in: Archiv für Kommunalwissenschaften, 3. Jg., S. 1-24

Hill, H. (1987), Die politisch-demokratische Funktion der kommunalen Selbtverwaltung nach der Reform, Baden-Baden

Hirsch, W.Z. (1964), Local versus Areawide Urban Government Services, in: National Tax Journal, Vol. 17, S. 331-339

Hirsch, W.Z. (1970), The Economics of State and Local Government, New York

Hirsch, W.Z. (1973), Urban Economics Analysis, New York

Hirsch, W Z.; Marcus, M.J. (1969), Intercommunity Spillovers and the Provision of Public Education, in: Kyklos (Internationale Zeitschrift fur Sozialwissenschaften), Vol. 22, S. 641-660

Hirsch, W.Z.; Segelhorst, E.W.; Marcus, M.J. (1964), Spillovers of Public Education Costs and Benefits, Los Angeles

Hirschman, A.O. (1974), Abwanderung und Widerspruch - Reaktionen auf Leistungsabfall bei Unternehmungen, Organisationen und Staaten, Tübingen

Hirshleifer, J. (1973), Where are we in the Theory of Information?, in: American Economic Review, Papers and Proceedings, Vol. 63, S. 31-39

Hochman, H. M.; Peterson, G. E. (Eds.) (1974), Redistribution through Public Choice, New York

Hochman, O. (1981), Land Rents, Optimal Taxation and Local Fiscal Independence in an Economy with Local Public Goods, in: Journal of Public Economics, Vol. 15, S. 59-85

Hochman, O. (1982a), Congestable Local Public Goods in an Urban Setting, in: Journal of Urban Economics, Vol. 11, S. 290-310

Hochman, O. (1982b), Clubs in an Urban Setting, in: Journal of Urban Economics, Vol. 12, S. 85-101 
Hotz, D.; Hillesheim, D. (1985), Raumwirksamkeit wirtschaftsbezogener Kommunalsteuern dargestellt am Beispiel der Gewerbesteuer, in: Raumforschung und Raumordnung, 43. Jg., Heft 5, S. 186-200

Hummel, M.; Körner, J.; Leibfritz, W. (1985), Strukturelle Auswirkungen des Steuersystems Gutachten im Auftrag des Bundesministers für Wirtschaft (Ifo-Studie zur Finanzpolitik, Nr. 33), München

Huppertz, P, (1977), Gewaltenteilung und antizyklische Finanzpolitik, Baden-Baden

Huppertz, P.; Wartenberg, U. (1978), Wirkt die Umsatzsteuer verteilungsneutral?, in: Wirtschaftsdienst, 58. Jg., S. 395-399

Hurwicz, L. (1960), Optimality and Informational Efficiency in Resource Allocation Processes, in: Arrow, K.J. et al (Eds.), Mathematical Methods in the Social Sciences, Stanford, S. $27-46$

Hurwicz, L. (1972), On Informationally Decentralized Systems, in: Radner, R.; McGuire, C.B. (Eds.), Decision and Organization, Amsterdam, S. 297-336

Hurwicz, L. (1973), The Design of Mechanisms for Resource Allocation, in: American Economic Review, Vol. 68, S. 1-30

Inman, R.P. (1982), The Economic Case for Limits to Government, in: American Economic Reviews, Vol. 72, S. 176-183

Institut "Finanzen und Steuern" (1966), Die große Finanzreform - Gutachten, Bonn

Institut "Finanzen und Steuern" (1978), Zur Bedeutung der Gebühren, Beiträge und anderer Verwaltungsabgaben furr den Haushaltsausgleich der Gebietskörperschaften (Brief Nr. 180), Bonn

Institut "Finanzen und Steuern" (1982), Modell für die Ablösung der Gewerbesteuer durch einen Gemeindeanteil an der Umsatzsteuer (Brief Nr. 211), Bonn

Institut "Finanzen und Steuern" (1986), Entwicklung der Realsteuerhebesätze der Gemeinden mit mehr als 50.000 Einwohnern in 1986 gegenüber 1985 (Brief Nr. 256), Bonn

Institut "Finanzen und Steuern" (1989), Die Entwicklung der Gemeindefinanzen in den 80er Jahren (Brief Nr. 285), Bonn

Institut "Finanzen und Steuern" (1992a), Die Gewerbesteuer im internationalen Vergleich (Brief Nr. 306), Bonn

Institut "Finanzen und Steurn" (1992b), Entwicklung der Realsteuerhebesätze der Gemeinden mit mehr als 50000 Einwohnern in 1992 gegenüber 1991 (Brief Nr. 310), Bonn

Jaeger, K. (1975), Steuern, Entschädigungen und das Coase-Theorem, in: Jahrbuch für Sozialwissenschaft, Bd. 26, S. 211-227

Jaspers, K. (1957), Vom Ursprung und Ziel der Geschichte, Frankfurt a.M./Hamburg

Jeanrenaud, C. (1975), Organisation de l'espace, effets externes et dépenses publiques, Neuchàtel

Jorgenson, D.W. (1967), The Theory of Investment Behavior, in: Ferber, R. (Ed.), Determinants of Investment Behavior, New York, S. 129-155 
Junkernheinrich, M. (1985), Dezentralisierung der regionalen Wirtschaftspolitik, in: Wirtschaftsdienst, 65. Jg., Heft 11, S. 576-581

Junkernheinrich, M. (1990), Gemeindefinanzen: Theoretische und methodische Grundlagen ihrer Analyse, Berlin

Junkernheinrich, M. (1991), Reform des Gemeindesteuersystems - Analyseergebnisse, Berlin

Kafoglis, M.Z. (1969), Local Service Charges: Theory and Practice, in: Johnson, H.L. (Ed.), State and Local Tax Problems, Knoxville, S. 164-187

Kappe, H. (1978), Die Auswirkungen der kommunalen Gebietsreform in Nordrhein-Westfalen auf Leistung und Wirtschaftlichkeit der Kreisverwaltungen: Folgerungen für die Funktionalreform, Aachen

Karl-Bräuer-Institut des Bundes der Steuerzahler (1978), Wirksamere Finanzkontrolle bei Bund, Ländern und Gemeinden - Analyse und Reformvorschläge (Schriftenreihe des Karl-Bräuer-Institus des Bundes der Steuerzahler, Heft 42), Wiesbaden

Karl-Bräuer-Institut des Bundes der Steuerzahler (1984), Abbau und Ersatz der Gewerbesteuer - Dastellung, Kritik, Vorschläge (Schriftenreihe des Karl-Bräuer-Institus des Bundes der Steuerzahler, Heft 57), Wiesbaden

Karrenberg, H. (1986), Zum Stand der Gewerbesteuerdiskussion, in: Zeitschrift für Kommunalfinanzen, 36. Jg., Heft 8, S. 170-177

Karrenberg, H. (1988a), Die Finanzlage der strukturschwachen Städte, in: Wirtschaftsdienst, 68. Jg., Heft 6, S. 302-309

Karrenberg, H. (1988b), Drei Gemeindesteuern unter einem Dach - der Vorschlag des Kronberger Kreises, in: Zeitschrift für Kommunalfinanzen, 38. Jg., Nr. 9, S. 194-196

Karrenberg, H. (1990), Unternehmensbesteuerung und Gewerbesteuer - Zur aktuellen Reformdiskussion, in: Zeitschrift für Kommunalfinanzen, 40. Jg., Nr. 1, S. 2-7

Karrenberg, H. (1992a), Weitere Demontage statt Reform der Gewerbesteuer - Zur aktuellen Steuerpolitik aus städtischer Sicht (Teil I u. Teil II), in: Zeitschrift für Kommunalfinanzen, 42. Jg., Heft 4, S. 78-82 und Heft 5, S. 105-110

Karrenberg, H. (1992b), Zur Reform des Gemeindesteuersystems - Vorschlag des Deutschen Städtetages zur unmittelbaren gemeindlichen Umsatzsteuerbeteiligung, in: Zeitschrift für Kommunalfinanzen, 42. Jg., Heft 9, S. 194-199

Karrenberg, H: (1992c), Das Zinsabschlaggesetz und seine Auswirkungen auf die Kommunen, in: Zeitschrift für Kommunalfinanzen, 42. Jg., Heft 12, S. 266-270

Karrenberg, H.; Münstermann, E. (1981), Gemeindefinanzbericht 1981, in: Der Städtetag (Zeitschrift für kommunale Praxis und Wissenschaft), 34. Jg., Heft 2, S. 55-85

Karrenberg, H.; Münstermann, E. (1984), Gemeindefinanzbericht 1984, in: Der Städtetag (Zeitschrift für kommunale Praxis und Wissenschaft), Heft 2, S. 81-119

Karrenberg, H.; Münstermann, E. (1992), Gemeindefinanzbericht 1992, in: Der Städtetag (Zeitschrift für kommunale Praxis und Wissenschaft), 45. Jg., Heft 2, S. 58-121

Kay, J.A. (1990), Tax Policy: A Survey, in: The Economic Journal, Vol. 100, S. 18-75

Kay, J.A.; King, M.A. (1986), The British Tax System (4. ed.), London/Oxford 
Keller, T. (1966), Das "Popitzsche Gesetz" und die Schweizer Gemeinden, in: Archiv für Kommunalwissenschaften, 5. Jg., S. 78-92

Kelling, O. (1986), Das Gewerbesteuerproblem, in: WSI-Mitteilungen, 39. Jg., Heft 7, S. 481491

Kentmann, K. (1978), Das Äquivalenzprinzip in den Gemeinden - Zur Theorie und Praxis der Entgeltfinanzierung unter besonderer Berücksichtigung des Konzepts der gruppenmäßigen Äquivalenz in Großstädten, Frankfurt a.M.

King, D.N. (1984), Fiscal Tiers: The Economics of Multi-Level Government, London

King, M.A. (1987), The Cash Flow Corporate Income Tax, in: Feldstein, M. (Ed.), The Effects of Taxation on Capital Accumulation, Chicago/London, S. 377-400

Kirsch, G. (1974), Ökonomische Theorie der Politik, Tübingen/Düsseldorf

Kirsch, G. (Hrsg.) (1977), Föderalismus, Stuttgart/New York

Kirsch, G. (1978), Föderalismus - Die Wahl zwischen intrakollektiver Konsenssuche und interkollektiver Auseinandersetzung, in: Deißig, W. (Hrsg.), Probleme des Finanzausgleichs I (Schriften des Vereins furr Socialpolitik, Bd. 96/I), Berlin, S. 9-43

Kirsch, G. (1980), Ordnungspolitik und interkollektive Beziehungen, in: Dettling, W. (Hrsg.), Die Zähmung des Leviathan, Baden-Baden, S. 163-184

Kirsch, G.; Theiler, J. (1976), Zur Verallgemeinerung von Buchanan-Tullocks allgemeiner ökonomischer Verfassungstheorie, in: Finanzarchiv, N.F., Vol. 35, S. 35-65

Kitterer, W. (1978), Die Belastung der privaten Haushalte mit indirekten Steuern, in: Mitteilungen des Rheinisch-Westfälischen Instituts für Wirtschaftsforschung, 29. Jg., S. 263280

Klaus-Dieter-Arndt-Stiftung (1986a), Wertschöpfung und Besteuerung - Ermittlung und Abgrenzung, Bonn

Klaus-Dieter-Arndt-Stiftung (1986b), Revitalisierung der Gewerbesteuer - Grundlegung eines Modells, Bonn

Kleinwächter, F. (1905), Gebühren und Verkehrssteuern, in: Jahrbücher für Nationalökonomie und Statistik, Bd. 29, 3. Folge, S. 433-466

Kloten, N.; Höpfner, K. (1967), Regionalpolitische Postulate und Urteilsregeln für Formen kommunaler Besteuerung, in: Archiv für Kommunalwissenschaften, 6. Jg., S. 336-358

Körner, J. (1974), Die Aufkommenselastizität des deutschen Steuersystems 1950 - 1973 (IfoStudien zur Finanzpolitik, Heft 16), München

Köster, T. (1984), Die Entwicklung kommunaler Finanzsysteme am Beispiel Großbritanniens, Frankreichs und Deutschlands 1790-1980, Berlin

Kolms, H. (1976), Finanzwissenschaft III (3. Aufl.), Berlin/New York

Kommission für die Finanzreform (1966), Gutachten über die Finanzreform in der Bundesrepublik Deutschland (2. Aufl.), Stuttgart

Kommission zur Verbesserung der steuerlichen Bedingungen für Investitionen und Arbeitsplätze (1991), Gutachten (Schriftenreihe des Bundesministeriums der Finanzen, Heft 46), Bonn 
Koopman, T. (1954), Mathematical Ground-work of Economic Optimization Theories (Paper read at the annual meeting of the Econometric Society, Dec. 1954), (zitiert nach Tiebout, 1956)

Koren, S. (1989), Steuerreformen im internationalen Vergleich, Berlin

Kraus, A. (1983), Zentrale und dezentrale Tendenzen im Föderalismus - Eine kritische Analyse im internationalen Vergleich, Göttingen

Krause-Junk, G. (1987), "Steuern der neunziger Jahre": Anmerkungen zu den Leitlinien der Arbeitsgruppe Steuerreform, in: Finanzarchiv, N.F., Vol. 45, S. 302-323

Krause-Junk, G. (1988), Steuern IV: Verteilungslehren, in: Handwörterbuch der Wirtschaftswissenschaften (HdWW), Stuttgart/Tübingen/Göttingen, Bd. 7. S. 332-356

Krause-Junk, G. (1989a), Noch ein Vorschlag für eine Gemeindesteuerreform, in: Wirtschaftsdienst, 69. Jg., Heft 8, S. 380-382

Krause-Junk, G. (1989b), Die Bedenken sind eine Einschätzungsfrage: Eine Erwiderung, in: Wirtschaftsdienst, 69, Jg., Heft 11, S. 575-576

Kremer, J. (1983a), Zur stufenweisen Ablösung der Gewerbesteuer, in: Steuer und Wirtschaft (Zeitschrift für die gesamte Steuerwissenschaft), 60. Jg., Nr. 1, S. 55-58

Kremer, J. (1983b), Zur Reform der Gewerbesteuer, in: Steuer und Wirtschaft (Zeitschrift für die gesamte Steuerwissenschaft), 60. Jg., Nr. 4, S. 334-336

Krüger, B. (1975), Externe Effekte der Produktion als Problem der Wirtschaftspolitik - Theoretische Lösungskonzepte und praktische Anwendungsmöglichkeiten, Frankfurt a.M.

Kühn, A. (1992), Hebesatz für Kfz-Steuer soll Gemeinden entschädigen, in: Handelsblatt vom 7./8. Aug. 1992, S. 6

Kuhn, T.; Hanusch, H. (1990), Vertical and Horizontal Equity and the Grants to Communities in the Federal Republic of Germany (Diskussionspapier; vorgelegt auf dem 46. Kongreß des "International Institute of Public Finance" (IIPF) in Brüssel vom 27.-30. August 1990)

Kulartz, H.-P. (1982), Kommunale Gebietsreform und Energieversorgung, Baden-Baden

Kullmer, L. (1988), Öffentliche Erwerbseinkünfte, in: Handwörterbuch der Wirtschaftswissenschaften (HdWW), Stuttgart/Tübingen/Göttingen, Bd. 5, S. 412-419

Ladd, H.F.; Doolittle, F.C. (1982), Which Level of Government Should Assist the Poor?, in: National Tax Journal, Vol. 35, S. 323-336

Landtag Rheinland-Pfalz (1986), Landtagsdrucksache 10/2185

Langkau, J.; Napp, H.-G.; Rahmann, B.; Roloff, O. (1989), Steuerstandort Bundesrepublik Deutschland - Eine vergleichende Analyse der Unternehmens- und Gemeindesteuern vor dem Hintergrund der Vollendung des gemeinsamen europäischen Binnenmarktes 1992, Bonn

Laufer, H. (1991), Das föderative System der Bundesrepublik Deutschland, Bonn

Lehmann, M. (1983), Kommunale Beitragserhebung - Zur Beitragsfähigkeit und zur Beitragsbemessung auf der Grundlage einer ökonomisch-juristischen Konzeption, Siegburg 
Leibfritz, W. (1984), Vorschläge zu einer kommunalen Finanzreform - Die Suche nach dem Stein des Weisen, in: Ifo-Schnelldienst, München, Nr. 7, S. 5-11

Leibfritz, W. (1989), Unternehmensteuerreform: Ein Überblick über Ziele, Probleme und Möglichkeiten, in: Ifo-Schnelldienst, 42. Jg., Nr. 12-13, S. 22-35

Leibfritz, W. (1990), Unternehmensteuerreform: Die Unvollendete, in: Ifo-Schnelldienst, 43. Jg., Nr. 1-2, S. 20-27

Leibfritz, W.; Teschner, S. (1981), Der Einfluß des Steuersystems und des kommunalen Finanzsystems auf die Landesentwicklung, Berlin

Leitermann, W. (1991), Subsidiarität und kommunale Selbstverwaltung in der Europäischen Gemeinschaft, in: Der Städtetag (Zeitschrift für kommunale Praxis und Wissenschaft), 44. Jg., S. 753-755

Leutner, B. (1977), Wirtschafts- und finanzpolitische Probleme einer Bodenwertzuwachsbesteuerung, Göttingen

Liedtke, C. (1972), Theorie der öffentlichen Güter und optimale Struktur einer Föderation, Berlin

Lindahl, E. (1919), Die Gerechtigkeit der Besteuerung - Eine Analyse der Steuerprinzipien auf der Grundlage der Grenznutzentheorie, Lund

Littmann, K. (1958/59), Raumwirtschaftiche Auswirkungen der Finanzpolitik, in: Finanzarchiv, N.F., 19. Jg., S. 367-381

Littmann, K. (1967), Übere einige Probleme einer Wirkungslehre öffentlicher Ausgaben, in: Timm, H.; Haller, H. (Hrsg.), Beiträge zur Theorie der öffentlichen Ausgaben (Schriften des Vereins für Socialpolitik, Bd. 47) Berlin, S. 277-298

Littmann, K. (1968), Die Gestaltung des kommunalen Finanzsystems unter raumordnungspolitischen Gesichtspunkten, Hannover

Littmann, K. (1980), Gewerbesteuer, in: Handbuch der Finanzwissenschaft, Tübingen, 3. Aufl., Bd. II, S. 607-632

Littmann, K. (1983), Ergebnisse und Empfehlungen des Gutachtens des Wissenschaftlichen Beirats beim Bundesministerium der Finanzen zur Reform der Gemeindesteuern - Sollte die Gewerbesteuer durch eine Wertschöpfungsteuer ersetzt werden?, in: Der Gemeindehaushalt, Heft 8, S. 178-184

Litvack, J.M.; Oates, W.E. (1970), Group Size and the Output of Public Goods: Theory and an Application to State-Local Finance in the United States, in: Public Finance, Vol. 25, S. $42-62$

Livesey, D.A. (1987), Central Control of Local Authority Expenditure, in: Oxford Review of Economic Policy, Vol. 3, S. 44-59

Lorenz-von-Stein-Institut für Verwaltungswissenschaften (1983), Gewerbesteuerreform, Lorenz-von-Stein-Institut fur Verwaltungswissenschaften an der Christian-Albrechts-Universität zu Kiel, Fachtagung vom 25.11.1983 (Arbeitspapiere, Nr. 11), Kiel

Luce, R.D.; Raiffa, H. (1957), Games and Decisions, New York

Mackscheidt, K. (1973), Zur Theorie des optimalen Budgets, Tübingen 
Mann, F.K. (1977), Abriß einer Geschichte der Finanzwissenschaft, in: Handbuch der Finanzwissenschaft, Tübingen, 3. Aufl., Bd. I, S. 77-98

Marchand, J.R.; Russell, K.P. (1973), Externalities, Liability, Separability and Resource Allocation, in: American Economic Review, Vol. 63, S. 611-620

Marcus, P. (1986), Umrisse einer kommunalspezifischen Besteuerungssystematik - Darstellung, Begründung, Anwendung (Schriften des deutschen Instituts für Urbanistik, Bd. 77), Stuttgart

Marcus, P. (1987), Das kommunale Finanzsystem der Bundesrepublik Deutschland, Darmstadt

Margolis, J. (Ed.) (1965), The Public Economy of Urban Communities, Washington D.C.

Margolis, J. (1968), The Demand for Urban Public Services, in: Perloff, H.S.; Wingo, L. (Eds.), Issues in Urban Economics, Baltimore/London, S. 527-565

Margolis, J. (Ed.) (1970), The Analysis of Public Output, New York

Maxwell, J.A.; Aronson, R.J. (1977), Financing State and Local Governments (3. ed.), Washington D.C.

McAllister, H.E. (1961), The Border Tax Problem in Washington, in: National Tax Journal, Vol. 14, S. 362-374

McGuire, M.C. (1974), Group Segregation and Optimal Jurisdictions, in: Journal of Political Economy, Vol. 82, S. 112-132

McLure, Ch.E. Jr. (1964), Commodity Tax Incidence in Open Economies, in: National Tax Journal, Vol 17, S. 187-204

McLure, Ch.E. Jr. (1967), The Interstate Exporting of State and Local Taxes: Estimates for 1962, in: National Tax Journal, Vol. 20, S. 49-77

McLure, Ch.E. Jr. (1969), The Inter-Regional Incidence of General Regional Taxes, in: Public Finance, Vol. 24, S. 457-483

Meade Committee (1978), The Struture and Reform of Direct Taxation - Report of a Committee chaired by Professor J. E. Meade, London/Boston/Sydney

Meade, J.E. (1952), External Economies and Diseconomies in a Competitive Situation, in: Economic Journal, Vol 62, S. 54-67

Meier, E. (1877), Über die Frage der Communalbesteuerung, in: Die Communalsteuerfrage: 10 Gutachten und Berichte (Schriften des Vereins für Socialpolitik, Bd. XII), Leipzig

Meisterling, G. (1986), Zur Problematik von Marktanalogien in der ökonomischen Theorie des Förderalismus, Frankfurt a.M./Bern/New York

Mennel, A. (1980), Steuern in Europa, USA, Kanada und Japan, Herne/Berlin

Micosatt, G.; Junkernheinrich, M. (1991), Reform des Gemeindesteuersystems - Methodische Grundlagen und Statistische Simulationen, Berlin

Mielenhausen, E. (1976), Marktfelder des Einzelhandels in urbanen Räumen, Berlin

Mielke, B. (1978), Die Kosten überörtlicher Funktionen von Großstädten, Marburg

Mieszkowski, P.; Zodrov, G.R. (1989), Taxation and the Tiebout Model: The Differential Effects of Head Taxes, Taxes on Land Rents, and Property Taxes, in: Journal of Economic Literature, Vol. 27, S. 1098-1146 
Mikesell, J.L. (1970), Central Cities and Sales Tax Rate Differentials: The Border City Problem, in: National Tax Journal, Vol. 23, S. 206-213

Milbradt, G.H. (1981), Überlegungen zu einer Reform des kommunalen Steuersystems aus ökonomischer Sicht, in: Deutsches Verwaltungsblatt vom 01. Juni 1981, Köln/Berlin, S. $522-528$

Milbradt, G.H. (1982), Die amerikanische "sales tax" und die französische "taxe professionelle" - Vorbilder der Neugestaltung des deutschen Gemeindefinanzsystems?, in: Der Gemeindehaushalt, Jg. 83, S. 28-34

Miller, S.M.; Tabb, W.K. (1973), A New Look at a Pure Theory of Local Expenditures, in: National Tax Journal, Vol. 26, S. 161-176

Millgramm, K.-H. (1990), Föderalismus und Individuum, in: Deutsches Verwaltungsblatt vom 15. Juli 1990 , S. 740-748

Mintz, J.; Tulkens, H. (1986), Commodity Tax Competition between Member States of a Federation: Equilibrium and Efficiency, in: Journal of Public Economics, Vol. 29, S. 133172

Mirrlees, J.A. (1971), An Exploration in the Theory of Optimum Income Taxation, in: Review of Economic Studies, Vol. 38, S. 175-208

Mohl., H. (1992), Die Einfuhrung und Erhebung neuer Steuern aufgrund des kommunalen Steuerfindungsrechts (Neue Schriften des Deutschen Städtetages, Heft 63), Stuttgart/Berlin/Köln/Mainz

Moxter, A. (1980), Steuerliche Gewinn- und Vermögensermittlung, in: Handbuch der Finanzwissenschaft, Tübingen, 3. Aufl., Bd. II, S. 203-237

Mueller, D.C. (1979), Public Choice, Cambridge

Müller, G.B. (1981), Zum bodenpolitischen Zweck des Erschließungsbeitrages, in: Der Gemeindehaushalt, 82. Jg., Heft 4, S. 95

Müller, P. (1987), Intertemporale Wirkungen der Staatsverschuldung, Frankfurt/Bern/New York/Paris

Münch, K.N. (1976), Kollektive Güter und Gebühren - Elemente einer Gebührentheorie für Kollektivgüter, Göttingen

Münscher, A. (1978), Die Verteilung der Gemeinde-Einkommensteuer nach raumordnungspolitischen Leitlinien, in: Informationen zur Raumentwicklung, Heft 2-3, S. 115-123

Münstermann, E. (1986), Grunderwerbsteuer muß Städten erhalten bleiben - Zur Diskussion der kommunalen Grunderwerbsteuerbeteiligung in Nordrhein-Westfalen, in: Der Gemeindehaushalt, 87. Jg., Heft 10, S. 224-226

Münstermann, E. (1991), Kommunaler Finanzausgleich in den neuen Ländern - Sonderprobleme und Entwicklungsphasen des Finanzausgleichs 1991, in: Der Gemeindehaushalt, 92. Jg., Heft 11, S. 241-247

Mulert, O. (1948), Die Neuordnung der kommunalen Verwaltung der Hansestadt Hamburg (Gutachten), Hamburg

Mumey, G.A. (1971), The "Coase Theorem": A Reexamination, in: Quaterley Journal of Economics, Vol. 85, S. 718-723

Muscheid, J. (1986), Die Steuerpolitik in der Bundesrepublik Deutschland 1949-1982, Berlin 
Musgrave, R.A. (1955), A Multiple Theory of the Budget (Paper read at the Econometric Society Annual Meeting, Dec. 1955), (zitiert nach Tiebout, 1956)

Musgrave, R.A. (1956), Diskussionsbeitrag auf der Detroit-Tagung der National Tax Association zum Problem Steuern versus Gebühren am 18. Oktober 1955, abgedruckt in: Proceedings of the 48th Annual Conference of Taxation, Sacramento (zitiert nach Münch, 1976)

Musgrave, R.A. (1959), The Theory of Public Finance, New York

Musgrave, R.A. (1961), Approaches to a Fiscal Theory of Political Federalism, in: National Bureau Committee of Economic Research (Ed.), Public Finances: Needs, Sources, and Utilization, Princeton, S. 97-122

Musgrave, R.A. (Ed.) (1965), Essays in Fiscal Federalism, Washington D.C.

Musgrave, R.A. (1969a), Provision for Social Goods, in: Margolis, J.; Guitton, H. (Eds.), Public Economics, New York/London, S. 124-144

Musgrave, R.A. (1969b), Theories of Fiscal Federalism, in: Public Finance, Vol. 24, S. 521532

Musgrave, R.A. (1970), Provision for Social Goods, in: Houghton, R.W. (Ed.), Public Finance - Selected Readings, Harmondsworth, S. 260-283

Musgrave, R.A.; Musgrave, P.B. (1984), Public Finance in Theory and Practice (4. ed.), New York

Mushkin, S.J.; Bird, R.M. (1972), Public Prices: An Overview, in: Mushkin, S.J. (Ed.), Public Prices for Public Products, Washington D.C., S. 3-25

Nachtkamp, H.H. (1986), Allokationswirkungen der Bestandsbesteuerung (Unter besonderer Berücksichtigung der Vermögensteuer, der Gewerbekapitalsteuer und der Grundsteuer in der Bundesrepublik Deutschland), in: Finanzarchiv, N.F., Vol. 44., S. 185-223

Napp, H.-G. (1990), Kommunale Finanzen und kommunale Wirtschaftsförderung - Grundlagen kommunaler Selbstverwaltung in den neuen Bundesländern (Reihe "Wirtschaftspolitische Diskurse" der Friedrich-Ebert-Stiftung, Nr. 6), Bonn

Napp, H.-G. (1993), Gemeindefinanzreform - Dauerthema ohne Lösungsperspektive?, Arbeitspapier des Fachbereichs Wirtschaftswissenschaften (Neue Folge Nr. 35) der Universität-Gesamthochschule Paderborn

Neenan, W.B. (1970), Suburban-Central-City Exploitation Thesis: One City's Tale, in: National Tax Journal, Vol. 23, S. 117-139

Negishi, T. (1972), Public Expenditure Determined by Voting with One's Feet and Fiscal Profitability, in: Swedish Journal of Economics, Vol. 74, S. 452-458

Nell-Breuning, O. von (1977), Vom Planungswertausgleich der Hauptkommission für die Baugesetzgebung zum Vorteilsausgleich des Regierungsentwurfs zur Bundesbaugesetznovelle 1976, in: Finanzarchiv, N.F., Vol. 36, S. 150-161

Nelson, J.C. (1962), The Pricing of Highway, Waterway, and Airway Facilities, in: American Economic Review, Papers and Proceedings, Vol. 52, S. 426-435

Netzer, D. (1970), Economics and Urban Problems - Diagnoses and Prescriptions, New York 
Neumann, F.J. (1874), Die progressive Einkommensteuer im Staats- und Gemeinde-Haushalt, (Schriften des Vereins für Socialpolitik, Bd. VIII), Leipzig

Neumann, F.J. (1896), Die Gestaltung des Preises, in: Schönberg, G. von (Hrsg.), Handbuch der Politischen Ökonomie, Tübingen, 4. Aufl., Bd. 1, S. 253-316

Neumann, M. (1971), Zur ökomischen Theorie des Föderalismus, in: Kyklos (Internationale Zeitschrift für Sozialwissenschaften), Vol. 24, S. 493-510

Neumark, F. (1961), Wirtschafts- und Finanzprobleme des Interventionsstaates, Tübingen

Neumark, F. (Hrsg.) (1964), Strukturwandlungen einer wachsenden Wirtschaft (Schriften des Vereins furr Socialpolitik, Bd. 30/II), Berlin

Neumark, F. (1970), Grundsätze gerechter und ökonomisch rationaler Steuerpolitik, Tübingen

Neumark, F. (1979), Möglichkeiten und Probleme einer angemessenen Steuer- und Finanzreform, in: Deutsches Institut für Urbanistik (Hrsg.), Möglichkeiten und Probleme einer angemessenen Steuer- und Finanzreform (Tagungsbericht der Sitzung des Kommunalwissenschaftlichen Arbeitskreises am 24. Nov. 1978 in Köln), Berlin, S. 11-45

Neumark, F. (1980), Überblick über die Personalsteuern, in: Handbuch der Finanzwissenschaft, Tübingen, 3. Aufl., Bd. II, S. 317-329

Niedersächsischer Landtag (1988), Landtagsdrucksache, 11/460

Niskanen, W.A. (1968), The Peculiar Economics of Bureaucracy, in: American Economic Review, Vol. 58, S. 293-305

Niskanen, W.A. (1971), Bureaucracy and Representative Government, Chicago/New York

Noltenius, J.D. (1952), Die Gesundung der Finanzverfassung der Deutschen Bundesrepublik, Bremen

Oates, W.E. (1969), The Effects of Property Taxes and Local Spending on Property Values: An Empirical Study of Tax Capitalization and the Tiebout Hypothesis, in: Journal of Political Economy, Vol. 77, S. 957-971

Oates, W.E. (1972), Fiscal Federalism, New York/Chicago/San Francisco/Atlanta

Oates, W.E. (Ed.) (1975), Financing the New Federalism - Revenue Sharing, Conditional Grants, and Taxation, Baltimore/London

Oates, W.E. (Ed.) (1977a), The Political Economy of Fiscal Federalism, Lexington/Toronto

Oates, W.E. (1977b), An Economist's Perspective on Fiscal Federalism, in: Oates, W. E. (Ed.) The Political Economy of Fiscal Federalism, Lexington/Toronto, S. 3-20

Oates, W.E. (1977c), Ein ökonomischer Ansatz zum Föderalismusproblem, in: Kirsch, G. (Hrsg.), Föderalismus, Stuttgart/New York, S. 15-26

Oberhauser, A. (1964), Die Eignung der Wertschöpfungsteuer als Gemeindesteuer, in: Timm, H.; Jecht, H., Kommunale Finanzen und Finanzausgleich, Berlin, S. 241-252

O'Brien, T. (1971), Grants-in-Aid: Some Further Answers, in: National Tax Journal, Vol. 24, S. $65-77$

Oettle, K. (1962), Ziele, Mittel und Orientierungshilfen der Gebührenpolitik, in: Der Gemeindehaushalt, 63. Jg., Heft 10, S. 217-245 
Olson, M. (1969), The Principle of "Fiscal Equivalence": The Division of Responsabilities among Different Levels of Government, in: American Economic Review, Vol. 59, S. 479-487

Olson, M. (1977), Das Prinzip "fiskalischer Gleichheit": Die Aufteilung der Verantwortung zwischen verschiedenen Regierungsebenen, in: Kirsch, G. (Hrsg.), Föderalismus, Stuttgart/New York, S. 66-76

Olson, M. (1985), Die Logik des kollektiven Handelns (2. Aufl.), Tübingen.

Olson, M.; Zeckhauser, R. (1970), The Efficient Production of External Economics, in: American Economic Review, Vol. 60, S. 512-517

Ostrom, V.; Tiebout, Ch.M.; Warren, R. (1961), The Organization of Government in Metropolitan Areas: A Theoretical Inquiry, in: American Political Science Review, Vol. 55, S. 831-842

Ott, M. (1980), Bureaucracy, Monopoly, and the Demand for Municipal Services, in: Journal of Urban Economics, Vol. 8, S. 362-382

Pagenkopf, H. (1978), Das Gemeindefinanzsystem und seine Problematik, Siegburg

Pahlke, J. (1967), Bestimmungsgründe für öffentliche Leistungen, in: Timm, H.; Haller, H. (Hrsg.), Beiträge zur Theorie der öffentlichen Ausgaben (Schriften des Vereins für Socialpolitik, Bd. 47), Berlin, S. 104-125

Pappermann, E.; Roters, W.; Vesper, E. (1976), Maßstäbe für die Funktionalreform im Kreis Exemplarische Erläuterung am Beispiel Nordrhein-Westfalens, (Kommunalwissenschaftliche Schriften des Deutschen Landkreistages, Bd. 4), Köln

Pareto, V. (1927), Manuel d'écomomie politique, Paris

Paulsen, A. (1965), Allgemeine Volkswirtschaftslehre (6. Aufl.), Bd. I, Berlin

Pauly, M.V. (1970a), Optimality, "Public" Goods, and Local Government: A General Theoretical Analysis, in: Journal of Political Economy, Vol. 78, S. 572-585

Pauly, M.V. (1970b), Cores and Clubs, in: Public Choice, Vol. 9, S. 53-65

Pauly, M.V. (1973), Income Redistribution as a Local Public Good, in: Journal of Public Economics, Vol. 2, S. 35-58

Pawlowsky, P. (1972), Räumliche externe Effekte öffentlicher Leistungen im föderativem Staat, Basel

Peacock, A.T.; Wisemann, J. (1967), The Growth of Public Expenditure in the United Kingdom (2. ed.), London.

Peacock, A.T.; Ricketts, M. (1983), Intergovernmental Fiscal Relations in a Unitary State: The Example of United Kingdom, in: Handbuch der Finanzwissenschaft, Tübingen, 3. Aufl., Bd. IV, S. 53-68

Peffekoven, R. (1969), Die Besteuerung des interregionalen Handels in den USA, in: Finanzarchiv, N.F., Vol. 28, S. 415-440

Peffekoven, R. (1975), Zur Theorie des Steuerexports, Tübingen 
Peffekoven, R. (1988), Finanzausgleich I: Wirtschaftstheoretische Grundlagen, in: Handwörterbuch der Wirtschaftswissenschaften (HdWW), Stuttgart/Tübingen/Göttingen, Bd. 2, S. $608-636$

Peffekoven, R. (1990), Deutsche Einheit und Finanzausgleich, in: Staatswissenschaften und Staatspraxis, Bd. 1, Heft 4, S. 485-511

Peltzman, S.; Tideman, T.N. (1972), Local versus National Pollution Control: Note, in: American Economic Review, Vol. 62, S. 959-963

Pennock, J.R. (1959), Federal and Unitary Government: Disharmony and Frustration, in: Behavioral Science (Official Publication of the Mental Health Research Institute, University of Michigan), Vol. 4, S. 147-157

Pestieau, P. (1977), The Optimality Limits of the Tiebout-Model, in: Oates, W.E. (Ed.), The Political Economy of Fiscal Federalism, Lexington/Toronto, S. 173-186

Pestieau, P. (1983), Fiscal Mobility and Local Public Goods. A Survey of the Empirical and Theoretical Studies of the Tiebout Model, in: Thisse, J.-F.; Zoller, H.G. (Eds.), Locational Analysis of Public Facilities, Amsterdam/New York/Oxford, S. 11-41

Pethig, R. (1979), Umweltökonomische Allokation mit Emissionssteuern, Tübingen

Pethig, R. (1985), Alternative Allocation Procedures for Public Goods: Towards a Comparative Analysis, in: Pethig, R. (Ed.), Public Goods and Public Allocation Policy, Frankfurt a.M./Bern/New York, S. 201-238

Petzold, G. (1983), Gewerbesteuer, München

Pigou, A.C. (1962), The Economics of Welfare (4. ed.), London

Pohmer, D. (1977), Wirkungen finanzpolitischer Instrumente, in: Handbuch der Finanzwissenschaft, Tübingen, 3. Aufl., Bd. I, S. 193-346

Pohmer, D. (1980), Allgemeine Umsatzsteuern, in: Handbuch der Finanzwissenschaft, Tübingen, 3. Auf., Bd. II, S. 647-707

Pollak, H. (1966), Wachstumsbedingte Verbrauchsstrukturänderungen und einige ihrer Konsequenzen für die Verbrauchsbesteuerung, Berlin

Pommerehne, W.W. (1978), Institutional Approaches to Public Expenditure: Empirical Evidence from Swiss Municipalities, in: Journal of Public Economics, Vol. 9, S. 255-280

Popitz, J. (1927), Der Finanzausgleich, in: Handbuch der Finanzwissenschaft, Tübingen, 1. Aufl., Bd. II, S. 338-375

Popitz, J. (1932), Der künftige Finanzausgleich zwischen Reich, Ländern und Gemeinden, Berlin

Postlep, R.-D. (1979), Räumliche Analyse der Kommunalverschuldung in der Bundesrepublik Deutschland, Baden-Baden

Postlep, R.-D. (1985), Wirtschaftsstruktur und großstädtische Finanzen: Einflüsse höherwertiger Dienstleistungen auf die kommunalen Steuereinnahmen und Ausgaben in verschiedenen Großstädten, Hannover

Radner, R. (1985), The Internal Economy of Large Firms, in: Supplement to the Economic Journal (Conference Papers), Vol. 96, S. 1-22 
Raecke, J. (1971), Das Kostendeckungsprinzip - Möglichkeiten und Grenzen seiner Anwendung bei Verwaltungsgebühren, Köln/Berlin/Bonn/München

Rahmann, B. (1988), Ziele, Prinzipien und Grundsätze der Besteuerung mit Bezug auf die Bundesrepublik Deutschland, in: Friedrich-Ebert-Stiftung (Hrsg.), Steuerpolitik als Gesellschaftspolitik (Dokumentation einer Konferenz der Friedrich-Ebert-Stiftung und des Instituts für Gesellschaftswissenschaften des Zentralkomitees der Ungarischen Sozialistischen Arbeiterpartei in Bonn am 17. und 18. Mai 1988), Bonn, S. 1-42

Rahmann, B. (1989), Reform der Gewerbesteuer und Gemeindefinanzen (Schriftenreihe des Forschungsinstituts der Friedrich-Ebert-Stiftung), Bonn

Rakers, J. (1979), Kommunale Verschuldung, Frankfurt a.M.

Ramser, H.J. (1968), Dezentrale Planung der Infrastrukturausgaben, in: Finanzarchiv, N.F., Vol. 27, S. 484-503

Randall, A. (1983), The Problem of Market Failure, in: Natural Resource Journal, Vol. 23, S. 131-148

Rau, G.; Rieger, G. (1981), Möglichkeiten einer Gemeindebeteiligung an der Umsatzbesteuerung, Melle

Rau, K.H. (1859), Grundsätze der Finanzwissenschaft (4. Aufl.), I. Abt., Leipzig/Heidelberg

Recker, E. (1978), Brauchen wir eine neue Kommunalsteuer?, in: Wirtschaftsdienst, 58. Jg., Heft 11, S. 564-568

Recker, E. (1979), Umsatzsteuerbeteiligung der Gemeinden aus der Sicht der Raumordnung Ziele und Modellrechnungen, in: Bundesforschungsanstalt für Landeskunde und Raumordnung (Hrsg.), Umsatzsteuerbeteiligung der Gemeinden? (Informationen zur Raumentwicklung, Heft 11/12), S. 689-705

Recker, E. (1983a), Das kommunale Steuersystem aus räumlicher Sicht: Stellungnahme zu einer Anhörung der F.D.P-Bundestagsfraktion und der F.D.P-Kommission "Föderalismus und Finanzverfassung", in: Raumforschung und Raumordnung (Bundesforschungsanstalt für Landeskunde und Raumordnung), Bonn-Bad Godesberg, Heft 3, S. 100-108

Recker, E. (1983b), Probleme der Gewerbesteuer und der Gemeindebeteiligung an der Einkommensteuer aus räumlicher Sicht, in: Jahrbuch für Regionalwissenschaft, Göttingen, 4. Jg. , S. 92-115

Recker, E. (1992), Die Zeit ist reif für eine Beteiligung der Kommunen am Umsatzsteueraufkommen, in: Handelsblatt vom 20. Nov. 1992

Recktenwald, H.C. (1967), Effizienz und innere Sicherheit, in: Kyklos (Internationale Zeitschrift für Sozialwissenschaften), Vol. 20, S. 607-641

Recktenwald, H.C. (1977a), Umfang und Struktur der öffentlichen Ausgaben in säkularer Entwicklung, in: Handbuch der Finanzwissenschaft, Tübingen, 3. Aufl., Bd. I, S. 715752

Recktenwald, H.C. (1977b), Ist die öffentliche Verschwendung systembedingt? - Das Leistungsprinzip muß stärker ins Bewußtsein rücken, in: Der Gemeinderat, 20. Jg., S. 11-14

Rees, R. (1984), The Public Enterprise Game, in: Supplement to the Economic Journal (Conference Papers), Vol. 94, S. 109-123

Rees, R. (1985a), The Theory of Principal and Agent - Part I, in: Bulletin of Economic Research, Vol. 37, S. 3-26 
Rees, R. (1985b), The Theory of Principal and Agent - Part II, in: Bulletin of Economic Research, Vol. 37, S. 75-95

Rehm, H. (1980), Die kommunale allgemeine Verbrauchsteuer - eine Lösung für die gemeindlichen Finanzprobleme?, in: Konjunkturpolitik, 26. Jg., Heft 1, S. 36-65

Rehm, H. (1981), Das kommunale Finanzproblem - Möglichkeiten und Grenzen für eine Lösung, in: Finanzarchiv, N.F., Vol. 39, S. 185-222

Rehm, H. (1982), Änderungsmöglichkeiten bei der Struktur und Bemessung der GemeindeSteuern, in: Ifo-Studien (Zeitschrift für empirische Wirtschaftsforschung), Berlin/München, Heft 1/2, S. 95-142

Reichmann, T.; Lange, C. (1980), Kapitalflußrechnung und Wertschöpfungsrechnung als Ergänzungsrechnungen des Jahresabschlusses im Rahmen einer gesellschaftsbezogenen Rechnungslegung, in: Zeitschrift für Betriebswirtschaft, 50. Jg., S. 518-542

Reischauer, R.D. (1975), General Revenue Sharing - The Program's Incentives, in: Oates, W.E. (Ed.), Financing the New Federalism - Revenue Sharing, Conditional Grants, and Taxation, Baltimore/London, S. 40-87

Reissert, B. (1986), Kommunales Hebesatzrecht zur Einkommensteuer, in: Demokratische Gemeinde, 88. Jg., Heft 3, S. 40-45

Renzsch, W. (1991), Finanzverfassung und Finanzausgleich - Die Auseinandersetzungen um ihre politische Gestaltung in der Bundesrepublik Deutschland zwischen Währungsreform und deutscher Vereinigung (1948-1990), Bonn

Richter, W.F. (1992), Kommunale Unternehmensbesteuerung: Grundsätzliche Anmerkungen zur Verwirklichung eines effizienten Systems, in: Zeitschrift für Wirtschafts- und Sozialwissenschaften, 112. Jg., S. 567-586

Richter, W.F.; Wiegard, W. (1990a), Effizienzorientierte Reform der Gewerbesteuer (Regensburger Diskussionsbeiträge, Nr. 213), Regensburg

Richter, W.F.; Wiegard, W. (1990b), Cash-flow Steuern: Ersatz für die Gewerbesteuer, in: Steuer und Wirtschaft (Zeitschrift für die gesamte Steuerwissenschaft), 67. Jg., S. 40-45

Rieger, G. (1983), Gewerbesteuer auf neuem Kurs - Entlastung der Wirtschaft durch Anrechnung der Gewerbesteuer auf die Umsatzsteuerlast, in: Der Gemeindehaushalt, 84. Jg., Heft 8, S. 187-188

Ritter, D. (1983), Abbau der Gewerbesteuer: Konzept eines Brückenschlages zwischen Wirtschaft und Gemeinden, in: Der Gemeindehaushalt, 84. Jg., Heft 8, S. 188-191

Ritter, W. (1983), Abbau der Gewerbesteuer - Ein Beitrag zur überfäligen Reform der Gemeindefinanzen und der Unternehmensbesteuerung, in: Betriebsberater (Zeitschrift für Recht und Wirtschaft), 38. Jg., S. 389-397

Röder, H. (1974), Ursachen, Erscheinungsformen und Folgen regionaler Mobilität - Ansätze zu ihrer theoretischen Erfassung (Beiträge zum Siedlungs- und Wohnungswesen und zur Raumordnung, Bd. 16), Münster

Roloff, O. (1987), Reform der kommunalen Finanzwirtschaft zur Sicherung kommunaler Finanzautonomie, in: RaumPlanung, Heft 38, S. 99-106

Roloff, O. (1989), Unternehmensbesteuerung im Europäischen Binnenmarkt 1992, in: WSIMitteilungen, 42. Jg., Heft 6, S. 326-334 
Roloff, O. (1991), Fiskalföderalismus oder Fiskalzentralismus im Europäischen Binnenmarkt, in: Wahl, J. (Hrsg.), Steuerpolitik vor neuen Aufgaben, Regensburg, S. 49-66

Romer, T.; Rosenthal, H. (1979a), Bureaucrats versus Voters: On the Political Economy of Resource Allocation by Direct Democracy, in: Quarterly Journal of Economics, Vol. 93, S. 563-587

Romer, T.; Rosenthal, H. (1979b), The Elusive Median Voter, in: Journal of Public Economics, Vol. 12, S. 143-170

Romer, T.; Rosenthal, H. (1980), An Institutional Theory of the Effect of Intergovernmental Grants, in: National Tax Journal, Vol. 33, S. 451-458

Rose, M. (1991a), Cash-flow-Gewerbesteuer versus zinsbereinigte Gewerbeertragsteuer, in: Rose, M. (Hrsg.), Konsumorientierte Neuordnung des Steuersystems, Berlin, S. 205-216

Rose, M. (Hrsg.) (1991b), Konsumorientierte Neuordnung des Steuersystems, Berlin

Rosen, H.S. (1980), What is Labor Supply and do Taxes Affect it?, in: American Economic Review (Papers and Proceedings), Vol. 70, S. 171-176

Rosenfeld, M. (1985), Ausgabeneffekte kommunaler Funktionalreformen - Zum Problem der Operationalisierung und empirischen Überprüfung des Popitzschen "Gesetzes von der Anziehungskraft des übergeordneten Etats", Baden-Baden

Rostin, W. (1979), Zwischenörtlicher Vergleich des Verbraucherpreisniveaus in 31 Städten, in: Wirtschaft und Statistik, Heft 6, S. 403-410

Rothenberg, J. (1970), Local Decentralization and the Theory of Optimal Government, in: Margolis, J. (Ed.), The Analysis of Public Output, New York, S. 31-68

Rufolo, A.M. (1979), Efficient Local Taxation and Local Public Goods, in: Journal of Public Economics, Vol. 12, S. 351-376

Sachverständigenkommission für die Finanzreform (1966), Gutachten über die Finanzreform in der Bundesrepublik Deutschland, Stuttgart/Köln/Berlin/Mainz

Sachverständigenrat zur Begutachtung der gesamtwirtschaftlichen Entwicklung, verschiedene Jahresgutachten

Sachverständigenrat zur Neubestimmung der kommunalen Selbstverwaltung beim Institut für Kommunalwissenschaften der Konrad-Adenauer-Stiftung (1980), Staat und Gemeinden, Köln

Sacks, S.; Harris, R. (1964), The Determinants of State and Local Government Expenditures and Intergovernmental Flow and Funds, in: National Tax Journal, Vol. 17, S. 75-85

Sälter, P.M. (1989), Externe Effekte: "Marktversagen" oder Systemmerkmal?, Heidelberg

Salmon, P. (1988), The Logic of Pressure Groups and the Structure of the Public Sector, in: Brenton, A.; Galeotti, G.; Salmon, P; Wintrobe, R. (Eds.), Villa Colombella Papers on Federalism (Proceedings of the Seminar held at Villa Colombella, Perugia, Italy, September 1984), Regensburg, S. 55-86

Samuelson, P.A. (1954), The Pure Theory of Public Expenditure, in: Review of Economics and Statistics, Vol. 36, S. 387-389

Samuelson, P.A. (1955), Diagrammatic Exposition of a Theory of Public Expenditure, in: Review of Economics and Statistics, Vol. 37, S. 350-356 
Samuelson, P.A. (1958), Aspects of Public Expenditure Theories, in: Review of Economics and Statistics, Vol. 40, S. 332-338

Samuelson, P.A. (1969), Pure Theory of Public Expenditures and Taxation, in: Margolis, J.; Guitton, H. (Eds.), Public Economics, New York/London, S. 98-123

Sandler, T.M.; Shelton, R.B. (1972), Fiscal Federalism, Spillovers and the Export of Taxes, in: Kyklos (Internationale Zeitschrift für Sozialwissenschaften), Vol. 25, S. 736-753

Sandler, T.; Tschirhart, J. (1980), The Economic Theory of Clubs: An Evaluative Survey, in: Journal of Economic Literature, Vol. 18, S. 1481-1521

Sandmo, A. (1976), Optimal Taxation: An Introduction to the Literature, in: Journal of Public Economics, Vol. 6, S. 37-54

Savelsberg, J.J. (1980), Kommunale Autonomie - Autonomie, Macht und Entscheidungen in Gemeinden, Frankfurt a.M.

Sax, E. (1887), Grundlegung der theoretischen Staatswirtschaft, Wien

Scitovski, T. (1954), Two Concepts of External Economies, in: Journal of Political Economy, Vol. 62, S. 143-151

Scott, A.D. (1950), A Note on Grants in Federal Countries, in: Economica, Vol. 17, S. 416422

Scott, A.D. (1952a), The Evaluation of Federal Grants, in: Economica, Vol. 19, S. 377-394

Scott, A.D. (1952b), Federal Grants and Resource Allocation, in: Journal of Political Economy, Vol. 60, S. 534-536

Scott, A.D. (1964), The Economic Goals of Federal Finance, in: Public Finance, Vol 19., S. 241-288

Seeger, R. (1969), Kommunalpolitische Bedeutung und Standort der Benutzungsgebühren Zur Frage der Nachfragelenkung mittels Gebührenpolitik, in: Der Gemeindehaushalt, 70. Jg., S. 272-275

Seiler, G. (1980), Ziele und Mittel des kommunalen Finanzausgleichs - Ein Rahmenkonzept für einen aufgabenbezogenen kommunalen Finanzausgleich, in: Pohmer, D. (Hrsg.), Probleme des Finanzausgleichs II, Berlin, S. 11-82

Seiler, G. (1988), Gemeinden III: Finanzen, in: Handwörterbuch der Wirtschaftswissenschaften (HdWW), Stuttgart/Tübingen/Göttingen, Bd. 3, S. 507-525

Sen, A.K. (1970), Collective Choice and Social Welfare, San Francisco

Sheshinski, E. (1973), Congestion and the Optimum City Size, in: American Economic Review (Papers and Proceedings), Vol. 63, S. 61-66

Siebert, H. (Hrsg.) (1982), Umweltallokation im Raum, Frankfurt a.M.

Sievert, O.; Naust, H.; Jochum, D.; Peglow, M.; Glumann, T. (1989), Steuern und Investitionen, Frankfurt a.M.

Sinn, H.-W. (1984a), Neue Wege der Unternehmensbesteuerung, in: Wirtschaftsdienst, 64. Jg., Heft 7, S. 328-334

Sinn, H.-W. (1984b), Systeme der Kapitaleinkommensbesteuerung - Ein allokationstheoretischer Vergleich, in: Bös, D.; Rose, M.; Seidl, Ch. (Hrsg.), Beiträge zur neueren Steuer- 
theorie (Referate des finanztheoretischen Seminars im Kloster Neustift bei Brixen 1983), Berlin, S. 209-238

Sinn, H.-W. (1985), Kapitaleinkommensbesteuerung, Tübingen

Sinn, H.-W. (1987), Alternativen zur Einkommensteuer, in: Steuersystem und wirtschaftliche Entwicklung (Bericht über den wissenschaftlichen Teil der 49. Mitgliederversammlung der Arbeitsgemeinschaft deutscher wirtschaftswissenschaftlicher Forschungsinstitute e.V. in Bonn am 6. und 7. Mai 1986; Beihefte zur Konjunkturpolitik, Heft 33), Berlin, S. 1150

Sinn, H.-W. (1989a), Neue Wege der Unternehmensbesteuerung: Eine Replik, in: Wirtschaftsdienst, 69. Jg, Heft 3, S. 159-164

Sinn, H.-W. (1989b), Cash-flow-Besteuerung noch einmal: Antwort auf die Antwort von Cansier, in: Wirtschaftsdienst, 69. Jg., Heft 5, S. 256-257

Slutsky, S.M. (1977), A Voting Model for the Allocation of Public Goods: Existence of an Equilibrium, in: Journal of Economic Theory, Vol. 14, S. 299-325

Smith, St. (1988), Should UK Local Government be Financed by a Poll Tax?, in: Fiscal Studies, Vol. 9, S. 18-28

Smith, T.R.; Shapiro, P. (1979), On the Spatial Equity of the California Sales Tax: Estimates of Imbalances in Tax Dollar Flows, in: Economic Geography, Vol. 55, S. 135-146

Sohmen, E. (1976), Allokationstheorie und Wirtschaftspolitik, Tübingen

Spahn, P.B. (1989), Die Gewerbesteuer ist besser als ihr Ruf?, in: Kommunale Steuer-Zeitschrift (Zeitschrift für das gesamte Gemeindeabgabenwesen), 38. Jg., Heft 11, S. 201208

Spang, W. (1968), Zur Theorie eines zweckrationalen Steuersystems unter Berücksichtigung der kommunalen Besteuerung, München

Sudgen, R. (1984), Reciprocity: The Supply of Public Goods trough Voluntary Contributions, in: Economic Journal, Vol. 94, S. 772-787

Schäfer, H.-J. (1986), Zur Zukunft der Gewerbesteuer, in: Der Städtetag (Zeitschrift für kommunale Praxis und Wissenschaft), 39. Jg., Heft 12, S. 775

Schäfer, H.-J. (1992a), Für die Sicherung der Gemeindefinanzen in Ost und West, in: Der Städtetag (Zeitschrift für kommunale Praxis und Wissenschaft), 45. Jg. Heft 2, S. 55-57

Schäfer, H.-J. (1992b); Der Vorschlag des Deutschen Städtetages zur unmittelbaren Beteiligung der Gemeinden am Umsatzsteueraufkommen als Teilersatz für die Gewerbesteuer, in: Kommunale Steuer-Zeitschrift (Zeitschrift für das gesamte Gemeindeabgabenwesen), 41. Jg., Heft 9, S. 161-163

Schäffle, A.E. (1880), Die Grundsätze der Steuerpolitik und die schwebenden Finanzfragen Deutschlands und Österreichs, Tübingen

Scharpf, F.W. (1985), Die Politikverflechtungs-Falle: Europäische Integration und deutscher Föderalismus im Vergleich, in: Politische Vierteljahreszeitschrift, 26. Jg., S. 323-356

Scherf, W. (1989), Das Krause-Junk-Modell: Ein geeigneter Ansatz zur Reform der Gewerbesteuer?, in: Wirtschaftsdienst, 69. Jg., Heft 11, S. 572-575 
Schleiter, M. (1985), Steuersystem und Unternehmenspolitik - Theorie und empirische Ergebnisse zum Einfluß des Steuersystems auf die Investitionsentscheidungen deutscher Industrieaktiengesellschaften, Köln

Schmalstieg, H. (1987), Steuerreform und Gemeindefinanzen - Ein ergänzender steuerlicher Ausgleich ist notwendig, in: Wirtschaftsdienst, 67. Jg., Heft 11, S. 546-549

Schmidt, K. (1980), Grundprobleme der Besteuerung, in: Handbuch der Finanzwissenschaft, Tübingen, 3. Aufl., Bd. II, S. 119-171

Schmidt, K. (1986), Reform der Unternehmensbesteuerung - Erfordernisse und Lösungswege, Berlin/Heidelberg

Schmidt-Jortzig, E. (1977), Gemeinden und Kreise vor den öffentlichen Aufgaben der Gegenwart, in: Deutsches Verwaltungsblatt, 01. Okt. 1977, S. 801-807

Schmitt, K. (1985), Reform des Gemeindesteuersystems - Auswirkungen der verschiedenen Vorschläge auf Gemeinden und Regionen, in: Ifo-Schnelldienst, 38. Jg., Nr. 30, S. 9-21

Schmitt, K. (1986), Räumliche Wirkungen von Gemeindesteuerreformvorschlägen (Gutachten im Auftrag des Bundesverbandes der Deutschen Industrie, Köln), Ifo-Studien zur Finanzpolitik, Nr. 35, München

Schmölders, G. (1949), Um ein rationales Steuersystem, in: Finanzarchiv, N.F., Vol. 11, S. 479-497

Schmölders, G. (1956), Steuersystem und Steuersystematik, in: Handbuch der Finanzwissenschaft, Tübingen, 2. Aufl., Bd. II, S. 326-334

Schmölders, G. (1970), Finanz- und Steuerpsychologie, Reinbek

Schneider, D. (1987), Reform der Unternehmensbesteuerung durch "Eckwerte" oder durch Cash-flow-Besteuerung, in: Betriebsberater (Zeitschrift für Recht und Wirtschaft), 42. Jg., S. 693-699

Schneider, E. (1965), Einführung in die Wirtschaftstheorie (2. Aufl.), Teil IV, Tübingen

Schnoor, H. (1987), Steuerreform und Gemeindefinanzen - Verheerende Folgen für strukturschwache Kommunen, in: Wirtschaftsdienst, 67. Jg., Heft 11, S. 549-551

Schönbäck, W. (1975), Die Bestimmungsgründe des Grades der Zentralität/Dezentralität offentlich-wirtschaftlicher Aktivitäten (1. Teil), in: Matzner, E. (Hrsg.), Der öffentliche Sektor - Forschungsmemoranden, 1. Jg., Heft 1, S. 76-113

Schönbäck, W. (1976), Die Bestimmungsgründe des Grades der Zentralität/Dezentralität öffentlich-wirtschaftlicher Aktivitäten (2. Teil), in: Matzner, E. (Hrsg.), Der öffentliche Sektor - Forschungsmemoranden, 2. Jg., Heft 1, S. 74-100

Schultz, U. (Hrsg.) (1986), Mit dem Zehnten fing es an - Eine Kulturgeschichte der Steuer, München

Schwarting, G. (1982), Grenzen der Kommunalverschuldung - Was leistet das kommunale Haushaltsrecht?, in: Zeitschrift für Kommunalfinanzen, 33. Jg., Nr. 5, S. 82-88

Schwarting, G. (1984), Wertschöpfungsteuer - Neue Belastungen für die Wirtschaft?, in: Wirtschaftsdienst, 64. Jg., Heft 2, S. 87-90

Schweisfurth, T. (1991), Privatwirtschaftliche Formen kommunaler Investitionsfinanzierung (DST-Beiträge zur Finanzpolitik, Reihe G, Heft 11), Köln 
Schweizer, U. (1982), Binnenwanderung und gesamtwirtschaftliche Effizienz, in: Journal of Institutional and Theoretical Economics, Vol. 138, S. 225-240

Schweizer, U. (1983), Edgeworth and the Henry George Theorem: How to Finance Local Public Projects, in: Thisse, J.-F.; Zoller, H. G. (Eds.), Locational Analysis of Public Facilities, Amsterdam/New York/Oxford, S. 79-93

Starrett, D.A. (1980), On the Method of Taxation and the Provision of Local Public Goods, in: American Economic Review, Vol. 70, S. 380-392

Statistisches Bundesamt (verschiedene Jahrgänge), Volkswirtschaftliche Gesamtrechnungen, Fachserie 18, Stuttgart/Mainz

Stein, L. von (1885), Lehrbuch der Finanzwissenschaft I - Die Finanzverfassung Europas, Die Finanzverwaltung Europas (5. Aufl.), Leipzig (neu erschienen Hildesheim/New York, 1975)

Stein, L. von (1886), Lehrbuch der Finanzwissenschaft II - Die Finanzverwaltung Europas (5. Aufl.), Leipzig (neu erschienen: Hildesheim/New York, 1975)

Steiss, A.W. (1975), Local Government Finance - Capital Facilities Planning and Debt Administration, Lexington/Mass.

Stemmler, H. (1973), Planungswertausgleich und/oder Wertzuwachsteuer? Ein Diskussionsbeitrag aus der Sicht gemeindlicher Bodenwirtschaft, in: Der Städtetag (Zeitschrift für kommunale Praxis und Wissenschaft), 24. Jg., Heft 3, S. 124-129

Stern, K. (1977), Das Staatsrecht der Bundesrepublik Deutschland, Band 1: Grundbegriffe und Grundlagen des Staatsrechts, Strukturprinzipien der Verfassung, München

Stern, K.; Burmeister, J. (1975), Die Verfassungsmäßigkeit eines landesrechtlichen Planungsgebots für Gemeinden, Düsseldorf

Stern, K.; Schmidt-Bleibtreu, B. (1990a), Verträge und Rechtsakte zur Deutschen Einheit (Band I: Staatsvertrag zur Währungs-, Wirtschafts- und Sozialunion mit Vertragsgesetz, Begründungen und Materialien), München

Stern, K.; Schmidt-Bleibtreu, B. (1990b), Verträge und Rechtsakte zur Deutschen Einheit (Band II: Einigungsvertrag und Wahlvertrag mit Vertragsgesetzen, Begründungen, Erläuterungen und Materialien), München

Steuerreformkommission (1971), Gutachten (Schriftenreihe des Bundesministeriums der Finanzen, Heft 17), Bonn

Stigler, G.J. (1970), The Theory of Price (3. ed.), New York

Stiglitz, J.E. (1977), The Theory of Local Public Goods, in: Feldstein, M.S.; Inman, R.P. (Eds.), The Economics of Public Services, London, S. 274-333

Stiglitz, J.E. (1983a), Public Goods in Open Economies with Heterogeneous Individuals, in: Thisse, J.-F.; Zoller, H.G. (Eds.), Locational Analysis of Public Facilities, Amsterdam/New York/Oxford, S. 55-78

Stiglitz, J.E. (1983b), The Theory of Local Public Goods Twenty-Five Years after Tiebout: A Perspective, in: Zodrov, G.R. (Ed.), Local Provision of Public Services: The Tiebout Model after Twenty-Five Years, New York, S. 17-53 
Stork, F. (1990), Kommunaler Finanzausgleich 1990, in: Städte- und Gemeinderat, Heft 4, S. 109-112

Strauß, W. (1984), Probleme und Möglichkeiten einer Substituierung der Gewerbesteuer, Opladen

Tait, A.A.; Morgan, D.R. (1980), Energiepolitik und Benzinbesteuerung, in: Finanzierung und Entwicklung, 17. Jg., Heft 2, S. 7-11

Tetsch, F. (1978), Raumwirkungen des Finanzsystems der Bundesrepublik Deutschland, Frankfurt a.M./Bern/Las Vegas

Tetsch, F. (1979), Die Beteiligung der Gemeinden an der Umsatzsteuer - Ein Vorschlag zur Reform des Gemeindesteuersystems, in: Raumforschung und Raumordnung, 37. Jg., S. 82-89

Thiede, W. (1981), Auswirkungen der Gebietsreform im Bereich des kommunalen Finanzausgleichs - Empirische Untersuchungen am Beispiel des Landes Niedersachsen, Baden-Baden

Thieme, W.; Prillwitz, G. (1981), Durchfuhhung und Ergebnisse der kommunalen Gebietsreform, Baden-Baden

Thiemeyer, T. (1964), Grenzkostenpreise bei öffentlichen Unternehmen, Köln/Opladen

Thisse, J.-F.; Zoller, H.G. (Eds.) (1983), Locational Analysis of Public Facilities, Amsterdam/New York/Oxford

Thompson, R.E. (1973), Revenue Sharing - A New Era in Federalism, Washington

Tiebout, Ch.M. (1956), A Pure Theory of Local Expenditures, in: Journal of Political Economy, Vol. 44, S. 416-424

Tiebout, Ch.M. (1961), An Economic Theory of Fiscal Decentralization, in: National BureauCommittee for Economic Research (Ed.), Public Finances: Needs, Sources and Utilization, Princeton, S. 79-96

Timm, H. (1961), Das Gesetz der wachsenden Staatsausgaben, in: Finanzarchiv, N.F., Vol. 21, S. 201-247

Timm, H. (1969), Gemeindefinanzpolitik in den Wachstumszyklen, in: Finanzarchiv, N.F., Vol. 28 , S. 441-459

Timm, H. (1981), Finanzwirtschaftliche Allokationspolitik, in: Handbuch der Finanzwissenschaft, Tübingen, 3. Aufl. Bd. III, S. 135-255

Tofaute, H. (1989), Muß die Steuerlast der deutschen Wirtschaft und ihrer Unternehmen gesenkt werden?, in: WSI-Mitteilungen, 42. Jg., Heft 6, S. 290-303

Torres, J. de (1967), Financing Local Government, New York

Troll, M. (1984), Neue Einheitswerte für den Grundbesitz - Zum Stand der Diskussion aus kommunaler Sicht, in: Der Gemeindehaushalt, 85. Jg., Heft 3, S. 57-61

Tullock, G. (1959), Problems of Majority Voting, in: Journal of Political Economy, Vol. 67, S. 571-579

Tullock, G. (1965), The Politics of Bureaucracy, Washington D.C. 
Tullock, G. (1970), Comment (zu J. Rothenberg, Local Decentralization and Theory of Optimal Government), in: Margolis, J. (Ed), The Analysis of Public Output, New York, S. $65-68$

Turvey, R. (1963), On Divergences between Social Cost and Private Cost, in: Economica, Vol. 30, S. 309-313

Ulrich, H. (1989), Die erste Million ist die schwerste: Alle Steuer-Ungerechtigkeiten im Überblick, Köln

Vardy, D.A. (1973), Population Mobility and Efficiency in the Provision of Regional Public Goods, in: Institute International de Finances Publiques (IIPF) (Ed.), Issues in Urban Public Finance, Saarbrücken, S. 82-100

Varian, H.R. (1985), Mikroökonomie (2. Aufl.), München

Voigt, R. (1975), Die Auswirkungen des Finanzausgleichs zwischen Staat und Gemeinden auf die kommunale Selbstverwaltung von 1919 bis zur Gegenwart, Berlin

Voss, F. (1987), Steuerreform und Gemeindefinanzen - Die Kommunen werden bei der Steuerreform nicht benachteiligt, in: Wirtschaftsdienst, Heft 11, S. 543-545

Voß, W. (1990), Nutzenpillover-Effekte als Problem des kommunalen Finanzausgleichs, Göttingen

Waffenschmidt, H. (1989), Entwicklung der kommunalen Finanzen, in: Kommunale Steuerzeitschrift, 38. Jg., S. 41-43

Wagener, F. (1974), Neubau der Verwaltung - Gliederung der öffentlichen Aufgaben und ihre Träger nach Effektivität und Integrationswert (2. Aufl.), Berlin

Wagner, A. (1877), Finanzwissenschaft, Erster Theil: Einleitung, Ordnung der Finanzwirthschaft, Finanzbedarf, Privaterwerb, Leipzig/Heidelberg

Wagnier, A. (1880), Finanzwissenschaft, Zweiter Theil: Gebühren und allgemeine Steuerlehre, Leipzig/Heidelberg

Wagner, A. (1890), Finanzwissenschaft, Zweiter Theil: Gebühren und allgemeine Steuerlehre (2. Aufl.), Leipzig/Heidelberg

Waldauer, Ch. (1973), Grant Structures and Their Effects on Aided Government Expenditures: An Indifference Curve Analysis, in: Public Finance, Vol. 28, S. 212-226

Walters, A.A. (1963), Production and Cost Functions: An Econometric Survey, in: Econometrica, Vol. 31, S. 1-66

Watrin, C. (1986), "Marktversagen" versus "Staatsversagen" - Zur Rolle von Markt und Staat in einer freien Gesellschaft, Zürich

Weber, M. (1922), Gesammelte Aufsätze zur Wissenschaftslehre, Tübingen

Weilepp, M. (1976), Expansive Gebührenpolitik zur Verbesserung der Finanzsituation?, in: Wirtschaftsdienst, 56. Jg. Heft 11, S. 576-579

Weinberger, B. (1969), Die Finanzwirtschaft der Gemeinden, in: Die öffentliche Verwaltung (Zeitschrift für Verwaltungsrecht und Verwaltungspolitik), 22. Jg., S. 825-829 
Weinberger, B. (1984), Neuordnung des Gemeindesteuersystems statt schrittweiser Gewerbesteuerbeseitigung, in: Kommunale Steuer-Zeitschrift (Zeitschrift für das gesamte Gemeindeabgabenwesen), 33. Jg., Heft 3, S. 41-46

Weisbrod, B.A. (1964), External Benefits of Public Education: An Economic Analysis, Princeton

Weisbrod, B.A. (1965), Geographic Spillover Effects and the Allocation of Resources to Education, in: Margolis, J. (Ed.), The Public Economy of Urban Communities, Washington D.C., S. 192-206

Weisbrod, B.A. (1977), The Voluntary Nonprofit Sector: An Economic Analysis, Toronto

Wenger, E. (1983), Gleichmäßigkeit der Besteuerung von Arbeits- und Vermögenseinkünften, in: Finanzarchiv, N.F., Vol. 41, S. 207-252

Wheaton, W.C. (1975), Consumer Mobility and Commodity Taxe Bases: The Financing of Local Public Goods, in: Journal of Public Economics, Vol. 4, S. 377-384

Wicksell, K. (1896), Finanztheoretische Untersuchungen, Jena

Wiegard, W. (1984), Steuerreform zur Beseitigung von Leistungshemmnissen I und II, in: Das Wirtschaftsstudium (WISU), Heft 3, S. 139-143 und Heft 4, S. 193-197

Wildasin, D.E. (1977), Public Expenditures Determined by Voting with One's Feet and Public Choice, in: Scandinavian Journal of Economics, Vol. 79, S. 326-337

Wildasin, D.E. (1980), Locational Efficiency in a Federal System, in: Regional Science and Urban Economics, Vol. 10, S. 453-471

Wildasin, D.E. (1986), Urban Public Finance, Chur/London/Paris/New York

Wildasin, D.E. (1989), Interjurisdictional Capital Mobility: Fiscal Externality and a Corrective Subsidy, in: Journal of Urban Economics, Vol. 25, S. 193-212

Wilde, J.A. (1968), The Expenditure Effects of Grant-In-Aid Programs, in: National Tax Journal, Vol. 21, S. 143-155

Wilke, D. (1973), Gebührenrecht und Grundgesetz - Ein Beitrag zum allgemeinen Abgabenrecht, München

Williams, A. (1966), The Optimal Provision of Public Goods in a System of Local Government, in: Journal of Political Economy, Vol. 74, S. 18-33

Williams, A. (1967), The Possibility of Oversupply of Public Goods: A Rejoinder, in: Journal of Political Economy, Vol. 75, S. 91-92

Williamson, O.E. (1975), Markets and Hierarchies: Analysis and Antitrust Implications, New York

Williamson, O.E. (1990), Die ökonomischen Institutionen des Kapitalismus, Tübingen

Wilson, J.D. (1986), A Theory of Interregional Tax Competition, in: Journal of Urban Economics, Vol. 19, S. 296-315

Wilson, J.D. (1987), Trade in a Tiebout Economy, in: American Economic Review, Vol. 77, S. 431-441

Wintrobe, R. (1988), Competitive Federalism and Bureaucratic Power, in: Breton, A.; Galeotti, G.; Salmon, P.; Wintrobe, R. (Eds.), Villa Colombella Papers on Federalism 
(Proceedings of the Seminar held at Villa Colombella, Perugia, Italy, September 1984), Regensburg, S. 9-31

Wiseman, J. (1987), The Political Economy of Federalism: A Critical Appraisal, in: Environment and Planning C: Government and Policy, Vol. 5, S. 383-410

Wissenschaftlicher Beirat beim Bundesministerium der Finanzen (1974), Entschließungen, Stellungnahmen und Gutachten 1949-1973, Tübingen

Wissenschaftlicher Beirat beim Bundesministerium der Finanzen (1982), Gutachten zur Reform der Gemeindesteuern in der Bundesrepublik Deutschland (Schriftenreihe des Bundesministeriums der Finanzen, Heft 31), Bonn

Wissenschaftlicher Beirat beim Bundesministerium der Finanzen (1988), Gutachten und Stellungnahmen 1974-1987, Tübingen

Wissenschaftlicher Beirat beim Bundesministerium der Finanzen (1989), Die Einheitsbewertung in der Bundesrepublik Deutschland - Mängel und Alternativen (Schriftenreihe des Bundesministeriums der Finanzen, Heft 41), Bonn

Wittmann, W. (1972), Einfürung in die Finanzwissenschaft (III. Teil), Stuttgart

Wittmann, W. (1978), Zur Effizienz der öffentlichen Ausgaben in der Schweiz, in: Schweizerische Zeitschrift für Volkswirtschaft und Statistik, $114 \mathrm{Jg}$., S. 393-411

Wittmann, W. (1979), Steuerung und Versorgung mit Staatsleistungen über das Äquivalenzprinzip, in: Bohley, P.; Tolkemitt, G. (Hrsg.), Wirtschaftswissenschaft als Grundlage staatlichen Handelns, Tübingen, S. 287-305

Wrage, V. (1975), Erfolg der Territorialreform - Auswirkungen der territorialen Neugliederung der Gemeinden in ausgewählten Kreisen Nordrhein-Westfalens (Schriftenreihe der Hochschule Speyer, Bd. 56), Berlin

Wrobel, B.; Münstermann, E.; Zabel, G. (1976), Kostendeckungsgrade kommunaler Gebührenhaushalte, in: Der Städtetag (Zeitschrift für kommunale Praxis und Wissenschaft), 29. Jg., Heft 7, S. 377-382

Wust, H.F. (1981), Föderalismus - Grundlage für Effizienz in der Staatswirtschaft, Göttingen

Zahn, H.-H. (1982), Die Einstellung der Bürger zu ihrer Gemeinde - dargestellt am Beispiel Brackwede-Bielefeld, Baden-Baden

Zeidler, A. (1985), Möglichkeiten zur Fortsetzung der Gemeindefinanzreform - Eine theoretische und empirische Analyse, Frankfurt a.M./Bern/New York

Zeitel, G. (1970), Kommunale Finanzstruktur und gemeindliche Selbstverwaltung, in: Archiv für Kommunalwissenschaften, 9. Jg., 1. Halbjahresband, S. 1-20

Zeitel, G. (1988), Gebühren und Beiträge, in: Handwörterbuch der Wirtschaftswissenschaften (HdWW), Stuttgart/Tübingen/Göttingen, Bd. 3, S. 347-355

Zielinski, H. (1975), Diskrepanz zwischen Aufgabenentwicklung und Finanzierung in den Gemeinden, Göttingen

Zielinski, H. (1977), Kommunale Selbstverwaltung und ihre Grenzen - Über den Einfluß von Staat und Wirtschaft auf die Gemeinden, Frankfurt a.M./New York

Zimmermann, F. (1971), Aktuelle Fragen des Rechts der kommunalen Gebühren und Beiträge, in: Verwaltungsarchiv, 62. Jg., S. 16-38 
Zimmermann, F. (1991), Ökologisch orientierte kommunale Gebühren - Überzogene Erwartungen und realistische Möglichkeiten -, in: Kommunale Steuer-Zeitschrift (Zeitschrift für das gesamte Gemeindeabgabenwesen), 40. Jg., Heft 12, S. 221-225

Zimmermann, H. (1988), Fortsetzung der Gemeindefinanzreform?, in: Der Gemeindehaushalt, 89. Jg., Heft 9, S. 193-196

Zimmermann, H.; Hardt, U.; Postlep, R.-D. (1987), Bestimmungsgründe der kommunalen Finanzsituation - Unter besonderer Berücksichtigung der Gemeinden in Ballungsgebieten (Gesellschaft für Regionale Strukturentwicklung e.V., Bd. 15), Bonn

Zimmermann, H.; Postlep, R.-D. (1980), Beurteilungsmaßstäbe für Gemeindesteuern, in: Wirtschaftsdienst, 60. Jg., Heft 5, S. 248-253

Zitzelsberger, H. (1985), Neuerliche Entwicklungstendenzen der Gewerbesteuer und Reformvorschläge, Siegburg

Zohlnhöfer, W. (1970), Lokalisierung und Institutionalisierung der Infrastrukturplanung im föderativen System: Das Beispiel der Gemeinschaftsaufgaben in der Bundesrepublik Deutschland, in: Jochimsen, R.; Simonis, U.E. (Hrsg.), Theorie und Praxis der Infrastrukturpolitik (Schriften des Vereins für Socialpolitik, N.F., Bd. 54), S. 681-712

Zwilling, E. (1971), Untersuchungen zu einem rationalen Steuersystem der Gemeinden, Meisenheim am Glan 
Hans-Georg Napp - 978-3-631-75263-0

Downloaded from PubFactory at 01/11/2019 06:33:05AM

via free access 


\section{FINANZWISSENSCHAFTLICHE SCHRIFTEN}

Band 1 Werner Steden: Finanzpolitik und Einkommensverteilung. Ein Wachstums- und Konjunkturmodell der Bundesrepublik Deutschland. 1979.

Band 2 Rainer Hagemann: Kommunale Finanzplanung im föderativen Staat. 1976.

Band 3 Klaus Scherer: Maßstäbe zur Beurteilung von konjunkturellen Wirkungen des öffentlichen Haushalts. 1977.

Band 4 Brita Steinbach: "Formula Flexibility" - Kritische Analyse und Vergleich mit diskretionärer Konjunkturpolitik. 1977.

Band 5 Hans-Georg Petersen: Personelle Einkommensbesteuerung und Inflation. Eine theoretisch-empirische Analyse der Lohn- und veranlagten Einkommensteuer in der Bundesrepublik Deutschland. 1977.

Band 6 Friedemann Tetsch: Raumwirkungen des Finanzsystems der Bundesrepublik Deutschland. Eine Untersuchung der Auswirkungen der Finanzreform von 1969 auf die Einnahmenposition der untergeordneten Gebietskörperschaften und ihrer regionalpolitischen Zieladäquanz. 1978.

Band 7 Wilhelm Pfähler: Normative Theorie der fiskalischen Besteuerung. Ein methodologischer und theoretischer Beitrag zur Integration der normativen Besteuerungstheorie in der Wohlfahrtstheorie. 1978.

Band 8 Wolfgang Wiegard: Optimale Schattenpreise und Produktionsprogramme für öffentliche Unternehmen. Second-Best Modelle im finanzwirtschaftlichen Staatsbereich. 1978.

Band 9 Hans P. Fischer: Die Finanzierung des Umweltschutzes im Rahmen einer rationalen Umweltpolitik. 1978.

Band 10 Rainer Paulenz: Der Einsatz finanzpolitischer Instrumente in der Forschungs- und Entwicklungspolitik. 1978.

Band 11 Hans-Joachim Hauser: Verteilungswirkungen der Staatsverschuldung. Eine kreislauftheoretische Inzidenzbetrachtung. 1979.

Band 12 Gunnar Schwarting: Kommunale Investitionen. Theoretische und empirische Untersuchungen der Bestimmungsgründe kommunaler Investitionstätigkeit in NordrheinWestfalen 1965-1972. 1979.

Band 13 Hans-Joachim Conrad: Stadt-Umland-Wanderung und Finanzwirtschaft der Kernstädte. Amerikanische Erfahrungen, grundsätzliche Zusammenhänge und eine Fallstudie für das Ballungsgebiet Frankfurt am Main. 1980.

Band 14 Cay Folkers: Vermögensverteilung und staatliche Aktivität. Zur Theorie distributiver Prozesse im Interventionsstaat. 1981.

Band 15 Helmut Fischer: US-amerikanische Exportförderung durch die DISC-Gesetzgebung. 1981.

Band 16 Günter Ott: Einkommensumverteilungen in der gesetzlichen Krankenversicherung. Eine quantitative Analyse. 1981.

Band 17 Johann Hermann von Oehsen: Optimale Besteuerung. (Optimal Taxation). 1982.

Band 18 Richard Kössler: Sozialversicherungsprinzip und Staatszuschüsse in der gesetzlichen Rentenversicherung. 1982.

Band 19 Hinrich Steffen: Zum Handlungs- und Entscheidungsspielraum der kommunalen Investitionspolitik in der Bundesrepublik Deutschland. 1983.

Band 20 Manfred Scheuer: Wirkungen einer Auslandsverschuldung des Staates bei flexiblen Wechselkursen. 1983. 
Band 21 Christian Schiller: Staatsausgaben und crowding-out-Effekte. Zur Effizienz einer Finanzpolitik keynesianischer Provenienz. 1983.

Band 22 Hannelore Weck: Schattenwirtschaft: Eine Möglichkeit zur Einschränkung der öffentlichen Verwaltung? Eine ökonomische Analyse. 1983.

Band 23 Wolfgang Schmitt: Steuern als Mittel der Einkommenspolitik. Eine Ergänzung der Stabilitätspolitik? 1984.

Band 24 Wolfgang Laux: Erhöhung staatswirtschaftlicher Effizienz durch budgetäre Selbstbeschränkung? Zur Idee einer verfassungsmäßig verankerten Ausgabengrenze. 1984.

Band 25 Brita Steinbach-van der Veen: Steuerinzidenz. Methodologische Grundlagen und empirisch-statistische Probleme von Länderstudien. 1985.

Band 26 Albert Peters: Ökonomische Kriterien für eine Aufgabenverteilung in der Marktwirtschaft. Eine deskriptive und normative Betrachtung für den Allokationsbereich. 1985.

Band 27 Achim Zeidler: Möglichkeiten zur Fortsetzung der Gemeindefinanzreform. Eine theoretische und empirische Analyse. 1985.

Band 28 Peter Bartsch: Zur Theorie der längerfristigen Wirkungen 'expansiver' Fiskalpolitik. Eine dynamische Analyse unter besonderer Berücksichtigung der staatlichen Budgetbeschränkung und ausgewählter Möglichkeiten der öffentlichen Defizitfinanzierung. 1986.

Band 29 Konrad Beiwinkel: Wehrgerechtigkeit als finanzpolitisches Verteilungsproblem. Möglichkeiten einer Kompensation von Wehrungerechtigkeit durch monetäre Transfers. 1986.

Band 30 Wolfgang Kitterer: Effizienz- und Verteilungswirkungen des Steuersystems. 1986.

Band 31 Heinz Dieter Hessler: Theorie und Politik der Personalsteuern. Eine Kritik ihrer Einkommens- und Vermögensbegriffe. 1993.

Band 32 Wolfgang Scherf: Die beschäftigungspolitische und fiskalische Problematik der Arbeitgeberbeiträge zur Rentenversicherung. Eine Auseinandersetzung mit der Kritik an der lohnbezogenen Beitragsbemessung. 1987.

Band 33 Andreas Mästle: Die Steuerunion. Probleme der Harmonisierung spezifischer Gütersteuern. 1987.

Band 34 Günter Ott: Internationale Verteilungswirkungen im Finanzausgleich der Europäischen Gemeinschaften. 1987.

Band 35 Heinz Haller: Zur Frage der zweckmäßigen Gestalt gemeindlicher Steuern. Ein Diskussionsbeitrag zur Gemeindesteuerreform. 1987.

Band 36 Thomas Kuhn: Schlüsselzuweisungen und fiskalische Ungleichheit. Eine theoretische Analyse der Verteilung von Schlüsselzuweisungen an Kommunen. 1988.

Band 37 Walter Hahn: Steuerpolitische Willensbildungsprozesse in der Europäischen Gemeinschaft. Das Beispiel der Umsatzssteuer-Harmonisierung. 1988.

Band 38 Ulrike Hardt: Kommunale Finanzkraft. Die Problematik einer objektiven Bestimmung kommunaler Einnahmemöglichkeiten in der gemeindlichen Haushaltsplanung und im kommunalen Finanzausgleich. 1988.

Band 39 Jochen Michaelis: Optimale Finanzpolitik im Modell überlappender Generationen. 1989.

Band 40 Bernd Raffelhüschen: Anreizwirkungen der sozialen Alterssicherung. Eine dynamische Simulationsanalyse. 1989.

Band 41 Berend Diekmann: Die Anleihe- und Darlehenstransaktionen der Europäischen Gemeinschaften. 1990.

Band 42 Helmut Kaiser: Konsumnachfrage, Arbeitsangebot und optimale Haushaltsbesteuerung. Theoretische Ergebnisse und mikroökonometrische Simulation für die Bundesrepublik Deutschland. 1990. 
Band 43 Rüdiger von Kleist: Das Gramm-Rudman-Hollings-Gesetz. Ein gescheiterter Versuch der Haushaltskonsolidierung. 1991.

Band 44 Rolf Hagedorn: Steuerhinterziehung und Finanzpolitik. Ein theoretischer Beitrag unter besonderer Berücksichtigung der Hinterziehung von Zinserträgen. 1991.

Band 45 Cornelia S. Behrens: Intertemporale Verteilungswirkungen in der gesetzlichen Krankenversicherung der Bundesrepublik Deutschland. 1991.

Band 46 Peter Saile: Ein ökonomischer Ansatz der Theorie der intermediären Finanzgewalten Die Kirchen als Parafisci. 1992.

Band 47 Peter Gottried: Die verdeckten Effizienzwirkungen der Umsatzsteuer. Eine empirische allgemeine Gleichgewichtsanalyse. 1992.

Band 48 Andreas Burger: Umweltorientierte Beschäftigungsprogramme. Eine Effizienzanalyse am Beispiel des "Sondervermögens Arbeit und Umwelt". 1992.

Band 49 Jeanette Malchow: Die Zuordnung verteilungspolitischer Kompetenzen in der Europäischen Gemeinschaft. Eine Untersuchung aufgrund einer Fortentwicklung der ökonomischen Theorie des Föderalismus. 1992.

Band 50 Barbara Seidel: Die Einbindung der Bundesrepublik Deutschland in die Europäischen Gemeinschaften als Problem des Finanzausgleichs. 1992.

Band 51 Ralph Wiechers: Markt und Macht im Rundfunk. Zur Stellung der öffentlich-rechtlichen Rundfunkanstalten im dualen Rundfunksystem der Bundesrepublik Deutschland. 1992.

Band 52 Klaus Eckhardt: Probleme einer Umweltpolitik mit Abgaben. 1993.

Band 53 Oliver Schwarzkopf: Die Problematik unterschiedlicher Körperschaftsteuersysteme innerhalb der EG. 1993.

Band 54 Thorsten Giersch: Bergson-Wohlfahrtsfunktion und normative Ökonomie. 1993.

Band 55 Li-Fang Chou: Selbstbeteiligung bei Arzneimitteln aus ordnungspolitischer Sicht. Das Beispiel der Bundesrepublik Deutschland. 1993.

Band 56 Harald Schlee: Einkommensteuerliche Behandlung von Transferzahlungen. Zur Neuordnung der Familienbesteuerung sowie der Besteuerung von Versicherungsleistungen und Sozialtransfers. 1994.

Band 57 Alexander Spermann: Kommunales Krisenmanagement. Reaktionen baden-württembergischer Stadtkreise auf steigende Sozialhilfekosten und Einnahmenausfälle (198092). 1993.

Band 58 Otto Roloff / Sibylle Brander / Ingo Barens / Claudia Wesselbaum: Direktinvestitionen und internationale Steuerkonkurrenz. 1994.

Band 59 Claudia Wesselbaum-Neugebauer: Internationale Steuerbelastungsvergleiche. 1994.

Band 60 Stephanie Miera: Kommunales Finanzsystem und Bevölkerungsentwicklung. Eine Analyse des kommunalen Finanzsystems vor dem Hintergrund der sich abzeichnenden Bevölkerungsentwicklung am Beispiel Niedersachsens unter besonderer Berücksichtigung des Landkreises Wolfenbüttel und seiner Gemeinden. 1994.

Band 61 Wolfgang Scherf: Die Bedeutung des kaldorianischen Verteilungsmechanismus für die gesamtwirtschaftlichen Wirkungen der staatlichen Neuverschuldung. 1994.

Band 62 Rainer Volk: Vergleich der Vergünstigungseffekte der verschiedenen investitionsfördernden Maßnahmen. 1994.

Band 63 Hans-Georg Napp: Kommunale Finanzautonomie und ihre Bedeutung für eine effiziente lokale Finanzwirtschaft. 1994. 2., unveränderte Auflage 1994. 
Band 64 Bernd Rahmann / Uwe Steinborn / Günter Vornholz: Empirische Analyse der Autonomie lokaler Finanzwirtschaften in der Europäischen Gemeinschaft. 1994.

Band 65 Carsten Kühl: Strategien zur Finanzierung der Altlastensanierung. 1994. 